
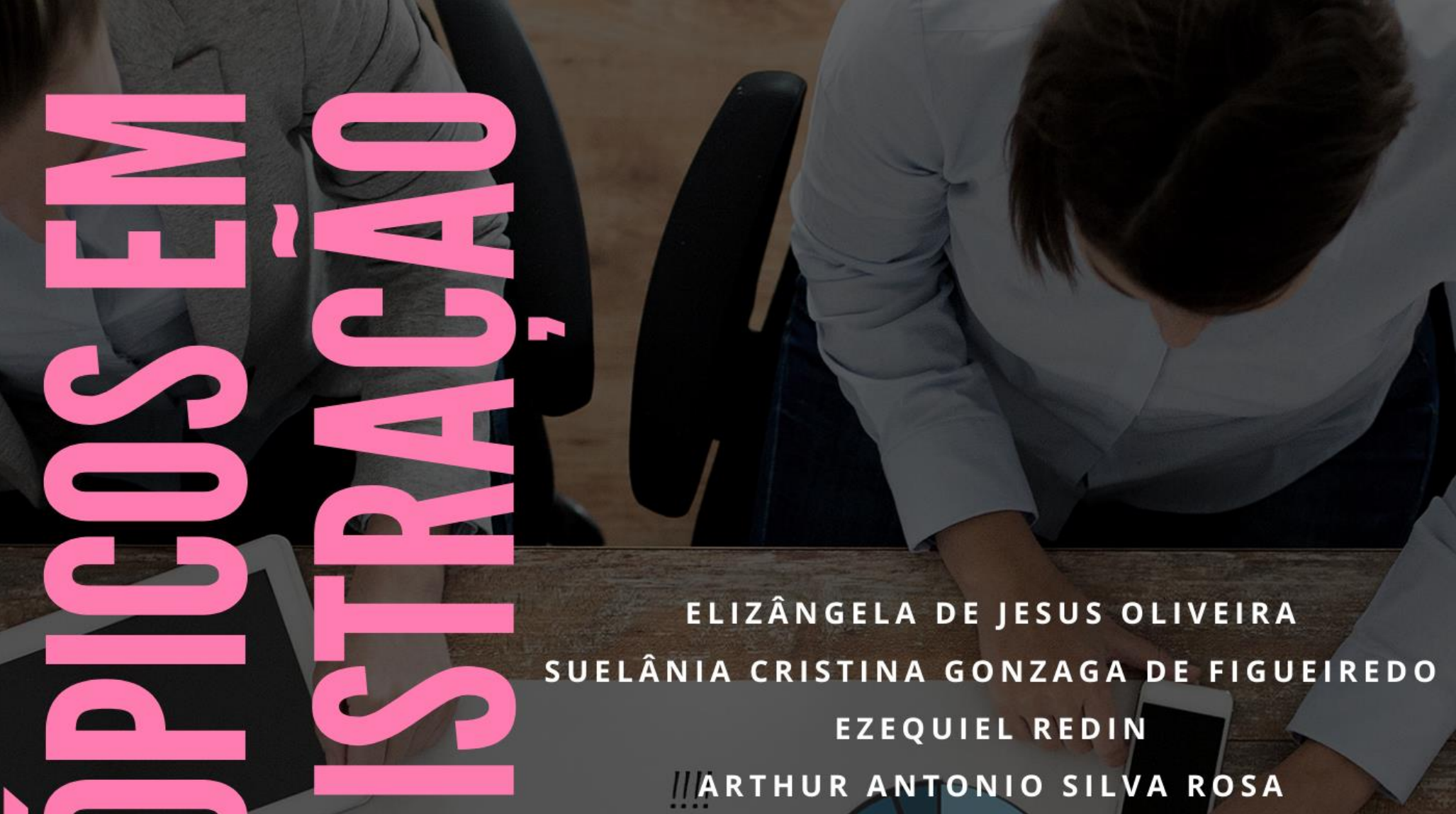

ELIZÂNGELA DE JESUS OLIVEIRA

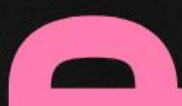

SUELÂNIA CRISTINA GONZAGA DE FIGUEIREDO

EZEQUIEL REDIN
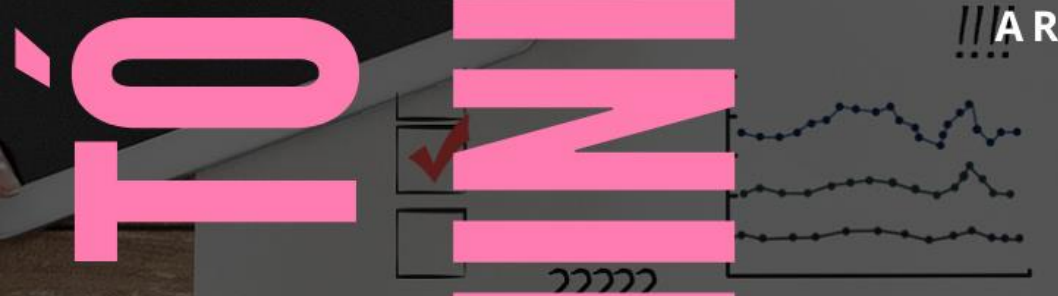

!! ARTHUR ANTONIO SILVA ROSA

(ORGANIZADORES)

\title{
Volume 39
}

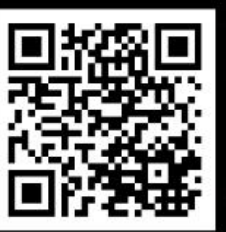


Elizângela de Jesus Oliveira

Suelânia Cristina Gonzaga de Figueiredo

Ezequiel Redin

Arthur Antonio Silva Rosa

(Organizadores)

\section{Tópicos em Administração Volume 39}

1a Edição

Belo Horizonte

Poisson

2021 


\section{Editor Chefe: Dr. Darly Fernando Andrade}

\section{Conselho Editorial}

Dr. Antônio Artur de Souza - Universidade Federal de Minas Gerais

Ms. Davilson Eduardo Andrade

Dra. Elizângela de Jesus Oliveira - Universidade Federal do Amazonas

Msc. Fabiane dos Santos

Dr. José Eduardo Ferreira Lopes - Universidade Federal de Uberlândia

Dr. Otaviano Francisco Neves - Pontifícia Universidade Católica de Minas Gerais

Dr. Luiz Cláudio de Lima - Universidade FUMEC

Dr. Nelson Ferreira Filho - Faculdades Kennedy

Ms. Valdiney Alves de Oliveira - Universidade Federal de Uberlândia

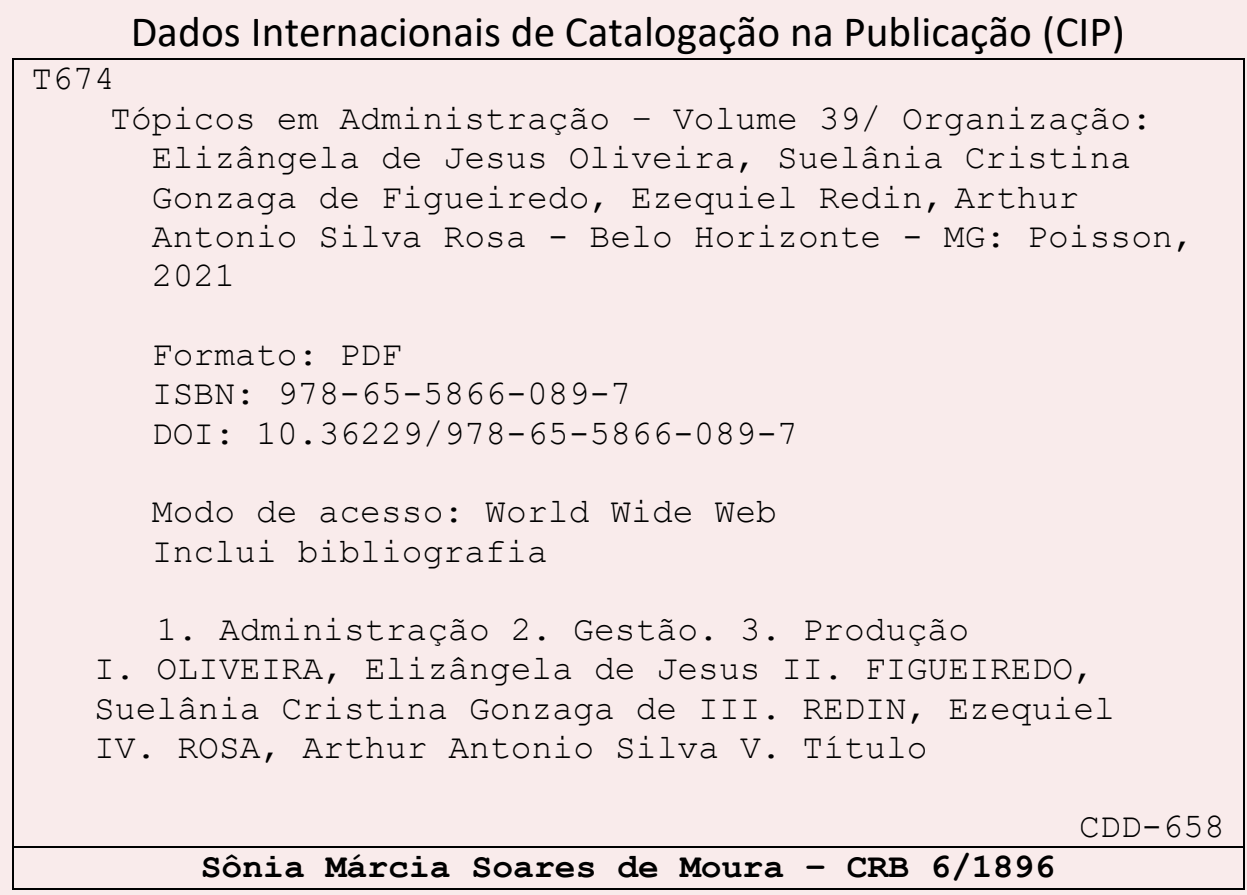

O conteúdo dos artigos e seus dados em sua forma, correção e confiabilidade são de responsabilidade exclusiva dos seus respectivos autores.

www.poisson.com.br

contato@poisson.com.br 


\section{SUMÁRIO}

Capítulo 1: 0 uso dos sistemas inteligentes de transporte para o aumento da eficiência no transporte público coletivo por ônibus

Wagner Luiz de Oliveira, Marcela Barbosa de Moraes

DOI: 10.36229/978-65-5866-089-7.CAP.01

Capítulo 2: Perfil familiar nos Empreendimentos Habitacionais de Interesse Social (EHIS) no município de Piumhi - Minas Gerais..

Fernando da Costa Barros, Humberto Coelho de Melo, Stella Maria Gomes Tomé, Tobias Ribeiro Ferreira DOI: 10.36229/978-65-5866-089-7.CAP.02

Capítulo 3: Avaliação do setor de saneamento no Brasil período 2015 usando o método Análise Envoltória de Dados (DEA). 21

Joel de Jesus Macedo, Armando Vaz Sampaio

DOI: 10.36229/978-65-5866-089-7.CAP.03

Capítulo 4: A construção da materilidade para um relato integrado em uma empresa de Saneamento Municipal. 37

Tatiana Gama Ricci, Marta Cristina Pelucio Grecco, Cecília Moraes Santostaso Geron

DOI: 10.36229/978-65-5866-089-7.CAP.04

Capítulo 5: Análise dos impactos econômicos decorrentes da instalação dos parques eólicos nos municípios da Região Sul do Brasil. 52

Lúbia Tamires Rintzel, Tiago Wickstrom Alves, Angélica Massuquetti

DOI: 10.36229/978-65-5866-089-7.CAP.05

Capítulo 6: Análise de agrupamentos obtidos com a relação Indíce de Desenvolvimento Humano e carga tributária dos municipios do estado da Paraiba, entre 2010 e 2018.

Mácio Augusto de Albuquerque, Ramylla de Almeida Batista

DOI: 10.36229/978-65-5866-089-7.CAP.06

Capítulo 7: A relação das políticas públicas e o bacharel em Turismo: 0 caso das Estâncias Turísticas no estado de São Paulo, Brasil 98

Aracelis Gois Morales Rigoldi, Graziela Oste Graziano Cremonezi, Karina Toledo Solha, Valéria Rueda Elias Spers, Marli Terezinha Vieira

DOI: 10.36229/978-65-5866-089-7.CAP.07 


\section{SUMÁRIO}

Capítulo 8: A implementação de um PMO - Planejamento e Inovação na Modernização da Administração Pública.

Linamara Rizzo Battistella, Lilian Aparecida Treff

DOI: $10.36229 / 978-65-5866-089-7 . C A P .08$

Capítulo 9: Governança eletrônica municipal e eficiência na distribuição de recursos públicos: Uma análise nos municípios mais populosos do Brasil..

Nyalle Barboza Matos, José Dionísio Gomes da Silva, Erivan Ferreira Borges, Victor Godeiro de Medeiros Lima

DOI: $10.36229 / 978-65-5866-089-7 . C A P .09$

Capítulo 10: Análisis de la gestión del talento humano en una institución pública, en Perú. 133

Kelly Milagritos Casana Jara, Irma Milagros Carhuancho Mendoza

DOI: $10.36229 / 978-65-5866-089-7 . C A P .10$

Capítulo 11: Mulheres no Conselho de Administração e o desempenho financeiro das empresas: Um estudo comparativo entre França e Brasil

Edmery Tavares Barbosa, Inajá Allane Santos Garcia, Azamor Cirne de Azevedo Filho, Micheli Aparecida Lunardi

DOI: $10.36229 / 978-65-5866-089-7 . C A P .11$

Capítulo 12: Resolução de problemas e tomada de decisão em contabilidade: Paradigma da subjetividade no confronto entre a essência e a forma. 162

Erivan Ferreira Borges, Diogo Henrique Silva de Lima, José Alves Dantas

DOI: 10.36229/978-65-5866-089-7.CAP.12

Capítulo 13: Gestão de Resultados: Accruals vs. operações reais, estratégias complementares ou substitutas? 175

Cristina Gaio, Ana Margarida Oliveira

DOI: 10.36229/978-65-5866-089-7.CAP.13

Capítulo 14: A evidenciação da DVA agrega valor às Empresas do Novo Mercado da BM\&FBOVESPA? Evidências trazidas através de estudo em painel e do Modelo de Ohlson 191

Roque Brinckmann, Fábio Minatto

DOI: 10.36229/978-65-5866-089-7.CAP.14 


\section{SUMÁRIO}

Capítulo 15: Análise das provisões nas empresas petrolíferas: BRICS versus NYSE. 204 Bruno Augusto Dias Gonçalves, Maisa de Souza Ribeiro, Lívia Maria Lopes Stanzani, Mariana Simões Ferraz do Amaral Fregonesi

DOI: $10.36229 / 978-65-5866-089-7 . C A P .15$

Capítulo 16: Aderência aos indicadores da Global Reporting Initiative (GRI) em empresas do setor de alimentos no Brasil e América Latina

Enio Antunes Rezende, Savio de Araújo Almeida

DOI: 10.36229/978-65-5866-089-7.CAP.16

Capítulo 17: Fertilizantes e sua relevância para o agronegócio brasileiro

Gabriel Severiano da Silva, João Víctor Carrelas dos Santos, Nathiely de Freitas Silvestre

DOI: 10.36229/978-65-5866-089-7.CAP.17

Autores: 


\section{Capítulo 1}

O uso dos sistemas inteligentes de transporte para o aumento da eficiência no transporte público coletivo por ônibus

\section{Wagner Luiz de Oliveira \\ Marcela Barbosa de Moraes}

Resumo: Os desafios do Transporte Público Urbano experimentado na maioria dos centros urbanos brasileiros incluem o congestionamento de tráfego, a provisão inadequada de operadoras para os passageiros em quantidade e oportunidade, gerenciamento de tráfego deficiente, entre outros. Sendo assim, os Sistemas Inteligentes de Transporte (ITS) buscam aplicar tecnologias de gerenciamento de transporte e informação aos Sistemas de Transporte Público para maximizar a eficiência da operação e melhorar a qualidade dos serviços aos usuários do sistema. Diante deste cenário, o presente artigo propõe analisar como os Sistemas Inteligentes de Transporte podem melhorar a qualidade do transporte público coletivo por ônibus. Para tanto, foi feita uma análise descritiva para detalhar as experiências de quatro grandes municípios brasileiros na implementação de projetos de Sistemas Inteligentes de Transporte. Os resultados obtidos demonstram que os ITS podem contribuir significativamente para efetividade da operação do Transporte Público Coletivo, pois estas tecnologias oferecem atribuições no controle, no monitoramento e na fiscalização de toda operação de transporte.

Palavras-chave: Transporte Urbano, Sistemas Inteligentes, Operação de Transporte. Área do Conhecimento: Ciências Sociais Aplicadas / Planejamento Urbano e Regional. 


\section{INTRODUÇÃO}

Os sistemas inteligentes desenvolvidos para o transporte público coletivo por ônibus podem melhorar a qualidade da operação de transporte e induzir o desenvolvimento de diferentes regiões em todo o país. A inserção dos Sistemas Inteligentes de Transporte - ITS definitivamente se tornou parte da gestão e gerenciamento desta atividade, já que existe uma tendência atual em tornar mais efetivo os deslocamentos dos indivíduos por razões ambientais e econômicas.

O uso dos Sistemas Inteligentes de Transporte podem ser considerados uma realidade nas grandes metrópoles no mundo. No Brasil a evolução do conceito ITS - Intelligent Transport System ocorreu fundamentalmente estruturada na tecnologia da informação, permanecendo em ritmo lento de evolução com poucas publicações e praticamente uma inexistência de normas que regulamente o desenvolvimento de uma arquitetura ITS a nível nacional (ANTP, 2016).

Neste sentido os ITS se mostram um sistema eficiente para otimizar o uso da infraestrutura de transportes já adicionada. Na ótica do transporte coletivo urbano, o objetivo principal dos sistemas inteligentes é disponibilizar aos passageiros do transporte coletivo uma locomoção mais eficiente, promovendo uma interação entre os passageiros e as linhas de ônibus (PEIXOTO e; FREITAS, 2013).

Diante deste contexto o objetivo deste artigo é analisar como os Sistemas Inteligentes de Transportes podem melhorar a qualidade do transporte público coletivo. Para tanto foi feita uma análise descritiva para detalhar as experiências de quatro grandes municípios brasileiros na implementação de projetos baseados em Sistemas Inteligentes de Transporte, para cada uma das cidades analisadas foram descritos o contexto, as funcionalidades do ITS e os principais resultados alcançados.

\section{METODOLOGIA}

Segundo Marconi e Lakatos (2008) métodos são na verdade um conjunto de atividades racionais e sistemáticas com a finalidade de chegar a um conhecimento válido ou verdadeiro, que determina qual o caminho a ser seguido, reduzindo a probabilidade de erros e apoiando as decisões do pesquisador. 0 método utilizado para este estudo foi a Pesquisa Bibliográfica e Documental.

A pesquisa sob o ponto de vista dos seus objetivos pode ser classificada como exploratória, pois visou tornar o tema explicito por meio de levantamento bibliográfico.

Segundo Marconi e Lakatos (2002) a pesquisa exploratória técnica, sistemática e exata, é quando o pesquisador se baseia em estudos já realizados por pesquisadores anteriores, a fim de descobrir o melhor método a ser trabalhado e se realmente o delineamento da pesquisa está correto.

O objetivo deste artigo é analisar como os Sistemas Inteligentes de Transporte podem melhorar a qualidade do transporte público coletivo por ônibus.

Para tanto foi feita uma análise descritiva para detalhar as experiências de quatro grandes municípios brasileiros na implementação de projetos baseados em Sistemas Inteligentes de Transporte, para cada uma das cidades analisadas foram descritos o contexto, as funcionalidades do ITS e os principais resultados alcançados.

\section{RESULTADOS}

Os problemas de mobilidade, segurança e meio ambiente exigem novas soluções para transformar o transporte urbano e interurbano em um meio de transporte sustentável. Diante disto, as aplicações de novas tecnologias de informação ao transporte público urbano podem contribuir decisivamente para este objetivo, embora não exclua a implantação de outras medidas.

Desta forma, Yang, L. (2010) argumentam que os sistemas inteligentes de transporte podem melhorar o tráfego nos grandes centros que por meio da tecnologia da informação oferecem maior controle e gerenciamento da operação de transporte.

De acordo com uma pesquisa do Ipea (2012) o aumento da infraestrutura viária por meio de mais ruas e viadutos não se apresenta como uma solução sustentável a longo prazo, pois de acordo com o estudo o incremento da capacidade das vias urbanas pode gerar ao contrário, um aumento da demanda por tráfego capaz de consumir grande parte da capacidade adicionada. 
De acordo com o 12ํㅡㄹ Encontro de Boas Práticas sobre ITS, realizado em 22 de novembro de 2011 na cidade de Porto Alegre, vários foram os resultados verificados à partir do uso da tecnologia ITS no sistema viário da cidade. 0 Quadro 1 demonstra os resultados operacionais e as correspondentes melhorias do transporte.

\begin{tabular}{|c|c|c|}
\hline \multicolumn{3}{|c|}{ Quadro 1- Melhorias Alcançadas } \\
\hline $\mathbf{N}^{\circ}$ & RESULTADOS & MELHORIAS \\
\hline 1 & $\begin{array}{c}\text { AUMENTO DA RECETA E } \\
\text { DEMANDA }\end{array}$ & $\begin{array}{l}\text { - Recuperação de demanda e; } \\
\text { - Aumento da satisfação dos passageiros. }\end{array}$ \\
\hline 2 & $\begin{array}{l}\text { REDUÇÄO DE CUSTOSDE } \\
\text { MANUTENÇÃO }\end{array}$ & $\begin{array}{l}\text { - Melhorias na operação de transporte, principalmente } \\
\text { em relação aos motoristas; e } \\
\text { - Controle de velocidade deservolvida nos trechos } \\
\text { críticos }\end{array}$ \\
\hline 3 & $\begin{array}{l}\text { REDUÇÄO DO CONSUMO DE } \\
\text { COMBUSTIVEL }\end{array}$ & $\begin{array}{l}\text { - Redução do excesso de consumo; e } \\
\text { - Condução e operação dos veículos de foma consciente } \\
\text { e econômica. }\end{array}$ \\
\hline
\end{tabular}

Segundo a NTU (2013) as melhorias refletiram nos passageiros como também nos gestores operadores, ao melhorar o nível de serviço prestado por meio das novas tecnologias e técnicas disponíveis. As melhorias do processo de transporte resultaram na qualidade do serviço prestado e no aumento da satisfação do passageiro, que exerce reflexo direto na manutenção, ou mesmo no aumento dos índices de demanda.

Segundo a NTU (2013) a implementação dos ITS na cidade de fortaleza no Ceará resultou no aperfeiçoamento das melhores práticas para o setor de transporte. Entretanto o uso destas novas tecnologias deve ser primeiramente, acompanhado de estudos e avaliações, considerando, os benefícios e os custos totais.

A implementação dos sistemas inteligentes na cidade de Goiânia apresentou algumas dificuldades em razão da gestão de inovação do sistema, isso ocorreu devido à inserção de tecnologias pioneiras para o setor. Sendo assim, alguns pontos positivos foram aprendidos, entre as quais pode-se destacar o planejamento de serviços.

Esse planejamento requer uma estratégia própria considerando as especificidades locais, ou seja, uma visão funcional da empresa naquele exato momento, claro, de acordo com seus objetivos norteados pelo seu mercado alvo. E o planejamento para o futuro é norteado para alcançar os resultados em longo prazo, e, o ponto chave, é que existe a necessidade de uma estratégia para atingir o alvo (ACKOFF, 1966, p. 52).

Na concepção da implantação dos ITS em Goiânia foi feito um planejamento eficaz amparado na base de dados de tráfego, para alcançar um controle satisfatório. Entretanto, houve escassez de mão de obra especializada na região, mas foi suprida com a importação de profissionais especializados de outras regiões do país.

Foi realizado investimentos em formação e implantação do software hastus, permitindo a realização da programação de pessoal juntamente com os horários das linhas de ônibus, essa complexidade exige o uso de ferramentas tecnológicas.

A RMTC apresentou grande conhecimento e disposição quanto a utilização dos ITS. O pioneirismo e a predisposição do consórcio fizeram com que a RMTC se tornasse referência para os demais sistemas.

De acordo com a NTU (2018) a implementação do ITS no sistema de transporte urbano público, tem a função de alcançar melhorias nos indicadores voltados a qualidade do serviço oferecido aos usuários como ordenamento, a pontualidade, a segurança, o controle e a informação aos usuários do transporte. 
No caso da cidade de Porto Alegre a implantação do ITS objetivava a melhoria do sistema de transporte público pela inserção de ferramentas inteligentes, sendo as principais prerrogativas do sistema:

- $\quad$ Alcançar eficiência de 97\%;

- Utilização de um software flexível;

- Implantação de telemetria online;

- Implantação de uma central de controle das operações;

- Controle por 24 horas, todos os dias da semana,

- Monitoramento da frota em tempo real,

Segundo dados publicados pela NTU (2013) foi constatado que no sistema de ônibus monitorado automaticamente à partir da implantação da tecnologia ITS no ano de 2011, houve uma melhora significativa no índice de pontualidade.

Foram também alcançados resultados positivos nos registros de velocidade acima de $50 \mathrm{Km} / \mathrm{h}$, por meio da fiscalização de algumas vias. Em três meses de monitoramento do indicador, foi constatado uma queda de $38 \%$ nas ocorrências, isto significa uma redução de mais de 2.600 ocorrências de excesso de velocidade nas vias em que a velocidade permitida era de $50 \mathrm{~km} / \mathrm{h}$.

Nas vias onde a velocidade máxima permitida era de $60 \mathrm{Km} / \mathrm{h}$, a redução constatada foi de $68 \%$ no período de cinco meses de acompanhamento, uma queda de aproximadamente 3.200 ocorrências. 0 Gráfico 1 abaixo demonstra essa redução.

Gráfico 1- Comparativo de velocidade Operacional

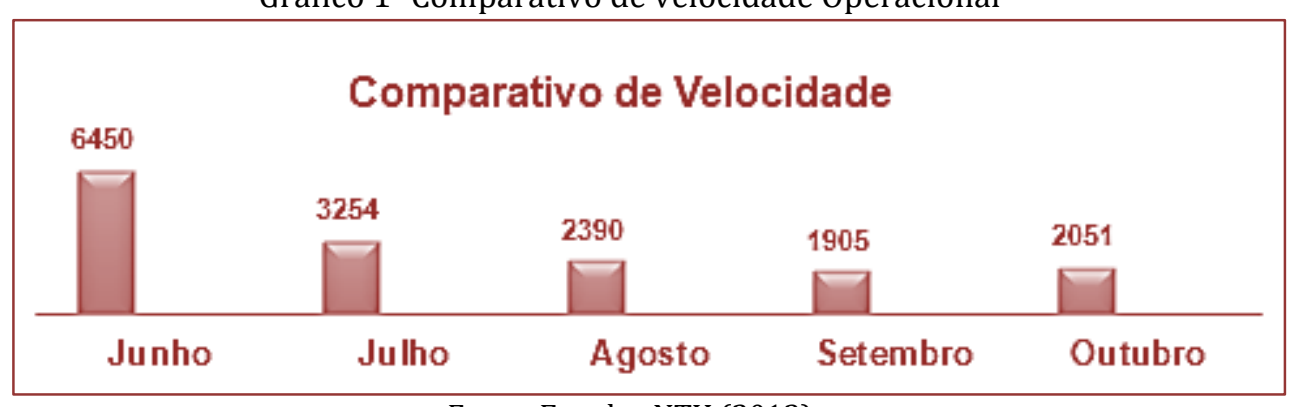

Fonte: Estudos NTU (2013)

Uma análise efetuada no período de junho a outubro de 2011 permitiu concluir que quando a velocidade é monitorada por sistemas eletrônicos, ou seja, há um monitoramento e controle da frota em tempo real, isso interfere positivamente no comportamento do motorista durante o período do seu trabalho. Com a redução dos excessos de velocidade foi alcançado simultaneamente uma queda de 5\% nos índices de ocorrências de acidentes, o que representa uma redução de 33 acidentes a menos no período de 2011 e 2012.

A inserção dos sistemas inteligentes na gestão do sistema urbano de transporte coletivo na cidade de Porto alegre melhorou significativamente a operação das linhas de ônibus no município, essa melhora pode ser observada através dos indicadores monitorados.

A criação de um centro operacional de controle garantiu um aperfeiçoamento no controle e gestão dos dados por meio de informações captadas em tempo real, que disponibilizadas para os operadores gestores contribuíram para o aperfeiçoamento da operação por meio de monitoramento e fiscalização da atividade de transporte.

Desde modo, segundo estudos da NTU o emprego do ITS na operação do sistema de transporte urbano coletivo em Porto Alegre convergiu para o aumento da satisfação dos usuários do sistema, pois ficou evidente que a qualidade do serviço com relação ao processo de deslocamentos das pessoas e produtos aumentou.

A utilização do ITS na cidade do Rio de Janeiro é amparada pelo regime atual de concessão e pelos projetos de BRT. Atualmente existe uma federação que representa as empresas de transportes do Estado denominada Fetranspor. 
Os ITS implantados na cidade do Rio de Janeiro são motivados pelos projetos, do BRT (Bus Rapid Transit) e do BRS (Bus Rapid System), em termos de sistemas inteligentes de transporte as implementações de novas tecnologias tem focado nas seguintes áreas:

- Biometria;

- Sistema de Bilhetagem Eletrônica;

- Gestão de Informações aos Usuários;

- Centro Operacional de Controle e Fiscalização Eletrônica;

O sistema de biometria é utilizado na bilhetagem eletrônica o que torna o sistema mais seguro, e menos suscetível a fraudes. Este sistema é utilizado em todo o Estado do Rio de Janeiro, todos os produtos utilizam tecnologia Smartcard sem contato, e os validadores se comunicam com o sistema por meio de antenas instaladas nas garagens das operadoras, em um sistema dedicado.

Os resultados alcançados pela implementação do BRS, são relativos a estes sistemas, que segundo estudos realizados pela NTU (2013), são:

Redução do tempo de viagem;

- Diminuição do tráfego, menos poluição e menor barulho;

- Melhor controle e monitoramento da operação;

- Controle do tráfego por meio de GPS e câmeras da prefeitura.

Após a operacionalização do ITS no sistema BRS foi constatada uma redução do tempo de percurso nos horários de pico, a implementação de sistemas inteligentes na cidade do Rio de Janeiro foram acompanhadas de outros projetos para alcançar a efetividade na operação do transporte público urbano, como: faixas reversíveis na orla, proibição para veículos de grande porte e a determinação de janelas com horários específicos para carga e descarga.

Todos esses projetos juntamente com os ITS refletem diretamente na operação do transporte público urbano na cidade do Rio de Janeiro, sendo possível aumentar a velocidade operacional dos ônibus em 84\%. Os sistemas garantiram melhor fluidez no tráfego com ganhos significativos para mobilidade urbana, com consequente redução energética e de emissões de poluentes no ar.

\section{DISCUSSÃO}

De acordo com Australia (2010) a função do ITS não é apenas melhorar as condições de tráfego nas vias, mas também tem o objetivo de tornar o setor de transporte mais seguro e sustentável, diminuindo os problemas ocasionados pelos congestionamentos dos tráfegos urbanos e efeitos das externalidades climáticas sobre o tráfego.

Entretanto, existem outras variáveis que envolvem o uso e a ocupação do solo, e a interação entre estes dois sistemas devem ser levados em consideração para o correto funcionamento das cidades, principalmente de um bom planejamento do solo junto com um sistema de transporte eficiente (MITCHELL, 2008).

Segundo Bodmer e Martins (2009) para o uso eficiente do solo é preciso gerir o espaço urbano que depende da ligação de duas áreas: política de transportes e política habitacional. Neste sentido a eficiência da atividade de transporte envolve gestão e planejamento, principalmente o gerenciamento integrado do uso do solo.

Para Maricato (2015) a efetividade dos deslocamentos não está ligado apenas com o padrão de transporte, mas com o uso e a ocupação do solo em um município.

De acordo com Puentes (2000) há uma contradição nos benefícios dos sistemas ITS, alguns autores defendem que o ITS além de otimizar o transporte podem melhorar os deslocamentos urbanos através da redução do uso de recursos naturais, mas outros argumentam que uma melhora na qualidade da atividade de transporte pode convergir para um aumento significativo de viagens, e assim despender maiores recursos. 
Deste modo, os sistemas inteligentes de transporte não são uma solução mágica para as externalidades ocasionadas pelos congestionamentos nas cidades. Embora estes sistemas possam garantir expansão na capacidade viária pela efetividade na gestão da operação de transporte, mas os ITS não tem capacidade de gerir toda a demanda por viagens, principalmente, na supremacia do transporte individual em detrimentos dos demais (PEARCE, 2000).

\section{CONCLUSÃO}

A inserção dos Sistemas Inteligentes de Transporte na operação do transporte público por ônibus tornou se imprescindível para o planejamento e gerenciamento desta atividade. Isso porque existe uma tendência em aprimorar e melhorar os deslocamentos de pessoas e produtos, por razões ambientais e econômicas.

Diante deste contexto, este estudo teve como objetivo analisar como o uso de Sistemas Inteligentes de Transporte podem melhorar a qualidade do transporte público coletivo por ônibus.

Para tanto, foi feita uma análise descritiva para detalhar as experiências de quatro grandes municípios brasileiros na implementação de projetos de Sistemas Inteligentes de Transporte, para cada um dos municípios foram descritos as funcionalidades dos ITS e os principais resultados alcançados.

A implementação dos sistemas inteligentes nas quatro capitais brasileiras demonstrou que os ITS podem agregar qualidade ao transporte público, pois estas tecnologias apresentam atribuições no controle, no monitoramento e na fiscalização de toda operação de transporte. Os benefícios e vantagens alcançadas pelo uso dos ITS estão claramente demonstrados por meio das experiências destas quatro capitais brasileiras.

Os Sistemas Inteligentes de Transporte podem contribuir para redução dos congestionamentos nos grandes centros e, ao mesmo tempo, são ferramentas que aliadas a outras ações complementares podem melhorar a mobilidade das pessoas. Além disso, os ITS contribuem para o aumento da produtividade dos sistemas de transporte, constituindo um mercado com elevado potencial econômico e com fortes projeções para o futuro.

\section{REFERÊNCIAS}

1. ACKOFF, R. L. The meaning of strategy planning. Mickinsey Quaterly, p. 48-61, Summer, 1966.

2. ASSOCIAÇÃO NACIONAL DE TRANSPORTES PÚBLICOS (ANTP) Sistema de Informação da Mobilidade Urbana - Simob. Relatório de 2016. São Paulo, 2016.

3. ASSOCIAÇÃO NACIONAL DAS EMPRESAS DE TRANSPORTES URBANOS (NTU). Relatórios Anuais 2009, 2012, 2014, 2016, 2018.

4. Boas práticas para nova mobilidade urbana: exemplos para aplicação da Lei n. 12.587/2012. Brasília, DF, 2012. Disponível em: <https://www.ntu.org.br/novo/upload/Publicacao/Pub635110576376336907.pdf>. Acesso em: 02 out. de 2018.

5. AUSTRALIA. House of Representatives Standing Committee on Transport Regional Services. The Parliament of the Commonwealth of Australia Moving on Intelligent Transport Systems. Camberra: Parliament of Australia, 2010. Disponível

em:< https://parlinfo.aph.gov.au/parlInfo/search/summary/summary.w3p;page=0;query=INTELLIGENCES\%20transporta tion\%20system;resCount=Default. Acesso em: 5 set. 2018.

6. BODMER, M.;. MARTINS, J. “Conceivinng competitive arrangements for public transport.” 29th Conference on Competition and Ownership in Land Transport, 2009.

7. BRASIL.Instituto de Pesquisas Econômicas Aplicadas (Ipea). Noticias. Brasilia, 2012. Disponível em: $<$ http://www.ipea.gov.br/portal/index>.

8. DE ANDRADE MARCONI, Marina; LAKATOS, Eva Maria. Técnicas de pesquisa: planejamento e execução de pesquisas, amostragens e técnicas de pesquisa, elaboração, análise e interpretação de dados. 2008.

9. ENCONTRO DE BOAS PRÁTICAS, 12ㅜㅜ 2013. Sistemas Inteligentes de Transporte - ITS. Brasília: Associação Nacional das Empresas de Transporte Urbano (NTU), 2013. 53p.

10. MARCONI, Marina de Andrade; LAKATOS, Eva Maria. Técnicas de pesquisa.5 ed. São Paulo: Atlas, 2002.

11. MARICATO, Ermínia. Para entender a crise urbana. CaderNAU, v.8, n. 1, p. 11-22, 2015. 
12. MEYER, M.D. Transport Planning for Urban Areas: A Retrospective Look and Future Prospects. Millennium. Special, 2000, no 1, vol 34, no 1, p. 143-171.

13. MITCHELL, B. Cidades engasgam com automóveis. Entrevista para a revista Mega Cidades, OESP, agosto, 2008.

14. PEARCE, V. (2000) ITS: Money Well Spent? Traffic Technology International, April/may 2000, p. 19-23.

15. PUENTES, R. (2000) Deep Impact. Traffic Technology International, april/May 2000, p. 106-109.

QU, Fengzhong; WANG, Fei-Yue; YANG, Liuqing. Intelligent transportation spaces: vehicles, traffic, communications, and beyond. IEEE Communications Magazine, v. 48, n. 11, 2010. 


\section{Capítulo 2}

Perfil familiar nos Empreendimentos Habitacionais de Interesse Social (EHIS) no município de Piumhi Minas Gerais

\section{Fernando da Costa Barros \\ Humberto Coelho de Melo \\ Stella Maria Gomes Tomé \\ Tobias Ribeiro Ferreira}

Resumo: As Habitacionais de Interesse Social (HIS) surgiram como meio de conter a carência habitacional brasileira, através de moradias para as famílias de baixa renda com o intuito de assegurar a qualidade de vida e a inclusão social. Devido ao aumento do déficit habitacional brasileiro nos últimos anos, a construção de habitações sociais ganhou espaço através da criação do Programa Minha Casa Minha Vida (PMCMV), no qual a população era escolhida de acordo com sua renda e condições específicas. Porém, é necessário não somente propiciar moradias a um baixo custo, mas também moradias que garantam qualidade e funcionalidade. Analisar as condições das Habitação de Interesse Social (HIS) contribui de modo significativo, para melhoria de processos, identificação das peculiaridades e fragilidades a percepção do usuário final do produto, de modo que seja possível garantir a qualidade das edificações, para a construção de novos empreendimentos. No município de Piumhi, desde 2006 foram construídos 7 conjuntos habitacionais, com um total de 434 habitações distribuídas em bairros distintos. Para analisar o perfil das famílias que residem nestes empreendimentos houve a necessidade da caracterização da população residente em cada localidade do município, tendo sido realizada pesquisas bibliográficas e de campo, para a qual desenvolveu-se questionário para Avaliação de Pós-Ocupação, aplicados aos moradores das habitações sociais. Além das informações coletadas através dos questionários, foi possível identificar, por meio de relatos pessoais, a constante insatisfação quanto às dimensões dos cômodos, assim como a qualidade das edificações. Atualmente, a pesquisa encontra-se em fase de análise dos dados obtidos através dos 275 questionários aplicados, e os resultados parciais divulgados neste trabalho permitem concluir que no ambiente dos conjuntos habitacionais de Piumhi habitam-se famílias tradicionais, na maioria com 3 ou 4 habitantes por residência (pais e filhos) e chefe de família principalmente o masculino, sendo que a maioria foi contemplada diretamente com o PMCMV.

Palavras-chave: Habitação de Interesse Social, Avaliação Pós ocupação, Perfil Familiar. 


\section{INTRODUÇÃO}

Com o objetivo de mitigar a insuficiência de moradias para a população brasileira e atender a população de baixa renda, o Programa Minha Casa Minha Vida (PMCMV) foi criado em 2009 através da iniciativa do Governo Federal, de modo, de diminuir o déficit habitacional e propiciar condições digna com padrões mínimos de sustentabilidade, segurança e habitabilidade. Em parceria com estados, municípios, empresas e entidades sem fins lucrativos, o programa vem mudando a vida de milhares de famílias brasileiras. É oportunidade para quem precisa e mais desenvolvimento para o Brasil (CAIXA,2017). O Programa Minha Casa Minha Vida teve um efeito na redução de outros componentes do déficit habitacional, como a habitação precária, que teve queda de $11 \%$ entre 2009 e 2017. Atualmente, representa $12 \%$ do déficit ou 967.270 unidades (ESTARQUE, 2019).

0 déficit habitacional segundo a Fundação João Pinheiro (2016), é conceituado como "deficiências dos estoques residenciais, envolvendo as famílias que vivem sem moradia ou em construções precárias". Este déficit inclui ainda a necessidade de construção de novas habitações para famílias de baixa renda, que em sua maioria vivem em moradias alugadas, pois em geral, comprometem cerca de $30 \%$ da sua renda ao locador para garantir uma moradia para suas famílias.

Investimento em programas de habitação de interesse social mostra-se benefício para todos os setores da economia. No período de 2010 a 2014, a adoção do PMCMV foi responsável pela redução de 2,8\% no déficit habitacional brasileiro (PORTAL BRASIL, 2017). Apesar de os investimentos nos programas de EHIS visarem a inclusão social e o desenvolvimento do país com a diminuição de famílias sem moradias, esse objetivo nem sempre é atingido, muitas das vezes os conjuntos são construídos às margens da cidade. Para FUENDES apud VALE (2012) a criação de conjuntos e a localização não são escolhidas casualmente, sendo uma política que busca adquirir grandes terrenos de baixo valor econômico e implantar habitações, cujas unidades depois de concluídas, apresentam péssima qualidade construtiva em muitas das vezes locais sem serviços básicos de saúde, escolas, comércios ou transporte, marcados pela precariedade favorecendo a exclusão social dos moradores desta localidade (VALE 2012, p.26).

Para garantir o direito à propriedade aos cidadãos, o Programa Minha Casa Minha Vida, iniciado em 2009, veio para facilitar a aquisição de habitações para famílias de baixa renda, priorizando as famílias com renda bruta mensal de até três salários mínimos (ESTARQUE, 2019).

Estarque (2019) ainda destaca que "mesmo com o Programa Minha Casa Minha Vida, o ônus excessivo do aluguel aumentou 70\% no período, atingindo 3,3 milhões de domicílios brasileiros em 2017, o equivalente a $42 \%$ do total do déficit".

Hebert (1979) apud Brandão; Heineck, (2003), destaca a relação pessoa-habitação, no campo da psicologia ambiental que "a habitação deve ser algo íntimo e sentimental, algo que estabelece relação entre as necessidades e as realizações pessoais dos usuários". Esta relação se estende pela funcionalidade dos ambientes e no comportamento do usuário, de modo que esta relação interfere no modo de vida.

Os obetivos deste trabalho consistem em proporcionar uma caracterização das famílias residentes nos Empreendimentos Habitacionais de Interesse Social que foram contempladas pelo Programa Minha Casa Minha Vida (PMCMV) no município de Piumhi-MG, desde o início do programa na década de 2000.

Para definir a qualidade de vida dos usuários é preciso mapear os padrões de comportamento de cada morador em relação aos aspectos sobre a moradia, tendo como ponto de referências as necessidades sociais e ambientais. Salienta-se que a percepção do usufruidor sobre os aspectos físicos e sociais devem ser classificados como forma de propor melhorias dos EHIS.

A partir das características familiares de uma certa localidade é possível relacionar a residência que favorece o conforto e bem-estar da família padrão que ali vive. Nesta perspectiva, a pesquisa consiste em relacionar as informações coletadas em campo, com o intuito de caracterizar o perfil das famílias que residem nas habitações sociais do município de Piumhi-MG.

Piumhi é um município do estado de Minas Gerais, localizado na região Centro-Oeste a $266 \mathrm{~km}$ da capital. Possuindo de unidade territorial no ano de 2015, 902,468 $\mathrm{Km}^{2}$, sendo que sua principal atividade econômica se concentra no comércio e na agropecuária (CIDADE CARINHO, 2019).

Possui uma população, segundo o IBGE (Instituto Brasileiro de Geografia e Estatística), conforme último censo realizado em 2010, de 31.883 habitantes e densidade demográfica de 35,33 habitantes por quilômetro quadrado. Estima-se um aumento do número de habitantes para 34.306 habitantes no ano de 2019. 
A Imagem 1 apresenta a pirâmide etária da população de Piumhi no ano de 2010, possui uma base também larga, porém com uma taxa de natalidade menor em face da população infantil e jovem, é possível identificar ainda que o número de mulheres é superior ao de homens e que a população adulta sobressalta as demais (DATAPEDIA, 2019).

Imagem 1 - Pirâmide etária Piumhi/MG, senso IBGE 2010.

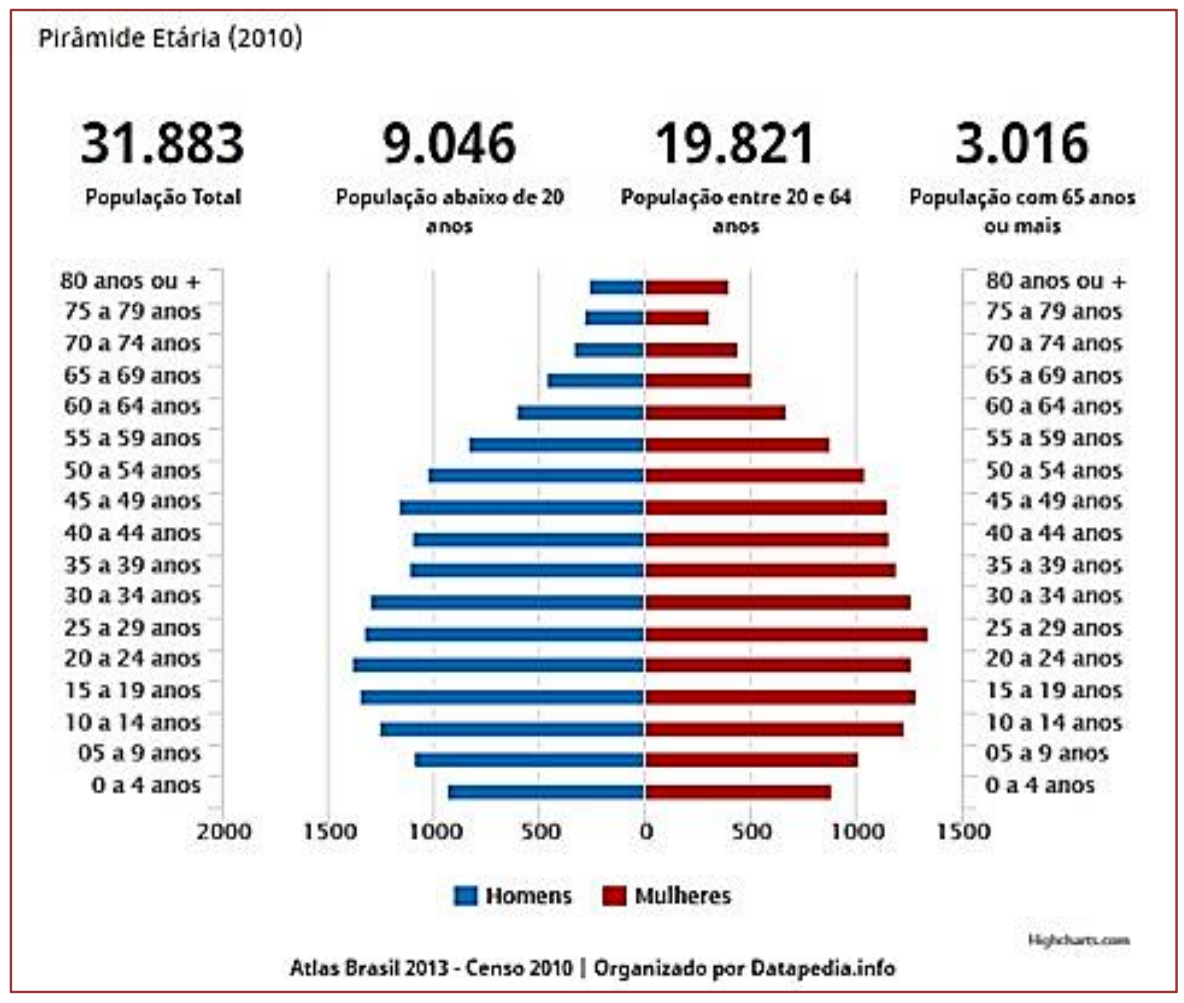

Fonte: Datapedia.info (2019).

Por meio de dados divulgados em Datapedia.info (2019) é possível verificar que no ano de 2014, a atividade econômica que mais gerou empregos na cidade foi o comércio, em torno de $31 \%$ dos empregados, seguido de administração pública 16\%, agropecuária 15,3\% e indústria e transformação 12,2\%. É notória também a importância da construção civil na geração de renda, mais de 200 pessoas trabalhavam neste setor, inclusive na construção de edifícios, serviços especializados para construção, obras de infraestrutura, de acabamento, fundação e terraplenagem, além dos comerciantes de materiais de construção que totalizavam cerca de $3 \%$ do total de empregados.

No ano de 2010 cerca de 18,72\% da população (5.889 habitantes), estava vulnerável à pobreza, ou seja, a renda domiciliar per capita era igual ou inferior a meio salário mínimo, enquanto no estado, a porcentagem passava de 28\% (Datapedia.info, 2019). 0 índice de pobreza e desigualdade que correspondente a incidência de pobreza era cerca de $24 \%$, enquanto da incidência de pobreza subjetiva era de 20,42\% (IBGE, 2019).

O município, em 2010, contava com 10.646 domicílios particulares permanentes, 2.575 moradias em condição de ocupação como imóveis alugados, onde locatário compromete a sua renda sobre a moradia; 6.858 imóveis moradias próprias, e 727 se encontravam em processo de aquisição (IBGE 2019).

\section{METODOLOGIA}

Para o desenvolvimento do presente trabalho realizou-se pesquisas bibliográficas e de campo. Através das pesquisas bibliográficas pôde-se obter um conhecimento prévio para elaboração dos questionários aplicados aos moradores dos conjuntos habitacionais, bem como possibilitou definir as estratégias de abordagem das famílias.

Para Günther (2008) apud Ono et al. (2018), a entrevista consiste em uma técnica tradicional, como método de pesquisa, tem o propósito de obter informações sistemáticas em diferentes áreas do 
conhecimento, sendo considerada de grande valia para compreender a interação pessoa-ambiente (ONO et al, 2018).

Para a pesquisa de campo, inicialmente definiu-se que as 434 habitações do município seriam visitadas, as quais estão distribuídas em 7 conjuntos habitacionais, sendo assim, os questionários seriam aplicados a todas elas.

\section{RESULTADOS E DISCUSSÕES}

Foram aplicados questionários a 275 famílias, compreendendo aproximadamente 63\% das residências, devido a fatores como a não presença de moradores nos horários das vistas ou até mesmo a desinteresse de algumas famílias em contribuir com a pesquisa.

Notou-se que a estratégia de divulgação preliminar através de panfletos e cartazes fixados nos comércios próximos aos conjuntos habitacionais contribuíram para o índice elevado de participação apresentado. Além da divulgação do trabalho, a equipe de pesquisa, sempre que visitava alguma família, os presenteava com caneca de louça com a divulgação da ação, o que também contribuiu de forma positiva no sentido de motivar a participação da população.

A Imagem 2, representa a localização dos conjuntos e o quantitativo de habitações e questionários aplicados.

Imagem 2: Questionários aplicados nas EHIS por Conjunto Habitacional

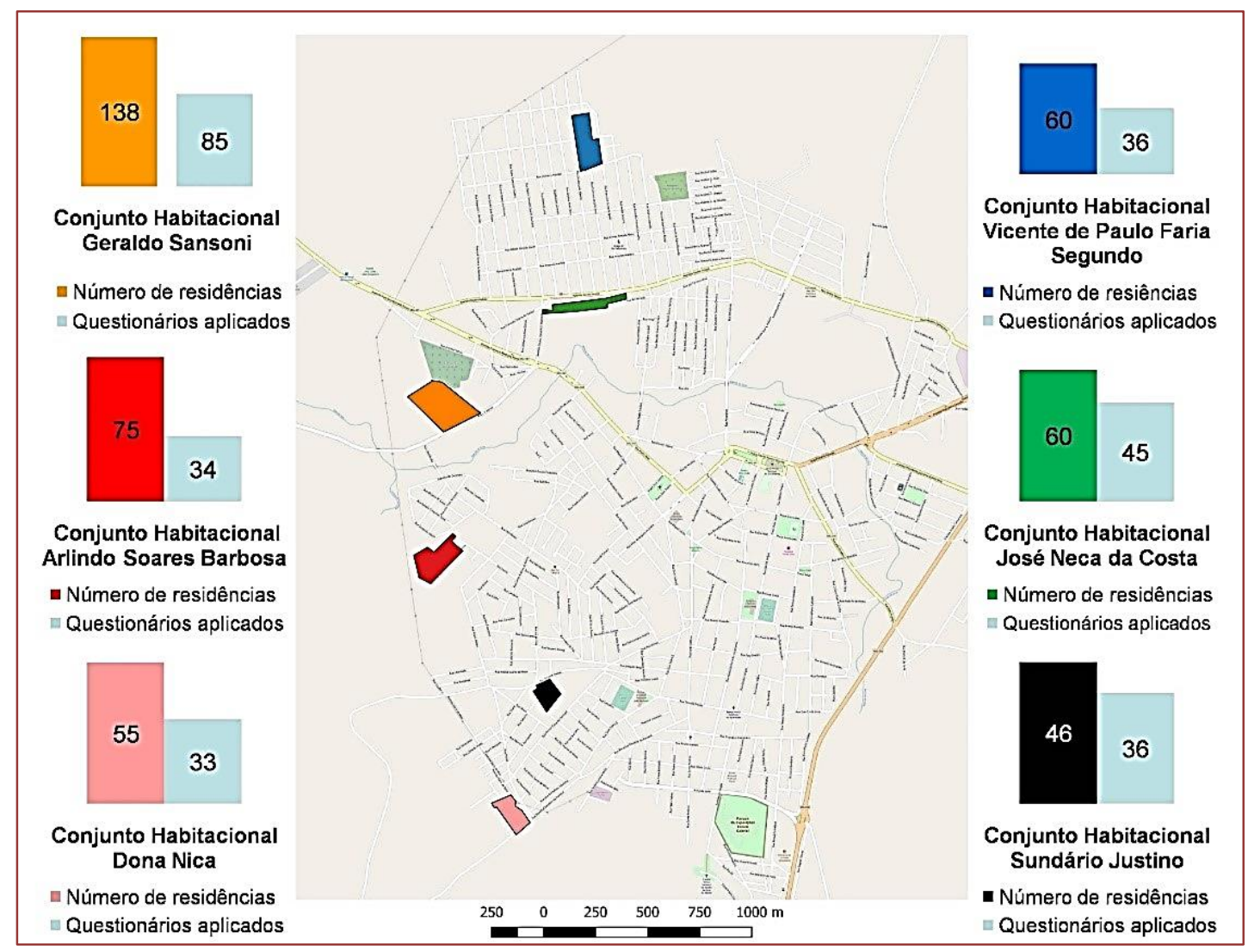

Fonte: Arquivo próprio (2019)

Através dos dados coletados na pesquisa de campo observou-se que 46\% das habitações abrigam 4 ou mais pessoas (gráfico 1) e, portanto, nestes casos cada dormitório é utilizado por mais de uma pessoa, implicando assim em um possível desconforto quando trata-se de habitações com 2 quartos. 
Gráfico 1 - Quantidade de pessoas que residem por edificações

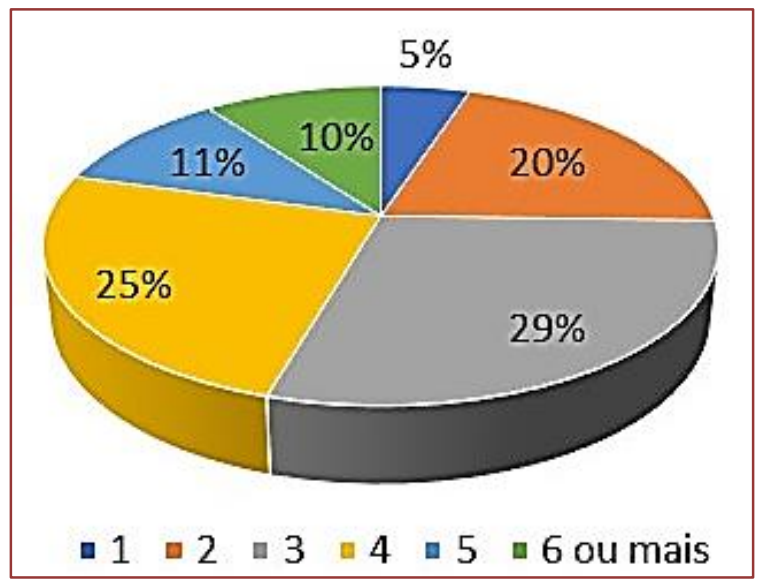

Fonte: Arquivo próprio (2019)

Outras informações importantes para análise do perfil familiar das habitações populares na cidade de Piumhi é a faixa etária composta pelas famílias. A tabela 1 mostra a proporção de habitantes das casas de acordo com a sua faixa etária. As habitações possuem em média 1 habitante menor de idade e 2 com idade entre 18 e 59 anos, enquanto que os habitantes acima de 59 anos se apresentam em apenas $18 \%$ da amostra investigada.

Em relação ao chefe de família verificou-se predominância do gênero masculino (gráfico 2), o que condiz com a situação atual do Brasil. Contudo há um aumento significativo da participação feminina, segundo o IBGE (2002). No contexto atual, a mulher vem ganhando espaço como gestora do lar, tornando-se provedora do arrimo familiar, através do trabalho.

Gráfico 2 - Sexo do chefe de família

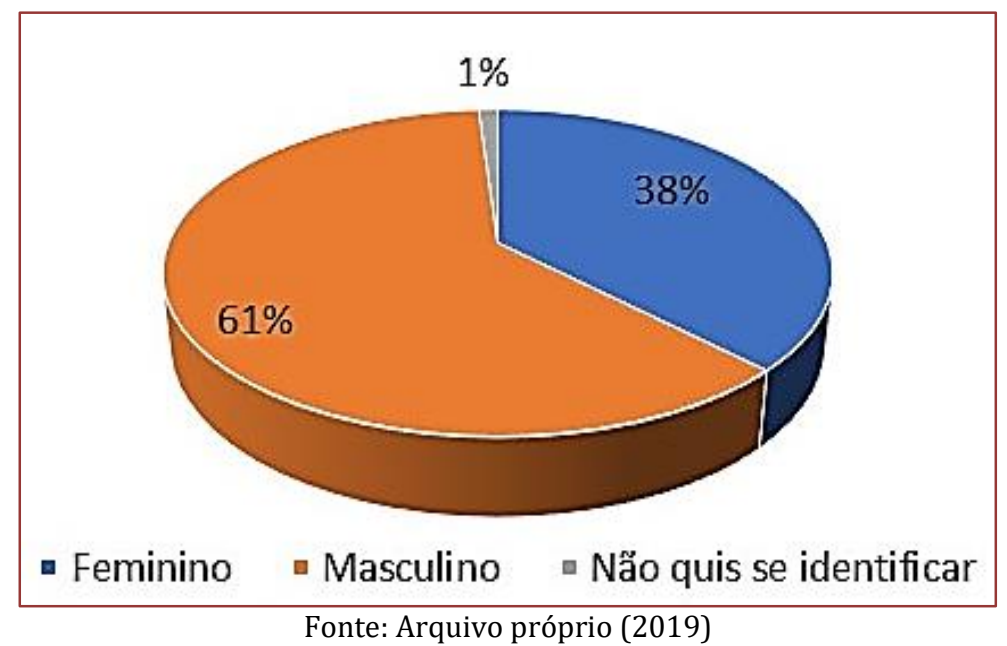

Em relação à quantidade de famílias que residem atualmente nas habitações populares (gráfico 3), verificou-se que $78 \%$ são famílias contempladas originalmente no programa MCMV. 
Gráfico 3 - Famílias contempladas originalmente no PMCMV

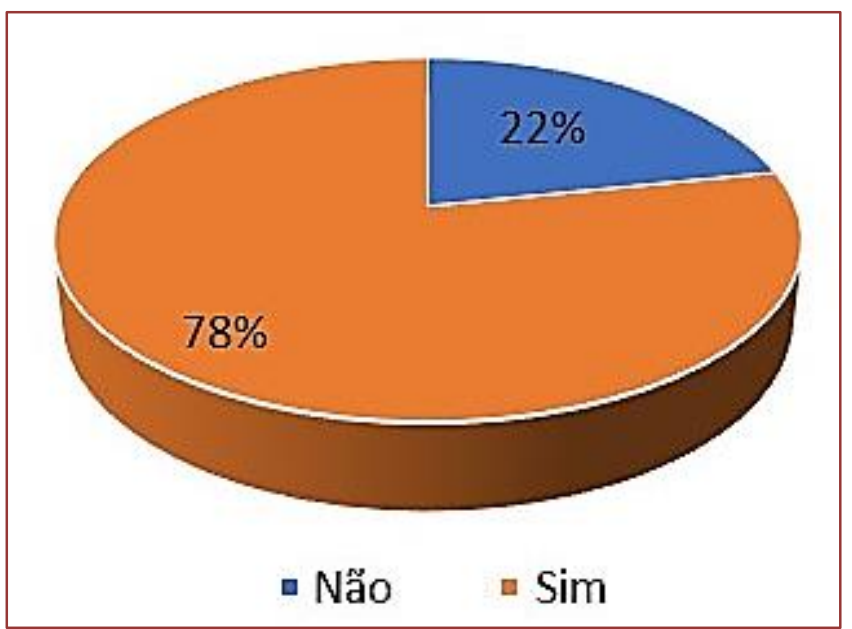

Fonte: Arquivo próprio (2019)

\section{CONCLUSÕES}

A utilização da Avaliação de Pós-Ocupação tem se mostrado eficiente para identificação dos objetivos propostos pelo estudo, além disso, essa ferramenta tem viabilizado a coleta das informações com confiabilidade para se mensurar e analisar os dados obtidos.

0 perfil familiar característico das famílias contempladas em EHIS de Piumhi, traduz-se de famílias compostas de 3 ou 4 integrantes (54\%), a tradicional família brasileira, com um pai, uma mãe e um ou dois filhos. Sendo assim há a necessidade de habitações condizentes com esse padrão. As famílias também apresentam poucos idosos, sendo que na maioria que os possuem, um parente próximo da família tradicional.

0 gênero do chefe de família é principalmente o masculino (61\%), porém não há tanta discrepância do feminino, o que demonstra que o aumento da presença das mulheres como chefe de família.

Acredita-se ainda que a partir da caracterização familiar do município de Piumhi, pode-se propor estudos que visem um modelo adequado de habitação. Ainda com a utilização de APOs, é possível realizar investigações técnicas e analisar a concepção das habitações sociais do município.

Os dados apresentados possibilitaram uma caracterização inicial das famílias, contudo, com a continuidade da pesquisa e a análise de outros dados obtidos dos questionários aplicados será possível compreender outros aspectos importantes da Pós-Ocupação desses Empreendimentos Habitacionais de Interesse Social.

\section{REFERÊNCIAS}

[1] BRANDÃO, Doulgas Queiro; HEINECK, Luis Fernando Mählmann. Significado multidimensional e dinâmico de morar: compreendendo as modificações na fase de uso e propondo flexibilidade nas habitações sociais. Ambiente Construido, [Oline], 2003, vol.3, n.4, p.35-48.

[2] ESTARQUE, Mariana. Déficit habitacional e população de rua crescentes desafiam gestão Bolsonaro. Folha de S.Paulo, São Paulo, 18 de nov. 2018. Disponível em: <https://folha.com/0tngm8zk>. Acesso em: 04 de abr. de 2019.

[3] FUNDAÇÃO JOÃO PINHEIRO. Centro de Estudos Políticos e Sociais. Déficit habitacional no Brasil 2013-2014. Disponível em: <http://www.fjp.mg.gov.br/index.php/produtos-e-servicos1/2742-deficit-habitacional-no-brasil-3>, Centro de Informações e Estatísticas, Belo Horizonte, 2016, p.92.

[4] InSTITUTO BRASILEIRO DE GEOGRAFIA E ESTATístiCA. Minas Gerais - Piumhi. Disponível em: <http://cidades.ibge.gov.br/painel/painel.php?codmun=315150> Acesso em: 15 de abril de 2019.

[5] INSTITUTO BRASILEIRO DE GEOGRAFIA E ESTATÍSTICA. Perfil das mulheres responsáveis pelos domicílios no Brasil 2000. Rio de Janeiro: IBGE, 2002.

[6] ONO, Rosaria; ORNSTEIN, Sheila Walbe; VILLA, Simone Barbosa; FRANÇA, Ana Judite G. Limongi. Avaliação pós-ocupação: na arquitetura, no urbanismo e no design: da teoria à prática. [S.l: s.n.], 2018. 
[7] PIUMHI (Município). Prefeitura Municipal de Piumhi 2017-2020. Disponível em:<http://prefeiturapiumhi.mg.gov.br/cidade-carinho/> Acesso em: 15 de abr. 2019.

[8] PORTAL BRASIL. Minha Casa Minha Vida acelera queda do déficit habitacional no País. Disponível em: <http://www.brasil.gov.br/infraestrutura/2016/03/minha-casa-minha-vida-acelera-queda-do-deficit-habitacionalno-pais> Acesso em: 20 de mar. 2019.

[9] VALE, Kátia Cristina do. Avaliação Pós-Ocupação do Conjunto Residencial. Gervásio Maia - PB. 2012.119 f. Dissertação (Mestrado em Urbanismo) -Universidade Federal da Paraíba, João Pessoa, 2012.

Participação em Congressos, publicações e/ou pedidos de proteção intelectual:

I Congresso de Pesquisa e Inovação do Sudeste (CONPISUD), 08 a 10 de maio de 2018. 


\section{Capítulo 3}

\section{Avaliação do setor de saneamento no Brasil período 2015 usando o método Análise Envoltória de Dados (DEA)}

\section{Joel de Jesus Macedo}

Armando Vaz Sampaio

Resumo: 0 uso de benchmarking é comum em ambiente regulado, no qual os reguladores buscam induzir a relação custo-eficiência ou coibir o poder de monopólio de uma empresa ou conjunto de empresas. Diante disso, o que se pretende, neste estudo, é analisar a eficiência do setor de saneamento no Brasil no período de 2015. Para atingir o objetivo, o estudo mensura a eficiência produtiva das empresas de saneamento do Brasil a partir do método Análise Envoltória de Dados (DEA). Quanto à contribuição, o estudo se destaca por adotar a variável esgoto tratado, pois, apesar de alguns estudos já terem utilizaram as técnicas de Análise Envoltória de Dados na mensuração da eficiência do setor, nenhum adotou a variável percentual de esgoto tratado. Os dados e as variáveis consideradas neste trabalho têm origem nas informações correspondentes a 18 Companhias Estaduais de Saneamento Básico (CESB), cujas estruturas são semelhantes, inclusive quanto à natureza jurídica, por exemplo. Quanto às variáveis utilizadas, foram consideradas o Opex como input (1), como output (3): o índice de tratamento de esgoto, a extensão de rede de água e esgoto e a quantidade de ligações ativas. Das 18 empresas analisadas sete podem ser consideradas benchmark: Cagece (CE), Casal (AL), Sabesp (SP) e Sanepar (PR), Cosanpa (PA), Agespisa (PI), Copasa (MG).

Palavras-chave: Saneamento Básico; Medidas de Eficiência; Análise Envoltória de Dados. 


\section{INTRODUÇÃO}

Os setores de infraestrutura e economias de redes, no Brasil, vêm passando por intenso processo de reestruturações e discussões. Em especial, o setor do saneamento básico vem ganhando, desde a implementação da Política Nacional de Saneamento, na década de 70, cada vez mais espaço nos debates acadêmicos e governamentais, principalmente nos aspectos relacionados à qualidade e aos preços praticados.

No contexto da Planasa, o assunto ganhou mais importância a partir da promulgação da Lei no 11.445, de 5 de janeiro de 2007, conhecida como Lei Nacional de Saneamento Básico (LNSB) ou Lei de Diretrizes Nacionais para o Saneamento Básico (LDNSB), que, entre outras prerrogativas, considera, em seu artigo $2^{\circ}$, alínea b, a eficiência econômica como um dos princípios fundamentais do serviço público de saneamento. Além disso, no âmbito dos princípios regulatórios, a Lei estabelece que as tarifas praticadas nesse setor devem assegurar tanto o equilíbrio econômico e financeiro dos contratos como a modicidade tarifária, mediante mecanismos que induzam a eficiência e eficácia dos serviços prestados, possibilitando a apropriação social dos ganhos de produtividade.

Apesar de a LNSB considerar a eficiência econômica como um dos princípios fundamentais, verifica-se que as companhias prestadoras do serviço de abastecimento de água e esgotamento sanitário, em sua maioria, ainda não incorporaram a produtividade e a eficiência econômica em seus modelos tarifários, e mesmo aquelas que as incorporaram não são muito transparentes quanto à metodologia adotada. Desde a instituição da LNSB, as empresas prestadoras do serviço de saneamento procuram, mesmo que timidamente, adequar-se às normas e exigências regulatórias. Como consequência da Lei, essas empresas buscam atingir objetivos comerciais, com prática de preços dos serviços e salários compatíveis com os do mercado, e, principalmente, procuram adotar padrões de eficiência. Independente da origem do capital (privado, estatal ou misto), a adequação do setor à LNSB conduz as empresas a um processo no qual a eficiência é uma variável decisiva para seu sucesso.

A preocupação com o desempenho do setor é mais antiga que a Lei do Saneamento Básico. Em 1995, foi instituído, dentro Programa de Modernização do Setor de Saneamento (PMSS), o Sistema Nacional de Informações sobre Saneamento (SNIS), vinculado à Secretaria Especial de Desenvolvimento Urbano da Presidência da República (SEDU) e executado com o apoio do Instituto de Pesquisas Econômicas Aplicadas (IPEA). Desde sua instituição, o SNIS passou a ser a principal fonte de informações a orientar o processo de transformação do setor de saneamento básico no Brasil, apoiando a formulação e execução da Política Nacional de Saneamento. Seu conteúdo apresenta informações desagregadas tais como: abastecimento de água e redes de esgoto e resíduos sólidos urbanos. As informações disponíveis no SNIS apresentam indicadores de cunho operacional, gerencial e financeiro.

O SNIS apresenta alguns dados sobre o desempenho dos operadores dos serviços de saneamento básico. Não existe um indicador total que permita dizer que esta ou aquela empresa é benchmark; antes, o que se observa é que determinada empresa é mais eficiente em determinado assunto e menos em outro. Nesse sentido, a análise de desempenho dos operadores assume relevância, permitindo o benchmarking entre os sistemas de saneamento de diferentes países ou região, o qual é determinante como ferramenta de apoio ao processo regulatório e à tomada de decisões, bem como à definição de estratégias por parte dos agentes. No contexto interno, esse tipo de análise permite o benchmarking entre operadores, estimulando ganhos de eficiência.

O benchmarking é uma sistemática de comparação da performance de uma companhia em relação a outras. No sentido mais amplo, é a comparação da produção entre entidades, que podem constituir-se como empresas, organizações, divisões, indústrias e projetos, entre outras formas. A ideia subjacente é comparar entidades que transformam algum tipo de insumo em produtos ou serviços. 0 uso de benchmarking é comum em ambiente regulado, no qual os agentes reguladores buscam induzir a relação custo-eficiência, ou para coibir o poder de monopólio de uma empresa ou conjunto de empresas.

Bogetoft e Otto (2011) destacam que o estudo de benchmarking é resultante de uma combinação de duas ciências tradicionais: uma tem origem na ciência da administração, na programação matemática e na pesquisa operacional; a outra tradição de pesquisa tem um cunho mais econômico. A primeira linha é uma classe voltada para abordagens de modelos de DEA, enquanto a perspectiva econômica está mais orientada para a econometria. 
Quanto à prática de benchmarking, Lindau, Costa e Sousa (2001) definem-na como um processo contínuo e sistemático utilizado para investigar o resultado, em termos de eficiência e eficácia, de unidades com processos e técnicas comuns de gestão. Assim, o benchmarking é um parâmetro de comparação entre o desempenho de empresas, processos, produtos, serviços e práticas (CAMP, 1993; 1998). Além disso, de acordo com Camp (1998), o benchmarking identifica processos, práticas e métodos gerenciais para avaliar um ambiente competitivo, de modo que se estabelece um monitoramento contínuo para garantir a descoberta das melhores práticas exercidas por outras empresas.

Diante desse cenário, o objetivo principal deste estudo é estimar a eficiência técnica do setor de saneamento no Brasil, no período de 2015, por meio da Análise Envoltória de Dados (DEA). A escolha do período se deu em virtude de ser o período mais recente com disponibilidade dos dados no SNIS. Em geral, o Sistema de Informações tem dois anos de defasagem para disponibilização dos dados.

Quanto à contribuição, o estudo se destaca por adotar a variável esgoto tratado, pois, apesar de alguns estudos já terem utilizaram as técnicas de Análise Envoltória de Dados na mensuração da eficiência do setor, nenhum adotou a variável percentual de esgoto tratado. Dado que essa variável tem cobertura tarifária para realização do tratamento, e caso a empresa não tratamento, pode ser vista como empresa eficiente, haja vista que comparada aos seus pares apresenta custo menor; no entanto, ela não prestou o serviço adequadamente, de modo que utilizar a variável esgoto coletado não justifica o custo, dado que o custo é inerente ao tratamento.

Aliados a todos estes possíveis problemas, um regulador não conhece todas as ações da empresa regulada. Sem pleno conhecimento, o regulador se defronta com limitações na regulação de tarifas. As empresas reguladas detêm mais informação sobre a gestão de suas respectivas áreas de concessão do que o regulador. 0 regulador pode conferir os custos efetivamente incorridos pela empresa, mas não tem como avaliar o grau de esforço despendido pela empresa para obtenção de melhores níveis de eficiências. Caso o regulador adote medidas de determinação de tarifas arbitrariamente, sem o real conhecimento dos custos, pode ferir o princípio da sustentabilidade econômica e financeira da companhia, ou, então, cobrar valores superiores aos devidos pelo usuário.

No entanto, para mitigar as "arbitrariedades", o regulador pode adotar métricas sem mesmo conhecer, por exemplo, a acuracidade e os detalhes dos custos de produção. Portanto, para determinar os custos eficientes dos prestadores de serviços sob sua jurisdição, o regulador pode recorrer aos métodos de benchmarking.

O trabalho justifica-se em virtude da necessidade, para o setor e para a sociedade, de uso de técnicas de mensuração de eficiência técnica para determinação de tarifas módicas, ou seja, tarifas que representem dois vetores: 1) ao prestador, a justa remuneração pela prestação dos serviços; e 2) ao usuário, a justa tarifa pela prestação dos serviços. Portanto, a aplicação dessas técnicas vai ao encontro da diretriz principal da Lei do Saneamento Básico, cuja atenção central é a modicidade tarifária, que carrega uma relação intrínseca com a eficiência.

\section{REVISÃO DA LITERATURA}

No domínio da teoria da produção, tem-se os conceitos de eficiência técnica, eficiência alocativa e eficiência de escala, bem como os conceitos mais avançados, como eficiência dinâmica e estruturais. Vários desses conceitos podem ser operacionalizados de maneiras diferentes. Podem, por exemplo, medir a eficiência técnica em termos de espaço de entrada, espaço de saída, ou ambos os espaços.

Houaiss (2001) define a eficiência como a virtude ou característica de conseguir o melhor rendimento com o mínimo de erros, dispêndio de insumos, tempo, recursos financeiros. Lovell (1993) conceitua a produtividade como um indicador que mede o quanto uma Decision Making Unit (DMU) consegue produzir, em termos de quantidade de produtos, com determinada quantidade de insumo. A eficiência pode ser compreendida como a comparação dos resultados alcançados com os recursos utilizados. Quanto mais resultados obtidos para determinada quantidade de recursos disponíveis, maior a eficiência técnica.

Ao focar na eficiência de determinada empresa, pode-se descrever a formalização do problema da seguinte maneira: uma empresa $k$ utiliza $m$ insumos $x^{k}=\left(x_{1}^{l}, \ldots, x_{m}^{k}\right) \in \mathbb{R}_{+}^{m}$ para produzir $n$ outputs $y^{k}=$ $\left(y_{1}^{k}, \ldots, x_{n}^{k}\right) \in \mathbb{R}_{+}^{n}$. O conjunto de planos de produção viável ou a combinação de inputs-outputs disponíveis para a empresa $k$ é dado pela tecnologia ou pelo conjunto de possibilidade de produção $T, T=$ $\left\{(x, y) \in \mathbb{R}_{+}^{n} \times \mathbb{R}_{+}^{m} \mid x\right.$ pode produzir $\left.y\right\}$. 
A eficiência está associada a uma questão de utilização de menor quantidade de insumos para produzir maior quantidade de produtos. Por exemplo, numa situação com duas empresas $\left(x^{1}, y^{1}\right)$ e $\left(x^{2}, y^{2}\right)$, diz-se que a empresa 2 domina ou é mais eficiente que a empresa 1 se não utilizar mais insumo para produzir no mínimo a mesma quantidade de produtos e é estritamente dominante se é melhor em pelo menos uma dimensão. Ou seja, diz-se que $\left(x^{2}, y^{2}\right)$ domina $\left(x^{1}, y^{1}\right)$ se e somente se $x^{2} \leq x^{1}, y^{2} \geq y^{1}$, e $\left(x^{1}, y^{1}\right) \neq$ $\left(x^{2}, y^{2}\right)$.

A dominância permite classificar parcialmente empresas. Algumas empresas podem ser comparadas, enquanto outras não o podem.

Figura 1 - Eficiência e dominância

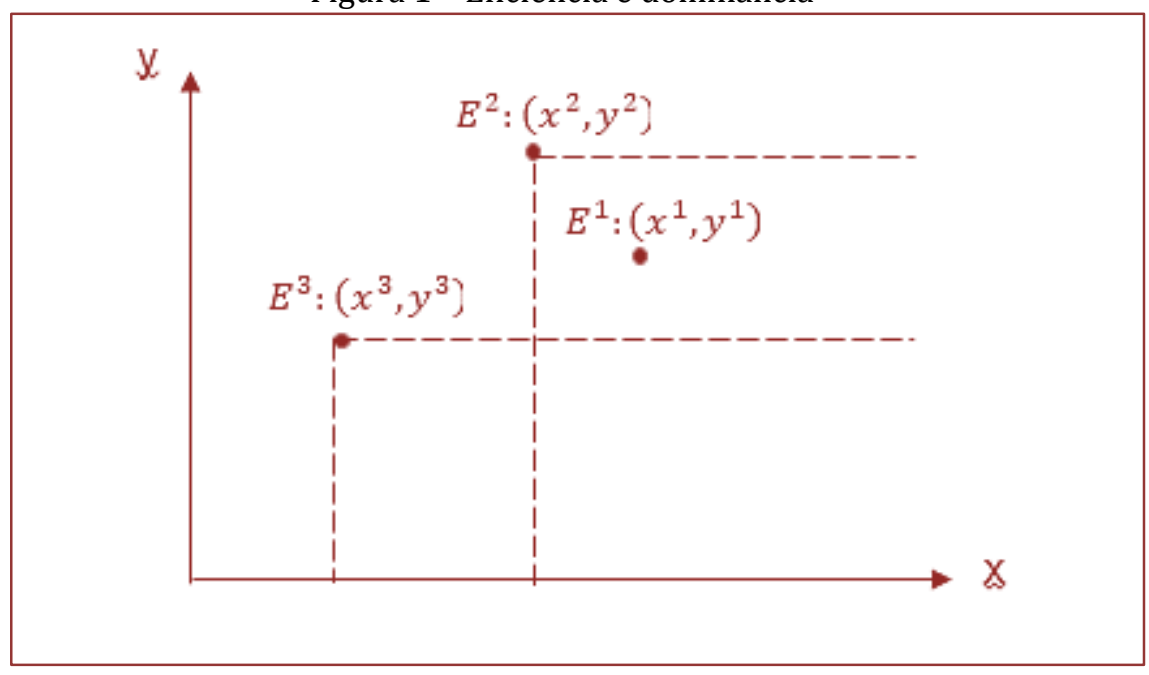

Fonte: Adaptado de Bogetoft e Otto (2011)

A

Figura 1 ilustra uma situação em que a empresa 2 domina ou é mais eficiente que a empresa 1, enquanto a empresa 3 não domina nem é dominada pela empresa 1 ou 2 . A noção de dominância é relevante, pois todos preferem um plano de produção mais eficiente ou dominante a um menos eficiente. Dessa maneira, a empresa 2 seria considerada um ponto de referência para a empresa 1 em termos de uso de poucos recursos para obtenção de saídas superiores às da empresa 1. Portanto, para que a empresa 2 seja mais eficiente que a empresa 1, é necessário que o produto esteja aumentando enquanto a quantidade de insumos é reduzida.

Na teoria econômica, as empresas eficientes são aquelas que não são dominadas por outras (BOGETOFT; OTTO, 2011). Para determinar quais empresas são eficientes, é necessário descrever todas as empresas possíveis. Para determinado conjunto de tecnologia $T$, a eficiência pode ser definida da seguinte forma: $(x, y)$ é eficiente em $T$ se e somente se não pode ser dominado por algum $\left(x^{\prime}, y^{\prime}\right) \in T$.

\subsection{EFICIÊNCIA PRODUTIVA: ABORDAGEM NÃO PARAMÉTRICA}

Os estudos da mensuração de eficiências por meio técnicas não paramétricas surgiram com Farrell (1957), que propôs um modelo empírico para o cálculo da eficiência relativa. Charnes, Cooper e Rhodes (1978), com base nas análises de Farrell (1957), generalizaram as equações deste autor em um problema de programação linear, possibilitando realizar cálculos que utilizavam múltiplos insumos e produtos. Essa generalização deu origem a uma técnica de fronteiras de produção e indicadores de eficiência produtiva denominada Data Envelopment Analysis (GOMES, 2003). Esse modelo passou a ser conhecido como modelo CCR, em homenagem a seus autores, ou modelo CRS, Constant Returns to Scale.

Banker, Charnes e Cooper (1984) criaram outro modelo, que considerava os ganhos de escala em seu cálculo. Esse modelo passou a ser identificado como modelo Variable Returns to Scale (VRS), ou modelo BCC, em homenagem aos autores. O BBC permite comparar as DMU que operam em escala semelhante. Assim, a eficiência de uma DMU é obtida dividindo-se sua produtividade pela maior produtividade entre as DMU cujos retornos de escala sejam semelhantes. Assim, a fronteira BCC apresenta linhas/facetas de 
ângulos variados, o que caracteriza uma fronteira linear em partes. A Erro! Fonte de referência não encontrada. apresenta uma comparação entre os dois tipos de fronteira, BCC e CCR.

Figura 2 - Comparação entre fronteiras dos modelos BCC e CCR

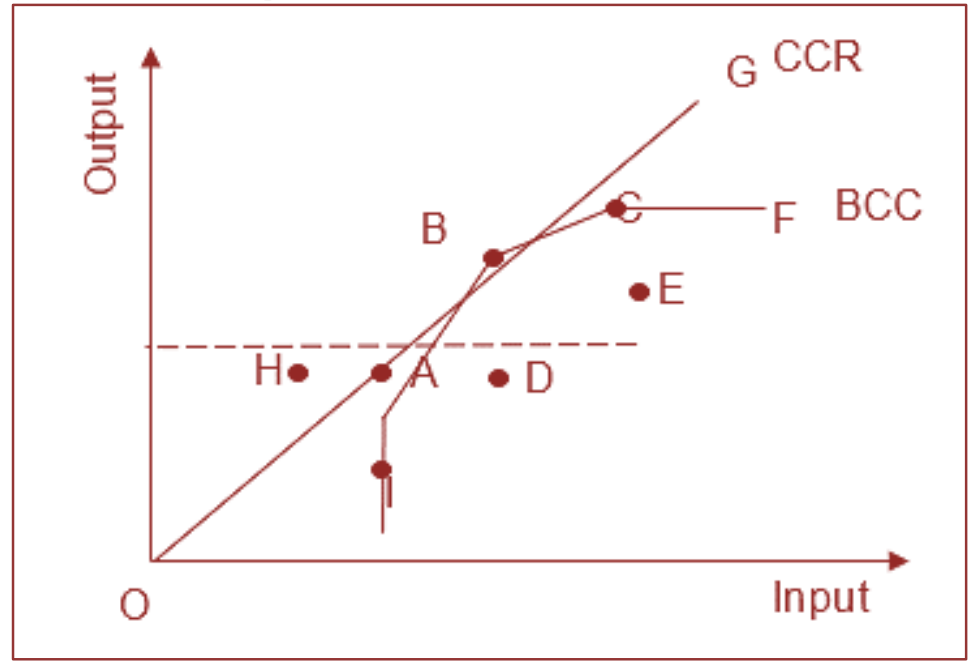

Fonte: Os autores (2017)

A Erro! Fonte de referência não encontrada. apresenta as fronteiras de produção dos métodos DEA/CRS e DEA/VRS para um input e um output. A fronteira associada à DEA/CRS é dada pelo segmento OG, e a ineficiência técnica do ponto D é dada pela distância DH. Nos modelos DEA/VRS, a fronteira tem uma forma segmentada linear, representada pela IABCF, e a ineficiência técnica do ponto D é a distância DA.

Uma DMU possui eficiência de escala quando os resultados obtidos no modelo DEA/CRS e DEA/VRS são os mesmos. Caso os resultados não sejam os mesmos, a ineficiência de escala é obtida pela diferença entre os escores de cada modelo.

Existem três tipos de Retorno Variável à Escala: Retorno crescente, em que o aumento da quantidade de inputs provoca um aumento, em maior proporção, na quantidade gerada de outputs. Isso ocorre quando uma DMU está operando muito abaixo de sua capacidade ótima; Retorno constante, em que o aumento da quantidade de inputs provoca um aumento em igual proporção na quantidade gerada de outputs. Isso ocorre quando uma DMU está operando em sua capacidade ótima; Retorno decrescente, em que o aumento da quantidade de inputs provoca um aumento em menor proporção na quantidade gerada de outputs. Isso ocorre quando a DMU está operando acima de sua quantidade ótima.

O Retorno Variável à Escala, BCC, significa que as DMU podem apresentar qualquer um dos três retornos à escala mencionados acima. No entanto, em virtude das diferenças entre os tipos de retornos à escala, os modelos CRS e VRS calculam tipos diferentes de eficiências, conforme a Figura 3.

Figura 3 - Modelos matemáticos e respectivas eficiências

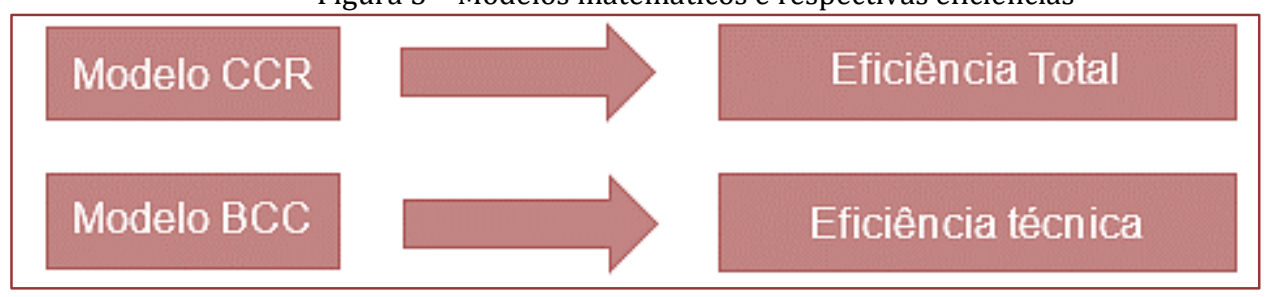

Fonte: Adaptado de Seiford (1990) e Sengupta (2000)

O modelo CCR compara uma DMU com todas as suas concorrentes, enquanto o BCC compara uma DMU apenas com aquelas que operam em uma escala semelhante. Assim, a eficiência técnica pode ser considerada uma componente da eficiência total, e a outra componente é a eficiência de escala, que pode ser definida como a eficiência relacionada ao fato de a empresa estar operando abaixo ou acima de sua 
escala ótima. Seiford (1990) e Sengupta (2000) apontam que, desde a criação do modelo CCR e do BCC, desenvolveu-se uma série de outros modelos, destinados aos mais diversos fins, e os resultados obtidos têm se tornado cada vez mais completos.

Os modelos de mensuração da eficiência produtiva podem ser orientados de duas formas: para a minimização dos insumos ou para a maximização dos produtos (COELLI; RAO; BATTESE, 1998).

Figura 4 - Modelo de orientação a insumo ou produto

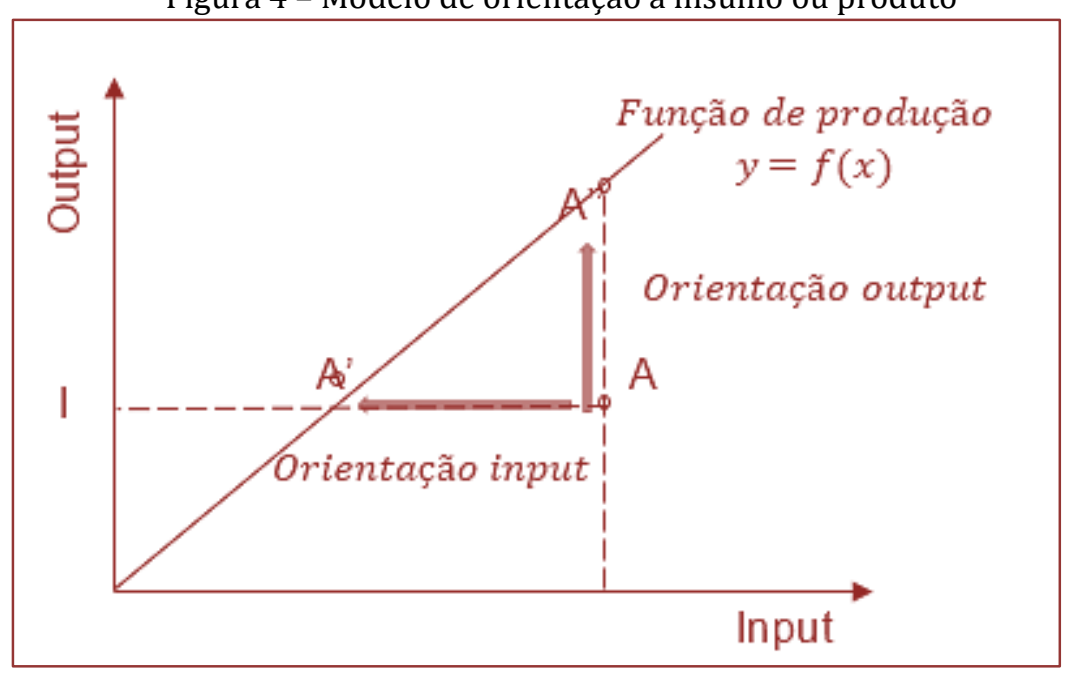

FONTE: Coelli, Rao e Battese (1998)

Por exemplo, no caso de a orientação ser para minimização dos inputs, o modelo busca responder à seguinte questão: dado o nível de outputs que uma unidade produz, qual é a redução que pode ocorrer nos inputs de modo a manter o corrente nível de outputs? Já os modelos orientados para a maximização dos outputs procuram responder à questão: dado o nível de inputs utilizado, qual é o maior nível de outputs que se pode alcançar, mantendo-se o nível dos inputs? (VILELA, 2004).

Sob o enfoque do uso eficiente dos recursos, também conhecida como orientação ao insumo, a medida de eficiência técnica, ou eficiência de Farrell, pode ser obtida pelo uso dos insumos $(E)$ de uma DMU $(X, Y)$ como a máxima contração radial do vetor de insumos $X$ que permite produzir a mesma quantidade de produtos Y, ou seja:

$$
E^{0}=E\left(\left(x^{0}, y^{0}\right) ; T^{*}\right)=\operatorname{Min}\left\{E \in \mathbb{R}_{+} \mid\left(E x^{0}, y^{0}\right) \in T^{*}\right.
$$

em que $E$ assume um valor que pode variar de 0 a 1 . Um valor unitário de $E$ igual a 1 indica que não há folga de insumos; ou seja, não é possível reduzir a quantidade de insumos e manter nível de produção. Para este caso, diz-se que a DMU é eficiente.

Essa técnica mede as eficiências das DMU dentro da gama de menos que ou igual a um. Wang, Chin e Yang (2007) argumentam que, se a DMU é avaliada como a melhor eficiência relativa (um), então, diz-se que DEA é eficiente; o contrário seria DEA não eficiente. As observações com índices de eficiência igual à unidade (um) delimitam a fronteira de eficiência. Qualquer observação com índice de eficiência menor que a unidade se localiza abaixo da fronteira, dentro do conjunto de produção. A distância das unidades ineficientes em relação à fronteira de eficiência equivale ao índice de eficiência ou ineficiência.

\subsubsection{FUNÇÃO DE PRODUÇÃO}

DEA combina a estimativa da tecnologia com a mensuração do desempenho relacionado a essa tecnologia. Dessa forma, a técnica integra os dois problemas básicos: i) definir um padrão de desempenho, a fronteira, e b) avaliar realizações em relação ao padrão estabelecido. Existem vários métodos de DEA que diferem em termos de tecnologia estimada e de conceito de eficiência. 
A literatura pressupõe que a definição DEA em geral envolve $K$ empresas que usam $m$ insumos para produzir $n$ produtos. Assume, ainda, que $x^{k}=\left(x_{1}^{k}, \ldots, x_{m}^{k}\right) \in \mathbb{R}_{+}^{m}$ é o insumo utilizado e $y^{k}=\left(y_{1}^{k}, \ldots, y_{m}^{k}\right) \in$ $\mathbb{R}_{+}^{m}$ são os produtos produzidos pela empresa $k$, e $k=1, \ldots, K$. Se os preços dos insumos e os preços dos produtos estão disponíveis, podem ser denotados como $w^{k}=\left(w_{1}^{k}, \ldots, w_{m}^{k}\right) \in \mathbb{R}_{+}^{m}$ e $p^{k}=\left(p_{1}^{k}, \ldots, p_{n}^{k}\right) \in \mathbb{R}_{+}^{n}$ para a empresa $k$, em que o subscrito representa o insumo e produto, e o sobescrito indica a empresa individual.

Em forma de vetor, o plano de produção de uma empresa pode ser escrito por $\left(x^{k}, y^{k}\right)$. 0 plano de produção de um conjunto de empresas pode ser escrito pela matriz $X=\left(x^{1}, x^{2}, \ldots, x^{k}\right)$, e o conjunto de produção dessas empresas, por: $Y=\left(y^{1}, y^{2}, \ldots, y^{k}\right)$. Finalmente, o conjunto de tecnologia ou conjunto de possibilidades de produção pode ser escrito por $T=\left\{(x, y) \in \mathbb{R}_{+}^{m} \times \mathbb{R}_{+}^{n} \mid x\right.$ pode produzir $\left.y\right\}$.

Bogetoft e Otto (2011) demonstram que DEA estima a tecnologia a partir do princípio da extrapolação mínima, a qual encontra o menor custo de produção, mantendo a regularidade de produção. Quando combinados o conceito de extrapolação mínima com o conceito de Farrell de mensurar a eficiência como uma melhora proporcional, obtêm-se os programas matemáticos considerados nas abordagens DEA.

\subsubsection{ESTUDOS REALIZADOS}

Segundo Bogetoft e Otto (2011), os métodos de benchmarking são uma combinação de duas tradições de pesquisa: uma tem suas origens na ciência da administração, programação matemática e pesquisa operacional, baseada na metodologia DEA, e a outra tem uma orientação mais econômica e econométrica, baseada na metodologia da Stochastic frontier analysis (SFA). De acordo com os autores, as duas linhas de pesquisa conviveram por muitos anos, cada uma com seu grupo de proponentes. Para eles, ambas as abordagens têm seus méritos, de modo que se pode vê-las como complementares e não como substitutas entre si.

Castro (2003) aponta a metodologia da DEA como ferramenta confiável para avaliar a eficiência das empresas de saneamento básico com os dados disponibilizados no Sistema Nacional de Informações (SNIS). Nessa linha, é oportuno apresentar os estudos que estão na esteira da análise de eficiência com o uso da DEA.

Abbott e Cohen (2009) analisaram 69 trabalhos sobre a eficiência ou a produtividade das empresas de saneamento. Segundo os autores, o método DEA tem sido muito utilizado para mensurar a eficiência e a produtividade das empresas do setor. Os autores destacam que o trabalho pioneiro sobre o assunto no setor é o de Byrnes, Grosskopf e Hayes (1986), que analisaram empresas, tanto privadas quanto públicas, nos Estados Unidos.

Desde então, diversos estudos com o uso da metodologia têm sido apresentados. Abbott e Cohen (2009) apontam que, nos últimos vinte anos, aumentou o interesse pela produtividade, a eficiência e as estruturas ótimas para as indústrias de abastecimento de água e de esgotamento sanitário. Os autores argumentam que, em parte, esse interesse se manifestou no aumento do uso de inúmeras técnicas estatísticas para determinar a produtividade e eficiência do setor de água em diversos países.

Norman e Stoker (1991) analisaram 28 empresas do setor na Inglaterra no período compreendido entre 1987 e 1988. Lambert, Dichev e Raffiee (1993) aplicaram a técnica para 238 empresas públicas e 33 empresas privadas nos Estados Unidos no ano de 1989. Sawkins e Accam (1994) verificaram a eficiência de empresas escocesas.

Aida et al. (1998) avaliaram a possibilidade de uso da DEA/VRS, com orientação ao output, como ferramenta para avaliar o desempenho dos prestadores de serviços de água sob as leis de águas do Japão. Os autores utilizaram cinco variáveis de entradas (quantidade equivalente de pessoal, despesa de exploração, ativo produtivo, população total do município atendido, extensão de rede de água), duas variáveis de saídas (volume de água consumido, receita operacional de água). 
Cubbin e Tzanidakis (1998) fizeram uma aplicação simultânea de DEA e análise de regressão numa comparação de custos para estabelecimento dos limites de tarifas, dentro do ambiente regulatório dos serviços de água e esgoto predominante na Inglaterra e em Gales. 0 objetivo era determinar uma fronteira eficiente, de modo a identificar possíveis reduções nos custos de operação que poderiam ser atingidas pelas empresas do setor. Os autores utilizaram uma variável de entrada (despesa de exploração - Opex) e três outputs (volume de água entregue, comprimento da rede de água, proporção de água distribuída não residencial). A amostra continha 29 empresas, que seriam as DMU para avaliação, sem referência alguma quanto à distinção de operar sistemas de água e esgoto ou apenas sistemas de água. Os autores buscavam identificar o mesmo ranking de eficiência; contudo, não foi isso que ocorreu. Os resultados da análise de regressão foram diferentes do DEA/CRS e ainda mais distintos dos obtidos pelo DEA/VRS.

Thanassoulis (2000) utilizou DEA/VRS com orientação ao output para estabelecer limites de preços em revisões tarifárias, fixadas pelo Office of Water Service (OFWAT), na Inglaterra e em Gales. 0 autor utilizou uma variável de entrada (despesas operacionais - Opex) e três variáveis de saída (número de conexões servidas, comprimento da rede de água, quantidade de água entregue).

Castro (2003) verificou a aplicabilidade da metodologia DEA/VRS, orientada ao produto, ao setor de saneamento brasileiro. Utilizou uma variável de entrada (despesa de exploração - Opex) e quatro variáveis de saída (volume de água consumido, extensão de rede de água, quantidade de ligações ativas de água, quantidade de ligações ativas de esgoto).

Carmo e Távora Junior (2003) utilizaram a DEA/CRS e DEA/VRS com orientação ao produto para mensurar as eficiências técnica e econômica dos prestadores de serviços de saneamento em 26 entidades estaduais brasileiras. Utilizaram cinco variáveis de entradas (mão de obra, volume de água produzido, volume de esgoto coletado, extensão da rede de água, extensão da rede de esgoto) e quatro variáveis de saída (volume de água faturado, volume de esgoto faturado, quantidade de economias ativas de água, quantidade de economias ativas de esgoto). Os resultados apontaram que a eficiência técnica é superior à eficiência de escala e que o setor apresenta retornos crescentes de escala.

Tupper e Resende (2004) utilizaram DEA/CRC e DEA/VRS, ambos com orientação ao output, para investigar a eficiência técnica das companhias de coleta e tratamento de esgoto das regiões Norte e Nordeste do Brasil em 2003 e 2004. Utilizaram três variáveis de entrada (extensão da rede de esgoto por ligações, volume de esgoto coletado, número total de empregados) e duas variáveis de saída (volume de esgoto tratado, número de domicílios atendidos por rede de esgotamento sanitário). Como resultado, encontraram um desempenho abaixo do ótimo e verificaram a possibilidade de diminuir as diferenças entre as regiões de modo a realizar uma melhor comparação de eficiência.

Sato (2011), a partir da técnica DEA, analisou a eficiência de 26 companhias de saneamento das capitais dos estados brasileiros, com dados entre os anos de 2005 e 2008. Utilizou modelos com retornos constantes e modelos com retornos variáveis de escala, e verificou grande variabilidade de eficiência entre as regiões do país, bem como espaço para melhoria de eficiência no setor.

Cruz et al. (2012) mensuraram a eficiência dos prestadores de serviços de abastecimento de água, comparando os prestadores de Portugal e Itália. No estudo, calcularam os escores de eficiência de 33 prestadores italianos e 55 prestadores portugueses de fornecimento de água potável e serviços de esgotamento sanitário, utilizando a técnica de benchmarking não paramétrica, DEA.

Barbosa (2012) procurou explicar o desempenho da regulação econômica do Brasil, a partir da inserção em ambiente regulatório, com uma amostra de 41 prestadoras de serviço de água e esgoto. Nesse trabalho, foi utilizado o DEA, input orientado, com o modelo aditivo Dynamic Slack Based Model (DSBM) para determinar o escore de eficiência e, posteriormente, foi utilizada a técnica de regressão Generalized Estimating Equation (GEE). 0 autor verificou que as prestadoras não estão ganhando produtividade ao longo do tempo e que as performances não são explicadas por experiência, âmbito de atuação e especialização das agências reguladoras.

Cruz e Ramos (2012) utilizaram a DEA/VRS com orientação ao produto para analisar a eficiência da Gestão do Saneamento Básico e seus impactos sobre a promoção da saúde no Brasil. Utilizaram cinco variáveis de entradas (cobertura por redes de abastecimento de água, cobertura por redes coletoras de esgoto, grau de urbanização, médicos por grupos de mil habitantes, PIB per capita). 


\section{MATERIAL E MÉTODO}

Para a aplicação do teste empírico DEA foram utilizados os dados do SNIS de 2015. O SNIS possui uma base de dados que contém informações e indicadores sobre a prestação de serviços de água e esgotos, de manejo de resíduos sólidos urbanos, e drenagem e manejo das águas pluviais urbanas. O SNIS publica anualmente os diagnósticos da situação da prestação de serviços de saneamento básico. Desde 1996, publica informações referentes à água e ao esgotamento sanitário; desde 2002, sobre resíduos sólidos urbanos; e desde 2015, sobre águas pluviais urbanas.

Os prestadores de serviço de abrangência regional, ou seja, as companhias estaduais de saneamento, são responsáveis pelo atendimento de 78,9\% dos municípios que informaram seus dados ao SNIS em 2015 para abastecimento de água, e de 56,5\% para esgotamento sanitário. Em termos de população urbana, esses percentuais são de 75,2\% para abastecimento de água e $66 \%$ para esgotamento sanitário. Como o objetivo deste trabalho é comparar a eficiência de empresas semelhantes, e dado que as Companhias Estaduais de Saneamento Básico (CESB) representam a maior parcela de atendimento, optou-se por essas companhias que possuem atendimentos regionais.

No SNIS há informações sobre 23 CESB em operação, ou seja, 23 unidades produtivas (DMU). Como a metodologias DEA pressupõe homogeneidade dos dados, este estudo será feito entre as empresas que apresentam estruturas semelhantes quanto à natureza jurídica, por exemplo. Feitas essas considerações acerca da amostra, as empresas a serem avaliadas são apresentadas no QUADRO 2.

QUADRO 2 - EMPRESAS A SEREM COMPARADAS

\begin{tabular}{|c|c|l|l|}
\hline \multicolumn{1}{|c|}{ EMPRESA } & UF & \multicolumn{1}{c|}{ SIGLA } & \multicolumn{1}{c|}{ EMPRESA } \\
\hline 1 & PA & Cosanpa & Companhia de Saneamento do Pará \\
\hline 2 & PI & Agespisa & Companhia de Águas e Esgotos do Piauí \\
\hline 3 & MA & Caema & Companhia de Águas e Esgotos do Maranhão \\
\hline 4 & CE & Cagece & Companhia de Água e Esgoto do Ceará \\
\hline 5 & PB & Cagepa & Companhia de Águas e Esgotos da Paraíba \\
\hline 6 & PE & Compesa & Companhia Pernambucana de Saneamento \\
\hline 7 & AL & Casal & Companhia de Saneamento de Alagoas \\
\hline 8 & RN & Caern & Companhia de Águas e Esgotos do Rio Grande \\
\hline 9 & SE & Deso & Companhia de Saneamento de Sergipe \\
\hline 10 & BA & Embasa & Empresa Baiana de Águas e Saneamento \\
\hline 11 & RJ & Cedae & Companhia Estadual de Águas e Esgotos \\
\hline 12 & MG & Copasa & Companhia de Saneamento de Minas Gerais \\
\hline 13 & ES & Cesan & Companhia Espírito-Santense de Saneamento \\
\hline 14 & SP & Sabesp & Companhia de Saneamento Básico do Estado de São Paulo \\
\hline 15 & RS & Corsan & Companhia Rio-Grandense de Saneamento \\
\hline 16 & SC & Casan & Companhia Catarinense de Águas e Saneamento \\
\hline 17 & PR & Sanepar & Companhia de Saneamento do Paraná \\
\hline 18 & GO & Saneago & Saneamento de Goiás S/A \\
\hline
\end{tabular}

FONTE: Os autores (2017)

Da amostra inicial das CESB, foram excluídas cinco empresas que não atenderam aos requisitos mencionados anteriormente. Cabe salientar que a quantidade de empresas está dimensionada para a quantidade de variáveis. De acordo com Lins e Meza (2000), a quantidade de DMU deve ser, no mínimo, o dobro da quantidade de variáveis. Gomes et al. (2004) sugerem que o número de DMU deve ser, no mínimo, o triplo da quantidade de variáveis.

\subsection{SELEÇÃO DOS INSUMOS E PRODUTOS}

Considera-se, para este trabalho, um input e três outputs como suficientes para proceder à avaliação de eficiência em fornecimento de serviços de saneamento com indicadores do SNIS. As siglas junto à descrição das variáveis serão adotadas ao longo deste trabalho. 


\begin{tabular}{|l|l|l|}
\hline \multicolumn{2}{|c|}{ Inputs } & \multicolumn{1}{c|}{ Outputs } \\
$\begin{array}{l}\text { Despesa de exploração } \\
\text { (Opex) }\end{array}$ & - Índice de tratamento de esgoto $(\% T)$ \\
- Extensão de rede de água e esgoto $(R)$ \\
- Quantidade de ligações ativas de água e esgoto $(L)$
\end{tabular}

Fonte: Os autores (2017)

A variável de input reflete as despesas com pessoal, produtos químicos, energia elétrica, despesas com água importada, despesas fiscais ou tributárias computadas no Opex, outras despesas de exploração, despesas com exportação de esgoto, isto é, reflete o Opex. Esses custos são necessários para a geração dos outputs.

Quanto às variáveis de outputs, verificou-se, a partir da revisão da literatura, que a maioria dos estudos adota a variável quantidade de ligações ativas de água e esgoto. Da mesma forma, também é comum o uso de extensão de rede de água e esgoto. Quanto à variável índice de tratamento de esgoto, nenhum dos trabalhos verificados a adotou. 0 uso desta variável na mensuração da eficiência é um diferencial em relação aos demais estudos realizados. Em virtude do objetivo deste trabalho, que é a mensuração da eficiência, é imprescindível que essa variável seja incluída como uma saída, uma vez que a eficiência tem forte relação com a modicidade tarifária.

O percentual de tratamento de esgoto assume relevância, pois é comum a cobrança pela coleta e tratamento do esgoto, mas boa parte do esgoto coletado não é tratado. Diante dessa afirmação, a inclusão desta variável é justificada, pois não considerá-la é desprezar a ineficiência do tratamento de esgoto, uma vez que o usuário paga por esse serviço. É comum, nos estudos de eficiência do setor, considerar o número de economias (residências) e ligações; contudo, se uma empresa atua em região com elevados índices de adensamento, comparada com seus pares, isso pode gerar um viés de resultado.

Um dos pressupostos na definição das variáveis inputs e outputs, quando da aplicação da metodologia da DEA é a forte correlação entre as variáveis de insumo e produto.

TABELA 14 - MATRIZ DE CORRELAÇÃO DAS VARIÁVEIS

\begin{tabular}{|c|c|c|c|c|}
\hline & Opex & $\begin{array}{l}\text { №. Lig. ativas } \\
(\mathrm{A}+\mathrm{E})\end{array}$ & $\begin{array}{l}\text { Exten. de } \\
\text { rede }(A+E)\end{array}$ & $\begin{array}{c}\text { Índice de } \\
\text { tratamento de (E) }\end{array}$ \\
\hline OPEX & 1,000 & & & \\
\hline$L(\mathrm{~A}+\mathrm{E})$ & 0,969 & 1,000 & & \\
\hline$R(\mathrm{~A}+\mathrm{E})$ & 0,919 & 0,966 & 1,000 & \\
\hline$\% T(\mathrm{E})$ & 0,982 & 0,971 & 0,922 & 1,000 \\
\hline
\end{tabular}

A TABELA 14 indica forte correlação entre as variáveis de entrada e saída, acima de 0,850, o que mostra que os inputs e outputs adotados são relevantes para a análise desejada.

\subsubsection{FUNÇÃO DE PRODUÇÃO DETERMINÍSTICA}

Na prática, raramente a tecnologia $T$ é conhecida. A análise da eficiência produtiva por meio da função de produção determinística supera essa problemática, estimando a tecnologia $T^{*}$ a partir de dados históricos ou transversais observados sobre as atividades reais de produção. Portanto, a ideia subjacente da literatura da DEA é que as empresas possuem uma tecnologia comum, neste caso, denotada por $T$.

A possibilidade de estimação da tecnologia $T$ de produção não é exclusividade da abordagem DEA. Isso também é feito em avaliações de desempenho com o uso de métodos de estatística tradicional, abordagens contábeis, etc. O caso particular da abordagem DEA é a forma como a aproximação da tecnologia é construída e as resultantes propriedades das avaliações. Tecnicamente, a DEA usa programação matemática e uma abordagem de análise de atividade, enquanto os métodos estatísticos são geralmente baseados em uma abordagem de máxima verossimilhança. 
Na DEA, a estimativa da tecnologia $T$ é construída de acordo com o princípio da extrapolação mínima: $T^{*}$ é o menor subconjunto de $\mathbb{R}_{+}^{m} \times \mathbb{R}_{+}^{n}$; ao construir o menor conjunto contendo as observações reais, o método extrapola o mínimo, que contém dados $\left(x^{k}, y^{k}\right), k=1, \ldots, K$ e satisfaz certos pressupostos tecnológicos específicos da abordagem dada, como, por exemplo, livre disponibilidade (free disposability), alguma forma de convexidade e retorno de escala: conforme demonstração a seguir:

- A1: Free disposability. Pode produzir menos com mais, isto é: $(x, y) \in T, x^{\prime} \geq x, e y^{\prime} \leq y \Rightarrow$ $\left(x^{\prime}, y^{\prime}\right) \in T$;

- A2: Convexity. Qualquer média ponderada dos planos de produção viáveis é viável como: $(x, y) \in$ $T,\left(x^{\prime}, y^{\prime}\right) \in T, \alpha[0,1] \Rightarrow \alpha(x, y)+(1-\alpha)\left(x^{\prime}, y^{\prime}\right) \in T$

- A3: $(\gamma)$ Returns to scale. A produção pode assumir alguma escala dado um conjunto de fatores: $(x, y) \in T, k \in \Gamma(\gamma) \Rightarrow k .(x, y) \in T$;

O pressuposto da free disposability estipula que podem ser descartados inputs e outputs desnecessários. 0 pressuposto da convexity afirma que qualquer média ponderada (combinação convexa) de planos de produção viáveis também é viável. A convexidade é necessária para que os sistemas de mercado com coordenação baseadas em preços funcionem eficientemente. 0 pressuposto de returns to scale sugere que não pode haver desvantagem em ser um grande produtor e possivelmente é uma desvantagem ser pequeno.

Como mencionado anteriormente, os modelos DEA compartilham a ideia de estimar a tecnologia usando uma abordagem de extrapolação mínima, e eles apenas diferem nos pressupostos assumidos. Também foram apresentados os pressupostos inerentes aos retornos variáveis de escala, que é o método adotado para este estudo. Combinando os pressupostos, pode ser definido um conjunto de parâmetros $\Lambda$ dado por $\left(\lambda \in \mathbb{R}_{+}^{K}\right)$.

Bogetoft e Otto (2011) demonstram que a extrapolação mínima da tecnologia é dada por:

$T^{*}(\gamma)=\left\{(x, y) \in \mathbb{R}_{+}^{m} \times \mathbb{R}_{+}^{n} \mid \exists \lambda \in \Lambda^{K}(\gamma): x \geq \sum_{k=1}^{K} \lambda^{k} x^{k}, y \leq \sum_{k=1}^{K} \lambda^{k} y^{k}\right\}$

Em que:

$$
\Lambda^{\mathrm{K}}(\mathrm{vrs})=\left\{\lambda \in \mathbb{R}_{+}^{\mathrm{K}} \mid \sum_{\mathrm{k}=1}^{\mathrm{K}} \lambda^{\mathrm{k}}=1\right\}
$$

As estimativas da tecnologia, o conjunto $T^{*}(\gamma)$, derivam da factibilidade das observações e dos pressupostos da regularidade, usando o princípio de extrapolação mínima, ou seja, o menor conjunto $T^{*}(\gamma)$, que contém dados e cumpre os pressupostos contidos no modelo chamado $(\gamma)$, conforme apresentado na Equação (2).

Quando combinada a ideia de extrapolação mínima com a ideia de Farrell, de medir eficiência como uma melhoria proporcional, obtêm-se os programas matemáticos considerados sinônimos da abordagem DEA. No lado do input, mede-se a eficiência Farrell da empresa 0 como a eficiência do input, conforme a Equação (4):

$$
E^{0}=E\left(\left(x^{0}, y^{0}\right) ; T^{*}\right)=\min \left\{E \in \mathbb{R}_{+} \mid\left(E x^{0}, y^{0}\right) \in T^{*}\right\}
$$


Ao inserir na Equação (4) a formulação $T^{*}(\gamma)$ apresentada na Equação (2), tem-se:

$$
\begin{gathered}
\min _{E, \lambda^{1}, \ldots, \lambda^{K}} E \\
\text { s.t } E x^{0} \geq \sum_{k=1}^{K} \lambda^{k} x^{k}, \\
y^{0} \leq \sum_{k=1}^{K} \lambda^{k} y^{k}, \\
\lambda \in \Lambda^{K}(\gamma)
\end{gathered}
$$

Na forma mais estendida, o problema da Equação (5) pode ser expresso da seguinte forma:

$$
\begin{gathered}
\text { s.t } E x_{i}^{0} \geq \sum_{\substack{E, \lambda^{1}, \ldots, \lambda^{K} \\
K}} \lambda^{k} x_{i}^{k}, \quad i=1, \ldots, m \\
y^{0} \leq \sum_{k=1}^{K} \lambda^{k} y_{j}^{k}, \quad j=1, \ldots, n
\end{gathered}
$$

Denotando a solução ótima dos modelos apresentados nas Equações (5) e (6) por $\left(E^{*}, \lambda^{*}\right)$, sendo $\lambda^{*}=$ $1, \ldots, K$, conforme já explorado, a $\left(D M U k^{0}\right)$ é eficiente se e somente se $E^{*}=1$ e todas as folgas nas restrições são nulas na solução ótima. A situação oposta ocorre se $E^{*}<1$ ou se $E^{*}=1$, com folgas positivas. Nestes dois últimos casos, a $D M U k^{0}$ é vista como ineficiente. Já os coeficientes $\lambda_{K}^{*}>0, k=$ $1, \ldots K$ indicam as DMU que compõem o conjunto de referência (peer set) da DMU $k^{0}$.

O modelo acima pressupõe que as DMU avaliadas apresentem retornos variáveis de escala, determinando uma fronteira que considera retornos crescentes ou decrescentes de escala na fronteira eficiente. Considera que um acréscimo no insumo poderá promover um acréscimo ou até mesmo um decréscimo no produto, não necessariamente proporcional.

\subsubsection{ORIENTAÇÃO AO INPUT E EFICIÊNCIA}

Quando uma empresa transforma $x$ unidades de determinado insumo em $y$ unidades de determinado produto, é possível avaliar sua eficiência a partir do quociente de produtividade total $\frac{y}{x}$. Este problema pode ser generalizado para situações de múltiplos insumos e múltiplos produtos, conforme a equação a seguir:

$$
\text { Eficiência }=\frac{u_{1} y_{1}+u_{2} y_{2}+\cdots+, u_{m} y_{m}}{v_{1} x_{1}+v_{2} x_{2}+\cdots+, v_{n} x_{n}}=\frac{U . Y}{V . X}
$$


Na equação acima, os vetores $V=\left(v_{1}, v_{2}, \ldots, v_{n}\right)$ e $U=\left(u_{1}, u_{2}, \ldots, u_{m}\right)$ representam os pesos atribuídos aos insumos e produtos, respectivamente. Essa equação demonstra a técnica que determina o índice de eficiência que assume valores entre 0 e 1 . No caso geral, o problema consiste em definir o índice de eficiência de uma empresa $k$ como a combinação linear de cada um dos $m$ produtos divididos pela combinação linear dos insumos $n$, conforme indicado a seguir:

$$
\frac{\sum_{j} u_{j} Y_{j k}}{\sum_{i} v_{i} X_{i k}}=\frac{u Y_{k}}{v X_{k}} \leq 1
$$

onde:

$$
\begin{aligned}
& k: 1, \ldots, \text { K empresas; } \\
& i: 1, \ldots, \text { m insumos de cada empresa; } \\
& j: 1, \ldots, n \text { produtos de cada empresas; } \\
& u \text { e } v: \text { vetores de pesos dos prudutos e insumos }
\end{aligned}
$$

Analisando as opções da metodologia DEA, o modelo mais apropriado para esta análise foi o modelo VRS com orientação ao insumo, pois, como o objetivo é avaliar a eficiência alcançando os menores custos possíveis, dados os níveis de produção, não seria viável que altos custos fossem compensados com a elevação dos outputs.

A eficiência técnica será mensurada por meio da abordagem de orientação ao insumo. Conforme apontado por Deprins, Simar e Tulkens (1984), a orientação ao input é a mais adequada, visto que as companhias podem se tornar mais eficientes apenas fornecendo determinado nível de output, a partir da utilização de uma menor quantidade de input.

\subsection{SOFTWARE}

O software adotado para realização DEA foi o $\mathrm{R}$, que dispõe de ampla variedade de técnicas estatísticas e gráficas, incluindo modelos lineares e não lineares, testes estatísticos clássicos, análise de séries temporais, classificação, agrupamento e outras características. Para este estudo foi utilizado o pacote Benchmarking que é dedicado aos modelos DEA.

\section{ANÁLISE DOS RESULTADOS}

Esta seção se destina de apresentar os resultados, gerados a partir do software utilizado para a mensuração da eficiência relativa, calculada por meio da técnica da Análise Envoltória de Dados, com rendimentos variáveis e orientação ao input.

Adotados os pressupostos da equação (6), obtêm-se os níveis de eficiência das empresas no período investigado, conforme se passa a demonstrar. A TABELA 1 apresenta as 18 empresas com seus respectivos escores de eficiência para o ano de 2015, medidos pela DEA. 


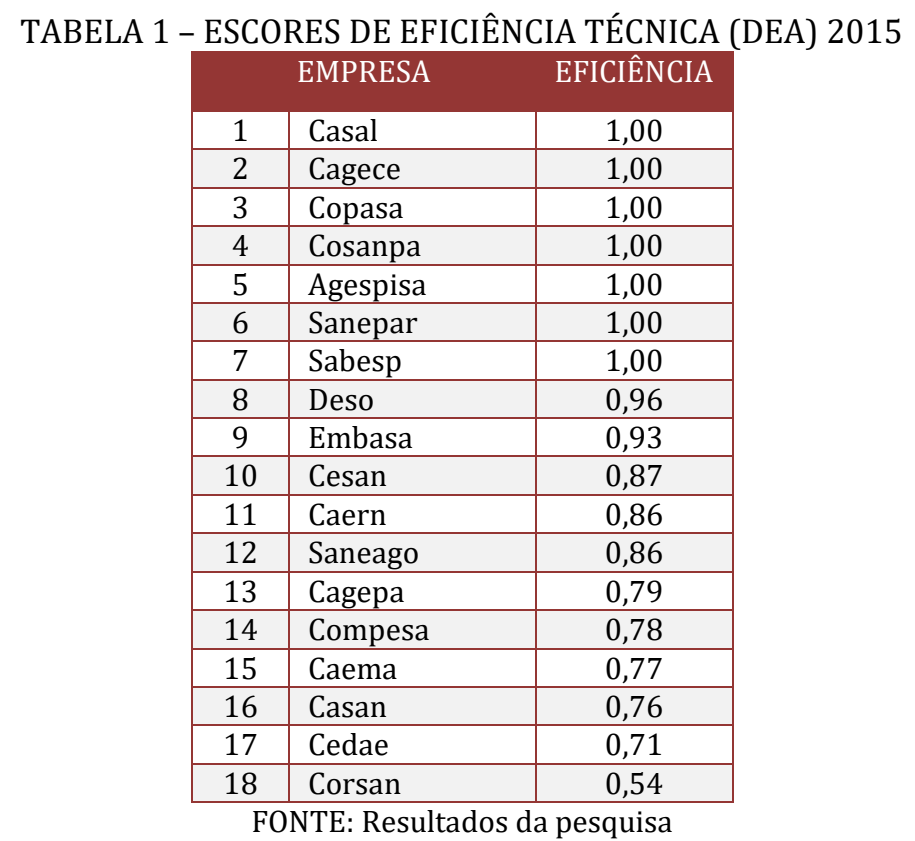

Os valores estimados das eficiências técnicas das empresas de saneamento individuais apresentados na TABELA 1 indicam que a eficiência técnica no período observado está entre 0,54 e 1 . A eficiência média indica que, na média, as empresas operaram abaixo do nível de eficiência. A média de 0,88 indica que, no conjunto, as empresas produziram cerca de $88 \%$ daquilo que elas poderiam produzir, dados os recursos disponíveis.

Tabela 2 - Estatística descritiva 2015

\begin{tabular}{|c|c|c|}
\hline INTERVALO DE EFICIÊNCIA & FREQUÊNCIA & PARTICIPACÃO \% \\
\hline $0,5<=\mathrm{E}<0,6$ & 1 & 5,6 \\
\hline \multicolumn{3}{|l|}{$0,6<=\mathrm{E}<0,7$} \\
\hline $0,7<=\mathrm{E}<0,8$ & 5 & 27,8 \\
\hline $0,8<=E<0,9$ & 3 & 16,7 \\
\hline $0,9<=\mathrm{E}<1$ & 2 & 11,1 \\
\hline$E=1$ & 7 & 38,9 \\
\hline \multicolumn{3}{|c|}{ EFICIÊNCIA } \\
\hline Mínimo & 0,54 & \\
\hline 1ㅇ quartil & 0,78 & \\
\hline Mediana & 0,90 & \\
\hline Eficiência média & 0,88 & \\
\hline 3o quartil & 1,00 & \\
\hline Máximo & 1,00 & \\
\hline
\end{tabular}

FONTE: Resultados da pesquisa

A eficiência técnica média das empresas sugere que existia um potencial para aumentar a produtividade do setor em 12\%. Das 18 empresas investigadas, sete estavam sobre a fronteira eficiente; isto é, 39\% das empresas podem ser consideradas eficientes.

Quanto maior for a frequência com que a empresa participa do grupo de referência, maiores são as chances de seu desempenho ser considerado excelente. A empresa que apresenta maior frequência é chamada de líder global, pois, do ponto de vista de outras seguidoras, ela é vista como a empresa com as melhores práticas, e isso chama a atenção de outras empresas.

Do ponto de vista regulatório, para estimular a eficiência, ao realizar o estudo de benchmarking e identificar que a empresa regulada é ineficiente, pode adotar os custos daquela considerada eficiente, forçando, portanto, a regulada a perseguir os custos da líder, considerada eficiente. Se a empresa tiver que adotar os custos de seus pares e enquanto não conseguir poderá incorrer em redução dos resultados da companhia. 


\section{CONSIDERAÇÕES FINAIS}

Apesar de a LNSB considerar a eficiência econômica um dos princípios fundamentais, as companhias prestadoras do serviço de abastecimento de água e esgotamento sanitário, em sua maioria, ainda não incorporaram a produtividade e a eficiência econômica em seus modelos tarifários, e mesmo aquelas que as incorporaram, não são muito claras quanto à metodologia adotada.

A fim de conhecer os níveis de eficiência e este estudo de benchmarking verificou a eficiência das empresas de saneamento do Brasil. A análise de desempenho dos operadores assume relevância, pois permite a avaliação e o apoio ao processo regulatório e à tomada de decisões, bem como a definição de estratégias por parte dos agentes. 0 benchmarking identifica processos, práticas e métodos gerenciais para avaliar um ambiente competitivo, de modo que se estabelece um monitoramento contínuo para garantir a descoberta das melhores práticas exercidas por outras empresas.

A análise empírica do estudo validou 18 companhias, um insumo e três produtos para aferir a capacidade de resposta das empresas na prestação do serviço. A metodologia adotada para a mensuração do desempenho das empresas, considerando-se a mesma amostra, foi a Análise Envoltória de Dados. Quanto às abordagens adotadas, cabe salientar que partem de pressupostos diferentes.

A técnica DEA combina a estimativa da tecnologia com a mensuração do desempenho relacionado a essa tecnologia. Dessa forma, a técnica integra os dois problemas básicos: a) definir um padrão de desempenho, a tecnologia, e b) avaliar realizações em relação ao padrão estabelecido. Esta técnica é determinística e os desvios em relação à fronteira de eficiência são tomados como unicamente devidos às ineficiências das DMU.

Das 18 empresas analisadas pela técnica DEA, sete empresas podem ser consideradas benchmark: Cagece (CE), Casal (AL), Sabesp (SP) e Sanepar (PR), Cosanpa (PA), Agespisa (PI), Copasa (MG). No ano de 2015 essas empresas apareceram como empresas de referência, sendo a eficiência verificada igual a 1.

Em suma, o presente estudo propôs a análise da eficiência incluindo o percentual de esgoto tratado. Como a Lei do Saneamento trata, entre outros fatores, da modicidade tarifária, é justo incluir a variável em questão, uma vez que é cobrado da população o tratamento do esgoto, também é comum o lançamento do esgoto no meio ambiente sem o correto tratamento.

\section{REFERÊNCIAS}

[1] ABBOTT, M.; COHEN, B. Productivity and efficiency in the water industry. Utilities Policy, v. 17, n. 3/4, p. 233$244,2009$.

[2] ABBOTT, M.; COHEN, B.; WANG, W. C. The performance of the urban water and wastewater sectors in Australia. Utilities Policy, v. 20, n. 1, p. 52-63, 2012.

[3] BANKER, R. D.; CHARNES, A.; COOPER, W. W. Some models for estimating technical and scales inefficiencies in Data Envelopment Analysis. Management Science, v. 30, n. 9, p. 1078-1092, Sept. 1984.

[4] BARBOSA, A. Pode a regulação econômica melhorar o desempenho econômico financeiro e a universalização dos serviços de águas e esgotos no Brasil? Brasília: SEAE, 2012.

[5] BOGETOFT, P.; OTTO, L. Benchmarking with DEA, SFA, and R. New York: Springer Verlag, 2011.

[6] CAMP, R. Benchmarking: identificando, analisando e adaptando as melhores práticas da administração que levam à maximização da performance empresarial. São Paulo: Pioneira, 1993.

[7] CAMP, R. Global cases in benchmarking: best practices from organizations around the world. Milwaukee: ASQ Quality, 1998.

[8] CARMO, C. M.; TÁVORA JUNIOR, J. L. Avaliação da eficiência técnica das empresas de saneamento brasileiras utilizando a metodologia DEA. In: ENCONTRO NACIONAL DE ECONOMIA, 31., 2003, Rio de Janeiro. Anais... Rio de Janeiro: ANPEC, 2003.

[9] CASTRO, C. E. T. de. Avaliação da eficiência gerencial de empresas de água e esgotos brasileiras por meio da Envoltória de Dados (DEA). 108 f. Dissertação (Mestrado em Engenharia de Produção) - Pontifícia Universidade Católica do Rio de Janeiro, Rio de Janeiro, 2003.

[10] CHARNES, A.; COOPER, W. W.; RHODES, E. Measuring the efficiency of decision making units. European Journal of Operational Research, v. 2, n. 6, p. 429-444, 1978.

[11] COELLI, T.; RAO, D. S. P.; BATTESE, G. An introduction to efficiency and productivity analysis. Dordrecht: Kluwer Academic Publishers, 1998. 
[12] CRUZ, C. E.; RAMOS, F. de S. Eficiência na gestão do saneamento básico e seus impactos sobre a promoção da saúde: uma aplicação da Análise Envoltória de Dados - DEA. In: XVII Encontro Regional de Economia, 17., 2012, Fortaleza. Anais... Fortaleza: ANPEC-Nordeste, 2012.

[13] CRUZ, N. F.; MARQUES, R. C.; ROMANO, G.; GUERRINI, A. Measuring the efficiency of water utilities: a crossnational comparison between Portugal and Italy. Water Policy, v. 14, n. 5, p. 841-853, 2012.

[14] CUBBIN, J.; TZANIDAKIS, G. Regression versus Data Envelopment Analysis for Efficiency Measurement: an application to the England and Wales regulated water industry. Utilities Policy, v. 7, p. 75-85, 1998.

[15] DEPRINS, D.; SIMAR, L.; TULKENS, H. Measuring labor-efficiency in post offices. In: MARCHAND, M.; PETISEAU, P.; TULKENS, H. (Eds.). The performance of public enterprises: concepts and measurements. Amsterdam: North-Holland, 1984. p. 243-268.

[16] FARRELL, M. J. The measurement of productive efficiency. Journal of the Royal Statistical Society: Series A (General), v. 120, n. 3, p. 253-290, 1957.

[17] GILLEN, D.; LALL, A. Developing measures of airport productivity and performance: an application of data envelopment analysis. Transportation Research-E, v. 33, p. 261-273, 1997.

[18] GOMES, E. G.; SOARES DE MELLO, J. C. C. B.; BIONDI NETO, L.; MEZA, L. A. Análise de eficiência das autoestradas federais brasileiras com portagens. Revista Portuguesa e Brasileira de Gestão, p. 68-75, 2004.

[19] LAMBERT, D., DICHEV, D.; RAFFIEE, K. Ownership and sources of inefficiency in the provision of water services. Water Resources Research, v. 29, p. 1573-1578, 1993.

[20] LINDAU, L. A.; COSTA, M. B. B.; SOUSA, F. B. B. Em busca do benchmark da produtividade de operadores urbanos de ônibus. In: CARLOS NASSI, A. B. et al. (orgs.). Transportes: experiências em rede. S.l.: Recope; Finep, 2001. p.199-221.

[21] LINS, M. P. E.; MEZA, L. A. Análise Envoltória de Dados e perspectivas de integração no ambiente de Apoio à Decisão. Rio de Janeiro: COPPE; UFRJ, 2000.

[22] LOVELL, K. Production frontiers and productive efficiency. In: FRIED, H.; LOVELL, K.; SCHMIDT, S. (Eds.). The measurement of productive efficiency: techniques and applications. Oxford: Oxford University Press, 1993. p. 3-67.

[23] NORMAN, M.; STOKER, B. Data Envelopment Analysis: the assessment of performance. Chichester: John Wiley, 1991.

[24] SATO, J. M. Utilização da Análise Envoltória de Dados (DEA) no estudo de eficiência do setor de saneamento. 43 f. Dissertação (Mestrado em Economia Regional) - Universidade Católica de Brasília, Brasília, 2011.

[25] SAWKINS, J. W.; ACCAM, B. Comparative efficiency measurement in the Scottish water industry: an application of data envelopment analysis. Discussion Paper, 94-12, University of Aberdeen, 1994.

[26] SEIFORD, L. M. A bibliography of data envelopment analysis (1978-1990). Amherst: The University of Massachusetts, 1990.

[27] SENGUPTA, J. K. Efficiency analysis by production frontiers: the nonparametric approach. Dordrecht: Kluwer Academic Publishers, 1989.

[28] SENGUPTA, J. K. Dynamic and stochastic efficiency analysis economics of data envelopment analysis. Singapura: World Scientific Publishing, 2000.

[29] THANASSOULIS, E. The use of data envelopment analysis in the regulation of UK water utilities: water distribution. European Journal of Operational Research, v. 126, n. 2, p. 436-453, 2000.

[30] TUPPER, H. C.; RESENDE, M. Efficiency and regulatory issues in the Brazilian water and sewage sector: an empirical study. Utilities Policy, v. 12, n. 1, p. 29-40, 2004.

[31] VILELA, D. L. Utilização do método Análise Envoltória de Dados para avaliação do desempenho econômico de coorporativas de crédito. 144 f. Dissertação (Mestrado em Engenharia de Produção) - Escola de Engenharia de São Carlos, Universidade de São Paulo, São Carlos, 2004.

[32] WANG, Y. M.; CHIN, K. S.; YANG, J. B. Measuring the performances of decision-making units using geometric average efficiency. Journal of the Operational Research Society, v. 58, p. 929-937, 2007. 


\section{Capítulo 4}

\section{A construção da materilidade para um relato integrado em uma empresa de Saneamento Municipal}

\section{Tatiana Gama Ricci \\ Marta Cristina Pelucio Grecco \\ Cecília Moraes Santostaso Geron}

Resumo: Este trabalho buscou, através de uma abordagem intervencionista, auxiliar a empresa estudada a iniciar a utilização das orientações do International Integrated Reporting Council (IIRC) para relato integrado em seu Relatório de Sustentabilidade, partindo-se da construção dos temas materiais. 0 trabalho justifica-se diante da necessidade da integração das informações financeiras e não financeiras da entidade estudada, de conhecer os impactos em outros capitais, além do financeiro, e de demonstrar a criação de valor a longo prazo a seus diversos stakeholders, principalmente a seus fornecedores de capital. Durante o desenvolvimento desse estudo, foi observado que os princípios para a construção dos temas materiais do IIRC e da Global Report International (GRI) são similares, com orientações recentes, sendo necessários investimentos em treinamentos e tempo para que a empresa consiga incorporar o pensamento integrado em suas ações, além de ser um processo de médio a longo prazo. 0 estudo também apresenta as contribuições, oportunidades e desafios ocorridos durante o processo, o que colabora com os práticos na implantação do relato integrado além de difundir as orientações do IIRC, fomentando uma discussão quanto a essa nova forma de comunicação da entidade com seus stakeholders.

Palavras-chave: GRI; IIRC; Relato Integrado; Relatório de Sustentabilidade. 


\section{INTRODUÇÃO}

Para Ott \& Pires (2009), há um desafio constante para a contabilidade, que é o aprimoramento de suas técnicas tendo em vista a evolução das necessidades da sociedade.

Atualmente, há uma evolução da necessidade das informações fornecidas pelas empresas. Assim apenas os demonstrativos financeiros não suprem a demanda por informações a respeito de como a empresa se relaciona com a sociedade e o meio ambiente.

Em 2009, o Príncipe de Gales, iniciou um movimento para harmonização entre os diversos relatórios corporativos que deu origem em 2013 às orientações para divulgação de uma comunicação integrada dos relatórios contábeis com as informações de natureza não financeira, propondo uma discussão a respeito de um novo modelo de negócios que tem como base seis capitais, ou seja, não só o capital financeiro, mas também o manufaturado, o humano, o intelectual, o social e o natural, surgindo assim o Relato Integrado (Carvalho \& Kassai, 2013).

Para divulgar as informações de natureza social e ambiental, também chamadas de informações não financeiras, as empresas podem adotar de forma a complementar suas informações financeiras, o balanço social, relatório de sustentabilidade, relato integrado, entre outros modelos, com o objetivo de fornecer a seus diversos usuários informações úteis que servirão de base para a tomada de decisões.

A estrutura internacional para relato integrado do International Integrated Reporting Council (IIRC) veio ao encontro dessa nova necessidade, fornecendo orientações baseadas em princípios, estimulando as empresas a demonstrarem seus recursos e o relacionamento com seus diversos capitais tanto em seu ambiente interno quanto externo.

A base deste trabalho inclui Estrutura Internacional para o Relato Integrado do IIRC e o Manual de Implementação e Princípios para Relato e Conteúdos Padrão divulgados pela GRI para o relatório de sustentabilidade, que são as diretrizes da Global Reporting International (GRI) na versão 4 (GRI G4), com ênfase nas questões materiais.

A Report Sustentabilidade, em sua publicação "Materialidade no Brasil - Um ensaio qualitativo" apresenta que os novos relatórios terão foco no que é material, tendo como base que as empresas precisam dar atenção às questões críticas trazidas por suas partes interessadas, sendo estas validadas pela alta gestão, e posteriormente incorporadas à estratégia do negócio (Report Sustentabilidade, 2014).

A materialidade envolve os temas que o relatório deve abordar, inclui questões de significativos impactos econômicos, ambientais e sociais para organização, ou questões que possam influenciar substancialmente as avaliações e decisões de stakeholders.

Partindo-se que o foco central das Diretrizes GRI G4 e do Relato Integrado é a materialidade, tendo como base que as empresas precisam dar atenção às questões críticas trazidas por suas partes interessadas, sendo estas validadas pela alta gestão, e posteriormente incorporadas à estratégia do negócio (Report Sustentabilidade, 2014), este estudo pretende auxiliar a empresa estudada na construção de seus temas materiais, dando início assim na utilização das orientações trazidas pelo IIRC em seu Relatório de Sustentabilidade. A empresa estudada nesta pesquisa é uma empresa de economia mista municipal de saneamento do interior do estado de São Paulo.

Para definir suas questões materiais será necessário incluir a participação de seus principais stakeholders e encaminhar tais temas para a validação pela alta gestão, incorporando as questões materiais à estratégia da empresa.

Assim, este trabalho irá responder a seguinte questão: Na prática, conforme as orientações trazidas pelo IIRC, como a empresa pode iniciar o preparo de suas informações de forma integrada, no que diz respeito à materialidade?

De maneira complementar será apresentado os desafios e oportunidades encontrados no decorrer da pesquisa, ao optar por iniciar o preparo de suas informações integradas em seu relatório de sustentabilidade de forma voluntária.

Este estudo se mostra atual e em consonância com o momento vivido por muitas organizações, que é o desafio de apresentar informações não financeiras e financeiras, utilizando as novas diretrizes da GRI G4 e as orientações do IIRC para relato integrado. Ademais, também contribuirá na gestão do atual processo de geração e integração das informações econômicas, ambientais e sociais, dentro do cenário da empresa estudada, podendo também ser utilizado como fonte de informações para outras empresas que buscam evidenciar essas informações. 
O amadurecimento para o preparo das informações integradas da empresa se dará de forma gradual, e nem é a pretensão desta pesquisa esgotar todo o tema com a conclusão da divulgação de um relato integrado no ano corrente. É necessário primeiramente desenvolver um pensamento integrado na empresa, com integração das áreas, introdução das orientações do IIRC e aos poucos incorporar tais orientações na elaboração das informações do Relatório de Sustentabilidade que a empresa já divulga.

\section{REFERENCIAL TEÓRICO}

A GRI é uma organização internacional independente, com sede em Amsterdã, criada em 1997 com a missão de disseminar a prática de relatório de sustentabilidade, de forma que ele se torne padrão entre as empresas. Ela fornece as diretrizes e orientações para facilitar a comunicação de informações do desenvolvimento sustentável de uma organização (GRI, 2007).

O IIRC é um conselho advindo de uma coalizão global de reguladores, investidores, empresas, definidores de padrões, profissionais do setor contábil e organizações não governamentais que compartilham uma visão da necessidade da evolução dos relatórios corporativos, defende que esses relatórios devem fornecer uma comunicação concisa a respeito da estratégia, governança, desempenho e suas perspectivas, considerando também o ambiente externo, apresentando, desta forma, a criação de valor no curto, médio e longo prazo (THEIIRC, 2013).

A utilização das diretrizes da GRI na versão quatro (GRI G4) e as orientações do IIRC, possibilita a integração das informações econômicas, ambientais e sociais, e tem como objetivo de integrar a sustentabilidade à estratégia da empresa (GRI, 2013a) melhorando a qualidade de suas informações, tornando-as mais transparente e com maior clareza para todas as suas partes interessadas. Essa iniciativa, além de representar uma melhora na transparência, auxilia a empresa a conhecer e demonstrar o seu processo de criação de valor no decorrer do tempo (curto, médio e longo prazo) e como a empresa realiza a manutenção deste valor (GRI, 2013a).

\subsection{MODELO GRI}

A GRI apresenta em seu Manual de Diretrizes para Relatório de Sustentabilidade que a finalidade de se elaborar relatórios de sustentabilidade é a prática de medir, divulgar e prestar contas para os diversos stakeholders dos impactos econômicos, ambientas e sociais da organização (GRI, 2006, p. 3). Em maio de 2013, durante a conferência global da GRI em Amsterdã, foi lançada a versão 4.0 das Diretrizes para Relato de Sustentabilidade (GRI G4), representando um novo desafio para as companhias que publicam balanços socioambientais, que é a necessidade de focar no que é realmente relevante para o negócio, realizando a comunicação de seu desempenho social, econômico e ambiental, considerando como obrigatórios os temas materiais e com processos mais detalhados de definição de conteúdo (Balby, 2013).

Uma das características das Diretrizes GRI G4 é o enfoque maior na materialidade. Como no próprio objetivo é apresentado, há uma preocupação em auxiliar no preparo do relatório de sustentabilidade com temas que sejam realmente relevantes. Sendo assim, o relatório deve abordar temas que sejam importantes na organização, ou seja, as questões que reflitam impactos econômicos, ambientais e sociais significativos ou questões que possam influenciar as decisões dos stakeholders (GRI, 2013a; GRI, 2013b).

Conforme o Manual de Implementação GRI G4 (GRI, 2013b), os princípios para definição do conteúdo do relatório, são: inclusão de stakeholders, contexto da sustentabilidade, materialidade e completude. Esses princípios servem para orientar na identificação do que será informado no relatório.

O princípio de inclusão de stakeholders está relacionado em conhecer e reconhecer as expectativas e interesses de seus mais diversos stakeholders, fornecendo respostas, no próprio relatório, de quais são as medidas adotadas para suprir essas expectativas e interesses.

O contexto da sustentabilidade é traduzido pelo Manual como a apresentação de informações a respeito do desempenho da organização com base em conceitos amplos e não apenas individuais. É necessário descrever o que a empresa pretende realizar, quais as decisões tomadas agora e quais podem ser tomadas futuramente para algum problema ou tendência.

A materialidade envolve os temas que o relatório deve abordar, inclui questões de significativos impactos econômicos, ambientais e sociais para organização, ou questões que possam influenciar substancialmente as avaliações e decisões de stakeholders. 
O princípio da completude garante que os temas materiais e seus limites estarão corretamente apresentados no relatório.

O Manual de Implementação GRI G4 apresenta também os princípios que asseguram a qualidade do relatório, que são o princípio do equilíbrio, da comparabilidade, da exatidão, da tempestividade, da clareza e da confiabilidade (GRI, 2013b). Esses princípios servem para garantir qualidade das informações relatadas e possuem a função de auxiliar na transparência e qualidade das informações para seus stakeholders, fornecendo subsídios para a realização de avaliações e tomadas de decisões.

O processo sugerido para definição dos temas materiais e limites apresentado no Manual de Implementação GRI G4, segue quatro etapas: identificação, priorização, validação e análise (GRI, 2013b).

As etapas são consideradas apenas orientações, porém a implementação dos princípios de definição do conteúdo do relatório são requisitos para que o relatório esteja em conformidade com as diretrizes da GRI, além de garantir a transparência nos relatórios de sustentabilidade (GRI, 2013b).

Conforme orientações do Manual de Implementação GRI G4 (GRI, 2013b) a etapa de identificação é o momento em que a organização seleciona entre uma relação de temas potencialmente relevantes, aqueles de maior impacto em suas atividades, ou seja, aqueles que possuem relevante impacto econômico, ambiental e social com relação à atividade da organização, devendo levar em consideração os princípios contexto de sustentabilidade e inclusão de stakeholders.

A etapa da priorização ocorre quando a organização define quais os temas relevantes da primeira etapa que serão priorizados, divulgados e tratados no relatório. Essa etapa tem como base o princípio da materialidade e inclusão de stakeholders, sendo que a priorização se dará através da identificação da significância dos impactos econômicos, sociais e ambientais e a influência dos stakeholders nas avaliações e decisões (GRI, 2013b).

A etapa da validação tem como base os princípios da completude e inclusão de stakeholders, sendo a etapa que finaliza a identificação dos temas relevantes que serão relatados. Os temas materiais identificados precisam ser aprovados pela alta gestão da empresa (GRI, 2013b).

Já a última etapa é a da análise, que conforme o Manual de Implementação (GRI, 2013b), é realizada após a publicação do relatório, de modo contínuo, preparando os trabalhos para o próximo relatório. Os princípios aplicados nesta etapa são contexto da sustentabilidade e engajamento de stakeholders.

\subsection{RELATO INTEGRADO}

Com o objetivo de se obter uma convergência entre as informações constantes nos relatórios de sustentabilidade e as informações das demonstrações financeiras, o IIRC constituiu uma comissão para desenvolver uma forma de apresentação das informações financeiras, ambientais, sociais e de governança, surgindo o formato integrado de comunicação (Carvalho \& Kassai, 2013).

A discussão a respeito de relato integrado se iniciou em 2009 com um movimento criado pelo Príncipe de Gales para harmonizar os diversos relatórios corporativos (Carvalho \& Kassai, 2013).

Em matéria divulgada pelo Instituto Ethos, o professor Nelson Carvalho, explica que a ideia não é ter um relatório único com todas as informações, mas sim informações harmônicas e coerentes entre si, sendo que na iniciativa da Accounting for Sustainability (A4S) sugere que as empresas passem a integrar as informações da área econômica com os dados sobre as questões sociais, ambientais e de gestão (Gonçalves, 2013).

O Relato Integrado é a busca por uma convergência entre o Relatório de Sustentabilidade no modelo GRI e as Demonstrações Contábeis, que conforme o Consultation Draft of the International <IR $>$ Framework Integrated Reporting, "um relatório integrado é uma comunicação concisa sobre como estratégia, governança, o desempenho de uma organização e perspectivas, no contexto de seu ambiente interno e externo, levam a criação de valor a curto, médio e longo prazo" (THEIIRC, 2013, p. 8).

Os conceitos de relato integrado são recentes, sendo que sua estrutura conceitual foi apresentada no Brasil primeiramente na Bolsa de Valores, Mercadorias e Futuros (BM\&BOVESPA) em 16 de abril de 2013. Uma apresentação semelhante também ocorreu na África do Sul, Alemanha, Austrália, Canadá, China, Estados Unidos, Índia Japão e Reino Unido (BM\&FBOVESPA, 2013). 
Em dezembro de 2013 foi publicada pelo IIRC a primeira versão da estrutura internacional para relato integrado na língua inglesa. Em março de 2014 foi traduzida para a língua portuguesa pela Federação Brasileira de Bancos (FEBRABAN), sendo publicada com a autorização do IIRC em maio de 2014 (THEIIRC, 2014).

A proposta do IIRC e suas diretrizes internacionais de relato integrado são mais do que simplesmente ter um único relatório ao final, é fazer com que desperte uma nova mentalidade nas organizações, que sejam divulgados não apenas números, mas também a relação entre estratégia, modelo de negócios e a geração de valor no longo prazo (Report Sustentabilidade, 2013).

Para o grupo de estudos do Relato Integrado no Brasil (Report Sustentabilidade, 2013) os cinco aspectos chaves do Relato Integrado são: materialidade, geração de valor, capitais, modelo de negócio e conectividade. Esses aspectos têm a função de dar base à construção de um relatório com informações consistentes a respeito da organização, como é seu comportamento no ambiente em que está inserida, seus riscos e oportunidades, além de apresentar quais são suas estratégias de utilização de recursos, seu desempenho alcançado no período e suas perspectivas ao longo do tempo.

No Relato Integrado, a materialidade é traduzida em temas que são essenciais, que podem afetar substancialmente a análise e a decisão dos leitores do relatório sobre a capacidade de a organização criar e preservar valor (THEIIRC, 2013).

Os capitais apresentados pelo IIRC compreendem os capitais financeiros, manufaturados, intelectuais, humanos, sociais e de relacionamento e naturais. Não há obrigatoriedade de utilizar essa categorização de capitais, mas eles devem ser considerados como um referencial e como base teórica para a demonstração da criação de valor para uma organização. Também não há uma hierarquia entre eles, de modo que todos os capitais são igualmente relevantes (THEIIRC, 2013).

O objetivo principal de a empresa elaborar um relato integrado utilizando sua estrutura conceitual é "explicar a provedores de capital financeiro como uma organização gera valor ao longo do tempo" concluindo que deve incluir informações relevantes tanto financeiras quanto não financeiras (THEIIRC, 2014, p. 7).

Os fornecedores de capital financeiro buscam informações mais profundas a respeito da empresa e do seu negócio para subsidiar a análise da capacidade que a empresa tem de gerar valor no decorrer do tempo, tanto para ela quanto para suas partes interessadas, inclusive para a sociedade, garantindo assim o retorno financeiro destes provedores de capital financeiro (THEIIRC, 2014).

Assim, para auxiliar na divulgação do relato integrado, o IIRC fornece orientações através de uma estrutura conceitual com o objetivo de estabelecer Princípios Básicos e Elementos de Conteúdo Framework $<$ IR $>$ (THEIIRC, 2014).

Os Princípios Básicos para a preparação de um relato integrado apresentados no Framework $\langle$ IR> (THEIIRC, 2014) são: foco estratégico e orientação futura, conectividade de informações, relação com as partes interessadas, materialidade, concisão, confiabilidade e completude, coerência e comparabilidade.

0 foco estratégico e orientação futura estão relacionados no contexto de que a empresa precisa demonstrar em seu relatório uma visão geral a respeito de sua estratégia e da capacidade que ela tem de gerar valor no decorrer do tempo, inclusive demonstrar quais capitais são utilizados e impactados.

A demonstração de conexões entre atividades do passado, presente e futuro, o relacionamento entre informações financeiras com as informações não financeiras e o relacionamento entre os diversos capitais, são informações que têm como suporte o princípio da conectividade da informação.

0 princípio de relações com partes interessadas afirma a importância do relacionamento com seus públicos interessados, com a necessidade de a empresa buscar conhecer suas necessidades.

A materialidade, como um princípio do relato integrado, significa que aqueles temas que afetam de forma significativa a geração de valor no decorrer do tempo, são os que devem ser divulgados.

0 relatório integrado deve ser conciso, sendo representado como o princípio que orienta que o relato não deve ser prolixo. Entretanto, as informações precisam ser claras e suficientes, devendo respeitar o equilíbrio entre os demais princípios, principalmente com o da completude e comparabilidade. 
O princípio da confiabilidade e completude tem como base o equilíbrio das informações, ou seja, os temas materiais devem ser informados em sua totalidade, sem informações imparciais, devem incluir informações tanto positivas quanto negativas. É neste princípio que a empresa se utiliza da ferramenta de auditoria interna ou externa, o que melhora a confiabilidade de suas informações. O princípio da completude apresenta também a orientação de que a empresa deve levar em consideração os temas materiais das outras empresas do mesmo setor.

A coerência e comparabilidade são princípios que têm como base que as informações de um relato integrado devem no decorrer do tempo se apresentarem com uma mesma lógica de sentido, sem contradições, e de forma que possam ser comparadas.

Para o processo de determinação da materialidade, o IIRC propõe as seguintes etapas: identificação de temas relevantes; avaliação; priorização e a determinação de informações a serem divulgadas (THEIIRC, 2014). Na identificação de temas relevantes será considerado àqueles temas que afetam ou podem vier a afetar a capacidade de a organização gerar valor, nem todos os temas relevantes identificados são considerados materiais, assim na avaliação é possível verificar se tal tema é suficientemente importante, ou seja, será material dependendo do seu efeito sobre o critério de geração de valor da empresa. A priorização é realizada tendo como base a magnitude do tema, já para a determinação das informações divulgadas, será considerado diferentes perspectivas, tanto interna quanto externas, inclusive demanda dos fornecedores de capitais financeiros e outros stakeholders.

Os Elementos de Conteúdo para relato integrado definidos pelo IIRC são identificados como orientações para auxiliar na construção do relato integrado. Não são considerados como uma estrutura fixa, eles devem ser utilizados como suporte para que a empresa demonstre a conexão entre as suas informações (THEIIRC, 2014).

São oito os Elementos de Conteúdo para o relato integrado, divididos entre os assuntos, nos quais o IIRC apresenta questões a serem respondidas para auxiliar a empresa na construção de suas informações integradas. Os assuntos dos Elementos de Conteúdo são: visão geral da organização e ambiente externo, governança, modelo de negócios, riscos e oportunidades, estratégia e alocação de recursos, desempenho, perspectiva e base de preparação e apresentação (THEIIRC, 2014).

Na análise de Fragalli (2014), as orientações trazidas pelo IIRC, não podem ser tratadas como um modelo fixo de relatório. A empresa deve analisar a melhor forma de relatar suas informações considerando os princípios, elementos e os aspectos relevantes, sendo que essas orientações se apresentam como uma proposta que "estimula uma mudança cultural na empresa, passando de informações geradas isoladamente, para um processo de integração entre todos os setores da organização, cujo resultado são informações claras e concisas" (Fragalli, 2014, p. 46).

\subsection{COMPARATIVO ENTRE AS DIRETRIZES GRI G4 E A ESTRUTURA INTERNACIONAL PARA 0 RELATO INTEGRADO DO IIRC}

Tanto as Diretrizes GRI quanto o IIRC apresentam princípios que orientam as empresas na construção de suas informações para garantir que haja transparência no processo de relatos e para dar suporte na sua preparação (GRI 2013b, THEIIRC, 2014).

São comuns tanto para a GRI quanto para o IIRC que as informações relatadas pelas empresas precisam ser divulgadas de forma clara, concisa, equilibrada, correta, confiável e completa, dando condições para seus usuários realizarem comparações no decorrer do tempo.

No relato das questões materiais, há também em comum a preocupação com as partes interessadas, ou seja, seus stakeholders, o que possibilita que a empresa conheça suas necessidades e demonstre como estão sendo tratadas (GRI, 2013a; THEIIRC, 2014).

Já alguns princípios apresentados pelo IIRC para o relato integrado trazem novos conceitos, como o foco estratégico e orientação para o futuro, que fortalecem a materialidade e a visão a longo prazo, e o princípio conectividade da informação, que fortalece o pensamento integrado, dando suporte para a empresa pensar e relatar as conexões entre suas atividades, entre seus diversos capitais, entre informações financeiras e não financeiras, entre informações quantitativas e qualitativas, e outras conexões (THEIIRC, 2014). 
Com relação às informações de conteúdo, tanto para o relatório de sustentabilidade GRI G4 quanto para o relato integrado, é necessário constar informações gerais a respeito do perfil da empresa, estratégia, informações sobre o relatório, materialidade, stakeholders e governança.

As Diretrizes GRI são consideradas uma referência internacional para qualquer tipo de organização interessada na divulgação de informações a respeito da forma de gestão, desempenho econômico, ambiental e social, bem como seus impactos nessas áreas, tem como objetivo auxiliar relatores a elaborar relatórios de sustentabilidade relevantes, com informações importantes a respeito de sustentabilidade e tornar o processo relato de sustentabilidade uma prática padrão (GRI 2013b).

Para o IIRC o relato integrado é um processo que resulta na comunicação concisa, sobre a criação de valor no decorrer do tempo (THEIIRC, 2014).

O Manual de Implementação GRI G4 apresenta como destinatário do Relatório de Sustentabilidade os stakeholders tanto interno quanto externo, sendo que suas informações beneficiam os mais diversos usuários (GRI, 2013b).

Já os fornecedores de capital financeiro são os principais destinatários do relato integrado podendo ser considerados como beneficiários de suas informações todas as partes interessadas que tenham interesse em saber qual é a capacidade da empresa em criar valor no decorrer do tempo, incluindo funcionários, clientes, fornecedores, parceiros de negócios, comunidades locais, legisladores, reguladores e responsáveis por políticas (THEIIRC, 2014).

A principal novidade apontada pelo IIRC que ganhou força com a nova versão das Diretrizes da GRI G4 é que a decisão final de temas materiais deve passar pelos administradores, criando assim um vínculo entre os tomadores de decisão e os resultados de gestão (Report Sustentabilidade, 2013).

As etapas determinação da materialidade, tanto do IIRC quanto das diretrizes da GRI G4, são bastante similares, envolve a identificação, priorização, avaliação, validação e análise dos temas, tendo como base o princípio de inclusão e engajamento de stakeholders e contexto de sustentabilidade. 0 que as orientações do IIRC trouxeram de novidade é a perspectiva a longo prazo que deve também ser considerada para a seleção dos temas materiais, assim é possível realizar uma consolidação harmônica entre os dois processos de determinação da materialidade, tendo como resultado os temas materiais que a empresa divulgará em seu relato integrado.

\subsection{DESAFIOS ENCONTRADOS EM PESQUISAS JÁ REALIZADAS}

Para o primeiro grupo de estudos do Brasil, criado para discutir o Relato Integrado, a busca pela integração dos dados financeiros e não financeiros é uma tendência mundial, e como se trata de um conceito novo, sua implantação encontrará alguns desafios, o que poderá trazer novas oportunidades de negócio e inovações (Report Sustentabilidade, 2013).

Um dos desafios citados pelo grupo é a integração interna, pois para se conseguir ter um pensamento integrado é necessário ter antes de tudo uma integração interna, para assim fazer com que os compromissos socioambientais façam parte da gestão. Outro desafio apontado é a valoração, na qual há a necessidade do engajamento dos profissionais de contabilidade com a criação de novas métricas que possibilite deixar tangíveis indicadores ambientais.

Em relação à materialidade, a conclusão em que o grupo de estudos chegou, é que ela deve ser uma questão de prioridade, sendo que a alta direção deve estar envolvida no processo de definição, só assim temas relacionados à gestão do negócio estarão presentes na materialidade.

Rodrigues (2014) realizou uma pesquisa a partir do Relatório Anual de 2012 da empresa Natura e conclui que o relatório ainda não oferecia informações suficientes para afirmar que havia uma integração entre as informações financeiras e não financeiras, ou seja, mostrava uma aparente divisão entre seu Relatório de Sustentabilidade e suas Demonstrações Contábeis. Destacou ainda que a Estrutura Conceitual do IIRC possuiu orientações pouco objetivas, sem clareza e objetividade, com parâmetros de difícil compreensão, o que torna as orientações do IIRC insuficientes para que as empresas as utilizem na elaboração do relatório integrado. Deste modo, as empresas ainda estão se adaptando à nova metodologia, sendo necessários investimentos financeiros e em tempo.

Já a pesquisadora Fragalli (2014) apresenta em seu estudo a aplicação do Framework $<I R>$ em uma propriedade agrícola, com o objetivo de identificar as restrições e potencialidades existentes na aplicação do Relato Integrado. A pesquisadora realizou um estudo de caso em seis ciclos produtivos e concluiu que o 
relato integrado está inserido na gestão do negócio, porém de maneira informal, sendo que o gestor da propriedade leva em consideração os elementos apontados no Framework $\langle I R>$, mas por falta de tempo e capacitação não é realizado a elaboração e divulgação do relatório integrado da propriedade.

Aponta ainda a mudança cultural e a quantidade de informações requeridas pelo Framework $<I R>$ como sendo restrições a sua aplicação, pois as empresas em geral não costumam divulgar informações a respeito de seu modelo de negócio e estratégia de forma detalhada, informações essas requeridas pelo IIRC.

Para Roth (2014) o principal benefício da relação integrada que uma empresa pode ter é o pensamento integrado, que é possível com a integração entre as informações sociais, ambientais e de governança com as informações financeiras, considerando os impactos a longo prazo nos diversos capitais e não apenas no capital financeiro, atribuindo o mesmo valor a outros critérios que não seja apenas o financeiro na tomada de decisões.

Porém, a implementação desta relação integrada pode ser difícil e cara, necessitando que a organização entenda e identifique o que é relevante, invista em educação e treinamento a seus empregados para que assim seja possível o entendimento a respeito da relação integrada (Roth, 2014).

0 relato integrado, da forma que se apresenta, contribuiu para mudanças tanto de comportamento quanto de atitude o que irá apresentar resultados para as necessidades deste século, com um novo modelo de negócio que utiliza outros capitais, não só o capital financeiro, tais como: natural, humano, social e de relacionamento, intelectual e manufaturado. Deste modo, a empresa alcança e descobre uma nova forma de criar valor para seus acionistas (Carvalho \& Kassai, 2013).

Os estudos de Zaro (2015) e Maciel (2015) foram realizados tomando como base as empresas do programa piloto do IIRC no Brasil. Para Zaro (2015), que realizou uma análise de conteúdo para identificar a divulgação dos Elementos de Conteúdo e integração dos capitais, destaca-se a necessidade de amadurecimento das divulgações em relação à integração e que entre os relatórios divulgados há exemplos de conectividade proposto pelo IIRC. No estudo de Maciel (2015) é apresentado que o Relato Integrado pode sim gerar maior transparência para os Relatórios Corporativos, porém sem conseguir afirmar se os mesmos garantem que a empresa ou a economia seja mais sustentável. Também destacou que o Framework é recente o que demandará tempo para total entendimento pelas empresas e dificuldades de comparação pelo fato de sua abordagem ser baseadas em princípios.

Os estudos a respeito da utilização das orientações do IIRC para relato integrado são recentes, pois as orientações foram publicadas em 2013 em Inglês e em 2014 em português, porém pode-se verificar que há interesse pela academia em estudar esses novos conceitos, conforme os trabalhos de Carvalho \& Kassai (2013), Fragalli (2014), Rodrigues (2014), Rooth (2014), Zaro (2015) e Maciel (2015), bem como o interesse por empresas de serviços, como o da consultoria Report Sustentabilidade (2013).

Fica claro que a empresa que se propõe a realizar a divulgação de suas informações econômicas, sociais e ambientais, de forma integrada terá diversos desafios, porém contribuirá para desenvolver um novo modelo de divulgação, conforme as necessidades atuais das empresas e da sociedade.

O que o IIRC espera é que o Relato Integrado se torne um padrão de comunicação para as empresas, e que os vários relatórios divulgados sem conexão e estáticos deixem de ser produzidos dando lugar ao relato integrado (THEIIRC, 2014).

\section{PROCEDIMENTOS METODOLÓGICOS}

Este estudo apresenta a possibilidade de conhecer com profundidade as orientações do IIRC para um Relato Integrado, as diretrizes da GRI G4, e também as informações financeiras e não financeiras da empresa estudada, apresenta como característica de um estudo de caso que é o de ter "profundidade e detalhamento" e será aplicada a abordagem intervencionista, pois tem como objetivo produzir resultados relevantes, com a pretensão de juntar teoria com a prática.

Foram propostas etapas com diversas atividades utilizando as orientações do IIRC para relato integrado e as diretrizes da GRI G4 com o objetivo de auxiliar a empresa na construção dos temas materiais.

A condução desta pesquisa teve como base as etapas de uma pesquisa-ação, que são resumidas por Freitas et al. (2010) em diagnóstico inicial, planejamento da ação, implantação e análise dos resultados. 
A pesquisadora realizou o diagnóstico inicial a partir da necessidade dos gestores da empresa estudada em integrar suas informações financeiras e não financeiras em seu Relatório de Sustentabilidade para suprir a demanda de informações dos seus fornecedores de capital.

Para isso, a primeira providência foi realizar um estudo das orientações do IIRC para relato integrado e uma pesquisa documental das informações da empresa estudada, constantes em seu Relatório de Sustentabilidade referente ao ano de 2012 e 2013 e informações constantes no Formulário de Referência referente ao ano de 2013, identificando quais informações que a empresa já elabora e quais informações a empresa terá necessidade de desenvolver além de analisar os Relatórios de Sustentabilidade de empresas do mesmo setor.

0 ponto de partida foi o primeiro dos cinco aspectos chaves de Relato Integrado, proposto pela Report Sustentabilidade (2013), a materialidade, assim pesquisadora iniciou os trabalhos para delinear quais as etapas necessárias para a construção dos temas materiais na empresa, respondendo, desta forma, a questão de pesquisa.

A construção das etapas teve como base a Estrutura Internacional para o Relato Integrado do IIRC (THEIIRC, 2014), o Manual de Implementação e Princípios para Relato e Conteúdos Padrão divulgados pela GRI (GRI, 2014c), especificamente no que se refere à materialidade.

Os dados foram coletados através da observação na modalidade participante natural, que é um procedimento único de estratégia para coleta de dados, no qual os fatos são percebidos diretamente pelo pesquisador, a pesquisadora deste estudo é funcionária do setor contábil fiscal da empresa estudada sendo um agente interventor.

A implantação dos trabalhos desta pesquisa foi realizada durante o ano de 2014 e 2015 através de encontros, em forma de reuniões participativas, apresentações e workshop, seguindo as etapas propostas por este estudo, sendo conduzidas pela pesquisadora e pela coordenadora dos trabalhos do Relatório de Sustentabilidade da empresa, contando também com a participação do setor de Governança Corporativa.

Todos os encontros foram realizados com convites formais aos participantes através de Outlook e confirmação de presença, a pesquisadora elaborou lista de presença e atas que estão devidamente arquivadas junto ao Setor de Gestão da Sustentabilidade da empresa. Tais documentos estão disponíveis para serem utilizados por auditorias (interna ou externa).

A análise dos resultados foi realizada quase que simultaneamente com a coleta dos dados, sendo que desde o primeiro encontro foram realizadas as primeiras observações, o que é um processo interativo no qual o pesquisador realiza a análise e no mesmo instante consegue realizar a interpr etação dos resultados.

\section{APRESENTAÇÃO E ANÁLISE DOS RESULTADOS}

Para iniciar o processo de relato integrado partindo-se da construção da materialidade, conforme a realidade da empresa estudada, foram adotadas as seguintes etapas: Etapa 1: pesquisa documental a respeito de temas materiais; Etapa 2: identificação dos stakeholders chaves; Etapa 3: consulta dos temas materiais junto aos stakeholders chaves e incorporação dos temas materiais na estratégia da empresa.

Na Etapa 1 os princípios norteadores são: materialidade, completude e comparabilidade tanto da GRI G4 quanto do IIRC. Tendo como base o princípio da completude foi realizado uma pesquisa documental nos relatórios de sustentabilidade de empresas do mesmo setor com objetivo de obter elementos e informações quanto aos temas materiais por elas utilizados.

No site da GRI há um banco de dados que possibilita consultar os Relatórios de Sustentabilidade das empresas que o publicam e realizar buscar por critérios de seleção.

Conforme o Manual de Implementação do GRI para a consolidação dos temas materiais, é necessário que a empresa também verifique as normas e acordos internacionais (GRI, 2013b).

A pesquisadora elencou os temas materiais dos Relatórios de Sustentabilidade de quatro empresas nacionais e uma empresa americana, todas do setor saneamento, dos anos de 2012 e 2013, realizou uma pesquisa também nos Relatórios de Sustentabilidade da própria empresa estudada, dos anos de 2012 e 2013, pesquisou também os acordos internacionais relacionado com questões ambientais e sociais em que a empresa é signatária. 
Consolidou todos os temas materiais pesquisados para apresentação ao Grupo de Trabalho de Sustentabilidade, que inclui funcionários de diversos setores da empresa, Setor de Gestão de Sustentabilidade e Setor de Governança.

Foram duas reuniões com o grupo que tiveram como objetivo identificação dos temas, ou seja, selecionar quais temas são potencialmente materiais para a empresa que serão encaminhados posteriormente para consulta junto aos stakeholders e alta gestão. Essas reuniões serviram também para uma maior integração entre os setores e os funcionários participantes.

Na primeira reunião foi explicado os princípios norteadores dos trabalhos, como foram selecionados os temas apresentados e o motivo do encontro.

O processo de determinação de materialidade inclui a identificação de assuntos relevantes, a avaliação da importância desses assuntos, a priorização de acordo com a importância e a determinação de quais informações será divulgada a respeito dos assuntos considerados relevantes (THEIIRC, 2014).

A visão de materialidade do IIRC é que os temas a serem considerados materiais são aqueles que podem vir a afetar a decisão dos leitores do relato a respeito da capacidade de a organização criar e preservar valor. Já para a GRI, os temas materiais devem considerar os impactos econômicos, sociais e ambientais da organização e sua percepção pelos seus stakeholders para determinar sua priorização (Report Sustentabilidade, 2013).

Primeiramente, da lista dos temas consolidados e apresentados foram identificados os considerados potencialmente materiais para a empresa, que são aqueles que podem fazer ou fazem parte da estratégia da empresa e já tiveram, têm, ou possam futuramente vir a ter impactos significativos não só econômico, mas também social e ambiental.

Com os temas potencialmente materiais já identificados os próximos passos são: realizar a consulta desses temas junto aos seus principais stakeholders e sua validação junto à alta gestão para assim se chegar aos temas materiais da empresa.

Nesta etapa foi possível realizar um estudo detalhado nos temas materiais de outras empresas do mesmo setor, isso deu a oportunidade de ampliar o conhecimento de assuntos considerados importantes por essas empresas e que também devem ser discutidos e tratados pela empresa estudada.

Na Etapa 2, os princípios norteadores do início desta etapa são: Inclusão de stakeholders da GRI G4 e Relação com partes interessadas do IIRC, porém para que haja de fato a inclusão dos stakeholders a empresa deve primeiramente identificá-los e medir qual a influência deles na empresa. A GRI reconhece a importância do engajamento de stakeholders para a organização quando afirma que o conteúdo a respeito do engajamento de stakeholders destacado em suas diretrizes não precisa se limitar apenas para fins de elaboração do relatório (GRI, 2013a). Para Sender \& Fleck (2004) um fator essencial para a manutenção de uma organização é a adequada gestão de seus stakeholders. Martins (2001) afirma que a importância em identificar as necessidades dos stakeholders e a satisfação dessas necessidades são ações que podem influenciar no desempenho da organização de forma positiva.

0 princípio inclusão do stakeholders deve nortear a pesquisa dos temas materiais, pois é através dele que a empresa conhecerá as expectativas de seus públicos, inserindo no relatório de sustentabilidade as informações a respeito das ações realizadas em respostas a essas expectativas (GRI, 2013b).

Primeiramente foi necessário identificar quais são os stakeholders da empresa, para auxiliar nesta etapa a pesquisadora utilizou o Anexo A da Norma Brasileira de Responsabilidade Social 16001 (NBR 16001:2012), que apresenta algumas perguntas, que colaboram na identificação dos stakeholders, tais como: "com quem a organização tem obrigações legais? quem poderia ser positivamente ou negativamente afetado pelas atividades ou decisões da organização? quem da cadeia de valor é afetado? " (NBR 16001, 2012, Anexo A). A NBR 16001 estava sendo implantada pelo Setor de Qualidade na mesma época, o que colaborou com os trabalhos de identificação dos stakeholders.

Esta etapa foi realizada através de um workshop com funcionários de diversas áreas, inclusive o setor de Gestão de Sustentabilidade e Governança, a abertura do workshop foi realizada pelo Presidente, o que fortaleceu a importância do evento e colabora com o envolvimento da alta gestão nos trabalhos.

Nesse encontro a pesquisadora realizou a apresentação das definições de stakeholders e a importância em realizar sua identificação e engajamento, em seguida o setor de Governança Corporativa apresentou a metodologia desenvolvida para avaliação dos stakeholders. Optou-se por realizar a identificação e classificação destes stakeholders através de um workshop com os próprios funcionários da empresa, assim 
além de realizar um treinamento com os mesmos foi possível realizar uma integração das relações de forma participativa. Os stakeholders mais importantes identificados foram: funcionários próprios e terceirizados, fornecedores de serviços e materiais, clientes/consumidores, sindicato dos trabalhadores, acionistas, fornecedores de capital e sociedade.

Nesta etapa a empresa teve a oportunidade de consolidar a teoria apresentada junto a seus próprios funcionários na identificação de seus stakeholders, o que posteriormente dará condições para realizar os trabalhos de engajamento com os mesmos, o que para Sender \& Fleck (2004) é um fator essencial para a manutenção de uma organização

Na Etapa 3, tanto para a GRI quanto para o IIRC apresentam que é necessário o envolvimento da alta gestão no processo de determinação da materialidade, criando assim um vínculo entre os assuntos divulgados nos relatórios não financeiros com a estratégia da empresa (Report Sustentabilidade, 2013).

As Diretrizes GRI G4 e as orientações para o Relato Integrado foram lançadas quase simultaneamente e a materialidade é apresentada como tema central para ambas. Desta forma é essencial para a empresa que pretenda utilizar esses conceitos conheça as questões apresentadas pelos seus públicos e realize posteriormente sua incorporação à estratégia do negócio (Report Sustentabilidade, 2014).

Inicialmente, foi proposto pela pesquisadora, realizar uma pesquisa quantitativa com os stakeholders para definição dos temas materiais, questionando esses stakeholders em relação ao seu ponto de vista da importância ou não do tema, obtendo respostas em escala de prioridade. Porém, poderia correr o risco de se obter um resultado não satisfatório, tendo quantidade de respostas sem um maior entendimento a respeito dos temas materiais pelos stakeholders consultados. Desta forma, a solução encontrada pela pesquisadora em conjunto com a coordenadora dos trabalhos de Gestão da Sustentabilidade, foi de realizar a consulta dos temas materiais junto a representantes internos dos principais stakeholders identificados anteriormente.

Essa solução levou em consideração a realidade da empresa estudada, que ainda não possui um engajamento consolidado com seus stakeholders e se encontra em conformidade com a orientação do princípio de inclusão de stakeholders para definição de conteúdo do Relatório de Sustentabilidade GRI G4 (GRI, 2013b).

Assim, tendo como base as orientações do IIRC para relato integrado e das Diretrizes da GRI a melhor opção foi realizar uma pesquisa qualitativa junto aos representantes internos dos principais stakeholders, com reuniões para discutição e apresentação dos temas propostos, possibilitando a manifestação dos mesmos.

Os temas potencialmente materiais identificados na "Etapa 1" seguiram para consulta junto aos representantes internos dos principais stakeholders identificados na "Etapa 2" com o objetivo de conhecer sua visão a respeito dos temas materiais pesquisados além de fornecer a possibilidade de inclusão de novos temas conforme suas necessidades e também de exclusão em caso de o tema não ser relevante.

Não há hierarquia entre os stakeholders para a consulta dos temas materiais, as consultas foram sendo realizadas em três reuniões conforme a disponibilidade de agenda de um grupo ou individualmente.

A realização de consulta dos temas materiais junto aos representantes dos principais stakeholders possibilitou o conhecimento pela empresa de quais são seus interesses e suas necessidades, seguindo o princípio de relações com partes interessadas das orientações do IIRC para relato integrado e de inclusão de stakeholders para materialidade da GRI G4.

Após a análise dos temas potencialmente materiais, os participantes elencaram quais os temas são relevantes para a empresa, de forma que tanto no curto, médio ou longo prazo são temas que impactam ou podem impactar positivamente ou negativamente no negócio, e que se divulgados irão fornecer maior transparência de suas ações e subsídios a seus stakeholders para a tomada de decisões, assim realizando a avaliação e priorização no processo de materialidade.

O setor de Ouvidoria, Governança e Gestão Sustentabilidade participaram ativamente dessas reuniões, pois são áreas de forte estratégia na empresa, principalmente por terem conhecimento das demandas dos clientes e fornecedores, além do amplo conhecimento dos riscos da empresa.

Na prática, para que realizar a integração dos temas materiais à estratégia da empresa, os mesmos foram levados para discussão à alta gestão, no caso da empresa estudada: Presidente, Diretores e Conselheiros, para análise, entendimento e validação, pois só assim esses temas passam a fazer parte da estratégia da empresa, com metas para curto, médio e longo prazo e também com um orçamento. 
Esse processo cumpre a etapa da validação para as diretrizes da GRI (GRI, 2013b) que estabelece que é de fundamental importância a aprovação pela alta gestão da definição dos temas materiais que serão incluídos no relatório.

No mesmo sentido, o IIRC apresenta no princípio de orientação da materialidade, que para o tema ser considerado material é necessário o entendimento desta condição da alta direção e da governança (THEIIRC, 2013). A discussão com a alta gestão teve como resultado a recomendação de inclusão de mais três temas que foram incorporados aos temas materiais.

A oportunidade gerada nesta etapa para a empresa foi de conhecer a visão de seus principais stakeholders e suas expectativas com relação à empresa no decorrer do tempo, além de possibilitar a inclusão dos temas materiais na estratégia da empresa, bem como fortalecer a integração e o engajamento interno com seus stakeholders.

\subsection{VISÃO GERAL DAS ETAPAS APLICADAS}

É necessário primeiramente desenvolver um pensamento integrado na empresa, com integração das áreas, introdução das orientações do IIRC e aos poucos incorporar tais orientações na elaboração das informações do Relatório de Sustentabilidade que a empresa já divulga.

0 exercício do pensamento integrado inclui a correta descrição das informações levando-se em conta uma conexão com a governança, estratégia e perspectivas, o que contribuirá para fornecer uma informação mais consistente em todas as suas divulgações, (Report Sustentabilidade, 2013), sendo esta a intenção de demonstração deste trabalho.

0 trabalho realizado para a construção da materialidade parte do princípio que os temas apontados devem ser o eixo central do Relato Integrado e que as questões críticas apontadas pelos seus stakeholders, ou público de interesse, devem ser levadas em consideração, devendo ser incorporadas à estratégia do negócio (Report Sustentabilidade, 2013).

Neste primeiro momento foram realizadas apenas consultas internas, com representantes de stakeholders considerados chaves pela empresa, tornando o processo de definição de materialidade maduro primeiro internamente com a participação da alta gestão para que haja a validação de que esses temas estejam incorporados à estratégia, desenvolvendo assim o pensamento integrado.

Não foi possível realizar consultas diretas com os stakeholders externos, pelo fato de a empresa ainda não possuir um engajamento externo. Essa realidade também pode ser a mesma de muitas empresas e até mesmo se tornar uma dificuldade na implantação do relatório de sustentabilidade e relato integrado, porém a empresa precisa buscar outras formas para conhecer a necessidade de seus stakeholders que retrate a realidade da empresa.

A conclusão da identificação dos temas materiais foi divulgada no Relatório de Sustentabilidade da empresa de 2015 e incorporados à estratégia da empresa, no qual os mesmos serão acompanhados e analisados nos próximos anos.

A função da pesquisadora nos encontros foi de apresentar as orientações para relato integrado e introduzi-las junto aos participantes que elaboram as informações para o Relatório de Sustentabilidade, aplicando de acordo com a realidade da empresa os princípios e elementos de conteúdo do Framework $<I R>$. Com relação aos temas materiais, o próximo passo será atribuir os limites, riscos, oportunidades e identificar os capitais envolvidos.

Como resultado da continuação da utilização das orientações do IIRC a empresa terá condições de montar sua Matriz de Materialidade e o seu Modelo de Negócio, com a priorização dos temas que mais possuem influência na capacidade de a empresa cumprir sua estratégia (GRI, 2013b; THEIIRC, 2013).

\section{CONSIDERAÇÕES FINAIS}

As empresas deparam-se com uma nova demanda, imposta tanto pela sociedade quanto pelos diversos stakeholders, demanda que vai além das informações financeiras, considerada como uma nova necessidade do século 21, que são as informações sociais e ambientais integradas com as informações financeiras (Pavan, 2014; Carvalho \& Kassai, 2013; Fragalli; 2014). 
Assim, surge o relato integrado como uma ferramenta capaz de satisfazer essa nova necessidade, com a introdução do pensamento integrado que incorpora visões a respeito de diversos capitais impactados, com atenção às necessidades de seus stakeholders, identificação do novo modelo de negócio, criação de valor no decorrer do tempo, demonstração das informações a respeito de estratégia, informações econômicas além de informações sociais e ambientais. Apesar de as orientações do IIRC para relato integrado serem abrangentes possuem sete princípios básicos com informações e suporte suficientes para que a empresa consiga construir suas informações integradas.

Este trabalho buscou auxiliar a empresa estudada na utilização das orientações do IIRC para relato integrado em seu relatório de Sustentabilidade, iniciando assim o preparo de suas informações de forma integrada, com relação à construção dos temas materiais.

Assim, a questão de pesquisa é respondida através da demonstração da aplicação das etapas desta pesquisa relacionadas à materialidade, que foi considerada como base para iniciar a divulgação de suas informações integradas.

Os desafios apresentados nos estudos citados no referencial teórico também foram os desafios encontrados pela pesquisadora na empresa estudada, sendo que as orientações do IIRC são recentes e que leva um tempo para as adaptações necessárias (Fragalli, 2014; Rodrigues, 2014). Além disso, torna-se necessário também o dispêndio de dinheiro e tempo (Rodrigues, 2014), a capacitação de funcionários e gestores (Roth, 2014; Fragalli, 2014).

Com a aplicação das etapas propostas a pesquisadora confirma que dentro da realidade da empresa estudada não é possível implantar as orientações para o relato integrado em um curto período de tempo. É um processo que pode demandar anos, com a necessidade da participação de pessoas de diversas áreas que se disponham a estudar os novos conceitos e discutir sua incorporação e implantação de novos processos na empresa, concluindo que a integração entre diversas áreas da empresa é essencial para a integração das informações.

Uma das maiores dificuldades encontrada pela pesquisadora na empresa estudada foi a disponibilidade de agenda para cumprir um cronograma de reuniões junto aos funcionários, o que pode ser explicado pelo ano de 2014 e 2015, ter sido atípico, com forte interferência da crise hídrica nas atividades dos profissionais da empresa. Todavia, mesmo com essa dificuldade, obteve-se grande evolução na aplicação das etapas com a participação dos funcionários e apoio da alta gestão.

O ponto forte encontrado é que o Setor de Gestão da Sustentabilidade está ligada diretamente Presidência, demonstrando que o interesse pela sustentabilidade parte do mais alto cargo de gestão da empresa, o que colabora quando da incorporação e implantação dos seus conceitos por toda a empresa.

Outro ponto forte são os compromissos, mesmo que voluntários, que a empresa já tem assumidos com questões de governança, sociais e ambientais, tais como a publicação das informações de gestão, seu desempenho econômico, social e ambiental através das diretrizes internacional de GRI. Inclui-se também a iniciativa de responder os indicadores Ethos, o compromisso com o Pacto Global e a assinatura de compromissos internacionais. Tais compromissos se tornam base para o disclosure de suas informações não financeiras e demonstra a preocupação com outros aspectos que não seja apenas o econômico.

Uma das oportunidades geradas na aplicação das etapas sugeridas, foi o conhecimento de temas materiais de outras empresas, isso fez com que a empresa saísse de seu próprio relatórios o que possibilitou uma visão global dos assuntos materiais trazidos pelas outras empresas. Outra oportunidade foi a identificação de seus próprios stakeholders, reconhecer o quanto eles são importantes para a manutenção da empresa e suas expectativas com relação aos temas materiais.

Conforme as orientações do IIRC se incorporam nos trabalhos do Relatório de Sustentabilidade nota-se uma maior integração entre os setores e que os novos termos e metodologia aos poucos se consolidam na empresa estudada.

A pesquisadora conclui que na empresa estudada houve o envolvimento da alta gestão em questões de sustentabilidade, o que torna o tema parte de sua estratégia. Houve a participação e colaboração dos funcionários das mais diversas áreas, confirmando de fato uma integração interna. A empresa também incentiva à participação em treinamentos relacionados com relato integrado e assuntos relacionados com sustentabilidade, fornecendo treinamentos e workshop a seus funcionários.

Para um disclosure completo de suas informações integradas no Relatório de Sustentabilidade conforme as orientações do IIRC a empresa estudada precisa continuar determinada em realizar o engajamento dos stakeholders, demonstrar o desempenho conforme seus temas materiais e o efeito nos diversos capitais, 
demonstrar quais são as implicações em seu modelo de negócio e desempenho futuro ao seguir suas estratégias, identificar e relatar seus principais riscos e oportunidades que afetam na capacidade que a empresa tem em gerar valor ao longo do tempo.

Sugere-se que as etapas aplicadas na empresa estudada possam auxiliar outras empresas, com o objetivo de verificar se o modelo utilizado se adapta também a sua realidade, difundindo assim a utilização das orientações do IIRC, proporcionando maior transparência e integração no disclosure das empresas, na busca de suprir a necessidade de informação dos mais diversos stakeholders.

\section{REFERÊNCIAS}

[1] Balby, C. (2013). Sobre a nova versão da GRI G4 e a Conferência GRI 2013. Disponível em: <http://ceciliabalby.blogspot.com.br/2013/05/normal-0-false-false-false-pt-br-ja-x.html>. Acesso em: 10 abr. 2014.

[2] BM\&FBOVESPA. 2013. Proposta global de relatório integrado para empresas é lançada na BM\&FBOVESPA. Disponível em:<http://www.bmfbovespa.com.br/novo-valor/pt-br/noticias/2013/IIRC-Proposta-global20130417.asp>. Acesso em 07 set. 2013.

[3] Carvalho, N. \& Kassai, J. R. (2013). Relato integrado: a próxima evolução contábil. In: Encontro Internacional sobre gestão empresarial e meio ambiente. São Paulo: FEA-USP.

[4] Fragalli, A. C. (2014). Relato Integrado de uma propriedade agrícola: um estudo de caso com base no Framework do International Integrated Reporting Council (IIRC).

[5] Freitas, J; Calbino, D.; Santos, A. \& Pereira, R. D. (2010). Em defesa do uso da Pesquisa-Ação na pesquisa em Administração no Brasil. Administração: Ensino e Pesquisa, v. 11, n. 3, p. 425-445.

[6] GRI - Global Reporting Initiative. (2006). Diretrizes para relatório de sustentabilidade. Versão 3.0. Disponível em <https://www.globalreporting.org/resourcelibrary/Brazil-Portuguese-G3-Reporting-Guidelines.pdf>. Acesso em 25 set. 2013.

[7] _. (2007). $\quad$ Quem $\quad$ somos. $\quad$ Disponível em <https://www.globalreporting.org/languages/Portuguesebrazil/Pages/default.aspx>. Acesso em 10 set. 2013.

[8] __ (2013a). G4 - Diretrizes para Relato de Sustentabilidade. Princípios para Relato e Conteúdo Padrão. Disponível em:<https://www.globalreporting.org/resourcelibrary/Brazilian-Portuguese-G4-Part-One.pdf >. Acesso em 17 fev. 2014.

[9] __ (2013b). G4 - Diretrizes para Relato de Sustentabilidade. Manual de Implementação. Disponível em:<https://www.globalreporting.org/resourcelibrary/Brazilian-Portuguese-G4-Part-Two.pdf >. Acesso em 17 fev. 2014.

[10] Gonçalves, B. (2013). Matéria Publicada pelo Instituto Ethos. Relatórios Integrados: uma nova dinâmica para a comunicação empresarial. Disponível em: <http://www3.ethos.org.br/cedoc/relatorios-integrados-uma-novadinamica-para-a-comunicacao-empresarial/\#.UkSROja5epo>. Acesso em 26 set. 2013.

[11] Maciel, P. A. (2015). Relato Integrado: análise da evolução da estrutura conceitual e sua aplicação nos relatórios das empresas no Brasil. Dissertação de Mestrado - FACC.

[12] Martins, U. U. M. (2001). Influência dos stakeholders na tomada de decisão organizacional - estudo de caso de uma empresa de segurança patrimonial. 2001. 128f. Dissertação (Mestrado em Engenharia de Produção) - Curso de Pós Graduação em Engenharia de Produção da Universidade Federal de Santa Catarina, Florianópolis.

[13] NBR 16001. Associação Brasileira de Normas Técnicas. Responsabilidade Social. Rio de Janeiro, 2012.

[14] Ott, E. \& Pires, C. B. (2009). Conceito e objetivos da contabilidade In: Ribeiro Filho, J. F.; Lopes, J.; Pederneiras, M. (Org.). Estudando teoria da contabilidade. 1. ed. São Paulo: Atlas, p. 57-74.

[15] PAVAN, Sukhdev. Corporação 2020 - Como transformar as empresas para o mundo de amanhã. São Paulo: Ed. Abril, 2014.

[16] Report Sustentabilidade. 2013. Relato integrado perspectiva brasileira. Disponível em: <http://www.reportsustentabilidade.com.br/2013/pt-br/relato-integrado>. Acesso em: 24 fev. 2014.

[17] _. 2014. Materialidade no Brasil um ensaio qualitativo. Disponível em:

<http://reportsustentabilidade.com.br/rpt_estudomaterialidade_20140127_final.pdf>. Acesso em: 08 abr. 2014.

[18] Rodrigues, A. P. F. (2014). Análise do grau de atendimento do relatório natura 2012 à proposta de estrutura conceitual para relatórios integrados. XI Congresso USP.

[19] Roth, H.P. (2014). Is Integrated Reporting in the Future? The CPA Journal, New York, v. 84, n. 3, p. 62-67. 
[20] Sender, G. \& Fleck, D. L. (2004). Folga organizacional e gestão de stakeholders: um estudo em bancos brasileiros. XXVIII Enanpad, Anais... Curitiba/PR, p. 1-16.

[21] THEIIRC. 2013. Consultation Daft of the International <IR > Framework - Integrated Reporting. Disponível em<http://www.theiirc.org/wp-content/uploads/2013/06/Consultation-Draft-of-the-InternationalIRFrameworkPortuguese.pdf $>$.Acesso em 25 set 2013.

[22] __ 2014. Copyright (C) Maio 2014 by International Integrated Reporting Council (IIRC). A Estrutura Internacional para o Relato Integrado. Disponível em<http://www.theiirc.org/wp-content/uploads/2014/04/13-1208-THE-INTERNATIONAL-IR-FRAMEWORK-Portugese-final-1.pdf>. Acesso em 20 jun. 2014.

[23] Zaro, E. S. (2015). Análise Comparativa de relatos integrados das empresas brasileiras a luz da estrutura conceitual. 2015. 170f. Dissertação de Mestrado UFSC, Florianópolis. 


\section{Capítulo 5}

\section{Análise dos impactos econômicos decorrentes da instalação dos parques eólicos nos municípios da Região Sul do Brasil}

\section{Lúbia Tamires Rintzel \\ Tiago Wickstrom Alves \\ Angélica Massuquetti}

Resumo: Dentre as fontes energéticas renováveis, a eólica vem apresentando, no Brasil, uma trajetória de expansão nos últimos anos. Entre 1998 e 2012, 108 parques eólicos entraram em operação no país, sendo que 27 estão localizados na Região Sul do Brasil. Diante da relevância de tal setor e considerando que apenas sete municípios desta região concentram $25 \%$ do total de parques eólicos brasileiros, o objetivo deste artigo é analisar os impactos econômicos decorrentes da instalação dos parques eólicos nos municípios da Região Sul do Brasil. A metodologia empregada foi o Método Estrutural Diferencial, considerando os municípios com parques eólicos, no período de 1998 a 2012, e também os municípios vizinhos a estes. Os dados utilizados referem-se ao emprego, à arrecadação fiscal e ao valor adicionado. Os resultados revelaram que quando os municípios passaram a ter parques eólicos, os mesmos obtiveram um maior incremento no emprego, na arrecadação fiscal ou no valor adicionado, em dado período de análise, podendo ser observado, especialmente, no estado do Rio Grande do Sul. Deste modo, a presença de parques eólicos nos municípios da Região Sul impacta positivamente nos fatores econômicos dos mesmos.

Palavras-chave: Energia Eólica. Região Sul. Método Estrutural Diferencial. 


\section{INTRODUÇÃO}

Dentre as fontes energéticas renováveis, a eólica vem apresentando, no Brasil, uma trajetória de expansão nos últimos anos. Melo (2014) destacou que o Brasil é um dos países mais competitivos na geração de energia eólica, o que justificaria a ampliação dos parques eólicos no país. Fruto desta expansão, em maio de 2017, havia, no Brasil, 443 usinas eólicas instaladas de acordo com a Associação Brasileira de Energia Eólica (ABEEólica) (2017a). Apesar da contribuição para a matriz energética do país, seus impactos econômicos para as comunidades locais são pouco conhecidos.

Mesmo com potencial de geração de energia eólica, o Brasil apresenta sucessivos problemas de abastecimento de energia. Essas crises energéticas decorrem, em boa parte, pela não exploração de fontes alternativas. A matriz energética brasileira é concentrada em energia baseada em hidroelétricas e, em função de secas prolongadas, o país tem enfrentado crises consecutivas. Nestes momentos, o país utiliza a energia fóssil, que possui um alto custo econômico e gera impactos ambientais negativos. Entretanto, é justamente nesses períodos de seca que ocorrem os melhores ventos para a produção de energia eólica, sendo, portanto, um momento oportuno para a fonte eólica, a qual causa poucos impactos ambientais, já que apenas uma pequena parte da terra é ocupada pela instalação dos parques eólicos, não ficando a mesma comprometida, e possui um tempo de instalação rápido (ABEEólica, 2015).

Melo (2014) ressaltou que diante de um panorama não muito animador, em relação aos investimentos em energias renováveis no mundo, o Brasil, assim como outros países em desenvolvimento, possui uma realidade diferenciada, sinalizando para um crescimento da energia eólica. A energia eólica, segundo a autora, poderia se tornar uma fonte importante para a matriz energética brasileira. No panorama mundial, destaca-se que no ano de 2013, o Brasil produzia a energia eólica mais competitiva do mundo.

A produção de energia eólica, segundo Castro (2005), gera benefícios ambientais e energéticos. Contudo, para o desenvolvimento das regiões onde há a instalação destes parques, é necessário que os projetos sejam desenvolvidos em parceria com as comunidades locais e que busquem a integração destas estruturas com a paisagem existente. Outro benefício verificado pela geração de energia eólica, observado por Costa e Prates (2005), é a redução das disparidades regionais. Parte desta redução se dá pela geração de renda oportunizada tanto pela instalação como pela manutenção dos parques, sendo a dinamização destes elementos o mais relevante. Neste mesmo sentido, Melo (2013) afirmou que a maior contribuição econômica nas localidades que abrigam os parques é a geração de emprego e de renda.

Alina-Florentina (2011) ressaltou que além dos ganhos ambientais, como a redução das emissões de gases de efeito estufa, o aumento da segurança e a estabilidade por meio da diversificação da carteira nacional de eletricidade, há vantagens sociais e econômicas, como a revitalização das economias rurais, havendo a criação de postos de trabalho, como trabalhadores para montagem, agrimensores, técnicos, engenheiros, advogados, banqueiros, dentre outros. Além da criação de postos de trabalho, há também benefícios para as comunidades locais decorrentes dos arrendamentos das terras e incrementos das receitas fiscais. Corroborando com Alina-Florentina (2011), Simas e Pacca (2013) destacaram que as energias renováveis, dentre elas a eólica, além dos benefícios socioeconômicos já citados, geram também inovação tecnológica e o desenvolvimento industrial. Em um sentido mais amplo, Costa e Prates (2005) ainda ressaltaram que, apesar de um custo maior de entrada no mercado, as energias renováveis são de suma importância, pois aumentam a segurança energética do país, reduzindo os riscos de abastecimento, além de garantir melhores condições ambientais e de saúde à população, diminuindo também as emissões de gases do efeito estufa.

Entretanto, nem todos os pesquisadores consideram que os benefícios da instalação de parques eólicos sejam positivos. Melo (2014) afirmou que historicamente o que motiva o interesse em investir em alguma fonte de energia são a segurança e a independência energética e o crescimento econômico e a competitividade, sendo que as demais variáveis são apenas decorrências. De acordo com Costa (2016), os problemas decorrem da existência de externalidades negativas, relacionadas às questões sociais e ambientais que não são contabilizadas e acabam sendo pagas pela sociedade local em função do modelo de exploração adotado, que não preserva as populações e o modo de vida das comunidades locais, embora reconheça que a produção de energia eólica é imprescindível.

No Brasil, conforme dados da ABEEólica, observados no início de maio de 2017, havia 443 usinas eólicas instaladas, gerando uma capacidade instalada de $11,03 \mathrm{GW}$ e possuindo uma capacidade em construção de 6,93 GW (ABEEólica, 2017a). Conforme os dados mensais de abril de 2017, a fonte eólica representou $7,2 \%$ de participação na matriz elétrica brasileira (ABEEólica, 2017b). Ainda em termos de geração de empregos decorrentes da implantação dos parques eólicos no Brasil, estima-se que foram gerados, em 2012, aproximadamente 15 mil empregos diretos. Calcula-se que sejam gerados 15 postos de trabalho por 
MW instalado e que a geração de empregos acumulada será superior a 280 mil postos de trabalhos diretos e indiretos até o final de 2020 (MELO, 2013).

Entre 1998 e o fim do ano de 2012, 108 parques eólicos entraram em operação no Brasil, sendo distribuídos em 33 municípios de 11 estados brasileiros. Em relação apenas aos parques eólicos instalados na Região Sul do Brasil, neste mesmo período, os três estados da região foram responsáveis por 27 parques eólicos, localizados em sete municípios (ABEEólica, 2016b). Ou seja, apenas sete municípios do sul do Brasil concentram 25\% do total de parques eólicos brasileiros. Diante da relevância de tal setor e verificando-se que persistem avaliações distintas em relação aos impactos da instalação dos parques eólicos, o objetivo deste artigo é analisar os impactos econômicos decorrentes da instalação dos parques eólicos nos municípios da Região Sul do Brasil. A abrangência do presente estudo é regional devido à trajetória de expansão do setor eólico nesta região. No que se refere ao recorte temporal, o mesmo decorre da necessidade de se ter um tempo mínimo de instalação para que os efeitos econômicos possam ocorrer na região de abrangência destes parques e também devido à disponibilidade dos dados.

Os impactos foram avaliados não de forma qualitativa, mas pela diferenciação das taxas de crescimento das variáveis econômicas entre os municípios com parques eólicos versus os municípios vizinhos sem parques eólicos. Assim, dimensões qualitativas do desenvolvimento econômico não foram contempladas neste artigo. Além disso, os resultados estão limitados pelo potencial e pelos vieses do modelo que foi utilizado, que é o Método Estrutural Diferencial para avaliar os diferenciais de crescimento.

Neste sentido, o artigo se justifica em função da oportunidade e da viabilidade. Oportunidade em função do espaço temporal que o país se encontra no processo de geração de energia eólica. Ou seja, como já houve um crescimento significativo dos parques instalados, é viável avaliar os impactos que eles têm causado nas regiões onde se encontram, ao mesmo tempo, como ainda há um potencial de crescimento elevado, indicando que haverá uma expansão ainda maior destes parques no Brasil. Assim, conhecer as transformações que eles estão causando nas regiões permitiria ajustar o processo para que os novos parques potencializassem os benefícios.

Após a presente introdução, inicialmente, na segunda seção, procede-se a análise do setor eólico brasileiro, observando a trajetória da energia eólica no Brasil. Na sequência, encontra-se a terceira seção, a qual se destina à análise da metodologia utilizada no presente estudo. Na quarta seção são apresentados os resultados do estudo e, por fim, as considerações finais encontram-se na quinta seção.

\section{SETOR EÓLICO BRASILEIRO}

Dentre as fontes energéticas que não causam a emissão de gases do efeito estufa, a energia mecânica contida nos ventos vem tomando papel de destaque, pois esta possui potencial energético que atende os requisitos quanto ao custo de produção, à segurança de fornecimento e à sustentabilidade ambiental. A experiência de países que já são líderes no setor de geração eólica demonstra que o rápido desenvolvimento da tecnologia e do mercado possui implicações socioeconômicas (MARTINS; GUARNIERI; PEREIRA, 2008).

Castro (2005) relatou que no começo do segundo milênio, fontes energéticas como a água, o vento e a lenha dominavam, contudo, estas fontes tradicionais foram substituídas por carvão, por petróleo, pela energia nuclear e pelo gás. Com o choque do petróleo na década de 1970, as energias renováveis ressurgiram com intuito de garantir a segurança e a diversidade de abastecimento energético, assim como a preocupação com o meio ambiente. Na atualidade, a energia eólica se caracteriza por possuir uma tecnologia madura e sendo uma das mais promissoras fontes de energias renováveis.

Conforme Souza et al. (2014), um processo de mudança ocorreu nos últimos anos no cenário energético mundial devido aos preços dos combustíveis fósseis terem sofrido elevações e aos impactos ambientais, acarretando investimentos e estudos em energia eólica. Neste sentido, o Brasil estabeleceu uma matriz energética baseada em energias renováveis, o que permitiu ao país, segundo Melo (2013), uma posição de destaque em nível mundial, onde $45 \%$ da matriz energética provêm de fontes que não emitem gás carbônico (CO2), contra menos de $20 \%$ da média mundial.

Em termos de energia eólica, o início de sua operação comercial foi 1992, com a instalação do primeiro aerogerador. Esta foi a primeira turbina eólica a entrar em operação comercial na América do Sul, localizada no arquipélago de Fernando de Noronha, no estado de Pernambuco, fruto de uma parceria entre o Centro Brasileiro de Energia Eólica (CBEE) e a Companhia Energética de Pernambuco (CELPE), por meio do financiamento do instituto de pesquisa dinamarquês Folkecenter (ABEEólica, 2016a). 
Nos dez anos seguintes, pouco se avançou na concretização da energia eólica como fonte alternativa de geração de energia no país devido à falta de políticas e ao alto custo dessa tecnologia. Porém, em 2001, com a crise energética, criaram-se políticas públicas para incentivar empreendimentos de geração eólica no país, como o Programa Emergencial de Energia Eólica (PROEÓLICA), o qual não obteve êxito e foi substituído pelo Programa de Incentivo a Fontes Alternativas de Energia Elétrica (PROINFA). Este, além de incentivar o desenvolvimento de fontes renováveis da matriz energética, também abriu caminho para a fixação da indústria de componentes e turbinas eólicas no país (ABEEólica, 2016a).

Inicialmente, foram realizados leilões de comercialização de energia voltados exclusivamente para a fonte eólica, chamado Leilão de Energia Reserva (LER) e, em 2010, passou-se a realizarem-se também os Leilões de Fontes Alternativas (LFA), estes compreendendo diversas fontes renováveis e competindo entre si para negociar sua energia nos leilões. Além do PROINFA e dos leilões, a energia eólica também é comercializada em uma escala menor no Mercado Livre, onde as condições contratuais são livremente negociadas entre as partes (ABEEólica, 2016a), chamado, conforme o Ministério de Minas e Energia de Ambiente de Contratação Livre (ACL) (MINISTÉRIO DE MINAS E ENERGIA, 2017).

Nos leilões de energia se realizam as concessões de novas usinas, buscando, por meio de contratos de fornecimento, atender a futura demanda de energia. Além dos já comentados anteriormente, PROINFA, LER, LFA e ACL, dentre as modalidades de leilões de energia há algumas conceituações próprias, como Leilão A-x, por exemplo. Esta nomenclatura indica um ano base no qual ocorre o leilão de compra de energia elétrica, sendo que a energia será fornecida em algum ano posterior ao ano base A. Como se pode exemplificar, sendo o Leilão A-3 realizado em 2013, onde A indica o ano base em que o leilão foi realizado, a energia passará a ser fornecida após 3 anos, portanto, em 2016 (ABRADEE, 2017). A Tabela 1 demonstra o tipo de contratação de cada MW da capacidade instalada da fonte eólica, de acordo com os dados mensais de janeiro de 2017 da ABEEólica. Destaca-se que a usina eólica de Tubarão, a qual resulta de um programa de Pesquisa e Desenvolvimento (P\&D), também é contabilizada.

Tabela 3 - Tipo de contratação da capacidade instalada da energia eólica

\begin{tabular}{|c|c|c|c|c|c|c|c|c|c|c|}
\hline Leilão & PROINFA & $\begin{array}{c}\text { LER } \\
2009\end{array}$ & $\begin{array}{c}\text { LER } \\
2010\end{array}$ & LFA 2010 & $\begin{array}{c}\text { LER } \\
2011\end{array}$ & A-3 2011 & A-52011 & A-5 2012 & $\begin{array}{c}\text { LER } \\
2013\end{array}$ & A-3 2013 \\
\hline $\begin{array}{l}\text { Potência } \\
\text { (MW) }\end{array}$ & 1303,1 & 1915,9 & 545,2 & 1293,4 & 797,8 & 1056,3 & 822,1 & 48,9 & 1403,8 & 791,7 \\
\hline $\begin{array}{c}\text { № } \\
\text { Parques }\end{array}$ & 53 & 71 & 20 & 48 & 31 & 44 & 33 & 2 & 62 & 39 \\
\hline Leilão & $\begin{array}{c}\text { A-5 } \\
\text { Dez/2013 }\end{array}$ & $\begin{array}{c}\text { A-3 } \\
2014\end{array}$ & $\begin{array}{c}\text { LER } \\
2014\end{array}$ & $\begin{array}{c}\text { A-5 } \\
\text { Nov/2014 }\end{array}$ & $\begin{array}{c}\text { LFA } \\
2015\end{array}$ & A-3 2015 & $\begin{array}{c}\text { LER } \\
\text { Nov/201 } \\
5\end{array}$ & ACL & P\&D & \\
\hline $\begin{array}{l}\text { Potência } \\
\text { (MW) }\end{array}$ & 2276,6 & 533,1 & 762,3 & 932,4 & 90,0 & 538,8 & 548,2 & 2284,2 & 2,1 & \\
\hline $\begin{array}{c}\text { № } \\
\text { Parques }\end{array}$ & 97 & 21 & 31 & 36 & 3 & 19 & 20 & 109 & 1 & \\
\hline
\end{tabular}

Fonte: Elaborado pelos autores a partir de dados da Agência Nacional de Energia Elétrica (ANEEL)

(ABEEólica, 2017b).

A implementação das políticas citadas anteriormente e a realização de leilões de energia proporcionaram ao Brasil que a fonte eólica passasse a ter importante participação na matriz energética. As 443 usinas instaladas (dados do início de maio de 2017) geraram uma redução de 19.045.167 toneladas ao ano (T/ano) de CO2. Isso equivaleria à emissão de CO2 evitada por cerca de 11 milhões de automóveis de acordo com ABEEólica (2017a). A distribuição dos parques eólicos ocorre basicamente em regiões próximas à costa litorânea. No Brasil, havia 108 parques eólicos até o ano de 2012, totalizando 2,5 GW de capacidade instalada (ABEEólica, 2016b) ${ }^{1}$.

Quando observada a matriz elétrica brasileira de dezembro de 2016, em relação às fontes que a compõem, a energia elétrica proveniente das hidrelétricas é a principal fonte, representando $61,20 \%$. Em segundo lugar está a energia proveniente da biomassa $(9,40 \%)$, em terceiro lugar a do gás natural $(8,60 \%)$ e, em quarto lugar, a energia eólica, representando $7,10 \%$ da matriz elétrica brasileira. Após, encontram-se a

\footnotetext{
${ }^{1}$ Conforme dados divulgados em janeiro de 2017 pela ABEEólica, que são disponibilizados mensalmente em uma parceria com a Agência Nacional de Energia Elétrica (ANEEL), a fonte eólica representou, no fim de 2016, uma capacidade instalada de 10,74 GW, representando 7,10\% no total das fontes que formam a matriz elétrica brasileira (ABEEólica, 2017b).
} 
energia originária do óleo (6,70\%), de Pequenas Centrais Hidrelétricas (PCH) (3,30\%), do carvão (2,40\%) e, por fim, a nuclear (1,30\%) (ABEEólica, 2017b). Nota-se que a fonte eólica vem se destacando dentre as fontes da matriz elétrica brasileira, assim como há uma maior preocupação com a utilização de fontes renováveis, as quais, além de reduzidos impactos ambientais, apresentam um menor custo em relação às fontes tradicionais. A capacidade instalada da energia eólica apresentou uma trajetória de crescimento ao longo dos anos, assim como uma prospecção de crescimento para o decorrer dos próximos anos. No ano de 2005, a capacidade instalada em MW era de apenas 27,1, seguindo um fluxo de crescimento, a perspectiva é de 13.094,0 MW para o ano de 2017. Com um crescimento estimado, em 2020, chegaria a 17.304,6 MW de capacidade instalada (ABEEólica, 2017b).

0 crescente uso de aparelhos eletrônicos, entre outras atividades da sociedade, e a economia atual reforçam a demanda por energia. Fontes alternativas de energia estão no mercado, buscando suprir esta demanda por energia e estas conquistam cada vez mais lugar no mesmo devido, principalmente, aos baixos impactos ambientais e aos altos custos das fontes energéticas tradicionais. Conforme Rossetto e Souza (2014), as energias renováveis estão se difundindo com rapidez nos países devido a sua produção ser limpa e pela sua forma sustentável, destacando que a energia eólica se sobressai por causar mínimos impactos na construção e na instalação dos aerogeradores ao meio ambiente. Em relação às energias renováveis, dentre elas a eólica, além dos benefícios socioeconômicos já citados, como a criação de empregos, o desenvolvimento regional e local, a geração e o acesso à energia, entre outros, encontram-se também a inovação tecnológica e o desenvolvimento industrial ${ }^{2}$ (SIMAS; PACCA, 2013).

Apesar de um custo maior de entrada no mercado, as energias renováveis são de suma importância, pois, segundo Costa e Prates (2005), estas aumentam a segurança energética do país, reduzindo os riscos de abastecimento, além de garantir melhores condições ambientais e de saúde à população e diminuindo também as emissões de gases do efeito estufa. Em países industrializados, a comercialização de tecnologias e serviços é outro benefício gerado pelo desenvolvimento de tecnologias ligadas às fontes renováveis. Já em países em desenvolvimento, as fontes renováveis contribuem para o desenvolvimento local, econômico, gerando melhorias na infraestrutura, em saúde, em educação, em novos postos de trabalho, em incrementos na renda, entre outros, e contribuindo para a diversificação da matriz energética.

\section{METODOLOGIA}

\subsection{MÉTODO ESTRUTURAL DIFERENCIAL}

Para atender ao objetivo proposto neste artigo, foi utilizado o Método Estrutural Diferencial, o qual é apresentado nesta subseção. Na busca por compreender quais as razões que levam determinada região ou país a apresentar um maior crescimento econômico ou estagnação em relação à outra, distintos autores buscaram criar modelos que explicassem tais diferenças, procurando também propor políticas governamentais em prol de minimizar essas desigualdades. Surgiram, então, o método Shift-Share ou Método Estrutural Diferencial criado por Daniel Creamer (ALVES, 1998).

O Método Estrutural Diferencial, em sua versão clássica, de acordo com Alves (1998), é um bom instrumento para a análise regional, pois o mesmo investiga o desenvolvimento de uma região por meio de dois fatores: o primeiro através da vantagem locacional de uma região, este sendo interno; e outro externo, que é o fato dessa região possuir indústrias dinâmicas a nível nacional. 0 fator utilizado para comparar os diferentes níveis de desenvolvimento entre as regiões é o volume de emprego e sua taxa de crescimento. Observa-se a relação que existe entre a variação do emprego regional com o setor em nível nacional e desse setor com a variação do emprego total do país. Outros fatores poderiam ser utilizados para descrever esta diferença de desenvolvimento entre as regiões, como o Produto Interno Bruto (PIB), a renda per capita, dentre outros.

De acordo com Scalabrin e Alves (2002), o uso do Método Estrutural Diferenciado é feito para verificar quais as variáveis que influenciaram no desempenho das regiões. Objetiva-se por meio deste método, encontrar resultados que permitam identificar o impacto econômico que a instalação dos parques eólicos causam aos municípios onde estão instalados, em um comparativo com municípios que não possuam

\footnotetext{
20 constante aperfeiçoamento e o melhoramento ocorrem nos aerogeradores, em busca de um melhor desempenho e aproveitamento dos mesmos. De acordo com Castro (2005, p.12), um acréscimo no tamanho das turbinas leva a vantagens econômicas e ambientais, pois “[...] quanto maior for a potência unitária mais energia é produzida, e melhor aproveitadas são as infraestruturas elétricas e de construção civil”.
} 
parques eólicos instalados. 0 efeito diferencial poderá estar ligado ao crescimento e desenvolvimento dos municípios.

A construção do modelo utilizado neste estudo baseou-se em Alves (1998) e Scalabrin e Alves (2002), sendo realizadas alterações necessárias para que o mesmo se adequasse aos propósitos do artigo. Para aplicação do método foram utilizadas variáveis de emprego, valor adicionado e arrecadação tributária.

Faz-se, a seguir, uma apresentação do modelo clássico do Método Estrutural Diferencial, tendo por base Alves (1998). A base para o desenvolvimento do referido método se dá com a construção de duas matrizes, conhecidas como matrizes de informação, onde haja informações sobre o emprego em cada setor de cada região, tanto para o ano inicial como para o ano final do período em análise, como se observa no Quadro 1.

Quadro 1 - Matriz de informações do modelo clássico

\begin{tabular}{|c|c|c|c|c|c|c|c|}
\hline Setores/Regiões & $\mathrm{R}_{1}$ & $\mathrm{R}_{2}$ & $\ldots$ & $\mathrm{R}_{\mathrm{j}}$ & $\ldots$ & $\mathrm{R}_{\mathrm{k}}$ & $\sum_{\mathrm{j}}$ \\
\hline $\mathrm{S}_{1}$ & $\mathrm{E}_{11}$ & $\mathrm{E}_{12}$ & $\ldots$ & $E_{1 j}$ & $\ldots$ & $E_{1 \mathrm{k}}$ & $\mathrm{E}_{1 \mathrm{n}}$ \\
\hline $\mathrm{S}_{2}$ & $\mathrm{E}_{21}$ & $\mathrm{E}_{22}$ & $\ldots$ & $E_{2 j}$ & $\ldots$ & $\mathrm{E}_{2 \mathrm{k}}$ & $\mathrm{E}_{2 \mathrm{n}}$ \\
\hline$\ldots$ & $\ldots$ & $\ldots$ & $\ldots$ & $\ldots$ & $\ldots$ & $\ldots$ & $\ldots$ \\
\hline $\mathrm{S}_{\mathrm{i}}$ & $\mathrm{E}_{\mathrm{i} 1}$ & $\mathrm{E}_{\mathrm{i} 2}$ & $\ldots$ & $E_{i j}$ & $\ldots$ & $\mathrm{E}_{\mathrm{ik}}$ & $\mathrm{E}_{\text {in }}$ \\
\hline$\ldots$ & $\ldots$ & $\ldots$ & $\ldots$ & $\ldots$ & $\ldots$ & $\ldots$ & $\ldots$ \\
\hline $\mathrm{Sh}_{\mathrm{h}}$ & $\mathrm{E}_{\mathrm{h} 1}$ & $E_{\mathrm{h} 2}$ & $\ldots$ & $E_{h j}$ & $\ldots$ & $E_{h k}$ & $E_{h n}$ \\
\hline$\sum_{\mathrm{i}}$ & $\mathrm{E}_{\mathrm{r} 1}$ & $\mathrm{E}_{\mathrm{r} 2}$ & $\ldots$ & $\mathrm{E}_{\mathrm{rj}}$ & $\ldots$ & $\mathrm{E}_{\mathrm{rk}}$ & $\mathrm{E}_{\mathrm{n}}$ \\
\hline
\end{tabular}

Sendo que, $\mathrm{S}_{\mathrm{i}}$ representava o setor $i$; $\mathrm{R}_{\mathrm{j}}$ representava a região $j$; E $\mathrm{ij}_{\mathrm{j}}$ representava o emprego no setor $i$ da região $j$; Erj representava o emprego total na região $j$; Ein representava o total do emprego nacional no setor $i$; e En dizia respeito ao emprego total no país (ALVES, 1998).

A partir da apresentação das variáveis utilizadas por Alves (1998), na sequência, procede-se com a formalização do modelo clássico do Método Estrutural Diferencial, que ocorre a partir da referida matriz de informações, com a formulação da relação existente entre as variações do emprego regional com as do setor em nível nacional assim como com as do emprego total do país. As variáveis utilizadas são:

a) Variação real do emprego: esta representa a variação real do emprego do setor $i$ na região $j$ no período de análise, $\Delta E_{i j}=E_{i j}-E_{i j}{ }_{i j}$ onde: $\mathrm{E}_{i j}$ é o emprego do final do período e $\mathrm{E}_{i j}$ é o emprego do início do período, a partir desta relação formula-se a taxa de crescimento do emprego $\left(e_{i j}\right)$ do setor $i$ na região $j$, também pode-se representar o emprego final do setor $i$ na região $j$, assim como sua variação;

b) Variação teórica do emprego: descreve a variação teórica do emprego do setor $i$ da região $j\left(\Delta_{t} E_{i j}\right)$ é definida como aquela que a região $j$ teria se seu emprego tivesse crescido à taxa $e$ (taxa de crescimento do emprego total em nível nacional), $\Delta_{t} E_{i j}=E^{o} i j(e-1)$;

c) Variação estrutural do emprego: dada pela diferença entre o crescimento do emprego real do setor $i$ em nível nacional e o crescimento do emprego geral no país, $\Delta_{e} E_{i j}=E^{o} o_{i j}\left(e_{i n}-e\right)$;

d) Variação diferencial do emprego: representada pela diferença do crescimento entre o emprego no setor $i$ em nível nacional e o emprego do setor $i$ na região $\left.j, \Delta_{d} E_{i j}=E_{i j} e_{i j}-e_{i n}\right)$. Em relação a variação real do emprego do setor $i$ da região $j\left(\Delta E_{i j}\right)$, será igual à variação teórica do emprego $\left(\Delta_{t} E_{i j}\right)$ mais a variação estrutural $\left(\Delta_{e} E_{i j}\right)$ e a diferencial $\left(\Delta_{d} E_{i j}\right)$, ou seja, $\Delta E_{i j}=\Delta_{t} E_{i j}+\Delta_{e} E_{i j}+\Delta_{d} E_{i j}$;

e) Variação líquida do emprego: obtida através da subtração da variação teórica da variação real, obtém-se uma equação que relaciona os efeitos líquidos e os efeitos estruturais e diferenciais. Explicitando a diferença de crescimento do emprego do setor $i$ da região $j$ e o apresentando em nível nacional, $\Delta E_{i j}-\Delta_{t} E_{i j}$ $=\Delta_{e} E_{i j}+\Delta_{d} E_{i j}$, sendo que o efeito líquido $\left(\Delta E_{i j}-\Delta_{t} E_{i j}\right)$ é igual à soma dos efeitos estrutural e diferencial em

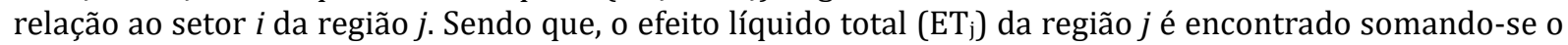
efeito líquido de cada setor, ou seja, $\sum_{i}\left(\Delta E_{i j}-\Delta_{t} E_{i j}\right)=\sum_{i}\left(\Delta_{e} E_{i j}\right)+\sum_{i}\left(\Delta_{d} E_{i j}\right)$, representando portanto o dinamismo da região $j$ em relação á média nacional, se este for maior do que zero, indica que a região j cresceu acima da média nacional o inverso é válido. 
Em relação ao efeito estrutural, se este for positivo [ $E_{i j}\left(e_{i n}-e\right)>0$ ], indica que o setor $i$ é dinâmico em nível nacional e a região $j$ possui seu dinamismo impulsionado por possuir de forma relevante este setor, ou seja, em sua estrutura produtiva há setores dinâmicos em nível nacional, sendo que o inverso é valido. Já se o efeito diferencial for positivo $\left[E^{o} i\left(e_{i j}-e_{i n}\right)>0\right.$ ] indica que a região $j$ possui vantagens locacionais em relação ao setor $i$, se este efeito diferencial for negativo, indica que a região apresenta desvantagens locacionais na produção do bem $i$ (ALVES, 1998).

Após a apresentação do modelo clássico do Método Estrutural Diferencial realizado com base em Alves (1998), realiza-se a aplicação do referido método com o intuito de atender o objetivo do presente estudo. Para que se torne possível observar os impactos econômicos gerados pela instalação dos parques eólicos nos municípios, utilizou-se a comparação entre $\Delta$ indicadores dos municípios com parques eólicos ( $\triangle \mathrm{MCPE})$ e $\Delta$ indicadores dos municípios sem parques eólicos ( $\triangle \mathrm{MSPE}$ ), sendo estes vizinhos aos com parques eólicos. Se $\triangle \mathrm{MCPE}$ for maior do que $\triangle \mathrm{MSPE}$, a localização de parques eólicos nos municípios leva a um maior dinamismo destes, apresentando um maior crescimento e desenvolvimento, refletindo em uma melhora nos indicadores. Esse dinamismo pode ser relativo ao efeito diferencial.

No efeito diferencial evidencia-se o quanto os indicadores dos municípios com parques eólicos instalados cresceu a mais ou a menos do que o daqueles municípios que não possuem parques eólicos instalados, sendo que resultados positivos indicam um crescimento acima da média dos demais municípios, indicando a vantagem locacional destes. Para uma melhor compreensão da relação matemática entre estes indicadores, no quadro 2 é apresentada a matriz de informações, a qual está adequada de modo a permitir que se visualizem as variáveis utilizadas para avaliação dos efeitos econômicos da instalação dos parques eólicos nos municípios da Região Sul.

Quadro 2 - Matriz de Informações

\begin{tabular}{|c|c|c|c|c|}
\hline Variáveis/Municípios & Município 1 & Município 2 & Município 3 & Município $n$ \\
\hline Emprego & $X^{t}$ & $\ldots$ & $\ldots$ & $X^{t} n$ \\
\hline Valor Adicionado & $\ldots$ & $\ldots$ & $\ldots$ & $\ldots$ \\
\hline $\begin{array}{l}\text { Arrecadação } \\
\text { Tributária }\end{array}$ & $\ldots$ & $\cdots$ & $\ldots$ & $\ldots$ \\
\hline$\ldots$ & $\ldots$ & $\ldots$ & $\ldots$ & $\ldots$ \\
\hline$\ldots$ & $\ldots$ & $\ldots$ & $\ldots$ & $\ldots$ \\
\hline$\ldots$ & $\ldots$ & $\ldots$ & $\ldots$ & $\ldots$ \\
\hline Variável $n$ & $X^{t} n$ & $\ldots$ & $\ldots$ & $X^{t} n$ \\
\hline
\end{tabular}

Onde: $X^{t}=$ dados das variáveis, no período $t$; $t=$ ano base com $t \in\{1999,2013\}$; $n=$ número de variáveis e municípios a serem utilizados;

\subsection{VARIÁVEIS, PERÍODO E MUNICÍPIOS DE ANÁLISE}

Para o presente estudo são utilizados os dados de emprego, valor adicionado e receita de impostos. As variáveis utilizadas para o Método Estrutural Diferencial Emprego foram obtidas através da Relação Anual de Informações Sociais (RAIS) (BRASIL, 2016). Sendo os dados analisados em dois períodos, que são: 1999-2006 e 2006-2013. A análise também leva em consideração o emprego por faixas salariais, considerando o salário mínimo (sm): até 1,00 sm; de 1,01 a 1,50 sm; de 1,51 a 2,00 sm; de 2,01 a 3,00 sm; de 3,01 a 4,00 sm; de 4,01 a 5,00 sm; de 5,01 a 7,00 sm; de 7,01 a 10,00 sm; de 10,01 a 15,00 sm; mais de $15,01 \mathrm{sm}$; e não classificado nessas faixas salariais $\{\tilde{n}$ class $\}$.

Em relação ao Método Estrutural Diferencial Valor Adicionado, os dados utilizados para esta análise foram obtidos do Instituto Brasileiro de Geografia e Estatística (IBGE) (IBGE, 2016), estes também foram analisados em dois períodos de tempo, que são: 1999-2006 e 2006-2013. Os dados de valor adicionado levados em consideração são: Valor Adicionado Bruto, a preços correntes, da Agropecuária (VAB Agropecuária); Valor Adicionado Bruto, a preços correntes, da Indústria (VAB Indústria); Valor Adicionado Bruto, a preços correntes, dos Serviços, inclusive Administração, Saúde e Educação Públicas e Seguridade Social (VAB Serviços); e Valor Adicionado Bruto, a preços correntes, da Administração, Saúde e Educação Públicas e Seguridade (VAB Administração). 
Os dados utilizados da Receita de Impostos foram coletados em duas bases de dados, devido à troca de sistema para disponibilizar os dados contábeis dos municípios brasileiros. Os dados dos anos de 2001 e 2006 foram obtidos no Sistema de Coleta de Dados Contábeis de Estados e Municípios (SISTN) (CAIXA ECONÔMICA, 2016), e os dados de 2013 foram obtidos no Sistema de Informações Contábeis e Fiscais do Setor Público Brasileiro (SISCONFI) (TESOURO NACIONAL, 2016), senda analisados em dois períodos: 2001-2006 e 2006-2013. Levaram-se em consideração os dados da Cota Parte Imposto sobre Circulação de Mercadorias e Prestação de Serviços (ICMS), do Imposto sobre Serviços de Qualquer Natureza (ISSQN/ISS) e do Imposto de Renda (IRRF/IR).

Portanto, as variáveis utilizadas levam em consideração:

a)Emprego:

- Emprego por faixas salariais, considerando o salário mínimo (sm): Até 1,00 sm; 1,01 a 1,50 sm; 1,51 a 2,00 sm; 2,01 a 3,00 sm; 3,01 a 4,00 sm; 4,01 a 5,00 sm; 5,01 a 7,00sm; 7,01 a 10,00 sm; 10,01 a 15,00 sm; Mais de 15,01 sm; $\{\tilde{n}$ class $\} ;$

b)Valor Adicionado:

- Valor Adicionado Bruto, a preços correntes, da Agropecuária (VAB Agropecuária);

- Valor Adicionado Bruto, a preços correntes da Indústria (VAB Indústria);

- Valor Adicionado Bruto, a preços correntes, dos Serviços, inclusive Administração, Saúde e Educação Públicas e Seguridade Social (VAB Serviços);

- Valor Adicionado Bruto, a preços correntes, da Administração, Saúde e Educação Públicas e Seguridade (VAB Administração);

c) Receita de Impostos:

- Cota parte Imposto sobre Circulação de Mercadorias e Prestação de Serviços (ICMS);

- Imposto sobre Serviços de Qualquer Natureza (ISSQN/ISS);

- Imposto de Renda (IRRF/IR).

O período levado em consideração, em decorrência da instalação dos parques eólicos, é de 1998 a 2012 , porém os anos analisados estão de acordo com a disponibilidade de informações das variáveis. A seguir menciona-se a disponibilidade dos dados utilizados:

a)Dados de emprego, anos analisados: 1999, 2006 e 2013;

b)Dados dos valores adicionados, anos analisados: 1999, 2006 e 2013;

c)Dados da receita de impostos, anos analisados: 2001, 2006 e 2013.

Os municípios da Região Sul que possuem parques eólicos foram utilizados no presente estudo e foram selecionados por meio de contato com a ABEEólica (2016b), segundo o qual pode-se identificar os municípios brasileiros da Região Sul que possuem parques eólicos instalados no período de 1998-2012³. Após essa primeira seleção, buscou-se identificar quais eram os municípios vizinhos a estes com parques eólicos instalados, para tal busca utilizou-se a análise gráfica dos municípios através da Confederação Nacional de Municípios (CNM) (CNM, 2016).

O Quadro 3 apresenta uma relação dos municípios com parque eólicos e os municípios vizinhos a estes, sendo organizado por grupos. Estes grupos foram configurados de acordo com a vizinhança, ou seja,

\footnotetext{
3 Paraná: Palmas (Eólio - Elétrica de Palmas - 1999); Rio Grande do Sul: Osório (Dos Índios - 2006, Osório - 2006, Osório 2 - 2012, Sangradouro - 2006, Sangradouro 2 - 2012, Sangradouro 3 - 2012), Palmares do Sul (Fazenda Rosário - 2011, Fazenda Rosário 3 - 2011, Palmares - 2010), Santana do Livramento (Cerro Chato I (Ex Coxilha Negra V) - 2012, Cerro Chato II (Ex Coxilha Negra VI) - 2011, Cerro Chato III (Ex Coxilha Negra VII) - 2011), Tramandaí (Elebras Cidreira 1- 2011); Santa Catarina : Água Doce (Água Doce - 2006, Amparo - 2011, Aquibatã - 2011, Campo Belo - 2011, Cascata - 2011, Cruz Alta - 2011, Parque Eólico do Horizonte - 2004, Salto - 2011), Bom Jardim da Serra (Bom Jardim - 2011, Eólica de Bom Jardim - 2002, Púlpito - 2011, Rio do Ouro - 2011, Santo Antônio - 2011) (ABEEÓLICA, 2016b).
} 
municípios com parques eólicos que possuíam municípios vizinhos em comum se encontram classificados no mesmo grupo. Portanto, esses grupos estão organizados segundo a proximidade geográfica.

Quadro 3 - Relação de grupos de municípios com parques eólicos e municípios vizinhos

\begin{tabular}{|c|c|c|c|c|c|c|c|}
\hline Municípios & Grupos & Estado & Possui Parque & Municípios & Grupos & Estado & $\begin{array}{l}\text { Possui } \\
\text { Parque }\end{array}$ \\
\hline Bituruna & 1 & Paraná & - & $\begin{array}{l}\text { Santana do } \\
\text { Livramento }\end{array}$ & 3 & $\begin{array}{c}\text { Rio } \\
\text { Grande do } \\
\text { Sul } \\
\end{array}$ & - \\
\hline Clevelândia & 1 & Paraná & - & São Gabriel & 3 & $\begin{array}{c}\text { Rio } \\
\text { Grande do } \\
\text { Sul }\end{array}$ & - \\
\hline Coronel Domingos Soares & 1 & Paraná & - & Uruguaiana & 3 & $\begin{array}{c}\text { Rio } \\
\text { Grande do } \\
\text { Sul } \\
\end{array}$ & - \\
\hline General Carneiro & 1 & Paraná & - & $\begin{array}{l}\text { Bom Jardim } \\
\text { da Serra }\end{array}$ & 4 & $\begin{array}{c}\text { Santa } \\
\text { Catarina }\end{array}$ & Sim \\
\hline Honório Serpa & 1 & Paraná & - & Grão Pará & 4 & $\begin{array}{c}\text { Santa } \\
\text { Catarina }\end{array}$ & - \\
\hline Mangueirinha & 1 & Paraná & Sim & Lauro Muller & 4 & $\begin{array}{c}\text { Santa } \\
\text { Catarina }\end{array}$ & - \\
\hline Palmas & 1 & Paraná & - & Morro Grande & 4 & $\begin{array}{c}\text { Santa } \\
\text { Catarina }\end{array}$ & - \\
\hline Balneário Pinhal & 2 & Rio Grande do Sul & - & Nova Veneza & 4 & $\begin{array}{c}\text { Santa } \\
\text { Catarina }\end{array}$ & - \\
\hline Capivari do Sul & 2 & Rio Grande do Sul & - & Orleans & 4 & $\begin{array}{c}\text { Santa } \\
\text { Catarina }\end{array}$ & - \\
\hline Caraá & 2 & Rio Grande do Sul & - & São Joaquim & 4 & $\begin{array}{c}\text { Santa } \\
\text { Catarina }\end{array}$ & - \\
\hline Cidreira & 2 & Rio Grande do Sul & - & Siderópolis & 4 & $\begin{array}{c}\text { Santa } \\
\text { Catarina }\end{array}$ & - \\
\hline Imbé & 2 & Rio Grande do Sul & - & Treviso & 4 & $\begin{array}{c}\text { Santa } \\
\text { Catarina }\end{array}$ & - \\
\hline Maquiné & 2 & Rio Grande do Sul & Sim & Urubici & 4 & $\begin{array}{c}\text { Santa } \\
\text { Catarina }\end{array}$ & - \\
\hline Mostardas & 2 & Rio Grande do Sul & - & Urupema & 4 & $\begin{array}{c}\text { Santa } \\
\text { Catarina }\end{array}$ & - \\
\hline Osório & 2 & Rio Grande do Sul & Sim & Água Doce & 5 & $\begin{array}{c}\text { Santa } \\
\text { Catarina }\end{array}$ & Sim \\
\hline Palmares do Sul & 2 & Rio Grande do Sul & Sim & Caçador & 5 & $\begin{array}{c}\text { Santa } \\
\text { Catarina }\end{array}$ & - \\
\hline Santo Antônio da Patrulha & 2 & Rio Grande do Sul & - & Catanduvas & 5 & $\begin{array}{c}\text { Santa } \\
\text { Catarina }\end{array}$ & - \\
\hline Tramandaí & 2 & Rio Grande do Sul & - & Ibicaré & 5 & $\begin{array}{c}\text { Santa } \\
\text { Catarina }\end{array}$ & - \\
\hline Viamão & 2 & Rio Grande do Sul & - & Joaçaba & 5 & $\begin{array}{c}\text { Santa } \\
\text { Catarina } \\
\end{array}$ & - \\
\hline Xangri-lá & 2 & Rio Grande do Sul & - & Luzerna & 5 & $\begin{array}{c}\text { Santa } \\
\text { Catarina }\end{array}$ & - \\
\hline Alegrete & 3 & Rio Grande do Sul & - & Macieira & 5 & $\begin{array}{c}\text { Santa } \\
\text { Catarina }\end{array}$ & - \\
\hline Cacequi & 3 & Rio Grande do Sul & - & Passos Maia & 5 & $\begin{array}{c}\text { Santa } \\
\text { Catarina } \\
\end{array}$ & - \\
\hline Dom Pedrito & 3 & Rio Grande do Sul & - & Ponte Serrada & 5 & $\begin{array}{c}\text { Santa } \\
\text { Catarina }\end{array}$ & - \\
\hline Lavras do Sul & 3 & Rio Grande do Sul & - & Salto Veloso & 5 & $\begin{array}{c}\text { Santa } \\
\text { Catarina }\end{array}$ & - \\
\hline Quaraí & 3 & Rio Grande do Sul & - & Treze Tílhas & 5 & $\begin{array}{c}\text { Santa } \\
\text { Catarina }\end{array}$ & - \\
\hline Rosário do Sul & 3 & Rio Grande do Sul & Sim & $\begin{array}{l}\text { Vargem } \\
\text { Bonita }\end{array}$ & 5 & $\begin{array}{c}\text { Santa } \\
\text { Catarina }\end{array}$ & - \\
\hline
\end{tabular}


Os resultados obtidos mediante o Método Estrutural Diferencial se limitam em função dos dados utilizados. Diante da disponibilidade de dados, tornou-se necessária a limpeza dos dados, excluindo-se os municípios com informações incompletas. Diante de tal panorama, em relação à Arrecadação Fiscal (CAIXA ECONÔMICA, 2016; TESOURO NACIOL 2016), foram excluídos da análise os seguintes municípios por estado: Rio Grande do Sul: Balneário Pinhal, Mostardas, Santo Antônio da Patrulha; e Santa Catarina: Treze Tilhas. Dos demais dados analisados, Emprego e Valor Agregado, não foi necessária a exclusão de nenhum município.

\section{RESULTADOS E DISCUSSÃO}

Na respectiva análise do Método Estrutural Diferencial, analisou-se apenas o Efeito Líquido e o Efeito Diferencial por questão de significância para o presente estudo.

\subsection{MÉTODO ESTRUTURAL DIFERENCIAL - EMPREGO}

Na sequência são apresentados os resultados do Método Estrutural Diferencial aplicado ao Emprego, considerando os municípios com parques eólicos e os municípios sem parques eólicos que são vizinhos a estes. Em um primeiro momento são apresentados os dados agregados destes municípios por estados e em um segundo momento por grupos, devido a proximidade com que se encontram estes municípios.

\subsubsection{MÉTODO ESTRUTURAL DIFERENCIAL - EMPREGO, SUBDIVISÃO ESTADOS}

Na Tabela 2 são sintetizados o Efeito Líquido e o Efeito Estrutural do Emprego no período 1999-2006 e 2006-2013, para municípios selecionados da Região Sul, sendo observados separadamente os municípios com e sem parques eólicos. As informações apresentadas estão agregadas por estado. Os resultados condizem com as médias do Efeito Líquido e do Efeito Estrutural por estado.

Tabela 2 - Efeito Líquido e Efeito Diferencial Emprego para total dos municípios da Região Sul por estado com e sem parques eólicos

\begin{tabular}{|l|c|c|c|c|}
$\begin{array}{l}\text { Municípios por estado } \\
\begin{array}{c}\text { segundo incidência de } \\
\text { parque eólico) }\end{array}\end{array}$ & $\begin{array}{c}\text { Efeito Líquido } \\
1999-2006\end{array}$ & $\begin{array}{c}\text { Efeito Líquido } \\
2006-2013 \\
\text { PARANÁ }\end{array}$ & $\begin{array}{c}\text { Efeito Diferencial } \\
1999-2006\end{array}$ & $\begin{array}{c}\text { Efeito Diferencial } \\
2006-2013\end{array}$ \\
\hline Sem Parque Eólico & $-171,30$ & $-32,84$ & $-177,59$ & $-32,84$ \\
\hline Com Parque Eólico & 1027,82 & 197,02 & 1065,57 & $-103,28$ \\
\hline \multicolumn{5}{|c|}{ RIO GRANDE DO SUL } \\
\hline Sem Parque Eólico & 121,03 & $-103,28$ & 121,03 & 464,77 \\
\hline Com Parque Eólico & $-544,63$ & 464,77 & $-544,63$ & 10,97 \\
\hline Sem Parque Eólico & 5,13 & SANTA CATARINA & $-115,23$ \\
\hline Com Parque Eólico & $-53,89$ & $-115,23$ & $-5,13$ & \\
\hline
\end{tabular}

Fonte: Elaborado pelos autores.

O estado do Paraná apresenta um parque eólico no período analisado, tendo como instalação deste o ano de 1999. Os resultados do Efeito Líquido demonstram que o município que possui parque eólico instalado apresentou, nos dois períodos, Efeito Líquido positivo (primeiro período: 1.027,82; e segundo período: 197,02), e os municípios que não possuem parques eólicos nos dois períodos apresentaram Efeito Líquido negativo (primeiro período: -171,30; e segundo período: -32,84). 0 mesmo ocorre no Efeito Diferencial dos municípios do estado do Paraná, sendo que os municípios com parque eólico apresentaram Efeito Diferencial positivo nos dois períodos: 1.065,57 no primeiro período; e 197,02 no segundo período. E os municípios sem parque eólico apresentaram valores negativos em ambos os períodos: -177,59 no primeiro período; e -32,84 no segundo período. Assim, através da análise dos resultados evidencia-se que o município que possui parque eólico em seu território possui vantagem locacional, apresentando crescimento do emprego, em comparação com os municípios que não possuem parque eólico, os quais tiveram retração no emprego. Esta vantagem locacional pode decorrer da existência de parque eólico neste município. 
No Rio Grande do Sul havia, no período de análise, 13 parques eólicos, os quais foram instalados no período de 2006 a 2012. De acordo com os resultados apresentados pelo Efeito Líquido e pelo Efeito Diferencial, percebe-se que municípios com parques eólicos instalados apresentam vantagem locacional no segundo período, diante de municípios vizinhos que não possuem parques eólicos instalados. Pode-se observar tal constatação por meio dos resultados: Efeito Líquido em municípios sem parques eólicos foi 121,03 e -103,28, respectivamente, no primeiro e no segundo períodos; e municípios com parques eólicos foi de -544,63 e 464,77, respectivamente, o Efeito Diferencial, onde municípios sem parques eólicos, respectivamente, no primeiro e no segundo períodos foi de 121,03 e -103,28; e municípios com parques eólicos foi de $-544,63$ e 464,77, respectivamente. Em conformidade com o apresentado, nota-se que municípios com parques eólicos apresentaram incremento no emprego, Efeito Líquido positivo no segundo período, possuindo também no referido período Efeito Diferencial positivo. Apresentaram, assim, vantagem locacional, a qual pode ocorrer devido à existência de parques eólicos nestes municípios, que passou a ser observada no segundo período em função da instalação dos parques eólicos.

No estado de Santa Catarina, no período 1998-2012, havia 13 parques eólicos, com instalação entre 2002 e 2011. Os resultados do Efeito Líquido para municípios sem parques eólicos apresentam, no primeiro período e no segundo períodos, valores positivos (5,13 e 10,97), enquanto municípios com parques eólicos apresentaram valores negativos em ambos os períodos $(-53,89$ e -115,23). 0 mesmo ocorre no Efeito Diferencial, sendo que os municípios sem parques eólicos apresentaram valores positivos $(5,13$ e 10,97) e os municípios com parques eólicos apresentaram valores negativos (-53,89 e -115,23). Para os municípios do estado de Santa Catarina, quando observado o emprego, a presença de parques eólicos não gerou vantagem locacional e nem mesmo incremento no emprego aos municípios que os abrigam, sendo que os municípios sem parques eólicos apresentam algum outro fator que lhes proporciona um Efeito Diferencial positivo, havendo vantagem locacional.

Portanto, após a análise dos municípios selecionados, os quais encontram-se agregados por estado, notase que, dos três estados analisados, apenas em Santa Catarina os municípios com parques eólicos não apresentaram Efeito Diferencial positivo no segundo período, ou seja, apenas estes não apresentaram vantagem locacional. Portanto, dos três estados da Região Sul analisados, os estados de Paraná e Rio Grande do Sul apresentaram vantagem locacional, sendo Paraná nos dois períodos de análise e Rio Grande do Sul apenas no último período, podendo esta diferença no período de impacto decorrer do tempo de instalação dos parques eólicos. Observa-se que a existência de vantagem locacional possa decorrer da existência de parques eólicos nos municípios.

\subsubsection{MÉTODO ESTRUTURAL DIFERENCIAL - EMPREGO, SUBDIVISÃO GRUPO}

Através do Método Estrutural Diferencial observou-se o emprego nos municípios com e sem parques eólicos da Região Sul, para tanto incorporou-se estes municípios em grupos, os quais estão dispostos devido a possuírem vizinhos em comum. A Tabela 3 apresenta os resultados das médias do Efeito Líquido e do Efeito Diferencial do emprego para grupos de municípios da Região Sul com e sem parques eólicos.

Tabela 3 - Efeito Líquido e Efeito Diferencial Emprego por grupos vizinhos de municípios da Região Sul com e sem parques eólicos

\begin{tabular}{|c|c|c|c|c|c|}
\hline \multicolumn{2}{|c|}{$\begin{array}{l}\text { Municípios por estado - grupos de } \\
\text { municípios vizinhos } \\
\text { (segundo incidência de parque eólico) }\end{array}$} & $\begin{array}{l}\text { Efeito Líquido } \\
\text { 1999-2006 }\end{array}$ & $\begin{array}{l}\text { Efeito Líquido } \\
\text { 2006-2013 }\end{array}$ & $\begin{array}{c}\text { Efeito Diferencial } \\
\text { 1999-2006 }\end{array}$ & $\begin{array}{c}\text { Efeito Diferencial } \\
2006-2013\end{array}$ \\
\hline \multicolumn{6}{|c|}{ (50) } \\
\hline \multirow{2}{*}{ Grupo 1} & Sem Parque Eólico & $-171,30$ & $-32,84$ & $-177,59$ & $-32,84$ \\
\hline & Com Parque Eólico & 1027,82 & 197,02 & 1065,57 & 197,02 \\
\hline \multicolumn{6}{|c|}{ RIO GRANDE DO SUL } \\
\hline \multirow{2}{*}{ Grupo 2} & Sem Parque Eólico & 519,28 & 204,04 & 519,28 & 204,04 \\
\hline & Com Parque Eólico & 199,24 & 748,66 & 199,24 & 748,66 \\
\hline \multirow{2}{*}{ Grupo 3} & Sem Parque Eólico & $-376,78$ & $-487,43$ & $-376,78$ & $-487,43$ \\
\hline & Com Parque Eólico & $-2776,22$ & $-386,89$ & $-2776,22$ & $-386,89$ \\
\hline \multicolumn{6}{|c|}{ SANTA CATARINA } \\
\hline \multirow{2}{*}{ Grupo 4} & Sem Parque Eólico & 129,38 & 262,76 & 129,38 & 262,76 \\
\hline & Com Parque Eólico & $-31,17$ & $-54,01$ & $-31,17$ & $-54,01$ \\
\hline \multirow{2}{*}{ Grupo 5} & Sem Parque Eólico & $-107,82$ & $-217,93$ & $-107,82$ & $-217,93$ \\
\hline & Com Parque Eólico & $-76,60$ & $-176,45$ & $-76,60$ & $-176,45$ \\
\hline
\end{tabular}


Fonte: Elaborado pelos autores.

O grupo 1 representa o estado do Paraná. Observando os resultados do Efeito Líquido, os mesmos evidenciam que os municípios que possuem parques eólicos instalados apresentaram, em ambos os períodos, Efeito Líquido positivo $(1.027,8$ e 197,02) e os municípios que não apresentam parques eólicos em seu território obtiveram, nos dois períodos, Efeito Líquido negativo (-171,30 e -32,84). Este também é o desempenho apresentado no Efeito Diferencial, onde os municípios com parques eólicos apresentaram Efeito Diferencial positivo nos dois períodos, 1.065,57 e 197,02; e os municípios sem parques eólicos apresentaram valores negativos em ambos os períodos: -177,59 e -32,84. Dessa maneira, os municípios que possuem parques eólicos expuseram alavancagem no emprego, assim como vantagem locacional, podendo ser decorrente da existência de parques eólicos.

No estado do Rio Grande do Sul há dois grupos, identificados como 2 e 3.0 grupo 2 apresentou, no primeiro e no segundo período, Efeito Líquido positivo tanto para municípios com parques eólicos $(199,24$ e 748,66) como para municípios sem parques eólicos $(519,28$ e 204,04). Quando analisados os resultados do Efeito Diferencial, o mesmo é igualmente positivo para ambos os períodos, para municípios com parques eólicos $(199,24$ e 748,66) e para municípios sem parques eólicos $(519,28$ e 204,04). Sendo assim, ambos os municípios pertencentes ao grupo 2 apresentam vantagem locacional e incremento no emprego. Observa-se que os municípios com parques eólicos, no segundo período de análise, apresentaram Efeito Líquido e Diferencial superior aos dos municípios sem parques eólicos.

O grupo 3 que faz parte do estado do Rio Grande do Sul, diferentemente do apresentado pelo grupo 2, exibe todos seus resultados negativos. Para o Efeito Líquido, municípios com parques eólicos tiveram seus valores negativos $(-2.776,22$ e -348,89) para o primeiro e o segundo períodos e os sem parques eólicos obtiveram Efeito Líquido iguais a $-376,78$ e $-487,43$. Os resultados do Efeito Diferencial também são negativos para o primeiro e segundo períodos analisados: municípios com parques eólicos $(-2.776,22$ e 386,89) e municípios sem parques eólicos $(-376,78$ e -487,43). No grupo 3 não há vantagem locacional, havendo no período analisado queda no emprego, porém é perceptível que a redução é menos acentuada nos municípios com parques eólicos, podendo a existência destes nos municípios amenizar a queda no emprego e da vantagem locacional.

Os grupos 4 e 5 condizem com o estado de Santa Catarina. No grupo 4, quando observado o Efeito Líquido, os municípios sem parques eólicos apresentaram resultados positivos em ambos os períodos, sendo 129,38 no primeiro período e 262,76 no segundo período, e os municípios com parques eólicos nestes períodos apresentaram resultado negativo de $-31,17$ e de $-54,01$. 0 Efeito Diferencial apresenta também resultado positivo para municípios sem parques eólicos $(129,38$ e 262,76) e negativo para municípios com parques eólicos $(-31,17$ e -54,01). No grupo 4, os municípios sem parques eólicos apresentam vantagem locacional, havendo incremento no emprego.

O grupo 5 apresenta, para ambos os períodos, resultado negativo, tanto para o Efeito Líquido como para o Efeito Diferencial, para municípios com e sem parques eólicos. O Efeito Diferencial para os municípios sem parques eólicos é de -107,82 e de -217,93 para o primeiro e segundo períodos, respectivamente, e para os municípios com parques eólicos é de -76,60 e de -176,45. O Efeito Diferencial é de -107,82 e -217,93 para municípios sem parques eólicos e de $-76,60$ e -176,45 para municípios com parques eólicos, para o primeiro e segundo períodos, respectivamente. Neste grupo não houve vantagem locacional.

Ao se realizar esta seleção por grupos de municípios que possuem vizinhos em comum, ou seja, por proximidade, observa-se que os resultados obtidos para o estado diferem dos resultados dos grupos no caso do estado do Rio Grande do Sul, o qual apresentou vantagem locacional quando observado por estado, no segundo período, já quando observado por grupos, um obteve vantagem locacional em ambos os períodos, ao passo que outro grupo não apresentou vantagem locacional em nenhum dos dois períodos. Ou seja, dentro de um mesmo estado pode haver regiões que apresentam vantagem locacional e regiões que não a apresentam. Os estados de Paraná e Santa Catarina convergiram os resultados dos grupos ao apresentado pelo total dos estados.

\subsection{MÉTODO ESTRUTURAL DIFERENCIAL - VALOR ADICIONADO}

Na sequência encontra-se a análise do Valor Adicionado através do Método Estrutural Diferencial, em um primeiro momento, por meio da subdivisão por estados e, após, subdividido por grupos. 


\subsubsection{MÉTODO ESTRUTURAL DIFERENCIAL - VALOR ADICIONADO, SUBDIVISÃO ESTADOS}

Na Tabela 4 são apresentados os dados da média do valor adicionado para o Efeito Líquido e o Efeito Diferencial, agregando os municípios por estado, sempre os classificando pela presença ou não de parques eólicos em seu território.

Tabela 4 - Efeito Líquido e Efeito Diferencial Valor Adicionado para total da Região Sul tado com e sem parques eólicos

\begin{tabular}{|c|c|c|c|c|}
\hline $\begin{array}{l}\text { Municípios por estado } \\
\text { (segundo incidência de parque } \\
\text { eólico) }\end{array}$ & $\begin{array}{c}\text { Efeito Líquido } \\
\text { 1999-2006 }\end{array}$ & $\begin{array}{c}\text { Efeito Líquido } \\
\text { 2006-2013 }\end{array}$ & $\begin{array}{c}\text { Efeito Diferencial } \\
\text { 1999-2006 }\end{array}$ & $\begin{array}{c}\text { Efeito Diferencial } \\
2006-2013\end{array}$ \\
\hline \multicolumn{5}{|c|}{ PARANÁ } \\
\hline Sem Parque Eólico & $-10511,08$ & 10400,90 & $-8674,21$ & 5875,41 \\
\hline Com Parque Eólico & 63066,49 & $-62405,37$ & 52045,26 & $-35252,48$ \\
\hline \multicolumn{5}{|c|}{ RIO GRANDE DO SUL } \\
\hline Sem Parque Eólico & 2165,65 & $-13584,15$ & 1846,30 & $-15234,75$ \\
\hline Com Parque Eólico & $-9745,43$ & 61128,68 & $-8308,34$ & 68556,35 \\
\hline \multicolumn{5}{|c|}{ SANTA CATARINA } \\
\hline Sem Parque Eólico & $-2083,02$ & 366,24 & $-2320,12$ & 366,24 \\
\hline Com Parque Eólico & 21871,68 & $-3845,49$ & 24361,22 & $-3845,49$ \\
\hline
\end{tabular}

Fonte: Elaborado pelos autores.

Observando os municípios agregados do Paraná, em relação ao Efeito Diferencial, os municípios sem parques eólicos apresentavam valor negativo $(-10.511,08)$ no primeiro período e positivo no segundo período $(10.400,90)$, e os municípios com parques eólicos apresentaram valor positivo no primeiro período $(63.066,49)$ e negativo no segundo período $(-62.405,37)$. Ou seja, os municípios com parques eólicos apresentaram uma queda no valor adicionado no segundo período ao passo que os municípios sem parques eólicos apresentaram incremento no valor adicionado. Analisando o Efeito Diferencial, observouse valor positivo $(52.045,26)$ para municípios com parques eólicos no primeiro período e negativo ($35.252,48$ ) no segundo período, enquanto nos municípios sem parques eólicos, no primeiro período, o valor foi negativo $(-8.674,21)$ e após, no segundo período, positivo $(5.875,41)$. Portanto, ao final do período analisado, os municípios sem parques eólicos apresentaram vantagem locacional.

Os municípios sem parques eólicos do estado do Rio Grande do Sul, no primeiro período, obtiveram Efeito Líquido positivo $(2.165,65)$ e os municípios com parques eólicos apresentaram valor negativo $(9.745,43)$. No segundo período, os municípios sem parques eólicos apresentaram queda no valor adicionado, com Efeito Líquido negativo $(-13.584,15)$. No mesmo período, os municípios com parques eólicos tiveram incremento no mesmo, com Efeito Líquido positivo $(61.128,68)$. 0 mesmo ocorre no Efeito Diferencial, no primeiro período, os municípios sem parques eólicos apresentavam valor positivo $(1.846,30)$ e, no segundo período, negativo $(-15.234,75)$ e os municípios com parques eólicos apresentavam Efeito Diferencial negativo no primeiro período $(-8.308,34)$ e positivo no segundo $(68.556,35)$, demonstrando que municípios com parques eólicos no segundo período passaram a apresentar vantagem locacional.

Em Santa Catarina, quando observado o Efeito Diferencial, os municípios sem parques eólicos no primeiro período obtiveram resultado negativo $(-2.083,02)$ e no segundo período positivo $(366,24)$. Os municípios com parques eólicos tiveram resultado positivo $(21.871,68)$ no primeiro período e negativo no segundo período $(-38.45,49)$. Ao observar o Efeito Diferencial, este foi positivo, no primeiro período, para municípios com parques eólicos $(46.270,21)$ e negativo para municípios sem parques eólicos $(-4.627,02)$ e, no segundo período, os municípios sem parques eólicos apresentaram desempenho positivo $(12.728,21)$ e municípios com parques eólicos desempenho negativo $(-127.282,13)$. Sendo assim, no segundo período, os municípios sem parques eólicos obtiveram vantagem locacional. 
Após a análise do Método Estrutural Diferencial para o valor agregado dos municípios selecionados com e sem parques eólicos, por estado, nota-se que apenas o estado do Rio Grande do Sul apresentou vantagem locacional para municípios com parques eólicos no segundo período de análise. Paraná e Santa Catarina possuíam vantagem locacional apenas no primeiro período, o inverso ao apresentado pelos municípios com parques eólicos ocorreu nos municípios sem parques eólicos. Nota-se que em um ou outro período, os municípios com e sem parques eólicos apresentaram vantagem locacional, ou seja, Efeito Diferencial positivo.

\subsubsection{MÉTODO ESTRUTURAL DIFERENCIAL - VALOR ADICIONADO, SUBDIVISÃO GRUPO}

Por meio do Método Estrutural Diferencial, esta subseção analisa os dados de valor agregado dos municípios da Região Sul do Brasil. Procede-se a análise por meio da junção dos municípios por grupos, os quais são de municípios vizinhos, organizados por estados e respeitando a existência ou não de parques eólicos nos mesmos. A Tabela 5 apresenta os resultados da média do Efeito Líquido e do Efeito Diferencial para os grupos analisados.

Tabela 5 - Efeito Líquido e Efeito Diferencial Valor Adicionado por grupos vizinhos de municípios da Regiãul com e sem parques eólicos

\begin{tabular}{|c|c|c|c|c|c|}
\hline \multicolumn{2}{|c|}{$\begin{array}{l}\text { Municípios por estado - grupos de } \\
\text { municípios vizinhos }\end{array}$} & $\begin{array}{l}\text { Efeito Líquido } \\
\text { 1999-2006 }\end{array}$ & $\begin{array}{c}\text { Efeito Líquido } \\
\text { 2006-2013 }\end{array}$ & $\begin{array}{c}\text { Efeito } \\
\text { Diferencial } \\
\text { 1999-2006 }\end{array}$ & $\begin{array}{c}\text { Efeito } \\
\text { Diferencial } \\
2006-2013\end{array}$ \\
\hline \multicolumn{6}{|c|}{ PARANÁ } \\
\hline \multirow{2}{*}{ Grupo 1} & Sem Parque Eólico & $-10511,08$ & 10400,90 & $-8674,21$ & 5875,41 \\
\hline & Com Parque Eólico & 63066,49 & $-62405,37$ & 52045,26 & $-35252,48$ \\
\hline \multicolumn{6}{|c|}{ RIO GRANDE DO SUL } \\
\hline \multirow{2}{*}{ Grupo 2} & Sem Parque Eólico & 37166,53 & $-2206,54$ & 35377,68 & 1047,36 \\
\hline & Com Parque Eólico & 19225,75 & 87134,00 & 19626,90 & 100922,26 \\
\hline \multirow{2}{*}{ Grupo 3} & Sem Parque Eólico & $-41585,45$ & $-27806,16$ & $-40067,93$ & $-35587,38$ \\
\hline & Com Parque Eólico & $-96658,97$ & $-16887,27$ & $-92114,07$ & $-28541,38$ \\
\hline \multicolumn{6}{|c|}{ SANTA CATARINA } \\
\hline \multirow{2}{*}{ Grupo 4} & Sem Parque Eólico & $-23927,43$ & 28110,66 & $-24121,77$ & 28110,66 \\
\hline & Com Parque Eólico & 2385,33 & $-5256,91$ & 3943,28 & $-5256,91$ \\
\hline \multirow{2}{*}{ Grupo 5} & Sem Parque Eólico & 17775,54 & $-24855,97$ & 17499,56 & $-24855,97$ \\
\hline & Com Parque Eólico & 41358,03 & $-2434,06$ & 44779,16 & $-2434,06$ \\
\hline
\end{tabular}

Fonte: Elaborado pelos autores.

O grupo 1 representa os municípios do estado do Paraná e ao se observar os municípios sem parques eólicos no primeiro período de análise, os mesmos possuem Efeito Líquido negativo $(-10.511,08)$, enquanto os municípios com parques eólicos possuem valor positivo $(63.066,49)$. No segundo período analisado, os municípios sem parques eólicos passaram a expor Efeito Líquido positivo $(10.400,90)$ e os municípios com parques eólicos apresentaram valor negativo $(-62.405,37)$. Observando os resultados do Efeito Diferencial, percebe-se que os municípios com parques eólicos apresentavam vantagem locacional no primeiro período, com Efeito Diferencial positivo $(52.045,26)$, ao mesmo tempo em que municípios sem parques eólicos possuíam resultados negativos $(-8.674,21)$. Porém, no segundo período, os municípios sem parques eólicos passaram a ter vantagem locacional, com Efeito Diferencial positivo $(5.875,41)$, e os municípios com parques eólicos resultados negativos $(-35.252,48)$. 
Os grupos 2 e 3 fazem parte do estado do Rio Grande do Sul. No grupo 2, os municípios com parques eólicos apresentaram resultados positivos em ambos os períodos e para ambos os efeitos: o Efeito Líquido do primeiro período foi de 19.225,75 e do segundo foi de 87.134,00, havendo incremento do valor adicionado em ambos os períodos, e o Efeito Diferencial do primeiro período foi de 19.626,90 e do segundo de 100.922,26, assim, ambos os períodos apresentaram vantagem locacional. Os municípios sem parques eólicos, no primeiro período, apresentaram Efeito Líquido positivo, com valor de 37.166,53, tendo incremento no valor adicionado dos municípios, e após queda no mesmo, com Efeito Líquido negativo de 2.206,54. Apesar de apresentar valor negativo no Efeito Líquido, os municípios sem parques eólicos obtiveram Efeito Diferencial positivo nos dois períodos, de 35.377,68 no primeiro período e de 1.047,36 no segundo, apresentando também vantagem locacional em ambos os períodos. Nos municípios com parques eólicos acredita-se que a presença dos mesmos nos municípios cause a vantagem locacional, ocasionando Efeito Líquido e Efeito Diferencial com maiores valores, no segundo período, em relação aos municípios que não possuem parques eólicos.

0 grupo 3, ao contrário do grupo 2, apresenta todos os seus resultados negativos. 0 Efeito Líquido para os municípios sem parques eólicos foi negativo no primeiro e no segundo períodos, respectivamente, 41.585,45 e -27.806,16, sendo que o mesmo acontece nos municípios com parques eólicos: primeiro período, -96.658,97, e no segundo, -16.887,27. Assim, todos os municípios do grupo 3 do estado do Rio Grande do Sul apresentaram queda no valor adicionado nos períodos 1999-2006 e 2006-2013. O Efeito Diferencial também demonstra que nenhum município apresentou vantagem locacional: no primeiro período, municípios sem parques eólicos apresentaram Efeito Diferencial negativo -40.067,93, assim como no segundo, -35.587,38, o mesmo é apresentado pelos municípios com parques eólicos, com -92.114,07 no primeiro período e -28.541,38 no segundo período. Portanto, os municípios do grupo 3 não apresentaram vantagem locacional.

Santa Catarina possui seus municípios de análise divididos em dois grupos, o 4 e o 5 . No grupo 4, os municípios sem parques eólicos, no primeiro período analisado, apresentaram Efeito Diferencial negativo $(-23.927,43)$ e no segundo período positivo $(28.110,66)$, o inverso acontece com os municípios com parques eólicos, os quais no primeiro período apresentaram Efeito Líquido positivo $(2.385,33)$ e no segundo período negativo $(-5.256,91)$. O Efeito Diferencial apresenta o mesmo movimento, no primeiro período com Efeito Diferencial negativo para municípios sem parques eólicos $(-24.121,77)$ e positivo no segundo período $(28.110,66)$, e os municípios com parques eólicos, com Efeito Diferencial positivo no período inicial $(3.943,28)$ e negativo no período seguinte $(-5.256,91)$. Deste modo, percebe-se que, no primeiro período os municípios com parques eólicos apresentaram vantagem locacional e, no segundo período, foram os municípios sem parques eólicos que obtiveram vantagem locacional.

O grupo 5 dos municípios do estado de Santa Cataria apresenta incremento no valor adicionado no primeiro período e após queda do mesmo no segundo período analisado para ambas as classificações de municípios. Nos municípios sem parques eólicos, no primeiro período, o Efeito Líquido foi positivo $(17.775,54)$ e negativo no segundo $(-24.855,97)$, e os municípios com parques eólicos apresentaram o mesmo movimento, com Efeito Líquido positivo no período 1999-2006 (41.358,03) e após negativo no período 2006-2013 (-2.434,06). O Efeito Diferencial apresenta a mesma configuração, onde os municípios com parques eólicos apresentaram Efeito Diferencial positivo no primeiro período $(44.779,16)$ e negativo no segundo $(-2.434,06)$, assim como os municípios sem parques eólicos, com 17.499,56 de Efeito Diferencial no primeiro período e de $-24.855,97$ no segundo período. Conforme exposto, tanto os municípios sem parques eólicos como os com parques eólicos apresentaram vantagem locacional apenas no primeiro período.

Posterior à análise em separado de cada um dos grupos de municípios, sendo cinco grupos organizados por estados, para os dados do valor adicionado por meio do Método Estrutural Diferencial, analisando o Efeito Líquido e o Efeito Diferencial, nota-se que os municípios com parques eólicos apresentaram Efeito Diferencial positivo nos dois períodos (1999-2006 e 2006-2013) apenas no grupo 2, pertencente ao estado do Rio Grande do Sul. Nos demais grupos, outros três obtiveram Efeito Diferencial positivo no primeiro período e apenas um grupo não obteve Efeito Diferencial em algum dos períodos. Ou seja, dos cinco grupos de municípios, quatro obtiveram Efeito Diferencial em algum dos períodos e um grupo obteve em ambos os períodos, para os municípios com parques eólicos. 0 mesmo ocorre para os municípios sem parques eólicos, apenas em períodos opostos. 


\subsection{MÉTODO ESTRUTURAL DIFERENCIAL - RECEITA DE IMPOSTOS}

Após a análise do Método Estrutural para os dados do emprego e do valor adicionado, procede-se nesta subseção a análise do Método Estrutural Diferencial para a receita de impostos. Inicialmente, realiza-se a análise dos resultados para o agregado de municípios, organizados por estado, e, após, para os grupos de municípios vizinhos, também por estados.

\subsubsection{MÉTODO ESTRUTURAL DIFERENCIAL - RECEITA DE IMPOSTOS, SUBDIVISÃO ESTADOS}

A Tabela 6 apresenta os resultados da média do Método Estrutural Diferencial para os dados da receita de impostos dos municípios selecionados, organizados por estados. Neste, o período de análise sofre uma pequena alteração devido à disponibilidade de dados, sendo os períodos 2001-2006 e 2006-2013. Analisase, em especial, a média do Efeito Líquido e do Efeito Diferencial.

Tabela 6 - Efeito Líquido e Efeito Diferencial Receita de Impostos para total dos municípios da Região Suor estado com e sem parques eólicos

\begin{tabular}{|c|c|c|c|c|}
\hline Municípios por estado & Efeito Líquido & Efeito Líquido & Efeito Diferencial & Efeito Diferencial \\
\hline $\begin{array}{l}\text { (segundo incidência de } \\
\text { parque eólico) }\end{array}$ & 1999-2006 & 2006-2013 & 1999-2006 & 2006-2013 \\
\hline \multicolumn{5}{|c|}{ PARANÁ } \\
\hline Sem Parque Eólico & $-388858,38$ & 150172,88 & $-358476,31$ & 194012,63 \\
\hline Com Parque Eólico & 2333150,29 & $-901037,27$ & 2150857,86 & $-1164075,75$ \\
\hline \multicolumn{5}{|c|}{ RIO GRANDE DO SUL } \\
\hline Sem Parque Eólico & $-8836,35$ & $-2989829,51$ & 14784,97 & $-3004689,79$ \\
\hline Com Parque Eólico & 33136,31 & 11211860,65 & $-55443,62$ & 11267586,71 \\
\hline \multicolumn{5}{|c|}{ SANTA CATARINA } \\
\hline Sem Parque Eólico & $-5226,19$ & $-131495,09$ & $-8783,66$ & $-137917,18$ \\
\hline Com Parque Eólico & 52261,94 & 1314950,94 & 87836,56 & 1379171,77 \\
\hline
\end{tabular}

Fonte: Elaborado pelos autores.

O estado do Paraná, de acordo com os municípios considerados para a análise, no primeiro período, observando o Efeito Líquido, o mesmo apresentou valor negativo para municípios sem parques eólicos ($388.858,38)$ e positivo para os com parques eólicos $(2.333 .150,29)$, demonstrando que houve incremento na receita de impostos dos municípios com parques eólicos no primeiro período. Porém, no segundo período, estes municípios tiveram queda na receita de impostos, com Efeito Líquido negativo (901.037,27), por sua vez, os municípios sem parques eólicos, neste segundo período, acumularam aumento da receita de impostos, com Efeito Líquido positivo de 150.172,88. O Efeito Diferencial revela que no primeiro período os municípios com parques eólicos apresentavam vantagem locacional, com Efeito Diferencial positivo $(2.150 .857,86)$ e no segundo período os mesmos apresentaram resultados negativos $(-1.164 .075,75)$. Os municípios sem parques eólicos, no primeiro período, obtiveram Efeito Diferencial negativo $(-358.476,31)$ e no segundo período positivo $(194.012,63)$, demonstrando, neste período, vantagem locacional.

Os municípios do Rio Grande do Sul que possuem parques eólicos apresentaram Efeito Líquido positivo em ambos os períodos, 2001-2006 e 2006-2013, com valores no primeiro de 33.136,31 e no segundo de 1.1211.860,65. Apesar do incremento na receita de impostos nos dois períodos, apenas no segundo período os municípios com parques eólicos apresentaram vantagem locacional, ocasionada possivelmente pela presença dos parques eólicos em seu território. No primeiro período o Efeito Diferencial foi de $55.443,62$ e no segundo de $11.267 .586,71$. Os municípios sem parques eólicos tiveram uma queda na receita de impostos nos períodos de análise, ficando com Efeito Líquido no primeiro período de -8.836,35 e no segundo período -2.989.829,51. Apesar de ter Efeito Líquido negativo no primeiro período, os municípios sem parques eólicos apresentaram vantagem locacional no mesmo, com Efeito Diferencial positivo de 14.784,97. Contudo, no segundo período, o mesmo foi negativo $(-3.004 .689,79)$. 
Em Santa Catarina, nos períodos de análise, os municípios com parques eólicos apresentaram em ambos os períodos incremento na receita de impostos e vantagem locacional, sendo que, no primeiro e no segundo períodos, respectivamente, o Efeito Líquido foi de 52.261,94 e de 1.314.950,94 e o Efeito Diferencial de 87.836,56 e de 1.379.171,77. Os resultados para os municípios sem parques eólicos revelam que os mesmos, nos períodos de análise, apresentaram retração na receita de impostos e não possuem vantagem locacional, sendo Efeito Líquido de -5.226,19 e de -131.495,09 e Efeito Diferencial de -8.783,66 e de $-137.917,18$.

De acordo com o apresentado, os resultados do Método Estrutural Diferencial para a receita de impostos, nos municípios com parques eólicos e nos sem parques eólicos, dos três estados analisados, Santa Catarina obteve Efeito Líquido e Efeito Diferencial positivo em ambos os períodos nos municípios com parques eólicos, possuindo, portanto, no período analisado, incremento na receita de imposto, podendo ser decorrente da vantagem locacional de possuir parques eólicos em seu território e os municípios sem parques eólicos apresentaram para ambos os períodos resultados negativos. Paraná obteve apenas no primeiro período de análise incremento na receita de impostos e vantagem locacional nos municípios com parques eólicos e, no segundo período, os municípios sem parques eólicos obtiveram resultados positivos. Já o estado do Rio Grande do Sul obteve incremento da receita de impostos nos municípios com parques eólicos em ambos os períodos, ao passo que os municípios sem parques eólicos acumularam queda no período. Porém, apenas no segundo período estes municípios com parques eólicos apresentaram vantagem locacional e no primeiro período os municípios sem parques eólicos apresentaram vantagem locacional.

\subsubsection{MÉTODO ESTRUTURAL DIFERENCIAL - RECEITA DE IMPOSTOS, SUBDIVISÃO GRUPOS}

A Tabela 7 elucida os resultados da média do Método Estrutural Diferencial para a receita de impostos, quando analisados os grupos de municípios vizinhos, com cinco grupos de análise, separando-os dentro destes, em municípios com parques eólicos e os sem parques eólicos, em dois períodos de análise 20012006 e 2006-2013.

Tabela 7 - Efeito Líquido e Efeito Diferencial Receita de Impostos por grupos vizinhos de municípios da Região Sul com e sem parques eólicos

\begin{tabular}{|c|c|c|c|c|c|}
\hline \multicolumn{2}{|c|}{$\begin{array}{l}\text { Municípios por estado - grupos de } \\
\text { municípios vizinhos }\end{array}$} & $\begin{array}{c}\text { Efeito Líquido } \\
\text { 1999-2006 }\end{array}$ & $\begin{array}{l}\text { Efeito Líquido } \\
\text { 2006-2013 }\end{array}$ & \multirow[t]{2}{*}{$\begin{array}{c}\text { Efeito Diferencial } \\
1999-2006\end{array}$} & \multirow[t]{2}{*}{$\begin{array}{c}\text { Efeito Diferencial } \\
2006-2013\end{array}$} \\
\hline \multicolumn{4}{|c|}{ PARANÁ } & & \\
\hline \multirow{2}{*}{ Grupo 1} & Sem Parque Eólico & $-388858,38$ & 150172,88 & $-358476,31$ & 194012,63 \\
\hline & Com Parque Eólico & 2333150,29 & $-901037,27$ & 2150857,86 & $-1164075,75$ \\
\hline \multicolumn{6}{|c|}{ RIO GRANDE DO SUL } \\
\hline \multirow{2}{*}{ Grupo 2} & Sem Parque Eólico & 1160638,14 & 515924,23 & 982269,07 & 365096,10 \\
\hline & Com Parque Eólico & 1591043,49 & 15974400,70 & 1396174,61 & 16063225,30 \\
\hline \multirow{2}{*}{ Grupo 3} & Sem Parque Eólico & $-1032126,53$ & $-6057364,03$ & $-831763,62$ & $-5953252,45$ \\
\hline & Com Parque Eólico & $-4640585,23$ & $-3075759,48$ & $-4410298,32$ & $-3119329,05$ \\
\hline \multicolumn{6}{|c|}{ SANTA CATARINA } \\
\hline \multirow{2}{*}{ Grupo 4} & Sem Parque Eólico & 123496,96 & 527249,91 & 136908,82 & 601920,22 \\
\hline & Com Parque Eólico & 146296,07 & 730835,69 & 146737,87 & 744282,52 \\
\hline \multirow{2}{*}{ Grupo 5} & Sem Parque Eólico & $-133949,35$ & $-790240,10$ & $-154476,13$ & $-877754,58$ \\
\hline & Com Parque Eólico & $-41772,18$ & 1899066,18 & 28935,25 & 2014061,02 \\
\hline
\end{tabular}


Os municípios do estado do Paraná encontram-se no grupo 1, onde, no primeiro período analisado, os municípios com parques eólicos apresentaram Efeito Líquido positivo $(2.333 .150,29)$, havendo incremento na receita de impostos. Porém, no segundo período, houve queda na mesma, sendo o Efeito Líquido negativo $(-901.037,27)$ e os municípios sem parques eólicos apresentaram Efeito Líquido negativo no primeiro período $(-388.858,38)$ e após, no segundo, tendo acréscimo na receita de impostos, o mesmo foi positivo $(150.172,88)$. O Efeito Diferencial também foi positivo no primeiro período para municípios com parques eólicos $(2.150 .857,86)$, tendo, neste período, vantagem locacional Porém, no segundo período, o Efeito Diferencial foi negativo para estes municípios $(-1.164 .075,75)$ e os municípios sem parques eólicos, no primeiro período, tiveram Efeito Diferencial negativo $(-358.476,31)$ e após, no segundo período, com Efeito Diferencial positivo $(194.012,63)$ passaram a ter vantagem locacional.

Os grupo 2 e 3, que compõem o estado do Rio Grande do Sul, apresentam trajetórias distintas, onde o grupo 2 apresentou Efeito Líquido positivo, nos períodos 2001-2006 e 2006-2013, tanto para municípios com parques eólicos $(1.591 .043,49$ e 15.974.400,70), como para os municípios sem parques eólicos $(1.160 .638,14$ e 515.924,23), tendo ambos incremento na receita de impostos. O Efeito Diferencial também é positivo para ambos os municípios, com e sem parques eólicos, nos dois períodos de análise, sendo o Efeito Diferencial dos municípios com parques eólicos de 1.396.174,61 e de 16.063.225,30 e o dos municípios sem parques eólicos de 982.269,07 e de 365.096,10, apresentando, deste modo, vantagem locacional.

0 grupo 3 apresenta apenas resultados negativos, ou seja, em ambos os períodos houve queda na receita de impostos, com Efeito Líquido de -1.032.126,53 e de -6.057.364,03 para os municípios sem parques eólicos e de -4.640.585,23 e -3.075.759,48 para os municípios com parques eólicos. O Efeito Diferencial também possui apenas valores negativos, sendo que os municípios de análise do grupo 3 não apresentaram vantagem locacional, com Efeito Diferencial de -831.763,62 e de -5.953.252,45 para os municípios sem parques eólicos e de $-4.410 .298,32$ e de $-3.119 .329,05$ para os municípios com parques eólicos.

No estado de Santa Catarina, composto pelos grupos 4 e 5, os municípios com presença de parques eólicos em seus territórios apresentaram vantagem locacional em ambos os períodos de análise. Observando primeiramente o grupo 4, nos dois períodos de análise, o Efeito Líquido foi positivo, tanto para municípios com parques eólicos $(146.296,07$ e $730.835,69)$ como para os municípios sem parques eólicos $(123.496,96$ e 527.249,91). Deste modo, todos tiveram aumento da receita de impostos. Ambos os municípios também apresentaram vantagem locacional, com Efeito Diferencial positivo nos períodos considerados para a análise, sendo municípios com parques eólicos de 146.737,87 e de 744.282,52 e municípios sem parques eólicos de 136.908,82 e de 601.920,22.

Em relação aos municípios com parques eólicos do grupo 5, apenas no primeiro período, 2001-2006, os mesmos obtiveram Efeito Líquido negativo $(-41.772,18)$, sendo no período seguinte, 2006-2013, o Efeito Líquido positivo $(1.899 .066,18)$. Os municípios sem parques eólicos, por sua vez, apresentaram Efeito Líquido negativo no primeiro período $(-133.949,35)$ e no segundo período $(-790.240,10)$, os mesmos também obtiveram Efeito Diferencial negativo, nos dois períodos de análise (-154.476,13 e -877.754,58), os municípios com parques eólicos expuseram vantagem locacional, em ambos os períodos, com Efeito Diferencial positivo $(28.935,25$ e $2.014 .061,02)$.

De acordo com o apresentado, dos cinco grupos de análise dos resultados do Método Estrutural Diferencial para a receita de impostos, em três grupos os municípios com parques eólicos tiveram resultados positivos para o Efeito Diferencial nos dois períodos de análise: um grupo do Rio Grande do Sul e dois de Santa Catarina e outro grupo também apresentou Efeito Diferencial positivo no primeiro período, Paraná, e apenas um grupo não apresentou vantagem locacional, sendo este um do Rio Grande do Sul, ou seja, obteve Efeito Diferencial negativo. Portanto, quando feita a análise por grupos, que considera os municípios que possuem municípios vizinhos em comum, a análise difere um pouco da apresentada pelos municípios no geral dos estados, isso se deve à proximidade, ou seja, os grupos dentro dos estados podem apresentar resultados distintos do estado como um todo, podendo haver variações regionais.

\section{CONSIDERAÇÕES FINAIS}

Diante do potencial eólico apresentado pelo Brasil e da capacidade instalada, a energia eólica passa a estar mais presente no cotidiano das pessoas. De acordo com o objetivo deste artigo, podem-se perceber os impactos econômicos dos parques eólicos nos municípios da Região Sul do Brasil, a qual contempla os estados do Paraná, do Rio Grande do Sul e de Santa Catarina, sendo que os municípios com parques eólicos 
foram mais dinâmicos do que os municípios vizinhos, sem parques eólicos, por vezes passando a apresentar vantagens, tendo incrementos na receita de impostos ou aumento dos empregos e até mesmo o aumento do valor adicionado dos setores da economia.

Dos três estados analisados, quando observados os municípios com e sem parques eólicos da Região Sul, os resultados para o estado do Rio Grande do Sul são os mais surpreendentes, quando observado emprego, receita de impostos e valor adicionado. Os mesmos revelam que, no primeiro período de análise, 1999-2006, período este em que quase não haviam parques eólicos instalados neste estado, os municípios sem parques eólicos apresentavam Efeito Líquido positivo, assim como Efeito Diferencial positivo para os resultados de emprego e de valor adicionado, ao passo que municípios com parques eólicos (em sua maioria ainda não possuíam os parques em operação em seu território) apresentavam resultados negativos, com queda no Efeito Líquido e no Efeito Diferencial. Após, no segundo período, 2006-2012, houve reversão no apresentado, ou seja, os municípios com parques eólicos passaram a ter Efeito Líquido positivo, assim como Efeito Diferencial positivo, ou seja, apresentaram incremento nas variáveis e vantagem locacional, sendo que os municípios sem parques eólicos apresentaram resultados negativos.

Por meio da análise do estado do Rio Grande do Sul, o qual apresentou a mesma trajetória para as três variáveis de análise, pode-se perceber que a presença de parques eólicos em seu território ocasionou uma mudança nas mesmas, passando de trajetórias negativas para incrementos no emprego, na receita de impostos e no valor adicionado, demonstrando, também, a vantagem locacional destes municípios, os quais possuem parques eólicos em seu território. Nos estado de Paraná e de Santa Catarina isto também ocorre, em um ou outro período, mas não em todas as variáveis concomitantemente como no estado do Rio Grande do Sul.

Observando os resultados por grupos de municípios vizinhos, notam-se resultados distintos dos apresentados pelos estados, ocorrendo que, dentro de um mesmo estado, podem existir regiões que apresentam vantagem locacional e regiões que não a apresentam. Como no estado do Rio Grande do Sul, como já discutido anteriormente, o total do estado apresentou resultados positivos em ambas as variáveis no segundo período, porém, quando observado os dois grupos deste estado, nota-se que um dos grupos (grupo 3) apresentou resultados negativos em ambos os períodos tanto para municípios com parques eólicos como para os municípios sem parques eólicos, para as três variáveis de análise. Já o grupo 2 do estado do estado do Rio Grande do Sul obteve, nos dois período de análise, Efeito Líquido positivo e Efeito Diferencial também positivo para municípios com parques eólicos, sendo que os sem parques eólicos, em sua maioria, também obtiveram resultados positivos, em ambas as variáveis.

O estado do Paraná, por possuir apenas um grupo, o mesmo apresenta as mesmas tendências do estado. No estado de Santa Catarina, na maior parte das vezes, os grupos apresentam a mesma tendência do estado. Portanto, pode-se perceber que existem variações regionais, onde as mesmas não condizem com o total dos municípios do estado.

Os resultados do emprego, do valor adicionado e da receita de impostos demonstraram com mais clareza o impacto dos parques eólicos nos municípios brasileiros. Devido ao atual contexto econômico, é muito importante ressaltar a importância do impacto no emprego, pois com constantes quedas no emprego, a instalação dos parques eólicos, além de gerar uma fonte de energia renovável, promovem as economias locais, principalmente através da geração de emprego, além do importante incremento nas receitas, proporciona um maior volume de recursos para ser utilizado. Por fim, destaca-se a importância de novas pesquisas, as quais considerem outras variáveis, além das utilizadas neste trabalho.

\section{REFERÊNCIAS}

[1] ALINA-FLORENTINA, Cucos. Social and economic impacts of wind power in corelation with the financial crises. The Annals of the University of Oradea. Economic Sciences, Romênia, v. 1, n. 2, p. 62-68, 2011.

[2] ALVES, Tiago Wickstrom. Análise da versão clássica do método estrutural-diferencial. Perspectiva Econômica, São Leopoldo, v. 33, n. 102, p. 5-22, 1998.

[3] ASSOCIAÇÃO BRASILEIRA DE ENERGIA ELÉTRICA (ABRADEE). Leilões de Energia. Setor Elétrico, Brasília, DF, 2017. Acesso em: <http://www.abradee.com.br/setor-eletrico/leiloes-de-energia>. Acesso em: 27 jan. 2017.

[4] ASSOCIAÇÃo BRASILEIRA DE ENERGIA EÓLICA (ABEEólica). Comunicação. São Paulo, 2015. Disponível em:<http://www.portalabeeolica.org.br/index.php/comunicacao. html>. Acesso em: 18 dez. 2015.

[5] ASSOCIAÇÃo BRASILEIRA DE ENERGIA EÓLICA (ABEEólica). Home. São Paulo, 2017a. Disponível em: < http://www.abeeolica.org.br/>. Acesso em: 12 maio 2017. 
[6] ASSOCIAÇÃO BRASILEIRA DE ENERGIA EÓLICA (ABEEólica). Levantamento de dados [mensagem pessoal], $2016 \mathrm{~b}$. Mensagem recebida por <XXX@hotmail.com> em: 08 mar. 2016.

[7] ASSOCIAÇÃO BRASILEIRA DE ENERGIA EÓLICA (ABEEólica). Nosso setor. São Paulo, 2016a. Disponível em: <http://www.portalabeeolica.org.br/index.php/nosso-setor.html>. Acesso em: 20 fev. 2016.

[8] ASSOCIAÇÃO BRASILEIRA DE ENERGIA EÓLICA (ABEEólica). Números ABEEólica. Dados Mensais ABEEÓLICA/Janeiro de 2017. São Paulo, 2017b. Disponível em: <http://www.abeeolica.org.br/dados-abeeolica/>. Acesso em: 24 jan. 2017

[9] BRASIL. Ministério do Trabalho. Relação Anual de Informações Sociais (RAIS), RAIS Vínculos: [1999, 2006 e 2013]. Brasília, DF, 2016. Disponível em: <http://bi.mte.gov.br/bgcaged/rais.php>. Acesso em: 08 nov. 2016.

[10] CAIXA ECONÔMICA. Federal, Sistema de Coleta de Dados Contábeis de Estados e Municípios (SISTN), Declaração: [2001 e 2006]. Brasília, DF, 2016. Disponível em: <ww3.tesouro.gov.br/estados_municipios/sistn_novosite.asp>. Acesso em: 24 nov. 2016.

[11] CASTRO, Rui M. G. Energias renováveis e produção descentralizada: introdução a energia eólica. Ed. 2.1 Lisboa: Universidade Técnica de Lisboa: Instituto Superior Técnico. Lisboa, Portugal, maio 2005.

[12] CONFEDERAÇÃO NACIONAL DE MUNICÍPIOS (CNM). Mapa municípios: Brasil. Brasília, DF, 2016. Disponível em: <http://www.cnm.org.br/municipios>. Acesso em: 12 set. 2016.

[13] COSTA, Heitor Scalambrini. Energia eólica e os desafios socioambientais. Instituto Humanitas UNISINOS, São Leopoldo, 5 jan. 2016. Disponível em: <http://www.ihu. unisinos.br/noticias/550440-energia-eolica-e-os-desafiossocioambientais>. Acesso em: 14 abr. 2016.

[14] COSTA, Ricardo Cunha da; PRATES, Cláudia Pimentel T. 0 papel das fontes renováveis de energia no desenvolvimento do setor energético e barreiras à sua penetração no mercado. BNDES Setorial, Rio de Janeiro, n. 21, p. 5-30, mar. 2005. Disponível em:<http://www.bibliotecaflorestal.ufv.br/handle/123456789/4210>. Acesso em: 10 fev. 2016.

[15] INSTITUTO BRASILEIRO DE GEOGRAFIA E ESTATÍSTICA (IBGE). Base de dados: [1999 a 2013]. Rio de Janeiro, 2016. Disponível em: <http://www.ibge.gov.br/home/ estatistica/economia/pibmunicipios/2010/default_base.shtm>. Acesso em: 06 out. 2016.

[16] MARTINS, F.R.; GUARNIERI, R. A.; PEREIRA, E. B. O Aproveitamento da Energia Eólica. Instituto Nacional de Pesquisas Espaciais, centro de Previsões do Tempo e Estudos Climáticos, São José dos Campos, São Paulo, Brasil. Revista Brasileira de Ensino de Física. v. 30, n. 1, 1304, 2008.

[17] MELO, Elbia. Energia renovável e mais competitiva. Brazilian Businnes: Revista da Câmara de Comércio Americana do Rio de Janeiro, Rio de Janeiro, n. 286, p. 39, maio/jun. 2014.

[18] MELO, Elbia. Fonte eólica de energia: aspectos de inserção, tecnologia e competitividade. Estudos Avançados, São Paulo, v. 27, n.77, p. 125-142, 2013.

[19] MINISTÉRIO DE MINAS E ENERGIA. Leilões de Energia Elétrica. Início, programas, Brasília, DF, 2017. Disponível em: <http://www.mme.gov.br/programas/leiloes_de_energia/menu/inicio.html>. Acesso em: 27 jan. 2017.

[20] ROSSETTO, Carolina; SOUZA, Joana Siqueira de. Avaliação Econômica da Implantação de Turbinas Eólicas por meio da Análise de Riscos. EdiPUC, v. 7, n. 1, 32p. 2014. Periódicos PUCRS. Revista da graduação, publicações de TCC.

[21] SCALABRIN, Idionir; ALVES, Tiago Wickstrom. Análise da geração de valor das empresas brasileiras, com ações em Bolsa, de 1996 a 2000 utilizando o método estrutural-diferencial. Contabilidade, Gestão e Governança, Brasília, DF, v. 5, n. 1, p. 133-155, 2002.

[22] SIMAS, Moana; PACCA, Sergio. Energia eólica, geração de empregos e desenvolvimento sustentável. Estudos Avançados, São Paulo, v. 27, n. 77, p. 99-116, 2013.

[23] SOUZA, Gustavo Henrique de. et al.. Gestão Energética e Inovação Sustentável: A Formação de Preço da Energia Eólica no Estado do Rio Grande do Norte. RAI, Revista de Administração e Inovação, 11.3, p. 255-280, 2014.

[24] TESOURO NACIONAL. Sistema de Informações Contábeis e Fiscais do Setor Público Brasileiro (SISCONFI), Consultar declaração: [2013]. Brasília, DF, $2016 . \quad$ Disponível em: <https://siconfi.tesouro.gov.br/siconfi/pages/public/declaracao/declaracao_list.jsf>. Acesso em: 30 nov. 2016. 


\section{Capítulo 6}

Análise de agrupamentos obtidos com a relação Indíce de Desenvolvimento Humano e carga tributária dos municipios do estado da Paraiba, entre 2010 e 2018

\section{Mácio Augusto de Albuquerque}

Ramylla de Almeida Batista

Resumo: Durante muito tempo em nosso país foi questionado o alto valor cobrado em tributações, esse questionamento traz à tona a real eficácia das políticas públicas promovidas de forma obrigatória pelos governantes oferecidas a população e financiadas com os recursos providos por essa tributação. As políticas públicas sociais são de responsabilidade do Estado brasileiro e serão abordadas nesta pesquisa de forma prioritária aquelas que alteram a ordem social em relação a fatores de longevidade, renda da população, educação, seguridade social, previdência, saúde, assistência social, educação, cultura e desporto.

Esta pesquisa tem como seu principal objetivo fazer uma análise da relação entre a Carga Tributária e o Índice de Desenvolvimento Humano (IDH) nos municípios paraibanos com o propósito de identificar igualdades entre os diversos fatores econômicos e políticos municipais, mostrando um possível contraponto ao critério já utilizado para análise do volume da carga tributária baseado em uma comparativa do volume do Produto Interno Bruto (PIB) apresentado no Relatório do "Resultado do Tesouro Nacional" divulgado pelo Ministério da Fazenda. O critério atual considera apenas os aspectos econômicos da carga tributária e despreza a relação existente entre as ações públicas governamentais e sua eficácia providas dessas contribuições tributárias da população.

Palavras-chave: Carga tributária. Políticas Sociais Efetivas. Desenvolvimento humano. IDH 


\section{INTRODUÇÃO}

0 método estatístico de analise multivariada refere-se de uma forma geral a analises de múltiplas variáveis e sua relação com o objeto de investigação. Entre os métodos estatísticos mais comum, ganha destaque a análise de cluster ou analise de agrupamento, pois é aplicável a diversas áreas. A técnica de análise de agrupamento tem como principal função a de organizar em grupos os objetos em estudo de forma que os membros de cada grupo apresentem semelhanças entre si.

Durante muito tempo em nossa nação, os contribuintes tributários, sejam eles pessoas físicas ou jurídicas, indivíduos ou entidades de classe representadas, questionam de forma negativa a quantidade de tributações. As repetitivas negativas em relação a tributação leva a questão principal sobre qual o real resultado da aplicação dos recursos dessa tributação e quais os benefícios reais estão sendo refletidos para a população, favorecendo seu verdadeiro desenvolvimento através de condições necessárias para o mesmo, como o fornecimento de recursos para os setores de saúde, previdência, assistência social, educação, cultura e desporto; e suas políticas de distribuição de renda que auxiliam a geração da mesma.

Em nossa Constituição datada de 1988, dos artigos 193 ao 219, está definida a arrecadação tributária como principal fonte do financiamento das políticas públicas destinadas ao desenvolvimento da população. A partir dessa definição surge o maior desafio para os gestores públicos, que seria o desafio de implantar políticas capazes de aumentar de forma eficaz o nível do bem-estar social da própria população utilizando os recursos captados.

A cobrança de tributos está definida em nosso país na Constituição Federal de 1988 (BRASIL, 2009), em seus artigos 145 ao 162 e regulamentado pelo Código Tributário Nacional (CTN) - Lei Complementar no 5.172, de 25 de outubro de 1966, e em diversos decretos, leis e normas legais. Os Tributos, segundo o artigo 5o do CTN (1966) são os impostos, taxas e contribuições de melhoria. Imposto é o tributo cuja obrigação tem por fato gerador uma situação independente de qualquer atividade estatal específica, relativa ao contribuinte, por exemplo, Imposto de Renda. Taxas são exigências financeiras a pessoa física ou jurídica para usar certos serviços fundamentais, por exemplo, Taxa de Incêndio. Por sua vez, Contribuição de Melhoria é o tributo cuja obrigação tem por fato gerador uma situação que representa um benefício especial auferido pelo contribuinte, por exemplo, em decorrência de obras públicas de que decorra valorização imobiliária.

Atualmente, no Brasil, os impostos cobrados de competência da União, são: a importação de produtos, exportação, renda e proventos de qualquer natureza, produtos industrializados, operações de credito, cambia, seguros ou relativas a títulos e valores imobiliários, propriedades territoriais rurais e grandes fortunas; de competência dos Estados e do Distrito Federal são: transmissão causa mortis e doação de quaisquer bens ou direitos, operações relativas à circulação de mercadorias e sobre prestações de serviços de transporte interestadual e intermunicipal e de comunicação, ainda que as operações se iniciem no exterior, e propriedade de veículos automotores, e de competência dos Municípios e do Distrito Federal são: propriedade predial e territorial urbana, transmissão "inter vivos" a qualquer título por ato oneroso, de bens imóveis, por natureza ou acessão física, e de direitos reais sobre imóveis, exceto os de garantia, bem como cessão de direitos a sua aquisição, e serviços de qualquer natureza; de acordo com a CTN de 1966.

Além dos tributos de competência da União, também é competência exclusiva da União as contribuições sociais destinadas ao financiamento da seguridade social. De acordo com a Constituição Federal, em seu artigo 194, no parágrafo único, dispõe que "compete ao poder público, nos termos da lei, organizar a seguridade social". 0 artigo 195 da Carta Magna define que a seguridade social será financiada por toda a sociedade, de forma direta ou indireta, nos termos da Lei, mediante recursos provenientes dos orçamentos da União, dos Estados, do Distrito Federal, e dos Municípios.

De acordo com a Receita Federal do Brasil, a carga tributária do país representa a massa de contribuição da população com tributos. 0 resultado obtido pode ser observado na Figura 1 na qual constitui o esforço social para o financiamento das atividades do Estado. A forma mais utilizada para o entendimento do volume da arrecadação tributária, constitui em uma comparativa com o Produto Interno Bruto (PIB). Nesta opção de comparativa leva-se em consideração apenas os fatores econômicos ou quantitativos da carga tributária. 
Figura 1 - Carga Tributária do Brasil no período de 2006 a 2015

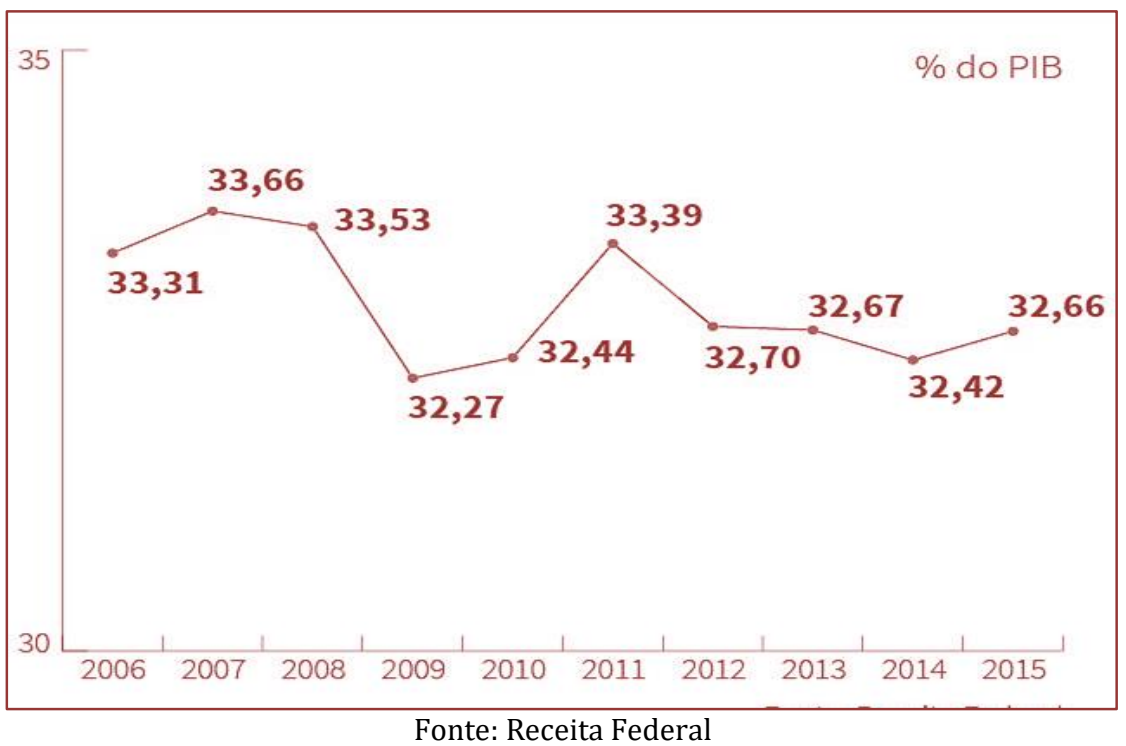

De acordo com a Receita Federal, no Brasil, a carga tributária total obtida no ano de 2015 foi de aproximadamente 32,66\% em relação ao PIB do mesmo ano. Essa analise permite aos governantes realizar ações e despesas, correspondentes a variável do cálculo do PIB.

\subsection{CARGA TRIBUTARIA NO BRASIL}

A coleta financeira dos impostos é uma pratica do governo utilizada para pagar as suas despesas. A carga tributária é estabelecida através de uma relação entre os tributos recebidos e o Produto Interno Bruto (PIB), que é a soma de tudo que é produzido no país.

Um dos fatores que causaram o aumento da carga tributária brasileira foi a redução do Produto Interno Bruto (PIB) em um determinado ano de crise. A contração da economia brasileira ocorrida em 2015 de, aproximadamente, 3,8\% fez com que a tributação representasse uma maior parcela em relação ao total.

Em parâmetros de monetização, não houve um real aumento na arrecadação tributária dos Municípios, Estados ou União. Subtraída da inflação do determinado período, houve uma queda na arrecadação tributária de 2015. Porem como o cálculo comparativo é em relação ao PIB do mesmo período, no qual foi constatado uma diminuição, surge um aumento da carga.

É possível notar através da Tabela 1, que no ano de 2016, a Carga Tributária Bruta (CTB) alcançou os $32,38 \%$, que em relação aos $32,11 \%$ do ano de 2015 , apresenta uma indicação positiva de $0,27 \%$. Essa variação é produto resultado da relação combinada da diminuição de 3,5\% do PIB e de $2,8 \%$ da arrecadação tributária em todos os níveis governamentais.

Tabela 1: carga tributária bruta - 2015 e 2016

\begin{tabular}{|c|c|c|}
\hline Componentes & 2015 & 2016 \\
\hline PIB & $5.995,79$ & $6.259,23$ \\
\hline Arreacadação & $1.925,45$ & $2.027,01$ \\
\hline Carga tributaria & $32,11 \%$ & $32,38 \%$ \\
\hline
\end{tabular}

No ano de 2016, foi possível observar uma redução de 3,5\% do PIB, em relação ao ano de 2015, chegando a aproximadamente $\mathrm{R} \$ 6,26$ trilhões, e sugerindo uma diminuição em seu segundo ano consecutivo. Essa variação da arrecadação foi calculada com base no deflator implícito do PIB no ano de 2016, que foi de 8,29\%.

Essa diminuição foi produto do resultado do valor adicionado de 3\% a preços básicos atrasados e do ajuste nos impostos sobre produtos líquidos de subsídios de 6,3\%. 0 resultado é refletido no desempenho de atividades da Agropecuária em (-4,3\%), da Industria em (-4,0\%) e de Serviços em (-2,6\%). 
É notável, em relação a arrecadação tributária, que em sua maioria o aumento da carga do ano de 2016 em relação ao ano de 2015, de aproximadamente 0,27\% do Produto Interno Bruto, deriva do IRPJ, do IRRF dos Municípios e da CSLL. Os tributos que incidem em bens e serviços como: ICMS, ISS, IPI, II, PIS e Cofins; seguiram o desempenho econômico, proporcionando diminuição em percentagens do Produto Interno Bruto.

\subsection{COMO CALCULA-SE A CARGA TRIBUTÁRIA NO BRASIL}

No Brasil, a carga tributária é produto da razão entre os tributos totais arrecadados pelos três níveis governamentais (União, Estados e Municípios) e por suas entidades do Sistema S (SESI, SENAI, SEBRAE, SENAC e demais); e por seu Fundo de Garantia por Tempo de Serviço (FGTS), e o Produto Interno Bruto (PIB). No ano de 2015, a carga tributária bruta brasileira foi de aproximadamente 33\% de seu PIB.

O cálculo da carga tributária bruta considera o total da arrecadação de tributos no período determinado. Porém o cálculo da carga tributária liquida, considera o arrecadado pelo Estado subtraindo-se o que retorna para a população através de projetos de transferência de renda, como pagamentos de benefícios previdenciários e assistências sociais (como rede de saneamento e outros).

\subsection{SÉRIE HISTÓRICA DA CARGA TRIBUTÁRIA NO BRASIL}

Nos anos de 2015 e 2016, a arrecadação tributária trouxe um aumento de forma consecutiva, atingindo a marca de 32,11\% e 32,38\% do PIB, porém ainda menor do que os 33,66\% obtidos em 2007 antes da crise econômica do ano de 2008.

A figura 2 demonstra a evolução da carga tributária brasileira em relação percentual ao PIB entre os anos de 2002 a 2016 .

Figura 2 - Carga Tributária do Brasil no período de 2002 a 2016

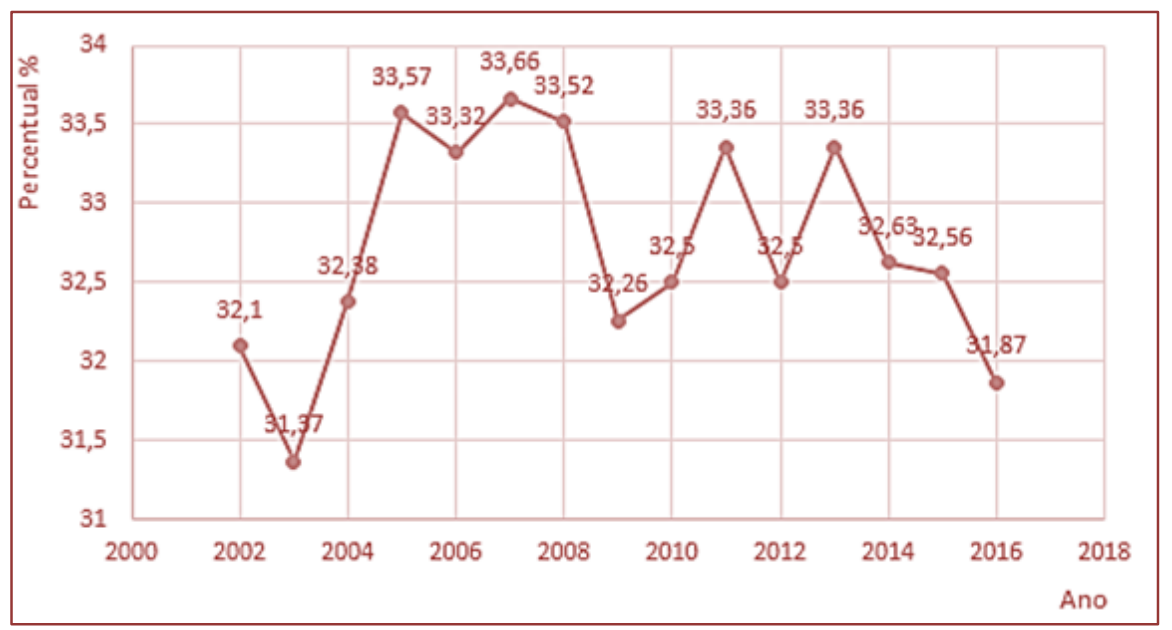

Fonte: Instituto Brasileiro de Planejamento Tributário

É notável através da Figura 2, que o total de carga tributária arrecadada no ano de 2016 foi de aproximadamente 31,87\% em relação percentual ao Produto Interno Bruto (PIB), permitindo ao governo o desenvolvimento de ações e despesas correspondente a essa variável.

\subsection{IDH E DESENVOLVIMENTO SOCIAL}

\subsubsection{IDH}

IDH é a sigla utilizada para o termo "Índice de Desenvolvimento Humano", uma métrica da Organização das Nações Unidas (ONU) que pretende avaliar e relacionar a qualidade de vida e o desenvolvimento econômico da população de uma determinada parcela. Anualmente é elaborado o Relatório de Desenvolvimento Humano $(\mathrm{RDH})$ através do Programa das Nações Unidas para o Desenvolvimento 
(PNUD) que tem como critérios a saúde, renda e educação. Esses critérios são avaliados da seguinte maneira:

- Saúde: expectativa de vida ao nascer.

- Educação: media de anos de estudo e anos de escolaridade esperados.

- Renda: medido pela Renda Nacional Bruta (RNB) com base na Paridade de Poder de Compra (PCC) por habitante.

O IDH varia entre 1 e 0 , onde a aproximação de 1 é o pais mais desenvolvido e a aproximação do 0 é o pais menos desenvolvido.

\subsubsection{IDH NO BRASIL}

No ano de 2014, o Brasil, foi considerado o 75o país no ranking com um IDH médio de 0,755, melhorando seu posicionamento em 9 nove posições, quando comparado em relação ao ano de 2010. Mesmo tendo uma população de aproximadamente 209 milhões de habitantes e uma média de pobreza de que chega a 9,96\%.

A Tabela 2, traz o ranking dos estados brasileiros, baseado no IDH nacional, considerando o Índice de Desenvolvimento Humano Municipal:

Tabela 2. Ranking do IDH dos estados brasileiros

\begin{tabular}{|c|c|}
\hline ESTADOS & IDH \\
\hline DF & 0,824 \\
\hline SP & 0,783 \\
\hline SC & 0,774 \\
\hline $\mathrm{RJ}$ & 0,761 \\
\hline PR & 0,749 \\
\hline $\mathrm{RS}$ & 0,746 \\
\hline ES & 0,740 \\
\hline GO & 0,735 \\
\hline MG & 0,731 \\
\hline MS & 0,729 \\
\hline MT & 0,725 \\
\hline $\mathrm{AP}$ & 0,708 \\
\hline $\mathrm{RR}$ & 0,707 \\
\hline TO & 0,699 \\
\hline RO & 0,690 \\
\hline $\mathrm{RN}$ & 0,684 \\
\hline $\mathrm{CE}$ & 0,682 \\
\hline AM & 0,674 \\
\hline $\mathrm{PE}$ & 0,673 \\
\hline SE & 0,665 \\
\hline $\mathrm{AC}$ & 0,663 \\
\hline $\mathrm{BA}$ & 0,660 \\
\hline $\mathrm{PB}$ & 0,658 \\
\hline $\mathrm{PA}$ & 0,646 \\
\hline PI & 0,646 \\
\hline MA & 0,639 \\
\hline $\mathrm{AL}$ & 0,631 \\
\hline Média & 0,747 \\
\hline Desvio padrão & 0,048 \\
\hline
\end{tabular}

Fonte: Autores. 
Figura 3 - IDH's oficiais divulgados pelo UNDP (s.d.) e pelo Atlas Brasil PNUD (s.d.) e os IDH's calculados através da média aritmética para o Brasil nos anos de 1991, 2000 e 2010

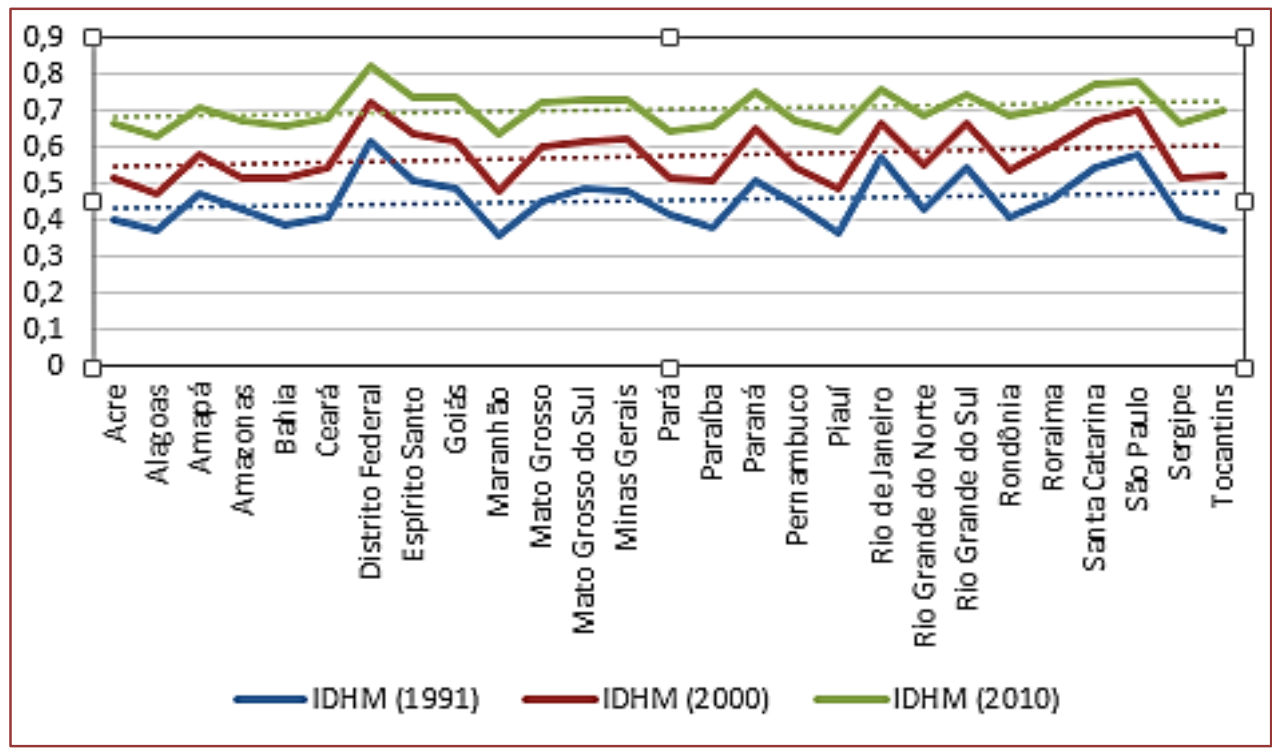

Fonte: UNDP

\subsubsection{COMO É CALCULADO O IDH}

O cálculo é feito através de três aspectos principais que são a renda, educação e saúde. A partir desses aspectos é possível observar as melhorias que trará um melhor IDH para a região ou localidade.

\subsubsection{DESENVOLVIMENTO SOCIAL}

O conceito de Desenvolvimento Social abrange tanto o capital humano quanto o capital social, consistindo na evolução desses componentes sociais e a forma como se relacionam. Consideramos que todo desenvolvimento é Desenvolvimento Social e não existe forma de se desenvolver sem que haja uma alteração tanto no capital social quanto no capital humano.

A relação existente entre o Desenvolvimento Social e o Desenvolvimento Econômico está tão enraizada que se é visível que quando há uma melhoria na vida da população, logo em seguida, a mesma opta por ter acesso a melhores serviços e bens gerando assim uma maior movimentação econômica. Entretanto, o Desenvolvimento Social requer também outros aspectos além dos econômicos, que muitas vezes são difíceis em serem reconhecidos, como situações de paz, oportunidades e afins.

No âmbito econômico, o desenvolvimento e melhoria das condições de vida populacional tem relação direta com uma maior produção de bens e serviços. Contudo, além da importância dada para tudo que se produz, torna-se também importante que o consumo básico das necessidades seja evidenciado em todas classes sociais pré-definidas por padrões econômicos.

Um dos critérios de maior importância para o Desenvolvimento Social é a qualidade institucional da população, que garanta que os bens públicos sejam fornecidos pelo governo e esse tipo de ambiente está sendo cada vez mais valorizado na avaliação da qualidade de vida populacional.

É a partir das necessidades imediatas da população e no redirecionamento dos recursos governamentais providos, em sua maioria, pela arrecadação tributária, que as decisões políticas-econômicas são baseadas garantindo assim o Desenvolvimento Social. A figura a seguir resume os impactos causados pelas políticas públicas financiadas pela arrecadação de tributos, e faz sua relação com o desenvolvimento humano. 
Figura 4 - Origens e fontes de recursos, políticas públicas e condições para o desenvolvimento humano.

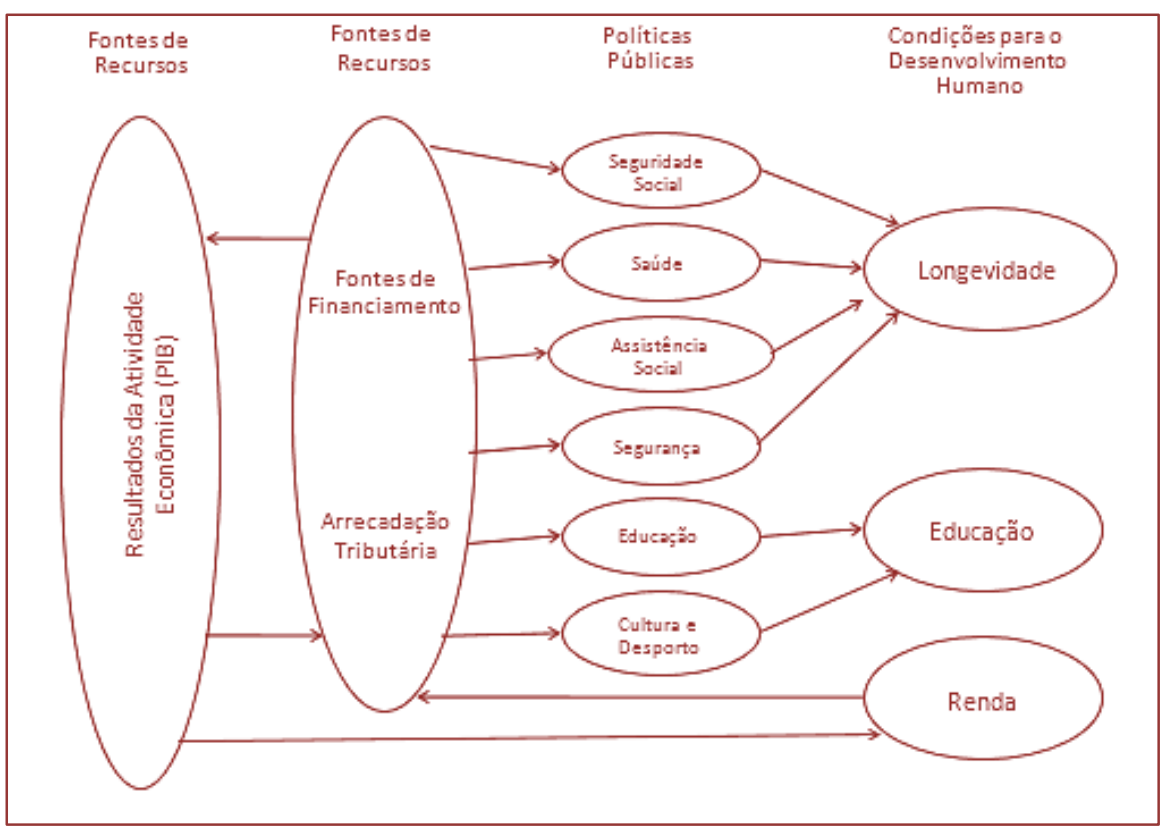

Fonte: Autores

As despesas governamentais são direcionadas pelas políticas públicas desenvolvidas, principalmente aquelas que são destinadas a investimentos e ações que desenvolva educação e longevidade, podendo assim modificar diretamente o cálculo do Índice de Desenvolvimento Humano (IDH). Portanto, a alteração no IDH corresponde a eficácia e eficiência da gestão pública em apresentar investimentos no aspecto educacional, cultural, de desporto, de saúde, de seguridade, de assistência social e de desenvolvimento da atividade econômica.

A partir dessas determinações, podemos definir as variáveis utilizadas no cálculo do IDH, classificando-as em suas causas e efeitos, resultando na Figura 5 apresentada abaixo:

Figura 5 - Relação de causas e efeitos das despesas do governo em políticas sociais

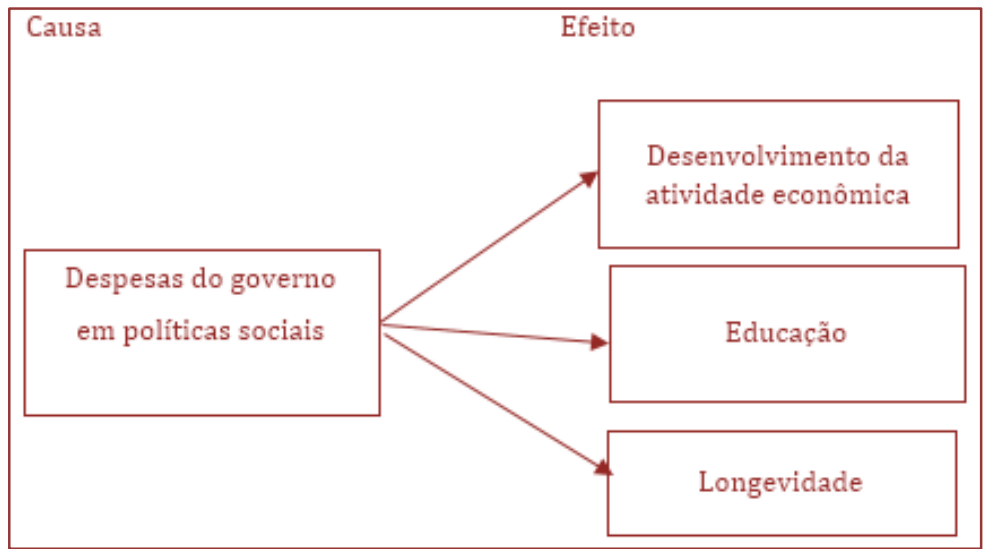

Fonte: Autores

\section{OBJETIVO}

O principal objetivo desse projeto é apresentar os resultados da avaliação da carga tributária dos municípios paraibanos, através de um método de leitura qualitativa. Esse método serve como ferramenta de avaliação, baseando-se na verificação da eficácia e eficiência da arrecadação tributária de cada microrregião, relacionando-as a indicadores do desenvolvimento humano populacional, trazendo a 
possibilidade de sua utilização como base para um comparativo com os demais índices de outras microrregiões.

Além disso, propõem-se a averiguação da relação existente entre a arrecadação tributária e o índice de desenvolvimento humano, de forma demonstrar a compatibilidade entre a carga tributária, o volume populacional e o IDH. Para isso, se faz necessário a utilização de dados sobre a arrecadação tributária dos municípios do estado da Paraíba, sobre a população estadual, além do conhecimento especifico sobre a estrutura de cálculo do Índice de Desenvolvimento Humano e a disponibilidade de informações e dados relacionados as microrregiões e municípios. A partir da compatibilidade desses elementos, poderemos desenvolver um modelo de analise, qualitativo da microrregião e da carga tributária.

\section{MÉTODO}

0 método recomendado poderá ser utilizado como ferramenta para a determinação da dimensão qualitativa do produto da arrecadação dos tributos refletindo o nível de desenvolvimento humano populacional, por mediação da identificação dos grupos em que cada microrregião está alocada, permitindo o comparativo de seus resultados com os demais grupos que comportam as demais microrregiões, bem como o posicionamento no grupo pertencente.

Essa leitura de grupos, associada à análise da composição do IDH, poderá estabelecer o viés em que as políticas públicas deverão ser norteadas, com foco na melhoria das condições de vida da população, podendo servir como mais uma ferramenta do painel de bordo (NEVES; OLIVEIRA, 20011) de gestores públicos, permitindo a estes, dentre outras possibilidades:

a). Identificar regiões que se destacam pelo nível de desenvolvimento humano atingido com a maior eficiência e eficácia da arrecadação tributária;

b). Analisar as políticas públicas que estão sendo executadas nessas regiões e que influenciam o aumento do IDH da população, possibilitando o benchmark para uma possível implementação destas ações em sua própria região, desde que adaptadas à sua realidade, acelerando seu processo, por meio de experiências já vivenciadas;

c). Analisar a realidade do agrupamento em que a sua região se encontra posicionada e de seus demais componentes.

Os dados estatísticos utilizados neste trabalho foram disponibilizados por diversos órgãos como: STN Secretaria do Tesouro Nacional, Receita Federal do Brasil, Instituto Brasileiro de Geografia e Estatística, Organização das Nações Unidas, Programa das Nações Unidas para o Desenvolvimento.

Este trabalho não objetiva a discursão da relação existente entre a carga tributária, o Índice de Desenvolvimento Humano e a efetividade das políticas públicas desenvolvidas, pois não pretende desenvolver um método de análise qualitativa para tal. A metodologia se desenvolve da seguinte forma:

\subsection{COLETA DE DADOS}

A coleta de dados relativos a cada indivíduo populacional a ser analisada foi feita. Essa população foi composta entre os municípios.

É necessário para a realização das análises os seguintes dados coletados: volume da arrecadação tributária do período determinado, população demográfica de cada município e o Índice de Desenvolvimento Humano referente.

A partir desses dados, pode-se construir o modelo de analise com o cruzamento dos mesmos explicitado a seguir: 
Tabela 3: Municípios paraibanos com sua respectiva arrecadação, população, media de arrecadação por habitantes e IDH.

\begin{tabular}{|c|c|c|c|c|}
\hline Municípios & Arrecadação & População & $\begin{array}{c}\text { Média } \\
\text { arrecadação/habitantes }\end{array}$ & IDH \\
\hline Água Branca & $1.305 .124,12$ & 9449 & 138,12 & 0,572 \\
\hline Aguiar & $218.130,21$ & 5530 & 39,44 & 0,597 \\
\hline Alagoa Grande & $1.510 .205,46$ & 28482 & 53,02 & 0,582 \\
\hline Alagoa Nova & $1.971 .338,93$ & 19686 & 100,14 & 0,576 \\
\hline Alagoinha & $1.037 .224,86$ & 13577 & 76,4 & 0,595 \\
\hline Alcantil & $380.128,97$ & 5239 & 72,56 & 0,578 \\
\hline Algodão de Jandaíra & $286.813,38$ & 2366 & 121,22 & 0,548 \\
\hline Alhandra & $2.275 .606,49$ & 18001 & 126,42 & 0,582 \\
\hline Amparo & $114.859,32$ & 2088 & 55,01 & 0,608 \\
\hline Aparecida & $568.727,91$ & 7676 & 74,09 & 0,606 \\
\hline Araçagi & $1.197 .323,20$ & 17224 & 69,51 & 0,578 \\
\hline Arara & $870.236,55$ & 12653 & 68,78 & 0,549 \\
\hline Araruna & $535.989,64$ & 18886 & 28,38 & 0,548 \\
\hline Areia & $760.497,66$ & 23837 & 31,9 & 0,567 \\
\hline Areia de Baraúnas & $175.960,02$ & 1927 & 91,31 & 0,594 \\
\hline Areial & $501.988,64$ & 6470 & 77,59 & 0,562 \\
\hline Aroeiras & $147.543,83$ & 19089 & 7,73 & 0,608 \\
\hline Assunção & $234.050,41$ & 3522 & 66,45 & 0,548 \\
\hline Baía da Traição & $205.608,40$ & 8007 & 25,68 & 0,609 \\
\hline Bananeiras & $1.981 .946,21$ & 21854 & 90,69 & 0,581 \\
\hline Baraúna & $95.325,96$ & 4222 & 22,58 & 0,568 \\
\hline Barra de Santa Rosa & $1.387 .748,14$ & 14160 & 98 & 0,558 \\
\hline Barra de Santana & $483.572,40$ & 8205 & 58,94 & 0,567 \\
\hline Barra de São Miguel & $424.458,04$ & 5611 & 75,65 & 0,562 \\
\hline Bayeux & $7.563 .338,60$ & 99758 & 75,82 & 0,572 \\
\hline Belém & $1.868 .318,02$ & 17083 & 109,37 & 0,649 \\
\hline Belém do B. do Cruz & $654.918,88$ & 7143 & 91,69 & 0,592 \\
\hline Bernardino Batista & $401.646,58$ & 3075 & 130,62 & 0,578 \\
\hline Boa Ventura & $209.938,09$ & 5751 & 36,5 & 0,558 \\
\hline Boa Vista & $1.052 .767,18$ & 6224 & 169,15 & 0,599 \\
\hline Bom Jesus & $627.279,01$ & 2399 & 261,48 & 0,649 \\
\hline Bom Sucesso & $260.052,07$ & 5037 & 51,63 & 0,597 \\
\hline Bonito de Santa Fé & $1.113 .737,46$ & 10806 & 103,07 & 0,592 \\
\hline Boqueirão & $1.190 .815,17$ & 16889 & 70,51 & 0,574 \\
\hline Borborema & $267.582,09$ & 5111 & 52,35 & 0,607 \\
\hline Brejo do Cruz & $1.270 .735,13$ & 13123 & 96,83 & 0,61 \\
\hline Brejo dos Santos & $389.788,56$ & 6197 & 62,9 & 0,558 \\
\hline Caaporã & $3.445 .644,26$ & 20363 & 169,21 & 0,597 \\
\hline Cabaceiras & $618.979,96$ & 5035 & 122,94 & 0,619 \\
\hline Cabedelo & $19.273 .447,19$ & 57926 & 332,73 & 0,602 \\
\hline Cachoeira dos Índios & $807.414,13$ & 9546 & 84,58 & 0,611 \\
\hline Cacimba de Areia & $258.060,27$ & 3557 & 72,55 & 0,748 \\
\hline Cacimba de Dentro & $1.144 .120,25$ & 16755 & 68,29 & 0,587 \\
\hline Cacimbas & $1.390 .215,97$ & 6814 & 204,02 & 0,596 \\
\hline Caiçara & $337.538,54$ & 7220 & 46,75 & 0,564 \\
\hline Cajazeiras & $5.459 .506,29$ & 58437 & 93,43 & 0,523 \\
\hline Cajazeirinhas & $170.416,72$ & 3033 & 56,19 & 0,592 \\
\hline Caldas Brandão & $601.408,26$ & 5637 & 106,69 & 0,679 \\
\hline Camalaú & $224.862,75$ & 5749 & 39,11 & 0,55 \\
\hline Campina Grande & $60.501 .405,01$ & 385276 & 157,03 & 0,568 \\
\hline Capim & $338.224,80$ & 5601 & 60,39 & 0,567 \\
\hline Caraúbas & $642.950,95$ & 3899 & 164,9 & 0,72 \\
\hline Carrapateira & $271.170,05$ & 2378 & 114,03 & 0,533 \\
\hline Casserengue & $631.589,62$ & 7058 & 89,49 & 0,585 \\
\hline Catingueira & $847.641,65$ & 4812 & 176,15 & 0,603 \\
\hline Catolé do Rocha & $1.234 .267,31$ & 28766 & 42,91 & 0,514 \\
\hline Caturité & $298.636,03$ & 4546 & 65,69 & 0,574 \\
\hline Conceição & $587.146,77$ & 18366 & 31,97 & 0,64 \\
\hline
\end{tabular}


Tópicos em Administração - Volume 39

Tabela 3: Municípios paraibanos com sua respectiva arrecadação, população, media de arrecadação por habitantes e IDH.(Continuação)

\begin{tabular}{|c|c|c|c|c|}
\hline Municípios & Arrecadação & População & $\begin{array}{c}\text { Média } \\
\text { arrecadação/habitantes }\end{array}$ & IDH \\
\hline Condado & $139.478,51$ & 6587 & 21,17 & 0,623 \\
\hline Conde & $3.875 .121,48$ & 21418 & 180,93 & 0,592 \\
\hline Congo & $290.656,95$ & 4692 & 61,95 & 0,594 \\
\hline Coremas & $691.904,02$ & 15149 & 45,67 & 0,618 \\
\hline Coxixola & $234.845,29$ & 1771 & 132,61 & 0,581 \\
\hline Cruz do Espírito Santo & $802.403,31$ & 16257 & 49,36 & 0,592 \\
\hline Cubati & $167.046,02$ & 6868 & 24,32 & 0,641 \\
\hline Cuité & $1.466 .846,20$ & 19950 & 73,53 & 0,552 \\
\hline Cuité de Mamanguape & $396.972,25$ & 6198 & 64,05 & 0,566 \\
\hline Cuitegi & $463.355,20$ & 6889 & 67,26 & 0,591 \\
\hline Curral de Cima & $299.733,79$ & 5214 & 57,49 & 0,57 \\
\hline Curral Velho & $119.789,30$ & 2505 & 47,82 & 0,524 \\
\hline Damião & $270.014,78$ & 4900 & 55,11 & 0,529 \\
\hline Desterro & $1.183 .534,82$ & 7991 & 148,11 & 0,606 \\
\hline Diamante & $664.703,47$ & 6616 & 100,47 & 0,521 \\
\hline Dona Inês & $1.598 .496,02$ & 10517 & 151,99 & 0,58 \\
\hline Duas Estradas & $316.240,27$ & 3640 & 86,88 & 0,566 \\
\hline Emas & $392.756,32$ & 3317 & 118,41 & 0,593 \\
\hline Esperança & $2.286 .086,78$ & 31095 & 73,52 & 0,545 \\
\hline Fagundes & $134.112,70$ & 11409 & 11,75 & 0,603 \\
\hline Frei Martinho & $425.887,96$ & 2933 & 145,21 & 0,595 \\
\hline Gado Bravo & $351.647,31$ & 8376 & 41,98 & 0,623 \\
\hline Guarabira & $4.278 .275,74$ & 55340 & 77,31 & 0,56 \\
\hline Gurinhém & $1.078 .596,11$ & 13872 & 77,75 & 0,641 \\
\hline Gurjão & $174.087,89$ & 3159 & 55,11 & 0,513 \\
\hline Ibiara & $1.187 .149,85$ & 6031 & 196,84 & 0,673 \\
\hline Igaracy & $328.860,05$ & 6156 & 53,42 & 0,556 \\
\hline Imaculada & $1.045 .683,83$ & 11352 & 92,11 & 0,625 \\
\hline Ingá & $1.369 .111,09$ & 18180 & 75,31 & 0,586 \\
\hline Itabaiana & $996.298,61$ & 24483 & 40,69 & 0,557 \\
\hline Itaporanga & $850.031,99$ & 23195 & 36,65 & 0,592 \\
\hline Itapororoca & $939.824,32$ & 16998 & 55,29 & 0,613 \\
\hline Itatuba & $828.284,28$ & 10201 & 81,2 & 0,615 \\
\hline Jacaraú & $1.774 .935,32$ & 13952 & 127,22 & 0,564 \\
\hline Jericó & $189.731,44$ & 7538 & 25,17 & 0,562 \\
\hline João Pessoa & $253.374 .951,13$ & 723514 & 350,2 & 0,558 \\
\hline Juarez Távora & $504.336,42$ & 7459 & 67,61 & 0,763 \\
\hline Juazeirinho & $676.976,09$ & 16776 & 40,35 & 0,579 \\
\hline Junco do Seridó & $576.443,60$ & 6643 & 86,77 & 0,567 \\
\hline Juripiranga & $621.693,59$ & 10240 & 60,71 & 0,617 \\
\hline Juru & $892.333,10$ & 9826 & 90,81 & 0,548 \\
\hline Lagoa & $222.187,06$ & 4681 & 47,47 & 0,57 \\
\hline Lagoa de Dentro & $691.047,80$ & 7370 & 93,76 & 0,563 \\
\hline Lagoa Seca & $1.457 .836,71$ & 25911 & 56,26 & 0,57 \\
\hline Lastro & $332.673,41$ & 2841 & 117,1 & 0,627 \\
\hline Livramento & $400.553,15$ & 7164 & 55,91 & 0,533 \\
\hline Logradouro & $274.998,61$ & 3942 & 69,76 & 0,566 \\
\hline Lucena & $1.548 .545,22$ & 11730 & 132,02 & 0,583 \\
\hline Mãe d'Água & $310.266,36$ & 4019 & 77,2 & 0,583 \\
\hline Malta & $373.145,47$ & 5612 & 66,49 & 0,542 \\
\hline Mamanguape & $2.667 .399,86$ & 42330 & 63,01 & 0,642 \\
\hline Manaíra & $110.739,51$ & 10759 & 10,29 & 0,585 \\
\hline Marcação & $350.923,60$ & 7611 & 46,11 & 0,543 \\
\hline Mari & $1.070 .163,68$ & 21173 & 50,54 & 0,529 \\
\hline Marizópolis & $439.803,46$ & 6173 & 71,25 & 0,548 \\
\hline
\end{tabular}


Tabela 3: Municípios paraibanos com sua respectiva arrecadação, população, media de arrecadação por habitantes e IDH.(Continuação)

\begin{tabular}{|c|c|c|c|c|}
\hline Municípios & Arrecadação & População & $\begin{array}{c}\text { Média } \\
\text { arrecadação/habitantes }\end{array}$ & IDH \\
\hline Massaranduba & 1.187.087,08 & 12910 & 91,95 & 0,608 \\
\hline Mataraca & $1.094 .950,49$ & 7404 & 147,89 & 0,567 \\
\hline Matinhas & $274.523,83$ & 4316 & 63,61 & 0,536 \\
\hline Mato Grosso & $136.172,47$ & 2702 & 50,4 & 0,541 \\
\hline Maturéia & $526.355,46$ & 5939 & 88,63 & 0,565 \\
\hline Mogeiro & $344.354,69$ & 12490 & 27,57 & 0,572 \\
\hline Montadas & $590.555,66$ & 4990 & 118,35 & 0,574 \\
\hline Monte Horebe & $359.814,25$ & 4508 & 79,82 & 0,59 \\
\hline Monteiro & $1.803 .934,88$ & 30844 & 58,49 & 0,587 \\
\hline Mulungu & $268.269,35$ & 9469 & 28,33 & 0,628 \\
\hline Natuba & $770.483,35$ & 10566 & 72,92 & 0,565 \\
\hline Nazarezinho & $261.099,58$ & 7280 & 35,87 & 0,541 \\
\hline Nova Floresta & $775.198,78$ & 10533 & 73,6 & 0,562 \\
\hline Nova Olinda & $230.481,75$ & 6070 & 37,97 & 0,601 \\
\hline Nova Palmeira & $732.405,31$ & 4365 & 167,79 & 0,573 \\
\hline Olho d'Água & $438.516,21$ & 6931 & 63,27 & 0,595 \\
\hline Olivedos & $119.656,00$ & 3627 & 32,99 & 0,572 \\
\hline Ouro Velho & $122.357,95$ & 2928 & 41,79 & 0,603 \\
\hline Parari & $218.997,19$ & 1256 & 174,36 & 0,614 \\
\hline Passagem & $119.203,70$ & 2233 & 53,38 & 0,584 \\
\hline Patos & $8.205 .863,59$ & 100695 & 81,49 & 0,62 \\
\hline Paulista & $1.686 .750,14$ & 11783 & 143,15 & 0,701 \\
\hline Pedra Branca & $342.076,53$ & 3721 & 91,93 & 0,587 \\
\hline Pedra Lavrada & $884.556,71$ & 7475 & 118,34 & 0,599 \\
\hline Pedras de Fogo & $2.276 .104,62$ & 27034 & 84,19 & 0,574 \\
\hline Pedro Régis & $266.158,71$ & 5779 & 46,06 & 0,59 \\
\hline Piancó & $972.381,95$ & 15465 & 62,88 & 0,621 \\
\hline Picuí & $1.312 .479,77$ & 18226 & 72,01 & 0,608 \\
\hline Pilar & $157.790,77$ & 11191 & 14,1 & 0,579 \\
\hline Pilões & $631.604,84$ & 6978 & 90,51 & 0,56 \\
\hline Pilõezinhos & $478.998,18$ & 5155 & 92,92 & 0,564 \\
\hline Pirpirituba & $640.093,57$ & 10319 & 62,03 & 0,595 \\
\hline Pitimbu & $2.498 .629,88$ & 17032 & 146,7 & 0,57 \\
\hline Pocinhos & $636.739,57$ & 17020 & 37,41 & 0,591 \\
\hline Poço Dantas & $639.614,72$ & 3752 & 170,47 & 0,525 \\
\hline Poço de José de Moura & $488.072,82$ & 3978 & 122,69 & 0,612 \\
\hline Pombal & $1.399 .098,17$ & 32117 & 43,56 & 0,634 \\
\hline Prata & $1.208 .025,59$ & 3854 & 313,45 & 0,608 \\
\hline Princesa Isabel & $1.022 .269,08$ & 21283 & 48,03 & 0,606 \\
\hline Puxinanã & $163.247,33$ & 12929 & 12,63 & 0,617 \\
\hline Queimadas & $2.546 .594,37$ & 41054 & 62,03 & 0,608 \\
\hline Quixaba & $307.416,02$ & 1699 & 180,94 & 0,622 \\
\hline Remígio & $646.839,48$ & 17582 & 36,79 & 0,607 \\
\hline Riachão & $258.102,08$ & 3274 & 78,83 & 0,542 \\
\hline Riachão do Bacamarte & $214.507,88$ & 4264 & 50,31 & 0,574 \\
\hline Riachão do Poço & $160.992,26$ & 4164 & 38,66 & 0,553 \\
\hline Riacho de S. Antônio & $78.031,32$ & 1722 & 45,31 & 0,555 \\
\hline Riacho dos Cavalos & $849.410,06$ & 8314 & 102,17 & 0,594 \\
\hline Rio Tinto & $896.772,40$ & 22979 & 39,03 & 0,568 \\
\hline Salgadinho & $264.043,61$ & 3508 & 75,27 & 0,585 \\
\hline Salgado de São Félix & $974.471,82$ & 11976 & 81,37 & 0,563 \\
\hline Santa Cecília & $467.832,36$ & 6661 & 70,23 & 0,568 \\
\hline Santa Cruz & $1.035 .340,05$ & 6471 & 160 & 0,525 \\
\hline Santa Helena & $988.489,77$ & 5369 & 184,11 & 0,618 \\
\hline Santa Inês & $156.544,33$ & 3539 & 44,23 & 0,609 \\
\hline
\end{tabular}


Tabela 3: Municípios paraibanos com sua respectiva arrecadação, população, media de arrecadação por habitantes e IDH.(Continuação)

\begin{tabular}{|c|c|c|c|c|}
\hline Municípios & Arrecadação & População & $\begin{array}{c}\text { Média } \\
\text { arrecadação/habitantes }\end{array}$ & IDH \\
\hline Santa Luzia & $789.115,56$ & 14729 & 53,58 & 0,572 \\
\hline Santa Rita & $8.312 .796,87$ & 120333 & 69,08 & 0,682 \\
\hline Santa Teresinha & $187.817,48$ & 4581 & 41 & 0,535 \\
\hline Santana de Mangueira & $500.068,51$ & 5332 & 93,79 & 0,594 \\
\hline Santana dos Garrotes & $519.591,60$ & 7266 & 71,51 & 0,622 \\
\hline Santo André & $224.744,07$ & 2638 & 85,19 & 0,627 \\
\hline São Bentinho & $202.644,98$ & 4138 & 48,97 & 0,627 \\
\hline São Bento & $23.406 .588,81$ & 30880 & 757,99 & 0,6 \\
\hline São Domingos & $264.044,79$ & 2851 & 92,61 & 0,58 \\
\hline São D. do Cariri & $167.053,58$ & 2420 & 69,03 & 0,606 \\
\hline São Francisco & $276.738,81$ & 3364 & 82,26 & 0,589 \\
\hline São João do Cariri & $150.460,74$ & 4344 & 34,64 & 0,548 \\
\hline São João do Tigre & $1.011 .363,48$ & 4396 & 230,06 & 0,622 \\
\hline São J. da Lagoa Tapada & $1.115 .857,31$ & 7564 & 147,52 & 0,552 \\
\hline São José de Caiana & $547.544,12$ & 6010 & 91,11 & 0,53 \\
\hline São José de Espinharas & $234.144,17$ & 4760 & 49,19 & 0,565 \\
\hline São José de Piranhas & $1.472 .945,49$ & 19099 & 77,12 & 0,577 \\
\hline São José de Princesa & $244.357,09$ & 4219 & 57,92 & 0,541 \\
\hline São José do Bonfim & $614.656,08$ & 3233 & 190,12 & 0,591 \\
\hline São J. do Brejo do Cruz & $289.322,21$ & 1684 & 171,81 & 0,565 \\
\hline São José do Sabugi & $126.555,82$ & 4010 & 31,56 & 0,578 \\
\hline São José dos Cordeiros & $231.128,71$ & 3985 & 58 & 0,581 \\
\hline São José dos Ramos & $1.174 .360,26$ & 5508 & 213,21 & 0,617 \\
\hline São Mamede & $858.412,73$ & 7748 & 110,79 & 0,556 \\
\hline São Miguel de Taipu & $442.693,60$ & 6696 & 66,11 & 0,641 \\
\hline São S. de L. de Roça & $963.392,67$ & 1141 & 844,34 & 0,548 \\
\hline São S. do Umbuzeiro & $215.893,88$ & 3239 & 66,65 & 0,594 \\
\hline São Vicente do Seridó & $266.815,09$ & 50151 & 5,32 & 0,581 \\
\hline Sapé & $1.570 .683,99$ & 10230 & 153,54 & 0,569 \\
\hline Serra Branca & $1.826 .520,85$ & 12971 & 140,82 & 0,555 \\
\hline Serra da Raiz & $144.282,49$ & 3204 & 45,03 & 0,628 \\
\hline Serra Grande & $356.708,64$ & 2975 & 119,9 & 0,626 \\
\hline Serra Redonda & $136.536,06$ & 7054 & 19,36 & 0,586 \\
\hline Serraria & $223.117,99$ & 6238 & 35,77 & 0,57 \\
\hline Sertãozinho & $757.336,78$ & 4395 & 172,32 & 0,547 \\
\hline Sobrado & $660.156,90$ & 7363 & 89,66 & 0,621 \\
\hline Solânea & $899.929,82$ & 26689 & 33,72 & 0,573 \\
\hline Soledade & $948.068,52$ & 13739 & 69,01 & 0,595 \\
\hline Sossêgo & $187.903,32$ & 3173 & 59,22 & 0,616 \\
\hline Sousa & $3.393 .562,86$ & 65807 & 51,57 & 0,573 \\
\hline Sumé & $1.834 .250,66$ & 16072 & 114,13 & 0,668 \\
\hline Taperoá & $842.286,44$ & 14938 & 56,39 & 0,551 \\
\hline Tavares & $265.361,53$ & 14103 & 18,82 & 0,578 \\
\hline Teixeira & $1.178 .820,50$ & 14153 & 83,29 & 0,586 \\
\hline Tenório & $196.212,42$ & 2816 & 69,68 & 0,605 \\
\hline Triunfo & $194.502,82$ & 9223 & 21,09 & 0,581 \\
\hline Uiraúna & $436.988,56$ & 14584 & 29,96 & 0,609 \\
\hline Umbuzeiro & $233.630,45$ & 9300 & 25,12 & 0,636 \\
\hline Várzea & $292.342,22$ & 2504 & 116,75 & 0,584 \\
\hline Vieirópolis & $325.760,68$ & 5045 & 64,57 & 0,707 \\
\hline Zabelê & $281.640,16$ & 2075 & 135,73 & 0,623 \\
\hline Média & $2.471 .523,15$ & $16.911,35$ & 89,8 & 0,59 \\
\hline Desvio padrão & 3394797,07 & 15997,52 & 47,98 & 0,03 \\
\hline
\end{tabular}

- IDH do ano de 2010 por município paraibano - Atlas do Desenvolvimento Humano no Brasil

- População - IBGE, Censo demográfico 20

- Arrecadação tributária do ano de 2010- Secretaria do Tesouro Nacional (SNT, 2020) 


\subsection{CRUZAMENTO DE DADOS}

Após a coleta dos dados, obtemos o cruzamento dos dados obtidos da arrecadação tributária per capita relacionados com o índice de Desenvolvimento Humano. Com esse cruzamento, apresentamos uma leitura, por meio da Figura 6, mostrando o grau de eficiência e eficácia da arrecadação tributária, mediante a comparação do volume dessa arrecadação com o nível mensurado de desenvolvimento da população, ou seja, com o IDH. Essa leitura pode viabilizar a determinação de clusters, objetivando a divisão em segmentos das análises. Na figura 6, é apresentada a visualização desejada para a apresentação do resultado do cruzamento de dados.

Figura 6: Relação entre o IDH e a arrecadação tributária per capita

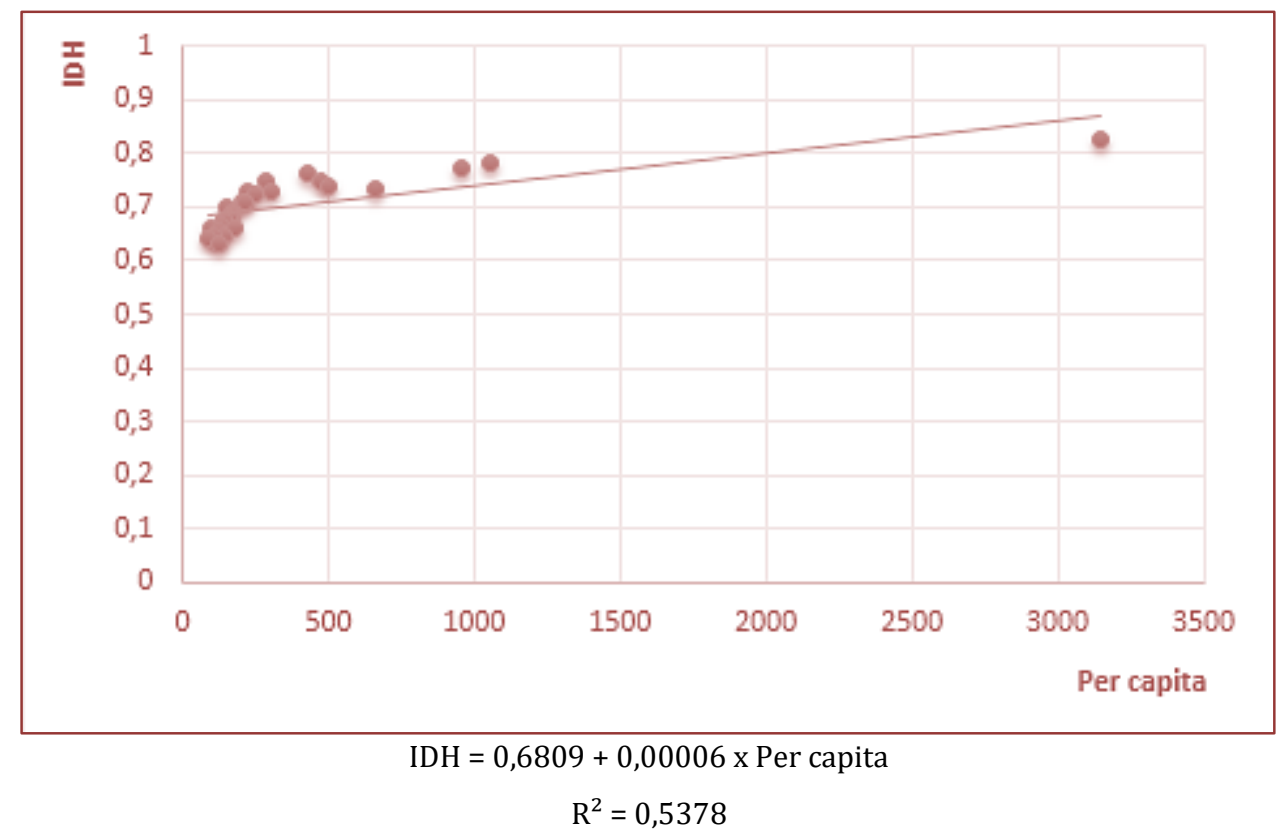

Essa equação nos diz que, para cada 1 ponto percentual de aumento da carga tributária, deveríamos ter um aumento de 0,00006 no IDH. Vejamos o caso do Brasil: a carga tributária é de 31,87\%. Pela equação, o IDH brasileiro deveria ser de 0,683.

O real médio é de 0,699. Ou seja, o IDH do Brasil está ajustado à sua carga tributária, considerando a média mundial.

Em um ranking de "IDH ajustado à carga tributária”, estaríamos em 73ํ lugar dentre 165 países.

\subsection{IDENTIFICACÃO DOS CLUSTERS OU AGRUPAMENTOS A SEREM ANALISADOS}

Inicialmente, os clusters são agrupados por suas semelhanças entre determinados elementos, por esse fator o agrupamento mais obvio seria de acordo com sua disposição regional, relacionando os elementos não apenas por suas semelhanças geográficas, mas como também por suas aproximações relacionadas ao desenvolvimento histórico de cada microrregião e sua disposição política. Porém, para haja uma melhor disposição entre os elementos foi optado por um agrupamento em relação a arrecadação tributária através de uma média aritmética que relaciona o Índice de Desenvolvimento Humano e a arrecadação tributária per capita. A partir dessa segregação adotada para os clusters, que consideramos determinante, foi possível uma melhor visualização de quais grupos possuem o melhor e o pior desempenho na aplicação e execução de políticas públicas de desenvolvimento.

Após a determinação do uso da média aritmética pré-definida, temos definidos 8 (oito) clusters categorizando os componentes em grupos distintos. 
- $\quad$ Cluster 1: Observa-se na Tabela 3 o cluster 1 composto pelos municípios de Aroeiras, Manaíra, Fagundes, Puxinanã, Pilar, Tavares e Serra Redonda.

Tabela 3: Cluster 1

\begin{tabular}{|c|c|c|c|c|}
\hline Cidades & Arrecadação & População & Média Arrec/Háb & $\begin{array}{c}\text { IDH } \\
(2010)\end{array}$ \\
\hline Aroeiras & $147.543,83$ & 19153 & 7,73 & 0,548 \\
\hline Manaíra & $110.739,51$ & 10955 & 10,29 & 0,543 \\
\hline Fagundes & $134.112,70$ & 11253 & 11,75 & 0,6 \\
\hline Puxinanã & $163.247,33$ & 13680 & 12,63 & 0,617 \\
\hline Pilar & $157.790,77$ & 11917 & 14,1 & 0,579 \\
\hline Tavares & $265.361,53$ & 14726 & 18,82 & 0,586 \\
\hline Serra Redonda & $136.536,06$ & 7041 & 19,36 & 0,57 \\
\hline Média & 159333,1 & 12675 & 13,19 & 0,57 \\
\hline Desvio Padrão & 31412,19 & 2724 & 3,17 & 0,02 \\
\hline
\end{tabular}

- $\quad$ Cluster 2: temos os municípios de Triunfo, Condado, Cubati, Baía da Traição, Umbuzeiro, Jericó, São Vicente do Seridó, Mogeiro, Araruna, Mulungu, Uiraúna, Sapé, Olivedos, São José do Sabugi, Conceição, Remígio, Areia, Solânea, Pocinhos, Itaporanga, Riachão do Poço, Nazarezinho, São João do Cariri, Serraria, Rio Tinto, Juazeirinho, Camalaú, Aguiar, Nova Olinda, Boa Ventura, Diamante, Riacho de Santo Antônio, Ouro Velho, Catolé do Rocha, Itabaiana, Marcação, Santa Teresinha, Gado Bravo, Pombal, Santa Inês, Pedro Régis, Princesa Isabel, São Bentinho, Coremas, Serra da Raiz, Cruz do Espírito Santo, Mato Grosso, Caiçara, Riachão do Bacamarte, Lagoa, Curral Velho, Sousa, Mari e Passagem.

Tabela 4: Cluster 2

\begin{tabular}{|l|c|c|c|c|}
\multicolumn{4}{c}{ Cidades } & \multicolumn{3}{c}{ Arrecadação } & População & Média & Arrec/Hab & IDH (2010) \\
\hline Baraúna & $95.325,96$ & 4892 & 19,49 & 0,558 \\
\hline Triunfo & $194.502,82$ & 9455 & 20,57 & 0,609 \\
\hline Condado & $139.478,51$ & 6654 & 20,96 & 0,594 \\
\hline Cubati & $167.046,02$ & 7797 & 21,42 & 0,566 \\
\hline Baía da Traição & $205.608,40$ & 8993 & 22,86 & 0,581 \\
\hline Umbuzeiro & $233.630,45$ & 9907 & 23,58 & 0,584 \\
\hline Jericó & $189.731,44$ & 7739 & 24,52 & 0,603 \\
\hline São Vicente do Seridó & $266.815,09$ & 10775 & 24,76 & 0,555 \\
\hline Mogeiro & $344.354,69$ & 13284 & 25,92 & 0,574 \\
\hline Araruna & $535.989,64$ & 20312 & 26,39 & 0,567 \\
\hline Mulungu & $268.269,35$ & 9902 & 27,09 & 0,565 \\
\hline Uiraúna & $436.988,56$ & 15242 & 28,67 & 0,636 \\
\hline Sapé & $1.570 .683,99$ & 52625 & 29,85 & 0,569 \\
\hline Olivedos & $119.656,00$ & 3932 & 30,43 & 0,603 \\
\hline São José do Sabugi & $126.555,82$ & 4141 & 30,56 & 0,617 \\
\hline Conceição & $587.146,77$ & 18982 & 30,93 & 0,592 \\
\hline Remígio & $646.839,48$ & 19621 & 32,97 & 0,607 \\
\hline Areia & $760.497,66$ & 22819 & 33,33 & 0,594 \\
\hline Solânea & $899.929,82$ & 26407 & 34,08 & 0,595 \\
\hline Pocinhos & $636.739,57$ & 18564 & 34,3 & 0,591 \\
\hline Itaporanga & $850.031,99$ & 24692 & 34,43 & 0,615 \\
\hline Riachão do Poço & $160.992,26$ & 4509 & 35,7 & 0,555 \\
\hline Nazarezinho & $261.099,58$ & 7301 & 35,76 & 0,562 \\
\hline São João do Cariri & $150.460,74$ & 4199 & 35,83 & 0,622 \\
\hline Serraria & $223.117,99$ & 6099 & 36,58 & 0,547 \\
\hline Rio Tinto & $896.772,40$ & 24176 & 37,09 & 0,585 \\
\hline Juazeirinho & $676.976,09$ & 18171 & 37,26 & 0,567 \\
\hline Camalaú & $224.862,75$ & 6013 & 37,4 & 0,567 \\
\hline & & & & \\
\hline
\end{tabular}


Tópicos em Administração - Volume 39

Tabela 4: Cluster 2(Continuação)

\begin{tabular}{|c|c|c|c|c|}
\hline Cidades & Arrecadação & População & $\begin{array}{c}\text { Média } \\
\text { Arrec/Hab }\end{array}$ & IDH (2010) \\
\hline Aguiar & $218.130,21$ & 5640 & 38,68 & 0,597 \\
\hline Nova Olinda & $230.481,75$ & 5949 & 38,74 & 0,573 \\
\hline Boa Ventura & $209.938,09$ & 5366 & 39,12 & 0,599 \\
\hline Diamante & $664.703,47$ & 6552 & 39,89 & 0,593 \\
\hline Riacho de S. Antônio & $78.031,32$ & 1948 & 40,06 & 0,594 \\
\hline Ouro Velho & $122.357,95$ & 3039 & 40,26 & 0,614 \\
\hline Catolé do Rocha & $1.234 .267,31$ & 30546 & 40,41 & 0,64 \\
\hline Itabaiana & $996.298,61$ & 24477 & 40,7 & 0,613 \\
\hline Marcação & $350.923,60$ & 8558 & 41,01 & 0,529 \\
\hline Santa Teresinha & $187.817,48$ & 4573 & 41,07 & 0,627 \\
\hline Gado Bravo & $351.647,31$ & 8316 & 42,29 & 0,513 \\
\hline Pombal & $1.399 .098,17$ & 32801 & 42,65 & 0,634 \\
\hline Santa Inês & $156.544,33$ & 3595 & 43,55 & 0,572 \\
\hline Pedro Régis & $266.158,71$ & 6089 & 43,71 & 0,542 \\
\hline Princesa Isabel & $1.022 .269,08$ & 23345 & 43,79 & 0,606 \\
\hline São Bentinho & $202.644,98$ & 4529 & 44,74 & 0,606 \\
\hline Coremas & $691.904,02$ & 15445 & 44,8 & 0,592 \\
\hline Serra da Raiz & $144.282,49$ & 3148 & 45,83 & 0,626 \\
\hline Cruz do Espírito Santo & $802.403,31$ & 17319 & 46,33 & 0,552 \\
\hline Mato Grosso & $136.172,47$ & 2908 & 46,83 & 0,565 \\
\hline Caiçara & $337.538,54$ & 7201 & 46,87 & 0,592 \\
\hline Riachão do Bacamarte & $214.507,88$ & 4521 & 47,45 & 0,553 \\
\hline Lagoa & $222.187,06$ & 4666 & 47,62 & 0,563 \\
\hline Curral Velho & $119.789,30$ & 2516 & 47,61 & 0,606 \\
\hline Sousa & $3.393 .562,86$ & 69444 & 48,87 & 0,668 \\
\hline Mari & $1.070 .163,68$ & 21837 & 49,01 & 0,548 \\
\hline Passagem & $119.203,70$ & 2419 & 49,28 & 0,62 \\
\hline Média & 487511,48 & 12980,91 & 36,62 & 0,59 \\
\hline Desvio Padrão & 366311,26 & 9108,76 & 7,07 & 0,02 \\
\hline
\end{tabular}

Fonte: autores

- Cluster 3: composto pelos municípios de São José de Espinharas, Itapororoca, Damião, Borborema, Gurjão, Amparo, Santa Luzia, Capim, Bom Sucesso, Sossêgo, Alagoa Grande, Lagoa Seca, Cajazeirinhas, Igaracy, Monteiro, Taperoá, Livramento, Curral de Cima, Juripiranga, Barra de Santana, Queimadas, Assunção, Mamanguape, São Miguel de Taipu, Brejo dos Santos, Pirpirituba, Piancó, Congo, Vieirópolis, Santa Rita, Matinhas, São José de Princesa, Caturité, São Sebastião do Umbuzeiro, Cuité de Mamanguape, Soledade, Logradouro, Juarez Távora, São José dos Cordeiros, São Domingos do Cariri, Tenório, Arara, Malta, Marizópolis, Cacimba de Dentro, Boqueirão, Olho d'Água, Salgadinho, Cuitegi, Aparecida, Alcantil e Esperança.

Tabela 5: cluster 3

\begin{tabular}{|l|c|c|c|c|}
\multicolumn{1}{c|}{ Cidades } & Arrecadação & População & Média Arrec/Hab & IDH (2010) \\
\hline São José de Espinharas & $234.144,17$ & 4682 & 50,01 & 0,577 \\
\hline Itapororoca & $939.824,32$ & 18664 & 50,35 & 0,564 \\
\hline Damião & $270.014,78$ & 5330 & 50,66 & 0,521 \\
\hline Borborema & $267.582,09$ & 5263 & 50,84 & 0,558 \\
\hline Gurjão & $174.087,89$ & 3428 & 50,78 & 0,625 \\
\hline Amparo & $114.859,32$ & 2238 & 51,32 & 0,606 \\
\hline Santa Luzia & $789.115,56$ & 15382 & 51,3 & 0,682 \\
\hline Capim & $338.224,80$ & 6523 & 51,85 & 0,533 \\
\hline Bom Sucesso & $260.052,07$ & 4975 & 52,27 & 0,592 \\
\hline Sossêgo & $187.903,32$ & 3555 & 52,86 & 0,573 \\
\hline Alagoa Grande & $1.510 .205,46$ & 28496 & 53 & 0,582 \\
\hline Lagoa Seca & $1.457 .836,71$ & 27503 & 53,01 & 0,627 \\
\hline Cajazeirinhas & $170.416,72$ & 3193 & 53,37 & 0,55 \\
\hline Igaracy & $328.860,05$ & 6117 & 53,76 & 0,61 \\
\hline Monteiro & $1.803 .934,88$ & 33222 & 54,3 & 0,628 \\
\hline Taperoá & $842.286,44$ & 15376 & 54,78 & 0,578 \\
\hline Livramento & $400.553,15$ & 7256 & 55,2 & 0,566 \\
\hline
\end{tabular}


Tópicos em Administração - Volume 39

Tabela 5: cluster 3(Continuação)

\begin{tabular}{|c|c|c|c|c|}
\hline Cidades & Arrecadação & População & Média Arrec/Hab & IDH (2010) \\
\hline Curral de Cima & $299.733,79$ & 5227 & 57,34 & 0,529 \\
\hline Juripiranga & $621.693,59$ & 10756 & 57,8 & 0,548 \\
\hline Barra de Santana & $483.572,40$ & 8359 & 57,85 & 0,567 \\
\hline Queimadas & $2.546 .594,37$ & 43967 & 57,92 & 0,608 \\
\hline Assunção & $234.050,41$ & 3990 & 58,66 & 0,609 \\
\hline Mamanguape & $2.667 .399,86$ & 44882 & 59,43 & 0,585 \\
\hline São Miguel de Taipu & $442.693,60$ & 7368 & 60,08 & 0,548 \\
\hline Brejo dos Santos & $389.788,56$ & 6449 & 60,44 & 0,619 \\
\hline Pirpirituba & $640.093,57$ & 10579 & 60,51 & 0,595 \\
\hline Piancó & $972.381,95$ & 16075 & 60,49 & 0,621 \\
\hline Congo & $290.656,95$ & 4786 & 60,73 & 0,581 \\
\hline Vieirópolis & $325.760,68$ & 5348 & 60,91 & 0,571 \\
\hline Santa Rita & $8.312 .796,87$ & 136586 & 60,86 & 0,627 \\
\hline Matinhas & $274.523,83$ & 4500 & 61,01 & 0,541 \\
\hline São José de Princesa & $244.357,09$ & 4003 & 61,04 & 0,565 \\
\hline Caturité & $298.636,03$ & 4852 & 61,55 & 0,623 \\
\hline São S. do Umbuzeiro & $215.893,88$ & 3489 & 61,88 & 0,581 \\
\hline Cuité de Mamanguape & $396.972,25$ & 6353 & 62,49 & 0,524 \\
\hline Soledade & $948.068,52$ & 14989 & 63,25 & 0,616 \\
\hline Logradouro & $274.998,61$ & 4332 & 63,48 & 0,583 \\
\hline Juarez Távora & $504.336,42$ & 7936 & 63,55 & 0,579 \\
\hline São J. dos Cordeiros & $231.128,71$ & 3628 & 63,71 & 0,556 \\
\hline São D. do Cariri & $167.053,58$ & 2615 & 63,88 & 0,589 \\
\hline Tenório & $196.212,42$ & 3058 & 64,16 & 0,581 \\
\hline Arara & $870.236,55$ & 13470 & 64,61 & 0,548 \\
\hline Malta & $373.145,47$ & 5759 & 64,79 & 0,642 \\
\hline Marizópolis & $439.803,46$ & 6617 & 66,47 & 0,608 \\
\hline Cacimba de Dentro & $1.144 .120,25$ & 17187 & 66,57 & 0,564 \\
\hline Boqueirão & $1.190 .815,17$ & 17804 & 66,88 & 0,607 \\
\hline Olho d'Água & $438.516,21$ & 6526 & 67,2 & 0,572 \\
\hline Salgadinho & $264.043,61$ & 3885 & 67,96 & 0,563 \\
\hline Cuitegi & $463.355,20$ & 6803 & 68,11 & 0,57 \\
\hline Aparecida & $568.727,91$ & 8347 & 68,14 & 0,578 \\
\hline Alcantil & $380.128,97$ & 5492 & 69,22 & 0,578 \\
\hline Esperança & $2.286 .086,78$ & 33007 & 69,26 & 0,623 \\
\hline Média & 778620,75 & 13081,29 & 59,46 & 0,58 \\
\hline Desvio Padrão & 638553,55 & 10784,26 & 4,96 & 0,03 \\
\hline
\end{tabular}

- $\quad$ Cluster 4: nesse grupo temos os municípios de Cacimba de Areia, Picuí, Barra de São Miguel, Araçagi, Santa Cecília, Alagoinha, Areial, Riachão, Cuité, São José de Piranhas, Guarabira, Nova Floresta, Natuba, Santana dos Garrotes, Monte Horebe, Itatuba, Ingá, Gurinhém, Patos, Mãe d'Água, Teixeira, Bayeux, Cachoeira dos Índios, Pedras de Fogo, Maturéia, Salgado de São Félix, Junco do Seridó, São Francisco, São Sebastião de Lagoa de Roça, Areia de Baraúnas, Casserengue, Sobrado, Massaranduba, São Domingos, São José de Caiana, Duas Estradas, Cajazeiras, Imaculada, Santo André e Belém do Brejo do Cruz. 
Tabela 6: Cluster 4

\begin{tabular}{|c|c|c|c|c|}
\hline Cidades & Arrecadação & População & Média Arrec/Hab & IDH (2010) \\
\hline Cacimba de Areia & $258.060,27$ & 3682 & 70,09 & 0,596 \\
\hline Picuí & $1.312 .479,77$ & 18703 & 70,17 & 0,608 \\
\hline Barra de S. Miguel & $424.458,04$ & 6036 & 70,32 & 0,572 \\
\hline Araçagi & $1.197 .323,20$ & 16987 & 70,48 & 0,549 \\
\hline Santa Cecília & $467.832,36$ & 6558 & 71,34 & 0,525 \\
\hline Alagoinha & $1.037 .224,86$ & 14489 & 71,59 & 0,595 \\
\hline Areial & $501.988,64$ & 6998 & 71,73 & 0,608 \\
\hline Riachão & $258.102,08$ & 3588 & 71,93 & 0,574 \\
\hline Cuité & $1.466 .846,20$ & 20338 & 72,12 & 0,591 \\
\hline São J. de Piranhas & $1.472 .945,49$ & 20251 & 72,73 & 0,591 \\
\hline Guarabira & $4.278 .275,74$ & 58833 & 72,72 & 0,673 \\
\hline Nova Floresta & $775.198,78$ & 10638 & 72,87 & 0,601 \\
\hline Natuba & $770.483,35$ & 10454 & 73,7 & 0,541 \\
\hline S. dos Garrotes & $519.591,60$ & 7031 & 73,9 & 0,594 \\
\hline Monte Horebe & $359.814,25$ & 4816 & 74,71 & 0,587 \\
\hline Itatuba & $828.284,28$ & 10962 & 75,56 & 0,562 \\
\hline Ingá & $1.369 .111,09$ & 18103 & 75,63 & 0,592 \\
\hline Gurinhém & $1.078 .596,11$ & 14129 & 76,34 & 0,556 \\
\hline Patos & $8.205 .863,59$ & 107605 & 76,26 & 0,701 \\
\hline Mãe d'Água & $310.266,36$ & 4009 & 77,39 & 0,542 \\
\hline Teixeira & $1.178 .820,50$ & 15161 & 77,75 & 0,605 \\
\hline Bayeux & $7.563 .338,60$ & 96880 & 78,07 & 0,649 \\
\hline Cac. dos Índios & $807.414,13$ & 10244 & 78,82 & 0,587 \\
\hline Pedras de Fogo & $2.276 .104,62$ & 28458 & 79,98 & 0,59 \\
\hline Maturéia & $526.355,46$ & 6569 & 80,13 & 0,572 \\
\hline Salgado de S. Félix & $974.471,82$ & 12140 & 80,27 & 0,568 \\
\hline Junco do Seridó & $576.443,60$ & 7150 & 80,62 & 0,617 \\
\hline São Francisco & $276.738,81$ & 3392 & 81,59 & 0,58 \\
\hline S. S. de L. de Roça & $963.392,67$ & 11661 & 82,62 & 0,594 \\
\hline Areia de Baraúnas & $175.960,02$ & 2128 & 82,69 & 0,562 \\
\hline Casserengue & $631.589,62$ & 7468 & 84,57 & 0,514 \\
\hline Sobrado & $660.156,90$ & 7783 & 84,82 & 0,573 \\
\hline Massaranduba & $1.187 .087,08$ & 13918 & 85,29 & 0,567 \\
\hline São Domingos & $264.044,79$ & 3073 & 85,92 & 0,548 \\
\hline São José de Caiana & $547.544,12$ & 6359 & 86,11 & 0,565 \\
\hline Duas Estradas & $316.240,27$ & 3596 & 87,94 & 0,603 \\
\hline Cajazeiras & $5.459 .506,29$ & 61993 & 88,07 & 0,679 \\
\hline Imaculada & $1.045 .683,83$ & 11819 & 88,47 & 0,557 \\
\hline Santo André & $224.744,07$ & 2521 & 89,15 & 0,6 \\
\hline B. do B. do Cruz & $654.918,88$ & 7342 & 89,2 & 0,578 \\
\hline Média & 1330082,55 & 17096,63 & 78,34 & 0,59 \\
\hline D. Padrão & 1072566,56 & 13864,72 & 5,3 & 0,03 \\
\hline
\end{tabular}

- $\quad$ Cluster 5: compostos pelos municipios de Lagoa de Dentro, Brejo do Cruz, Pedra Branca, Barra de Santa Rosa, Juru, Bananeiras, Bonito de Santa Fé, Alagoa Nova, Pilões, Pilõezinhos, Santana de Mangueira, Riacho dos Cavalos, Caldas Brandão, Carrapateira, Várzea, Montadas, Belém, Sumé, Cabaceiras, São Mamede, Emas, Algodão de Jandaíra, Pedra Lavrada, Poço de José de Moura, Bernardino Batista, Alhandra, Lucena, Lastro, Coxixola, Serra Grande, Jacaraú, Parari, Zabelê, Água Branca, Mataraca, Pitimbu, Serra Branca e Paulista. 
Tabela 7: Cluster 5

\begin{tabular}{|c|c|c|c|c|}
\hline Cidades & Arrecadação & População & Média Arrec/Hab & IDH (2010) \\
\hline Lagoa de Dentro & $691.047,80$ & 7719 & 89,53 & 0,57 \\
\hline Brejo do Cruz & $1.270 .735,13$ & 14122 & 89,98 & 0,597 \\
\hline Pedra Branca & $342.076,53$ & 3801 & 90 & 0,599 \\
\hline Barra de Santa Rosa & $1.387 .748,14$ & 15384 & 90,21 & 0,562 \\
\hline Juru & $892.333,10$ & 9867 & 90,44 & 0,57 \\
\hline Bananeiras & $1.981 .946,21$ & 21318 & 92,97 & 0,568 \\
\hline Bonito de Santa Fé & $1.113 .737,46$ & 11917 & 93,46 & 0,574 \\
\hline Alagoa Nova & $1.971 .338,93$ & 20849 & 94,55 & 0,576 \\
\hline Pilões & $631.604,84$ & 6635 & 95,19 & 0,56 \\
\hline Pilõezinhos & $478.998,18$ & 4976 & 96,26 & 0,564 \\
\hline Santana de Mangueira & $500.068,51$ & 5162 & 96,87 & 0,535 \\
\hline Riacho dos Cavalos & $849.410,06$ & 8526 & 99,63 & 0,568 \\
\hline Caldas Brandão & $601.408,26$ & 6014 & 100 & 0,568 \\
\hline Carrapateira & $271.170,05$ & 2659 & 101,98 & 0,603 \\
\hline Várzea & $292.342,22$ & 2810 & 104,04 & 0,707 \\
\hline Montadas & $590.555,66$ & 5669 & 104,17 & 0,59 \\
\hline Belém & $1.868 .318,02$ & 17676 & 105,7 & 0,592 \\
\hline Sumé & $1.834 .250,66$ & 16966 & 108,11 & 0,627 \\
\hline Cabaceiras & $618.979,96$ & 5611 & 110,32 & 0,611 \\
\hline São Mamede & $858.412,73$ & 7724 & 111,14 & 0,641 \\
\hline Emas & $392.756,32$ & 3522 & 111,52 & 0,595 \\
\hline Algodão de Jandaíra & $286.813,38$ & 2567 & 111,73 & 0,548 \\
\hline Pedra Lavrada & $884.556,71$ & 7843 & 112,78 & 0,574 \\
\hline Poço de José de Moura & $488.072,82$ & 4307 & 113,32 & 0,612 \\
\hline Bernardino Batista & $401.646,58$ & 3501 & 114,72 & 0,558 \\
\hline Alhandra & $2.275 .606,49$ & 19588 & 116,17 & 0,582 \\
\hline Lucena & $1.548 .545,22$ & 13080 & 118,39 & 0,583 \\
\hline Lastro & $332.673,41$ & 2737 & 121,55 & 0,533 \\
\hline Coxixola & $234.845,29$ & 1921 & 122,25 & 0,641 \\
\hline Serra Grande & $356.708,64$ & 2909 & 122,62 & 0,586 \\
\hline Jacaraú & $1.774 .935,32$ & 14431 & 122,99 & 0,558 \\
\hline Parari & $218.997,19$ & 1771 & 123,66 & 0,584 \\
\hline Zabelê & $281.640,16$ & 2240 & 125,73 & 0,623 \\
\hline Água Branca & $1.305 .124,12$ & 10234 & 127,53 & 0,572 \\
\hline Mataraca & $1.094 .950,49$ & 8434 & 129,83 & 0,536 \\
\hline Pitimbu & $2.498 .629,88$ & 19065 & 131,06 & 0,57 \\
\hline Serra Branca & $1.826 .520,85$ & 13699 & 133,33 & 0,628 \\
\hline Paulista & $1.686 .750,14$ & 12347 & 136,61 & 0,587 \\
\hline Média & 972006,72 & 8936,87 & 109,48 & 0,59 \\
\hline Desvio Padrão & 571528,22 & 5078,42 & 11,98 & 0,02 \\
\hline
\end{tabular}

Fonte: autores

- Cluster 6: composto pelos municípios de Frei Martinho, Desterro, São José da Lagoa Tapada, Campina Grande, Nova Palmeira, Boa Vista, Sertãozinho, Dona Inês, Caraúbas, Conde, Quixaba, Santa Cruz, Caaporã, São José do Brejo do Cruz, Poço Dantas, Santa Helena, Catingueira, São José do Bonfim, Cacimbas e São José dos Ramos. 
Tabela 8: Cluster 6

\begin{tabular}{|l|c|c|c|c|}
\hline \multicolumn{1}{|c|}{ Cidades } & Arrecadação & População & Média Arrec/Hab & IDH (2010) \\
\hline Frei Martinho & $425.887,96$ & 2989 & 142,49 & 0,641 \\
\hline Desterro & $1.183 .534,82$ & 8297 & 142,65 & 0,58 \\
\hline S. J. da Lagoa Tapada & $1.115 .857,31$ & 7630 & 146,25 & 0,53 \\
\hline Campina Grande & $60.501 .405,01$ & 409731 & 147,66 & 0,72 \\
\hline Nova Palmeira & $732.405,31$ & 4906 & 149,29 & 0,595 \\
\hline Boa Vista & $1.052 .767,18$ & 7051 & 149,31 & 0,649 \\
\hline Sertãozinho & $757.336,78$ & 5024 & 150,74 & 0,621 \\
\hline Dona Inês & $1.598 .496,02$ & 10453 & 152,92 & 0,545 \\
\hline Caraúbas & $642.950,95$ & 4162 & 154,48 & 0,585 \\
\hline Conde & $3.875 .121,48$ & 24670 & 157,08 & 0,618 \\
\hline Quixaba & $307.416,02$ & 1956 & 157,17 & 0,622 \\
\hline Santa Cruz & $1.035 .340,05$ & 6583 & 157,27 & 0,618 \\
\hline Caaporã & $3.445 .644,26$ & 21828 & 157,85 & 0,602 \\
\hline S. J. do Brejo do Cruz & $289.322,21$ & 1801 & 160,65 & 0,581 \\
\hline Poço Dantas & $639.614,72$ & 3888 & 164,51 & 0,525 \\
\hline Santa Helena & $988.489,77$ & 5889 & 167,85 & 0,609 \\
\hline Catingueira & $847.641,65$ & 4932 & 171,87 & 0,574 \\
\hline São José do Bonfim & $614.656,08$ & 3557 & 172,8 & 0,578 \\
\hline Cacimbas & $1.390 .215,97$ & 7173 & 193,81 & 0,523 \\
\hline São José dos Ramos & $1.174 .360,26$ & 5957 & 197,14 & 0,541 \\
\hline Média & 4130923,19 & 27423,85 & 159,69 & 0,59 \\
\hline D. Padrão & 5637048,18 & 38230,72 & 11,08 & 0,04 \\
\hline
\end{tabular}

- Cluster 7: composto pelos municípios de Ibiara, São João do Tigre, Bom Jesus, Cabedelo, Prata e João Pessoa.

Tabela 9: Cluster 7

\begin{tabular}{|l|c|c|c|c|}
\multicolumn{1}{c|}{ Cidades } & Arrecadação & População & Média Arrec/Hab & IDH (2010) \\
\hline Ibiara & $1.187 .149,85$ & 5929 & 200,23 & 0,586 \\
\hline São João do Tigre & $1.011 .363,48$ & 4422 & 228,71 & 0,552 \\
\hline Bom Jesus & $627.279,01$ & 2561 & 244,94 & 0,597 \\
\hline Cabedelo & $19.273 .447,19$ & 67736 & 284,54 & 0,748 \\
\hline Prata & $1.208 .025,59$ & 4209 & 287,01 & 0,608 \\
\hline João Pessoa & $253.374 .951,13$ & 809015 & 313,19 & 0,763 \\
\hline Média & 46113702,71 & 148978,67 & 259,77 & 0,64 \\
\hline D. Padrão & 69087082,81 & 220012,11 & 35,14 & 0,08 \\
\hline
\end{tabular}

- $\quad$ Cluster 8: composto pelo município de São Bento.

Tabela 10: Cluster 8

\begin{tabular}{|l|c|c|c|c|}
\multicolumn{1}{|c|}{ Cidades } & Arrecadação & População & Média Arrec/Hab & IDH (2010) \\
\hline São Bento & $23.406 .588,81$ & 2521 & 757,99 & 0,6 \\
\hline \multicolumn{4}{|c|}{ Fonte: autores }
\end{tabular}

Os clusters foram classificados como observado acima, a partir do cruzamento de dados da arrecadação tributária, considerando a quantidade de habitantes (per capita) com o IDH. 


\section{RESULTADOS}

OBS.: os dados referentes ao IDH (2018) não foram divulgados até a data de conclusão do relatório, não permitindo a análise total, porém ainda assim foi possível obter os agrupamentos através da média dos dados disponíveis.

\section{Número de agrupamentos a serem analisados: 8 clusters}

Através das análises obtidas de acordo com os cruzamentos dos dados, foram destacados os grupos que se encontram em uma situação similar. Os clusters foram identificados pelo método de cálculo da média aritmética da arrecadação tributária per capita do Índice de Desenvolvimento Humano (IDH). Foi utilizado o método da distância de Mahalonobis e a técnica de agrupamento da média das distâncias adotado para a predefinição dos números de clusters permitindo identificar seus elementos, revelando assim, de forma gráfica, os entes que aplicam com maior ou menor eficiência e eficácia sua arrecadação tributária.

Através do cruzamento dos dados de arrecadação e do IDH, foi possível melhor aproximar cada elemento em seu grupo levando em consideração sua real condição e seu desempenho de desenvolvimento por meio da aplicação dos recursos em políticas públicas.

Para melhor compreensão das diferenças entre os diversos municípios do estado da Paraíba, inicialmente tornar-se necessário a apresentação de alguns gráficos:

Figura 7: População por município paraibano

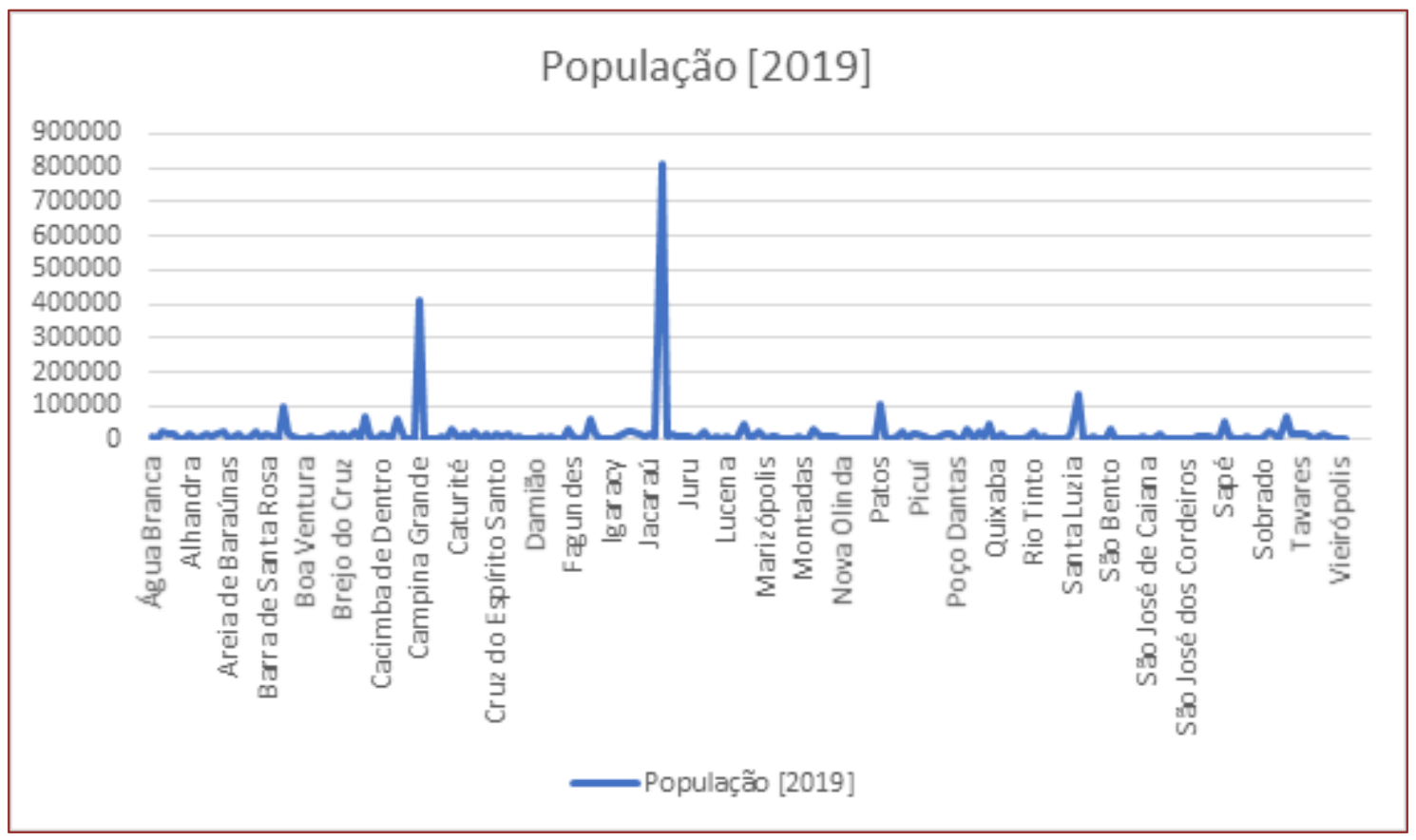

Após uma breve comparação entre os índices populacionais dos municípios paraibanos, podemos observar que a maior concentração populacional se dá no cluster 7, que apesar de não ter o maior número de municípios como seus elementos, tem como elemento de destaque a capital paraibana, João Pessoa, que além de ter o maior índice populacional possui também a maior concentração populacional por $\mathrm{km}^{2}$, que é de aproximadamente $3.421 \mathrm{hab} / \mathrm{km}^{2}$. 
Figura 8: IDH por município paraibano

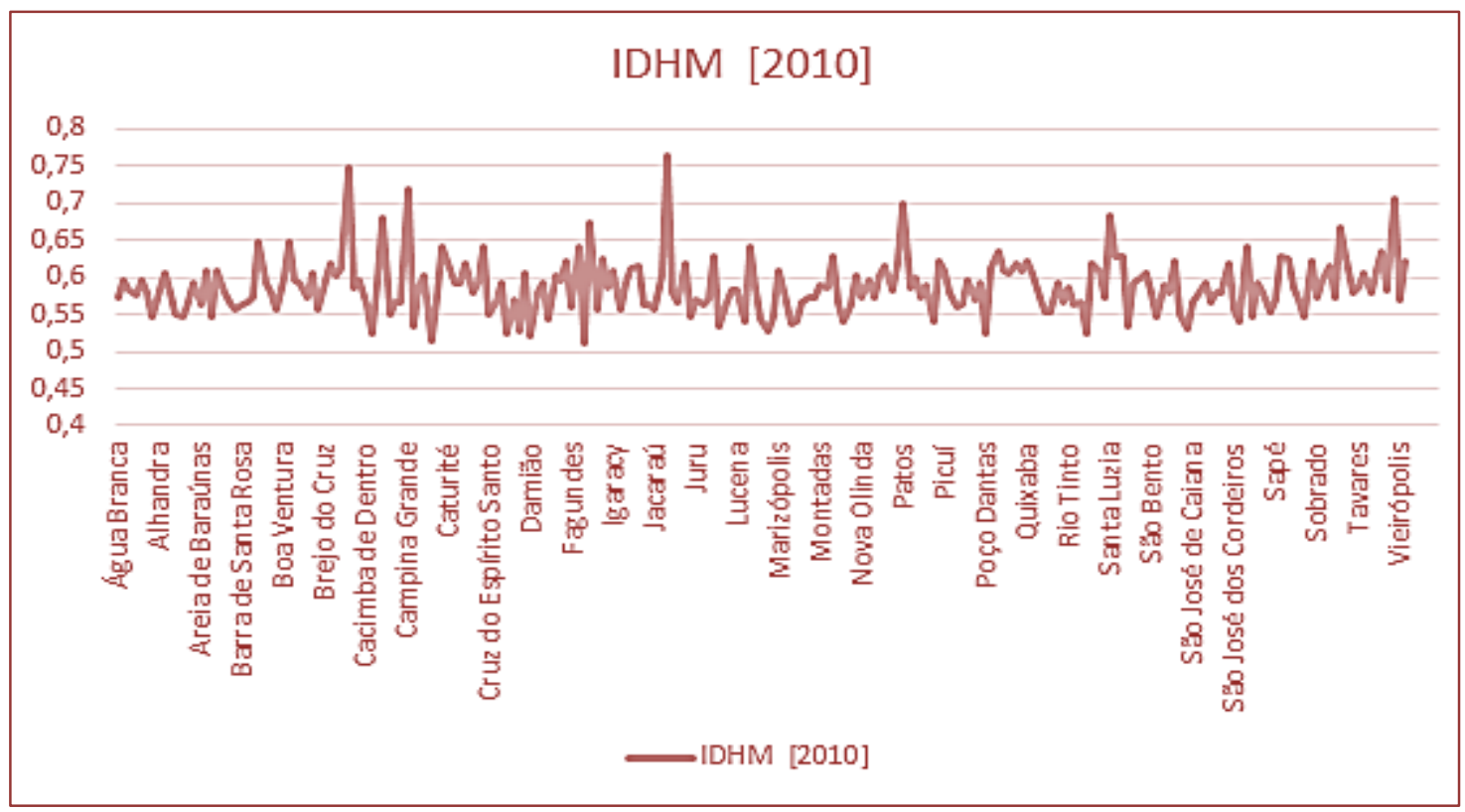

Ao compararmos o Índice de Desenvolvimento Humano de cada município do estado paraibano, notamos que o cluster que apresenta a maior média em relação ao IDH é o cluster 7, isso pode representar uma melhor eficácia na aplicação de políticas públicas voltadas para melhorias sociais. Enquanto isso percebemos que o cluster com a pior média relacionada ao IDH é o cluster 1, esse grupo além de dispor em seus elementos alguns dos piores Índices de Desenvolvimento Humano, dispõe também de uma baixa arrecadação tributária em relação ao índice populacional.

Figura 9: Média de arrecadação tributária por habitante de cada município paraibano.

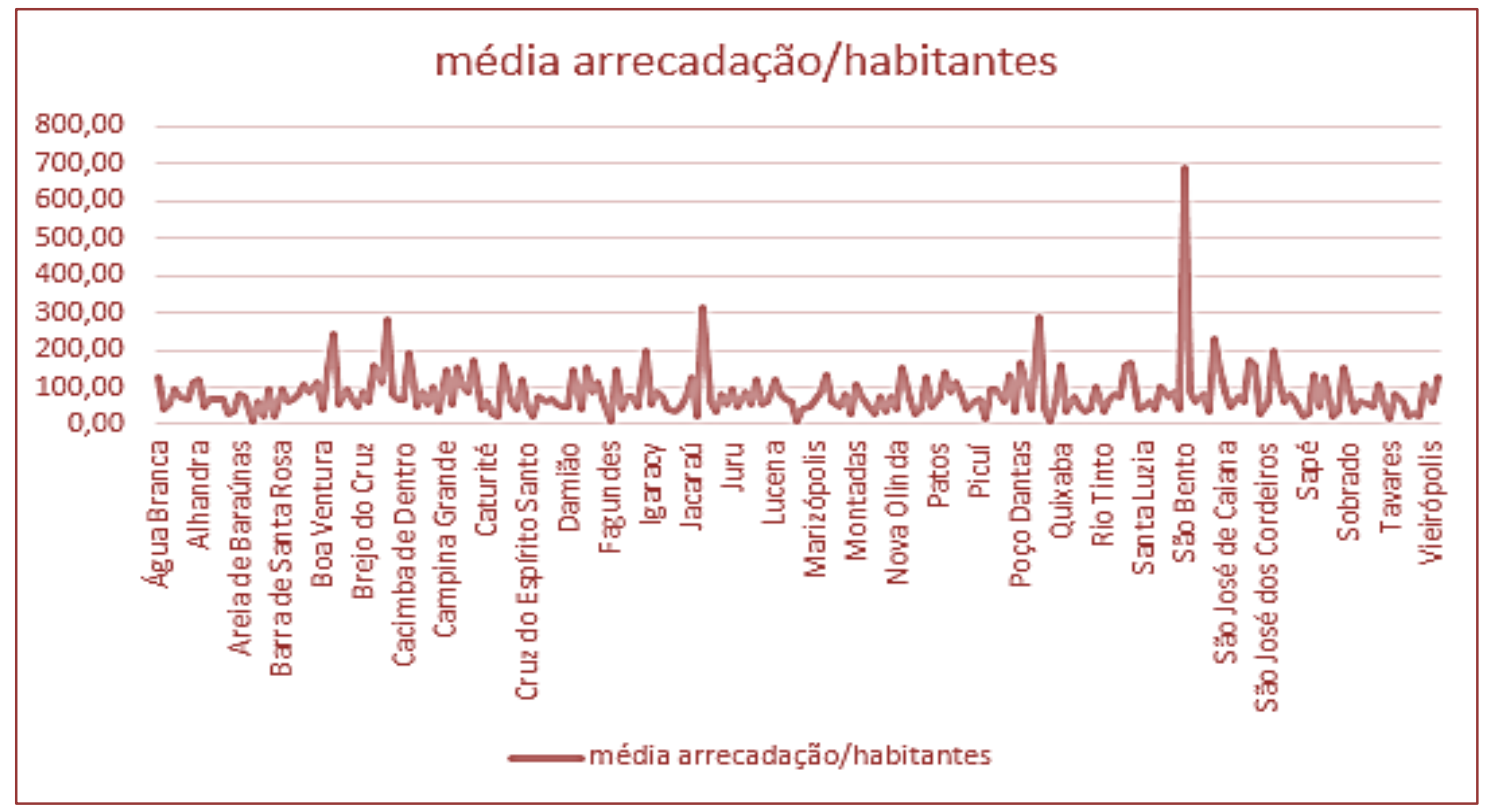

Em seguida, foi feito uma análise das condições que determinaram os clusters e seus elementos, e em sequência chegamos a seguinte analise: 
Cluster 1: representado pelos municípios de Aroeiras, Manaíra, Fagundes, Puxinanã, Pilar, Tavares e Serra Redonda. 0 grupo com o pior índice de desenvolvimento humano devido a sua baixa média de arrecadação tributária de aproximadamente $\mathrm{R} \$ 13,19$ por habitante. 0 cluster 1 traz entre seus elementos o município de Aroeiras com o pior arrecadamento tributário do estado da Paraíba, cerca de apenas $\mathrm{R} \$ 7,70$ por habitante, apesar de apresentar uma média salarial, em 2018, de 1,5 salários mínimos, apenas aproximadamente $6,5 \%$ da população municipal estava empregada fazendo assim com que a média de arrecadação seja tão baixa. Além do mais, a baixa empregabilidade do município acaba por diminuir consideravelmente o IDH municipal, que utiliza a média de empregabilidade em seu cálculo.

Cluster 2: com o maior número de elementos, é composto pelos municípios de Triunfo, Condado, Cubati, Baía da Traição, Umbuzeiro, Jericó, São Vicente do Seridó, Mogeiro, Araruna, Mulungu, Uiraúna, Sapé, Olivedos, São José do Sabugi, Conceição, Remígio, Areia, Solânea, Pocinhos, Itaporanga, Riachão do Poço, Nazarezinho, São João do Cariri, Serraria, Rio Tinto, Juazeirinho, Camalaú, Aguiar, Nova Olinda, Boa Ventura, Diamante, Riacho de Santo Antônio, Ouro Velho, Catolé do Rocha, Itabaiana, Marcação, Santa Teresinha, Gado Bravo, Pombal, Santa Inês, Pedro Régis, Princesa Isabel, São Bentinho, Coremas, Serra da Raiz, Cruz do Espírito Santo, Mato Grosso, Caiçara, Riachão do Bacamarte, Lagoa, Curral Velho, Sousa, Mari e Passagem. Esse grupo tem a segunda maior concentração populacional e a maior extensão territorial entre os demais clusters, mesmo assim tem a segunda pior média de arrecadação tributária. Esse baixo desempenho relacionado a arrecadação pode ser atribuído a alguns elementos com uma média de empregabilidade muito baixa, como é o caso do município de Gado Bravo, que apenas 5,8\% de sua população estava ocupada no ano de 2018 e mesmo com a média salarial de aproximadamente 1,8 salários mínimos sua média de arrecadação per capita foi de apenas $\mathrm{R} \$ 42,29$ e seu IDH de cerca de 0,513.

Outro membro de destaque deste cluster é o município de Marcação, em 2018, possuía um salário médio de 1,6 salários mínimos, porem a proporção de pessoas ocupadas era de apenas 5,9\% em relação a população total, ocupando uma das últimas posições no ranking em comparação aos demais municípios.

Cluster 3: composto pelos municípios de São José de Espinharas, Itapororoca, Damião, Borborema, Gurjão, Amparo, Santa Luzia, Capim, Bom Sucesso, Sossêgo, Alagoa Grande, Lagoa Seca, Cajazeirinhas, Igaracy, Monteiro, Taperoá, Livramento, Curral de Cima, Juripiranga, Barra de Santana, Queimadas, Assunção, Mamanguape, São Miguel de Taipu, Brejo dos Santos, Pirpirituba, Piancó, Congo, Vieirópolis, Santa Rita, Matinhas, São José de Princesa, Caturité, São Sebastião do Umbuzeiro, Cuité de Mamanguape, Soledade, Logradouro, Juarez Távora, São José dos Cordeiros, São Domingos do Cariri, Tenório, Arara, Malta, Marizópolis, Cacimba de Dentro, Boqueirão, Olho d'Água, Salgadinho, Cuitegi, Aparecida, Alcantil e Esperança. O desempenho desse grupo é considerado mediano, possui indicadores que se destacam como a segunda maior dimensão territorial dentre os outros clusters devido ao maior numero de elementos presentes em sua composição.

A média aritmética do IDH desse cluster é de 0,58, fazendo assim com que esse cluster tenha o penúltimo lugar em um ranking comparativo entre os demais clusters. Entre seus elementos, os que ganham maior destaque são os municípios de:

- Damião: com aproximadamente 13,70 mortes a cada 1.000 nascimentos, tem um dos maiores índices de mortalidade infantil, não só do Estado, mas também do País. Com esgotamento sanitário adequado de apenas 1,4\%; trazendo assim uma justificativa para o baixo IDH e a ineficácia das políticas públicas desenvolvidas pelo gestor.

- Cuité de Mamanguape: o município possui cerca de 97,8\% de suas receitas providas de fontes externas. Com um índice de mortalidade infantil de 1,087\%, o município possui apenas 2,1\% do esgotamento sanitário adequado e urbanização de vias públicas de menos de 0,2\%; o que explica o seu baixo desempenho em ofertar a sua população qualidade de vida e um Índice de Desenvolvimento aceitável.

- Curral de Cima: com uma densidade demográfica de cerca de $61,21 \mathrm{hab} / \mathrm{km}^{2}$, o município possui apenas $7,8 \%$ da população ocupada de maneira formal. 0 índice de mortalidade infantil é consideravelmente alto, cerca de 14,08 mortes a cada 1.000 nascimentos. E a mais baixa taxa de urbanização adequada do estado paraibano, $0 \%$. 
Cluster 4: composto pelos municípios de Cacimba de Areia, Picuí, Barra de São Miguel, Araçagi, Santa Cecília, Alagoinha, Areial, Riachão, Cuité, São José de Piranhas, Guarabira, Nova Floresta, Natuba, Santana dos Garrotes, Monte Horebe, Itatuba, Ingá, Gurinhém, Patos, Mãe d'Água, Teixeira, Bayeux, Cachoeira dos Índios, Pedras de Fogo, Maturéia, Salgado de São Félix, Junco do Seridó, São Francisco, São Sebastião de Lagoa de Roça, Areia de Baraúnas, Casserengue, Sobrado, Massaranduba, São Domingos, São José de Caiana, Duas Estradas, Cajazeiras, Imaculada, Santo André e Belém do Brejo do Cruz.

Esse cluster está entre os 3 clusters mais populosos e com a terceira maior extensão territorial dentre os demais, porém o mesmo tem a $5^{\text {a }}$ pior média do IDH com cerca de 0,5867. Esse resultado de baixo desempenho pode ser atribuído a alguns membros de menor sucesso em sua composição, tais como:

- Casserengue: com uma densidade demográfica de aproximadamente 35,05 hab $/ \mathrm{km}^{2}$, porém um arrecadamento tributário médio de apenas $\mathrm{R} \$ 84,57$ por habitante. Com cerca de $97 \%$ da receita bruta ser de origem externa, o município apresenta um déficit muito significativo em relação ao desenvolvimento urbano e questões voltadas para a saúde interna, com uma média de 10,5 internações por diarreia a cada 1.000 habitantes em 2016, percebemos uma má administração de recursos relacionados a base sanitária e estrutural da cidade.

- Santa Cecília: possui um índice de mortalidade infantil de 10,42 óbitos por mil nascidos vivos, e o Índice de Desenvolvimento Humano Municipal de 0,525. Com um PIB per capita em 2017 de $\mathrm{R} \$ 8.087,73$, obteve uma arrecadação tributária média de apenas $\mathrm{R} \$ 71,34$ por habitante, resultado devido ao percentual de receitas oriundas de fontes externas de 95,7\%.

- Natuba: população estimada de 10.454 pessoas de acordo com o IBGE no censo de 2019, possui uma densidade demográfica de 51,53 hab $/ \mathrm{km}^{2}$ e uma arrecadação tributaria média de R\$73,70. 0 IDHM (Índice de Desenvolvimento Humano Municipal) de 0,541 e uma taxa de mortalidade infantil de 11,24 óbitos por mil nascidos vivos.

Cluster 5: compostos pelos municipios de Lagoa de Dentro, Brejo do Cruz, Pedra Branca, Barra de Santa Rosa, Juru, Bananeiras, Bonito de Santa Fé, Alagoa Nova, Pilões, Pilõezinhos, Santana de Mangueira, Riacho dos Cavalos, Caldas Brandão, Carrapateira, Várzea, Montadas, Belém, Sumé, Cabaceiras, São Mamede, Emas, Algodão de Jandaíra, Pedra Lavrada, Poço de José de Moura, Bernardino Batista, Alhandra, Lucena, Lastro, Coxixola, Serra Grande, Jacaraú, Parari, Zabelê, Água Branca, Mataraca, Pitimbu, Serra Branca e Paulista. Apesar da quantidade de elementos, possui a menor media populacional dentre os demais, e possui a 4⿳a maior dimensão territorial, porém uma arrecadação de apenas $\mathrm{R} \$ 36.936 .255,46$ no ano de 2010. O cluster tem uma média de IDHM aproximado de 0,5856 e uma população de 339.601 pessoas. Alguns de membros de maior destaque do cluster são:

- Lastro: com um IDHM de apenas 0,533 devido ao alto índice de mortalidade infantil (cerca de 18,18 óbitos por mil nascidos), o município possui um déficit considerável em urbanização adequada de vias públicas que e apenas 13,6\% do esgotamento sanitário é adequado. Com 97,1\% de suas receitas oriundas de fontes externas, seu PIB per capito em 2017 era de apenas $\mathrm{R} \$ 9.571,15$, isso refletiu em sua arrecadação tributaria que foi de apenas $\mathrm{R} \$ 121,55$ por habitante.

- Santana de Mangueira: com uma população de apenas 5.331 habitantes, o município faz fronteira com o estado pernambucano e tem uma área de $460,2 \mathrm{~km}^{2}$, por isso uma densidade demográfica de 12,5 hab $/ \mathrm{km}^{2}$ e cerca de $\mathrm{R} \$ 96,87$ de arrecadação tributária média por habitante. Apesar do péssimo índice de urbanização adequada, a arborização de vias publicas é de cerca de $96,5 \%$, em contra ponto tem um esgotamento sanitário de apenas 5,1\%. 0 município teve em 2015 cerca de 96,1\% de suas receitas oriundas de fontes externas e um PIB per capito em 2017 de R $\$ 7.782,22$.

Cluster 6: composto pelos municípios de Frei Martinho, Desterro, São José da Lagoa Tapada, Campina Grande, Nova Palmeira, Boa Vista, Sertãozinho, Dona Inês, Caraúbas, Conde, Quixaba, Santa Cruz, Caaporã, São José do Brejo do Cruz, Poço Dantas, Santa Helena, Catingueira, São José do Bonfim, Cacimbas e São José dos Ramos. Os 20 membros desse cluster apresentam uma média de 0,5929 em relação ao seu IDHM, porem o mesmo tem membros que se destacam de forma muito contrarias aos demais, pois tem em sua composição um dos três municípios com o melhor IDH da Paraíba e ao mesmo tempo um dos quatro municípios com pior IDH, que são:

- Cacimbas: o 4o pior IDH do estado paraibano com 0,523, teve um PIB per capito em 2017 de $\mathrm{R} \$ 6,587,55$ e apenas cerca de $7,1 \%$ da população era de pessoas ocupadas, tem uma média salarial 
dessas pessoas de aproximadamente 1,7 salários mínimos. Com sua receita sendo formada em 96,9\% de fontes externas, teve uma média de arrecadação tributaria de $\mathrm{R} \$ 193,81$ por habitante. Relacionado a estrutura adequada de moradia, apenas $30,5 \%$ da população possui esgotamento sanitário adequado e 1,3\% de urbanização de vias públicas satisfatória de acordo com os padrões do PNUD.

- Campina Grande: considerado um dos principais polos industriais do Nordeste, o município conta com uma população fixa de aproximadamente 409.731 habitantes segundo o IBGE em 2019, possui uma densidade demográfica de 648,31hab $/ \mathrm{km}^{2}$. Com uma media salarial superior a 2,2 salários mínimos, tem uma media de $27 \%$ de sua população considerada de forma ocupada formalmente. Da população apresentada pelo ultimo censo, mais de $25 \%$ não é natural do município, isso se dá pela grande quantidade de postos de trabalho ofertados pelas industrias lotadas no município e também pelas universidades que atraem estudantes de todos os lugares do país; em relação a taxa de escolarização o município uma média de 97,6\% entre 6 e 14 anos. Referente a economia local, o PIB per capita em 2017 foi de $\mathrm{R} \$ 21.077,30$, o 6을 maior do estado paraibano, com isso apenas $75 \%$ de suas receitas foram oriundas de fontes externas. O IDH do município é de 0,720. Esse alto Índice do Desenvolvimento Humano conta com o auxílio da estrutura sanitária adequada em grande escala que o mesmo apresenta, cerca de $84,1 \%$ da população possui esgotamento sanitário adequado em sua residência e 19,4\% das vias públicas são urbanizadas adequadamente.

Cluster 7: composto pelos municípios de Ibiara, São João do Tigre, Bom Jesus, Cabedelo, Prata e João Pessoa. 0 cluster com maior média IDH dentre todos, aproximadamente 0,64 , e também maior volume populacional, esse cluster demonstra os melhores resultados em relação as aplicações dos recursos para a melhoria da condição de vida de sua população. Entre os elementos dispostos nesse cluster temos os 2 melhores IDH's do estado paraibano, que são os municípios de Joao Pessoa e Cabedelo. 0 membro deste cluster, a cidade de São Joao do Tigre, apesar de seu IDH não tão satisfatório, ainda assim apresenta um resultado positivo para a aplicação de politicas publicas efetivas.

- São Joao do Tigre: apesar da população de apenas 4.422 pessoas, possui uma arrecadação tributaria de aproximadamente $\mathrm{R} \$ 228,71$; ao analisarmos as condições de disposição dos recursos cerca de $97,2 \%$ das receitas são oriundas de fontes externas, e apenas 7,5\% da população é considerada ocupada de maneira formal. Esses pontos apesar de se dispor de forma negativa, em relação aos demais municípios com resultados de arrecadação tributária e rendimentos semelhantes, o município conseguiu apresentar um IDH melhor desenvolvido em comparação ao restante dos elementos semelhantes nesses fatores.

- João Pessoa: a capital do estado paraibano, considerado principal centro financeiro e econômico da Paraíba. População estimada em 2019 de 809.015 pessoas, sem considerar a população de migrações pendulares sazonais ou diárias. Com média salarial superior a 2,8 salários mínimos e uma proporção de pessoas ocupadas de 36,1\%. 0 município apresentou em 2017 um PIB per capita de R \$24.319,82, o $4^{\circ}$ maior do Estado. E apenas 66,1\% de suas receitas foram de fontes externas. O IDHM é de 0,763, o maior do estado. As condições de moradia são bastante satisfatórias, com cerca de 70,8\% do esgotamento sanitário adequado e $25,1 \%$ das vias devidamente urbanizadas.

- Cabedelo: com um IDHM médio de 0,748, é o segundo município paraibano com o melhor desempenho em relação as melhorias na qualidade de vida de seus habitantes. 0 município possui uma população de 67.736 pessoas e com uma dimensão geográfica de apenas $29,873 \mathrm{~km}^{2}$, tem uma densidade demográfica de 1.815,57 hab $/ \mathrm{km}^{2}$. Apesar da alta concentração populacional, a média salarial chega a ser superior a 2,8 salários mínimos e a proporção de pessoas ocupadas formalmente atingi um percentual de 33,2\%. Isso contribui para o desempenho do seu PIB, o segundo maior do estado, que em 2017 alcançou a marca de $\mathrm{R} \$ 42.556,16$ per capita e apenas $65,8 \%$ de suas receitas foram obtidas através de fontes externas.

Cluster 8: composto pelo município de São Bento. Com uma população estimada de 34.031 habitantes, a cidade possui uma densidade demográfica de 124,41 hab $/ \mathrm{km}^{2}$ e o IDHM de 0,580, o município em 2010 obteve uma média de arrecadação tributaria de $\mathrm{R} \$ 687,80$ por habitante, o que acabou sendo incompatível com sua média salarial de apenas 1,6 salários mínimos e um pessoal ocupado de cerca de 10,5\% formalmente. Além disso o PIB per capita em 2017 foi de $\mathrm{R} \$ 12.442,97$ e o percentual de receitas oriundas de fontes externas superou os 93\%. Com esses resultados econômicos, podemos concluir que o 
desempenho das politicas publicas desenvolvidas na cidade não suprem a real necessidade da sua população.

Porém, ainda é necessária uma melhor analise dos governos e suas tendências politicas para entendermos de forma mais objetiva, quais as reais políticas públicas necessárias para que se melhore os desempenhos de forma mais favorável e compatível a arrecadação dos vários elementos.

\section{CONCLUSÃO}

Por todo o processo de desenvolvimento deste projeto de pesquisa, foi notável que os resultados obtidos, através da avaliação da carga tributária dos municípios do estado da Paraíba, são indicadores da efetividade e eficácia da aplicação dos recursos arrecadados, em contra partida ao IDHM (Índice de Desenvolvimento Humano Municipal) e através dos métodos de agrupamento aplicados como base na análise, obtivemos uma comparação com os demais indicadores de desenvolvimento social entre os elementos de acordo com a utilização dos clusters.

Também foi clara a correlação entre o desenvolvimento humano e a arrecadação tributária, demonstrando a compatibilidade verdadeira entre as médias populacionais, cargas tributarias e o IDH. Nesta analise utilizamos dados coletados sobre a população de cada município, o Índice de Desenvolvimento Humano Municipal e a arrecadação tributaria. E a partir da base de dados definida, desenvolvemos o método de analise qualitativo de carga tributária correlacionado ao IDHM.

O método empregado para o desenvolvimento do trabalho em questão, reafirma a correlação da carga tributária aplicada a população e seu IDHM, permitindo assim uma leitura de modo qualitativa dos dados, respeitando densidade demográfica em contra ponto a renda média de cada população.

O governo é o principal responsável pelo desenvolvimento e aplicação de políticas públicas, direcionando as receitas arrecadadas, através da tributação imposta a população, aos seguimentos mais necessitados de investimentos específicos para um melhor resultado social. Os principais setores são: educação, longevidade e renda, que são os índices considerados no cálculo do IDH municipal.

As analises dos dados utilizados para a estruturação dos clusters, traz aos gestores municipais uma melhor visão de como aplicar com isonomia os seus recursos para que todos os segmentos se encontrem de forma equivalente, de acordo com o desempenho verificado através de uma leitura qualitativa dos dados dispostos pela da arrecadação tributária. Essa correlação entre o IDH e a tributação arrecadada é de suma importância para o processo de tomada de decisões da gestão pública, auxiliando a compreensão das medidas necessárias para a correção socioeconômica que precisam ser intensificadas e de quais trazem consequências desfavoráveis para o desenvolvimento a serem retificadas.

Essa analise auxilia também, de forma técnica, a discursão sobre a devida destinação de demais verbas oriundas de outros recursos governamentais, podendo utiliza-los para desenvolver ações que trarão real melhoria da população, em relação as condições de saúde e educação local favorecendo assim o aumento do IDH. Porem cabe apenas aos gestores o aprofundamento do estudo relacionado as melhorias e desenvolvimento social e econômico, através de políticas públicas mais eficazes.

A população também pode utilizar essa analise para melhorar e intensificar o monitoramento das ações desenvolvidas por seus gestores, observando o impacto causado na qualidade de vida através dessas ações e assim, cobrando dos representantes políticos a devida atenção para os setores mais necessitados.

\section{AGRADECIMENTOS}

Agradecemos a Coordenação do programa institucional de iniciação cientifica da UEPB, pelo apoio do presente trabalho, PIBIC/UEPB

\section{REFERENCIAS}

[1] BRASIL, Constituição Federal de 1988 disponível em http://www.presidencia.gov.br/legislacao/. Acesso em 16 de janeiro de 2020 .

[2] DERLIEN, H-U. (2001), “Una comparación internacional en la evaluación de las políticas públicas”. Revista do Serviço Público, número 52 (1) Edição 105-123, http://www.enap.gov.br/index.php?option=com_docman\&task=cat_view\&gid=806. Acesso em 13 de fevereiro de 2020. 
[3] FARIA, Carlos Aurélio Pimenta de. Artigo “A Política da Avaliação de Políticas Públicas". Volume 20. Edição 59. 2005, disponível em http://www.mapp.ufc.br. Acesso em 17 de fevereiro de 2020.

[4] NEVES S., J. A.; OLIVEIRA, M. S. . Análise de clusters obtidos com a relação carga tributária e IDH. In: VII Congresso Nacional de Excelência em Gestão, 2011, Niterói - RJ. Anais do VII Congresso Nacional de Excelência em Gestão, 2011.

[5] SEN, AMARTYA. Desenvolvimento como liberdade. São Paulo: Editora Companhia das Letras, 2008.

[6] SECRETARIA DO TESOURO NACIONAL (BRASIL). Volume de arrecadação tributária no ano de 2008 por unidade da federação. Disponível em http://www.tesouro.fazenda.gov.br/estados_municipios/index.asp. Acesso 24 de dezembro de 2019.

[7] SALVADOR, Evilásio. A Distribuição da Carga Tributária, Quem Paga a Conta ? São Paulo - 3ạa Edição: Editora Globo, 2005.

[8] PROGRAMA DAS NAÇÕES UNIDAS NO BRASIL (PNUD3). Ranking do Brasil no IDH. Disponível em http://www.pnud.org.br/idh/. Acesso em 29 de setembro de 2019.

[9] PROGRAMA DAS NAC̄̃ES UNIDAS NO BRASIL (PNUD1). Mapa mundi do IDH em 2016. www.pnud.org.br/rdh/destaques/index.php?lay=inst\&id=dtq\#d2006.Acesso em 25 dezembro de 2019.

[10] INSTITUTO BRASILEIRO GEOGRAFIA E ESTATíSTICA - IBGE4 (BRASIL). Censo demográfico 2016, disponível em http://www.ibge.gov.br/home/estatistica/populacao/censo2000/tabelabrasil111.shtm. Acesso em 04 de maio de 2020.

[11] IBGE - Instituto Brasileiro de Geografia e Estatística. IBGE cidades. Disponível em: https://cidades.ibge.gov.br/. Acesso em: 15 abr. 2020. 


\section{Capítulo 7}

A relação das políticas públicas e o bacharel em Turismo: O caso das Estâncias Turísticas no estado de São Paulo, Brasil

Aracelis Gois Morales Rigoldi

Graziela Oste Graziano Cremonezi

Karina Toledo Solha

Valéria Rueda Elias Spers

Marli Terezinha Vieira

Resumo: Apesar de o turismo ser reconhecido pela sua capacidade de promover o desenvolvimento de localidades e, ser considerado extremamente relevante, muitos dos municípios paulistas ainda carece de uma melhor estruturação e de uma gestão profissional. Esta situação se deve a diversos fatores, entre eles, destaca-se a incipiência e o pouco profissionalismo na gestão de políticas públicas de turismo em diferentes instâncias, seja municipal ou estadual. Considera-se que esta situação poderia ser minimizada com a incorporação de bacharéis em turismo no quadro técnico destes organismos, afinal o Estado de São Paulo, tem forte tradição na formação superior destes profissionais. É a partir deste questionamento que esse artigo se propõe a discutir o papel deste profissional na gestão de políticas públicas de turismo nos municípios paulistas que são denominados como Estâncias Turísticas. Para tanto, este trabalho segue a metodologia qualitativa com pesquisa descritiva e exploratória, além de entrevistas com os secretários estaduais de turismo do Estado de São Paulo. Como resultado verifica-se que, apesar dos agentes políticos reconhecerem a importância do bacharel em turismo para a gestão das políticas públicas de turismo, a sua inserção na gestão de políticas públicas ainda é muito restrita.

Palavras chave: Bacharel em turismo. Políticas Públicas de Turismo. Gestão de Destinos Turísticos. Estâncias Turísticas. 


\section{INTRODUÇÃO}

No Brasil, a atividade turística vem apresentando dados positivos apesar de toda crise econômica, instabilidade do cenário político, desemprego, oscilação cambial do dólar, entre outros eventos registrados no país nos últimos anos. Independentemente deste cenário, o turismo mostra-se cada vez mais atuante e em constante crescimento, uma fonte geradora de emprego, renda e dados econômicos cada vez mais satisfatórios, Segundo dados do Ministério do Turismo (2021), a atividade turística gerou mais de 21,5 mil de empregos no ano de 2020, destacando o segmento de hospedagens e alimentação, evidenciando um fator significativo para o mercado econômico nacional.

Nessa conjuntura, é válido destacar a importância do envolvimento do turismo no contexto político, econômico e social para o fortalecimento e o desenvolvimento da qualidade de vida do turismo e do munícipe, que apesar de toda a instabilidade econômica, pandêmica e o aumento do desemprego do país, o setor da atividade turística continua em ascensão, gerando divisas econômicas significativas.

Dentre os estado brasileiros, o Estado de São Paulo se destaca como o maior receptor e emissor de turistas no Brasil, o que demonstra a sua importância econômica no cenário turístico interno, destacando-se como o estado líder nacional na movimentação econômica do país, com mais de 44 milhões de viagens (SÃO PAULO, 2021). Todavia, apesar da sua importância como destino emissor e receptor, o Estado de São Paulo apresenta uma grande fragilidade em suas estruturas institucionais, situação verificada por Solha (2005), ao estudar o papel dos organismos estaduais de turismo no desenvolvimento do turismo nacional.

A institucionalização do Turismo na Administração do Estado, teve uma trajetória caracterizada pelo forte vínculo com as diretrizes nacional, restringindo-se em muitos momentos apenas à implementação de projetos e ações demandas pela Embratur, com poucas iniciativas do próprio Estado. Dentre elas destacase a proposição da criação das Estâncias Paulistas, política que até recentemente se apoiava exclusivamente na disponibilização de recursos.

No início da década de 1990, o governo do estado de São Paulo aprova uma legislação especifica a lei 7.862/1992, que por meio do Departamento de Apoio ao Desenvolvimento dos Municípios TurísticosDADETUR, lotado na Secretaria Estadual de Turismo, o estado de São Paulo reúne 70 municípios denominados estâncias turísticas, com o objetivo de alavancar o turismo paulista, por meio de recursos financeiros recebidos do Fundo de Melhoria das Estâncias- FUMTUR, para que os recursos sejam aplicados em projetos de infraestrutura relacionados ao desenvolvimento e fortalecimento do turismo.

No entanto a partir de 2010, em função das crescentes demandas dos outros municípios paulistas, o DADETUR começa a discutir a necessidade de atualizar a Lei das Estâncias, propondo que houvesse contrapartidas para este o investimento realizado, estimulando os municípios a aprimorarem sua gestão do turismo, se tornando mais competitivos. Assim, surge uma nova legislação para as estâncias paulistas, que conforme a lei complementar n.1.261 de 29 de abril de 2015 e a de n. 16.283 de 15 de julho de 2016 estabelecem condições e novos requisitos para a permanência da classificação das Estâncias. A nova lei inclui uma série de exigências desde a elaboração de um plano diretor de turismo, criação de conselhos municipais de turismo deliberativos, estudos de demanda, inventários turísticos e propõe a criação de 140 municípios de interesse turístico denominado MITs. A lei ainda garante após uma regulamentação, ainda não publicada, a rotatividade, a cada três anos, de três municípios, buscando promover uma maior competitividade entre os municípios Estâncias e as cidades classificadas Municípios de Interesse Turístico.

Além de qualificar os destinos turísticos paulista, se pretende também, inseri-los no cenário do turismo nacional e internacional, ampliando a ampliando a capilaridade e se tornando de fato um grande e diversificado destino receptor. Contudo é preciso superar algumas fragilidades, pois apesar de diversas cidades paulistas serem reconhecidas legalmente como estâncias, muitas não apresentam nenhuma estrutura turística sustentável, com o intuito de promover o turismo não só com olhar para o turista, mas também na qualidade da comunidade local. (DWYER, L. et al 2009; Solha et al, 2010)

Nessa síntese, com os dados apresentando o crescimento do turismo, qual seria a presença dos profissionais de turismo na gestão das políticas públicas em municípios que se destacam no incremento da atividade turística? Se os dados apontam o turismo como uma atividade crucial de sustentação econômica local, regional e nacional e que visa o crescimento econômico do país, o bacharel em turismo poderia contribuir de modo relevante na gestão destes destinos, e em especial na implementação de ações de qualificação das estâncias turísticas paulistas para atenderem às novas diretrizes indicadas pela legislação recentemente aprovada.

Nesse sentido, o presente estudo tem como objetivo verificar a importância do bacharel em turismo no contexto do desenvolvimento das políticas públicas de turismo nas secretarias municipais ou afins, em 
particular nos municípios Estâncias do Estado de São Paulo. Para tanto, foi necessário discutir questões como a atuação e a regulamentação profissional do bacharel em turismo, a importância desse profissional na gestão pública de turismo, como também a sua inserção no quadro técnico das estâncias turísticas do estado de São Paulo.

\section{TURISMÓLOGO: REGULAMENTAÇÃO E COMPETÊNCIA}

Para evidenciar a importância do bacharel em turismo para o desenvolvimento e fortalecimento do turismo, é necessário refletir: quem é este profissional? Quais são suas habilidades e conhecimentos? Qual é o seu papel no desenvolvimento do turismo em um município?

Importante salientar que o bacharel em turismo não é uma profissão regulamentada e sim reconhecida no Brasil pela lei 12.591 de 18 de janeiro de 2012, que disciplina a sua atuação como turismólogo na atuação de:

I - planejar, organizar, dirigir, controlar, gerir e operacionalizar instituições e estabelecimentos ligados ao turismo;

II - coordenar e orientar trabalhos de seleção e classificação de locais e áreas de interesse turístico, visando ao adequado aproveitamento dos recursos naturais e culturais, de acordo com sua natureza geográfica, histórica, artística e cultural, bem como realizar estudos de viabilidade econômica ou técnica;

III - atuar como responsável técnico em empreendimentos que tenham o turismo e o lazer como seu objetivo social ou estatutário;

IV - diagnosticar as potencialidades e as deficiências para o desenvolvimento do turismo nos Municípios, regiões e Estados da Federação;

V - formular e implantar prognósticos e proposições para o desenvolvimento do turismo nos Municípios, regiões e Estados da Federação;

VI - criar e implantar roteiros e rotas turísticas;

VII - desenvolver e comercializar novos produtos turísticos;

VIII - analisar estudos relativos a levantamentos socioeconômicos e culturais, na área de turismo ou em outras áreas que tenham influência sobre as atividades e serviços de turismo;

IX - pesquisar, sistematizar, atualizar e divulgar informações sobre a demanda turística;

X - coordenar, orientar e elaborar planos e projetos de marketing turístico;

XI - identificar, desenvolver e operacionalizar formas de divulgação dos produtos turísticos existentes;

XII - formular programas e projetos que viabilizem a permanência de turistas nos centros receptivos;

XIII - organizar eventos de âmbito público e privado, em diferentes escalas e tipologias;

XIV - planejar, organizar, controlar, implantar, gerir e operacionalizar empresas turísticas de todas as esferas, em conjunto com outros profissionais afins, como agências de viagens e turismo, transportadoras e terminais turísticos, organizadoras de eventos, serviços de animação, parques temáticos, hotelaria e demais empreendimentos do setor; 
$\mathrm{XV}$ - planejar, organizar e aplicar programas de qualidade dos produtos e empreendimentos turísticos, conforme normas estabelecidas pelos órgãos competentes;

XVI - emitir laudos e pareceres técnicos referentes à capacitação ou não de locais e estabelecimentos voltados ao atendimento do turismo receptivo, conforme normas estabelecidas pelos órgãos competentes;

XVII - lecionar em estabelecimentos de ensino técnico ou superior;

XVIII - coordenar e orientar levantamentos, estudos e pesquisas relativamente a instituições, empresas e estabelecimentos privados que atendam ao setor turístico. (Brasil, 2012, s.p)

Para a Associação Brasileira de Bacharéis em Turismo (ABBTUR, s.d.), que luta pela regulamentação da categoria, há uma diferenciação nas nomenclaturas de bacharel em turismo e turismólogo. Para a entidade o bacharel em turismo, é o profissional egresso dos cursos superiores de turismo e/ou hotelaria, que difundem ideias, realiza planejamentos por meio de análises crítica com responsabilidade técnica e ética, garantindo a sustentabilidade, a pesquisa e o desenvolvimento de novas tecnologias. Já o turismólogo, não precisa ter nenhum pré-requisito acadêmico e de formação, pois segundo a lei 12.591/2012, o turismólogo é livre o exercício da profissão.

No entanto, o fato de o profissional de turismo ter sido reconhecido já é um grande avanço para a área, que há mais de 30 anos sofre e luta com esse descaso. Salienta-se que, o reconhecimento perante a lei $12.591 / 2012$ traz à tona o papel do turismólogo, mostrando o seu exercício e requisito na profissão, mas não coloca em evidencia quem são esses profissionais devido a não regulamentação que traria explicito a competência da formação acadêmica superior.

Com relação à formação acadêmica, Ansarah (2002) descreve que o primeiro curso de turismo no Brasil se iniciou na década de 1970, na cidade de São Paulo, na universidade Anhembi Morumbi, e teve seu auge nos anos 1990, em que o país apresentava um grande crescimento no setor de turismo. Na década de 2000, segundo Beni (2006) houve uma grande diminuição dos cursos, devido a diversos motivos como; falta de inserção desses profissionais no mercado de trabalho, falta de regulamentação e reconhecimento, má qualidade dos cursos, entre outros fatores.

No estado de São de Paulo várias instituições públicas e privadas, dispersas por todo o território paulista, oferecem formação superior em turismo, com projetos pedagógicos que contemplam propostas de formação voltadas tanto para atuação junto a empreendimentos turísticos, quanto ao planejamento e gestão de localidades turísticas, embasados nas Diretrizes Curriculares para os cursos de Graduação em Turismo que estabelecem que:

Art. 3o 0 curso de graduação em Turismo deve ensejar, como perfil desejado do graduando, capacitado e aptidão para compreender as questões científicas, técnicas, sociais, econômicas e culturais, relacionadas com o mercado turístico, sua expansão e seu gerenciamento, observados os níveis graduais do processo de tomada de decisão, apresentando flexibilidade intelectual e adaptabilidade contextualizada no trato de situações diversas, presentes ou emergentes, nos vários segmentos do campo de atuação profissional. (MEC, 2006)

Entre as competências e habilidades desejadas na formação destes profissionais podem-se destacar no estudo aquelas relacionadas à possibilidade de sua atuação na gestão pública do turismo:

I - compreensão das políticas nacionais e regionais sobre turismo;

II - utilização de metodologia adequada para o planejamento das ações turísticas, abrangendo projetos, planos e programas, com os eventos locais, regionais, nacionais e internacionais;

III - positiva contribuição na elaboração dos planos municipais e estaduais de turismo; 
IV - domínio das técnicas indispensáveis ao planejamento e à operacionalização do Inventário Turístico, detectando áreas de novos negócios e de novos campos turísticos e de permutas culturais;

V - domínio e técnicas de planejamento e operacionalização de estudos de viabilidade econômico-financeira para os empreendimentos e projetos turísticos;

VI - adequada aplicação da legislação pertinente;

VII - planejamento e execução de projetos e programas estratégicos relacionados com empreendimentos turísticos e seu gerenciamento;(...) (MEC, 2006)

Apesar de a ABBTUR defender a regulamentação da profissão, esta questão ainda é bastante polêmica, autores como Trigo (2015) e Beni (2012), salientam sobre a não regulamentação do turismólogo, ressaltando que no setor de turismo só se sobressai os melhores, independente de regulamentação legal, e que esse assunto já não é tão importante na maioria dos profissionais que conseguem ver a evolução do mercado turístico e que tem outra perspectiva sobre a questão. Trigo (2015) afirma que, em nenhum local do mundo existe a regulamentação da profissão de turismólogo, uma que pode atuar em diversas áreas como eventos, agências, transportes, cultura, lazer, entre outros.

Nesse sentido apesar da polêmica, segue-se a visão proposta por Trigo (2015), que independente da regulamentação se o profissional de turismo quiser ser realmente reconhecimento no mercado, é necessário investir na formação profissional, com cursos de atualização, visão de futuro, empreendedorismo, para que o melhor capacitado possa ter o merecido reconhecimento. Assim, na academia é necessário à formação continuada com cursos, especializações, mestrados e doutorados, e na área privada e pública é importante que o profissional continue sempre se atualizando, nos mais variados cursos de capacitação que o mercado requisite, sempre elencando a sustentabilidade social, cultural e econômica com uma consciência ética, eficácia e eficiente.

\section{A ATUAÇÃO DO PROFISSIONAL DE TURISMO NAS POLÍTICAS PÚBLICAS}

Nesse artigo considera-se que o profissional de turismo formado na área e/ou ao bacharel em turismo é reconhecido como turismólogo, frisando que esse profissional tem sua atuação diretamente ligada as competências para atuar no mercado. Ainda assim, quando se habilita a atuação de mercado com as competências pode-se compreender a importância do turismólogo na implantação das políticas públicas de turismo, sendo notória a percepção da importância do turismólogo para a execução e implantação das políticas públicas de turismo em gestões públicas municipais, estaduais e federais, conforme ilustra a figura 1 a seguir.

Figura 1. Atuação e competência do turismólogo para as políticas públicas de turismo

\begin{tabular}{|c|c|c|}
\hline Atuação & Competência & \\
\hline $\begin{array}{l}\text { - Diagnosticar } \\
\text { potencialidades as } \\
\text { deficiências a } \\
\text { desenvolvimento do turismo; } \\
\text { Formular e implantar } \\
\text { prognósticos e proposições } \\
\text { para o desenvolvimento do } \\
\text { turismo; } \\
\text { - Criar e implantar } \\
\text { roteiros e rotas turísticas; } \\
\text { Desenvolver } \\
\text { comercializar novos produtos } \\
\text { turísticos. }\end{array}$ & $\begin{array}{l}\text { - Compreender } \\
\text { políticas nacionais e regionais } \\
\text { sobre turismo; } \\
\text { Planejar ações turísticas, } \\
\text { abrangendo projetos, planos e } \\
\text { programas; } \\
\text { Domínio e técnicas de } \\
\text { planejamento } \\
\text { Contribuir } \\
\text { elaboração dos planos municipais } \\
\text { e estaduais de turismo; } \\
\text { - Planejar e executar } \\
\text { projetos e programas estratégicos } \\
\text { e o gerenciamento. }\end{array}$ & $\begin{array}{l}\text { Turismólogo apto para: } \\
\text { Implantar, executar, gerir } \\
\text { Políticas Públicas de } \\
\text { Turismo } \\
\text { que visam o crescimento e } \\
\text { desenvolvimento local, } \\
\text { regional, estadual, nacional } \\
\text { e internacional da atividade } \\
\text { turística pautado no } \\
\text { desenvolvimento e no bem- } \\
\text { estar coletivo }\end{array}$ \\
\hline
\end{tabular}

Fonte: Elaborada pelas autoras a partir da Lei no 12.591/2012 e MEC (2006). 
É notória a percepção da importância do turismólogo para a execução e implantação das políticas públicas de turismo em gestões públicas municipais, estaduais e federais. Entretanto, são poucos os estudos que tratam a relação da importância do turismólogo e sua atuação nas áreas das políticas públicas. Mais difícil ainda é encontrar dados que possam contribuir para traçar um panorama da inserção destes profissionais no universo da gestão das políticas públicas, e a absorção do conhecimento desse profissional para o fortalecimento do turismo no local.

No entanto, as políticas públicas de turismo são ações que direcionam os caminhos para atingir os objetivos propostos, determinando as prioridades e estabelecendo programas que zelem para a preservação e conservação dos atrativos e da comunidade local. Para essa concretização o planejamento turístico é o instrumento capaz de definir o percurso a ser realizado com a capacidade do profissional de turismo em tomar as decisões para o fortalecimento da atividade turística. Ruschmann (2016) e Fratucci (2014) evidenciam que o planejamento turístico além de almejar como alcançar os objetivos, é também o processo de indagar os caminhos e as tomadas de decisões, prevendo suas vantagens e desvantagens com antecedência, controle, eficiência e direção.

Fernandes (2011) descreve que a gestão das políticas públicas no turismo deve ser implantada nas ações de gerenciamento e fortalecimento do setor, atingindo metas de acordo com o plano local, estadual e nacional do turismo, sendo de grande importância para o conjunto de tomadas de decisão. Ainda assim, para Gastal e Moesch (2007) uma política pública de turismo deve juntar estratégias junto ao trade turístico e a sociedade, de forma conjunta com todos os setores do turismo como hotelaria, restaurantes, atrativos rurais, atrativos naturais, agências de viagens, entre outros, formando um todo de partes que produz qualidade para o destino turístico.

A gestão na área de políticas públicas em turismo não se restringe a técnica, pois prescinde de um conjunto de conhecimentos teóricos e práticos, associados à habilidade de tomar decisões, solucionar problemas, gerenciar programas com a competência de promover o desenvolvimento social. Isso leva a um desafio central que é a necessidade da profissionalização da gestão, para a formulação e implantação de políticas públicas no setor do turismo focando a sustentabilidade.

Panosso Netto e Trigo (2015), Beni (2012), Dias; Mattos (2012), Cruz, (2016) salientam que o sucesso do turismo na área pública está ligado diretamente ao profissionalismo, que por meio de pessoas capacitadas e qualificadas no setor, é possível realizar políticas públicas focadas no planejamento participativo em longo prazo, no pensamento do bem viver, proporcionando infraestrutura, satisfação e qualidade do turismo não só para os turistas como também principalmente para os moradores locais.

Para Winkert e Vicentini (2015), é relevante ressaltar a importância do profissional do turismo na área pública em todas as decisões que envolvam o planejamento e administração da atividade turística, na qual o profissional de turismo deve ter além da capacidade e a clareza dos objetivos, possa também compreender os possíveis obstáculos que a atividade pode causar, buscando soluções para as futuras ameaças. Cabe ao profissional de turismo, o planejamento de ações que estejam em sintonia com o desenvolvimento sustentável, focando o bem-estar e a harmonia do ambiente natural e cultural com a comunidade local.

Para tanto, as pesquisas realizadas na área de políticas públicas de turismo por autores como Beni (2012), Hall (2004), César (2011) e Silva (2015) observam que, a atividade turística nem sempre está cercada de uma gestão capacitada, revelando profissionais atuando em órgãos públicos com uma grande fragilidade em relação aos conhecimentos técnicos e teóricos da atividade turística sustentável.

\section{METODOLOGIA}

O presente estudo segue o método qualitativo que, segundo Creswel (2014) e Merrian (2015) a pesquisa qualitativa estuda um tema ou questão que precisa ser explorado, identificando aspectos que não podem ser medidos facilmente, utilizando-se de dados como entrevistas, observações, documentos entre outros. Beltrão e Nogueira (2011) salientam que a revisão da literatura e a análise documental se destacam por apresentar dados, informações, registros, elementos que promovem diversas possibilidades de pesquisas futuras e analise de interpretações.

Ainda assim, a pesquisa é descritiva e exploratória que, após as coletas dos dados encaminha-se para análise e discussão. Kocher (2011) salienta que, a "pesquisa exploratória não se trabalha com a relação entre variáveis, mas com o levantamento da presença das varáveis e da sua caracterização quantitativa ou 
qualitativa" (p.27) com o objetivo de aprofundar-se no tema em questão. As técnicas da pesquisa foram embasadas em pesquisa bibliográfica e análise documental constituído pelos temas de estudo.

Os dados foram coletados da pesquisa quantitativa não publicada no ano de 2016 com as 70 estâncias paulistas que o Observatório do Turismo e Eventos da São Paulo Turismo da cidade de São Paulo realizou a pedido da Associação das Prefeituras das Cidades Estâncias do Estado de São Paulo [APRECESP], com o objetivo de averiguar resultados das estâncias paulistas para poder conhecer o andamento da atividade turística perante esses municípios. Todas as estâncias receberam e responderam um formulário contendo perguntas relacionadas ao quadro de recursos humanos, atividades realizadas, fontes de recursos, meios de divulgação, períodos de demanda turística, entre outros questionamentos. Os resultados desta pesquisa foram disponibilizados para esse estudo, que fez um recorte temático considerando apenas os questionamentos que poderiam contribuir para elucidar a questão de pesquisa.

Para melhor apreciação e análise dos resultados da pesquisa do Observatório do Turismo e Eventos da São Paulo Turismo, o presente estudo buscou averiguar o pensamento dos secretários de turismo do estado de São Paulo no ano de 2017 e 2018, por meio de entrevistas abertas realizadas na secretaria de turismo do estado de São Paulo, que segundo Sampieri (2013) "as entrevistas abertas se baseiam em um roteiro geral de conteúdo e o entrevistador tem toda a flexibilidade para trabalhar com elas” (p.426). Salienta-se a necessidade das entrevistas com os secretários estaduais de turismo devido que, as políticas públicas das gestões municipais de turismo aqui tratada pelas estâncias, estão diretamente ligadas ao Dadetur, lotado na Secretaria estadual de Turismo de São Paulo.

Nesse cenário, após a coleta dos dados a pesquisa segue a análise e interpretação dos resultados manifestando elementos que permite uma visão do todo na reflexão de pensar e conhecer a realidade dos fatos apresentados na conjunção da teoria com a prática apresentada.

\section{RESULTADOS E DISCUSSÃO}

\subsection{O PROFISSIONAL DE TURISMO NAS ESTÂNCIAS TURÍSTICAS DO ESTADO DE SÃO PAULO}

O Estado de São Paulo apresenta uma legislação de ação de política pública que beneficia municípios que se destacam por possuírem atrativos turísticos com recursos financeiros para desenvolverem projetos de infraestrutura para o turismo, podendo esse programa ser modelo para outros estados, o que ressalta a importância de profissionais de turismo atuando para o fortalecimento dessas obras em ações de políticas públicas que beneficiam o desenvolvimento da atividade.

O Estado apresenta 70 cidades denominadas estâncias turísticas, que eram classificadas até o ano de 2014 como; balneárias, climáticas, hidrominerais e turísticas, de acordo com suas especificações locais. Atualmente todas são denominadas estâncias turísticas e apresentam atrativos e recursos turísticos, desempenhando um papel de crescimento econômico local, regional, estadual e/ou nacional.

Apesar dos estudos, são poucas as pesquisas sobre a temática das estâncias turísticas paulistas com políticas públicas de turismo, destacando-se as obras de Aulicino (1991), que evidenciam alguns impactos e benefícios nos municípios para as estâncias, que na época da análise era um total de 44 cidades consideradas estâncias. No entanto, as estâncias turísticas hoje apresentam um contexto econômico e social bem diferente da época analisada da autora, e, portanto, apresenta com outros desafios.

A dissertação de Juliano (2015) intitulada 'Avaliação do impacto de políticas públicas em indicadores sociais: turismo e desigualdades nas estâncias de São Paulo' trata das políticas públicas de turismo nas estâncias paulistas, e indica que apesar do crescimento das ações públicas o turismo não consolida o desenvolvimento para as desigualdades sociais. Galvão (2018) discute a novas legislações paulistas publicadas e sua ênfase na necessidade do planejamento, na obra intitulada "Estâncias e municípios de interesse turístico: o exemplo de São Paulo como incentivo ao turismo para o Brasil". Além dessas obras, destacam-se dois textos que foram gerados como resultados de uma ação do Dadetur para repensar a legislação vigente em 2010, o primeiro faz uma análise da trajetória de criação das Estâncias (Raimundo et al, 2010) e o outro traz uma discussão sobre os desafios e perspectivas (Solha et al, 2010).

Todavia, a partir do ano de 2015 surge a lei n.1.261/2015, que apesar da falta da regulamentação até o presente momento do estudo, destaca-se por ser uma ação de política pública que evidencia a necessidade de atuações no desenvolvimento do turismo com ações que realmente fortaleçam o crescimento da atividade, colocando os municípios turísticos em raqueamento a cada três anos no que concerne aos recebimentos dos recursos financeiros. Apesar da nova lei para as estâncias ser um grande passo nas políticas públicas de turismo do Estado, ressalta-se ainda que, é necessário melhorar essas legislações 
enfatizando a importância das obras turísticas para o desenvolvimento sustentável, na qual o turismo só será bom para o turista quando primeiramente for benéfico à população local.

Caraguatatuba foi o primeiro município elevado à condição de estância em 1947, completando em 2018 setenta e um anos de história como estância, recebendo durante todo este período, recursos na época vindos do Fomento de Urbanização e Melhoria das Estâncias (FUMEST), atual Fundo de Melhoria dos Municípios Turísticos (FUMTUR) alocado no Departamento de apoio ao desenvolvimento dos municípios turísticos (DADETUR). Assim como Caraguatatuba, muitos outros municípios recebem investimentos do governo do Estado destinados a melhoria da infraestrutura no turismo, como pode se observar no Quadro 1 .

Quadro 1 - Relação dos municípios e o ano crescente de elevação à condição de Estância Turística

\begin{tabular}{|l|l|l|l|l|l|}
\hline \multicolumn{2}{c}{ Município } & Ano Aunicípio & 1979 & Batatais & 1994 \\
\hline Caraguatatuba & 1947 & Itu & 1979 & Ilha Comprida & 1995 \\
\hline Cananéia & 1948 & São Pedro & 1979 & Eldorado & 1995 \\
\hline Guarujá & 1948 & Embu das Artes & 1986 & Paraguaçu Paulista & 1997 \\
\hline Iguape & 1948 & Campos do Jordão & 1986 & Ribeirão Pires & 1998 \\
\hline Ilhabela & 1948 & Atibaia & 1986 & São José do Barreiro & 1998 \\
\hline Itanhaém & 1948 & Águas da Prata & 1986 & Holambra & 1998 \\
\hline São Sebastião & 1948 & Águas de Lindóia & 1986 & Salto & 1999 \\
\hline Ubatuba & 1948 & Águas de Sta Bárbara & 1986 & Ilha Solteira & 2000 \\
\hline Cunha & 1948 & Águas de São Pedro & 1986 & 2000 \\
\hline Sta R.do P.Quatro & 1950 & Amparo & 1986 & Pereira Barreto & 2000 \\
\hline Campos N. Paulista & 1955 & Ibirá & 1986 & Ibiúna & 2001 \\
\hline Nuporanga & 1962 & Lindóia & 1986 & Joanópolis & 2001 \\
\hline Bragança Paulista & 1964 & Monte Alegre do Sul & 1986 & Salesópolis & 2001 \\
\hline Caconde & 1966 & Poá & 1986 & Paranapanema & 2002 \\
\hline Analândia & 1966 & Serra Negra & 1986 & Avaré & 2002 \\
\hline São B.do Sapucaí & 1967 & Socorro & 1986 & São L.do Paraitinga & 2002 \\
\hline Santo Ant do Pinhal & 1967 & Bananal & 1987 & Piraju & 2003 \\
\hline Peruíbe & 1974 & São Roque & 1990 & Santa Fé do Sul & 2003 \\
\hline São Vicente & 1977 & Presidente Epitácio & 1990 & Tupã & 2014 \\
\hline Mongaguá & 1977 & Bertioga & 1993 & Brotas & 2014 \\
\hline Aparecida & 1978 & Ibitinga & 1993 & Olímpia & 2014 \\
\hline Santos & 1979 & Tremembé & 1993 & Guaratinguetá & \\
\hline Praia Grande & 1979 & Morungaba & 1994 & & \\
\hline Barra Bonita & 1979 & Igaraçu do Tiete & 1994 & & \\
\hline
\end{tabular}

Fonte: Secretaria de Turismo do Estado de São Paulo, 2018

Nesse contexto, em que é possível conhecer os municípios que recebem recursos financeiros do Dadetur, é crucial contextualizar a importância do profissional de turismo no desenvolvimento deste setor nas estâncias turísticas. Mas será que os órgãos públicos dessas prefeituras paulistas estão atuando com profissionais de turismo, que tem um campo de atuação e competência para a área? Todavia, aos olhos da classe política, a caracterização para um município elevado a estância tem sido mais focada nos poderes econômicos providos do Fumtur, do que no desenvolvimento local que o turismo proporciona.

Na pesquisa pôde-se verificar que, dentre os 70 municípios considerados estâncias turísticas, todas declararam um setor, departamento, secretaria municipal ou diretoria que se sobrecarrega das diretrizes do turismo municipal, no entanto quando analisados os fatos observa-se que, apenas $28,6 \%$ das estâncias têm uma secretaria municipal de turismo especifica apenas para o desenvolvimento do turismo; $34,3 \%$ revelam que a estrutura do turismo está constituída em departamentos e/ou diretorias de turismo; $18,6 \%$ dos municípios apresentam a secretaria de turismo e cultura juntos; $11 \%$ revelam a secretaria de turismo interligada com a secretaria de desenvolvimento econômico; e, 7,5\% evidenciaram a secretaria de turismo relacionada com a secretaria de esportes e/ou lazer.0 resultado salienta um quadro satisfatório que, apesar de somente $28,6 \%$ das estâncias terem uma secretaria municipal somente de turismo, todas revelam um setor ligado ou não com outra secretaria ou departamento para o desenvolvimento da atividade.

No que concerne ao quadro de recursos humanos os dados sinalizam a maioria das estâncias com menos de 9 funcionários, tendo apenas as estâncias com maior número de habitantes o seu quadro com mais de 10 funcionários, demonstrando que $50 \%$ das estâncias têm de 1 a 4 pessoas, resultando em um quadro de 
servidores insuficiente para o desenvolvimento de ações em uma secretaria de turismo, considerando execução de planos, programas e projetos, conforme ilustra a tabela 2 a seguir.

Tabela 2. Número de funcionários nas secretarias de Turismo das estâncias turísticas

\begin{tabular}{|c|c|c|}
\hline Número de funcionários & Estâncias & $\%$ \\
\hline 1 & 5 & $7,1 \%$ \\
\hline 2 & 9 & $12,9 \%$ \\
\hline 3 & 12 & $17,1 \%$ \\
\hline 4 & 9 & $12,9 \%$ \\
\hline 5 a 9 & 16 & $22,9 \%$ \\
\hline 10 ou mais & 19 & $27,1 \%$ \\
\hline Total & 70 & $100,0 \%$ \\
\hline
\end{tabular}

Fonte: Dados do relatório do Observatório do Turismo (2016), adaptado pelas autoras

A tabela 2 demonstra que $27 \%$ das estâncias contam com 10 ou mais funcionários no seu quadro de servidores e que, quando analisado perante as demais estâncias observa-se que 73\%dos municípios possuem menos de 9 funcionários. Ainda assim, nos resultados estratificados observa-se que as cidades que relatam maiores números de servidores são as litorâneas e de maior número populacionais como Santos, São Vicente, Ilhabela, Mongaguá, Bertioga, Guarujá e Ubatuba.

Na comparação entre colaboradores concursados e comissionados, as estâncias apresentam um quadro de funcionários comissionados maior do que concursados nas secretarias ou nos departamentos de turismo, enaltecendo uma hipótese de que projetos perdem a continuidade na gestão pública por mudanças de mandato e/ou instabilidade no emprego, conforme ilustra a tabela 3, na qual a maioria das estâncias turísticas com 32,9\%aponta um servidor comissionado e, 28,6\% das cidades relatam ter um servidor concursado.

Tabela3 - Número de funcionários comissionados e concursados nas secretarias de turismo das estâncias turísticas

\begin{tabular}{|c|c|c|c|c|}
\hline \multirow{2}{*}{ Funcionários } & \multicolumn{3}{c}{$\begin{array}{c}c \mid \\
\text { Eargos comissionados }\end{array}$} & \multicolumn{3}{c|}{ Cargos concursados } \\
& 3 & $4,3 \%$ & 8 & $\%$ \\
\hline 0 & 23 & $32,9 \%$ & 20 & $28,4 \%$ \\
\hline 1 & 14 & $20,0 \%$ & 13 & $18,6 \%$ \\
\hline 2 & 11 & $15,7 \%$ & 6 & $8,6 \%$ \\
\hline 3 & 6 & $8,6 \%$ & 4 & $5,7 \%$ \\
\hline 4 & 9 & $12,9 \%$ & 9 & $12,9 \%$ \\
\hline 5 a 9 & 4 & $5,7 \%$ & 10 & $14,3 \%$ \\
\hline 10 ou mais & $\mathbf{7 0}$ & $\mathbf{1 0 0 , 0} \%$ & $\mathbf{7 0}$ & $\mathbf{1 0 0 , 0} \%$ \\
\hline Total & &
\end{tabular}

Fonte: Dados do relatório do Observatório do Turismo (2016), adaptado pelas autoras

No entanto, as estâncias elencadas aqui que apresentam um quadro de mais de 10 funcionários, retratam a realidade de servidores mais concursados do que comissionados nas secretarias e/ou departamentos de turismo. 0 estudo não pode afirmar por não ter pesquisas empíricas sobre o fato, mas considera-se que as cidades litorâneas vêm desenvolvendo um trabalho contínuo de turismo e, por apresentarem maior número de servidores concursados fomenta-se a questão da continuidade de programas e ações para o desenvolvimento e fortalecimento do turismo.

Muitas prefeituras têm a dificuldade ou a falta de vontade de inserir nos seus quadros de recursos humanos servidores efetivos por motivos de custo, visão da gestão municipal e, por ter o poder de acompanhar a nomeação e exoneração de pessoas com maior facilidade nomeada em comissão, principalmente em cidades pequenas. Para tanto, quando as pessoas comissionadas não têm conhecimento ou formação na área, a atividade turística do município sofre um atraso de crescimento, perspectiva e desenvolvimento do turismo não só no que tange ao trade turístico, mas principalmente ao fortalecimento do turismo perante a comunidade local. 
Diante desse contexto, quando se analisa a inserção do profissional de turismo nas estâncias turísticas do estado de São Paulo o quadro é satisfatório apresentando um total de 88 profissionais de turismo atuando nesses municípios. Entretanto, quando comparado com a soma de todos os funcionários o resultado é extremamente tímido, em que, em um total de 705 pessoas trabalhando nas secretarias e departamentos afins de turismo encontram-se apenas $12,5 \%$ de profissionais de turismo, manifestando um número muito baixo na perspectiva do fomento ao turismo no estado de são Paulo por meio da política pública de turismo nas estâncias turísticas.

Observa-se por meio da tabela 4 que $40 \%$ das estâncias mantêm apenas um profissional de turismo na prefeitura, enquanto que 21,4\% relataram não terem nenhum profissional da área. Cabe ressaltar que, a pesquisa não evidencia o nível desse profissional e também a sua participação no planejamento das ações das secretarias de turismo, só retrata que esse profissional tem formação acadêmica e/ou técnica na área de turismo, o que demonstra a competência para atuar na área das políticas públicas de turismo.

Tabela 4 - Número de profissionais de turismo nas secretarias de Turismo das estâncias turísticas

\begin{tabular}{|c|c|c|}
\hline Número de profissionais de turismo & Estâncias & $\%$ \\
\hline 0 & 15 & $21,4 \%$ \\
\hline 1 & 28 & $40,0 \%$ \\
\hline 2 & 13 & $18,6 \%$ \\
\hline 3 & 6 & $8,6 \%$ \\
\hline 4 & 4 & $5,7 \%$ \\
\hline 5 a 9 & 3 & $4,3 \%$ \\
\hline 10 ou mais & 1 & $1,4 \%$ \\
\hline Total & $\mathbf{7 0}$ & $\mathbf{1 0 0 , 0} \%$ \\
\hline
\end{tabular}

Fonte: Dados do relatório do Observatório do Turismo (2016), adaptado pelas autoras

Evidencia-se que, pouco se aproveita dos estudantes formados na área apesar de todo o conhecimento desses profissionais, a inserção deles no mercado de trabalho nos órgãos públicos é ainda muito incipiente demonstrado aqui pelas secretarias e/ou diretorias e departamentos de turismo das 70 estâncias turísticas do estado de São Paulo. A tabela 4 ainda releva que, 21,4\% das estâncias não apresentam nenhum profissional da área, mas sinaliza que as estâncias turísticas que demonstraram 4 ou mais profissionais de turismo nos municípios $(11,4 \%)$ são as cidades que possuem mais servidores concursados e, quando analisado esse dado, observa-se que as cidades litorâneas são as que possuem mais profissionais de turismo, o que releva a hipótese apresentada de continuidade e profissionalização de programas na gestão de turismo.

Para melhor validação desses resultados, o presente estudo entrevistou os secretários de turismo do estado de São Paulo. Apesar da vontade política demonstrada pelos entrevistados é relevante salientar que, a gestão da pasta de turismo no estado de São Paulo vem sofrendo alterações de comando que dificultam as ações em longo prazo, com programas que visam o fortalecimento do turismo. Observa-se que, no decorrer da pesquisa, a secretaria de turismo do estado passou por três secretários num processo temporal de apenas um ano e meio, sinalizando que apesar da boa vontade de todos envolvidos, as dificuldades da permanência do cargo do secretário estadual no procedimento das ações turísticas e gerenciais também afetam o desencadeamento nas ações de turismo das estâncias municipais.

A primeira entrevista ocorreu na data de 19 de junho de 2017 no gabinete do secretário estadual de turismo na época na cidade de São Paulo, denominado aqui entrevistado 1, que permaneceu no cargo de Secretário Estadual de Turismo data de 09/08/2016 até a data de 02/09/2018. Quando questionado sobre a importância do turismólogo para o desenvolvimento do turismo nas estâncias paulista, o entrevistado 1 não se conteve em ressaltar a importância do bacharel em turismo como também de enumerar algumas cidades que se diferem devido à profissionalização na gestão, como a cidade de Brotas, Caconde, Santos, Ilhabela, São Vicente, Santos.

O entrevistado 1 também salientou a importância da articulação das estâncias perante a nova legislação de no $1.261 / 2015$, destacando que a partir da nova lei o envolvimento do setor profissional de turismo para que os municípios consigam se manter no chamado "ranqueamento das estâncias paulistas" será indispensável e muito importante. Ainda para o secretário da época, a aplicação dos planos diretores de turismo serão ferramentas de forte atuação do turismólogo para com o desenvolvimento e fortalecimento do setor no estado de São Paulo, apesar de a nova lei evidenciar a necessidade de um profissional de turismo na elaboração do plano diretor de turismo. 
A segunda entrevista, denominada entrevistado 2 ocorreu em 24 de abril de 2018, em que o entrevistado 2esclareceu que a nova legislação de 2015 dá uma "chacoalhada" nas cidades que são estâncias, com o objetivo de manifestar uma competição saudável entre os municípios paulistas fortalecendo o desenvolvimento do turismo, e que, os municípios que contém profissionais de turismo se destacam e se descararão na frente nessa competição. Ainda assim, o entrevistado 2 salientou que, em sua gestão foi nítido a importância do turismólogo na atuação na Secretaria Estadual de Turismo, onde os profissionais foram os responsáveis pelos pareceres técnicos para o pleito das cidades que estão buscando a denominação do município de Interesse turístico, evidenciando as competências de atuação para análise técnica como: elaboração do plano diretor de turismo, inventários turísticos, pesquisa de demanda turística, entre outros fatores.

O entrevistado 2 também ressaltou que, os gestores públicos devem se atentar para a profissionalização da equipe, ponderando que o bacharel em turismo é o elemento competente com as habilidades técnicas para gerenciar ações de desenvolvimento do turismo, realizar programas que visam à sustentabilidade, o fortalecimento local e regional, além de compor de teorias conceituais e práticas que aspiram ao amadurecimento do turismo em longo prazo, apesar da realidade da maioria das Estâncias ainda não se atentarem para isso. 0 entrevistado 2 permaneceu no cargo até a data de 05 de abril de 2018.

A terceira entrevista aconteceu em 10 de julho de 2018, em que o entrevistado 3 que permaneceu no cargo até a data de 18 de dezembro de 2018, salientou como os demais entrevistados que, as estâncias são locais privilegiadas e aptas para desenvolver o turismo e, as secretarias de turismo dos municípios estão desenvolvendo projetos como implantação de sinalização dos pontos de visitação, revitalização e construção de equipamentos, recapeamento e pavimentação de ruas, entre outras. 0 entrevistado 3 ainda salientou que, antes que haja a liberação dos recursos estaduais, a equipe técnica de turismo da secretaria estadual de turismo analisa os projetos apresentados pelos municípios e, ressalta que os investimentos devem ser utilizados para fomentar a atividade e melhorar os serviços públicos prestados à população das localidades.

O entrevistado 3 discorreu que o ranqueamento é uma forma de estimular os Municípios Turísticos a investirem ainda mais no fomento do setor com profissionais formados na área de turismo. Na entrevista, o entrevistado 3 destacou que, para a elaboração da regulamentação do ranqueamento da legislação de 2015serãonecessárias várias audiências públicas para ouvir principalmente a classe técnica formada por bacharéis de turismo, professores, grupos de pesquisas que tem a capacidade e a competência para discutir a regulamentação do ranqueamento com técnica e profissionalismo. Contudo, o entrevistado 3 salientou que os profissionais de turismo são responsáveis pela pesquisa, planejamento, organização e promoção das atividades ligadas ao setor e que são de vital importância para a gestão das políticas púbicas nas estâncias e nos municípios de interesse turístico.

Apesar de todos os entrevistados fomentarem a importância do profissional de turismo para o mercado da gestão das políticas públicas a atuação do turismólogo é ainda muito incipiente no setor da gestão das políticas públicas de turismo, em especial aqui nas estâncias paulistas, ocasionando a falta de fortalecimento do crescimento do turismo no estado de São Paulo. Acredita-se que, a maioria dos municípios considerados estâncias não conseguiu fortalecer o turismo comparado com a análise do tempo de recursos financeiros recebidos. Será que se os governantes das estâncias tivessem admitidos turismólogos nos setores competentes técnicos e/ou cargos políticos, o cenário do turismo atual das estâncias poderia ser outro? Enfim, infelizmente não é possível encontrar estudos, dados, pesquisas, que possa validar essa questão.

\section{CONSIDERAÇÕES FINAIS}

0 artigo traz à tona uma reflexão da importância do profissional de turismo para o desenvolvimento e fortalecimento real do turismo nas gestões das políticas públicas e, em especial nas estâncias turísticas do estado de São Paulo. Como visto a inserção do profissional de turismo ainda é muito reduzido na gestão das políticas públicas de turismo, em especial aqui representado pelo estudo nas estâncias turísticas que recebem recursos financeiros do DADETUR para aplicação de obras de infraestrutura voltados para o fortalecimento do turismo, em que 21,4\% dos municípios considerados estâncias não apresentam nenhum profissional atuando nas secretarias municipais de turismo e, quando a secretaria apresenta um quadro de profissionais de turismo com 3 ou mais funcionários o resultado é ainda mais assustador, revelando que somente $20 \%$ das estâncias turísticas retratam essa realidade. 
Apesar de a pesquisa demonstrar dados do ano de 2016, poucas mudanças foram vistas ao longo dos últimos anos, haja vista que, o cenário econômico do país e das gestões públicas não evoluiu e, a partir do ano de 2020 com a pandemia COVID 2019 as contratações foram mais escassas ainda.

Todavia, evidencia-se a necessidade da inserção de turismólogos nas estâncias paulistas, haja vista que, muitas dessas cidades são consideradas estâncias por ato legal, mas não de fato, podendo ocasionar o descaso e o desperdício do dinheiro público que poderiam ser melhores empregados para o fortalecimento do turismo em longo prazo, apesar de todos os entrevistados sinalizarem que as estâncias estão percebendo a importância do profissional de turismo para implantação de projetos, programas e planos que visam o desenvolvimento do turismo em nível social, ambiental e econômico.

Considera-se imprescindível a defesa da importância do profissional de turismo nos nas ações das políticas públicas, para que estas localidades possam atingir seu potencial de desenvolvimento turístico, tornando-as mais competitivas no cenário regional e nacional. Ressalta-se que o bacharel em turismo pode ser um agente promotor da competitividade dos destinos, pois é dotado de formação, competências e habilidades que, se empregados devidamente, podem fazer diferença no desenvolvimento local e regional.

Acredita-se que essa pesquisa possa trazer um pensamento crítico e reflexivo da quantidade de recursos financeiros que já foram investidos nessas estâncias durante todos esses anos desde a criação da primeira estância balneária em 1947, e a implicação disso no desenvolvimento do setor do turismo. É importante a reflexão desse contexto não só para a inserção do profissional no cenário público, mas para a autonomia técnica desses turismólogos que possam sobressair sobre os interesses políticos e imediatistas locais.

Para tanto, será que os municípios estão realmente se preparando para o fortalecimento e desenvolvimento do turismo? Nesse contexto, até quando as cidades vão continuar no amadorismo? Será que a nova lei n.1.261/2015 no estado de São Paulo poderá interferir na inserção do turismólogo na atuação da gestão das políticas públicas? Ou estamos falando apenas em jogo de poder, onde quem pôde mais, ganha mais.

Retomando do ponto de partida deste trabalho de evidenciar a importância do bacharel em turismo no contexto das políticas públicas de turismo nas secretarias municipais ou afins, em especial aqui representado nos municípios Estâncias do Estado de São Paulo, a questão não se encerra, apenas alimenta o assunto para que novas pesquisas possam surgir no âmbito do estudo das gestões das políticas públicas de turismo, salientando a relação do bacharel em turismo com as ações das políticas públicas de turismo sejam em âmbito municipal, estadual e federal.

\section{AGRADECIMENTO}

O presente trabalho foi realizado com apoio da Coordenação de Aperfeiçoamento de pessoal de Nível Superior - Brasil (CAPES) - Código de financiamento 001

\section{REFERÊNCIAS}

[1] ABBTUR - ASSOCIAÇÃO BRASILEIRA DOS BACHARÉIS EM TURISMO -Quem é o bacharel em turismo. São Paulo, (s.d). Disponível em: http://www.abbtur.com.br/abbtur/conteudo.asp?cod=3. Acesso em: 20 set. 2020.

[2] ANSARAH, M. G. R. Formação e capacitação do profissional em turismo e hotelaria: reflexões e cadastro das instituições educacionais no Brasil. São Paulo: Aleph, 2002.

[3] ASSOCIAÇÃO DAS PREFEITURAS DAS CIDADES ESTÂNCIAS DO ESTADO DE SÃO PAULO - APRECESP, 2016. Disponível em: http://www.aprecesp.com.br/. Acesso em: 30 out. 2019.

[4] AULICINO, M. P. Turismo e Estâncias: impactos e benefícios para os municípios. São Paulo: Futura, 2001.

[5] BENI, M. C. Política e planejamento de turismo no Brasil. São Paulo: Aleph, 2006.

[6] BENI, M. C. Planejamento estratégico e capacidade de gestão. São Paulo: Manole, 2012.

[7] BRASIL. Ministério da Educação MEC. Resolução n. 13, de 24 de novembro de 2006, Brasília, DF; Ministério do turismo, 2006. Disponível em: http://portal.mec.gov.br/cne/arquivos/pdf/rces13_06.pdf. Acesso em: 21 set. 2019.

[8] BRASIL. Presidência da República. Lei n. 12.591 de 18 de janeiro de 2012. Reconhece a profissão de Turismólogo e disciplina o seu exercício. Brasília, DF; Ministério do turismo, 2012. Disponível em: http://www.planalto.gov.br/ccivil_03/_ato2011-2014/2012/lei/112591.htm . Acesso em: 10 abr. 2019. 
[9] BRASIL. Ministério do Turismo. Notícias: Turismo gerou mais de 21,5 mil de empregos em 2020. Brasília, DF; Ministério do turismo, 2021. Disponível em: https://www.gov.br/pt-br/noticias/viagens-eturismo/2021/02/turismo-gerou-mais-de-21-5-mil-empregos-em-2020. Acesso em: 10 jan. 2021.

[10] BELTRÃO, R. E. V. \& NOGUEIRA, F. A. A pesquisa documental nos estudos em administração pública e gestão social no Brasil. Anais. Enanpad, 35. Rio de Janeiro: Anpad, 2011. Disponível em: http://www.anpad.org.br/admin/pdf/EPQ2700.pdf. Acesso em: 10 jan. 2020.

[11] CATRAMBY, T. C V. \& COSTA, S. R. R. Qualificação profissional em turismo como fator de competitividade do setor. Caderno Virtual de Turismo, 4(3), 26-34, 2004. Disponível em: http://www.ivt.coppe.ufrj.br/caderno/index.php/caderno/article/view/60/55. Acesso em: 10 jan. 2020.

[12] CARVALHO, K. D. \& GUZMÁN, S. J. El turismo em la dinámica territorial ¿lógica global, desarrollo local? Estudios y Perspectivas en Turismo, 20(2), 441-461, 2011. Disponível em: https://www.redalyc.org/pdf/1807/180717607010.pdf. Acesso em: 10 jan. 2020.

[13] CESAR, P. de A. B. Turismo e desenvolvimento sustentável: análise dos modelos de planejamento turístico. Caxias do Sul-RS: Educs, 2011.

[14] CRESWELL, W. J. Investigação qualitativa e projeto de pesquisa. Porto Alegre, Penso, 2014.

[15] CRUZ, R. C. Políticas públicas de turismo no Brasil e pesquisa interdisciplinar: uma análise sobre o passado e o presente e reflexões sobre o futuro. In: Azevedo, M. I.; Calabre, L.; Bartholo, R.; Lima, M. A. G.; Moraes, E.A.; Egrejas, M; Lima, D. R.. (Orgs). Turismo, natureza e cultura: diálogos interdisciplinares e políticas públicas. Rio de Janeiro: Fundação Casa de Rui Barbosa. (Ebook), 2016.

[16] DWYER, L., EDWARDS, D. MISTILIS, N., ROMAN, C. \& SCOTT, N. Destination and enterprise management for a tourism future. Tourism Management, 30, 63-74, $2009 . \quad$ Disponível em: http://fac.ksu.edu.sa/sites/default/files/3_3_0.pdf. Acesso em: 10 jul. 2019.

[17] DIAS, R. \& MATOS, F. Políticas Públicas: princípios, propósitos e processos. São Paulo: Atlas, 2012.

[18] FERNANDES, I. P. Planejamento e organização do Turismo. Rio de Janeiro: Elsevier, 2011.

[19] FRATUCCI, A. Turismo e território: relações e complexidade. Caderno Virtual de Turismo. v 14(1), 87-96, 2014. Disponível

em: https://www.researchgate.net/publication/272685381_Turismo_e_territorio_relacoes_e_complexidades. Acesso em: 10 jul. 2019.

[20] GALVÃO, P. R (Org.). Estâncias e municípios de interesse turístico: o exemplo de São Paulo como incentivo ao turismo para o Brasil. Curitiba: Juruá, 2018.

[21] GASTAL, S. \& MOESCH, M. M. Turismo, políticas públicas e cidadania. São Paulo: Aleph, 2007.

[22] HALL, C. M. Planejamento do Turismo: política, processos e relacionamentos. São Paulo: Contexto, 2004.

[23] JULIANO, T. Avaliação do impacto de políticas públicas em indicadores sociais: turismo e desigualdades nas estâncias de São Paulo. Dissertação. Mestrado em Sustentabilidade na Gestão Ambiental, Universidade Federal de São Carlos, Sorocaba, 2015. Disponível em: http://www.ppgsga.ufscar.br/alunos/banco-de-dissertacoes/2015/tiagojuliano-ppgsga-ufscar.pdf. Acesso em: 10 jul. 2019.

[24] KÖCHE, J. C. Fundamentos de metodologia científica: teoria da ciência e iniciação à pesquisa. Petrópolis, RJ: Vozes, 2011.

[25] MERRIAM, S. B. Qualitative research: a guide to design and implementation. San Francisco: Jossey-Bass, 2015.

[26] OBSERVATÓRIO DO TURISMO E EVENTOS DA CIDADE DE SÃO PAULO. Relatório: pesquisa da Aprecesp 2016. São Paulo, 2017

[27] PANOSSO NETO, A. \& TRIGO, L. G. G. Cenários do turismo brasileiro. São Paulo: Aleph, 2009.

[28] RAIMUNDO, S., ALMEIDA, M. V., SOLHA, K. T. \& ALDRIGUI, M.Análise da cronologia da criação das estâncias turísticas do Estado de São Paulo. Anais... VII Seminário da Anptur, 2010. Disponível em: https://www.researchgate.net/publication/280235665_Analise_da_Cronologia_de_Criacao_das_Estancias_Turisticas_ no_Estado_de_Sao_Paulo. Acesso em: 10 jul. 2019.

[29] ROSA, L. V. C., BALSA, L. A. G., TONIN, S. \& COSTA, V. M. F. Trajetória de carreira do profissional formado em Turismo. Rosa dos Ventos - Turismo e Hospitalidade, 8(1), 1-10, 2016. Disponível em: http://www.ucs.br/etc/revistas/index.php/rosadosventos/article/view/3363. Acesso em: 10 jul. 2019.

[30] RUSCHMANN, D. Turismo e planejamento sustentável: a proteção do meio ambiente. Campinas: Papirus. (Ebook kindle), 2016.

[31] SAMPIERIERI, H. R., COLLADO, F.C. \& LUCIO, B.P. M. del. Metodologia de pesquisa. Porto Alegre, Penso, 2013. 
[32] SANTOS, E. G. C. O despertar de um sonho: a inserção do turismólogo no mercado de trabalho de Salvador: Unifacs, 2015.

[33] SÃO PAULO (Estado). Lei no 1.261 de abril de 2015. Estabelece condições e requisitos para a classificação de Estâncias e de Municípios de Interesse Turístico e dá providências correlatas. São Paulo: Governo Estadual, 2015a. Disponível em: https://www.al.sp.gov.br/norma/17459. Acesso em: 03 mar. 2019.

[34] SÃO PAULO (Estado). Lei no 16.283 de julho de 2016. Dispõe sobre o Fundo de

[35] Melhoria dos Municípios Turísticos e dá providências correlatas. São Paulo, Governo Estadual, 2016. Disponível em: https://www.al.sp.gov.br/norma/178743. Acesso em: 03 mar. 2019.

[36] SÃo PAULO (Estado). Seade acompanhará dados do turismo do Estado de São de Paulo. São Paulo, Governo Estadual, 2021. Disponível em: https://www.saopaulo.sp.gov.br/spnoticias/seade-acompanhara-dados-do-turismodo-estado-de-sao-paulo/. Acesso em: 12 jan. 2021.

[37] SILVA, F. C. da. A formação de agenda de políticas públicas de turismo em âmbito local: os casos de Ouro Preto (MG) e Paraty (RJ). Tese. Doutorado em Administração Pública e Governo, Fundação Getúlio Vargas, São Paulo, 2015. Disponível em: http://bibliotecadigital.fgv.br/dspace/handle/10438/13649. Acesso em: 10 jul. 2019.

[38] SOLHA, K.T. Órgãos estaduais de Turismo no Brasil. IN. Trigo, L. G. G.; PANOSSO NETTO, A.; CARVALHO, M. A.; PIRES, P. dos S. Análises regionais e globais do turismo brasileiro. (p. 39-47). São Paulo: Roca, 2005.

[39] SOLHA, K.T., ALDRIGUI, M., ALMEIDA, M. V. \& RAIMUNDO, S. (2010). Estâncias turísticas do Estado de São Paulo: apontamentos históricos sobre sua origem, situação atual e perspectivas de desenvolvimento. Anais... VII Seminário da Anptur. Disponível em: https://www.researchgate.net/publication/280235578_Estancias_Turisticas_do_Estado_de_Sao_Paulo_Apontamentos _Historicos_sobre_suas_Origens_Situacao_Atual_e_Perspectivas_de_Desenvolvimento. Acesso em: 10 jul. 2019.

[40] TRIGO, L. G. G. Regulamentação profissional em turismo: um erro histórico. Turismo: Estudos \& Práticas, 4(2), 96-106, 2015. Disponível em: Acesso em: 10 jul. 2019. Disponível em: http://periodicos.uern.br/index.php/turismo/article/view/1684/909. Acesso em: 10 jul. 2019.

[41] WINKERT, S. L.; VICENTINI, P. W. A contribuição do turismo e do turismólogo para o desenvolvimento local. Anais... IX Fórum Internacional de Turismo do Iguassu, Foz do Iguaçu, Paraná, 2015. Disponível em: https://festivaldeturismodascataratas.com/wp-content/uploads/2015/12/1.-A-Contribui\%C3\%A7\%C3\%A3o-doTurismo-e-do-Turism\%C3\%B3logo-para-o-Desenvolvimento-Local.pdf. Acesso em: 10 jul. 2019. Disponível em: Acesso em: 10 jul. 2019. 


\section{Capítulo 8}

\section{A implementação de um PMO - Planejamento $e$ Inovação na Modernização da Administração Pública}

\section{Linamara Rizzo Battistella \\ Lilian Aparecida Treff}

Resumo : Este artigo apresenta a implementação de um Project Management OfficePMO, baseado na linha Project Management Institute - PMI, em uma Secretaria de Governo do Estado de São Paulo, descrevendo o processo de implantação, soluções adotadas, atribuições e atividades desenvolvidas, dificuldades enfrentadas, lições aprendidas, resultados e benefícios, além de demonstrar a funcionalidade da metodologia estruturada no gerenciamento de projetos. Sugere-se ainda, que as Organizações Públicas e Privadas possam conhecer e comparar os resultados obtidos com as recomendações propostas, para que planejem de forma efetiva suas próprias implantações. 0 modelo de Escritório de Gerenciamento de Projetos para a Secretaria de Estado foi desenvolvido a partir dos resultados obtidos do diagnóstico de maturidade em gerenciamento de projetos e adequado à realidade do órgão governamental. Neste caso específico, o PMO foi criado para apoiar de forma significativa e contundente as estratégias da organização por meio da padronização, integração e organização dos processos, utilizando boas práticas em gerenciamento de projetos. Devido ao fato que, diversos projetos eram gerenciados simultâneamente, foi utilizada uma Estrutura Organizacional Matricial Forte com um alto valor na gestão de projetos, possibilitando respostas mais rápidas para as mudanças inerentes à dinâmica organizacional.

Palavras-chave: Gestão de Projeto; PMO; Metodologia; Administração Pública.

Uma versão deste artigo foi apresentada no VI SINGEP - Simpósio Internacional de Gestão de Projetos, Inovação e Sustentabilidade - V Encontro Luso-Brasileiro de Estratégia 


\section{INTRODUÇÃO}

Atualmente nas empresas, é muito comum à aplicação e desenvolvimento de projetos nos mais diversos ramos de atividade. Isto fez com que a metodologia de Gestão de Projetos cada vez mais ganhasse espaço no ambiente corporativo. Uma prática que vem sendo adotada nos dias de hoje é a implantação dos Escritórios de Gerenciamento de Projetos - PMO ou mais conhecidos como PMO - Project Management Office. Este escritório tem a função de centralizar as melhores práticas de Gestão de Projetos nas empresas em que são implantados, assim como funcionar como uma fonte de consulta e esclarecimento de dúvidas e problemas para os gerentes de projetos, tornando-se um prestador de serviços. É neste cenário que este trabalho se insere, visando apresentar a implementação de um PMO, descrevendo as etapas desenvolvidas, incluindo o planejamento e as fases de implantação.

Historicamente, os projetos nunca foram vistos nesta Secretaria de Governo do Estado de São Paulo como estratégicos ao cumprimento da sua missão e visão. Assim, além de não existir um processo sistematizado de gestão de projetos, apresentava dificuldades no processo de viabilização dos projetos, com as atividades decorrentes da sua missão. A nossa proposta foi uma mudança deste paradigma, com consequentes modificações na estrutura de tomada de decisão. Alinhado ao Planejamento Estratégico da Secretaria de Governo do Estado de São Paulo, tendo como objetivos: dar orientação e suporte que permita a organização desenvolver seus projetos da forma mais eficiente e eficaz possível; apoiar as partes interessadas no gerenciamento e controle dos projetos; criar e disponibilizar o registro e documentação dos projetos implementados de forma a manter uma base de dados histórica útil como referência à "lições aprendidas" para futuros projetos e, assegurar a taxa de sucesso no processo de gestão de projetos, foi criado o Escritório de Gerenciamento de Projetos - PMO.

\subsection{OPORTUNIDADE PERCEBIDA (JUSTIFICATIVA)}

Muitas organizações estão adotando processos formais de gestão de projetos que lhes assegurem a conclusão dos projetos no prazo definido, dentro do orçamento e com o nível de qualidade adequado. Parte da competência na gestão de projetos advêm da proposta de implementar processos e práticas inovadores em todas as organizações públicas e privadas.

Com o crescente e progressivo benefícios da gestão de projetos, destaca-se a implementação de um Project Management Office - PMO, baseado na linha Project Management Institute - PMI, em Organizações Públicas com intuito de solucionar vários problemas de caráter operacional, além de garantir a qualidade total na entrega dos produtos tangíveis-intangíveis e alcançar resultados com excelência. A Administração Pública necessita criar estruturas para apropriar-se dos conhecimentos tácitos de seus funcionários e transformálo em inovações, refletindo diretamente em benefícios à sociedade e evitando desperdício ou mádistribuição dos seus recursos financeiros.

De acordo com Verzuh ${ }^{4}$ (1999), quando uma Organização apresenta grande demanda de projetos e as abordagens são desestruturadas e indisciplinadas, há ineficiências e prejuízos significativos nos resultados. Portanto, a metodologia de gestão de projetos pode ser considerada um processo complexo que implica em mudanças significativas da cultura de uma Organização para uma nova forma de realizar negócios (Crawford5, 2002).

Estima-se que há mais de 50.000 Escritórios de Gerenciamento de Projetos (PMOs) de algum tipo nos Estados Unidos (Rollins, 2003 apud Patah 6 , 2004). No Brasil, o gerenciamento de projetos vem crescendo de forma considerável nos últimos anos, reforçando a relevância de sua implementação, principalmente em Organizações Públicas com intuito de garantir as melhores práticas no gerenciamento de projetos.

Considerando a grande demanda e complexidade dos tipos de projetos na Secretaria de Governo do Estado de São Paulo, identificou-se pouca visibilidade do desempenho real dos projetos pela alta administração e várias ocorrências de retornos durante a aplicabilidade do processo de viabilização. Em adição, havia baixa qualidade das informações sobre o status dos projetos para tomada de decisões estratégicas. Diante disso, optou-se pela implementação de um PMO no referido Órgão Público, criando um ambiente de assessoria para conduzir a mudança de cultura orientada a resultados. Esta estratégia define e aplica os processos de gerenciamento de projetos (iniciação, planejamento, viabilização, execução,

\footnotetext{
${ }^{4}$ Verzuh E. The fast forward MBA in Project Management. New York: John Wiley \& Sons: 1999.

${ }^{5}$ Crawford J K. The Strategic Project Office: Business Case and Implementation Strategy. 2001. Disponível em http://www.pmsolutions.com, Acesso em 14 abr. 2002.

6 Patah LA. Alinhamento estratégico de estrutura organizacional de projetos: Uma análise de múltiplos casos. Dissertação apresentada à Escola Politécnica da Universidade de São Paulo - São Paulo, 2004.
} 
monitoramento e controle e encerramento), proporcionando melhor desempenho dos projetos gerenciados pela Secretaria de Estado, por meio de uma metodologia funcional e consolidada.

\subsection{SOLUÇÃO ADOTADA}

As soluções adotadas para a obtenção de resultados com excelência no gerenciamento de projetos na Administração Pública foram à definição e contratação de recursos humanos para gerenciar, planejar e monitorar todos os projetos, infra-estrutura e de comunicações, garantir recursos financeiros, materiais, tecnológicos e de tempo suficientes para o desenvolvimento das atividades, monitoramento e controle, registro de lições aprendidas e gestão do conhecimento.

A duração do processo de implementação do PMO (Quadro 1) na Secretaria de Estado foi de seis meses, sendo dividido em cinco fases:

Quadro 1 - Fases Metodologia de Implementação

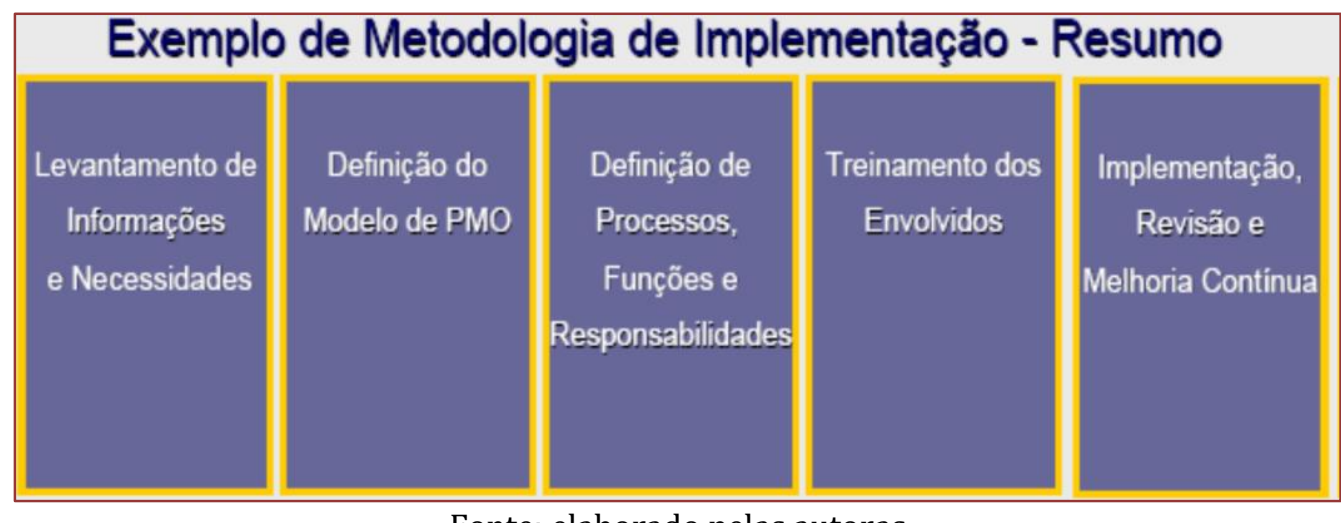

Fonte: elaborado pelas autoras

Estas fases foram previamente definidas com base na maturidade de gestão de projetos, nas melhores práticas de gestão, nos processos operacionais, nas diretrizes do planejamento estratégico, nos recursos físicos e humanos disponíveis e na natureza dos projetos.

As atribuições e/ou atividades desenvolvidas do PMO são: garantir a aplicação da metodologia de gerenciamento de projetos e a qualidade do projeto (quality assurance); padronizar informações, elaborar cronogramas e relatórios, definir estimativas; ser elemento central de informações em gestão de projetos e de apoio aos times de projetos; atuar na resolução de conflitos nos projetos; prover treinamentos e ferramentas adequadas para execução das melhores práticas de gerenciamento de projetos; identificar os riscos de cada projeto com intuito de definir e aplicar ações preventivas e/ou corretivas para preservação do plano de gerenciamento de projetos; aplicar o ciclo PDCA (plan-planejar, do-executar, check-checar e act-agir) para obter o aperfeiçoamento da metodologia proposta dos projetos; monitorar prazos, custo e desempenho no cumprimento dos requisitos contratuais; controlar o histórico dos projetos da organização para utilização futura de novos projetos na forma de lições aprendidas, e gerenciar o Portfólio de Programas e Projetos da Secretaria de Estado.

Dentre as dificuldades enfrentadas e lições aprendidas, destacam-se aceitação da metodologia de gerenciamento dos projetos pelas lideranças; alinhamento do PMO com o Planejamento Estratégico da Instituição; disponibilização dos recursos técnicos (hardware e software) atualizados para aplicar os processos de gerenciamento dos projetos; recrutamento, seleção e treinamento do pessoal necessário para compor a equipe (pessoas qualificadas para gerenciar e prestar suporte técnico aos projetos); compreensão do papel e atribuição do PMO pelas partes interessadas; entendimento do PMO como meio de geração de resultados e prestador de serviços.

É importante salientar que algumas vantagens relevantes da aplicabilidade desta metodologia em nossa organização foi envolvimento da alta administração; definição das funções e responsabilidades de todos os envolvidos no processo de implementação; melhoria na comunicação entre os departamentos; medição e monitoramento das atividades do escopo do projeto na forma de scorecards; suporte, apoio, identificação e mapeamento do perfil psicológico dos stakeholders. Além da otimização do processo de execução dos 
projetos com o auxílio de especialistas técnicos, fomentando ações de Política Pública e distribuição efetiva dos recursos financeiros.

O posicionamento do PMO na Estrutura Organizacional da Secretaria de Governo do Estado de São Paulo foi definido de modo a causar o menor impacto possível à organização e a contribuir da melhor maneira para atingir os seus objetivos estratégicos. Dessa forma, foi elaborada uma "Planilha de Descrição de Cargo" para cada função definida no organograma. É relevante ratificar que a existência do PMO está a serviço de toda organização, conectado com as áreas de negócios e compartilhando informações.

\section{REFERENCIAL TEÓRICO}

Muitas organizações como Petrobrás, Rede Globo, VALE, Michelin, Daiichi Sankyo estão adotando processos formais de gestão de projetos que lhes assegurem a conclusão dos projetos no prazo definido, dentro do orçamento e com o nível de qualidade adequado. Parte da competência na gestão de projetos advém da proposta de implementar processos e práticas inovadoras em todas as organizações públicas e privadas.

O objetivo geral deste artigo, é adaptar uma metodologia de gerenciamento de projetos, sistematizando os modos de conversão do conhecimento (Nonaka e Takeuchi, 1997), e integrá-los a partir de uma visão sistêmica. Neste sentido, visa otimizar os resultados monitorando as atividades durante a execução dos projetos para evitar erros, retrabalho, garantir a transparência na relação com os stakeholders, simplificar processos e promover a flexibilidade das tarefas da equipe priorizando o aprendizado e a melhoria contínua.

A proposta foi investigar alguns dos métodos e modelos de gestão de projetos. Segundo Jefferson Duarte, executivo Internacional e alguns Especialistas em Gerenciamento de Projetos, seguem os modelos mais utilizados, apontando as características e os benefícios de cada um: 1. Apesar de não ser considerado um método de gestão de projetos propriamente dito, mas sim um processo de padronização que nomeia e identifica etapas, regras e áreas do conhecimento, o PMBOK é a mais importante bibliografia de gestão de projetos do mundo; 2. Classificado como um método de gestão de projetos ágil, o Scrum foi inicialmente desenvolvido para o setor de software, mas pode ser facilmente aplicado a qualquer tipo de projeto. A metodologia central do Scrum está baseada em pequenos passos. Assim, em vez de focar no resultado final, a meta principal é dividida em pequenas e curtas etapas, que duram até 4 semanas. Tais etapas são denominadas sprints; abrangendo aspectos de gerenciamento, controle e organização de qualquer tipo de projeto; 3. 0 Kanban é um framework da gestão ágil que funciona para diversos tipos de equipe, já que ele é muito visual e facilmente adaptável à sua realidade. Pode incorporar as Sprints e traduzir todo o trabalho que precisa ser executado em cartões, facilitando a gestão das tarefas para agilizar as entregas ; 4. Formada por diversas associações nacionais e internacionais de gestão de projetos, a International Project Management Association (IPMA) é uma organização sem fins lucrativos que tem como principal objetivo disseminar conhecimentos e práticas de gestão de projetos aplicadas em diversas companhias do mundo inteiro, sejam elas públicas ou privadas. Tomando como base a premissa de que as competências (combinação entre conhecimento, habilidades, comportamento e experiência) são os pilares de toda a gestão de projetos, a IPMA criou o chamado olho das competências, dividido em competências técnicas, contextuais, comportamentais e suas subdivisões; 5. O Project Model Canvas é uma ferramenta de aparência bastante simples, mas que tem muito poder quando o assunto é gerenciar projetos de maneira precisa. Fundamentado em conceitos de neurociência, o método Canvas diz que, ao tornar as ideias palpáveis e visíveis com a criação do quadro de post-its, o processo torna-se mais facilmente compreensível. Para isso, os colaboradores devem fazer 6 perguntas fundamentais: por que, o que, quem, como, quando e quanto?; 6. O Design Thinking é o conjunto de ideias e insights para abordar problemas, relacionados a futuras aquisições de informações, análise de conhecimento e propostas de soluções. 0 processo de Design Thinking combina empatia, criatividade e racionalidade para atender as necessidades do usuário e criar soluções bem sucedidas e de forma inovadora. Ou seja, de forma colaborativa, todos os profissionais se engajem na solução e na entrega do projeto. 0 foco deste estudo foi criar estruturas para que a referida Secretaria de Governo do Estado de São Paulo tendo como base os modelos supracitados, criasse um processo funcional para a execução bem-sucedida dos projetos, e se apropriasse dos conhecimentos tácitos de seus funcionários transformando-os em inovações, refletindo diretamente em benefícios à sociedade na geração de Projetos de Políticas Públicas. 


\section{METODOLOGIA}

Como elementos essenciais e insumos foram considerados o momento atual da Secretaria de Governo do Estado de São Paulo, a organização dos processos e a observação de como eram realizadas as práticas de gestão de projetos (maturidade), de que forma estava definida a gestão das suas atividades e a comunicação entre seus setores (qual o modelo de estrutura organizacional), a existência de processos e ferramentas específicos de gestão da qualidade, dentre outros. Esses foram os fatores de estudo decisivos na escolha e desenho do tipo, características e consequentemente da Metodologia de Gestão de Projetos a ser implantada. Os resultados obtidos na aplicação da metodologia de gestão de projetos foram balizados na comparação com as práticas recomendadas na literatura sobre o assunto.

Tratou-se de uma pesquisa exploratória de natureza qualitativa, transversal (início e fim) e de campo. Os instrumentos de pesquisa foram: questionário, entrevista, análise documental e procedimentos (como aplicar o questionário, como analisar os documentos, como fazer as entrevistas). Os sujeitos da pesquisa foram os gestores (11) que participaram do processo de implementação da metodologia de gerenciamento de projetos.

\section{ANÁLISE DOS RESULTADOS}

Os resultados e benefícios desta metodologia foram total visibilidade dos processos de gerenciamento de projetos pela alta administração; garantia da gestão padronizada de projetos; acompanhamento detalhado de cada projeto; monitoramento de indicadores de desempenho, qualidade e entrega; análise e acompanhamento de riscos; apoio às equipes de desenvolvimento quanto ao gerenciamento e controle dos projetos; status report mensal de todos os projetos para o Sponsor; maior alinhamento dos projetos com os objetivos estratégicos da organização; centralização e disponibilização das informações dos projetos de forma rápida, atualizada e confiável; registro e documentação dos projetos executados de forma a manter uma base de dados histórica, como referência a "lições aprendidas" para futuros projetos, baseadas no ciclo de gestão do conhecimento. A interação que forma a espiral do conhecimento organizacional apresenta as quatro etapas de conversão do conhecimento, aplicada aos processos de gerenciamento de projetos: 1) socialização, representando o compartilhamento do conhecimento tácito entre os indivíduos; 2) externalização, que é a explicitação do conhecimento tácito individual para o grupo; 3) combinação, que é a difusão e sistematização do conhecimento gerado na etapa de externalização e, por fim 4) internalização, sendo a conversão do conhecimento recém-criado em conhecimento tácito da organização (Figura 1).

Figura 1 - Modos de conversão do conhecimento

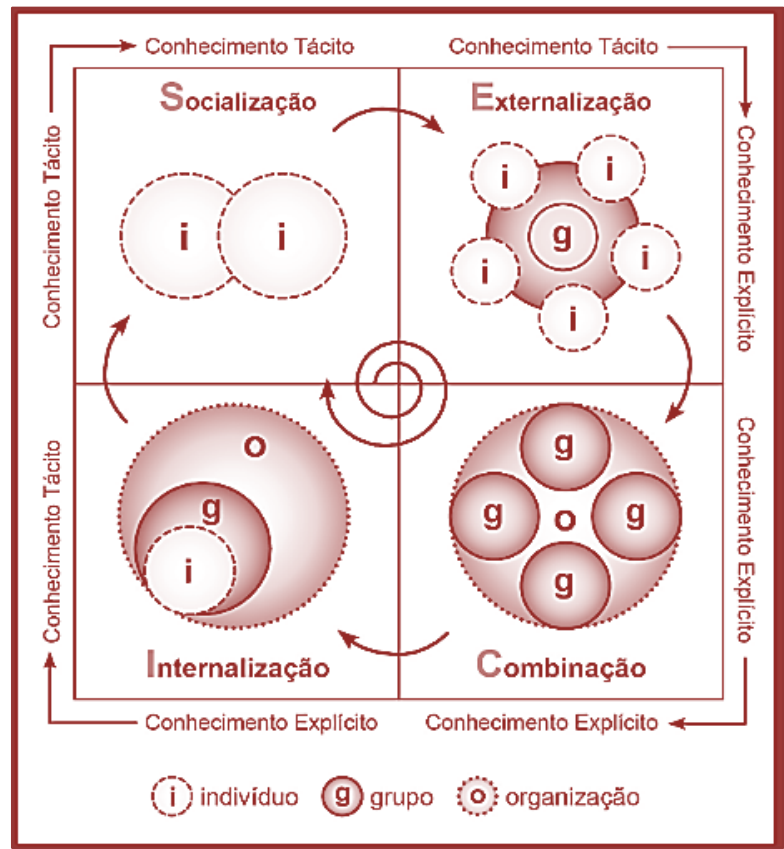

Fonte: Nonaka e Takeuchi (1995) 
É importante considerar o processo de geração de conhecimento novo, o que permite a aplicação de uma metodologia com foco na criação e propagação do conhecimento para organização e para o sucesso de projetos em uma Autarquia Pública. Além de garantir a qualidade total (quality assurance) na entrega dos produtos tangíveis-intangíveis, e alcançar resultados com excelência.

\subsection{DESEMPENHO E EFETIVIDADE DOS PROGRAMAS}

No período de junho/2009 até dezembro/2018, cerca de 200 Projetos foram registrados no Portfólio de Programas e Projetos da Secretaria, demonstrados por status e orientado por eixos (Ações Estratégicas; Trabalho, Esporte, Recreação e Lazer; Cultura, Cidadania e Garantia de Direitos; Proteção, Assistência Social e Moradia Inclusivas; Saúde e Reabilitação; Tecnologia; Educação). As ações obedecem uma lógica cooperativa em que diversos saberes e competências são necessários para a realização dos objetivos propostos. Para citar apenas um exemplo, a realização do curso de Formação de Cuidadores, aparece na classificação "Educação", mas têm uma interface direta com as áreas de Saúde, Garantia de Direitos e Tecnologia.

O Portfólio de Programas e Projetos com seus respectivos resultados, possibilitou um melhor acompanhamento dos mesmos, por meio da transparência no gerenciamento e compartilhamento de informações, e seu alinhamento com o Planejamento Estratégico da Secretaria, contribuindo diretamente para o alcance das metas Institucionais. Outrossim, as apresentações referentes aos resultados dos projetos às partes interessadas, denominadas Ciclo Contínuo de Avaliação Crítica, tinham como objetivo a externalização e socialização do conhecimento, fortalecendo a base das Lições Aprendidas, incorporando novos métodos de trabalho - como parte da rotina, e podendo, ainda, direcionar esse Portifólio para o campo de atuação de Políticas Públicas.

Ressalva-se que nessas reuniões são demonstrados formulários, baseados na metodologia, tais como: Declaração de Escopo, Plano de Gerenciamento de Riscos, Planilha de Atribuições e Responsabilidades, Plano de Gerenciamento da Comunicação, Estrutura Analítica de Projeto-EAP e Relatório de Progresso. Portanto, a metodologia do gerenciamento de projeto auxilia no detalhamento das informações, tornandose uma referência sobre como o projeto deve ser conduzido e quais resultados que ele deve gerar; estabelece processos que garantam a qualidade do produto final; evita readequações e solicitações de mudanças, bem como inclusões e exclusões no escopo, reduzindo o risco de expectativas sobre as entregas e assegurando a excelência dos resultados

\subsection{EFETIVIDADE DOS RESULTADOS}

Durante a fase de implementação do PMO e aplicabilidade da metodologia de gestão de projetos poucos recursos financeiros foram empregados, uma vez que não houve gastos com produtos tecnológicos e treinamento dos envolvidos. Ressalva-se, ainda, que o planejamento e monitoramento permanente durante o processo de gerenciamento dos projetos da Secretaria assegurou a efetiva e regular gestão dos recursos públicos. Após a implementação do PMO, constatamos uma mudança de cultura e mindset com a aplicabilidade da metodologia, proporcionando aos usuários decisões baseadas em dados e informações mais consistentes e consolidadas, construindo uma base sólida de conhecimento.

\subsection{CICLOS DE AVALIAÇÃO PERIÓDICA (INTERVENÇÃO)}

Com o objetivo de medir o desempenho dos projetos, foi utilizado o Painel de Controle (Quadro 2 - Painel de Bordo) de Projetos, contendo indicadores baseados em critérios de avaliação de performance dos projetos e dos stakeholders. Cabe evidenciar que, o acompanhamento dos projetos teve como foco a aplicação do Contínuo Controle de Qualidade - CCQ (processo de melhoria contínua) alinhados com a metodologia proposta. Destarte, o modelo de intervenção adotado foi à implantação de uma Sistemática de Monitoramento e Avaliação, com a aplicação de Reuniões periódicas e Ritual de Análise Crítica das metas, desempenho e resultados alcançados.

Os ciclos de avaliação periódica visam estabelecer momentos de análise, reflexão e discussão conjunta sobre o desempenho e resultados da execução dos programas, projetos e ações; com exposição das razões do não cumprimento ou superação de metas, destacando-se os problemas enfrentados e as iniciativas tomadas na correção de rumos e no compartilhamento de lições aprendidas. É um momento oportuno para avaliação de indicadores de desempenho e efetividade; bem como, para fortalecimento das relações de parcerias e proposição de ações benéficas (como oportunidades de melhorias) relativas à execução dos 
serviços, condução dos planos de trabalho e às melhorias nos processos operacionais e gerenciais do parceiro e do Órgão Público.

Quadro 2 - Exemplo de Painel de Bordo (criado pelas autoras)

\begin{tabular}{|c|c|c|c|c|c|c|}
\hline \multirow[b]{2}{*}{ Critérios de Avaliação } & \multirow[b]{2}{*}{ Projeto A } & \multirow[b]{2}{*}{ Projeto B } & \multirow[b]{2}{*}{ Projeto C } & \multirow[b]{2}{*}{ Projeto D } & \multirow[b]{2}{*}{ ProjetoE } & \multirow[b]{2}{*}{ PORTFÓLIO } \\
\hline & & & & & & \\
\hline 1 VISÃO GERAL (35\%) & $83,3 \%$ & $100,0 \%$ & $83,3 \%$ & $100,0 \%$ & $100,0 \%$ & $93,3 \%$ \\
\hline 1.1 Grau de envolvimento da instituição parceira & 2 & 2 & 1 & 2 & 2 & $90,0 \%$ \\
\hline 1.2 Inclusões e/ov exclusões no escopo do projeto & 1 & 2 & 2 & 2 & 2 & $90,0 \%$ \\
\hline 1.3 Execução de resoluções & 2 & 2 & 2 & 2 & 2 & $100,0 \%$ \\
\hline 2 INDICADORES (25\%) & $100,0 \%$ & $100,0 \%$ & $100,0 \%$ & $100,0 \%$ & $100,0 \%$ & $100,0 \%$ \\
\hline 2.1 Atividades realizadas & 2 & 2 & 2 & 2 & 2 & $100,0 \%$ \\
\hline 2.2 Orçamento realizado & 2 & 2 & 2 & 2 & 2 & $100,0 \%$ \\
\hline 3 DOCUMENTOS (15\%) & $50,0 \%$ & $100,0 \%$ & $100,0 \%$ & $100,0 \%$ & $100,0 \%$ & $90,0 \%$ \\
\hline 3.1 Gestão de riscos & 0 & 2 & 2 & 2 & 2 & $80,0 \%$ \\
\hline 3.2 Relatório de progresso & 2 & 2 & 2 & NA & 2 & $100,0 \%$ \\
\hline 4 STAKEHOLDERS (25\%) & $83,3 \%$ & $100,0 \%$ & $75,0 \%$ & $100,0 \%$ & $100,0 \%$ & $91,7 \%$ \\
\hline 4.1 Participação do Gestor do Contrato & 1 & 2 & 2 & 2 & 2 & $90,0 \%$ \\
\hline 4.2 Participação do Especialista Técnico & 2 & 2 & NA & NA & NA & $100,0 \%$ \\
\hline 4.3 Avaliação da Instituição Parceira & $\overline{2}$ & $\overline{2}$ & 1 & 2 & 2 & $90,0 \%$ \\
\hline TOTAL POR PROJETO & $82,5 \%$ & $100,0 \%$ & $87,9 \%$ & $100,0 \%$ & $100,0 \%$ & $94,1 \%$ \\
\hline
\end{tabular}

\begin{tabular}{|c|c|c|}
\hline \multicolumn{3}{|c|}{ LEGENDAS } \\
\hline NA-Não Avaliado & $\mathrm{Nl}$ - Não Informado & \\
\hline Nota 2 & Nota 1 & Nota 0 \\
\hline \multicolumn{3}{|l|}{ I VISÃO GERAL (35\%) } \\
\hline $\begin{array}{l}\text { 1.1 Participa sem requerer solicitações do } \\
\text { EGP (Escritório de Gestão de Projetos). }\end{array}$ & Participa quando solicitado pelo EGP. & Não participa, mesmo que solicitado pelo EGP. \\
\hline $\begin{array}{l}\text { 1.2 Apresenta inclusões e/ou exclusões - } \\
\text { até } 3 \text { (três). }\end{array}$ & $\begin{array}{l}\text { Apresenta inclusões e/ov exclusões, mantend } \\
\text { se em padrão tolerado - } 4 \text { (quatro) a } 5 \text { (cinco) }\end{array}$ & $\begin{array}{l}\text { - Apresenta inclusões e/ou exclusões, acima do tolerado } \\
-6 \text { (seis). }\end{array}$ \\
\hline 1.3 Cumprimento integral das resoluções. & Cumprimento parcial das resoluções. & Descumprimento das resoluções. \\
\hline \multicolumn{3}{|l|}{2 INDICADORES (25\%) } \\
\hline 2.1 Atividades realizadas. & Atividades realizadas parcialmente. & Atividades não realizadas. \\
\hline 2.2 Entre $95 \%$ e $100 \%$ & Desvio de $94 \%$ a $70 \%$. & Desvio abaixo de $69 \%$. \\
\hline \multicolumn{3}{|l|}{ 3DOCUMENTOS (15\%) } \\
\hline 3.1 Não apresenta riscos. & Apresenta riscos gerenciáveis. & Apresenta riscos não gerenciáveis. \\
\hline 3.2 Resultados atingidos. & Resultados atingidos parcialmente. & Resultados não atingidos. \\
\hline \multicolumn{3}{|l|}{4 STAKEHOLDERS (25\%) } \\
\hline $\begin{array}{l}\text { 4.1 A emissão de pareceres ocorre } \\
\text { conforme períodos planejados. }\end{array}$ & $\begin{array}{l}\text { A emissão de pareceres ocorre com atraso } \\
\text { aos períodos planejados. }\end{array}$ & A emissão de pareceres não ocorre. \\
\hline $\begin{array}{l}4.2 \text { Tem acompanhado frequentemente a } \\
\text { execução das atividades, intervindo } \\
\text { quando necessário. }\end{array}$ & $\begin{array}{l}\text { Tem acompanhado a execução das } \\
\text { atividades, mas, só intervém sê solicitado. }\end{array}$ & $\begin{array}{l}\text { Não acompanha a execução das } \\
\text { atividades. }\end{array}$ \\
\hline $\begin{array}{l}4.3 \text { Implementa o projeto de forma } \\
\text { autônoma não requerendo } \\
\text { monitoramento ostensivo. }\end{array}$ & $\begin{array}{l}\text { Implementa o projeto de forma autônoma, } \\
\text { mas, requer monitoramento ostensivo. }\end{array}$ & $\begin{array}{l}\text { Não implementa o projeto de forma } \\
\text { autônoma e requer monitoramento } \\
\text { ostensivo. }\end{array}$ \\
\hline
\end{tabular}




\section{CONSIDERAÇÕES FINAIS}

A implantação do Escritório de Gerenciamento de Projetos descrito foi o primeiro passo para que este se torne altamente eficiente em suas proposições. Podemos verificar que os procedimentos desenvolvidos só serão completamente aceitos se a utilização destes for realizada de forma permanente e institucionalizada.

Um ponto importante para que esta implantação obtivesse sucesso deve-se à prática de disseminar as informações junto aos interessados de forma gradativa, ou seja, não foi passado todo conteúdo de uma única vez. Isto facilitou a adaptação dos envolvidos, permitindo absorver as funcionalidades e benefícios das novas ferramentas e metodologia na gestão dos projetos aos poucos, sem que as rotinas diárias de trabalho as quais estavam acostumados fossem alteradas drasticamente.

Isto só foi possível devido às discussões durante a fase de iniciação do PMO, úteis no sentido de que as ferramentas pudessem ser adaptadas à realidade que a Secretaria necessitava. Em um primeiro momento, a simplificação dos procedimentos era vital para que os gestores de projetos aceitassem a metodologia. Outro fator que auxiliou muito foi o mapeamento dos funcionários em relação ao seu conhecimento em Gestão de Projetos. Este mapeamento mostrou o nível em que se encontravam as lideranças envolvidas e a necessidade da criação de uma matriz de capacitação para o desenvolvimento de conhecimentos e competências específicos em gerenciamento de projetos.

Outro ponto importante a ser mencionado é que os resultados não aparecem de forma rápida, mas sim com o tempo. Aqueles que utilizaram à metodologia e sempre estavam tirando dúvidas com os membros do PMO perceberam uma diminuição no número de problemas durante a execução de seus projetos, mas ainda havia muito a melhorar.

Para que as organizações consigam amadurecer ao ponto de se implantar um PMO é necessário que se quebrem paradigmas, trabalhem e invistam na mudança de cultura, criem um ambiente de colaboração favorável com ganhos claros para todos e não apenas para os executivos. Além de definir um padrão de trabalho a ser utilizado de forma democrática e sem muitas imposições, alinhando a estratégia da organização aos projetos e objetivos a serem alcançados. Enfim, construir um caminho para ser trilhado passo a passo, num ambiente safe to fail que estimule a criatividade e inovação, por meio de estratégias de engajamento para que as partes interessadas consigam entender a importância do projeto e apoiem as mudanças.

Por conseguinte, este alinhamento fomenta a consolidação de fundamentos na construção de uma nova administração pública, garantindo a credibilidade de seus serviços de forma eficiente e eficaz, focados em benefícios tecnológicos e sócio-político-culturais para a sociedade. Consequentemente, pretendemos demonstrar que trabalhar segundo uma metodologia de gerenciamento de projetos é essencial para obter sucesso na expansão da cultura desse modelo de gestão para gerar resultados sustentáveis em uma organização tanto pública quanto privada.

\section{REFERÊNCIAS}

[1] ARAUJO, Osnaldo. Análise SWOT (Strengths, Weaknesses, Opportunities, Threats) ou (Forças, Fraquezas, Oportunidades e Ameaças). Página pessoal Osnaldo Araújo mai.2010 Disponível em: http://www.dearaujo.ecn.br/cgibin/asp/analiseSwot.asp. Acesso em 29 de mai. 2010.

[2] CRAWFORD, J. K. Making a Place for Success, Project Management Best Pratices Report, Junho de 2000.

[3] DAI, X. C. (2001) The role of the project management office in achieving project success. Doctoral thesis. USA: The George Washington University.

[4] DINSMORE, P.C., Winning in business with enterprise Project management. New York. Amacon Books. 1999.

[5] GERHARD, E., Causas e consequências da implantação de um PMO - Project Management Office. Monografia (Graduação em Informática). São Leopoldo: Universidade do Vale do Rio dos Sinos, 2004.

[6] KERZNER, H., Gestão de Projetos As Melhores Práticas. Porto Alegre. Bookman. 2002.

[7] MARTINS, V. A.; MARTINS, M. R.. Competências organizacionais para Escritórios de Gerenciamento de Projetos (PMO): ensaio para um modelo de análise. 2005 (Seminários em Administração). Disponível em http://www.ead.fea.usp.br/emead/8semead/resultado/trabalhosPDF/361. pdf. Acesso em 11/07/2007.

[8] NONAKA, I.; TAKEUCHI, H. Criação de conhecimento na empresa. Rio de Janeiro: Campus, 1997.

[9] PRADO, Darci - Gerenciamento de Projetos nas Organizações. Editora de Desenvolvimento Gerencial, Minas Gerais (2000). 
[10] PMI. A guide de Project Management Body of Knowledge (PMBOK® Guide). Fifth Edition. Newton Square, PA: PMI, 2013a.

[11] QUELHAS, Osvaldo e BARCAUI, André B, - Perfil de Escritórios de Gerenciamento de Projetos em Organizações Atuantes no Brasil.

[12] SARAIVA, Enrique; FERRAREZI, Elisabete. Políticas Públicas: coletânea. Brasília,DF:ENAP, 2006. V. 1 e 2.

[13] SENGE, P. M. A quinta disciplina. São Paulo: Best Seller, 2001.

[14] SATO, C. E. Y.; DERGINT, E. A.; HATAKEYAMA, K. A utilização do Escritório de Projetos como instrumento para a melhoria da produtividade sistêmica das organizações.Disponível em:

http://www.ppgte.cefetpr.br/semanatecnologia/comunicacoes/a_utilizacao_do.pdf.

[15] SBRAGLIA, R.; RODRIGUEZ, I., GONZÁLEZ, F., Escritório de Gerenciamento de projetos: teoria e prática. Artigo (série de working papers no 02/007) - Faculdade de Administração da Faculdade de Economia, Administração e Contabilidade - Departamento de Administração. Disponível em: http://www.ead.fea.usp.br/ wpapers/2002/ 02007.PDF>. Acesso em: 09/04/2007.

[16] TREFF L, BATTISTELLA LR. Inovação em Gestão de Projetos na Administração Pública. Rio de Janeiro: Brasport, 2013.

[17] VARGAS, Ricardo V. Gerenciamento de Projetos: estabelecendo diferenciais competitivos: Brasport, $6^{\underline{a}}$ ed. 2009.

[18] YIN, Robert K. Estudo de Caso - planejamento e métodos. 2. ed. Porto Alegre: Bookman, 2001. 


\section{Capítulo 9}

Governança eletrônica municipal e eficiência na distribuição de recursos públicos: Uma análise nos municípios mais populosos do Brasil

Nyalle Barboza Matos

José Dionísio Gomes da Silva

Erivan Ferreira Borges

Victor Godeiro de Medeiros Lima

Resumo: As reformas no setor público e utilização de práticas de governo e governança eletrônica podem ser capazes de melhorar as condições socioeconômicas dos municípios, e a utilização de recursos de maneira eficiente. Com efeito, este trabalho tem por norte discutir: Os municípios mais populosos do Brasil estão cumprindo com as práticas de governança eletrônica em consonância com a legislação vigente e sendo eficientes na distribuição dos recursos públicos? Para elucidar o problema, foi reunida uma amostra com os municípios brasileiros com mais de cem mil habitantes, a fim de verificar a conformidade de seus sítios eletrônicos com as práticas de governança eletrônica. A pontuação média da amostra foi de 44,92\%, o que indica ineficiência dos governos para divulgar informações de forma transparente. Quanto a relação de práticas de governança eletrônica nos municípios e a proxy usada para eficiência na distribuição dos recursos públicos, por meio do modelo de regressão censurada utilizado, a variável mais representativa é o IDHM em sua categoria longevidade, que possui coeficiente significante para explicar a governança em todos os níveis de governança ensejados, com coeficiente máximo de $84,8 \%$. De forma geral, os resultados do modelo utilizado sinalizam que, uma melhoria nas condições socioeconômicas em decorrência da melhor utilização e distribuição dos recursos pode aumentar a adoção das práticas de governança eletrônica.

Palavras-chave: Governança eletrônica; Eficiência municipal; Transparência. 


\section{INTRODUÇÃO}

Recentemente, o advento das tecnologias de informação e comunicação (TIC) passou a interferir significativamente na forma como a informação é disseminada, possibilitando maior rapidez, alcance e disponibilidade de dados e serviços online de interesse público. 0 governo brasileiro vem aderindo a essa revolução, transformando o modo como o Estado desempenha seu papel e aperfeiçoando o funcionamento dos serviços em todas as suas esferas (Mello, 2009).

Segundo Prado (2009), o que hoje é definido como governo eletrônico (e-gov) surge como consequência dessas novas tecnologias de informação, das amplas reformas do Estado e da emergência por temas como accountability, termo que é conceituado como um conjunto de mecanismos de prestação de contas que atuam de modo a garantir o controle público das ações dos governantes, permitindo aos cidadãos maior participação e cobrança das metas traçadas pelo poder público, aumentando a exigência por transparência de seus atos (DINIZ et al., 2009).

No Brasil, preceitos da New Public Managament (NPM) têm sido empregados para combater e inovar acusações de um setor público ineficaz, burocrático e ineficiente, instituindo novo foco na obtenção de resultados, tais como estratégia, uso da descentralização, incentivo à criatividade, à participação da cidadania e criação de transparência dos atos públicos, implantando sistemas políticos que amadureçam cada vez mais a cidadania e favoreçam a accountability (MANDL; DIERX; ILZKOVITZ, 2008).

Avaliar os impactos ocasionados por temas emergentes, como governo eletrônico e NPM, no aumento da transparência, do controle social e da accountability nas diferentes esferas de governo, tem despertado o interesse de estudos que suscitam a discussão de possíveis relações entre os resultados refletidos pelos indicadores sociais de eficiência no gasto público e o aumento da transparência e governança no controle da despesa.

O Brasil tem evoluído no sentido de adequar seus sistemas de governos às novas tecnologias. A Lei de Responsabilidade Fiscal (LRF), tem contribuído para a adesão de práticas de governança eletrônica, definida por Pina, Torres e Acerete (2007) como um conjunto de processos mediados pelas TICs, que interferem, tanto na prestação de serviços, antes prestados apenas de maneira presencial, como no aumento da participação cidadã, contribuindo cada vez mais para práticas de boa governança, que são colocadas à disposição da população 24 horas por dia, por meio da Internet, aproximando governo e cidadãos.

Curristine, Lonti e Jourmard (2007) ressaltam a importância do e-gov para melhorar a eficiência dos recursos, na medida em que fornece programas e informações que facilitam uma melhor distribuição da receita pública de acordo com as necessidades dos cidadãos, priorizando ações para as áreas mais carentes de serviços públicos. Essas práticas permitem a elaboração de políticas eficazes que supram as necessidades individuais e promovam o desenvolvimento social e econômico (DINIZ et al., 2009).

Dentro dessa perspectiva, o governo eletrônico atua potencializando os serviços públicos em conjunto com a ideia de aumento da eficiência. Para Almquist et al., (2013), o aumento da eficiência centra-se na capacidade do governo de transformar sua receita em bens públicos e serviços que beneficiam a economia e promovam o crescimento.

Sob esse prisma, na maioria dos países as práticas e-gov têm sido objeto de pesquisas que procuram identificar outros fatores que expliquem sua utilização ou não, procurando correlações com variáveis como Produto Interno Bruto (PIB) e o Índice de Desenvolvimento Humano (IDH), que contribuam para explicar a utilização de práticas de governança eletrônica, sustentando a teoria de que municípios com melhores condições socioeconômicas mostraram-se mais aderentes às práticas de governança eletrônica (BEUREN; MOURA; KLOEPPEL, 2013).

Um estudo desenvolvido por Prado (2009) analisou 322 trabalhos internacionais cujo tema principal envolvia governo eletrônico e seus reflexos na sociedade, revelando que a análise da literatura aponta para um consenso de que a implantação de novos programas de governo eletrônico contribui no aumento da transparência e no combate à corrupção.

No entanto, ainda que haja esse consenso a respeito das práticas de boa governança e da implantação de programas de governo eletrônico, entende-se que ainda há uma lacuna em relação às pesquisas que relacionam o aumento na utilização das práticas de governança eletrônica às melhorias nas condições socioeconômicas dos municípios, e a distribuição de recursos públicos de maneira eficiente. 
Do acima exposto, surge o questionamento que norteará esta pesquisa: os municípios mais populosos do Brasil estão cumprindo as práticas de governança eletrônica em consonância com a legislação vigente e sendo eficientes na distribuição dos recursos públicos?

A resposta a essa pergunta poderá contribuir para explicar a relação de mais uma variável resultante do aumento da transparência das práticas governamentais em todo o mundo e a consequente pressão na utilização de recursos públicos de forma eficiente.

\section{FUNDAMENTAÇÃO TEÓRICA}

\subsection{GOVERNO E GOVERNANÇA ELETRÔNICA}

Diniz et al. (2009) afirmam que o governo eletrônico surge como consequência da evolução do uso estratégico das TICs como elemento viabilizador de um novo modelo de gestão pública. As definições de governo eletrônico não se restringem apenas à simples automação dos processos e disponibilização de serviços públicos por meio de serviços online na Internet, mas são abrangentes à maneira como o governo, através das TICs, atinge os seus objetivos para cumprimento do papel do Estado (PRAD0, 2009; DINIZ et al. 2009).

Explorando o uso das novas tecnologias, o governo eletrônico possui um enorme potencial democrático, haja vista que aumenta a participação popular e a transparência, fazendo o governo oferecer o que não quer mostrar e mencionar o que poderia esconder, o que pode ocasionar governos cada vez menos corruptos (PINHO, 2008).

Schewester (2009) mapeou a trajetória de utilização do governo eletrônico estabelecendo quatro fases: em um primeiro momento as ferramentas de e-gov foram utilizadas como forma de comunicação intragovernamental, alimentando sistemas de informações dentro das próprias organizações públicas; a segunda fase de utilização começa a criar portais que, com o surgimento da rede mundial de computadores, começam a ser preenchidos com informações de acesso e utilidade pública; posteriormente, o e-gov passa a oferecer serviços e transações online; e, por fim, a última etapa sugere um canal interativo, em que o cidadão possa realmente solicitar serviços dos quais esteja necessitando.

No Brasil, o estágio de informatização e materialização de governo eletrônico refere-se à construção de portais governamentais, nos quais é possível concentrar e disponibilizar os serviços e informações inerentes à gestão, promovendo a realização facilitada de negócios e o acesso à identificação das necessidades sociais (AGOSTINETO; RAUPP, 2010).

Os portais de governo na Internet são sítios eletrônicos públicos que permitem ao cidadão realizar um conjunto de serviços, tais como o acesso a informações públicas disponíveis e canais de comunicação com o governo. Considerando que as políticas de governo eletrônico são meios de implementação das definições políticas da governança eletrônica, os portais de governo se configuram como instrumentos específicos para acesso às informações e serviços públicos pelos cidadãos (PRAD0, 2009).

No Brasil, as primeiras utilizações de e-gov iniciaram-se com a construção do portal da Controladoria Geral da União (CGU) e Projetos do Programa de Governo Eletrônico Brasileiro, cuja plataforma engloba inúmeros projetos nas mais diversas áreas, que contribuem para a melhoria da sociedade, maximizando as funções de governo eletrônico, fazendo-o funcionar como um canal de relacionamento para que o cidadão possa participar no processo de implantação das políticas públicas.

Com intuito de avaliar o propósito de criação desses mecanismos sob a ótica daqueles que seriam os maiores interessados, Damian e Merlo (2013) inovaram ao analisarem os serviços de sites de governo eletrônico, avaliando, de modo inovador e complementar, aspectos considerados por importantes estudos realizados nessa área, tendo em conta o ponto de vista do cidadão, usuário dos serviços avaliados, identificando aspectos importantes para os usuários dos serviços de e-gov que poderiam não estar recebendo a devida atenção de seus gestores.

Na literatura, governo e governança eletrônica têm sido explorados com o intuito de medir seus impactos sociais, como forma de transformação e evolução das práticas de governo, que surgiram como resposta a uma demanda cada vez mais crescente por transparência e eficiência nos serviços públicos, à ligação do $e$ gov como mecanismo de governança eletrônica e a conceitos como accountability, transparência e controle social. Alguns estudos (BASU, 2004; CIBORRA, 2005; PINA; TORRES; ACERETE, 2007) relacionaram empiricamente os impactos do governo eletrônico sobre o desenvolvimento local e eficiência nos 
governos. No Brasil, estudos relacionados ainda tratam da forma como as práticas estão sendo ou não implantadas.

\subsection{ESTUDOS ANTERIORES QUE RELACIONAM GOVERNANÇA E DISTRIBUIÇÃO DE RECURSOS}

A eficiência é um princípio constitucional abrangente a todo agente público (art. 37, CF 1988), que deve realizar as suas atribuições com qualidade, dedicação, celeridade e eficácia no serviço prestado. Além da eficiência, a nova administração pública se preocupa com o resultado do desempenho dos gestores com as finanças e com aspectos institucionais, visto que são cada vez mais cobradas pela legislação medidas que permitam a fiscalização das ações governamentais, como a Lei de Responsabilidade Fiscal, Lei de Transparência e, mais recentemente, a Lei de Acesso à Informação.

0 conceito de eficiência no setor público está atrelado à premissa de gerar o máximo potencial de benefícios para a população, comparando entradas e saídas ou custos e benefícios. Aplicando essa analogia às atividades de gastos dos governos, a receita pública é eficiente quando, dado o montante gasto, produz o maior benefício possível para a população dos municípios. Na maioria das vezes essa comparação é feita para um total de receitas públicas ou para receitas relacionadas com funções específicas, como saúde, educação, redução da pobreza, a construção de infraestruturas e assim por diante (AFONSO; SCCHUKNECHT; TANZI, 2006).

Eficiência Pública, para esta pesquisa, é considerada como relação ótima entre recursos aplicados e resultados alcançados, esses medidos não somente em termos financeiros, mas em função de indicadores sociais (MATIAS-PEREIRA, 2008).

Quanto à utilização de indicadores sociais para a medição de desempenho no setor público, Sano e Montenegro Filho (2013) realçam a necessidade de mais eficiência, eficácia e efetividade (3Es) nas ações governamentais e da mensuração de seus reflexos no desenvolvimento social. Para os autores, uma avaliação sistemática, contínua e eficaz é limitada pela falta de clareza quanto a indicadores de desempenho no setor público.

No Brasil, uma pesquisa semelhante realizada por Beuren, Moura e Kloppel (2013), examinou a relação entre alocação eficiente de recursos e a adoção de práticas de governança eletrônica nos 26 estados brasileiros, utilizando a mesma metodologia de Mello (2009) para mensurar um índice de governança e, para o cálculo da eficiência na utilização das receitas, foram usados como outputs os indicadores sociais PIB per capita e IDH dos estados, entendendo que esses refletiriam o melhor emprego de recursos por parte dos governos, utilizando-os como proxy de desenvolvimento para cada estado. Os autores constataram que os estados com melhores práticas de governança eletrônica são os que apresentaram maior eficiência na utilização das receitas, com correlação positiva para as variáveis.

A relação entre os índices criados a partir da ficha de verificação proposta nesta pesquisa, em conjunto com a eficiência na distribuição de recursos públicos por utilização dos indicadores sociais, é importante no sentido de associar o envolvimento dos municípios analisados com o movimento descrito anteriormente como nova administração pública, que preconiza o gasto público com eficiência e a capacidade de produzir mais com menos recursos, acompanhando a tendência dos governos atuais.

0 quadro 1 é uma síntese dos estudos nacionais que se propuseram a estudar a relação entre práticas de governança eletrônica e seus benefícios, como aumento da transparência e consequente aumento do controle social e accountability, com o aumento da eficiência na utilização dos recursos públicos, relação essa fundamentada na aplicação da Teoria da Agência no setor público, supondo que a quantidade, qualidade e o tipo de informação revelada pelo agente - gestor público -, favorecem a sua permanência como agente e asseguram a defesa dos interesses do principal - cidadão -, o que representa melhorias nas suas condições de vida no aspecto socioeconômico.

Esses estudos têm em comum a hipótese de que os governos com maiores investimentos em áreas de saúde e educação, e maior grau de desenvolvimento social e humano, seriam mais transparentes, divulgando uma maior quantidade de informações sobre a sua administração. Nesse sentido, este estudo acrescenta variáveis explicativas, que podem contribuir para estabelecer uma relação significativa entre o incremento na distribuição eficiente dos recursos em termos de indicadores socioeconômicos e o aumento da governança eletrônica por parte dos municípios. 
Quadro 1: Estudos anteriores e correlação de variáveis.

\begin{tabular}{|c|c|c|}
\hline Autores & Variáveis relacionadas & Contribuições \\
\hline Sousa et al. (2015) & $\begin{array}{l}\text { Densidade Demográfica, Urbanização, } \\
\text { Gastos sociais, Competição Política, } \\
\text { Renda, Nível Educacional, População e } \\
\text { idade. }\end{array}$ & $\begin{array}{l}\text { Identificação dos fatores determinantes dos níveis } \\
\text { de transparência ativa com a utilização de e-gov } \\
\text { (TGA) nos estados brasileiros e sua variação. } \\
\text { Constatou que as variáveis níveis de educação e } \\
\text { renda foram as que mais influenciavam } \\
\text { positivamente o aumento da TGA. }\end{array}$ \\
\hline $\begin{array}{c}\text { Ribeiro e } \\
\text { Zuccoloto (2012) }\end{array}$ & $\begin{array}{l}\text { Índice Firjan de Desenvolvimento } \\
\text { Municipal (IFDM) - nas categorias de } \\
\text { educação, emprego e renda e saúde. }\end{array}$ & $\begin{array}{l}\text { Criação do Índice de Transparência Fiscal dos } \\
\text { Municípios (ITFM) e associação da transparência a } \\
\text { melhores indicadores de desenvolvimento } \\
\text { socioeconômico. }\end{array}$ \\
\hline Cruz et al. (2012) & $\begin{array}{l}\text { PIB per capita, receita orçamentária, } \\
\text { Índice de Desenvolvimento Humano } \\
\text { Municipal (IDH-M), Taxa de } \\
\text { Alfabetização, Índice Firjan de } \\
\text { Desenvolvimento Municipal (IFDM), } \\
\text { Índice de Responsabilidade Fiscal, } \\
\text { Social e de Gestão dos municípios } \\
\text { (IRFS), Índice de Potencial de Consumo } \\
\text { (IPC) e Dinamismo municipal. }\end{array}$ & $\begin{array}{l}\text { Criação do índice de transparência (ITGP-M) e } \\
\text { associação entre as condições socioeconômicas dos } \\
\text { municípios e os níveis de transparência, concluindo } \\
\text { que melhores condições socioeconômicas tendem a } \\
\text { implicar maior nível de transparência por parte dos } \\
\text { municípios. }\end{array}$ \\
\hline Mello (2009) & $\begin{array}{l}\text { Desenvolvimento Econômico (Produto } \\
\text { Interno Bruto) e Desenvolvimento } \\
\text { Social (Índice de Gini e IDH). }\end{array}$ & $\begin{array}{l}\text { Criação do IGEB (Índice de Governança Eletrônica } \\
\text { dos Estados Brasileiros) e evidenciação de } \\
\text { correlação significativa entre governança eletrônica } \\
\text { e variáveis de desenvolvimento econômico e social. }\end{array}$ \\
\hline
\end{tabular}

Fonte: Elaboração própria.

Para Mello (2009), a relação desses indicadores com a governança eletrônica e a quantidade de informações, divulgadas compulsoriamente ou não, dos municípios se justifica por considerar que a boa governança pode atuar na redução da corrupção, na prestação de contas, descentralização governamental, melhorando a gestão dos recursos públicos e a igualdade perante a lei, sendo essencial na redução da pobreza e no aumento da qualidade de vida dos cidadãos, permitindo que estes influenciem as políticas que promovam o crescimento e incentivem a prestação de serviços públicos eficientes.

\section{METODOLOGIA}

Este estudo analisa os portais de transparência dos municípios brasileiros, sítios eletrônicos de acesso público e de caráter obrigatório por força legal, sob os aspectos de governança e a legislação vigente, através da elaboração de um índice de Governança dos Municípios, utilizando uma métrica previamente estabelecida em estudos anteriores.

Quanto à abordagem do problema, este estudo segue a tipologia de pesquisa quantitativa, utilizando-se um modelo de regressão tobit para quantificar a relação entre o índice de governança criado e os indicadores sociais dos municípios. Essa regressão truncada determina quais variáveis influenciam a governança eletrônica em um município.

No Brasil, segundo o Instituto Brasileiro de Geografia e Estatística (IBGE, 2010), existem 5.570 municípios. A pesquisa contempla o universo com todos os municípios brasileiros obrigados pela legislação a prestarem contas de suas ações via portal eletrônico numa amostragem não-probabilística e por conveniência, cujo critério de seleção engloba todos os municípios brasileiros com mais de 100 mil habitantes, de acordo com o censo do IBGE de 2010.

O censo brasileiro de 2010 revela 283 municípios com mais de 100 mil habitantes distribuídos por todo território, todos eles obrigados pela Lei Complementar no 131/2009 a manter um portal de transparência atualizado e com um mínimo de informações exigidas.

A escolha da amostra se deu com base no estudo realizado por Cruz et al. (2012), que identificou que o tamanho da população era uma variável estatisticamente significativa para explicar os fatores que contribuíam para as variações na transparência fiscal dos municípios que, embora sujeitos a uma mesma legislação sobre a divulgação dos dados, possuíam níveis diferentes de transparência.

O período de coleta de dados para avaliação dos portais de transparência ocorreu entre 15 de julho a 20 de novembro de 2014. Os sites foram encontrados e visitados por meio de uma pesquisa em um site de 
busca, o Google, no endereço www.google.com.br, sendo a busca realizada por palavras chaves, com o nome do município seguido da palavra "portal da transparência" ou "prefeitura municipal de".

Para analisar os portais por meio da observação direta os procedimentos iniciais seguiram a sequência de Cruz et al. (2012), com os seguintes passos: ao acessar a página inicial, o conteúdo era acessado a partir do mapa do site; quando a página inicial não continha mapa do site, a busca era feita a partir dos links existentes na página principal; as informações não localizadas eram buscadas por meio do serviço de busca, caso fosse disponibilizado no site.

$\mathrm{Na}$ atribuição dos quesitos de governança são enumerados com base nas metodologias utilizadas nos estudos listados no Quadro 1, acrescentando as novas exigências da Lei de Acesso a Informação. Em cada site municipal visitado foram distribuídas notas entre zero e dois para cada prática observada, em que 0 (zero) significa que a prática não foi encontrada, um (1) quando identificado o cumprimento parcial da prática e dois (2) quando observado o cumprimento integral.

Os resultados das análises dos quesitos de avaliação dos portais foram comparados com as variáveis relacionadas no Quadro 2, abaixo, coletadas do site "Atlas de Desenvolvimento PNUD”, referentes aos censos brasileiros dos anos de 2000 a 2010, a fim de captar a variação dos indicadores nesse período e, então, associar o incremento das práticas de governança eletrônica que têm como marco no Brasil a edição da Lei de Responsabilidade Fiscal (2000) e correlacioná-las com a variável resultante da avaliação dos portais de transparência, chamada de Índice de Governança Eletrônica Municipal (IGEM).

Quadro 2: Resumo das variáveis utilizadas.

\begin{tabular}{|c|c|c|c|}
\hline Variável & Indicador & Definição & $\begin{array}{l}\text { Relação } \\
\text { esperada } \\
\text { na } \\
\text { regressão }\end{array}$ \\
\hline Dependente & $\begin{array}{l}\text { IGEM (Índice de } \\
\text { Governança } \\
\text { Eletrônica } \\
\text { Municipal) }\end{array}$ & $\begin{array}{l}\text { Indicador resultante da avaliação das práticas elencadas na } \\
\text { ficha de avaliação, variando de } 0 \text { a } 1 \text {, representando o nível de } \\
\text { governança municipal }\end{array}$ & \\
\hline Independente & $\begin{array}{l}\text { IDHM (Índice de } \\
\text { Desenvolvimento } \\
\text { Humano } \\
\text { Municipal) }\end{array}$ & $\begin{array}{l}\text { Índice composto que agrega três das mais importantes } \\
\text { dimensões do desenvolvimento humano: a oportunidade de } \\
\text { viver uma vida longa e saudável, de ter acesso ao conhecimento } \\
\text { e ter um padrão de vida que garanta as necessidades básicas, } \\
\text { representadas pela saúde, educação e renda. }\end{array}$ & Positiva \\
\hline $\begin{array}{l}\text { Independent } \\
\mathrm{e}\end{array}$ & $\begin{array}{l}\text { IDHM - } \\
\text { Longevidade }\end{array}$ & $\begin{array}{l}\text { Indicador responsável por medir a expectativa de vida ao } \\
\text { nascer, mostrando o número médio de anos que as } \\
\text { pessoas viveriam a partir do nascimento, mantidos os } \\
\text { mesmos padrões de mortalidade observados no ano de } \\
\text { referência. }\end{array}$ & Positiva \\
\hline Independente & IDHM - Educação & $\begin{array}{l}\text { Indicador do Acesso ao conhecimento, medido pela composição } \\
\text { de indicadores de escolaridade da população adulta e do fluxo } \\
\text { escolar da população jovem. }\end{array}$ & Positiva \\
\hline Independente & IDHM - Renda & $\begin{array}{l}\text { Indicador do Padrão de vida, medido pela renda municipal per } \\
\text { capita, ou seja, a renda média de cada residente de } \\
\text { determinado município. É a soma da renda de todos os } \\
\text { residentes, dividida pelo número de pessoas que moram no } \\
\text { município - inclusive crianças e pessoas sem registro de renda. }\end{array}$ & Positiva \\
\hline Independente & $\begin{array}{l}\text { Taxa de } \\
\text { Analfabetismo }\end{array}$ & $\begin{array}{l}\text { Percentagem das pessoas analfabetas de um grupo etário, em } \\
\text { relação ao total de pessoas do mesmo grupo etário no } \\
\text { município. }\end{array}$ & Negativa \\
\hline Independente & $\begin{array}{l}\text { Percentual de } \\
\text { mais pobres }\end{array}$ & $\begin{array}{l}\text { Percentual de pessoas consideradas pobres - com rendimento } \\
\text { domiciliar inferior a } \mathrm{R} \$ 70 \text { per capita). }\end{array}$ & Negativa \\
\hline Independente & Índice de Gini & $\begin{array}{l}\text { É um instrumento usado para medir o grau de concentração de } \\
\text { renda. Ele aponta a diferença entre os rendimentos dos mais } \\
\text { pobres e dos mais ricos. Numericamente, varia de } 0 \text { a } 1 \text {, sendo } \\
\text { que } 0 \text { representa a situação de total igualdade, ou seja, todos } \\
\text { têm a mesma renda, e o valor } 1 \text { significa completa desigualdade } \\
\text { de renda, ou seja, quando uma só pessoa detém toda a renda do } \\
\text { lugar. }\end{array}$ & Negativa \\
\hline
\end{tabular}

Fonte: Elaborado pela autora, com base em Atlas de Desenvolvimento Humano (2014). 
A escolha das variáveis para estabelecer a relação proposta neste estudo teve como base aquelas utilizadas por estudos anteriores, em que autores dissertam que alguns indicadores sociais poderiam ser influenciados pela transparência e iniciativas de governança eletrônica. Para testar esta relação com outros indicadores sociais, sobre uma nova proxy de eficiência, a variável dependente (IGEM) e as variáveis independentes - indicadores sociais de eficiência - foram correlacionadas e estimadas por meio de um modelo de regressão tobit, considerando a variação dos indicadores entre os anos de 2000 e 2010.

\section{RESULTADOS DA PESQUISA}

\subsection{GOVERNANÇA ELETRÔNICA NOS MUNICÍPIOS BRASILEIROS}

A primeira etapa desta análise consiste em visitar os portais de transparência municipais e aplicar a listagem de verificação de acordo com os itens propostos na ficha de avaliação, e a partir da pontuação final, a atribuir o Índice de Governança Eletrônica Municipal (IGEM ) aos municípios selecionados na amostra, considerando que todos estes, juntamente com a União, os Estados e o Distrito Federal, estão legalmente obrigados a disponibilizarem em tempo real em meios eletrônicos, informações pormenorizadas sobre a suas execuções orçamentárias e financeiras.

Em face dessa obrigatoriedade, é esperado que toda a amostra cumpra a legislação, entretanto, verificouse que dos 283 municípios pesquisados, sete ainda não apresentaram portal de transparência ou sítio eletrônico em que se possa encontrar as informações exigidas legalmente. Esse resultado corresponde a menos de 3\% da amostra e é considerado baixo, quando comparado a estudos como o de Cruz et al. (2012), Ribeiro e Zuccolotto (2012), e Wright e Paulo (2014), em que quase metade da amostra não disponibilizava site oficial ou portal da transparência.

Um apanhado geral sobre a situação dos portais pesquisados pode ser inferido por meio da Tabela 1, que traz a estatística descritiva da amostra, resultando da soma das quatro categorias de governança eletrônica: práticas de conteúdo, serviços, participação cidadã e usabilidade e acessibilidade.

Tabela 1 - Estatística descritiva IGEM.

\begin{tabular}{|l|c|}
\hline \multicolumn{2}{|c|}{ Índice de Governança Eletrônica } \\
\hline Média & 0.4492 \\
\hline Erro padrão & 0.0075 \\
\hline Mediana & 0.4861 \\
\hline Modo & 0.5278 \\
\hline Desvio padrão & 0.1264 \\
\hline Variância da amostra & 0.0160 \\
\hline Mínimo & 0.1389 \\
\hline Máximo & 0.6667 \\
\hline \multicolumn{2}{|c|}{ Fonte: Dados da pesquisa (2014). }
\end{tabular}

A média da pontuação obtida pelos municípios da amostra foi de 44,92\% do atendimento às práticas elencadas, com máxima de 66,67\% para os municípios de Fortaleza (CE) e São José dos Campos (SP), e mínima de 13,87\% para os municípios de Marituba (PA) e Codó (MA). Utilizando uma amostra semelhante composta pelos 100 municípios mais populosos do país, Silva et al. pontuam que é um nível de divulgação de informações insatisfatório, considerando a concentração do desenvolvimento socioeconômico e a participação no PIB brasileiro nos maiores municípios, que nesse caso, possuem média de governança eletrônica inferior a $50 \%$ das práticas verificadas.

\subsection{RELAÇÃO ENTRE GOVERNANÇA ELETRÔNICA E EFICIÊNCIA NA UTILIZAÇÃO DOS RECURSOS PÚBLICOS}

Buscando estabelecer relação entre a governança eletrônica dos municípios mais populosos do Brasil e a distribuição eficiente dos recursos públicos, usando como proxies os indicadores econômicos, foram 
levantados na literatura, aqueles que mais representavam e refletiam as melhorias nas condições socioeconômicas nas localidades estudadas.

Dessa forma, foram coletados, no site Atlas Brasil, os dados referentes ao IDHM geral e em suas dimensões, Renda, Longevidade e Educação, Taxa de Analfabetismo, Percentual de mais Pobres e Índice de Gini, referentes aos anos de 2000 e 2010, para obter sua variação.

A abordagem quantitativa do problema para esclarecer a relação proposta, estabelece que a variável dependente deste estudo representada pelo índice de Governança eletrônica Municipal, apresenta como característica a censura, pelo fato de não ser livremente distribuída entre $-\infty$ e $+\infty$, variando de 0 a 1 , sendo assim, a escolha do modelo Tobit de regressão é uma alternativa adequada para o caso (GUJARATI, 2011).

Em relação aos pressupostos da regressão, foram utilizados os seguintes procedimentos: teste de ShapiroWilk - normalidade dos resíduos -, em relação à heterocedasticidade do modelo, utilizou-se a opção do erro padrão robusto, e, para verificação da multicolinearidade das variáveis, foi usado o Fator de Inflacionamento da Variância (FIV), para indicar o efeito que as outras variáveis dependentes têm sobre o erro padrão de um coeficiente de regressão, sendo a regressão considerada adequada quando este é menor que 5,00 (GUJARATI, 2011).

Quanto à normalidade dos resíduos, verificada por meio do teste Shapiro-Wilk, apenas foram consideradas as variáveis Taxa de Analfabetismo, Índice de Gini e Percentual dos mais Pobres, por não apresentarem problema de normalidade, entretanto, alguns autores, como Brooks (2002) e Corrar, Paulo e Dias Filho (2007), afirmam que de acordo com o teorema do limite central, para amostras com mais de 100 observações, é possível relaxar o pressuposto de normalidade dos resíduos. Quanto ao pressuposto da normalidade, Wright e Paulo (2014) afirma que em casos como esse, em que a relação proposta não tem a finalidade preditiva de explicar a governança eletrônica, mas apenas de elencar indicadores sociais que possam determinar sua variabilidade, a normalidade se torna menos preocupante.

A variável representada pelo índice composto do IDHM e a Taxa de Analfabetismo foram eliminadas da análise de regressão por apresentarem forte correlação com as demais. Para apresentar os resultados do modelo Tobit, considerando que este não permite uma interpretação direta dos coeficientes obtidos na regressão, foram calculados o efeito marginal de cada regressor, condicional a valores estritamente positivos da variável dependente.

Os resultados de cada regressão para os quatro modelos, divididos de acordo com a mediana, para cada nível de governança encontrado na amostra, buscam verificar se a utilização e aderência a práticas de governança eletrônica nos municípios aumenta a eficiência na distribuição de recursos públicos em função dos indicadores sociais analisados. A Tabela 2 apresenta os efeitos marginais de cada variável sobre a variação no índice de governança proposto.

Tabela 2 - Resultado dos efeitos marginais Tobit.

\begin{tabular}{|c|c|c|c|c|}
\hline Variáveis & (1) & (2) & (3) & (4) \\
\hline \multirow{2}{*}{ IDHM - Renda } & -1.094* & $-3.314^{* * *}$ & $-1.946^{* * *}$ & $-3.124 * * *$ \\
\hline & $(0.586)$ & $(1.068)$ & $(0.649)$ & $(0.949)$ \\
\hline \multirow[t]{2}{*}{ IDHM - Longevidade } & $0.541^{* *}$ & $1.381^{* *}$ & $0.848^{* * *}$ & $1.276^{* * *}$ \\
\hline & $(0.263)$ & $(0.552)$ & $(0.308)$ & $(0.489)$ \\
\hline \multirow[t]{2}{*}{ IDHM - Educação } & 0.214 & $0.788^{* *}$ & $0.470^{* *}$ & $0.763^{* *}$ \\
\hline & $(0.197)$ & $(0.346)$ & $(0.210)$ & $(0.311)$ \\
\hline \multirow[t]{2}{*}{ Percentual de mais Pobres } & -0.0803 & -0.150 & -0.100 & -0.165 \\
\hline & $(0.0564)$ & $(0.126)$ & $(0.0666)$ & $(0.110)$ \\
\hline \multirow[t]{2}{*}{ Índice de Gini } & $0.201^{*}$ & 0.312 & $0.256^{* *}$ & $0.387^{* *}$ \\
\hline & $(0.108)$ & $(0.229)$ & $(0.123)$ & $(0.192)$ \\
\hline \multirow[t]{2}{*}{ Constant } & $0.510^{* * *}$ & $0.563^{* * *}$ & $0.501^{* * *}$ & $0.531^{* * *}$ \\
\hline & $(0.0334)$ & $(0.0788)$ & $(0.0412)$ & $(0.0685)$ \\
\hline Pseudo R2 & -0.2919 & 0.5339 & -0.1514 & -0.5901 \\
\hline \multicolumn{5}{|c|}{$\begin{array}{c}\text { (erro padrão robusto em parêntese) }{ }^{* * *} \mathrm{p}<0.01,{ }^{* *} \mathrm{p}<0.05,{ }^{*} \mathrm{p}<0.1 \\
\text { Modelo } 1 \text { Abaixo da mediana } \\
\text { Modelo } 2 \text { Acima da mediana } \\
\text { Modelo } 3 \text { Abaixo do primeiro quartil } \\
\text { Modelo } 4 \text { Acima do terceiro quartil }\end{array}$} \\
\hline
\end{tabular}


Como é demostrado na Tabela 2, muitas das variáveis independentes têm efeito significativo sobre o índice de governança eletrônica municipal, em seus diferentes níveis; e, dentre os sinais esperados para os indicadores, apenas dois coeficientes (IDHM- Renda e Índice de Gini) não condizem com o esperado. A variável mais significativa em termos absolutos é o IDHM Longevidade, que se mostra estatisticamente significante em todos os níveis de governança apresentados. Esse indicador sintetiza as condições sociais, de saúde e de salubridade de uma população, ao considerar as taxas de mortalidade em suas diferentes faixas etárias, englobando todas as causas de morte, tanto por doenças quanto por causas externas, tais como violência e acidentes (ATLAS BRASIL, 2014).

Ressalta-se que o coeficiente de determinação (Pseudo R-quadrado), responsável por medir o grau de ajustamento da regressão às observações e indicar a proporção da variabilidade da variável dependente explicada pelas variáveis independentes, só se mantém positivo, e capaz de explicar o percentual da variação do índice de governança ocorrida nos indicadores sociais, em um modelo: no nível de governança situado acima da mediana, no qual as variações na governança são explicadas em 53,39 pelas variáveis independentes.

Analisando estimativas dos modelos de regressão, o coeficiente positivo e significativo da variável IDHM Educação, em todos os níveis de governança, indica que a relação entre a divulgação de informações dos governantes à sociedade, por meio de dispositivos de governo eletrônico, e o nível de escolaridade da população residente, é positiva, conforme encontrado por Wright e Paulo (2014).

O mesmo não aconteceu com a variável IDHM - Renda, correspondente à razão entre o somatório de todos os rendimentos de todos os indivíduos residentes no município e o número total desses indivíduos (ATLAS BRASIL, 2014). Esse indicador apresentou coeficiente negativo para todos os níveis de governança encontrados, o que vai de encontro à teoria preceituada pelo Banco Mundial (2000) e a OECD (2003), que a renda per capita estaria positivamente associada à boa governança, assim como nos estudos de e Kaufmann e Kraay (2002), que encontraram, em uma análise de âmbito nacional, uma alta correlação entre governança e renda per capita. Considerando esse mesmo pressuposto, o percentual de mais pobres em um município deveria influenciar significativamente o comportamento do índice de governança, porém, o indicador não apresentou significância em nenhum quartil.

Outro resultado que não condiz com a teoria aplicada sobre governança eletrônica no setor público e com os achados de estudos anteriores é a relação entre o Índice de Gini, a relação esperada era que, quanto menor o índice, maior fosse a governança em um município, o que não ocorreu em nenhum nível de governança estabelecido.

Os coeficientes e os sinais das variáveis e seus efeitos marginais, indicam que há uma maior preocupação dos municípios com a transparência e com as informações disponibilizadas em seus portais, na medida em que os governos aplicam recursos e investem de forma eficiente, principalmente em saúde e educação, o que demonstra uma preocupação com os gastos nessas áreas, e com medidas tomadas para melhorar a qualidade da gestão e a relação com a comunidade na qual está inserida.

Os resultados encontrados, analisando o efeito marginal das variáveis independentes para cada nível de governança, permitem deduzir que, para cada estágio que um município atinge, no que diz respeito à divulgação de boas práticas de governança eletrônica, diferentes variáveis podem ser utilizadas para intermediar essa relação.

Ademais, as variáveis mais significativas encontradas nesta pesquisa corroboram os achados de Mello (2009), que ao analisar os estados brasileiros, verificou que aqueles mais desenvolvidos e com maior IDH eram também os mais bem classificados com maior número de práticas de governança eletrônica implantadas.

Assim como na pesquisa de Beuren, Moura \& Kloeppel, (2013), que revelou que a combinação entre os recursos públicos utilizados e o produto dos indicadores socioeconômicos, em decorrência da distribuição desses recursos, são variáveis que contribuem significativamente para explicar a utilização de práticas de governança eletrônica nos estados brasileiros, os resultados sinalizam que, no conjunto, e de formas diferentes para influenciar cada nível de governança eletrônica, uma melhoria nas condições socioeconômicas em decorrência da melhor utilização dos recursos pode proporcionar um aumento na adoção das práticas de governança eletrônica. 


\section{CONSIDERAÇÕES FINAIS}

Este estudo se propôs a compreender a relação entre as práticas de governança adotadas nos portais eletrônicos dos municípios brasileiros com mais de 100 mil habitantes e eficiência na distribuição de recursos públicos, usando como proxies indicadores sociais, disponibilizados pelo PNUD. Para isso, procedeu-se em duas etapas, no primeiro momento, foi verificada a conformidade dos sítios eletrônicos dos municípios com as práticas de governança eletrônica mais lembradas pela literatura e com a legislação vigente, com destaque para as Lei de Transparência e de Acesso à Informação.

A segunda etapa da pesquisa consiste em uma vez analisada a governança eletrônica e suas principais práticas observadas nos municípios, estabelecer uma correlação destas com a eficiência na distribuição dos recursos públicos, representada por meio de indicadores sociais, como o Índice de Desenvolvimento Humano Municipal (IDHM), Índice de Gini, percentual de mais pobres e taxa de analfabetismo. Os resultados encontrados demonstraram que a maior pontuação obtida pela amostra foi de $66,67 \%$, referente aos municípios de Fortaleza (CE) e São José dos Campos (SP), e mínima de 13,87\%, para os municípios de Marituba (PA) e Codó (MA). A pontuação média dos municípios da amostra foi de 44,92\% do atendimento às práticas elencadas, não chegando nem a $50 \%$ do esperado para divulgar informações para a sociedade de forma transparente.

Dessa forma, acredita-se que ainda há muito a se melhorar na gestão municipal, no que diz respeito ao investimento de esforços condizentes com as diversas tecnologias de informação colocadas à disposição para atingir o patamar esperado de prestação de contas e para que a população possa, enfim, exercer um controle social mais eficaz e dinâmico perante as ações dos atos da gestão pública, atendendo os pressupostos da teoria da agência aplicada ao setor público.

A associação de melhores práticas de governança eletrônica à melhores indicadores sociais fica esclarecida quando feita uma comparação para mostrar que entre os municípios que apresentam maiores índices de governança apresentam também mais qualidade de vida e de desenvolvimento humano, analogamente àqueles que possuem nível de governança abaixo da mediana, que possuem alguns indicadores inferiores, quando comparados à media nacional e àqueles que possuem menor governança.

A análise da regressão pelo modelo Tobit e seus efeitos marginais demonstrou um poder explicativo aceitável apenas quando se escolhem níveis de governança acima da mediana encontrada, servindo para explicar 53,39\%, das variações sofridas pelo índice adotado como variável dependente, o que revela que podem ainda existir melhores variáveis e fatores que contribuam para melhor corroborar os pressupostos dados pela relação entre a adoção de práticas de governança e a eficiente distribuição dos recursos. Para o caso dos municípios analisados, pode ocorrer de a noção de eficiência ser mais bem observada na incorporação de outras variáveis que possam refletir melhor a distribuição dos recursos públicos, com o aumento da qualidade de vida.

Considerando que esta investigação analisou apenas os portais eletrônicos dos 283 municípios mais populosos, recomenda-se para pesquisas futuras o estudo de outras instituições, utilizando os quesitos de avaliação aqui propostos ou incluindo mais dados a serem observados e outras variáveis a serem relacionadas com esse índice, ou ainda uma análise quantitativa dessa relação, considerando os inputs recursos - e outputs - indicadores sociais - como nova proxy da eficiência.

Os resultados da pesquisa são relevantes para que cidadãos e funcionários ligados a esses municípios possam verificar o estágio e a evolução das práticas de governança e da transparência na divulgação de informações, as quais devem ser claras e acessíveis a todos os interessados, em meios de comunicação eficazes, com destaque para a Internet, sem no entanto, encerrar a necessidade de evoluir na busca por melhores esclarecimentos das temáticas envolvidas.

\section{REFERÊNCIAS}

[1] AFONSO, A.; FERNANDES, S. Measuring Local Government Spending Efficiency: Evidence for the Lisbon Region. Regional Studies, v. 40(1), p. 39-53, 2006.

[2] AFONSO, A.; SCHUKNECHT, L.; TANZI, Vito. Public Sector Efficiency: An

[3] Iternational Comparison. Public Choice, v. 123, p. 321-347, 2005.

[4] AGOSTINETO, R. C.; RAUPP, F. M. Prestação de contas por meio de portais eletrônicos: um estudo em câmaras municipais da Grande Florianópolis. Revista Universo Contábil, FURB, Blumenau, v. 6, n. 3, jul./set., p. 64-79, 2010 . 
[5] ALMQUIST, R.; GROSSI, G.; HELDEN, J. V.; REICHARD, Christoph. Public sector governance and accountability. Critical Perspectives on Accounting. n. 24, p. 479-487, 2013.

[6] Atlas do Desenvolvimento Humano nas Regiões Metropolitanas Brasileiras. Brasília: PNUD, Ipea, FJP, 2014. [acesso em 25 nov 2014].

[7] BASU, S. E-Government and Developing Countries: An Overview. International Review of Law Computers \& Technology, v. 18, n. 1, março, p. 109-132, 2004.

[8] BRASIL. Controladoria Geral da União. Acesso à informação pública: uma introdução à Lei 12.527, de 18 de novembro de 2011. Brasília, 2011a. Disponível em: <http://www.cgu.gov.br/acessoainformacao/materiaisinteresse/CartilhaAcessoaInformacao.pdf>. Acesso em: 22 jan. 2015.

[9] BEUREN, I. M.; MOURA, G. D.; KLOEPPEL, N. R. Práticas de governança eletrônica e eficiência na utilização das receitas: uma análise nos estados brasileiros. Revista de Administração Pública. Rio de Janeiro, v. 47 n. 2, p. 421-441, mar/abril 2013.

[10] BROOKS, C. Introductory econometrics for finance. Cambridge: Cambridge University Press, 2002.

[11] CIBORRA, C. Interpreting e-government and development Efficiency, transparency or governance at a distance? Information Technology \& People. v. 18 n. 3, p. 260-279, 2005

[12] CORRAR, L. J.; PAULO, E.; DIAS FILHO, J. M. (Coords.). Análise multivariada para cursos de administração, ciências contábeis e economia. São Paulo: Atlas, 2007.

[13] CRUZ, C. F.; SILVA, L. M.; SANTOS, R. Transparência na gestão fiscal: um estudo a partir dos portais eletrônicos dos maiores municípios do Estado do Rio de Janeiro. Contabilidade, gestão e governança. Brasília, v. 12, n. 3, p.102, 2009.

[14] CRUZ, C. F.; FERREIRA, A. C. S.; SILVA, L. M.; MACEDO, M. A. S. Transparência da Gestão pública municipal: um estudo a partir dos portais eletrônicos dos maiores municípios brasileiros. Revista de Administração Pública, Rio de Janeiro v. 46, n. 153 jan./fev. 2012.

[15] CURRISTINE, T.; LONTI, Z.; JOUMARD, I.. Improving Public Sector Efficiency: Challenges and Opportunities. OECD Journal on Budgeting. v. 7, n. 1, 2007.

[16] DAMIAN, I. P. M; MERLO, E. M. Uma análise dos sites de governos eletrônicos no Brasil sob a ótica dos usuários dos serviços e sua satisfação. Revista de Administração Pública. Rio de Janeiro, v. 47, no 4, jul./ago. p. 877-99, 2013.

[17] DINIZ, E. H. et al. O governo eletrônico no Brasil: uma perspectiva histórica a partir de um modelo estruturado de análise. Revista de Administração Pública. Rio de Janeiro, v. 43, no 1, jan/fev. p. 23-48, 2009.

[18] GUJARATI, D. Econometria Básica. São Paulo: Makron Books.Quarta Edição, 2011.

[19] IBGE, INSTITUTO BRASILEIRO DE GEOGRAFIA E ESTATÍSTICA. Contagem da População Censo Brasileiro, 2010.

[20] KAUFMANN, D.; KRAAY, A. Growth without Governance. Economia, v. 3, n. 1, 169-229, 2002.

[21] MANDL, U.; DIERX, A.; ILZKOVITZ, F. The effectiveness and efficiency

[22] of public spending.Economic and Financial Affairs. Economic Papers 301, 2008.

[23] MATIAS-PEREIRA, J.. Administração Pública Comparada: Uma Avaliação das Reformas Administrativas do Brasil, EUA e União Europeia. RAP. Revista Brasileira de Administração Pública, v. 42, 2008.

[24] MELLO, G. R. Estudo das práticas de governança eletrônica: instrumento de controladoria para a tomada de decisões na gestão dos estados brasileiros. 2009. 188 f. Tese (Doutorado) - Curso de Ciências Contábeis, Departamento de Contabilidade e Atuária da Faculdade de Economia, Administração e Contabilidade, Universidade de São Paulo, São Paulo, 2009.

[25] OECD. OECD Reviews of Human resources Management in Government, Belgium, Brussels, Capital Region, Federal Government, Flemish Government, French Community, Walloon Region Advance copy, 2003.

[26] PINA, V., TORRES, L.; ACERETE B. Are ICTs promoting government accountability?: A comparative analysis of e-governance developments in 19 OECD countries. Critical Perspectives on Accounting, v. 2, n. 1, fev., p. 583-602, 2007.

[27] PRADO, O. Governo eletrônico, reforma do estado e transparência: o programa de governo eletrônico do Brasil. 2009. Tese (Doutorado em Administração Pública e Governo). Escola de Administração de Empresas de São Paulo. 197 p. 2009. 
[28] RAUPP, F. M.; PINHO, J. A. G de. Prestação de contas, transparência e participação em portais eletrônicos de câmaras municipais. In: 12 Congresso USP de Controladoria e Contabilidade, 2012, São Paulo, 2012. Anais... São Paulo, USP, 2012.

[29] RIBEIRO, C. P. P.; ZUCCOLOTTO, R. Identificação dos fatores determinantes da transparência na gestão pública dos municípios brasileiros. Concurso Nacional de Monografias Conselheiro Henrique Santillo. 1ํㅡ Lugar. Tribunal de Contas do Estado de Goiás. 2012.

[30] SANO, H.; MONTENEGRo FILHO, M. J. F. As Técnicas de Avaliação da Eficiência, Eficácia e Efetividade na Gestão Pública e sua Relevância para o Desenvolvimento Social e das Ações Públicas. Desenvolvimento em Questão, Editora Unijuí, ano 11, n. 22 jan./abr, 2013.

[31] SOUSA, R.G.; WRIGHT, G. A.; PAULO, E.; MONTE, P. A. A janela que se abre: Um estudo empírico dos determinantes da transparência ativa nos governos dos estados brasileiros. Revista Ambiente Contábil, v. 7. n. 1, p. 176 - 195, jan./jun. 2015.

[32] SCHWESTER, R. W. Examining the Barriers to e-Government Adoption. Eletronic Jornal of e-government, v. 7, n. 1, 2009, p. 113-122.

[33] WRIGHT, G. A.; PAULO, E. Análise dos Fatores Determinantes da Transparência Fiscal Ativa nos Municípios Brasileiros. In: VIII Congresso ANPCONT, 2014, Rio de Janeiro. VIII Congresso ANPCONT, 2014. 


\section{Capítulo 10}

\section{Análisis de la gestión del talento humano en una institución pública, en Perú}

\section{Kelly Milagritos Casana Jara}

Irma Milagros Carhuancho Mendoza

Resumen. En esta sociedad moderna la gestión del talento humano resulta ser una necesidad, sin embargo, se administra a pesar de las limitantes, la motivación es escasa y hace falta mejorar las relaciones interpersonales. En consecuencia, la gestión del talento humano se ha convertido en un factor primordial para la calidad del producto que ofrece la entidad, incluso se encuentra como factor competitivo con las organizaciones modernas. Este artículo busca analizar la gestión del talento humano en una institución pública. La metodología de la investigación tuvo un enfoque cualitativo, se aplicó el método estudio de caso, analítico e inductivo, las subcategorías del estudio correspondieron a los procesos para integrar, organizar, recompensar y desarrollar al personal profesional, las unidades informantes estuvieron conformadas por seis funcionarios públicos, la técnica de recolección de datos consistió en una entrevista de ocho preguntas abiertas, aplicada a través de una guía de entrevista, el método de análisis de datos se realizó a través de la codificación y triangulación usando el programa informático ATLAS.ti versión 8. La gestión del talento humano en una institución pública de Perú no cuenta con un programa de gestión del talento humano, aún se encuentra en proceso de implementación, reajuste y dirección. En tal sentido fortaleciendo y motivando al recurso humano se incrementarán sus conocimientos y habilidades en diversas áreas, logrando consigo el compromiso con la institución y generando un personal proactivo, con actitud, mejor capacitado y que su labor sea adecuadamente remunerada para cubrir sus necesidades.

Palabras clave: gestión; talento humano; desempeño; desarrollo profesional. 


\section{INTRODUCCIÓN}

El recurso humano debe comprometerse a asumir retos, se centrará en buscar y dar soluciones que enriquezcan el valor humano como colaborador y competidor. Para que surja este valor, es preciso: primero, ser co-protagonistas de la gestión, fomentar estrategias y alianzas con los jefes de línea; segundo, exhibir experticia en el desarrollado de las labores, garantizando eficacia y eficiencia; tercero, supervisar y defender los derechos de los trabajadores, exponiendo déficits de gestión y velando su compromiso con la organización (Mendes, 2012). Por ello este trabajo de investigación tiene como objetivo analizar la gestión del talento humano en una institución pública, en Perú. Enfatizo en que las entidades públicas, deben replantear la gestión del talento humano enfocados en la empatía, capacidades y profesionalismo de cada uno de sus colaboradores, compartiendo y motivando sus buenas prácticas en el trabajo, frente a ello me planteo la siguiente pregunta ¿Cómo se desarrolla la gestión del talento humano en una institución pública, en Perú?

\section{FUNDAMENTACIÓN TEÓRICA}

\subsection{TEORÍA DE LAS RELACIONES HUMANAS}

Se inició en el año 1932 con la experiencia de Hawthorne, la cual combatía con los supuestos clásicos a través del énfasis en las personas y en las relaciones humanas, lo materializó en dos enfoques uno de ellos en la organización formal y el otro contemplaba a la motivación, el liderazgo, la comunicación y la dinámica de grupo. Buscó la integración y comportamiento social de los empleados, con sus necesidades psicológicas y la atención hacia nuevas formas de recompensas y sanciones no materiales, mejorar los aspectos emocionales y no racionales del comportamiento de las personas (Chiavenato, 2011).

El efecto Hawthorne, influye en esta teoría, donde explica que los trabajadores responden directamente con productividad toda vez que, ellos sientan como son tratados o atendidos en sus necesidades (Griffin y Ebert, 2005).

Este trabajo se basó en la teoría de las relaciones humanas, que como bien se describe es una teoría integral que abarca tanto la organización formal en todos sus ámbitos, así como la labor del recurso humano, comportamiento y satisfacción de sus necesidades; ambas enfocadas a garantizar el equilibrio interno y externo de la organización.

\subsection{GESTIÓN DEL TALENTO HUMANO}

Administrar a los colaboradores de una organización, es decir el recurso humano, implica tener estrategias enfocadas en planificar, organizar, desarrollar, coordinar y controlar al recuso humano; generando motivación, promoción, eficiencia y compromiso para que la organización pueda alcanzar sus objetivos (Montes y Gonzáles, 2006).

La administración de recursos humanos es una función, un conjunto de políticas, de decisiones y prácticas que se desarrollan para atraer, desarrollar y mantener dentro de la organización a las personas cuyos talentos fortalecerán la competitividad en el mercado de la organización (Chiavenato, 2009).

El término recurso humano, hace énfasis a que el hombre sea un ser reemplazable, así como una pieza de máquina; pero realmente es así, y si lo sustituimos lograremos el mismo éxito. Las organizaciones han invertido en estrategias para potenciar el talento de sus trabajadores, a pesar de que no es de fácil administración el producto que obtendremos después de un correcto manejo, será exitoso (Esparragoza, 2002).

\subsubsection{DE INTEGRAR A LAS PERSONAS}

Actividad que tiene el objetivo de escoger entre todos los candidatos reclutados, a los profesionales adecuados o ideales para el cargo en la convocatoria presentada, es decir, el de contratar al colaborador que tenga y cumpla con el perfil buscado y que más se adapte al puesto (Veiga y Peixoto, 2015). Se caracteriza por integrar, proveer, abastecer, otorgar el recurso humano a la organización, aquí destacan los siguientes eventos:

Mercado de recursos humanos: Constituida por profesionales que tienen el perfil adecuado y cuentan con las capacidades solicitadas para laboral; son el conjunto de candidatos potenciales para poder cubrir esa plaza vacante en la empresa (Chiavenato, 2007). 
Perfil: Corresponde al conjunto de caracteres que engloba, el perfil del puesto a ocupar, la noción teórica y práctica, las competencias de cada uno de los candidatos y otros detalles que previamente fueron definidos por el jefe y que deben incluirse al momento de evaluar al nuevo profesional que se desea incorporar (Alles, 2007).

Reclutamiento de personal: Definida como aquel proceso encargado de atraer a los mejores candidatos para un puesto de trabajo en una organización. A su vez puede ser de tipo interno o externo. (Chiavenato, 2009).

Selección de personal: Filtro de ingreso de las personas a una organización, para aquellos que cumplan con los requisitos o características deseadas. Inicia con la solicitud, luego con el desarrollo de los exámenes de selección, seguida por la etapa de entrevistas, posteriormente la evaluación física - médica y la decisión final (Chiavenato, 2009).

\subsubsection{DE ORGANIZAR A LAS PERSONAS}

Destinado a encargarse de orientar a las personas en el cargo o puesto a desempeñar, así como de la evaluación del desempeño en sus funciones; destacan algunos ítems a considerar:

Indicador: Caracteriza la aprobación de un determinado programa, es una medida referencial de alguna relación existente entre el resultado y sus componentes. Es medible, preciso, demostrable, de utilidad, de fácil comprensión e interpretación, aprobado por la organización y sin sesgos para evitar que sean refutadas (Franklin, 2007).

Orientar al personal: De nada sirve reclutar y seleccionar al personal óptimo, si es que no sabe lo que va a realizar; en esta etapa es deber de la organización explicarle - guiarle - encaminarlo y dejarle en claro las funciones que desarrollará y cómo es la cultura organizacional de la organización (Chiavenato, 2009).

Modelado del trabajo: Cada organización tiene un diseño de trabajo y por ende un diseño de puestos que figura en el organigrama; aquí el personal deberá realizar todas las actividades/tareas que se planearon, modelaron y organizaron para su puesto incluida su relación con los otros puestos, según el diseño organizacional (estructura de la organización) de la entidad donde labora (Chiavenato, 2009).

Perfil o diseño de puesto: Engloba a todos aquellos requisitos que caracterizan el puesto de trabajo los cuales están en relación directa con lo que la organización necesita; de su correcta definición, caracterización y aplicación dependerá para que el proceso de incorporar a un nuevo profesional sea el adecuado (Alles, 2007).

Evaluación del desempeño: Tenemos a la autoevaluación realizada por el gerente, por el mismo personal y el gerente, por el propio equipo de trabajo, por las personas de su alrededor, la realizada al gerente, por una comisión evaluadora (Chiavenato, 2009).

Retroalimentación: El beneficio será mayor si esta actividad es planificada, se realiza de manera inmediata post evaluación, es centrada a la actividad específica y sobre lo que se evidenció (Cabello; Gutiérrez; Grau, 2015).

\subsubsection{DE RECOMPENSAR A LAS PERSONAS}

Se enfoca en motivar e incentivar económicamente o productos alternativos al recurso humano que labora, para que de esta manera pueda satisfacer sus necesidades o por lo menos las básicas; entre ellas tenemos:

Remuneración: La total está compuesta por: la remuneración básica es decir el dinero que recibe mensualmente o por horas efectivas, los incentivos salariales como son los bonos de productividad o de participación por resultados, y las prestaciones como es el seguro de salud, de vida, alimentos subsidiados, entre otros (Chiavenato, 2009).

Programa de incentivos: Genera que los profesionales trabajen en beneficio de la entidad donde se labora. Incluye remuneraciones más altas, premios, vacaciones, promover a otros puestos, distribución de las utilidades e incluso opción de compra de acciones de la empresa (Chiavenato, 2009).

Prestaciones y servicios: Se les otorga como un paquete integral acorde con el perfil y actividades del personal, incluyen planes de asistencia médica, alimentación, seguro de vida, pago por antigüedad, pensión de jubilación, transporte, uso de clubes, becas u otros (Chiavenato, 2009). 


\subsubsection{DE DESARROLLAR A LAS PERSONAS}

Se caracteriza por velar por el avance personal y profesional del recurso humano, haciéndolo más competitivo, destacado y cualificado en comparación con las organizaciones de la competencia:

Capacitación: A través de la aplicación de esta actividad los profesionales mejoran y obtienen nuevas competencias las que contribuirán a que sean productivas con creatividad e iniciativa, enfocadas en el marco del desarrollo exponencial y valor agregado no sólo a la persona sino también a la organización y clientes. El proceso consta de cuatro etapas: diagnóstico, diseño, ejecución y evaluación (Chiavenato, 2009).

Diagnóstico de la necesidad: Estrategia para conocer a ciencia cierta los datos mínimos necesarios para tomar una decisión en cuanto a una actividad que se pretenda ejecutar; este proceso ahorra tiempo, costo y determinación. Nos otorgará las bases, los indicadores, los lineamientos de los programas en concreto de la institución (Reza, 2006).

Desarrollo de las personas y organización: Entre los métodos tenemos la rotación de puesto dentro o fuera de su organización, ser asesor, ser coach, poder participar en comisiones - cursos - seminarios internos o externos, continuar con sus estudios de carrera, entre otros (Chiavenato, 2009).

Motivación: Estímulo que se otorga al colaborador para lograr obtener algún beneficio. Para Reeve (2001) se entiende como aquel proceso psicológico que infiere y expone el origen de la conducta humana y sus principales variantes de comportamiento (Peña, Cañoto y Santalla, 2006).

\subsubsection{DE RETENER A LAS PERSONAS}

Encargada del fomento de las condiciones deseables para que el recurso humano se encuentre satisfecho y pleno laborando en el puesto y organización donde está:

Relación con los empleados: El objetivo de estas actividades es crear un ambiente de confianza, de empatía, de solidaridad y de buena comunicación que permitan que se solucionen en lo posible, los problemas del personal y se cumpla con las metas establecidas por la organización (Chiavenato, 2009).

Higiene, seguridad y calidad de vida: La higiene está íntimamente relacionada con las condiciones del entorno/ambiente (luz, ruido, temperatura, estrés, ergonomía, etc.) de trabajo. La seguridad incluye evitar el riesgo de accidentes, incendios y robos. (Chiavenato, 2009).

\subsubsection{DE SUPERVISAR A LAS PERSONAS}

Se aplica para poder realizar la revisión de las diferentes actividades y de los resultados del recurso humano:

Base de datos y sistema de información: Sistema de información tecnológica, donde se encuentran los datos codificados, donde se pueden procesar y obtener todos los indicadores de las actividades que realice el personal, como: la puntualidad, la productividad, licencias con o sin goce de haber, etc. (Chiavenato, 2009).

\section{METODOLOGÍA}

Tiene un enfoque cualitativo el cual inicia con una idea, luego esta se concretiza y finalmente se aplica; en ella influyen la hermenéutica, la fenomenología tradicional y la interacción simbólica (Monje, 2011). Se recomienda principalmente que se aplique cuando el tema a estudiar no se ha explorado o simplemente ha sido poco revisado (Hernández, 2014). Según el método de la investigación cualitativa ésta corresponde a un estudio de caso, para ser más específicos se trata de una evaluación intensa y profunda de múltiples ámbitos de un fenómeno social o entidad. El objetivo es estudiar, analizar y comprender en detalle las particularidades de la investigación fenomenológica a realizar (Monje, 2011). Con el método inductivo se deducirá lo que sucede de un número determinado de casos al número total de casos estudiados (Duhalde, 1999). Y con el método analítico se segmentará un determinado problema en sus principales componentes o partes, para que puedan ser estudiados de manera individual; es común observar estos métodos en estudios experimentales. 
Corresponde a un estudio de casos, es decir una evaluación completa, detallada, sistemática e individualizada de un hecho. Con el método analítico se estudiará de manera segregada a cada una de las partes que componen el título a investigar (Rodríguez, 2005). El método inductivo, se apoya en determinadas expresiones particulares para inferir expresiones generales (Muñoz, 2015).

Categoría: Nace del marco teórico, con ellas se determinan qué conceptos se utilizarán para dar respuesta a la pregunta de investigación, pueden dividirse en subcategorías (Monje, 2011). Se consideró a una categoría (Gestión del talento humano) con cuatro subcategorías (integrar, organizar, recompensar y desarrollar) conforme al objetivo de la investigación.

Categorización: Permite identificar la aparición de constructos lógicos de la información, la cual fue recopilada en la entrevista a las unidades informantes o las hechas a través de documentos, videos u otros (Galeano, 2013).

Unidades informantes y Técnica de recolección de datos. La información se obtuvo de seis funcionarios (J, $\mathrm{R}, \mathrm{A}, \mathrm{G}, \mathrm{M}, \mathrm{O}$ ), se los visitó en la institución donde laboran, se explicó el objetivo de la investigación y accedieron a la entrevista; debido a que son funcionarios públicos y siendo necesario preservar el derecho a la intimidad, no se consigan los nombres. Se aplicó la siguiente Guía de entrevista:

1. ¿Cómo se realiza el proceso de reclutamiento de personal?

2. ¿Para el proceso de selección de personal, se cumple con los lineamientos de la institución?

3. ¿En qué consiste el proceso de evaluación de desempeño del personal?

4. ¿Qué tipos de remuneración hay para el personal de la institución?

5. ¿Qué tipos de incentivos se otorga al personal que destaca profesionalmente?

6. ¿Cuáles son las prestaciones y servicios que percibe el personal de la institución?

7. ¿De qué manera se determina las necesidades de capacitación del personal?

8. ¿De qué manera la institución fomenta el desarrollo profesional del personal?

En una investigación cualitativa la entrevista que mejor se aplica es una de tipo semiestructurada; aquí el sujeto encargado de interrogar tiene un plan de trabajo de manera general que va adaptando a las respuestas del entrevistado (Packer, 2013). La guía de entrevista contiene los tópicos a investigar, el entrevistador lo direccionará conforme el entrevistado va respondiendo (Kvale, 2011).

\subsection{MÉTODOS DE ANÁLISIS DE DATOS}

Primera etapa: La Codificación, proceso para el análisis de los datos. Charmaz (2014) define a el código como una inferencia simple, sencilla, corta; que permite analizar la información recibida, cada uno de los códigos se entrelazan entre sí y a la vez con la información teórica debidamente sustentada (Monge, 2015). En esta investigación se usó de base al autor Idalberto Chiavenato.

Segunda etapa: La Triangulación, procedimiento encargado de reunir la información recolectada, luego permite enlazar dicha información con el objetivo de la investigación (Cisterna, 2005).

Tercera etapa: Como instrumento de cruce de información se usó el programa informático ATLAS.ti 8 que permitió analizar la información obtenida en este caso en particular los textos. Asimismo, en la tabla 1 se presentan las subcategorias e indicadores, los mismos que fueron codificados previa a la triangulación, de tal forma que luego del análisis se identificó los indicadores emergentes.

Tabla 1. Matriz de categoría y subcategoría

\begin{tabular}{|c|c|c|}
\hline Categoría & Subcategoría & Codificación a priori \\
\hline $\begin{array}{l}\text { Gestión del } \\
\text { talento } \\
\text { humano }\end{array}$ & $\begin{array}{l}\text { Integrar } \\
\text { Organizar } \\
\text { Recompensar } \\
\text { Desarrollar }\end{array}$ & $\begin{array}{l}\text { Perfil, reclutamiento, selección } \\
\text { Indicadores, evaluación desempeño, retroalimentación, diseño } \\
\text { de puesto } \\
\text { Remuneración, incentivos, prestaciones y servicios } \\
\text { Diagnóstico de necesidad, capacitación, desarrollo profesional, } \\
\text { motivación }\end{array}$ \\
\hline
\end{tabular}

Fuente: Elaboración propia. 


\section{RESULTADOS}

Gestión del talento humano

Figura 1 Procesos de la gestión del talento humano.

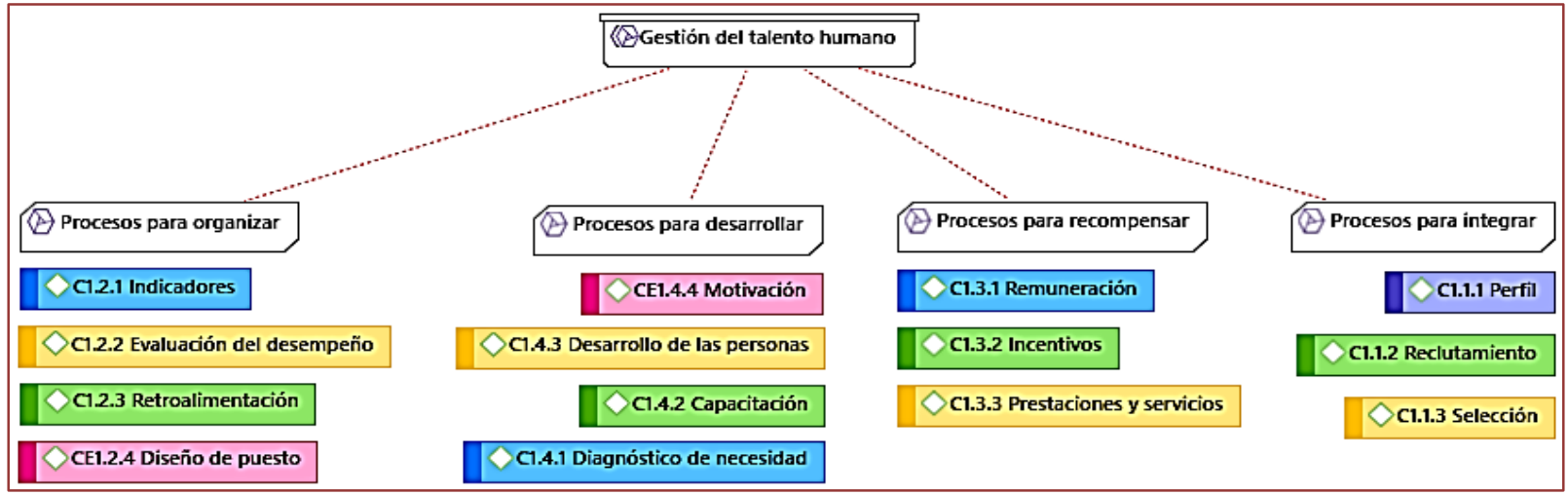

La Figura 1 muestra los procesos de gestión del talento humano.

Los resultados obtenidos son relevantes y consistentes que responden al objetivo planteado pues se enfocaron en virtud de las cuatro subcategorías y posterior categoría, de la investigación:

\section{Proceso para integrar al personal}

Figura 2 Proceso para integrar al personal

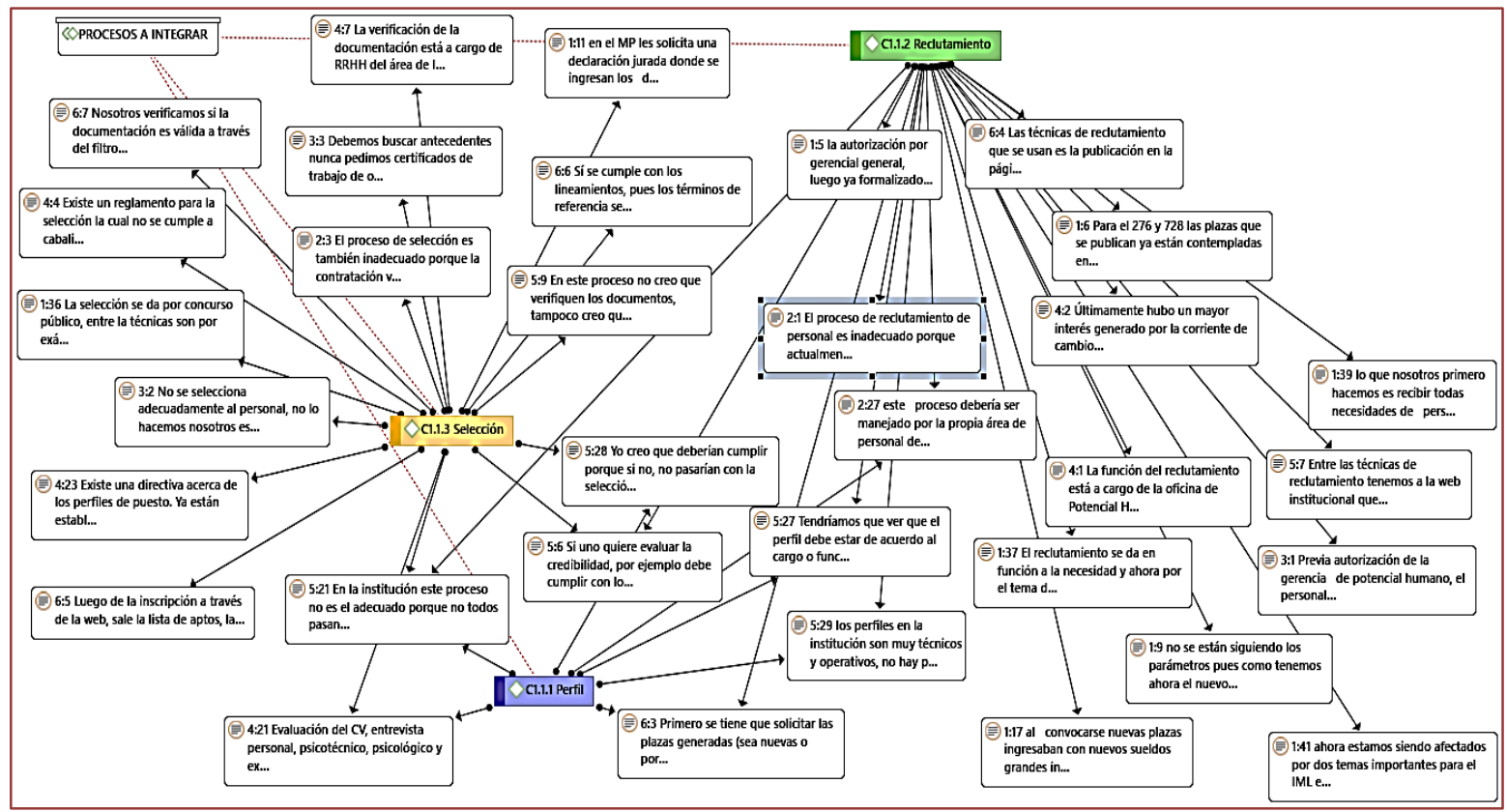

Definir el perfil del futuro profesional que ingresará a la institución, debe estar enfocada dentro de los lineamientos de la organización dos de los entrevistados mencionan: "El perfil debe estar de acuerdo al cargo o función, se debe seguir ese perfil. Hay un perfil del servidor público que menciona que la persona es honesta, laboriosa, tiene conocimiento" (M). “... los perfiles en la institución son muy técnicos y operativos, no hay perfil de valores o ética, si lo hubiera le cambiamos el rostro a la institución". "En la institución este proceso no es el adecuado porque no todos pasan un examen de cualidades, de virtudes; además uno debe de saber que es la imagen de la institución. Uno debe meterse bien en la cabeza que si bien es cierto es una institución pública, uno debe estar comprometido y brindar un servicio como una institución privada ... Yo creo que deberían cumplir porque si no, no pasarían con la selección” (M).

"Primero se tiene que solicitar las plazas generadas (sea nuevas o por renuncia) para que sea canalizado por la gerencia general, luego ésta autoriza ese requerimiento y lo deriva a potencial humano (sede 
central) quien elabora los términos de referencia del perfil” (R); “... este proceso debería ser manejado por la propiaárea de personal, que es la que debería formular el perfil y orientar el reclutamiento a las necesidades específicas que solo nuestra institución conoce” (0).

"El reclutamiento se da en función a la necesidad y ahora por el tema del nuevo código procesal penal se genera una mayor necesidad de profesionales, equipos, laboratorios. Considero que no es adecuada la manera de reclutar, lo primero que deben hacer es buscar información para verificar la verdadera necesidad .... no se están siguiendo los parámetros ... lo que nosotros primero hacemos es recibir todas necesidades de personal a nivel nacional, luego verificamos a nivel estadístico la carga laboral" (A); "... este proceso debería ser manejado por la propia área de personal, que es la que debería formular el perfil y orientar el reclutamiento a las necesidades específicas que sólo nuestra institución conoce... es inadecuado porque actualmente se encuentra bajo el control de la Gerencia de Personal, la que tiene una perspectiva diferente de nuestra institución, nuestra intervención en el proceso es parcial" (0).

"... Primero se tiene que solicitar las plazas generadas sea nuevas o por renuncia, para que sea canalizado por la gerencia general, luego ésta autoriza ese requerimiento y lo deriva a potencial humano quien elabora los términos de referencia del perfil. La central indica en qué fecha va a salir el cronograma de convocatoria, previa elevación al ministerio de trabajo que en un plazo de 15 días da la autorización. Se publica en la página web institucional las fechas de presentación de curriculum, entrevista y resultados" (R); "sí existe esa necesidad, se eleva el documento a la oficina de potencial humano para que se genere todo el proceso de contratación la autorización por gerencial general, luego ya formalizado pasa a potencial humano y este lo envía a presupuesto y allí se separa un dinero para contratación del personal, esos documentos, también llegan al ministerio de trabajo y ellos aprueban" (A).

"El reglamento para la selección ... no se cumple a cabalidad" (J). "El proceso de selección es inadecuado porque la contratación va dirigida a cubrir las necesidades de emergencia y no una planificación racional" (0). "Este proceso no es el adecuado porque no todos pasan un examen de cualidades, de virtudes" (M). "Existe una directiva acerca de los perfiles de puesto, establecidos, elaborados y autorizados" (J). "La evaluación del curriculum vitae, entrevista personal, psicotécnico, psicológico y examen de conocimiento de acuerdo al perfil del puesto y la verificación de la documentación está a cargo de recursos humanos" (J). "Debemos buscar antecedentes nunca pedimos certificados de trabajo de otras entidades o referencia para corroborar con la antigua empresa" (G). "En este proceso no creo que verifiquen los documentos" (M).

\section{Proceso para organizar al personal}

"La solución podría ser un programa de incentivos y debería percibirlos a base de metas establecidas ... ejemplo entrega de post facto en una semana... Si uno quiere evaluar la credibilidad, por ejemplo, debe cumplir con los plazos de entrega de trabajo ... cuando uno era 276 semestralmente nos evaluaban y nos daban la hoja para autoevaluar: colaboración, puntualidad, capacidad técnica, responsabilidad, identificación con la institución" (M).

"No tenemos un método para determinar las necesidades de capacitación ... Se podría aplicar encuestas", "los términos de referencia se piden que el postulante cumpla con los requisitos mínimos", "A modo de sugerencia sacar estadísticas de cuanto es lo que ha atendido, cuanto me queda como pendiente y saber en qué está fallando ese servidor", "A los CAS se les evalúa cada 3 meses y entre esos ítems está si es puntual, si cumple con las metas trazadas con varios rubros y de acuerdo a eso se tiene una valoración" (R). "... lo que nosotros primero hacemos es recibir todas necesidades de personal a nivel nacional, luego verificamos a nivel estadístico la carga laboral" (A).

"Sí se hace en base a una ficha de evaluación de desempeño, en base a porcentajes, lo evalúa el jefe inmediato" (J). "debería permitirse recibir una gratificación de acuerdo al cumplimiento de metas de acuerdo al diseño de un presupuesto por resultados que beneficiaría a la organización y a los trabajadores", "Se realiza una encuesta nacional de necesidades de capacitación dirigidas a todo el personal, sus requerimientos son recopilados, ordenados y se les asigna una prioridad de acuerdo a varios factores que incluyen los requerimientos priorizados de ciertos peritajes, de lo requerido por los usuarios externos y al plan de desarrollo de la organización” (0).

“Cada 6 meses los 276, es un formato digital donde hay parámetros de evaluación de responsabilidad, conocimiento, en el caso de los CAS es más subjetivo de comportamiento de relaciones humanas. El del 276 es de conocimiento, aprendizaje, grado de responsabilidad ante sus funciones. El personal firma su evaluación y saben en qué están fallando", "Las evaluaciones de desempeño deberían ser ventajas, pero siempre y cuando se le haga un seguimiento intenso. Se puede mejorar poniendo metas y objetivos con 
plazos y así pasar a siguientes fases durante el primer año, por ejemplo, retroalimentar sus errores, hacerles también auditorias para la calidad más no punitivos. Se hace a través de los jefes, pero tampoco nuestros jefes están muy capacitados y a todos les ponen notas altas que pareciera que no lo merecen" (G).

"Sí se hace en base a una ficha de evaluación de desempeño, en base a porcentajes, lo evalúa el jefe inmediato, .... no los podemos despedir si el calificativo es bajo, el proceso es largo" (J). "La evaluación del desempeño del personal no se realiza de una forma planificada. Sus intervenciones responden a observaciones puntuales en base a quejas o denuncias de los usuarios. Solo se realizan auditorias reactivas cuando se produce una denuncia contra algún trabajador, no existen auditorias preventivas. No existe una auditoria programada" (0).

“El personal firma su evaluación y saben en qué están fallando. Por lo tanto, la retroalimentación cae sobre el evaluado pues al ser personas adultas y al saber que están mal debe corregirlos. Muchos de ellos no aceptan sus calificaciones a pesar de que se les comunica. ... Se puede mejorar poniendo metas y objetivos con plazos y así pasar a siguientes fases durante el primer año, por ejemplo, retroalimentar sus errores, hacerles también auditorias para la calidad más no punitivos (G).

"El que debería evaluar sería el jefe inmediato porque de acuerdo a ello podría indicar los resultados que está teniendo con el servidor que está asignado a su despacho. A los CAS se les entrega una copia después que ha sido visado por presidencia. No se está aplicando la retroalimentación de la evaluación" (R). "Tendríamos que ver que el perfil debe estar de acuerdo al cargo o función, se debe seguir ese perfil ... los perfiles en la institución son muy técnicos y operativos, no hay perfil de valores o ética, si lo hubiera le cambiamos el rostro a la institución ... Yo creo que deberían cumplir porque si no, no pasarían con la selección." (M).

Figura 3: Proceso para organizar al personal

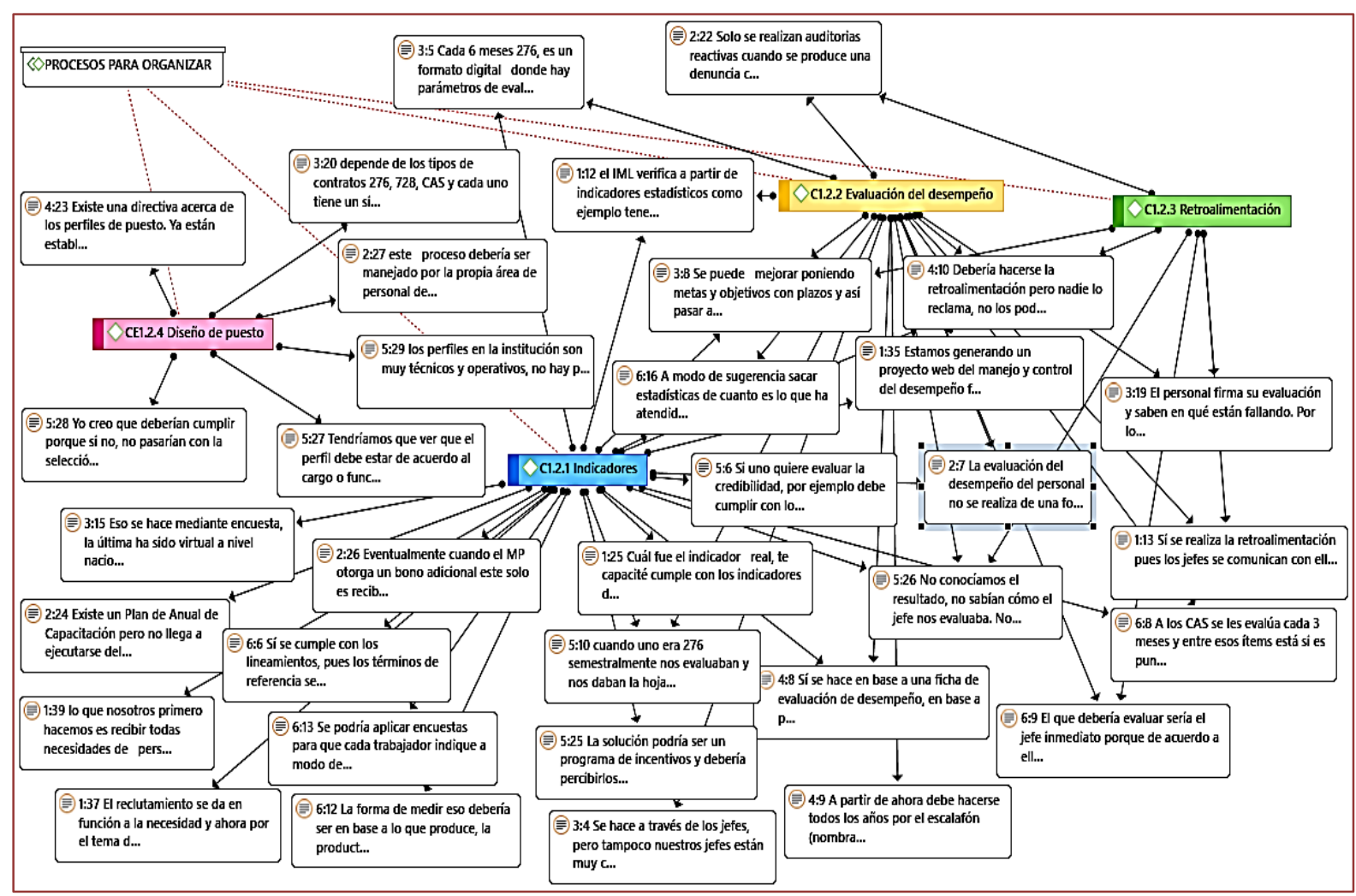


Figura 4: Proceso para recompensar al personal

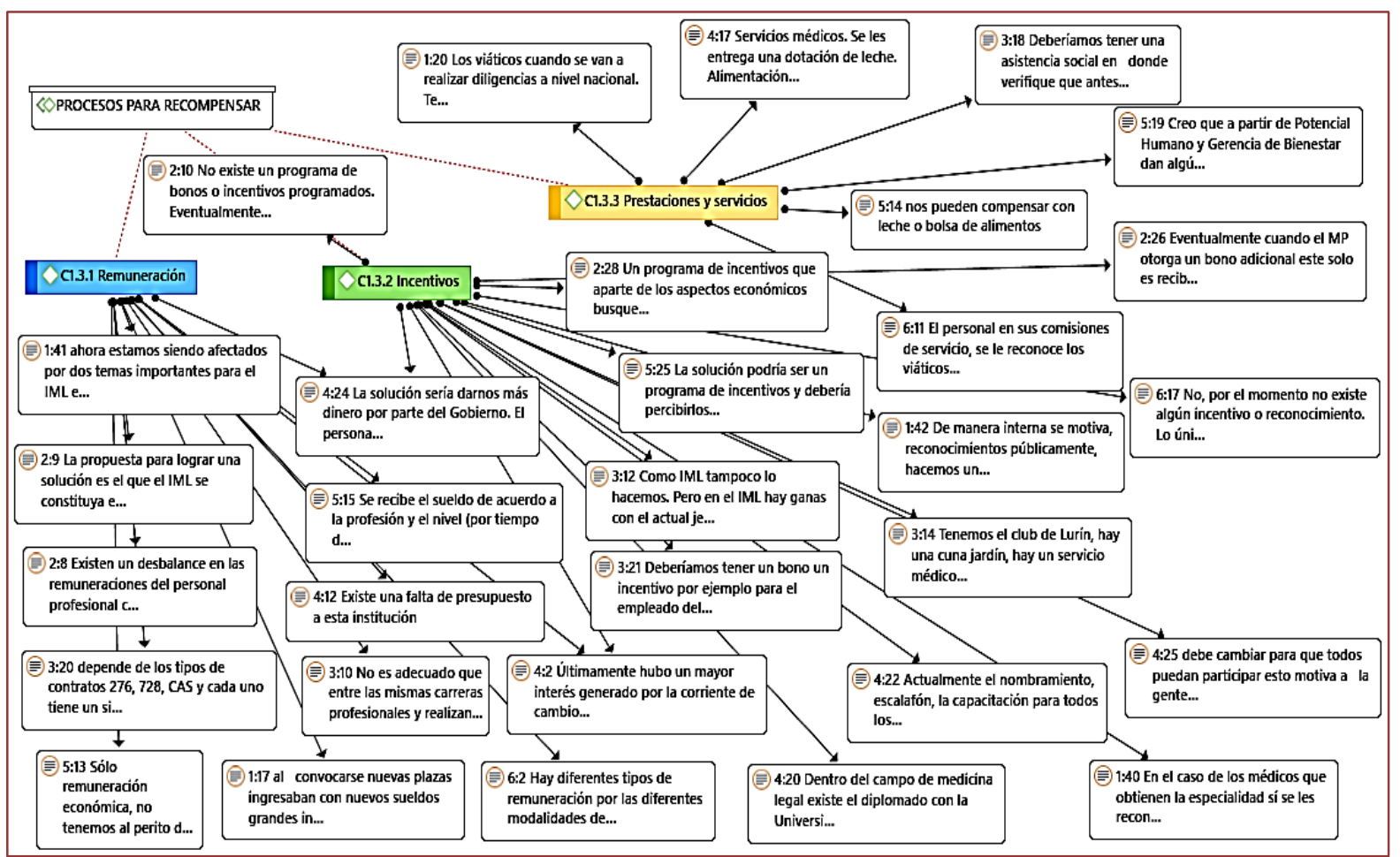

"Depende de los tipos de contratos 276, 728, CAS y cada uno tiene un sistema de remuneración diferente para las profesiones" (G). "La solución sería darnos más dinero por parte del Gobierno. El personal debe estar contento con su trabajo, debe tener un estímulo o motivación. Últimamente hubo un mayor interés generado por la corriente de cambio, reconocimiento de posibilidades de mejora, la valoración económica. Existe una falta de presupuesto a esta institución" (J). "Existen un desbalance en las remuneraciones del personal profesional con respecto a lo que señala la ley. No es adecuado que entre las mismas carreras profesionales y realizando las mismas actividades no es adecuado percibir de manera diferente. Lo que se está gestionando es que las leyes sean aplicadas para que entre los profesionales ganen su sueldo de una manera justa" (0).

"Al convocarse nuevas plazas ingresaban con nuevos sueldos grandes incrementos provocando una disparidad grande de sueldos entre los antiguos y los nuevos entonces se genera una disparidad, por ello no podíamos permitir que los médicos antiguos se vayan. Pues antes el personal no postulaba a pesar de las plazas, o postulaba era gente sin experiencia, gente que sólo iba a estar 3 meses o gente desmotivada y esa experiencia que obtenían se iban ante mejoras ofertas" (A). "Hay diferentes tipos de remuneración por las diferentes modalidades de servicio, que va en contra del derecho laboral. Las remuneraciones se perciben conforme al régimen como en el CAS es su sueldo y el aguinaldo en julio y diciembre y para los 276 contratados y 728 bonos mensuales, pero los 276 nombrados no. Pero son permanentes" (R). "Sólo remuneración económica, no tenemos al perito del mes. Se recibe el sueldo de acuerdo a la profesión y el nivel (por tiempo de servicio). El que gana más son los médicos Cas y los que gana menos son los asistentes administrativos" (M). "Tenemos el club, hay una cuna jardín, hay un servicio médico sólo para consulta, pero ni siquiera es unidad básica como par control de funciones vitales, no se puede suturar. Deberíamos tener un bono un incentivo por ejemplo para el empleado del mes los que no tuvieron ninguna queja” (G).

“De manera interna se motiva, reconocimientos públicamente, hacemos un compartir interno, o cuando cumplimos metas nos vamos a almorzar. En el caso de los médicos que obtienen la especialidad sí se les reconoce económicamente. A mi parecer se debería generar becas o pasantías internacionales o beneficios para capacitarse más pues generará beneficios a la institución (A)". "La solución podría ser un programa de incentivos y debería percibirlos a base de metas establecidas en base a nuestros clientes: funcionarios, el público, en base a metas. Ejemplo entrega de post facto en una semana. Dicha propuesta de incentivos podría ser similar a la que dan al personal de las empresas privadas" (M). "Eventualmente se otorga un bono adicional este solo es recibido por el personal contratado por la modalidad 728 y Cas, no por los 
276. El personal del régimen 276 solo recibe un sueldo completo al cumplir 25 y 30 años de servicios como gratificación" (0).

“No, por el momento no existe algún incentivo o reconocimiento. Lo único que tenemos es para las personas que tienen un periodo de antigüedad presentado servicios le entregan una placa o pin cuando están por cesar. La propuesta es que debería hacerse un reconocimiento, de repente no económico porque genera un prejuicio en el presupuesto, pero de repente organizar una ceremonia una reunión donde se le entrega un diploma, un reconocimiento por la labor porque la persona ha sobresalido, posibilidad de mejores ambientes acondicionados que a pesar de las limitaciones ha avanzado y le damos la logística" (R). "Los servicios médicos, se les entrega una dotación de leche. Alimentación al personal que está de guardia. Club de esparcimiento. Campañas de salud. Convenios con instituciones para descuentos en evaluaciones oftalmológicas, oncológicos" (J).

"Deberíamos tener una asistencia social en donde verifique que antes de irse de vacaciones debemos hacernos un examen general de salud y de la misma manera al regresar" (G). "Los viáticos cuando se van a realizar diligencias a nivel nacional. Tenemos beneficios como entrega de leche. Atención médica, odontología, campañas de salud" (A). "Nos pueden compensar con leche o bolsa de alimentos. Creo que a partir de Potencial Humano dan algún beneficio como campaña de salud, chequeos médicos, entradas a cine a tarifas reducidas, tarifas corporativas, préstamos de dinero, tarjetas de crédito, crédito en casas comerciales" (M).

"El personal en sus comisiones de servicio, se le reconoce los viáticos, que cubre su movilidad o pasaje y estadía con alimento. Existe lo que es la guardería "la cuna jardín". Otras prestaciones son las asistencias médicas que también está centralizada, existe el "tópico" a nivel de la central el consultorio médico que abarca la parte psicológica, odontológica que está en la central” (R).

\section{Proceso para desarrollar al personal}

Figura 5: Proceso para desarrollar al personal

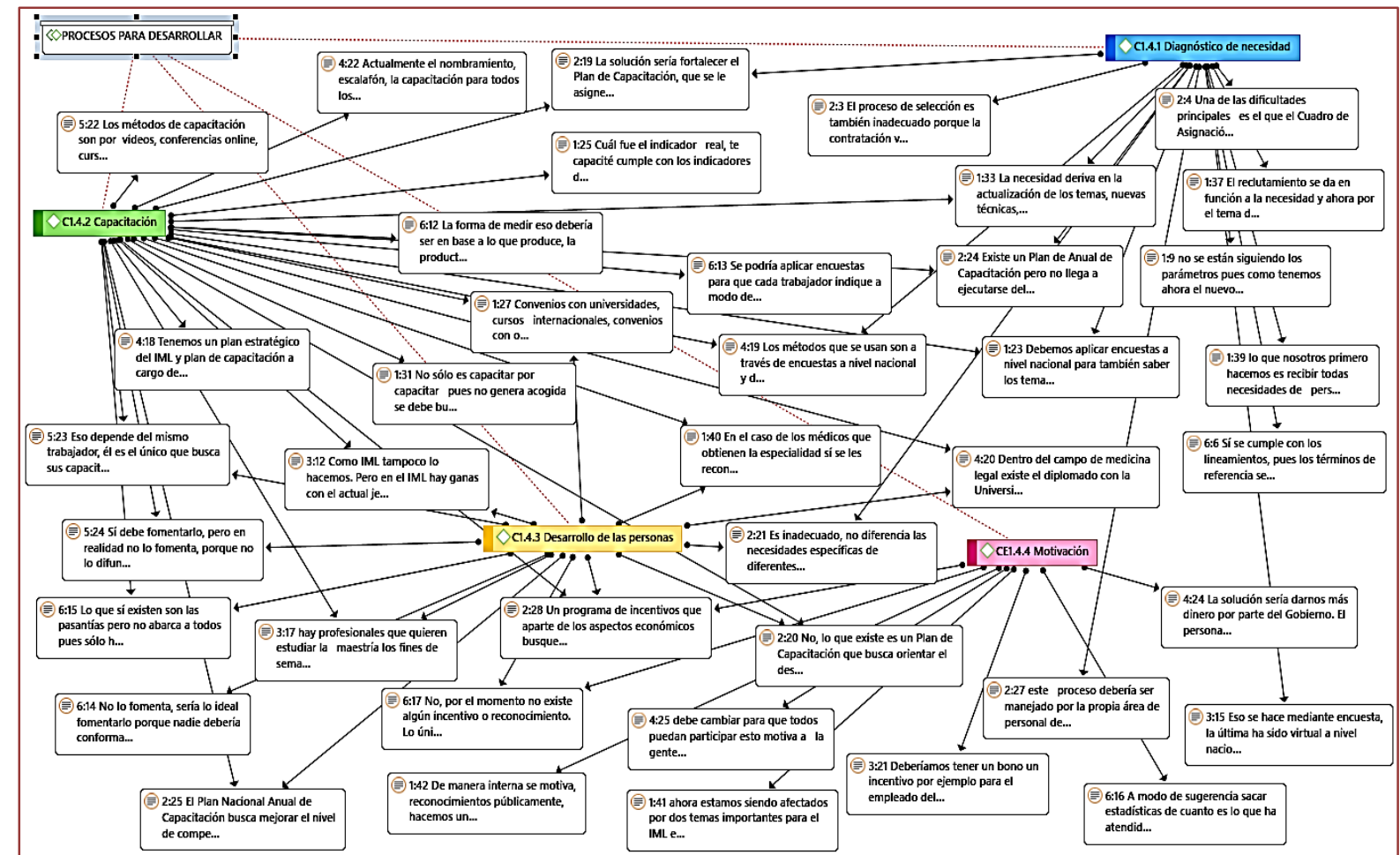

"Eso se hace mediante encuesta, la última ha sido virtual a nivel nacional. Entre las cuales se ha pedido al personal enviar sus temas para la realización de un taller que hicimos recientemente. El plan de capacitación se está realizando actualmente" (G).

"Existe un Plan de Anual de Capacitación, pero no llega a ejecutarse del todo por las limitaciones de presupuesto" (0). "Sí se cumple con los lineamientos, pues los términos de referencia se piden que el 
postulante cumpla con los requisitos mínimos de acuerdo a la necesidad que existe y el lugar, donde va a prestar el servicio y eso sí se tiene que cumplir, el filtro va en base a su hoja de vida anexados con sus documentos en la cual certifican que cumplan con lo mínimo ya sea experiencia laboral en la rama o especialidad. Si es que no entregan la declaración jurada, es necesario que lo sustente (R).

Durante la entrevista mencionaron, que: "Los métodos que se usan son a través de encuestas a nivel nacional y directivas para captar al personal" (J). "Los métodos que se usan son a través de encuestas a nivel nacional y directivas para captar al personal. Está en proyectos cursos, diplomados, para su posterior difusión ... la capacitación para todos los profesionales remunerada con pago de cursos. Tiene que haber un presupuesto para pasantías internacionales para médicos y no médicos. Tenemos un plan estratégico y plan de capacitación. El plan es anual, internacional, nacional, regional" (J).

"Sí debe fomentarlo, pero en realidad no lo fomenta, porque no lo difunde eso queda anónimo, capacitación unos pocos, becas no hay becas. La solución es divulgar los programas de capacitación fuera del país, las personas podrían alcanzar algunas becas, publicidad para postular a ellas" (M).

"Es inadecuado, no diferencia las necesidades específicas de diferentes grupos profesionales y administrativos y tampoco tiene continuidad. Un programa de incentivos que aparte de los aspectos económicos busque la revalorización del trabajado a través de programas de capacitación y reconocimiento a la labor que desarrollan sería fundamental. No, lo que existe es un Plan de Capacitación que busca orientar el desarrollo profesional" (0).

"Hay profesionales que quieren estudiar la maestría los fines de semana, piden dobles turnos en día de semana para viajar y se les autoriza, pero no está normado, se le brinda facilidades para que se desarrolle" (G). "No, por el momento no existe algún incentivo o reconocimiento. Lo único que tenemos es para las personas que tienen un periodo de antigüedad presentado servicios le entregan una placa o pin cuando están por cesar." (R).

\section{DISCUSIÓN}

Constituye un arduo trabajo el macro proceso de la gestión del talento humano, trabajar con el recurso humano no es nada sencillo más aún si no se cuenta con las condiciones y motivaciones para cada uno de los trabajadores; con el pasar del tiempo se tenga previsto o no, se cuenta con herramientas para integrar, organizar, remunerar y desarrollar al profesional; el punto de quiebre es cuando se aplica poco o no se siguen adecuadamente los procedimientos paras fomentar el avance del profesional; pues si no los mantenemos en ese rumbo de contrastante mejora, lo más probable es que renuncie y se vaya a la competencia generando un caos, baja productividad e insatisfacción del cliente interno y externo.

Si el área usuaria no participa en el desarrollo del perfil del profesional ya genera disconfort en la organización e incluso que el proceso de integración de personal no sea el adecuado. Si a eso le agregamos, que el perfil no incluye una evaluación de cualidades o virtudes, la organización caería en lo monótono y sin desarrollo. Lo cual concuerda con los hallazgos de una institución pública de Pakistán donde se realizó un estudio en la cual el 56\% del personal expresó que las actividades que realizaban no estaban acordes con las tareas que en principio se describieron (Ashraf, 2017) esto indica que el perfil que buscaba la institución no iba de la mano con el perfil del puesto que se solicitó al inicio de la convocatoria.

Esta investigación permitió demostrar que un adecuado proceso de integración de personal con la definición correcta del perfil, conllevará a la competitividad organizacional; así lo refuerza y también coincide con nuestros hallazgos otro estudio realizado en la ciudad de Huancayo, donde evidenciaron que la estrategia de incorporación de personal obtuvo una correlación de Pearson del 0.67, la cual es significativa para la relación entre la gestión del talento humano y la generación de una entidad competitiva (Rojas, 2016). En esta estrategia de integrar personal, debe considerarse de todas maneras la definición del perfil profesional que se requiere para dicha convocatoria, esto tiene que ir de la mano con las políticas y objetivos de la organización.

El proceso de reclutamiento es aquel utilizado para ganar un profesional en la institución, es necesario que se involucre todo el equipo de gestión de la organización. Una publicación internacional coincide con esta investigación pues establece que la variable atracción del talento tuvo una correlación múltiple cuadrada del 0.94 (validez: 0.20) significando que debe ser considerada para lograr una adecuada gestión del talento (Mahfoozi et al., 2018), la cual se refuerza con un estudio nacional en la ciudad de Huancayo, quien encontró que la estrategia de incorporación de personal presentó una correlación significativa de Pearson 
del 0.67 lo cual refleja que este proceso constituye una estrategia para la competitividad de la institución (Rojas, 2016).

Se asemeja a los resultados obtenidos, otro estudio de investigación realizado a servidores públicos de gobiernos autónomos descentralizados, los cuales reflejaron que el 73\% de ellos expresó que en su institución no se realiza un diagnóstico situacional sobre la necesidad de nuevos profesionales (Marcillo, 2014). No podemos dejar de lado que para integrar más profesionales debemos tener en cuenta la necesidad real y las políticas de la institución.

Conforme a lo encontrado con el indicador de selección de personal, aún tenemos déficit como institución pública; primero porque el área que directamente necesita personal no participa en dicho proceso; segundo que la verificación documentaria no es realizada de manera completa para identificar la experiencia del postulante, y por último se obvian o no se consideran técnicas de selección importantes para incluir dentro de la institución a profesionales competentes como es la evaluación psicológica completa. Comparándonos con otra institución pública coincidimos con la realizada en Pakistán sobre el trabajo publicado sobre este proceso, obteniendo como resultados que, el 56\% de los trabajadores realiza actividades diferentes a lo que se describió en el momento de la descripción del puesto (Ashraf, 2017) es decir en el proceso de selección de personal.

Nuestros hallazgos coinciden también con una investigación realizada en la ciudad de Chiclayo donde el $63 \%$ de los trabajadores refieren que el proceso de selección no es riguroso y en otra pregunta el $60 \%$ afirma que para ocupar un puesto se debe tener en cuenta la preparación del profesional (Sempertegui, 2005) en otras palabras la experiencia; puntos importantes para recalcar e incluir en este proceso de la institución.

Los resultados obtenidos en las entrevistas abordan que en la institución sí se cuenta con algunos indicadores, los cuales resultan ser subjetivos como por ejemplo en la ficha de evaluación por modalidad de contrato; por otro lado, no todos los procesos de las diferentes actividades de la institución cuentan con indicadores, está limitado al número de capacitaciones, el tema de la renovación de contratos, al número de casos atendidos o carga laboral por parte de los profesionales y a los requerimientos de recursos de las áreas de trabajo.

En una publicación sobre una entidad pública en Pakistán obtuvieron que el 56\% del personal desarrolla sus labores en discordancia con lo descrito para ese puesto (Ashraf, 2017) lo que indica que y se asemeja a la información dada por los entrevistados, que en este proceso los indicadores no permiten o falsamente miden la labor con las competencias del profesional; se obtuvo los mismos resultados con otra investigación que encontró que el $100 \%$ de la muestra analizada refirió que no existe un programa continuo de mejora que use correctamente las herramientas y defina objetivos (Marcillo, 2014) esto confirma que si no se establecen correctamente indicadores de desempeño la organización tendrá dificultades en el desarrollo y rechazo de sus recursos humanos.

El sistema de evaluación del desempeño nos permite medir al 100\% las actividades que se realizan en la institución; por la información obtenida de los entrevistados este proceso es evaluado por el jefe inmediato superior, se cuenta con una ficha de evaluación que se realiza cada cierto tiempo medido en meses para ver las capacidades de los profesionales CAS y 276 la cual refiere uno de ellos que es subjetiva. Cuentan con programa estadístico que les permite determinar el número de casos atendidos el cual es limitado, existe la falencia que no se realiza el seguimiento de las mismas lo que impide mejorarlas. Además, uno de ellos refirió que la misma no se encontraba dentro de la planificación organizacional de la institución.

La información proporcionada durante la entrevista permitió estar acorde con un estudio sobre competitividad de una organización señaló que la estrategia de supervisión tiene un índice Pearson significativa con el 0.81 estableciendo que esta estrategia de supervisión logrará que la institución sea exitosa y competitiva (Rojas, 2016). Los resultados de otra publicación desarrollada en el sur de Manabi encaja con esta investigación, pues obtuvieron que el $77 \%$ de los participantes no daba fe de que las evaluaciones realizadas hayan servido para potenciar las capacidades de los profesionales (Marcillo, 2014). Se confirma que, si en este proceso no se plantea un objetivo, no se planifica su aplicación y futura verificación los profesionales no tendrían la manera de saber cómo podrían mejorar.

El proceso de retroalimentación se caracteriza por constituir un método de verificación sobre las observaciones realizadas en la fase de la evaluación del desempeño, no tiene un fin de sancionar, su objetivo es la mejor continua. El 50\% de los entrevistados refirieron que no existe un proceso de retroalimentación por lo tanto no sabían cómo fueron calificados por el jefe inmediato, ni en qué punto 
deberían mejorar. Dos de ellos hicieron hincapié que en la institución si se realiza este proceso, pero de manera parcial y enfocada a las actividades según contrato CAS o 276 del personal. Uno de ellos recalcó que se espera que, para la nivelación de algunos profesionales, ésta se realice de manera anual. Uno de ellos refirió que se constituye en una ventaja siempre y cuando se realice un seguimiento intenso es decir el propio feedback.

Hay dos publicaciones donde hay semejanzas entre los resultados de esta investigación con la de ellos; una de ellas en la ciudad de Colombia, una investigación desde la perspectiva de gestores del recurso humano, concluyeron que sólo un $66 \%$ de las empresas han implementado acciones proactivas hacia el cambio como es la preparación de sus colaboradores (Pardo y Díaz, 2014); esto quiere decir que, para que exista una preparación antes de evaluó, se identificó falencias, y se retroalimentó preparándolos para el éxito. En otro estudio realizado en gobiernos autónomos, refirieron en su totalidad es decir el 100\% que no había un programa de mejora continua a los profesionales (Marcillo, 2014) lo que indica que no se ha considerado un feedback de las actividades que se realizan en sus instituciones. Lo cual entorpece su laborar y competitividad en el mercado, generando incluso rechazo por sus propios colaboradores.

Con el diseño de puestos daremos a conocer si realmente los conocimientos y las cualidades del profesional van acorde con la labor que realiza en la institución. A la entrevista uno de ellos refirió que el perfil del profesional debe ser acorde con el perfil del puesto donde se va a desempeñar; otro de ellos mencionó que la remuneración del profesional dependerá del tipo de contrato que tenga lo que sugiere también del tipo de puesto; un tercero hizo hincapié que el perfil del puesto ya se encuentra establecido incluso con resolución. Un estudio en gobiernos descentralizados si se halló semejanzas pues determinaron que el 32\% de los entrevistados refirieron que la institución sí diseñaba el perfil del puesto conforme a los requerimientos del cargo (Marcillo, 2014). Nos damos cuenta de que, para el diseño del puesto se necesita decisión, compromiso y flexibilidad en torno al cambio constante del entorno y empoderamiento de la institución.

La remuneración es considerada como parte del proceso para recompensar a las personas, durante la entrevista cinco de ellos fueron enfáticos y asertivos en referir que la remuneración varía según el tipo de contrato de los profesionales, es decir sea CAS, 728 ó 276; a pesar de ser de la misma rama profesional y realizar las mismas actividades en la misma organización, lo cual ocasiona malestar entre los mismos colegas e incluso con algunas renuncias de profesional con experiencia. Otro entrevistado refirió que se debía a la falta de presupuesto designado por el Gobierno. Así mimo lo obtenido coincide con un estudio acerca de las prácticas innovadoras de gestión humana en empresas quiénes identificaron que el $44 \%$ de ellas no cuenta con algún criterio para establecer la remuneración a sus colaboradores (Arévalo, Bayona y Rico, 2017). Punto álgido en la institución que debe ser una de sus prioridades para la gestión de sus profesionales.

Durante la entrevista la mitad de ellas refirió que no se cuenta con un programa establecido de incentivos a los profesionales, uno de los motivos es el hecho de que no existe un presupuesto asignado a dicha proceso. Pero se entrega algunos incentivos como por ejemplo para los médicos que cuenta con especialidad luego de un proceso de verificación le dan un bono económico, otro es cuando el profesional estudia se le puede otorgar una licencia con goce de haber para evitar descuentos y uno de ellos además mencionó que hacen reuniones internas (una especie de compartir) generadas con sus propios recursos. Los resultados de dos investigaciones coinciden con los hallazgos de la presente investigación; un estudio sobre la generación de ventajas competitivas en una universidad obtuvo como resultado que los incentivos tienen una correlación significativa del 0.76 , es decir que constituye un socio estratégico para lograr la competitividad de la organización (Rojas, 2016). Y la otra investigación obtuvo como resultado que el 78\% de los entrevistados de los gobiernos autónomos refirió que no existen planes de incentivos institucionales (Marcillo, 2014). Por lo tanto, se infiere que a pesar de constituir una variable de motivación no es considerada en cuenta, pudiendo ocasionar malestar entre los colaboradores de la institución.

Al evaluar este indicador, se identificó que la institución si cuenta y aplica el proceso de recompensar a los profesionales a través de las prestaciones y servicios; los entrevistados mencionaron algunos de estos servicios como es la entrega de leche, dotación de alimentos en jornadas laborales, otorgamiento de viáticos en diligencias, descuentos en cursos con entidades que cuenten con convenio con la institución, campañas integrales de salud, centros de esparcimiento, entre otros. Así mismo hay una tesis que coincidió con la nuestra, en este estudió sobre la gestión del talento humano y sus ventajas competitivas, se determinó que la variable recompensa obtuvo una correlación significativa (Pearson) del 0.76, que denotó su constitución como un socio estratégico para el éxito y desarrollo de una organización competitiva (Rojas, 2016). Este término de recompensa comprende un programa de completo de 
prestaciones y servicios que otorga la organización a todos sus colaboradores independientemente del tipo de contrato, remuneración, área o profesión.

Para poder determinar las diferentes necesidades de los colaboradores usan la encuesta; la cual por su naturaleza no es aplicable a los diferentes servicios o prestaciones que ofrece, no es determinante para la incorporación de nuevo personal en la institución. Este diagnóstico muchas veces no permite que sea plasmado en el plan operativo y sea ejecutado a cabalidad con resultados incluidos como sucede con ciertos proyectos o actividades por falta de presupuesto. Así se determinó y coincidió con esta investigación, una tesis publicada sobre la optimización del talento humano en los gobiernos autónomos, determinando que el $100 \%$ de los entrevistados expresó que en su entidad no se les realizaba el proceso de evaluación para identificar su satisfacción con respecto al trabajo que realizan (Marcillo, 2014) lo que quiere decir que no realizan un diagnóstico de la verdadera necesidad que prestan los colaboradores.

Los entrevistados mencionaron que no se cumple a cabalidad el plan de capacitaciones que cuenta la Institución, es reducido el número de vacantes para dichos eventos o que los participantes son elegidos por ser conocidos de alguien y no porque verdaderamente necesita capacitarse; entonces también hace falta el seguimiento de estas. En un estudio que está acorde con la nuestra sobre prácticas de gestión del talento humano se evidenció que sólo un $22 \%$ de las empresas cuenta con un programa de capacitación (Arévalo, Bayona y Rico, 2017). Otro estudio también coincide con esta investigación, la cual estuvo enfocado en la gestión del talento en organizaciones checas quien halló que el 66.5\% de ellas incluye dentro de su plan de trabajo algún tipo de capacitación (Vnoučková, 2016). Se añade a los anteriores otra investigación que coincide y refuerza nuestros hallazgos; sobre desarrollo organizacional desde la visión de los líderes en gestión, cuyo resultado fue que el 67\% de las empresas refiere que las capacitaciones son eficaces como parte del desarrollo de la organización (Pardo y Díaz, 2014).

En cuando al desarrollo de las personas nos refirieron el déficit, primero de un diagnóstico real de la necesidad de formación, segundo déficit de presupuesto lo cual se obtiene como resultado que no se cuenta con un programa destinado al desarrollo de los profesionales. A nivel internacional coincide con la nuestra, pues se publicó un estudio sobre la construcción de un modelo de gestión del talento, obtuvieron que la variable desarrollo del talento obtuvo una correlación múltiple cuadrada de 0.90 (la validez requiere ser de 0.20 ) lo cual se interpreta que esta variable debe ser incluida en el modelo para lograr una óptima gestión del talento (Mahfoozi et al., 2018). Otra investigación que se asemeja con nuestros hallazgos, sobre gestión del talento humano consignó dentro de sus resultados que sólo el 7\% de ellos cuenta con un programa para el desarrollo profesional de las personas (Arévalo, Bayona y Rico, 2017). Permitir e incentivar que los colaboradores de una crezcan académicamente constituye una fortaleza para la organización generando el despegue e innovación.

Incentivar a que los colabores de una institución sigan y cumplan con la misión y visión de la institución no es sencillo, implica mucho más que asignarles un simple sueldo mínimo; el punto central es la motivación y así como en los anteriores indicadores los entrevistados señalaron que no cuentan con un programa destinado a la motivación de los profesionales. La mayoría de ellos enfatizó en algunos ejemplos que deberían ser aplicados por la institución para motivar a los colaboradores, entre ellos tenemos: los reconocimientos por la buena labor y cumplimiento de metas realizadas en público en una ceremonia, un diploma, la entrega de una placa de felicitaciones, un bono por ser el empleado del mes el cual cumplió las metas y no tuvo ninguna queja; obviamente todo ello deberá guardar relación con los indicadores de evaluación previamente establecidos. Los resultados de un estudio nacional concuerdan con nuestros hallazgos; sobre el tema de las estrategias de gestión del talento y el logro de ventajas competitivas determinó que la motivación obtuvo una correlación significativa del 0.74 , lo que implica sostener que este factor constituye un socio estratégico para aumentar la competitividad organizacional (Rojas, 2016).

\section{CONCLUSIONES}

La gestión del talento humano en una institución pública en Perú no cuenta con un programa de gestión del talento humano, aún se encuentra en proceso de implementación, reajuste y dirección; enfocadas en las áreas económica (presupuesto), planificación y lineamientos de gestión. El proceso para integrar personas no es realizado por el área usuaria, no se está cumpliendo a cabalidad con los lineamientos de la institución en relación con quien dirige el proceso, define el perfil y verifica la documentación que se presenta en el reclutamiento. En el proceso para organizar personas, el perfil del puesto ya se encuentra establecido, pero no cuenta con indicadores claros, el ámbito de aplicación de la ficha de evaluación del desempeño es limitado a ciertos servicios y profesionales, no hay un continuo seguimiento (retroalimentación) de la evaluación. El proceso para recompensar personas presenta disparidad de las 
remuneraciones entre las mismas profesiones y actividades, no se ha implementado un programa de incentivos que se aplique a todas las áreas de la institución. Constituye una fortaleza el programa de prestaciones y servicios que se brinda a todos los profesionales. En el proceso para desarrollar personas, no existe una estrategia de trabajo que garantice conocer las reales necesidades, no se ejecuta en su totalidad el plan de capacitación que tienen, no existe un programa de desarrollo ni de motivación de sus profesionales. Esta investigación cualitativa permitió hacer el estudio de esta institución, evaluarla de manera completa, detallada, con información directamente de los funcionarios. La gestión del talento humano en esta institución pública está en proceso de implementación, reajuste y dirección, con incidencia en el presupuesto, lineamientos y planificación. Fortaleciendo y motivando el recurso humano se incrementarán sus conocimientos y habilidades en diversas áreas obteniéndose el compromiso con la institución y generando un personal proactivo, con actitud, mejor capacitado y que su laborar sea adecuadamente remunerada para cubrir sus necesidades.

\section{AGRADECIMIENTOS}

A cada una de las personas que me brindaron su respaldo y apoyo incondicional para la realización de este trabajo.

\section{REFERÊNCIAS}

[1] Alles, M. (2007). Rol del jefe. Cómo ser un buen jefe. Buenos Aires: Granica S.A.

[2] Arévalo, J., Bayona, R., y Rico, D. (2017). Las prácticas innovadoras de la gestión humana: una necesidad estratégica de las microempresas. Revista Ciencias Estratégicas, Vol. 25-No. 37;15-24.

[3] Ashraf, J. (2017). Examining the public sector recruitment and selection, in relation to job analysis in Pakistan. Journal Cogent Social Sciences , 3:1-11.

[4] Cabello, A., Gutiérrez, R., y Grau, A. (2015). Administración y gestión de las comunicaciones de la dirección. España: Nobel.

[5] Chiavenato, I. (2007). Administración de recursos humanos. El capital humano de las organizaciones. México: McGraw Hill.

[6] Chiavenato, I. (2009). Gestión del Talento Humano. México, D.F.: McGraw-Hill.

[7] Chiavenato, I. (2011). Introdução à Teoria Geral da Administração. Rio de Janeiro: Campus.

[8] Cisterna, F. (2005). Categorización y triangulación como procesos de validación del conocimiento en investigación cualitativa. Theoria, 61-71.

[9] Duhalde, M. (1999). La investigación en la escuela. Un desafío para la formación docente. Buenos Aires: Ediciones novedades educativas.

[10] Esparragoza, A. (2002). Administración de recursos humanos y talento humano. https://www.gestiopolis.com/administracion-de-recursos-humanos-y-talento-humano/.

[11] Franklin, E. (2007). Auditoría Administrativa. México: Pearson.

[12] Galeano, M. (2013). Diseño de proyectos en la investigación cualitativa. Medellín: Fondo editorial Universidad EAFIT

[13] Griffin, R., y Ebert, R. (2005). Negocios. México, D.F.: Pearson Educación.

[14] Hernández, R. (2014). Metodología de la investigación. México, D.F.: McGrawHill.

[15] Kvale, S. (2011). Las entrevistas en Investigación Cualitativa. Madrid: Morata.

[16] Mahfoozi, A., Salajegheh, S., Ghorbani, M., y Sheikhi, A. (2018). Developing a talent management model using government evidence from a large-sized city, Iran. Journal Cogent Business y Management, 5:1-15.

[17] Marcillo, N. (2014). Modelo de gestión por competencias para optimizar el rendimiento del talento humano en los gobiernos autónomos descentralizados del sur de Manabi. (Tesis de doctorado). Universidad Privada Antenor Orrego: Trujillo, Perú.

[18] Mendes, I. M. (2012). Gestão estratégica de recursos. Perceção dos dirigentes do I.G.F.S.S. I.P., sobre a gestão estratégica de recursos humanos e os possíveis impactos na performance. (Tese de mestre). Instituto Politécnico de Setúbal. Escola Superior de Ciências Empresariais: Setúbal, Portugal.

[19] Monge, C. (2015). La codificación en el método de investigación de la grounded theory o teoría fundamentada. Innovaciones educativas, 77-84. 
[20] Monje, C. (2011). Metodología de la investigación cuantitativa y cualitativa. Guía didáctica. Neiva: Universidad Surcolombiana.

[21] Montes, J.; Gonzáles, P. (2006). Selección de personal. La búsqueda del candidato adecuado. https://books.google.com.co/books?id=0jkELJ2nfVwCyprintsec=frontcoverydq=reclutamiento+internyhl=es\#v=onep ageyq=reclutamiento\%20internyf=false

[22] Muñoz, C. (2015). Metodología de la investigación. México, D.F.: Oxford University Press.

[23] Packer, M. (2013). La ciencia de la investigación cualitativa. Bogotá: Uniandes.

[24] Pardo, C., y Díaz, O. (2014). Desarrollo del talento humano como factor clave para el desarrollo organizacional, una visión desde los líderes de gestión humana en empresas de Bogotá D.C. Revista Suma de Negocios, 5(11): 39-48.

[25] Peña, G., Cañoto, Y., y Santalla, Z. (2006). Una introducción a la psicología. Caracas: Universidad Andrés Bello.

[26] Reza, J. (2006). Nuevo diagnóstico de necesidades de capacitación y aprendizaje en las organizaciones. México, D.F.: Panorama.

[27] Rodríguez, E. (2005). Metodología de la investigación. Tabasco: Universidad Juárez Autónoma de Tabasco.

[28] Rojas, N. (2016). La gestión del talento humano y la generación de ventajas competitivas en el consorcio de la Universidad Continental de Huancayo, 2016. (Tesis de doctorado). Universidad Nacional de Educación Enrique Guzmán y Valle: Lima, Perú.

[29] Sempertegui, H. (2015). Selección de personal por competencias para la gestión del talento humano. Revista Horizonte Empresarial, vol. 2 (2) 223-235.

[30] Sullivan, J. (13 de September de 2004). Talent Management Defined: Is It a Buzzword or a Major Breakthrough? Obtenido de ERE Recruiting Intelligence: https://www.ere.net/talent-management-defined-is-it-abuzzword-or-a-major-breakthrough/

[31] Veiga, L., y Peixoto, J. (2015). Gestão de Pessoas. Rio de Janeiro: Colégio Politécnico da Universidade Federal de Santa Maria.

[32] Vnoučková, L. (2016). Practices of Talent Management in Organisations in the Czech Republic. Acta Universitatis Agriculturae et Silviculturae Mendelianae Brunensis, 64(2): 701-709. 


\section{Capítulo 11}

Mulheres no Conselho de Administração e o desempenho financeiro das empresas: Um estudo comparativo entre França e Brasil

\section{Edmery Tavares Barbosa \\ Inajá Allane Santos Garcia \\ Azamor Cirne de Azevedo Filho \\ Micheli Aparecida Lunardi}

Resumo: 0 modelo de uma boa gestão é, historicamente, atribuído aos homens. Diante dos estereótipos consolidados fica difícil para a sociedade aceitar um novo modelo mental de mulheres dirigentes. Aspectos estes estudados sob a ótica do fenômeno denominado "teto de vidro". A quebra desse paradigma é importante, uma vez que um grupo formado por pessoas parecidas tende a olhar para os problemas e soluções da mesma forma. Considerando estudos realizados a respeito da presença feminina no CA e a performance da empresa, o presente artigo busca realizar um estudo comparativo entre empresas brasileiras e francesas quanto a influência da presença de mulheres no CA e a performance financeira. A amostra inicial das empresas francesas é composta pelas companhias que compõem os índices CAC 40 e SBF 120 da Bolsa de Paris-FR. Para o cenário brasileiro foram selecionadas aquelas que compunham o índice BOVESPA, composto por 100 ações mais líquidas, perfazendo um total de 100 empresas. Com base nos dados coletados para o presente estudo, observou-se que no Brasil, 44,5\% das empresas investigadas não apresentam mulheres no CA. Inversamente, apenas 3 empresas apresentaram esse cenário na França (Cassino, Euler e IPSOS). No cenário francês, observa-se que 18 empresas ultrapassam o limite estabelecido por Lei, ou seja, apresentam mais de $40 \%$ de assentos ocupados por mulheres. Uma delas, do setor de energia, apresenta uma proporção de 63\% de mulheres no CA. Apesar dessa diferença, por meio do teste de Mann Whitney verifica-se que não há diferença estatística significante entre o grupo das empresas que contém mulheres no CA e o grupo das empresas que não contém mulheres no CA tanto no cenário brasileiro como o francês.

Palavras-chave: Conselho de Administração; Diversidade; Governança Corporativa. 


\section{INTRODUÇÃO}

A medida que as empresas ampliam suas atividades comerciais, aumenta a necessidade de desenvolver mecanismos de controle e boa governança a fim de minimizar os conflitos de interesse entre agente e principal, conforme Teoria da Agencia de Jensen e Meckling (1976). 0 agente, representado pelo gestor e o principal representado pelos proprietários da organização.

Um dos mecanismos da boa governança corresponde à composição do Conselho de Administração (CA) das corporações, o qual deve representar os interesses dos financiadores do capital, ou seja, do principal. Bueno (2014) alerta que o processo de composição de um CA deve buscar a inclusão do maior número de elementos capazes de traduzir uma missão extremamente complexa, como alinhar os interesses do proprietário e dos agentes. Neste sentido, Tonello (2013) diz que o ideal é que o CA seja composto por participantes com uma variedade de conhecimentos e expertises nas mais diversas áreas: finanças, contabilidade, gestão de riscos, compliance, comércio exterior, marketing, recursos humanos e pesquisa e desenvolvimento. Desta maneira, há maiores possibilidades de definir estratégias para alinhar os interesses do agente e do principal. No entanto, percebe-se que o cenário do mercado de trabalho é impactado nos dias de hoje por uma aparente resistência a contratação de mulheres, sobretudo, quando se passa a analisar a participação de mulheres em nível de comando das organizações. Apoiando-se em Lazzaretti, Godoi e Camilo (2012), historicamente, o modelo de uma boa gestão é atribuído aos homens. Diante dos estereótipos consolidados fica difícil para a sociedade aceitar um novo modelo mental de mulheres dirigentes. Aspectos estes estudados sob a ótica do fenômeno denominado "teto de vidro".

Se faz necessário quebrar esse paradigma, uma vez que um grupo formado por pessoas parecidas tende a olhar para os problemas e soluções da mesma forma. Segundo Bueno (2014) a existência de diversidade permite que as ideias dominantes sejam desafiadas, favorecendo um melhor diálogo com clientes ou colaboradores, por meio da inovação, melhor pensamento "fora da caixa" e melhor governança. Categoricamente, Andrieux (2013) defende que a diversidade de gênero é a oportunidade de diversificação de competências nas organizações, podendo gerar maior vantagem competitiva, ao aproveitar melhor os recursos, conforme apregoa a Teoria da Dependência dos Recursos (Pfeffer e Salanick, 1978).

Para Shrader, Blackburn, Lies (1997), a diversidade pode impactar na composição do CA, e consequentemente na Governança Corporativa. Apesar da discussão, Erhardt, Werbel e Shrader (2003) declaram que poucas pesquisas foram realizadas sobre a presença da mulher no Conselho de Administração e sua relação com a performance da organização. Nesse sentido, algumas iniciativas surgiram a fim de garantir que as mulheres capacitadas ocupem espaço nos Conselhos Administrativos.

A Noruega foi o primeiro país a defender e introduzir cotas obrigatórias para mulheres nos CA das corporações. Bueno (2014) diz que esse processo começou em 2003 pela inserção de uma cota voluntária de $40 \%$ de participação feminina. A autora explica que sem sucesso no início, o governo norueguês tornou obrigatório o cumprimento de cota mínima, estabelecendo rigorosas penas. Em 2011, os CAs noruegueses já contavam com $44 \%$ de aderência. Apesar do cumprimento da meta, foi necessário um trabalho intenso de treinamento e capacitação de possíveis candidatas ao cargo, finalizando o processo quase uma década após a promulgação da lei. Em defesa de cotas compulsórias, outros países promulgaram Leis defendendo a inserção das mulheres no CA, a exemplo da Irlanda (2004), Islândia (2006), Espanha (2007) e a França que estima atingir 40\% até 2017 para empresas listadas em bolsa (Ferreira, 2013; 2013; Bueno, 2014).

No Brasil, apesar do país ser conhecido por sua diversidade, o tema ainda é relativamente novo no ambiente empresarial (Fleury, 2000). Tramita no Congresso, projeto de Lei do Senado no 112 de 2010 de autoria da Senadora Maria do Carmo Alves, a proposta de um percentual mínimo de participação de mulheres nos CAs das organizações, contrariando o posicionamento do Instituto Brasileiro de Governança Corporativa (IBGC) pela não obrigatoriedade de cotas para mulheres nos CA. Jain (1998, apud Fleury, 2000) declara que o crescimento econômico é um pré-requisito para o sucesso de ações afirmativas e que a legislação é uma condição necessária para seu êxito, muito embora não seja a única.

Wood (1987, apud Landrieux-Kartochian, 2010) defendia que a diversidade, sobretudo de gênero é uma fonte de performance, pois suas equipes são mais criativas. 0 primeiro trabalho empírico a analisar a relação presença feminina nas empresas e sua performance é de autoria de Sharderet al (1997). Os autores analisaram 200 empresas americanas e constataram que diante da baixa representatividade de mulheres no CA, não foi possível obter uma relação estatisticamente significante. Belghiti-Mahut e Lafont (2009), no entanto, apontam para uma relação significativa entre presença de mulheres no CA e a performance econômica das empresas. 
No Brasil, uma série de pesquisadores analisam a relação do CA e o desempenho econômico (Martins et al. 2012; Massaini et al, 2014; Politelo e Cunha, 2014; Rocha et al, 2014; Silva e Martins, 2015) porém, não se observam estudos comparativos nessa seara. Poucos estudos comparativos acerca da realidade dos CA entre países são observados (Rocha et al, 2014), nesse sentido, Gang, Bender e Scotto (2014) declaram que estudos sobre o CA na França são escassos. Quanto ao enfoque da participação da mulher, Lima et al (2013) ressaltam que o tema é oportuno, principalmente porque ainda há pouca pesquisa científica revelando a situação específica das mulheres executivas que enfrentam outros desafios ligados a um ambiente ainda masculino. São relevantes estudos que aprofundam nesta questão e contribuam para a compreensão da mulher a respeito da dinâmica dos gêneros nos altos postos executivos. Logo, senão procurar a raiz do problema, dificilmente o "teto de vidro" será quebrado e, portanto, a participação das mulheres em cargos de direção pouco será observada (McKinsey, 2007). Diante do exposto, apresente pesquisa objetiva realizar um estudo comparativo entre empresas brasileiras e francesas quanto a influência da presença de mulheres no CA e a performance financeira. Verificar se as empresas que possuem mulheres no Conselho Administrativo apresentam desempenho financeiro diferente das organizações que não possuem mulheres em seu Conselho Administrativo.

A escolha das empresas brasileiras e francesas se dá ao considerar que o Brasil é um dos países da América Latina que mais mantém relação comercial com a França. Segundo a Embaixada Francesa no Brasil: os intercâmbios comerciais franco-brasileiros dobraram em relação a 2003; o Brasil representa o principal mercado latino-americano para a França, absorvendo mais de um terço (36\%) de nossas exportações para a região, passando do México (19\%), Argentina (11\%), Colômbia e Chile (8\%). A França compra produtos agroalimentares do Brasil e exporta para o Brasil bens de equipamento, além de preparações farmacêuticas.

A opção em comparar empresas de um país com forte apelo feminista (França) com outro essencialmente paternalista (Brasil), confere a intenção de, por meio do conhecimento do modelo desse primeiro, aprimorar práticas de países ditos paternalistas que possam auxiliar na condução de ações que favoreçam maior participação das mulheres nos CA.

0 artigo segue na seção 2 com a fundamentação teórica, na seção 3 apresenta-se a metodologia. As seções 4 e 5 encontram-se, respectivamente, a análise e discussão dos dados e as considerações finais.

\section{FUNDAMENTAÇÃO TEÓRICA}

\subsection{DIVERSIDADE DO CONSELHO DE ADMINISTRAÇÃO VERSUS DESEMPENHO: EVIDÊNCIAS EMPÍRICAS}

Segundo Fleury (2000), desde a década de 60, nos EUA e no Canadá os movimentos políticos a favor da integração racial defendiam a promulgação de lei em prol da igualdade de oportunidade de educação e trabalho para os cidadãos, independente da raça, gênero e idade. Agocs e Burr (1996, apud Fleury, 2000) explicam que por exigência legal, as empresas que mantinham contratos com o governo ou que dele recebiam incentivos, deveriam trabalhar para garantir a diversidade e inserção das minorias, entre elas, mulheres, hispânicos, asiáticos e índios. Ainda segundo a autora, a gestão da diversidade foi uma resposta à diversificação crescente da força de trabalho e à competitividade do mercado. A autora completa que em um país no qual as empresas enfrentam os desafios da competitividade e das fusões e aquisições, trazendo à tona novos atores com diferentes culturas, a diversidade se torna um tema relevante.

A concepção do CA, por si só, remete a ideia de diversidade, uma vez que o mesmo é resultado da escolha dos acionistas que, por meio de votação, elegem uma quantidade específica de membros responsáveis em representar os melhores interesses dos proprietários. Para Larrate (2013), o CA é responsável "pelo monitoramento da gestão, aconselhamento e fiscalização dos gestores" e, portanto, para desempenhar seu papel, é de fundamental importância que sejam independentes e não tenham nenhum vínculo ou relação de interesse com a empresa. Silveira (2015) alerta que em empresas com base acionária mais ampla e acionistas distantes, o CA desempenha um papel ainda mais importante ao monitorar e mitigar os inevitáveis conflitos de interesse. Lembrando que o próprio CA pode apresentar conflitos de interesse, defendendo os interesses de determinados acionistas em detrimento dos benefícios a longo prazo da empresa.

A composição do CA não é uma escolha fácil. Cox (1994, apud Fleury, 2000) e Ferreira (2013) analisam essa questão sob a ótica da relação custo x benefício. Quanto aos benefícios da diversidade, os autores apresentam os seguintes: formas variadas de resolver problemas baseado em histórias e experiências de vida diversificadas; network ampliada e maior acesso à recursos (provavelmente empresas com esse foco, 
pouco observam os aspectos relacionados ao gênero, idade e etnia); incentivo ao desenvolvimento da carreira das minorias; maior alinhamento com as expectativas da sociedade, com foco na relação com os stackholders, investidores e busca pela legitimidade (empresa com esse apelo social, tendem a observar mais os fatores relacionados ao gênero e a etnia). Quanto aos prováveis custos da diversidade do CA, o autor elenca as seguintes dificuldades: dificuldade de relacionamento e comunicação; o risco de escolher conselheiro com pouca experiência e inadequada qualificação e que apresentem conflitos de interesse e com pouco alinhamento aos interesses dos acionistas.

0 presente estudo não ambiciona discutir o conceito do que venha ser um bom CA, uma vez que a formação do CA vai de acordo com as necessidades de cada empresa. Apoiando-se na Teoria dos Sistemas, em que as empresas influenciam e são influenciadas pelo meio no qual estão inseridas, busca-se trazer a baila a reflexão por meio dos estudos já realizados sobre eventuais fatores que podem levar as empresas a elegerem mais ou menos mulheres para compor o CA das organizações e como isso se comporta em termos de performance financeira.

Adams e Ferreira (2009) defendem que a entrada das mulheres no conselho tem impacto significativo no resultado das empresas. Para eles quanto maior diversidade de gênero, maior esforço de monitoramento e acompanhamento. Porém, no estudo de Rose (2007), não identificou-se qualquer relação entre a presença de mulheres no CA e o desempenho financeiro das empresas Dinamarquesas no período de 1998 a 2001. Sob uma ótica diferente, Campbell e Minguez-Vera (2008) realizaram um estudo na Espanha e observaram que existe correlação positiva entre a presença de mulheres nas organizações e o valor da empresa.

Belghiti-Mahut e Lafont (2010) investigaram 110 empresas listadas na Bolsa de Valores francesa (EURONEXT) no período de 2003 a 2008. Segundo esse estudo, a participação das mulheres no período de 2003 a 2007 passou de 5,56\% para 7,4\%. Importante dado observado, é que 1/3 das mulheres presentes no CA fazem parte da família do proprietário da empresa. Utilizando o teste Q de Tobin, identificaram relação positiva entre a presença feminina e a performance da empresa.

Gregoir, Maury e Palomino (2013) em seus estudos, identificaram que a proporção de gestoras aumentou consideravelmente depois de 2006 nas maiores empresas que compõem os Índices CAC 40 e SBF 120 da EURONEXT. Eles observaram que esse aumento não se deu pela quantidade a mais de novas mulheres no mercado, mas pela concentração das mesmas mulheres ocupando cadeiras em vários conselhos. Ainda segundo esses autores, esse aumento ocorreu, sobretudo, a partir da adoção da Lei Monsieur Copé e Madame Zimmerman no início de 2011 que prever que as empresas com mais de 500 empregados e uma receita de pelo menos 50 milhões de euros tenham 40\% de mulheres compondo o CA.

Dang, Bender e Scotto (2014) realizaram um estudo com empresas do Índice SBF 120 da Euronext Paris e observaram que a presença das mulheres apresenta influencia no capital social e humano das empresas. Ainda sobre o cenário francês, Dang, Ngnyen e Chi-Vo (2014) realizaram um estudo longitudinal com uma amostra de empresas francesas que compõem o índice SBF 120 no período de 2000 a 2009 antes da obrigatoriedade da Lei da cota de $40 \%$ de assentos no CA destinados às mulheres e constataram que do período de 2004 a 2009 houve uma maior participação de mulheres no CA, sugerindo uma provável quebra do "teto de vidro", independente da obrigatoriedade imposta pela Lei.

Considerando as pesquisas realizadas no âmbito do Brasil, Lazzarettiet al (2012) relevam que das 99 empresas brasileiras analisadas, juntas somavam 836 assentos nos seus CA, sendo que 45, ou seja, 5,4\% deles são ocupados por mulheres e todas elas de nacionalidade brasileira. Os autores ainda informam que quanto mais tempo a empresa tem no mercado, maior a chance dele ter mais mulheres ocupando o CA.

No estudo de Rocha et al (2014), foram analisadas 91 empresas brasileiras de capital aberto relacionadas no ranking da Revista Exame Melhores e Maiores (2013), no período de 2010 e 2013. Diante de tantas variáveis analisadas, os autores constataram que a presença de mulheres no CA mostrou positiva relação ao desempenho (ROE) e ao valor da empresa (Q de Tobin). Igualmente, Massainiet al(2014) apresenta que apesar da baixa representatividade de mulheres no CA, 7,1\% em relação as 202 empresas investigadas foi possível confirmar uma relação positiva e significante entre a presença feminina no CA e o resultado financeiro das organizações pesquisadas. Semelhante ao estudo de Rocha et al (2014) e Massaini et al (2014), o presente estudo tem o objetivo de verificar a presença de mulheres no CA e o desempenho da organização, porém, a diferença existe quanto a comparação dos resultados obtidos na amostra das empresas brasileiras e francesas.

Dang, Bender e Scotto (2014) observam que pesquisas sobre CA são meramente descritivas, porém, duas perspectivas teóricas têm sido usadas para discutir seu papel no desempenho da empresa, são elas a Teoria da Agência (Jensen e Meckling, 1976)como a necessidade de mitigar os conflitos entre agente e 
proprietários e a Teoria da Dependência dos Recursos (Pfeffer e Salanicik, 1978)que traz elementos para refletir sobre o papel dos membros do sexo feminino como fornecedores de recursos que seus colegas homens podem não prover.

Quadro 01: Conselho de Administração e enfoque teórico.

\begin{tabular}{|c|c|c|}
\hline Teoria & Abordagem & Autores \\
\hline \multirow{6}{*}{$\begin{array}{l}\text { Teoria da } \\
\text { Agência }\end{array}$} & $\begin{array}{l}\text { A diversidade pode impactar na composição dos conselhos e } \\
\text { consequentemente na Governança Corporativa }\end{array}$ & Shraderetal, 1997. \\
\hline & $\begin{array}{l}\text { Os diretores do sexo feminino são mais propensos a levantar mais } \\
\text { perguntas do que os diretores tradicionais. }\end{array}$ & $\begin{array}{l}\text { Carter, Simkins e } \\
\text { Simpson (2003) }\end{array}$ \\
\hline & $\begin{array}{l}\text { A questão da diversidade do CA pode ser vista, sobretudo sob a ótica da } \\
\text { GC, notadamente na relação proprietário-agente. }\end{array}$ & $\begin{array}{l}\text { Martin e Pignatel } \\
\quad(2004) .\end{array}$ \\
\hline & $\begin{array}{l}\text { As mulheres são mais propensas a trazer uma nova perspectiva sobre } \\
\text { questões complexas, que por sua vez podem ajudar a resolver } \\
\text { preconceitos informativos na formulação da estratégia ou resolução de } \\
\text { problemas. }\end{array}$ & $\begin{array}{c}\text { Dewatripoint, Jewitt e } \\
\text { Tirole (1999); } \\
\text { Westphal e Milton } \\
\text { (2000); Francour, } \\
\text { Labelle e Sinclair- } \\
\text { Desgagne (2008) }\end{array}$ \\
\hline & $\begin{array}{l}\text { A presença do gênero feminino pode ter um impacto sobre a gestão das } \\
\text { empresas, na medida em que os diretores do sexo feminino são mais } \\
\text { exigentes. }\end{array}$ & $\begin{array}{l}\text { Adams e Ferreira } \\
\text { (2009); Farrell e } \\
\text { Hersch (2009); Neklili } \\
\text { e Gatfaoui (2013) }\end{array}$ \\
\hline & $\begin{array}{l}\text { Diretores femininos tendem a atender melhor que seus colegas homens. } \\
\text { Os resultados sugerem que os CA com diversidade de gênero são mais } \\
\text { propensos a fazer um esforço no monitoramento dos interesses dos } \\
\text { proprietários. }\end{array}$ & $\begin{array}{l}\text { Adams e Ferreira } \\
\qquad(2009)\end{array}$ \\
\hline \multirow{7}{*}{$\begin{array}{l}\text { Teoria da } \\
\text { Dependência } \\
\text { dos Recursos }\end{array}$} & $\begin{array}{l}\text { As ligações com o CA podem proporcionar recursos importantes tais } \\
\text { como canais de aconselhamentos, de legitimidade e de comunicação. }\end{array}$ & $\begin{array}{l}\text { Pfeffer e Salanick } \\
\text { (1978); Daily, Dalton } \\
\text { e Carmella (2003) }\end{array}$ \\
\hline & $\begin{array}{l}\text { A legitimidade de uma organização é concebida pelos seus membros } \\
\text { sociais e esta pode ser reforçada com a nomeação de mulheres no CA. } \\
\text { Esse evento envia uma mensagem positiva tanto para mulheres que estão } \\
\text { atuando no mercado como potenciais candidatas. }\end{array}$ & $\begin{array}{l}\text { Meyer e Rowan } \\
\text { (1977); Ashforth e } \\
\text { Gilbs (1990). }\end{array}$ \\
\hline & $\begin{array}{l}\text { A ausência de mulheres pode penalizar a empresa ao reter seus melhores } \\
\text { talentos do sexo feminino e aquisição de novos. A reputação da empresa } \\
\text { aumenta com a aquisição de mulheres. }\end{array}$ & $\begin{array}{l}\text { Daily, Certo e Dalton } \\
\text { (1999) }\end{array}$ \\
\hline & $\begin{array}{l}\text { As mulheres são consumidoras potenciais, portanto, podem trazer outro } \\
\text { ponto de vista em termos de abordagem e de marketing. }\end{array}$ & Daily et al (1999) \\
\hline & $\begin{array}{l}\text { Os recursos derivam do capital humano de membros do CA, mas também } \\
\text { do seu capital social, ou seja, nas relações com diversas redes de } \\
\text { empresas e partes interessadas. }\end{array}$ & $\begin{array}{l}\text { Hillman e Dalziel } \\
\text { (2003); Singh et al } \\
\text { (2008) }\end{array}$ \\
\hline & $\begin{array}{l}\text { As mulheres mantem uma rede relacionamentos maior que homens. } \\
\text { Podem se relacionar melhor com os clientes, os empregados, bem como } \\
\text { com importantes investidores institucionais. }\end{array}$ & Hillmanetal (2007) \\
\hline & $\begin{array}{l}\text { A Teoria da Dependência ajudou a constatar que apenas o controle } \\
\text { familiar do capital explica a proporção de mulheres no CA. }\end{array}$ & Moulin e Point (2012) \\
\hline
\end{tabular}

Fonte: Adaptado de Erhardt, Werbel e Shrader (2003), Martin e Pignatel (2004), Moulin e Point (2012)e Dang, Bender e Scotto (2014).

Conforme observado no Quaro 01, inúmeros trabalhos realizados sobre a temática usam a Teoria da Agencia e da Dependência dos Recursos para compreender o cenário da diversidade no CA e sua relação com a performance da empresa.

\section{METODOLOGIA}

\subsection{AMOSTRA E COLETA DOS DADOS}

A amostra inicial das empresas francesas é composta pelas companhias que compõem os índices CAC 40 e SBF 120 da Bolsa de Paris-FR, perfazendo um total de 120 empresas, conforme fizeram Dang, Bender e Scotto (2014) em seu estudo. Esses autores consideram que as empresas que compõem o Índice SBF 120 
são maiores em termos de valor de mercado e volume negociado na Euronext de Paris. Quanto às empresas brasileiras, dentre as empresas listadas na Bovespa (Bolsa de Valores de São Paulo), foram selecionadas aquelas que compunham o índice BOVESPA, composto por 100 ações mais líquidas, perfazendo um total de 100 empresas.

Quanto às informações relacionadas à composição do Conselho Administrativo, optou-se por capturá-las diretamente no site das empresas, mais especificamente na seção Relacionamento com o Investidor (RI). Para classificação quanto ao gênero foi observado os pronomes "she" e "he", sobretudo no site das empresas francesas em que alguns nomes são comuns aos dois gêneros. Quando não era possível a identificação pela bibliografia ou quando não tinha imagem do (a) conselheiro (a), recorreu-se ao site de busca "google" para pesquisar imagens do membro e assim, classificar corretamente o gênero: "feminino" ou "masculino".

Em relação às informações financeiras para calcular o ReturnOnAssets (ROA), indicador financeiro que mede a rentabilidade das empresas sobre os investimentos foram utilizadas as seguintes fontes,

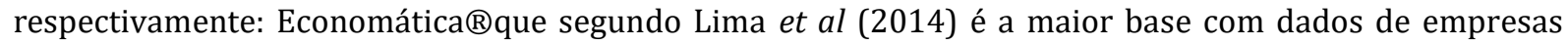
listadas na BOVESPA; e os sites Zonebourse e Boursorama para informações financeiras das empresas francesas. A escolha do ROA para representar o desempenho financeiro neste estudo deu-se por ser o índice mais utilizado na literatura para a mensuração do desempenho. A coleta de dados foi realizada ao final de 2015, logo, tomou-se como base os dados financeiros do ano calendário de 2014. Assim, foram consideradas as últimas informações atualizadas no site das empresas investigadas, tanto para o Brasil como para a França.

Algumas empresas foram excluídas da amostra por não apresentarem informações completas ou por não terem sido encontradas informações sobre o CA. Ficando assim, uma amostra final de 86 empresas francesas e 89brasileiras. A seguir são apresentadas a análise e discussão dos dados, considerando a quantidade de membros do CA e quantos desses são do gênero feminino. Além de uma classificação setorial para identificar qual setor mais abriga mulheres em seus conselhos. Para dar maior detalhamento da área de atuação das empresas, a classificação tomou como base os subsetores da classificação proposta pela BOVESPA para o mercado brasileiro e da EURONEXT para as empresas francesas.

\subsection{TESTES ESTATÍSTICOS}

Com o objetivo de verificar se o ROA das empresas que possuem mulheres no CA é diferente estatisticamente do ROA das empresas que não possuem mulheres no CA, realizou-se o teste de médias. Porém, para verificar qual o teste de médias é mais adequado, foi preciso realizar o Teste de Normalidade (Kolmogorov-Smirnov ou Shapiro-Wilk), observando se os dados seguiam uma distribuição normal ou não, conforme as Tabelas 01 e 02.

Tabela 01 - Testes de Normalidade para a amostra das empresas brasileiras

\begin{tabular}{|c|c|c|c|c|c|c|}
\hline \multirow{2}{*}{ Situação } & \multicolumn{3}{c}{ Kolmogorov-Smirnov } & \multicolumn{4}{c|}{ Shapiro-Wilk } \\
& Statistic & df & Sig. & Statistic & df \\
\hline 0 & 0,464 & 51 & 0,000 & 0,183 & 51 & 0,000 \\
\hline 1 & 0,211 & 38 & 0,000 & 0,776 & 38 & 0,000 \\
\hline
\end{tabular}

Estão incluídas na Situação 0 e 1 as empresas que não possuem e possuem mulheres na composição do Conselho Administrativo, respectivamente.

$$
\text { Fonte: dados da pesquisa. }
$$

Tabela 02 - Testes de Normalidade para a amostra das empresas francesas

\begin{tabular}{|c|c|c|c|c|c|c|}
\hline \multirow{2}{*}{ Situação } & \multicolumn{3}{|c|}{ Kolmogorov-Smirnov } & \multicolumn{3}{|c|}{ Shapiro-Wilk } \\
\hline & Statistic & df & Sig. & Statistic & df & Sig. \\
\hline 0 & 0,371 & 3 & & 0,783 & 3 & 0,074 \\
\hline 1 & 0,307 & 84 & 0,000 & 0,562 & 84 & 0,000 \\
\hline
\end{tabular}

Estão incluídas na Situação 0 e 1 as empresas que não possuem e possuem mulheres na composição do Conselho Administrativo, respectivamente. 
Para comparação de médias de duas amostras usa-se o teste paramétrico t de Student se os pares comparados seguirem uma distribuição normal. Como os pares não seguiram uma distribuição normal, como verificado nos testes de normalidade, o teste para comparação de médias foi o teste equivalente não paramétrico U de Mann-Whitney.

\section{ANALISE DE DISCUSSÃO DOS DADOS}

\subsection{CONSELHO DE ADMINISTRAÇÃO DAS EMPRESAS FRANCESAS}

Ao verificar os dados das 86 empresas francesas analisadas, percebe-se que há 1.043 conselheiros no total, o que totaliza uma média de 12 conselheiros por empresa, conforme Tabela 03. Do total de conselheiros, 332 assentos são ocupados por mulheres, o que representa $31,8 \%$ da amostra, perfazendo uma média de aproximadamente 4 mulheres por CA.

Segundo Banco Mundial, em relação à quantidade de bolsas listadas, a Euronext apresenta a 5ㅜ posição. Em 2012 eram 862 empresas listadas, perdendo apenas para Alemanha (4 $\left.4^{\underline{a}}\right)$, Japão (3 ${ }^{\underline{a}}$ ), China (2 ) e Estados Unidos (1ํㅡㄹ (Informoney, 2013). Considerando esse dado, Moulin e Point (2013) fizeram uma estimativa que com o advento da Lei que obriga a destinar $40 \%$ de assentos para mulheres no horizonte do ano de 2017 haveria entre 550 e 1350 assentos ocupados por mulheres. Provavelmente os autores consideraram apenas a quantidade de empresas do Índice SBF 120.

Ao contemplar todas as empresas listadas na Bolsa de Paris com dados da Euronext (2015) constam 868 ações listadas em bolsa, dessas, 754 correspondem à empresas francesas e 114 estrangeiras. Supõe-se que cada empresa francesa tenha no mínimo 3 membros no CA e 10 no máximo, logo, com a aplicação da Lei deveria ter, no mínimo, 904 e no máximo, 3016 mulheres participando do CA. Considerando que o presente estudo foi realizado com 11\% das empresas listadas na Bolsa de Paris, a quantidade de mulheres da amostra equivale aproximadamente à estimativa de mulheres previstas para 2017.

Além dessas informações, na Tabela 03 observa-se que o setor que apresenta maior quantidade de membros é de Construção e Engenharia, totalizando 80 conselheiros entre homens e mulheres. Esse setor também se destaca pela representatividade feminina, com 28 mulheres participando do conselho das empresas do referido setor, ou seja, 35\% de conselheiras. Inclusive, uma das conselheiras é de nacionalidade brasileira. Esses dados Contrariam a ideia de que os setores mais "masculinizados" tem menor presença de mulheres e corrobora com o estudo de Moulin e Point (2013) que ao estudarem o perfil das mulheres que ocupavam o CA das grandes empresas do Índice SBF 120 prevaleciam aquelas com laço familiar, excelente nível de escolaridade e estrangeiras.

Na sequencia, o setor de Consultoria Empresarial totaliza 62 membros, desses, 18 são mulheres; seguido do setor de Bancos com 60 conselheiros, sendo 21 mulheres. Por outro lado, os setores que apresentaram uma quantidade menor de conselheiros, são respectivamente: Máquinas e Equipamentos Industriais com 5 assentos, 3 deles ocupados por mulheres.

Em relação ao ROA, observa-se que o setor que apresentou melhor média, foi o de Alimentos Processados $(0,500)$, no entanto, esse está representado por apenas uma empresa. Os setores que apresentaram ROA negativo são da área de Saúde, uma de Instalação e Serviços para Saúde e a outra relacionado a Medicamentos e Pesquisa de Biotecnologia, respectivamente, com um total de 34 e 37 membros no CA e $24 \%$ e $32 \%$ de participação feminina. Esse resultado diverge daquele realizado por Martin e Pignatel (2004) que observaram em 2003 uma baixa proporção de mulheres em mandatos ativos nas empresas. Das 16.663 pessoas ocupando cargos de liderança, 1.339 ocupados por mulheres, representando 8\%. Observando-se assim, um significativo aumento da participação de mulheres no CA das empresas francesas nos últimos 11 anos.

Isso pode ser devido a duas razões históricas. Swart (1985, apud Dang, Bender eScotto, 2014) explica que a elite empresarial francesa apresenta dois padrões específicos. 0 primeiro corresponde à formação desses líderes ocorrer nas Escolas de elite, chamadas "GrandesÉcoles" como as da área de tecnologia e negócios, como a HEC (ÉcoledesHautesĖtudesCommerciale) e ESSEC (École Supérieuredes Sciences Economiques et Commerciales). 0 segundo padrão confere a carreira política que muitos desses fazem após sua graduação. Ainda segundo os pesquisadores, o estudo realizado com o CA das empresas francesas, evidenciou que $10 \%$ das mulheres que participam do CA apresentam algum vínculo familiar ou tem formação nas Instituições de Ensino de prestígio da França. Com isso, os autores atestam que como ocorreu na Noruega, o aumento da proporção de mulheres mediante promulgação de Lei não provocou diminuição na qualificação profissional das candidatas eleitas a atuarem nos Conselhos, uma vez que 
existe um trabalho conjunto com as Escolas de Comércio que desenvolveram formação por meio do "FemaleConseil Pool".

Tabela 03 - Participação de mulheres por setor das empresas francesas

\begin{tabular}{|c|c|c|c|c|c|c|}
\hline Setor & $\begin{array}{l}\text { Qtde de } \\
\text { Empresas }\end{array}$ & $\begin{array}{l}\text { rança } \\
\text { Composição do } \\
\text { CA }\end{array}$ & $\%$ & $\begin{array}{l}\text { Qtde de } \\
\text { Mulheres }\end{array}$ & $\%$ & $\begin{array}{l}\text { Média do } \\
\text { ROA }\end{array}$ \\
\hline Alimentos processados & 1 & 8 & 0,77 & 4 & $50 \%$ & 0,5000 \\
\hline Artigos de escritório & 1 & 12 & 1,15 & 4 & $33 \%$ & 0,3330 \\
\hline Bancos & 4 & 60 & 5,75 & 21 & $35 \%$ & 0,0025 \\
\hline Bebidas & 1 & 15 & 1,44 & 4 & $27 \%$ & 0,0289 \\
\hline Companhia aérea & 1 & 16 & 1,53 & 4 & $25 \%$ & 0,0081 \\
\hline Conglomerado industrial & 1 & 10 & 0,96 & 1 & $10 \%$ & 0,0237 \\
\hline Construção e engenharia & 6 & 80 & 7,67 & 28 & $35 \%$ & 0,0248 \\
\hline Consultoria financeira & 2 & 23 & 2,21 & 7 & $30 \%$ & 0,0526 \\
\hline Diagnósticos e exames & 2 & 14 & 1,34 & 3 & $21 \%$ & 0,0474 \\
\hline Distribuição de alimentos & 1 & 13 & 1,25 & 0 & $0 \%$ & 0,0182 \\
\hline Equipamentos de transporte & 2 & 21 & 2,01 & 8 & $38 \%$ & 0,0526 \\
\hline Equipamentos e componentes elétricos & 5 & 58 & 5,56 & 23 & $40 \%$ & 0,0178 \\
\hline Instalações e serviços para saúde & 4 & 34 & 3,26 & 8 & $24 \%$ & $-0,1161$ \\
\hline $\begin{array}{l}\text { Fonds de placement dansl'immobilier } \\
\text { commercial }\end{array}$ & 3 & 39 & 3,74 & 14 & $36 \%$ & 0,0413 \\
\hline Gestão de águas & 1 & 17 & 1,63 & 5 & $29 \%$ & 0,0095 \\
\hline Grandes magazines & 2 & 21 & 2,01 & 6 & $29 \%$ & 0,0048 \\
\hline Hotéis & 1 & 12 & 1,15 & 5 & $42 \%$ & 0,0274 \\
\hline Indústria aeroespacial & 4 & 51 & 4,89 & 13 & $25 \%$ & 0,0349 \\
\hline Indústria alimentícia & 1 & 16 & 1,53 & 7 & $44 \%$ & 0,0395 \\
\hline Siderurgia & 2 & 20 & 1,92 & 3 & $15 \%$ & 0,0139 \\
\hline Logiciel e tecnologia & 3 & 26 & 2,49 & 6 & $23 \%$ & 0,0240 \\
\hline Máquinas e Equipamentos Industriais & 1 & 5 & 0,48 & 3 & $60 \%$ & 0,0161 \\
\hline Material de construção & 1 & 17 & 1,63 & 7 & $41 \%$ & 0,0504 \\
\hline $\begin{array}{l}\text { Medicamentos e pesquisa de } \\
\text { biotecnologia }\end{array}$ & 4 & 37 & 3,55 & 12 & $32 \%$ & $-0,1165$ \\
\hline Publicidade e Marketing & 3 & 33 & 3,16 & 11 & $33 \%$ & 0,0363 \\
\hline Petróleo e gás & 2 & 24 & 2,30 & 9 & $38 \%$ & 0,0257 \\
\hline Produção de espetáculos & 1 & 16 & 1,53 & 6 & $38 \%$ & 0,1406 \\
\hline Produtora de lentes de contato & 1 & 16 & 1,53 & 3 & $19 \%$ & 0,0914 \\
\hline Cosméticos e produtos pessoais & 2 & 24 & 2,30 & 7 & $29 \%$ & 0,1028 \\
\hline Projetos e operações imobiliárias & 1 & 10 & 0,96 & 3 & $30 \%$ & 0,0433 \\
\hline Química de base & 2 & 22 & 2,11 & 9 & $41 \%$ & 0,0420 \\
\hline Roupas e acessórios & 1 & 17 & 1,63 & 4 & $24 \%$ & 0,1144 \\
\hline Serviços de Telecomunicações & 1 & 15 & 1,44 & 5 & $33 \%$ & 0,0139 \\
\hline Serviços de Consultoria empresarial & 5 & 62 & 5,94 & 18 & $29 \%$ & 0,0397 \\
\hline Serviços e Consultoria em Informática & 4 & 50 & 4,79 & 13 & $26 \%$ & 0,0462 \\
\hline Serviços & 4 & 51 & 4,89 & 24 & $47 \%$ & 0,0238 \\
\hline Seguradora & 3 & 43 & 4,12 & 15 & $35 \%$ & 0,0192 \\
\hline Supermercado & 1 & 16 & 1,53 & 4 & $25 \%$ & 0,0299 \\
\hline Transportes & 1 & 19 & 1,82 & 5 & $26 \%$ & 0,0245 \\
\hline Total & 86 & 1.043 & 100 & 332 & $32 \%$ & \\
\hline
\end{tabular}

Fonte: dados da pesquisa, 2015.

Harigan (1981 e Hillmanet al, 2007apudDang, Bender e Scotto, 2014)observaram que a quantidade de mulheres pode aumentar sobretudo das empresas de menor porte. Logo, o resultado identificado por meio das grandes empresas não pode ser generalizado às Pequenas e Médias Empresas (PMEs). Martin e Pignatel (2004) enfatizam que os homens são maioria nas grandes empresas, enquanto que as mulheres se contentam em participar de empresas com menor envergadura econômica. 


\subsection{CONSELHO DE ADMINISTRAÇÃO DAS EMPRESAS BRASILEIRAS}

As 89 empresas brasileiras analisadas somam 754 assentos no CA, desses, 49 estão representados por mulheres, correspondendo a 6,7\% das vagas ocupadas, ou seja, menos de uma mulher por CA. Observa-se a baixa participação de mulheres no CA, contrariando, os dados do IBGE que, no último senso realizado em 2010, declarou que as mulheres são maioria no Brasil, e que o analfabetismo entre as mulheres é menor que entre o grupo masculino, além disso, 19,2\% das mulheres tem ensino completo, contra 11,5\% de homens. Elementos esses que podem justificar a dificuldade das mulheres em quebrarem o "teto de vidro" no Brasil, que segundo Fleury (2000) confere a "barreira cultural a não aceitação do preconceito e da discriminação racial" e de gênero.

Conforme Tabela 04, observa-se que muitos setores empresariais não apresentam participação de mulheres no CA. Entre eles, Bebidas, Construção e Engenharia, Madeira e Papel, Máquinas e Equipamentos, Mineração, Petróleo, Gás e Biocombustíveis, Saúde e Serviços (essas constam com empresas da área de Educação). Em contrapartida, o setor que apresenta maior concentração de membros por conselho é o de Energia, composto por 12 empresas, uma média de 9,9 conselheiros. No entanto, o setor como um todo está composto por 6 mulheres apenas, ou seja, menos de uma mulher por conselho. Os setores que apresentam maior proporção de mulheres são, por ordem decrescente, Exploração de Rodovias (18,8\%), Tecidos, Vestuário e Calçados e Computadores tem cada um 15,38\% dos assentos ocupados por mulheres, seguidos de Previdência e Seguro $(13,04 \%)$ e Produtos de Uso Pessoa e Limpeza $(12,5 \%)$.

Tabela 04 - Participação de mulheres por setor das empresas brasileiras

\begin{tabular}{|c|c|c|c|c|c|c|}
\hline Setor & $\begin{array}{l}\text { Qtde de } \\
\text { Empresas }\end{array}$ & $\begin{array}{c}\text { Brasil } \\
\text { Composição do } \\
\text { CA }\end{array}$ & $\%$ & $\begin{array}{l}\text { Qtde de } \\
\text { Mulheres }\end{array}$ & $\%$ & $\begin{array}{l}\text { Média do } \\
\text { ROA }\end{array}$ \\
\hline Agropecuária & 1 & 10 & 0,0133 & 1 & 0,1000 & $-0,03143$ \\
\hline Água e Saneamento & 1 & 10 & 0,0133 & 1 & 0,1000 & 0,0278 \\
\hline Alimentos Processados & 7 & 53 & 0,0703 & 4 & 0,0755 & 0,0195 \\
\hline Bebidas & 1 & 11 & 0,0146 & 0 & 0,0000 & 0,1370 \\
\hline Comércio & 3 & 25 & 0,0332 & 3 & 0,1200 & 0,0409 \\
\hline Comércio e Distribuição & 1 & 10 & 0,0133 & 1 & 0,1000 & 0,0508 \\
\hline $\begin{array}{l}\text { Computadores e } \\
\text { Equipamentos }\end{array}$ & 2 & 13 & 0,0172 & 2 & 0,1538 & 0,0898 \\
\hline Construção e Engenharia & 5 & 32 & 0,0424 & 0 & 0,0000 & 0,0438 \\
\hline Diversos & 6 & 46 & 0,0610 & 6 & 0,1304 & 0,1156 \\
\hline Energia Elétrica & 12 & 119 & 0,1578 & 6 & 0,0504 & 0,0501 \\
\hline Exploração de Imóveis & 5 & 35 & 0,0464 & 2 & 0,0571 & 0,1672 \\
\hline Exploração de Rodovias & 1 & 11 & 0,0146 & 2 & 0,1818 & 0,0642 \\
\hline Holdings Diversificadas & 2 & 18 & 0,0239 & 1 & 0,0556 & 0,0340 \\
\hline $\begin{array}{l}\text { Intermediários } \\
\text { Financeiros }\end{array}$ & 5 & 46 & 0,0610 & 3 & 0,0652 & 0,0360 \\
\hline Madeira e Papel & 3 & 28 & 0,0371 & 0 & 0,0000 & 0,0127 \\
\hline $\begin{array}{l}\text { Máquinas e } \\
\text { Equipamentos }\end{array}$ & 2 & 21 & 0,0279 & 0 & 0,0000 & 0,0423 \\
\hline Material de Transporte & 3 & 22 & 0,0292 & 2 & 0,0909 & 0,0291 \\
\hline Mineração & 2 & 17 & 0,0225 & 0 & 0,0000 & $-5,1953$ \\
\hline $\begin{array}{l}\text { Petróleo. Gás e } \\
\text { Biocombustíveis }\end{array}$ & 2 & 16 & 0,0212 & 0 & 0,0000 & 0,0114 \\
\hline Previdência e Seguros & 3 & 23 & 0,0305 & 3 & 0,1304 & 0,1327 \\
\hline $\begin{array}{l}\text { Produtos de Uso Pessoal } \\
\text { e de Limpeza }\end{array}$ & 1 & 8 & 0,0106 & 1 & 0,1250 & 0,0753 \\
\hline Químicos & 1 & 11 & 0,0146 & 1 & 0,0909 & 0,0145 \\
\hline Saúde & 2 & 16 & 0,0212 & 0 & 0,0000 & 0,1004 \\
\hline
\end{tabular}


Tabela 04 - Participação de mulheres por setor das empresas brasileiras(continuação)

\begin{tabular}{|c|c|c|c|c|c|c|}
\hline Setor & $\begin{array}{l}\text { Qtde de } \\
\text { Empresas }\end{array}$ & $\begin{array}{c}\text { Brasil } \\
\text { Composição do } \\
\text { CA }\end{array}$ & $\%$ & $\begin{array}{l}\text { Qtde de } \\
\text { Mulheres }\end{array}$ & $\%$ & $\begin{array}{l}\text { Média do } \\
\text { ROA }\end{array}$ \\
\hline $\begin{array}{l}\text { Serviços Financeiros } \\
\text { Diversos }\end{array}$ & 3 & 30 & 0,0398 & 1 & 0,0333 & 0,2694 \\
\hline Serviços & 1 & 7 & 0,0093 & 0 & 0,0000 & 0,0503 \\
\hline Siderurgia e Metalurgia & 3 & 23 & 0,0305 & 1 & 0,0435 & 0,0069 \\
\hline $\begin{array}{l}\text { Tecidos, Vestuário e } \\
\text { Calçados }\end{array}$ & 2 & 13 & 0,0172 & 2 & 0,1538 & 0,1923 \\
\hline Telefonia Fixa & 2 & 25 & 0,0332 & 1 & 0,0400 & 0,0024 \\
\hline Telefonia Móvel & 1 & 10 & 0,0133 & 1 & 0,1000 & 0,0456 \\
\hline Transporte & 4 & 33 & 0,0438 & 2 & 0,0606 & 0,0021 \\
\hline Outros & 2 & 12 & 0,0159 & 2 & 0,1667 & 0,0754 \\
\hline Total & 89 & 754 & $100 \%$ & 49 & $6 \%$ & \\
\hline
\end{tabular}

Fonte: dados da pesquisa, 2015.

Esse resultado pode ser reflexo do que Lanfer (2003, apud Martin e Pignatel,2004) observou em sua pesquisa. Segundo o autor, no CA as mulheres se deparam com o fenômeno denominado "teto de vidro" e a um bom número de obstáculos visíveis ou não que as impedem de ocupar massivamente os postos mais prestigiados e estratégicos das instâncias do poder econômico.

\subsection{COMPARANDO OS RESULTADOS}

Na tabela 05, observa-se a quantidade total de assentos do CA das empresas analisadas tanto no Brasil como na França. Percebe-se que para as empresas do Brasil, cerca de 6,49\% dos assentos é ocupado por mulheres, enquanto que para as empresas francesas, a média alcança $31,83 \%$, demonstrando que na França a presença feminina no Conselho Administrativo é mais significativa do que no Brasil. A quantidade mínima de assentos nas empresas brasileiras e francesas incluídas na amostra corresponde a 5, demonstrando que o menor Conselho Administrativo contém cinco lugares. Ao verificar o ponto máximo, é possível identificar que a maior quantidade de assentos é verificada nas empresas francesas que chega a 19 lugares, enquanto que nas empresas brasileiras o máximo é de 15.

Tabela 05 - Participação de Mulheres

\begin{tabular}{|c|c|c|c|c|c|c|c|}
\hline País & $\begin{array}{c}\text { Total de } \\
\text { Assentos }\end{array}$ & $\begin{array}{l}\text { Total de } \\
\text { Mulheres }\end{array}$ & $\%$ & Média & Min & Máx & Desv. Padrão \\
\hline Brasil & 754 & 49 & 6,49 & 8 & 5 & 15 & 0,4022 \\
\hline França & 1043 & 332 & 31,83 & 12 & 5 & 19 & 0,1812 \\
\hline
\end{tabular}

Fonte: dados da pesquisa, 2015.

Com base nos dados coletados para o presente estudo, observou-se que no Brasil,das 89 empresas, $44,5 \%$ não apresentam mulheres no CA . Inversamente, apenas 3 empresas apresentam esse cenário na França (Cassino, Euler e IPSOS). No cenário francês, observa-se que 18 empresas ultrapassam o limite estabelecido por Lei. Uma delas, do setor de energia, apresenta uma proporção de $63 \%$ de mulheres no CA. Assim como, 3 empresas do setor bancário.

A Tabela 06 a seguir, apresenta dados comparativos em relação ao CA com e sem mulheres no Brasil e na França. Analisando, inicialmente, a média do ROA para as empresas do cenário brasileiro, é possível perceber que as empresas que apresentam mulheres no CA apresentaram um ROA maior, se comparado a média do ROA das empresas sem mulheres. Em relação ao cenário francês, o resultado foi o inverso, a média do ROA das empresas que não apresentam mulheres foi superior à média do ROA das empresas que tem o CA composto por membros do gênero feminino. 
Tabela 06 - CA com e sem mulheres x ROA.

\begin{tabular}{|c|l|c|c|}
\hline \multirow{3}{*}{ País } & Parâmetros & ROA - CA sem Mulheres & ROA - CA com Mulheres \\
\hline \multirow{5}{*}{ Brasil } & Média & $-0,05148$ & 0,05097 \\
\cline { 2 - 4 } & Min. & $-5,19771$ & $-0,03143$ \\
\cline { 2 - 4 } & Max. & 0,17896 & 0,33178 \\
\cline { 2 - 4 } & Desv. Pad. & 0,51965 & 0,09115 \\
\hline \multirow{5}{*}{ França } & Média & 0,0346 & 0,01820 \\
\cline { 2 - 4 } & Min. & 0,0182 & $-0,50806$ \\
\cline { 2 - 4 } & Max. & 0,0433 & 0,15309 \\
\cline { 2 - 4 } & Desv. Pad. & 0,0210 & 0,18355 \\
\hline
\end{tabular}

Fonte: dados da pesquisa, 2015.

Para as empresas brasileiras que compõe a amostra, a média do ROA das empresas que não possuem mulheres no CA foi negativa, ao contrário da média do ROA das empresas que possuem mulheres no CA. Enquanto que para as empresas francesas, os resultados foram inversos, onde as empresas que contém mulheres no CA apresentaram uma média negativa para o ROA. Porém, para se afirmar que essas diferenças são significativas estatisticamente, realizou-se um teste de médias para as duas amostras, empresas brasileiras e francesas.

\subsubsection{TESTE DE MÉDIAS NÃO PARAMÉTRICO U DE MANN-WHITNEY}

\subsubsection{EMPRESAS BRASILEIRAS E FRANCESAS COM E SEM MULHERES NO CA}

Para verificar se há significância estatística no ROA das empresas que contém e não contém mulheres no Conselho de Administração, realizou-se o teste de Mann Whitney. Para as empresas brasileiras, os resultados dos testes foram os apresentados na Tabela 07.

Tabela 07 - Comparação entre as empresas brasileiras com e sem mulheres no CA

\begin{tabular}{|l|c|}
\hline \multicolumn{2}{|c|}{ Teste de Média } \\
\hline Mann-Whitney U & 936,000 \\
\hline Wilcoxon W & $1.677,000$ \\
\hline Z & $-0,274$ \\
\hline Asymp. Sig. (2-tailed) & 0,784 \\
\hline
\end{tabular}

Fonte: dados da pesquisa, 2015.

Conforme tabela 06 , o p-valor do teste foi de 0,784 , ou seja, maior que o nível de significância adotado pelo estudo $(78,4 \%>5 \%)$, portanto, considerando o nível de significância de 5\%, pode-se afirmar que os dois grupos tem a mesma distribuição. Portanto não há diferença estatística significante entre o grupo das empresas que contém mulheres no CA e o grupo das empresas que não contém mulheres no CA.

Semelhante ao resultado anterior, para as empresas brasileiras, os resultados para as empresas francesas apontam que também não há uma diferença estatística entre o ROA das empresas que possuem mulheres no CA e o ROA das empresas que não possuem mulheres no CA, conforme dados da Tabela 08.

Tabela 08 - Comparação entre as empresas francesas com e sem mulheres no CA

\begin{tabular}{|l|c|}
\hline \multicolumn{2}{|c|}{ Teste de Medias } \\
\hline Mann-Whitney U & 106,000 \\
\hline Wilcoxon W & 3676,000 \\
\hline Z & $-0,465$ \\
\hline Asymp. Sig. (2-tailed) & 0,642 \\
\hline
\end{tabular}

Fonte: dados da pesquisa, 2015. 
Esses resultados significam que independentemente das empresas possuírem mulheres na composição do Conselho de Administração, o retorno sobre os investimentos não é estatisticamente diferente, ou seja, para as amostras analisadas, as empresas que possuem mulheres no CA não possuem desempenho superior quando comparadas as empresas que não possuem mulheres em seu quadro do CA.

\section{CONSIDERAÇÕES FINAIS}

A diferença entre a presença de mulheres no Conselho de Administração das empresas listadas em bolsas dos dois países é grande. 0 fator legislação pode influenciar esse resultado, cabendo, portanto, uma análise mais aprofundada sobre o perfil dessas mulheres, no que se refere a sua formação, instituição de ensino nas quais se formaram, experiência e percurso profissional.

Observou-se que as empresas que apresentam maior quantidade de mulheres na França são empresas de energia, máquinas industriais e publicidade. Empresas estas que demandam maior atenção em relação ao meio ambiente e uma cobrança maior no fator criatividade. Assim como na França, no Brasil não se apresenta uma tendência entre empresas de um setor específico da economia com presença maior de mulheres, variando de empresas do setor de educação, eletrodomésticos e alimentos.

Em relação à formação, tanto no Brasil como na França as mulheres apresentam maior tempo de estudos que seus congêneres masculinos (IBGE, 2010; INSEE, 2014). No entanto, esse fator parece não ser levado em consideração no processo de inserção de mulheres no mercado de trabalho. Esse resultado pode ser reflexo das barreiras existente no seio do poder, tanto o poder econômico como o poder político BelghitiMahut e Lafont (2010).

Apesar dos resultados sinalizarem que não há diferença significativa no retorno sobre os investimentos para empresas que apresentam ou não mulheres no CA, o estudo chama a atenção para necessidade de aprofundar o debate sobre o papel das instituições de ensino e de políticas públicas voltadas para melhor capacitação das mulheres.

Reconhecendo as limitações do presente estudo, sugere-se para pesquisas futuras: a) considerar a Teoria de Hofsted para analisar aspectos relacionados a cultura do país na participação de mulheres no CA das empresas; b) analisar outros indicadores de performance, como o $\mathrm{Q}$ de Tobin, e; c) verificar por meio de uma análise mais aprofundada quais os fatores que podem levar as empresas a elegerem mais ou menos mulheres para compor o CA das organizações. Além desses, por meio de estudo de caso, sob a lente da Teoria Institucionalista acompanhar o poder de influência das mulheres que ocupam assento no CA em relação a decisões relacionadas a investimento, a inovação e pesquisa e desenvolvimento.

\section{REFERENCIAS}

[1] Andrieux, M.-A. (2013). Paritéet capital Féminin: quels enjeux de compétitivité et de croissance ? Les Annonces de la Seine - Numéro 18.

[2] Adams, R. B.; Ferreira, D. (2009). Women in the boardroom and their impact on governance and performance. Journal of Financial Economics, v. 94, p. 291- 309.

[3] Belghiti-Mahut, S.; Lafont, A.-L. (2009). PRESENCE DES FEMMES DANS LE TOP MANAGEMENT ET PERFORMANCE FINANCIERE DES ENTREPRISES: UNE ETUDE EXPLORATOIRE. Disponível em: http://www.reimsms.fr/agrh/docs/actes-agrh/pdf-des-actes/2009belghitimahut-lafont013.pdf (2010). Lien entre présence des femmes dans le top management et performance financière des entreprises en France. Gestion, 27(5), 131-146.

[4] Bueno, M.L.C.L. (2014). Os benefícios e os desafios da diversidade e da equidade na composição dos conselhos de administração. In: Candeloro, A.P.P. e Benevides, M. M. (Coordenação). Governança Corporativa em foco: inovações e tendências para a sustentabilidade das organizações. São Paulo: Saint Paul.

[5] Campbell, K.;Minguez-Vera, A. (2007). Gender Diversity in the Boardroom and Firm Financial Performance.Journal of Business Ethics. Volume 83. pp 435-451

[6] Dang, R.; Bende, A.-F.;Scotto, M.-J. (2014).Women on French corporate board of directors: How do they differ from their male counte parts? The Journal of Applied Business Research, v. 30, n.2.

[7] Dang, R.; Ngnyen, D. K.; Vo, L. -C. (2014). Does the glass ceiling exist? A longitudinal study of women's progress on French Corporate Boards.Disponívelem: http://www.ipag.fr/wpcontent/uploads/recherche/WP/IPAG_WP_2014_239.pdf 
[8] Gregoir, S.; Maury, T.-P.Palomino, F. (2013). La féminisation des Conseilsd'Administration des grandes entreprises en France: au delà des apparences. Nice: EDHEC - Business School Pôle de Recherche en Economie, Evaluation des Politiques Publiques et Reforme de l'Etat.

[9] Erhard, N.L.; Werbel, J. D.; Shader, C. B. (2003).Board of director diversity and firm financial performance.Corporate Governance, v. 11, n. 2, p. 102-111.

[10] Ferreira, D. (2013). Board Diversity. In: Baker, H. K., \& Anderson, R. (Ed.). Corporate governance: a synthesis of theory, research, and practice. The Robert W. Kolb series in finance.New Jersey: Wiley

[11] Fleury, M.T.L. (2000). GERENCIANDO A DIVERSIDADE CULTURAL: experiências de empresas brasileiras. RAE - Revista de Administração de Empresas. RAE .v. 40 . n. 3.

[12] IBGC (2012). Relatório de Mulheres na Administração das Empresas BrasileirasListadas - 2010 e 2011.

[13] Landrieux- Kartochian, S. (2004). La contributiondesfemmes a la performance: une revue de lalitterature. Disponível em: http://cergor.univparis1.fr/docsatelecharger/docdar es\%20landrieux.pdf

[14] Larrate, M. Governança Corporativa e Remuneração dos Gestores. Atlas, 2013.

[15] Lazzaretti, K. Godoi, C. K.; Camilo, S. P. O. (2012). Desigualdade de Gênero nos Conselhos de Administração das Empresas Brasileiras: uma análise à luz do fenômeno do Teto de Vidro. XXXVI Encontro da ANPAD.

[16] Lima et al. (2013). O Teto de Vidro das Executivas Brasileiras. Pretexto. Volume 14. N 4. Belo Horizonte. P. $65-80$.

[17] Martin, V.; Mignatel, I. (2004). Lesinstances de pouvoir de 500 premiers groupsfrançais: um monde “androcentrique". RevueFrançaise de Gestion. Pages 161 - 172

[18] Martins, O. S.; Mazer, L. P.; Lustosa, P. R. L. Paulo, E. (2012). Características e competências dos conselhos de administração de bancos brasileiros e sua relação com seu desempenho financeiro.Revista Universo Contábil, Blumenau, v. 8, n. 3, p. 40-61.

[19] Massaini, S. A. (2014). Análise da representação feminina na alta administração e sua relação com o desempenho financeiro da empresa. In: XVII SEMEAD. Seminários em Administração. Outubro de 2014. São Paulo.

[20] McKinsey \& Company (2007). Women Matter. La mixité, levier de performance del'entreprise. Women'sForum for The Economy\&Society.

[21] Moulin, Y.; Point, S. (2013). Lesadministratricesdes grandes groupesfrançaiscotés. Quel "atouts" previligecier? RevueFrançaise de Gestion. Pages 15 - 32

[22] Rocha, R. M.; Santos, T. M. N.; De Luca, M. M. M; Vasconcelos, A. C. (2014). Conselho de Administração e Desempenho nas Maiores Companhias listadas na BM\&FBOVESPA.

[23] V Congresso Nacional de Administração e Ciências Contábeis -AdCont.

[24] Shrader, C. B.; Blackburn, V. B.; Lies, P. Women In Management AndFirm Financial Performance: AnExploratoryStudy. JournalofManagerialIssues, Vol. 9, No. 3, pp. 355-372

[25] Silva, C. P.; Martins, O. S. (2015). Mulheres no Conselho Afetam o Desempenho Financeiro? Uma Análise da Representação Feminina nas Empresas Listadas na BM\&FBOVESPA. XV Congresso USP de Contabilidade e Controladoria.

[26] Silveira, A. Di M. (2015). Governança Corporativa no Brasil e No Mundo. Teoria e Prática. 2 ed. Rio de Janeiro: Elsevier.

[27] Tonello, M. (2010).Board composition and organization issues. In: Baker, H. K., \& Anderson, R. (Ed.). Corporate governance: a synthesis of theory, research, and practice. The Robert W. Kolb series in finance.New Jersey: Wiley 


\section{Capítulo 12}

Resolução de problemas e tomada de decisão em contabilidade: Paradigma da subjetividade no confronto entre a essência e a forma

\section{Erivan Ferreira Borges}

\section{Diogo Henrique Silva de Lima \\ José Alves Dantas}

Resumo: Este trabalho teve como objetivo identificar se no processo de tomada de decisão em contabilidade os elementos formais prevalecem sobre os aspectos essenciais. Para tanto, foram adotados critérios de julgamento a partir de exemplos práticos relacionados às funções da contabilidade utilizando-se fundamentos teóricos relacionados ao processo de tomada de decisão em contabilidade, envolvendo aspectos comportamentais e de julgamentos e elementos filosóficos subjacentes para resolução de problemas. Metodologicamente, caracterizou-se como um estudo exploratório, envolvendo uma amostra de 153 indivíduos, composta por profissionais e estudantes de graduação e pós-graduação em ciências contábeis. Os resultados indicam que os pressupostos assumidos não podem ser rejeitados, evidenciando que na avaliação do nível individual de importância dado a uma decisão, evidência e/ou procedimento aplicável a um caso, os aspectos formais têm maior relevância, ainda que existam situações que apontem em sentido contrário, como se existissem profissionais que já superam o paradigma. Considerações são feitas sobre o nível de maturidade da inserção do paradigma da subjetividade no contexto brasileiro, o que explicaria o modelo de decisão adotado pela maioria dos profissionais.

Palavras-chave: Decisão contábil. Resolução de problemas. Essência sobre a forma. Subjetividade. 


\section{INTRODUÇÃO}

O processo de tomada de decisão contábil traz a inerente necessidade de se considerar os componentes de historicidade e criticidade. Sobre o primeiro ponto, a evolução das práticas e conceitos exige que esta ciência atenda de imediato às demandas corporativas e às expectativas do mercado (Hendricksen \& Van Breda, 1999; Schmidt, 2000).

Quanto à criticidade, pode-se dizer que é uma questão proeminente e de reflexão diária exigida dos profissionais. É um exercício hermenêutico permanente, fruto da subjetividade trazida pelas normas internacionais e sua consequente introdução no normativo contábil adotado no país.

0 processo também pode ser considerado um exercício de julgamento diário que inclui a relação entre fatores psicológicos e variáveis subjetivas que devem ser analisadas sob uma perspectiva racional e traduzidos de forma objetiva, considerando a necessidade de reporte para decisão por parte do usuário (Chang, Yen \& Duh, 2002; Fuji \& Slomski, 2003).

O Conselho Federal de Contabilidade (CFC) e o Comitê de Pronunciamentos Contábeis (CPC), principais condutores do processo normativo, acabam por confirmar essa impressão. Em meio aos inúmeros normativos que regulam a vida financeira e contábil da entidade, a Estrutura Conceitual para Relatório Financeiro - CPC 00 (R2) representa o principal fundamento para a análise prévia da continuidade das transações e eventos empresariais.

A partir desses pressupostos, um dos pontos que merece destaque na abordagem a partir dos princípios é a delimitação de que na sua aplicação a situações concretas, a essência das transações deve prevalecer sobre seus aspectos formais_CPC 00 (R2)]. Isso porque a ciência contábil, e todo o seu arcabouço teórico, no que tange à mensuração, pode ser considerada subjetiva e inexata (Lustosa, 2009; Relvas, 2008). Sob o ponto de vista da subjetividade, o valor correto de um ativo, por exemplo, embora possa ser exato, é, inerentemente, subjetivo (Lustosa, 2009). Essas características não tornam precárias as informações produzidas pela contabilidade, mas antes tornam-na mais transparente por considerar que também são reflexos de conflitos e contextos sociais, podem sofrer influência de comportamentos, e ainda devem guardar consonância com certos trade off observados entre a ciência e as exigências das regras societárias e fiscais.

Em que pese o processo de decisão contábil (como julgamento) assuma essas variações, presume-se considerar que, sob o aspecto historicidade, os profissionais frequentemente tomam suas decisões baseados mais em aspectos formais em detrimento aos aspectos essenciais, que, em tese, exigem muito mais subjetividade.

Presume-se que esse ideal de aplicação representa a aplicação empírica (comum) daquilo que se conhece como Princípio de Ockam, ou princípio da parcimônia; postulado que prega a simplicidade como elemento subjacente à decisão científica (Lima \& Shneider, 2013). Esse aprendizado é uma construção histórica materializada pela fixação de dados pelo agente tomador de decisão.

0 conceito de fixação de dados é proveniente dos pressupostos da fixação funcional em psicologia. Por esse fenômeno, operadores e usuários das informações contábeis tomam decisões baseadas em conceitos aprendidos e fixados em experiências passadas (Eysenck \& Keane, 2007; Nascimento, Ribeiro \& Junqueira, 2008; Neufeld, Brust \& Stein, 2011).

Proposições filosóficas também podem ajudar a entender, senão explicar, o comportamento e as decisões tomadas por profissionais diante de situações conflitantes, tendo de escolher e naturalmente renunciar opções, considerando elementos de dever, significantes e significadores da decisão (Bonder, 1995; Sartre, 2014; Kant, 2002; Kant, 2003; Lisboa, 1997; Borges \& Medeiros, 2007).

Esses argumentos suportam a elaboração deste trabalho, que tem como objetivo identificar se na resolução de conflitos e problemas, e no processo de tomada de decisão em contabilidade os elementos formais prevalecem sobre os aspectos essenciais. Para tanto, são adotados critérios de julgamento a partir de exemplos práticos relacionados às funções complementares à contabilidade (D'áuria, 1953; Magalhães et al., 2009) - auditoria, enquanto revisão, e perícia contábil - que condicionam uma hierarquia de aplicações e que servem de parâmetros para estabelecer as variáveis que identificam os vetores de decisão.

Para o alcance desse objetivo foram aplicados questionários com questões que induzem ao processo de decisão, tendo como público alvo profissionais e estudantes da área contábil. As hipóteses subjacentes ao objetivo de pesquisa consideram que (1) na avaliação do nível individual de importância dado a cada decisão, evidência ou procedimento aplicável a um caso, os aspectos estéticos têm maior relevância na 
tomada de decisão; e, que (2) na escolha ou renúncia de uma das situações, a evidência ou procedimento aplicável que não se predem a forma serão as descartadas.

\section{REFERENCIAL TEÓRICO}

\subsection{FATORES INFLUENTES NOS TRAD OFFS ENTRE ESSÊNCIA SOBRE A FORMA E OBJETIVIDADE}

Para Sartre (2014), toda escolha envolve um processo de renúncia entre alternativas. Questões de julgamento e decisão envolvendo aspectos formais e de essência têm sido recorrentes nas discussões que envolvem o processo de decisão contábil. Ainda que a literatura deixe clara a supremacia da relevância sobre a objetividade, da essência sobre a forma, estes trad offs ainda provocam inquietações de forma recorrente.

No que tange à essência sobre a forma, as práticas contábeis adotadas no Brasil, com destaque para o período pós CPC, têm delimitado em quase todos os documentos que sugerem a aplicação do pressuposto de que, na avaliação de situações concretas, a decisão deve ser tomada levando-se em conta a prevalência da essência das informações sobre sua forma (destaque nos CPC 00-R2, por exemplo).

Esse arcabouço também fora absorvido pelo regramento societário e fiscal - conforme se depreende do Decreto n. 9.580/2018, que regulamenta o imposto sobre a renda (Decreto n. 9.580, 2018), e dispositivos que alteram a lei societária e fiscal (Lei n. 6.404, 1976; Lei n. 11.638, 2007; Lei n. 11.941, 2009) - mas não se pode afirmar que sua efetiva aplicação tenha alcançando êxito, seja pela inerente dificuldade dos profissionais em traduzir isso na prática diária, seja pela opção dada pelo próprio normativo, ao permitir que fossem adotados regimes (tributários) diferentes para tratar informações e dados contábeis e fiscais.

Essa permissividade impede a materialização desse exercício de julgamento por parte dos profissionais em contabilidade. Três situações, entre outras, podem ser tomadas para exemplificar esta dificuldade:

(I) a sistematização do imposto de renda em regimes tributários diferenciados privilegia a objetividade e a forma, pois os regimes como o Simples e Lucro Presumido, que são materializados pela gestão em regime de caixa, acabam sendo adotados pela maioria das empresas nacionais, ratificando a possibilidade apontada por Bierman (1963) e Relvas (2008);

(II) essa mesma sistematização, mesmo considerando o regime de Lucro Real, exige periodicamente a entrega de protocolos e declarações que devem atender a regras específicas para reporte e apresentação, convencionando entre os gestores práticas específicas para atender essas exigências sem vieses ou diferenciações; e,

(III) questões envolvendo a resolução ou dissolução da sociedade - Lei no 10.406 , de 24 de outubro de 2002 - exigem a aplicação de conceitos objetivos com base na situação patrimonial da sociedade na data da resolução, verificada em balanço especialmente levantado para tal fim.

A adoção da simplificação nesses casos não é justificada apenas pela possibilidade de se atender a uma gama maior de clientes, mas também de não se incorrer em opções de decisões que não atendam às determinações dos órgãos fiscalizadores, quase todas pautadas na objetividade.

Além desses aspectos, o comportamento também é resultante de aspetos psicológicos (abordagem de fixação funcional), que acabam por induzir o profissional a adotar um comportamento conservador (privilegiando a objetividade) no trato e divulgação da informação contábil.

\subsection{ASPECTOS COMPORTAMENTAIS ENVOLVIDOS NO PROCESSO DE DECISÃO EM CONTABILIDADE}

Para Chang, Yen e Duh (2002), a maioria das tarefas contábeis requer que os contadores façam julgamentos na coleta e apresentação de informações para a tomada de decisão dos gestores. As alterações observadas na contabilidade brasileira, resultantes principalmente da Lei n. 11.638 (2007), ratificaram a utilização da subjetividade do profissional contábil na análise das transações que afetam o patrimônio das empresas.

A prevalência da essência sobre a forma jurídica é um exemplo desse novo contexto que requer julgamentos e avaliações e faz com que contadores, auditores e peritos assumam uma maior responsabilidade na execução dos seus trabalhos.

Contudo, é preciso reconhecer que os seres humanos apresentam limitações no processamento de todas as informações disponíveis quando da análise de uma situação (Simon, 1956). Pesquisas em psicologia 
evidenciam que a restrição de racionalidade econômica ilimitada dos indivíduos resulta no uso de recursos simplificadores por parte destes, conhecidos como atalhos mentais ou heurísticas. São elas: a autoconfiança excessiva, o otimismo, a representatividade, o conservadorismo, a perseverança, a ancoragem e a disponibilidade (Aldrighi \& Milanez, 2005; Yoshinaga, et al., 2004; Barberis \& Thaler, 2002).

Conforme a heurística da autoconfiança, as pessoas são excessivamente autoconfiantes em seus julgamentos e não são acuradas quando estimam probabilidades. A maioria dos indivíduos também é otimista, ou seja, apresenta uma visão irrealista das suas habilidades, acreditando estar acima da média em relação a suas habilidades, senso de humor e avaliação de investimentos (Yoshinaga, et al., 2004; Barberis \& Thaler, 2002).

A heurística da representatividade evidencia que as pessoas tendem a atribuir maior peso a eventos ou experiências recentes, desconsiderando a média de longos períodos (Ritter, 2003). 0 conservadorismo consiste na lentidão no processo de atualização de crenças quando do surgimento de novas informações.

De acordo com a perseverança, quando os indivíduos formam uma opinião são relutantes em aceitar algo que a contrarie, mesmo diante de fortes evidências nessa direção. Quando formam estimativas, começam com alguma posição inicial, possivelmente um valor arbitrário, e o ajustam durante o surgimento de novas informações. Essa heurística é definida como ancoragem. Por fim, segundo o viés de disponibilidade, quando os indivíduos avaliam a probabilidade de um evento, geralmente procuram suas memórias para obter informações relevantes (Yoshinaga, et al., 2004; Barberis \& Thaler, 2002).

A utilização dessas heurísticas no processo decisório pode conduzir a importantes vieses de decisão e avaliação, que podem resultar em erros sistemáticos graves (Kahneman \& Tversky, 1973). Por outra via, é possível que essas relutâncias psicológicas expliquem a dificuldade dos profissionais em contabilidade em absorver e aplicar na prática fundamentos subjetivos que o processo de julgamento da essência sobre forma exige.

Segundo Lima et al. (2011), mais do que os profissionais, a profissão contábil, cujo objeto de estudo é o patrimônio das empresas e suas variações, é essencialmente conservadora. Logo, essa heurística pode exercer influência significativa nas avaliações realizadas por contadores, auditores e peritos em situações concretas, principalmente quando da análise da primazia da essência sobre a forma.

Destarte, profissionais contábeis conservadores podem ser propensos a valorizar mais elementos formais e objetivos num processo de avaliação do que a essência do contexto, por essa exigir maior interpretação e uso da subjetividade. Se isso realmente for o que acontece, tem-se uma grande limitação à aplicação de práticas contábeis mais modernas e que representem com mais fidedignidade o patrimônio das entidades.

\subsection{JULGAMENTOS E SUBJETIVIDADE EM AUDITORIA E PERICIA}

No cumprimento da sua função, o profissional se envolve em julgamentos complexos em praticamente todos os trabalhos, conforme ressaltam Gramling, Rittenberg e Johnstone (2012). Envolve-se em questões subjetivas sobre se as posições do cliente em relação aos números e às evidenciações contábeis são apropriadas ou sobre a materialidade de alguma incorreção na divulgação financeira, que possa requerer a modificação da opinião no relatório de auditoria.

Particularmente em relação ao julgamento das informações financeiras preparadas pela administração, a subjetividade é exercida pelo profissional em questões como: (i) a manutenção do registro de determinado ativo, considerando as perspectivas dos fluxos de caixa futuro; (ii) a mensuração do valor justo de um ativo financeiro para o qual não exista um mercado líquido; (iii) o registro/evidenciação de uma contingência, tendo em vista a sua probabilidade de ocorrência e o seu possível valor monetário; (iv) a estimação de perdas incorridas ou esperadas, conforme o modelo contábil, de um determinado recebível; (v) a realização do teste de impairment aplicável a determinados ativos, nas condições requeridas nas normas contábeis; entre outras.

Sobre a materialidade, Alexander e Jermakowicz (2006) destacam que o parâmetro de divulgação financeira a ser considerado pelas empresas é o de divulgar qualquer informação material que assegure que as demonstrações não sejam enganosas, seja tal informação requerida especificamente ou não. Nesse sentido, o papel do auditor é julgar se esse preceito de divulgação do que é material é observado nas demonstrações preparadas pela administração. 
Considerando, porém, que a definição da materialidade não é algo objetivo, o auditor deve exercer o seu julgamento profissional para decidir se algo que deixou de ser divulgado. Ou ainda se a distorção identificada alcança o que seria o limite da materialidade.

Por fim, também é possível destacar aspectos subjetivos no próprio exercício do ceticismo profissional do auditor. Um exemplo nesse sentido pode se depreender do relato de Jones (2010) sobre as investigações de reguladores britânicos sobre a atuação dos auditores independentes em eventos antecedentes à crise financeira de 2008.

Para os investigadores, os auditores precisam pôr à prova os pressupostos assumidos pela administração, especialmente na aferição do valor de ativos, mas em alguns casos percebe-se que eles buscam evidências para corroborar a opinião da administração (Jones, 2010). Ainda no âmbito da crise financeira de 2008 pode-se destacar como outro exemplo, o caso da investigação promovida pela Justiça dos EUA em relação à falência do Lehman Brothers. No relatório, o investigador afirmou que a auditoria externa Ernst \& Young deveria ser processada "por, entre outras coisas, seu fracasso em questionar e desafiar divulgações impróprias ou inadequadas nos comunicados financeiros" (Chaves, 2010).

\subsection{RESOLUÇÃO DE PROBLEMAS E SEUS ELEMENTOS FILOSÓFICOS SUBJACENTES}

A resolução de problemas, julgamentos e tomada decisão também envolve a avaliação de situações de contexto prático, envolvendo essência e forma, e o trad off necessário entre escolha e renúncia.

As duas situações podem ser analisadas levando-se em conta elementos filosóficos que orientam a ética, a moral e a existência. Sobre a ética e a moral, o que é certo ou errado do ponto de vista profissional também decorre da introjeção de juízos (ética) que se manifestam pela prática (moral) diária na aplicação de regras e normas que estão vinculadas, por exemplo, a uma sociedade profissional, como é o caso dos contabilistas (Lisboa, 2007; Borges \& Medeiros, 2007). Nesse caso, o respeito ao dever é uma condição de racionalidade assumida por quem escolhe fazer parte de um grupo (Kant, 2002; Kant, 2003).

No paradigma escolha e renúncia, não há como se furtar da proposição existencialista de que a existência precede a essência. E isso, naturalmente, provoca a construção de uma realidade a partir das decisões tomadas pelo indivíduo. Portanto, por sua liberdade de escolhas (Sartre, 2014b). Estas, por outro lado, revelam a necessária renúncia de opções, que são julgadas pelo indivíduo como menos necessárias à construção da sua essência. Assim, pode-se considerar que o entendimento ou o alcance do que seja a "essência" só será obtido a partir de um conjunto decisões tomadas pelo indivíduo no seu viver; e, consequentemente, por sua experiência, como resultado desse processo construtivo.

Resoluções de problemas e decisões profissionais não fogem à regra, mas também estão ligadas a certos preceitos que são tomados como universais e devem ser obedecidos pelos componentes destas profissões. 0 que de certa forma estabelece um rito de ações e atitudes que têm por fim apresentar uma decisão que reflita uma aceitação sistêmica, minimizando problemas ou rejeições por parte do grande grupo. Essa condição, presume-se, é uma variável significante advinda do processo de tomada de decisão, tendo como um dos seus significadores esta condição de aceitação universal (Bonder, 1995).

Para Bonder (1995), o significador não define o significante, mas revela modelos e processos de pensá-lo e entendê-lo melhor. Destaca que as semelhanças entre situações podem revelar o que está oculto do que é aparente. Para ele, uma coisa não é tão claramente uma coisa até que se possa dizer que se parece com outra. Nesse contexto, a busca por semelhanças permite encontrar mais saber, pois as soluções se expressam pelas semelhanças. 0 conhecimento desses fundamentos possibilita fazer uso dos julgamentos para evitar os bloqueios pessoais e estéticos, presos à forma, percebendo um quadro maior, não imediato e recontextualizado, que revele a natureza daquilo que só é evidente quando revelado (Bonder, 1995).

Portanto, decisões são necessariamente comparativas, e pelo princípio do individualismo, ao fazer uma coisa se assemelhar a outra, sabendo que não são idênticas, aprende-se sobre o mundo e define-se o que é essencial.

\section{METODOLOGIA}

Entendida como exploratória, por buscar apresentar novas dimensões ainda não conhecidas (Raupp \& Beuren, 2012), a pesquisa foi realizada a partir da elaboração de um instrumento com questões que induzem ao processo de decisão, seja pela aplicação de procedimentos seja pela decisão em si sobre um fato contábil. Logo, o público alvo do estudo foram os profissionais da área e alunos, de graduação e pós- 
graduação, do curso de Ciências Contábeis do município de Natal-RN. Foram incluídas ainda questões de natureza censitária, tendo a participação de 153 indivíduos. A coleta foi realizada por meio do Google Docs e in loco.

O questionário aplicado foi composto de oito questões principais. Cada uma apresentando um contexto de tomada de decisão em auditoria ou perícia contábil, bem como três alternativas de ação, denominadas de A, B e C, para a resolução do problema (a questão oito apresentou apenas duas alternativas, A e B). Das três alternativas, duas focaram procedimentos padrões/formais de ação e uma apresentou uma postura cujos elementos essenciais prevaleciam aos aspectos formais. Na questão oito foram apresentadas duas alternativas, uma com ênfase na forma e a outra na essência.

Aos respondentes foi solicitado que estabelecessem uma ordem de importância para aplicação de cada procedimento apresentado nos contextos. Logo, para as questões 1 a 7 havia seis opções: $A-B-C, A-C-B, B-A$ $C, B-C-A, C-A-B$ e $C-B$ - $A$. Para questão 8 , apenas duas: $A-B$ ou $B$ - $A$. Posteriormente, também foi solicitado que o participante do estudo indicasse qual opção ele renunciaria totalmente.

Pelas premissas adotadas e pela suposição de conservadorismo do profissional contábil (ênfase nos aspectos formais em detrimento aos de essência), assume-se que as duas alternativas mais formais se revelam como mais usuais e mais próximas da aplicação empírica do conhecimento (senso comum), sendo utilizadas como proxies para medir a prevalência de aspectos formais. Acredita-se também que a terceira opção, por representar um posicionamento mais subjetivo, seja menos usual. Logo, espera-se que ela represente a última opção de escolha dos indivíduos, sendo também aquela que será descartada.

Para cada questão, a alternativa menos usual (menos formal) é respectivamente: 1(C), 2(B), 3(C), 4(C), 5(B), 6(B), 7(C) e 8(B). Espera-se que elas representem as últimas opções na escolha, e considerando o processo necessário de renúncia e descarte, sejam as alternativas apontadas.

As questões apresentadas no instrumento de pesquisa estão destacadas na Tabela 1.

Tabela 1: Questões apresentadas no instrumento de pesquisa

A empresa "X" tem 301 funcionários recebendo salário mensalmente, conforme observado pelo Auditor no
relatório de retorno bancário relativo ao mês de março/2x15, que confirma os depósitos em conta corrente de
cada um dos empregados. Um dos objetivos do trabalho do auditor é verificar a efetividade da quantidade e
vínculo de funcionários em comparação aos dados obtidos em folha. Sob essa premissa, qual a ordem de
importância você daria aos procedimentos abaixo para obter evidências suficientes e adequadas quanto ao
objetivo descrito?
(A) Conferência do livro de registro dos empregados;
(B) Conferência do livro de registro dos empregados e da Relação Anual de informações Sociais - RAIS;
(C) Reunião com data e hora marcada com todos os funcionários;
Durante a realização de um trabalho de auditoria, o auditor detecta distorção relevante que vem afetando as
finanças da empresa a mais de 2 (dois) anos. Pelo seu planejamento, ele só terá condições de concluir
efetivamente os exames, e, portanto, quantificar 100\% do dano, com mais 20(vinte dias) de trabalho. Na data
de hoje, porém, ele tem condições de mensurar 15\% (quinze por cento) do impacto.
Considerando esses aspectos, qual ordem de importância você daria as seguintes decisões?
(A) Concluir os exames na data prevista em seu programa/planejamento e prestar as informações com
maiores níveis de segurança;
(B) Prestar as informações de forma imediata com os níveis de segurança já alcançados;
(C) Aprofundar os exames para obter o maior entendimento possível em até 10 dias.




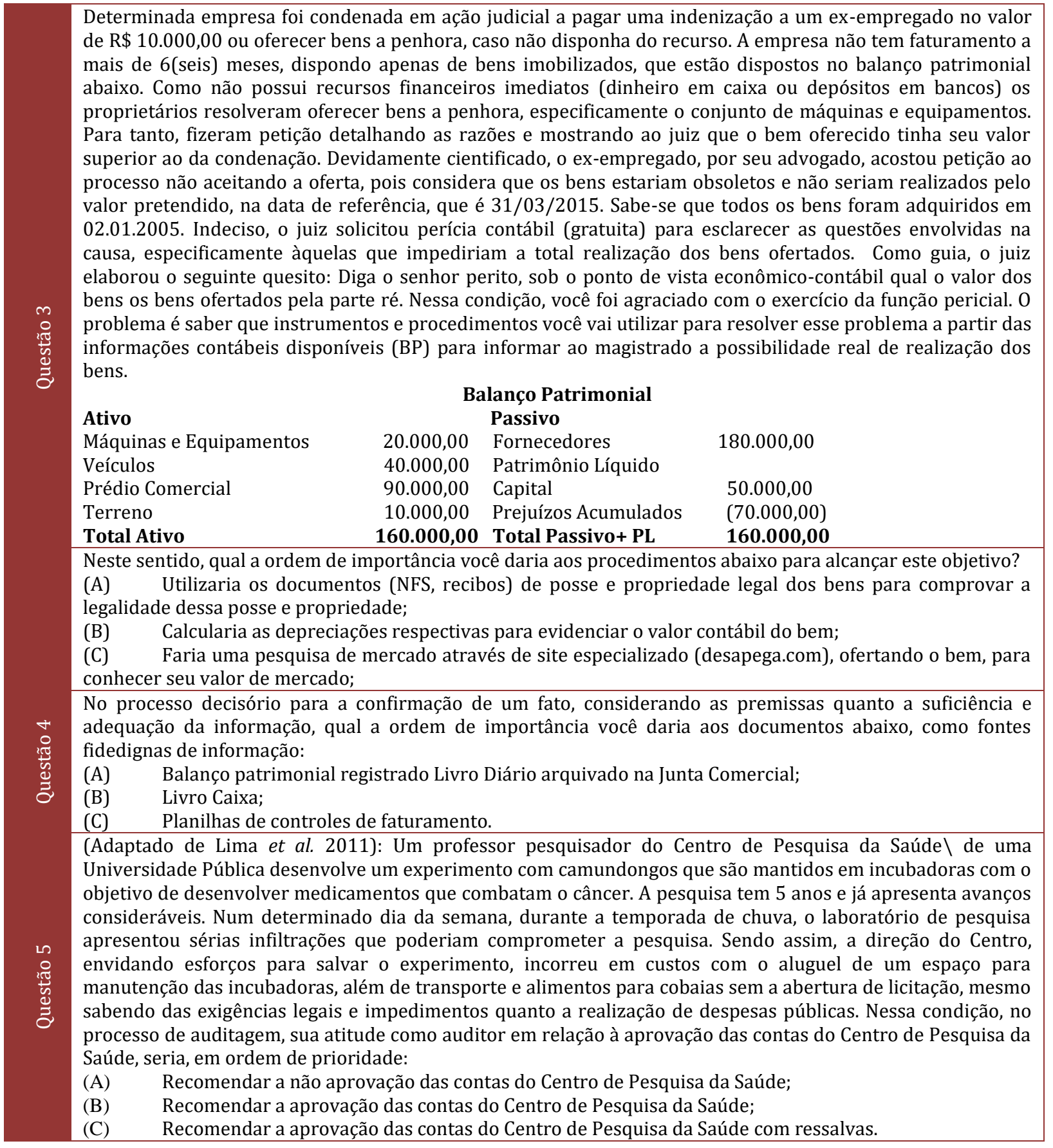




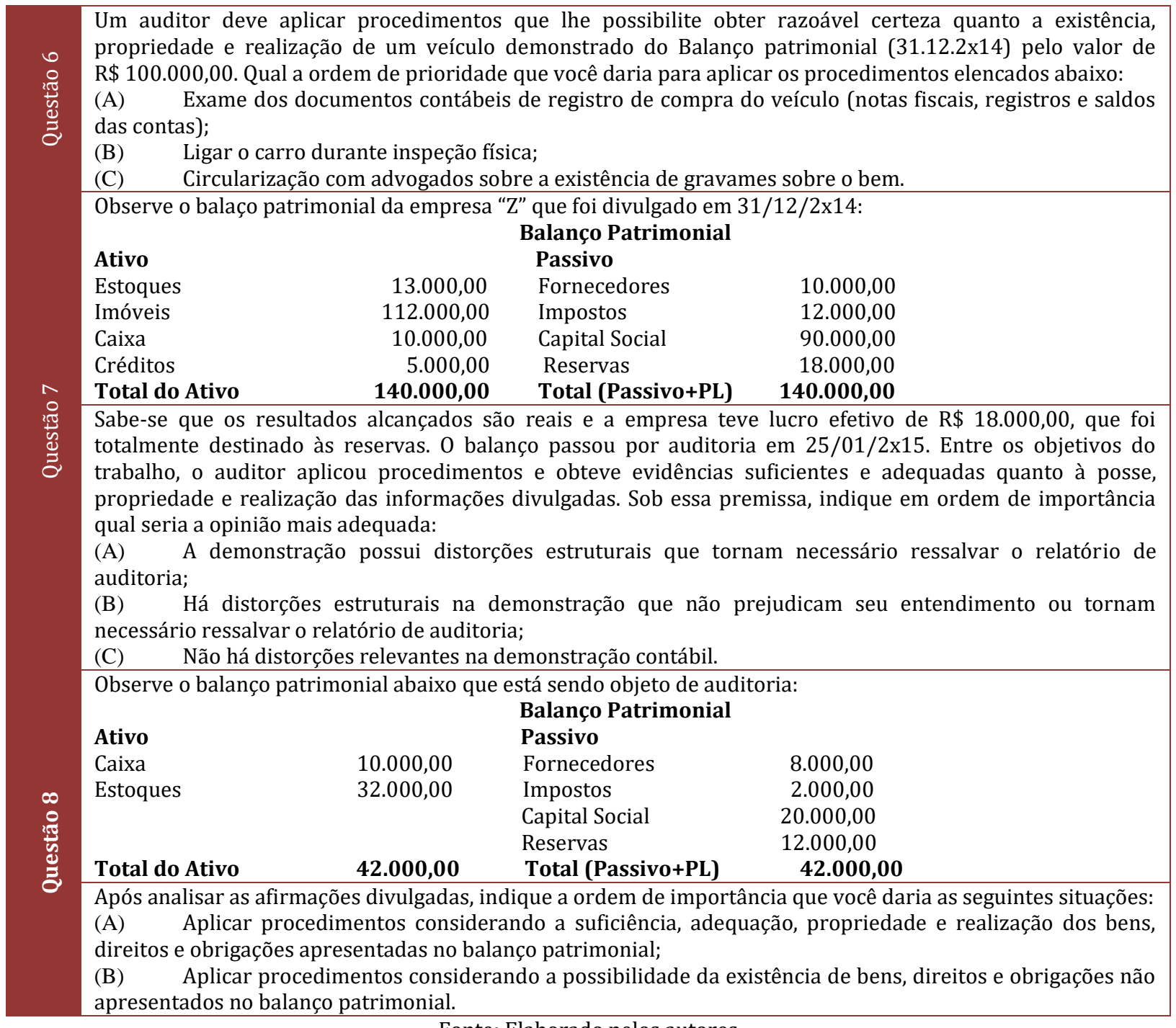
Fonte: Elaborado pelos autores

É importante ratificar que não há alternativas certas ou erradas. Todas as alternativas podem ser adotadas/aplicadas nas situações problema apresentadas. Tão somente se procura observar a prevalência na escolha das opções. Escolhas mais usuais identificam a prevalência da forma e o descarte da alternativa menos comum confirma isso.

Assim, as hipóteses operacionais estabelecidas neste estudo são:

$\boldsymbol{H}_{1 A}$ - Na avaliação do nível individual de importância dado a cada decisão, evidência e/ou procedimento aplicável a um caso, os aspectos formais, representados pelas alternativas mais usuais, têm maior relevância na tomada de decisão.

$\boldsymbol{H}_{1 B}$ - Na escolha ou renúncia de uma das situações, a evidência e/ou procedimento menos usual aplicável a um caso, será descartado.

Para análise dos dados, os indivíduos foram agrupados de acordo com suas respostas em três grupos, sendo denominados de vetores de decisão: (a) decisão pela forma, (b) decisão pela essência e (b) decisão pela forma-essência. 0 grupo vetor forma inclui os participantes que consideraram como mais importante as alternativas mais formais. 0 grupo classificado como vetor essência representa os indivíduos que atribuíram maior grau de relevância à opção menos formal. Por fim, o grupo denominado forma-essência é 
composto de participantes que consideraram como mais importante um procedimento formal, seguido do menos formal e do outro mais formal, respectivamente.

Para comprovar que os indivíduos, quando envolvidos em contextos contábeis, atribuem mais relevância aos aspectos mais pragmáticos $\left(\boldsymbol{H}_{1 A}\right)$, a proporção de indivíduos do grupo vetor formal deve ser estatisticamente maior que a proporção de indivíduos do grupo vetor essência.

Da mesma maneira, para ser possível concluir que, no caso de renúncia, os procedimentos menos formais são descartados pelo tomador de decisão $\left(\boldsymbol{H}_{1 B}\right)$, o percentual de participantes que excluiu a opção menos usual tem que ser estatisticamente maior daquele que excluiu a opção padrão.

Para avaliar a diferença de proporções dos grupos, recorreu-se ao teste não paramétrico qui-quadrado de Pearson, considerando um nível de significância de 5\%. A regra de decisão é: para cada questão analisada, se o valor do teste for elevado (pequeno) e seu nível de significância for inferior (superior) a 0,05 pode-se concluir que existe (não existe) diferença estatística nas proporções dos grupos.

Além dessas hipóteses, parte-se do pressuposto de que o gênero, a categoria (profissional ou discente) a titulação, e a instituição de origem dos respondentes não influenciam significativamente o processo de decisão sob as premissas descritas.

Para detectar se existe associação significativa entre essas variáveis categóricas também se utilizou o teste qui-quadrado de Pearson a um nível de 5\%. Nesse caso, a estatística qui-quadrado de Pearson testa se duas variáveis são independentes. Se o valor de significância for pequeno o suficiente (nesse estudo, menor que 0,05) então a hipótese de que as variáveis são independentes é rejeitada e a hipótese de que elas são, de alguma maneira, relacionadas, é aceita.

\section{RESULTADOS OBSERVADOS}

Foram analisadas as avaliações de 153 indivíduos, sendo 86 alunos de graduação (56,2\%), 17 alunos de pós-graduação (11,1\%) e 50 profissionais de mercado (32,7\%). Destes, 72 têm gênero feminino $(47,1 \%)$ e 81 do masculino (52,9\%). Quanto à titulação dos participantes, $111(72,5 \%)$ são graduandos ou já possuem uma graduação e estão fazendo o curso de Contábeis; 22 (14,4\%) são especialistas; 14 (9,2\%) mestres; e $6(3,9 \%)$ doutores. Procedidos aos tratamentos, os resultados foram categorizados e sumarizados na Tabela 2, que traz a identificação das questões, as frequências observadas, as estatísticas de Pearson e o vetor de decisão.

Pelos resultados gerais destacados na Tabela 2, observa-se que o vetor de decisão pela forma foi o escolhido em sete questões ( $Q 1 ; Q 2 ; Q 3, Q 4 ; Q 6 ; Q 7 ; Q 8)$, situação que não possibilita rejeitar a hipótese de que na avaliação do nível individual de importância dado a cada decisão, evidência e/ou procedimento aplicável a um caso, os aspectos formais têm maior relevância na tomada de decisão. Essa constatação é convalidada pela outra regra de decisão apresentada, ou seja, pelo descarte da opção menos usual nas $Q 1$ C; $Q 2-B ; Q 4-C ; Q 6-B ; e, Q 7-C$.

Testadas outras varáveis influentes sobre as constatações, observou-se que o fato de ser discente ou profissional de mercado; do gênero masculino ou feminino; de ser graduado, especialista, mestrado e doutorado; de IES pública ou privada não exerceu influência significativa nos resultados do estudo. A maioria dos indivíduos considera como mais importante às alternativas mais formais, descartando o procedimento menos formal numa situação de renúncia.

Dessa forma, ratificando o objetivo do trabalho, os dados não permitem rejeitar a hipótese que na resolução de problemas e no processo de tomada de decisão em contabilidade os profissionais priorizam os elementos formais em detrimento dos essenciais. 
Tabela 2: Estatística Descritiva e Resultados do teste Qui-quadrado

\begin{tabular}{|c|c|c|c|c|c|c|c|c|}
\hline \multirow{2}{*}{ Questões } & \multicolumn{5}{|c|}{ Frequência e Alternativas } & \multicolumn{2}{|c|}{$\begin{array}{l}\text { Qui-quadrado de } \\
\text { Pearson }\end{array}$} & \multirow{2}{*}{ Vetor de Decisão } \\
\hline & Freq. & Forma & Essência & $\begin{array}{l}\text { Forma- } \\
\text { Essência }\end{array}$ & $\begin{array}{l}\mathrm{F}_{\mathrm{ac}} \\
\mathrm{Fr}_{\mathrm{ac}}\end{array}$ & Valor & Sig & \\
\hline \multirow{2}{*}{ Q1 } & $f_{i}$ & 112 & 19 & 22 & 153 & \multirow{2}{*}{109,529} & \multirow{2}{*}{0,000} & \multirow{2}{*}{$\begin{array}{c}\text { Aspectos formais têm maior } \\
\text { relevância. }\end{array}$} \\
\hline & $\mathrm{fr}_{\mathrm{i}}$ & $73,2 \%$ & $12,4 \%$ & $14,4 \%$ & $100 \%$ & & & \\
\hline \multirow{2}{*}{ Q1.1 } & $f_{i}$ & 94 & 59 & \multirow{2}{*}{ NA } & 153 & \multirow{2}{*}{8,007} & \multirow{2}{*}{0,005} & \multirow{2}{*}{$\begin{array}{l}\text { Renúncia do procedimento } \\
\text { menos formal. }\end{array}$} \\
\hline & $\mathrm{fr}_{\mathrm{i}}$ & $61,4 \%$ & $38.6 \%$ & & $100 \%$ & & & \\
\hline \multirow{2}{*}{ Q2 } & $f_{i}$ & 90 & 36 & 27 & 153 & \multirow{2}{*}{45,529} & \multirow{2}{*}{0,000} & \multirow{2}{*}{$\begin{array}{l}\text { Aspectos formais têm maior } \\
\text { relevância. }\end{array}$} \\
\hline & $\mathrm{fr}_{\mathrm{i}}$ & $58,8 \%$ & $23,5 \%$ & $17,6 \%$ & $100 \%$ & & & \\
\hline \multirow[b]{2}{*}{ Q2.1 } & $f_{i}$ & 97 & 54 & \multirow{2}{*}{ NA } & 151 & \multirow{2}{*}{12,245} & \multirow{2}{*}{0,000} & \multirow{2}{*}{$\begin{array}{l}\text { Renúncia do procedimento } \\
\text { menos formal. }\end{array}$} \\
\hline & $\mathrm{fr}_{\mathrm{i}}$ & $64,2 \%$ & $35,8 \%$ & & $100 \%$ & & & \\
\hline \multirow{2}{*}{ Q3 } & $f_{i}$ & 75 & 39 & 39 & 153 & \multirow{2}{*}{16,941} & \multirow{2}{*}{0,000} & \multirow{2}{*}{$\begin{array}{l}\text { Aspectos formais têm maior } \\
\text { relevância }\end{array}$} \\
\hline & $\mathrm{fr}_{\mathrm{i}}$ & $49 \%$ & $25,5 \%$ & $25,5 \%$ & $100 \%$ & & & \\
\hline \multirow{2}{*}{ Q3.1 } & $f_{i}$ & 73 & 80 & \multirow{2}{*}{ NA } & 153 & & & \\
\hline & $\mathrm{fr}_{\mathrm{i}}$ & $47,7 \%$ & $52,3 \%$ & & $100 \%$ & 0,320 & 0,571 & Inconclusivo \\
\hline 04 & $f_{i}$ & 102 & 21 & 30 & 153 & & $0 \cap 00$ & Aspectos formais têm maior \\
\hline Q4 & $\mathrm{fr}_{\mathrm{i}}$ & $66,7 \%$ & $13,7 \%$ & $19,6 \%$ & $100 \%$ & 17,294 & 0,000 & relevância. \\
\hline & $f_{i}$ & 88 & 62 & & 150 & & & Renúncia do procedimento \\
\hline Q4.1 & $\mathrm{fr}_{\mathrm{i}}$ & $58,7 \%$ & $41,3 \%$ & NA & $100 \%$ & 4,507 & 0,034 & menos formal. \\
\hline & $\mathrm{f}_{\mathrm{i}}$ & 52 & 19 & 82 & 153 & & $00 \cap 0$ & Aspectos forma-essência \\
\hline Q5 & $\mathrm{fr}_{\mathrm{i}}$ & $34 \%$ & $12,4 \%$ & $53,6 \%$ & $100 \%$ & 38,941 & 0,000 & têm maior relevância \\
\hline & $\mathrm{f}_{\mathrm{i}}$ & 53 & 99 & & 152 & & & Renúncia do procedimento \\
\hline Q5.1 & $\mathrm{fr}_{\mathrm{i}}$ & $34,9 \%$ & $65,1 \%$ & NA & $100 \%$ & 13,921 & 0,000 & mais formal. \\
\hline 06 & $f_{i}$ & 99 & 18 & 35 & 152 & 72013 & 0.000 & Aspectos formais têm maior \\
\hline Q6 & $\mathrm{fr}_{\mathrm{i}}$ & $64,7 \%$ & $11,8 \%$ & $22,9 \%$ & $100 \%$ & $/ 2,013$ & 0,000 & relevância. \\
\hline & $f_{i}$ & 102 & 48 & & 150 & & & Renúncia do procedimento \\
\hline Q6.1 & $\mathrm{fr}_{\mathrm{i}}$ & $68 \%$ & $32 \%$ & NA & $100 \%$ & 19,440 & 0,000 & menos formal. \\
\hline & $\mathrm{f}_{\mathrm{i}}$ & 111 & 25 & 17 & 153 & 106510 & 0.000 & Aspectos formais têm maior \\
\hline Q' & $\mathrm{fr}_{\mathrm{i}}$ & $72,5 \%$ & $16,3 \%$ & $11,1 \%$ & $100 \%$ & 106,510 & 0,000 & relevância. \\
\hline & $\mathrm{f}_{\mathrm{i}}$ & 108 & 42 & & 150 & & & Renúncia do procedimento \\
\hline Q7.1 & $\mathrm{fr}_{\mathrm{i}}$ & $72 \%$ & $28 \%$ & NA & $100 \%$ & 29,040 & 0,000 & menos formal. \\
\hline 08 & $\mathrm{f}_{\mathrm{i}}$ & 90 & 63 & NA & 153 & 4765 & 0.029 & Aspectos formais têm maior \\
\hline QO & $\mathrm{fr}_{\mathrm{i}}$ & $58,8 \%$ & $41,2 \%$ & $\mathrm{NA}$ & $100 \%$ & 4,700 & & relevância. \\
\hline 081 & $f_{i}$ & 82 & 68 & $N A$ & & & & \\
\hline Q 0.1 & $\mathrm{fr}_{\mathrm{i}}$ & $54,7 \%$ & $45,3 \%$ & INA & 150 & $1, \mathrm{JU} /$ & 0,203 & meonctustvo \\
\hline
\end{tabular}

Fonte: Dados da pesquisa

Por outro lado, os resultados observados em relação às questões $Q 3, Q 5$ e $Q 8$ são diferenciados, revelando alguns aspectos não previstos no estudo:

(I) Inicialmente, os resultados da questão Q3 evidenciam a prevalência da forma sobre a essência, uma vez que a maior parte dos indivíduos (49\%) utilizou o vetor de decisão pela forma. Contudo, na convalidação (descarte necessário em Q-3.1), a maior parte dos pesquisados (52,3\%) renunciou a um dos procedimentos formais, apesar de não existir significância estatística nas diferenças das proporções observadas;

(II) Sobre a questão $Q 5$ os indivíduos pesquisados estariam envolvidos significativamente pela regra de decisão apresentada, quanto à prevalência da forma sobre a essência nas suas decisões, mas esse envolvimento não é suficientemente capaz para defini-los taxativamente como integrantes comuns do grupo que têm estes vetores como subjacentes às suas decisões.

Talvez essa condição (sobre esse achado) seja explicada pela proposição existencialista relacionada à construção da essência do indivíduo, aqui entendida como experiência, levando-o a perceber situações que o fazem sair do modelo comum, e naturalmente alterar seu processo de escolha.

Por outro lado, não se pode de fato afirmar que o mesmo pertenceria a o outro grupo, considerando que suas decisões ainda carregam elementos de fixação de dados, quando intercala opções forma-essênciaforma.

Observa-se que existe um conflito de decisão sobre um tema de impacto social relevante, pela expectativa de gerar medicamentos que podem combater uma doença grave. Talvez a avaliação deste impacto na vida 
das pessoas tenha influenciado o grupo de participantes, revelando um nível diferenciado e tênue entre o que de fato é suficiente e material para reconhecer ou não a restrição formal como totalmente direcionadora da decisão.

(III) Em relação à questão Q8, observa-se um comportamento conservador, demonstrando por 58,8\% dos indivíduos, que tomaram suas decisões a partir da forma. No entanto, considerando a necessária renúncia de opções, não se pode afirmar estatisticamente que a maior dos participantes renunciou o procedimento menos formal.

De forma geral, essas constatações, quando relacionadas aos fundamentos teóricos discutidos, reforçam o sentimento de que a formação, e naturalmente as decisões que são tomadas por contabilistas durante a sua trajetória profissional, podem ser explicadas por fatores normativos e legais que acabam por fortalecer o aspecto conservador da sua atuação.

Não meramente os componentes normativos, que se analisados sob uma perspectiva de recompensas, já revelariam parte deste comportamento conservador, pois não atender normas tributárias e societárias, por exemplo, podem resultar em prejuízos e penalidades tanto para o usuário como para o operador da informação contábil. Tomando a norma como um componente de aceitação universal, objetivo e de fácil aplicação, não parece atrativo decidir fora dessa visão cartesiana, embasando a decisão em elementos subjetivos (que levariam a essência), que exigem a percepção de situações abrangentes, inclusive ocultas, para ser definida.

Além dos elementos pragmáticos voltados à forma, não justificados pela aplicação consciente do princípio da parcimônia, mas numa ancoragem pautada na norma como aceitação universal, existem ainda elementos subjacentes filosóficos e comportamentais que podem ajudar a entender esse modo de ação. A inclusão dos fundamentos subjetivos no contexto contábil brasileiro é relativamente recente, sem tempo de maturação histórica, e, portanto, crítica, que permita aos profissionais (e estudantes como pseudosprofissionais) o estabelecimento de um referencial que os qualifique a aplicar, no presente, conceitos aprendidos e fixados em experiências passadas, validando os pressupostos da fixação funcional em psicologia.

Nessa condição, o papel de da contabilidade, por seu operador, de atender de imediato às demandas corporativas e às expectativas do mercado apontadas por Hendricksen e Van Breda (1999) e Schmidt (2000), por exemplo, estaria comprometido. No entanto, essa não é a única face que se revela com os achados, mas também a de que a ciência contábil no Brasil está passando por um momento de amadurecimento de um conceito que passe a fazer parte inerente de sua aplicação. Portanto, um momento histórico.

Essa mesma acepção pode ser utilizada sob a perspectiva existencialista, considerando que a essência do ser é construída por suas decisões, renunciando diariamente opções que não lhes parece a mais adequada em dada oportunidade. Como a subjetividade, nesse caso, existe antes da definição de um comportamento que revela essência, fruto de uma realidade vivida, ainda há um caminho relativamente longo a percorrer para que se possa tê-la (a subjetividade) como essência definida. Essa condição, associada à fixação de dados, no futuro, talvez passe a representar naturalmente os vetores de decisão destes profissionais no contexto brasileiro.

\section{CONSIDERAÇÕES FINAIS}

A tentativa de avaliar a relação entre essência e forma no contexto de decisão profissional em contabilidade evidenciou uma supremacia do paradigma formal em relação à essência. No entanto, as considerações resultantes dos dados analisados, ainda que sejam apresentadas com bases em estatísticas que medem a significância, não podem ser consideradas como definitivas. Simplesmente porque representa uma tentativa exploratória de associar um tema complexo como a inserção da subjetividade no processo decisório em contabilidade a bases de estudos filosóficos e comportamentais num contexto de construção histórica ainda primária, como é o caso brasileiro.

Mesmo com massificação acadêmica da contabilidade como ciência inexata e subjetiva, o normativo que rege a aplicação desta ciência foi (e ainda é em alguns casos) historicamente traduzido para a prática em bases objetivas; portanto, conservadoras. A edição da Lei n. 11.638 (2007) representa o marco de inclusão legal da subjetividade nesse contexto, passando-se apenas oito anos de sua determinação como obrigatória, mas sem evidencias técnicas e científicas que permitam confirmar sua efetivação. 
Talvez os resultados observados possam ser novamente investigados incluindo a variável tempo como definidor da maturidade da absorção coletiva da condição de subjetividade que deve existir no momento da decisão profissional, possibilidade levantada no estudo, mas não investigada empiricamente.

\section{REFERÊNCIAS}

[1] Aldrighi, D. M., \& Milanez, D. Y. (2005) Finança Comportamental e a Hipótese de Mercado Eficiente. Revista de Economia Contemporânea, 9(1), 41-72.

[2] Alexander, D., \& Jermakowicz, E. (2006). A True and fair view of the principles rules debate. Abacus, 42(2), $132-164$

[3] Barberis, N., \& Thaler, R. (2003). A survey of behavioral finance. In G.M. Constantinides, M. Harris \& R. M. Stulz (Eds.). Handbook of the Economics of Finance (Vol. 1, Chap. 1, pp. 1053-1128). Amsterdam: Elsevier

[4] Bonder, N. (1995). O Segredo judaico de resolução de problemas. (10a ed.) Rio de Janeiro: Imago.

[5] Borges, E. F, \& Medeiros, C.A.F (2007). Comprometimento e ética profissional: um estudo de suas relações junto aos contabilistas. Revista e Contabilidade e Finanças, 18(44), 60-71.

[6] Bierman, H. Jr. (1963). Measurement and accounting. The Accounting Review, 38(3), 501.

[7] Chang, C. J., Yen, S. H., \& Duh, R. R. (2002). An Empirical Examination of Competing Theories to Explain the Framing Effects. Behavioral Research in Accounting, 14(1), 35-64.

[8] Chaves, D. (2010, março 12). JP Morgan e Citi podem enfrentar a justiça por colapso do Lehman Brothers. 0 Estado de São Paulo.

[9] D’áuria, Francisco (1953). Revisão e Perícia Contábil. Companhia Editora Nacional. São Paulo.

[10] Decreto n 9.580, de 22 de novembro de 2018 (2018)9. Regulamenta a tributação, fiscalização, arrecadação e administração do Imposto sobre a Renda e Proventos de Qualquer Natureza. Diário Oficial da União. Brasília, DF.

[11] Eysenck, W. M, \& Keane, M. T. (2007). Manual de Psicologia Cognitiva (5a ed.) Porto Alegre: Artmed.

[12] Fuji, A. H, \& Slomski, V. (2003). Subjetivismo Responsável: Necessidade ou ousadia no estudo da contabilidade. Revista Contabilidade \& Finanças, 14(33), 33-44.

[13] Gramling, A. A., Rittenberg, L. E., \& Johnstone, K. M. (2012). Auditoria. São Paulo: Cengage Learning.

[14] Hendriksen, E. S., \& Van Breda, M. (1999). Teoria da contabilidade. São Paulo: Atlas.

[15] Jones, A. (2010, July 22). Inglaterra: qualidade de auditoria em xeque. Publicado originalmente no Financial Times, Londres. Jornal Valor Econômico.

[16] Kahneman, D., \& Tversky, A. (1973). On the Psychology of Prediction. Psychological Review, 80, 237-251.

[17] Kant, I. (2002). Crítica da razão pura (Coleção A obra prima de cada autor). São Paulo: Martin Claret.

[18] Kant, I. (2003). Fundamentos da metafísica dos costumes e outros escritos (Coleção A obra prima de cada autor). São Paulo: Martin Claret.

[19] Lei n. 6.404, de 15 de dezembro de 1976 (1976). Dispõe sobre as sociedades por ações. Diário Oficial da União. Brasília, DF.

[20] Lei n. 10.406, de 10 de Janeiro de 2002 (2002). Institui o Código Civil. Diário Oficial da União. Brasília, DF.

[21] Lei n. 11.638, de 28 de dezembro de 2007 (2007). Altera e revoga dispositivos da Lei no 6.404, de 15 de dezembro de 1976, e da Lei no 6.385, de 7 de dezembro de 1976, e estende às sociedades de grande porte disposições relativas à elaboração e divulgação de demonstrações financeiras. Diário Oficial da União. Brasília, DF.

[22] Lei n. 11.941, de 27 de maio de 2009 (2009). Altera a legislação tributária federal relativa ao parcelamento ordinário de débitos tributários; concede remissão nos casos em que especifica. Diário Oficial da União. Brasília, DF.

[23] Lima, D. H. S., Borges, E. F., Gomes, J. D. G. S., \& Gomes, A. M. (2011). Análise da influência do conservadorismo na formação da opinião dos operadores da contabilidade. Interface - Revista do Centro de Ciências Sociais Aplicadas, $8(2), 92-122$.

[24] Lima, R. P. S., \& Schneider, J. H. J. (2013). Guilherme de Ockham: conhecimento, singular e primum cognitum. Horizonte Científico, 7(1).

[25] Lisboa, L. P. et al. (1997). Ética Geral e Profissional e Contabilidade (2a ed). São Paulo: Atlas.

[26] Lustosa, P. R. B. (2009). Ativo e sua Mensuração. In. Ribeiro Filho, J. F., Lopes, J., \& Pederneiras, M. (Org.). Estudando Teoria da contabilidade (pp. 85-105). São Paulo: Atlas. 
[27] Magalhães, A. D. F., Souza, C., Favero, H. L., \& Lonardoni, M. (2009). Perícia Contábil: Uma Abordagem Teórica, Ética, Legal, Processual e Operacional (7a ed.) São Paulo: Atlas.

[28] Nascimento, A. R., Ribeiro, D. C., \& Junqueira, E. R. (2008, julho). Estado da arte da abordagem comportamental da contabilidade gerencial: análise das pesquisas internacionais. Anais do Congresso USP de Controladoria e Contabilidade, São Paulo, SP, Brasil, 8.

[29] Neufeld, C. B., Brust, P. G., \& Stein, L. M. (2011). Bases Epistemológicas da Psicologia Cognitiva Experimental. Psicologia: Teoria e Pesquisa, 27(1), 103-112.

[30] Raupp, F. M., Beuren, I. M. (2012) Metodologia da pesquisa aplicável às ciências sociais. In I. M. Beuren, (Org.). Como elaborar trabalhos monográficos em contabilidade: teoria e prática (pp. 76-97). São Paulo: Atlas.

[31] Relvas, T. R. S. (2008, agosto). Relação entre a mensuração contábil e a mensuração científica. Anais do Congresso Brasileiro de Contabilidade, Gramado, RS, Brasil, 18.

[32] Ritter, J. R. (2003). Behavioral Finance. Pacific Basin Finance Journal, 11(4), 429-437.

[33] Santos, A., \& Grateron, I. R. G. (2003). Contabilidade criativa e responsabilidade dos auditores. Revista Contabilidade \& Finanças, 14(32), 7-22.

[34] Sartre, J. P. (2014-a). O Ser e o Nada: Ensaio de Ontologia Fenomenológica (12a ed.) Petrópolis: Vozes.

[35] Sartre, J. P. (2014-b). O Humanismos é um existencialismo (3a ed.). Petrópolis: Vozes.

[36] Schmidt, P. (2000). História do Pensamento Contábil. Porto Alegre: Bookman.

[37] Simon, H. A. (1956). Rational Choice and the Structure of the environment. Psychological Review, 63(2), 129-

138.

[38] Yoshinaga, C. E., Oliveira, R. F., Silveira, A. D. M., \& Barros, L. A. B. C. (2004, agosto). Finanças Comportamentais: Uma Introdução. Anais do Seminários em Administração, São Paulo, SP, Brasil, 7. 


\section{Capítulo 13}

Gestão de Resultados: Accruals vs. operações reais, estratégias complementares ou substitutas?

\section{Cristina Gaio}

Ana Margarida Oliveira

Resumo :É com base na informação contabilística das empresas, nomeadamente nos resultados, que os stakeholders analisam o desempenho e a posição financeira das empresas, tomam decisões e perspetivam o seu desempenho futuro. Através da gestão de resultados, é possível aumentar artificialmente os resultados e as expetativas de crescimento dos mesmos, refletindo um melhor desempenho futuro da empresa. A gestão de resultados pode ser feita essencialmente por duas vias: accrual earnings management e real earnings management. Este estudo pretende analisar se os gestores utilizam estas estratégias de gestão de resultados de forma complementar ou substituta, numa amostra de empresas cotadas europeias. Como medida de accrual earnings management foi considerada os Discretionary accruals segundo o modelo Jones modificado (Dechow et al., 1995). Como medida de real earnings management foi construída uma medida agregada de duas medidas sobejamente usadas na literatura: abnormal level of operational cash flow e abnormal level of production (Roychowdhury, 2006). Os resultados evidenciam uma associação negativa entre as duas estratégias, ou seja, que elas são usadas de forma substituta e não complementar pelas empresas analisadas. Os resultados sugerem também que quanto maior for a utilização dos accruals no período precedente para gerir os resultados, maior será a tendência para as empresas porem em prática estratégias de real earnings management para compensar o efeito reversivo dos accruals.

Palavras-chave: Gestão de resultados, real earnings management, accrual earnings management, empresas europeias 


\section{INTRODUÇÃO}

Durante muito tempo, defendeu-se a ideia de que o único objetivo das empresas era gerar valor para os seus acionistas. Na segunda metade do século XX, Freeman (1984) afirmou que, para além dos interesses dos acionistas, a empresa deve ter em consideração os interesses de muitos outros stakeholders no momento da tomada de decisão. No entanto, muitas empresas mantêm-se focadas na maximização do valor para os acionistas e na minimização dos custos de agência que a sua atividade acarreta. Para que o capital da empresa aumente, é preciso que os investidores estejam dispostos a investir, graças à expetativa que têm de que a empresa terá um desempenho futuro positivo (Joosten, 2012). Neste sentido, as empresas têm interesse em relatar informação financeira que demonstre a sua capacidade de não só gerar resultados positivos e permanentes, como também de atingir as previsões dos analistas (Degeorge et al., 1999).

É com base na informação contabilística das empresas, nomeadamente nos resultados, que os stakeholders analisam o desempenho e a posição financeira das empresas, tomam decisões e perspetivam o seu desempenho futuro. Assim, facilmente se compreende a importância da qualidade dos resultados e dos respetivos processos de monitorização. No entanto, os gestores têm tendência para, de forma estratégica, gerirem este indicador de desempenho, que é um dos mais utilizados pelos stakeholders no processo de tomada de decisão (Francis et al., 2003; Graham et al., 2005).

Ora, através da gestão de resultados, é possível aumentar artificialmente os resultados e as expetativas de crescimento dos mesmos, de maneira a formar uma expetativa de melhor desempenho futuro da empresa e aumentar, em última instância, o valor da mesma (Dechow et al., 2003; Healy \& Palepu, 1993).

Existem duas estratégias fundamentais para gerir os resultados: accruals-based earnings management $(A E M)$, baseado no uso de estimativas e de juízos de valor na aplicação das normas contabilísticas; e o real earnings management (REM), quando os gestores alteram o período de execução e/ou a estruturação de uma operação, investimento ou financiamento. Ambas as formas de gestão de resultados envolvem tentativas dos gestores para aumentarem ou diminuírem os resultado reportados. Contudo, enquanto que as estratégias de $A E M$ não têm influência sobre as atividades operacionais da empresa, as estratégias de $R E M$ afetam as atividades operacionais, podendo afetar igualmente o desempenho futuro da mesma (Gunny, 2010).

A literatura sobre gestão de resultados existente é maioritariamente direcionada para a análise de $A E M$. No entanto, a crescente literatura em REM tem demonstrado que as práticas de REM vão no sentido de aumentar os resultados relatados (Roychowdhury, 2006; Cohen et al., 2008; Gunny, 2010; Zang, 2012). Assim, e dada a crescente preocupação em torno das consequências económicas da prática de REM (Roychowdhury, 2006), torna-se importante aprofundar o conhecimento sobre REM, bem com estudar a forma como as estratégias de gestão de resultados interrelacionam-se, uma vez que a escassa literatura dedicada aos estudo conjunto das duas estratégias apresenta resultados mistos.

De facto, autores como Cohen \& Zarowin (2010), Mizik \& Jacobson (2012) e Chen et al. (2012) defendem que a combinação de múltiplas estratégias de gestão de resultados poderá permitir alcançar objetivos estratégicos e atingir as previsões de resultados dos analistas de mercado. Porém, as outros autores corroboram a ideia de que os gestores utilizam as estratégias de gestão de resultados de forma substituta. Neste sentido, destaca-se o estudo de Zang (2012) que argumenta que $A E M$ e REM são estratégias substitutas graças à sua índole sequencial, isto é, as estratégias de $R E M$ são utilizadas durante o ano fiscal e, no final do ano, é ajustado o nível de utilização das estratégias de $A E M$ consoante o nível das práticas de $R E M$ realizadas. Como tal, as estratégias de $A E M$ e $R E M$ estabelecem entre si uma relação de substituição direta no final do ano fiscal, sendo que quando se verifica que o nível das práticas de $R E M$ é inesperadamente elevado, os gestores diminuirão o nível de práticas de $A E M$ e vice-versa.

Assim, o objetivo deste estudo é analisar de que forma as estratégias de gestão de resultados, $A E M$ e $R E M$, são utilizadas em empresas cotadas da U.E., isto é, se são aplicadas de forma complementar ou substituta. Para o efeito, foi analisada uma amostra de 510 empresas cotadas da U.E., para um período de 8 anos, entre o ano de 2009 e 2016. Para o cálculo da medida das estratégias de $A E M$, foi seguido o modelo de Jones modificado (Dechow et al., 1995), enquanto que para calcular a medida das estratégias de REM foi utilizada a metodologia de Roychowdhury (2006). De modo a que fosse possível analisar os efeitos de ambas as componentes das estratégias de $R E M$, procedeu-se ao cálculo de uma variável agregada representativa do nível de utilização de estratégias de $R E M$, através da construção de um ranking para as empresas da amostra. 
Este estudo reparte-se em cinco secções. Na segunda secção é apresentada a revisão da literatura, na qual se definem os conceitos fundamentais, nomeadamente, os conceitos de gestão de resultados, estratégias de $A E M$ e REM, bem como os estudos já realizados sobre o tema proposto. Seguidamente, é apresentada na terceira secção à metodologia utilizada, incluindo uma breve caraterização dos dados amostrais. A análise empírica de resultados é feita na quarta secção e, por fim, na quinta secção são apresentadas as considerações finais.

\section{REVISÃO DA LITERATURA}

\subsection{GESTÃO DE RESULTADOS}

Schipper (1989:92) define gestão de resultados como "Purposeful intervention in the external financial reporting process, with the intent of obtaining some private gain (as opposed to, say, merely facilitating the neutral operation of the process". Numa definição mais abrangente, Healy \& Wahlen (1999: 368) defendem que a gestão de resultados "occurs when managers use judgment in financial reporting and in structuring transactions to alter financial reports to either mislead some stakeholders about the underlying economic performance of the company, or to influence contractual outcomes that depend on reported accounting numbers".

Através da gestão de resultados, é possível aumentar artificialmente os resultados e as expetativas de crescimento dos mesmos, refletindo um melhor desempenho futuro da empresa e aumentando, em última instância, o valor da mesma (Dechow et al., 2003; Healy \& Palepu, 1993). No mesmo sentido, Burgstahler \& Eames (2006) e Matsumoto (2002) demonstram que os gestores tomam iniciativas para evitar não só resultados negativos inesperados, mas também para conseguir cumprir ou superar as expetativas dos analistas. Também Brown et al. (1987) referem que os gestores têm incentivos para evitar resultados negativos inesperados, uma vez que tais resultados podem levar a revisões de preços negativas e fragilizar a reputação das empresas. Assim, Matsumoto (2002) revela que para atingir objetivos, os gestores podem optar por gerir resultados quando acreditam que os utilizadores de informação financeira não detetam as práticas de gestão de resultados executadas. Deste modo, os gestores podem aumentar os resultados, se estes estiverem aquém das expetativas, ou diminuí-los caso os tenham ultrapassado e consoante a estratégia adotada pela empresa.

Os gestores têm consciência das oportunidades para gerir resultados (Nelson et al., 2003; Nelson et al., 2002) e, normalmente, são recompensados por aplicarem estratégias de gestão de resultados que façam com que os objetivos dos analistas de mercado sejam atingidos ou ultrapassados (Myers et al., 2007). Por outro lado, podem optar por pôr em prática as estratégias de gestão de resultados de forma a reduzir resultados (Joosten, 2012) quando os objetivos forem ultrapassados, para que as expetativas dos diversos intervenientes de mercado não se alterem. Neste sentido, Becker et al. (2003) aferem que os auditores têm uma maior tendência para questionar os julgamentos e escolhas contabilísticas que aumentam os resultados, por oposição àquelas que diminuem os mesmos. Alternativamente, Chen et al. (2012) revelam que os gestores reportam resultados menores do que os verdadeiramente gerados quando as suas empresas enfrentam severas dificuldades e já estão a registar diversos prejuízos. Desta forma, os gestores preferem "guardar" os bons resultados para períodos de melhor desempenho e reportar todos os maus resultados num só período de atividade.

Para além dos incentivos que derivam dos mercados capitais, existem outras motivações que levam os gestores a praticarem gestão de resultados. Healey \& Wahlen (1999) classificam os incentivos à prática de gestão de resultados em cinco grandes grupos: objetivos pessoais dos gestores, questões contratuais, questões fiscais, custos políticos e mercado de capitais. Coppens \& Peek (2005) argumentam que certas praticas de gestão de resultados resultam somente da pressão exercida pelos mercados de capitais, e como tal são especificas das empresas cotadas.

\subsection{ESTRATÉGIAS DE ACCRUAL EARNINGS MANAGEMENT E REAL EARNINGS MANAGEMENT}

Os resultados podem ser geridos por duas vias: através dos accruals, $A E M$, já que os resultados são compostos por duas componentes, os accruals e os fluxos de caixa, e através de operações reais, $R E M$. Segundo Zang (2012), existem muitos estudos sobre gestão de resultados através de estratégias de $A E M$, mas só nos anos mais recentes é que se tem dado maior atenção à gestão de resultados conseguida através de estratégias de REM.

Zang (2012) refere que as estratégias de $A E M$ se consubstanciam na alteração de métodos contabilísticos 
ou estimativas calculadas no âmbito da realização de uma determinada transação retratada nas demonstrações financeiras.

As estratégias de $A E M$ incluem, por exemplo, a alteração das políticas adotadas de depreciação e valorização de ativos e as estimativas efetuadas para as perdas por imparidade e provisões (Joosten, 2012). No entanto, Matsumoto (2002) alerta para a dificuldade de se fazer gestão de resultados. Por um lado, a informação financeira e as práticas contabilísticas são, frequentemente, alvo de escrutínio por parte dos auditores e dos membros do board e, por outro lado, como os accruals implicam a sua reversão nos períodos subsequentes, é improvável que os gestores optem por uma gestão de accruals contínua para aumentar sucessivamente os resultados em cada período.

De acordo com Roychowdhury (2006), as estratégias de REM desviam a empresa do curso normal do seu negócio, podendo afetar negativamente o desempenho futuro da mesma, com o intuito de atingir os resultados estipulados, levando os stakeholders a acreditarem que os resultados foram obtidos no decorrer das atividades normais de negócio. Roychowdhury (2006) defende que as estratégias de REM permitem alcançar objetivos de curto prazo mas é improvável que contribuam para aumentar o valor da empresa no longo prazo, pois certas práticas realizadas no período corrente para aumentar os resultados poderão ter um efeito negativo nos fluxos de caixa de períodos futuros.

As estratégias de REM incluem, por exemplo, descontos no preço para aumentar temporariamente as vendas, sobreprodução para relatar menores custos dos bens vendidos e redução das despesas discricionárias para aumentar as margens de negócio. Assim, as estratégias de REM podem ser definidas como ações postas em prática capazes de alterar os resultados e influenciar o relato de informação financeira, através da alteração do timing ou da estrutura de uma atividade operacional, de investimento ou de financiamento e que podem provocar consequências menos boas para o negócio (Dechow et al., 2000; Ewert \& Wagenhofer, 2005; Zang, 2012).

No entanto, existe também evidencia contraria na literatura. Gunny (2010) demonstra que nem sempre a aplicação de estratégias de REM resulta num menor desempenho futuro e defende que fazer gestão de resultados utilizando estratégias de $R E M$ não demonstra um comportamento oportunista por parte dos gestores e poderá proporcionar benefícios que permitirão um melhor desempenho futuro ou sinalização dos mesmos.

Em suma, os gestores são incentivados a aplicar estratégias de $A E M$ e de REM para gerir resultados porque se sentem pressionados pelos stakeholders para cumprir os objetivos estratégicos estipulados (Chen et al., 2012). Se existem incentivos para se fazer gestão de resultados, surge a questão de como é que os gestores optam por práticas de $A E M$ e/ou $R E M$, isto é, se as estratégias de $A E M$ e $R E M$ são complementares ou substitutas (Chen et al., 2012).

\subsection{EVIDENCIA DE COMPLEMENTARIDADE E DE SUBSTITUIÇÃO}

\subsubsection{EVIDÊNCIA DE COMPLEMENTARIDADE}

Dada a existência de diferentes estratégias de gestão de resultados, é provável que os gestores recorram a ambas as estratégias ao mesmo tempo (Zang, 2012). 0 facto de as estratégias de gestão de resultados serem complementares implica que os gestores coordenem a utilização de diversas ferramentas de gestão de resultados, de forma a que a empresa suporte menos custos, ganhe mais benefícios e obtenha o melhor efeito desejado, seja ele o aumento ou a diminuição dos resultados num dado período (Chen et al., 2012).

Nesse sentido, Mizik \& Jacobson (2012) referem que uma empresa pode optar por usar ambas as estratégias de gestão de resultados para obter o melhor efeito combinado e inflacionar os seus resultados. Já Cohen \& Zarowin (2010), estudando a aplicação de ambas as estratégias de gestão de resultados em torno dos anos de seasoned equity offering (SEO), concluem que, nesses anos, as empresas utilizavam as estratégias de $A E M$ e $R E M$ de forma complementar.

Por outro lado, Chen et al. (2012) argumenta que a análise custo-benefício das diferentes estratégias de gestão de resultados faz com que os gestores alterem a prioridade de aplicação de uma estratégia em detrimento da outra mas não elimina nenhuma opção de gestão de resultados disponível. Neste sentido, as estratégias de $R E M$ e $A E M$ não são mutuamente exclusivas e a combinação de múltiplas estratégias pode permitir alcançar os mesmos objetivos. Adicionalmente, como uma gestão de resultados proeminente pode atrair maior escrutínio por parte dos auditores, reguladores e intervenientes no mercado, é sensato afirmar que os gestores optam, em média, por apresentar uma magnitude de gestão de resultados mais baixa através da utilização de múltiplas estratégias, em lugar de uma magnitude de gestão de resultados 
mais elevada resultante da utilização de apenas um tipo de estratégia.

\section{EVIDÊNCIA DE SUBSTITUIÇÃO}

0 facto de as estratégias de gestão de resultados serem substitutas, implica que os gestores escolham a ferramenta de gestão de resultados que acarrete menos custos e mais benefícios em detrimento das restantes, excluindo a coordenação entre estratégias, de forma a gerar o melhor efeito desejado, seja ele o aumento ou a diminuição de resultados num dado período (Chen et al., 2012). De acordo com Zang (2012), o trade-off entre as estratégias de gestão de resultados é função dos custos relativos se as empresas sofrerem restrições associadas a cada uma das estratégias de gestão de resultados.

Barton (2002) evidencia que os desvios nas diversas atividades de negócio e os accruals discricionários são estratégias parcialmente substitutas no alisamento de resultados. Por sua vez, Zang (2012) demonstra que as estratégias de $A E M$ e REM são substitutas no final do ano fiscal graças à sua índole sequencial, isto é, as estratégias de REM são utilizadas durante o ano fiscal e, no final do ano, analisa-se o nível de utilização das mesmas e ajusta-se o nível de utilização das estratégias de $A E M$ de acordo com o nível das práticas de REM anterior. Assim, as estratégias de $A E M$ e REM estabelecem entre si uma relação de substituição direta no final do ano fiscal, sendo que quando se verifica que o nível das práticas de REM é inesperadamente elevado, os gestores irão diminuir o nível de práticas de $A E M$ e vice-versa. Também Gunny (2010) reforça a ideia de que as estratégias de $A E M$ deverão ser utilizadas no final do ano ou quadrimestre fiscal, sendo que os gestores enfrentam incertezas quanto às práticas de gestão de resultados que 0 auditor permitirá.

Com base no estudo de Zang (2012), Joosten (2012) conclui que as empresas europeias cotadas aplicam estratégias de $R E M$ e $A E M$ de forma substituta para diminuir resultados. Se no final do ano se verifica que as operações reais postas em prática durante o ano são superiores às que, no início, se esperava aplicar, ficando com resultados abaixo do que se pretendia, então passa-se a utilizar mais accruals para aumentar e, assim, alcançar os resultados pretendidos.

Por outro lado, Badertscher (2011) analisou em que medida é que o grau e a duração da sobrevalorização de uma empresa afetam a escolha das estratégias de gestão de resultados alternativas. Os resultados sugerem que quanto maior é o tempo durante o qual uma empresa permanece sobrevalorizada, maior a tendência para a prática de gestão de resultados, de forma a atingir expetativas de desempenho irrealistas e, assim, manter a sobrevalorização. Adicionalmente, existe evidência de que as empresas sobrevalorizadas optam por aplicar, inicialmente, estratégias de $A E M$ até estarem sujeitas a demasiadas restrições quanto à sua utilização, momento em que se transita para a aplicação de estratégias de REM, ainda que estas possam acarretar mais custos. Como tal, Badertscher (2011) sugere que as estratégias de $A E M$ e REM são substitutas, uma vez que as empresas optam por uma estratégia de gestão de resultados periodicamente, de forma a sustentar a sua sobrevalorização.

Em termos evolutivos, Cohen et al. (2008) tendo como base a implementação do Sarbanes-Oxley Act (SOX), em 2002, conclui que a aplicação de estratégias de $A E M$ teve um grande crescimento no período que antecedeu a implementação do $S O X$, seguindo-se uma grande decréscimo no período pós-SOX, enquanto que as práticas de REM tiveram uma evolução contrária. Como tal, e porque a aplicação de estratégias de $A E M$ atrai um maior escrutínio por parte dos auditores e reguladores, existe evidência de que as estratégias de $A E M$ aplicadas nas empresas que fazem gestão de resultados foram substituídas por estratégias de REM, após a implementação do $S O X$.

Assim, são vários os autores que sugerem que os gestores estão mais dispostos a fazer gestão de resultados através de estratégias de REM, ao invés da aplicação de estratégias de $A E M$ porque, apesar de acarretarem maiores custos, são técnicas mais difíceis de detetar (Bruns \& Merchant, 1990; Graham et al., 2005). Os gestores podem preferir utilizar estratégias de $R E M$ em detrimento de estratégias de $A E M$ porque tomar decisões contabilísticas agressivas envolvendo a gestão de accruals é caraterizada como uma medida mais arriscada em matéria de regulação e litígio (Gunny, 2010). Além disso, a empresa pode ter uma flexibilidade limitada quanto à gestão de accruals, pois as práticas de $A E M$ estão condicionadas pelas operações de negócio da empresa e pelas práticas de $A E M$ executadas em anos anteriores (Barton et al., 2002). Gunny (2010) reforça ainda que a utilização de estratégias de REM em detrimento das estratégias de $A E M$ pode ser uma consequência de se caminhar para uma regulação contabilística mais restritiva quanto à liberdade de se fazerem julgamentos na tomada de decisões contabilísticas. No mesmo sentido, Ewert \& Wagenhofer (2005) denotaram que a utilização de estratégias de REM aumenta quando os princípios contabilísticos são mais restritivos, tornando a utilização de estratégias de $A E M$ mais difícil. 
Porém, os gestores podem ter preferência pela prática de $A E M$ por oposição a práticas de $R E M$, já que as primeiras podem ser realizadas após o final do ano fiscal, quando a necessidade de gerir resultados é acrescida, enquanto que as práticas de REM deverão ser executadas antes do final do ano fiscal (Gunny, 2010). Também Payne \& Robb (2000) encontraram evidência de que as empresas com resultados abaixo das expetativas dos analistas utilizam com maior frequência estratégias de $A E M$ e Roychowdhury (2006) afirma que a presença de investidores sofisticados restringe a utilização de estratégias de REM.

Por fim, é importante ter em consideração que analisar apenas uma estratégia de gestão de resultados isoladamente não explica o efeito geral das formas de gestão de resultados (Fields et al., 2001; Zang, 2012), isto é, se os gestores considerarem as estratégias de REM e $A E M$ complementares ou substitutas, então a análise isolada de cada uma das estratégias não proporciona conclusões definitivas. Em particular, Joosten (2012) alerta que a análise isolada da utilização de estratégias de $A E M$ não explica o efeito total das atividade de gestão de resultados, uma vez que as empresas cotadas europeias escolhem pôr em prática $A E M$ ou $R E M$ para gerir resultados.

\section{DADOS E METODOLOGIA}

\subsection{SELEÇÃO E CARATERIZAÇÃO DA AMOSTRA}

Os dados da amostra foram retirados da base de dados Amadeus do Bureau Van Dijk, versão 14.07, durante o mês de Julho de 2017. Os dados foram recolhidos para um período de 8 anos, de 2009 a 2016, sendo que a amostra inicial era constituída por todas as empresas cotadas dos 28 Estados Membros da U.E., cujo ativo total no último ano de publicação dos dados (2016) não fosse inferior a 43 milhões de euros e que tivessem um mínimo de 250 trabalhadores ${ }^{7}$.

Seguidamente, foram excluídas as empresas pertencentes aos setores financeiro e da administração pública, uma vez que estas estão sujeitas a um sistema de contabilidade e regulamentação próprios. No mesmo sentido, excluíram-se as empresas para as quais se apresentava informação insuficiente para o cálculo das medidas de $A E M$ e REM. Tendo como base estudos anteriores, estabeleceu-se o limite mínimo de 5 empresas por país e de 4 empresas por setor de atividade (Gaio, 2010; Cohen et al., 2008).

Posteriormente, com o propósito de eliminar os efeitos eventualmente provocados por valores extremos, excluíram-se os outliers das variáveis contabilísticas, necessárias para o cálculo das medidas de $A E M$ e $R E M$ e variáveis independentes, ou seja, retiraram-se os valores abaixo e o correspondente ao percentil $1 \mathrm{e}$ os valores acima e o correspondente ao percentil 99.

Assim, a amostra final compreende 510 empresas, pertencentes a 7 países da U.E. e 13 setores de atividade, totalizando 4080 observações.

A Tabela I apresenta a composição da amostra por país. Verifica-se que 28,63\% das empresas que constituem a amostra são de França, 25,29\% do Reino Unido e 22,75\% da Alemanha.

Tabela I - Composição da amostra por país

\begin{tabular}{|l|c|c|}
\multicolumn{1}{c}{ País } & Número de empresas & $(\%)$ \\
\hline Alemanha & 116 & $22,75 \%$ \\
\hline Espanha & 31 & $6,08 \%$ \\
\hline Finlândia & 31 & $6,08 \%$ \\
\hline França & 146 & $28,63 \%$ \\
\hline Grécia & 20 & $3,92 \%$ \\
\hline Reino Unido & 129 & $25,29 \%$ \\
\hline Suécia & 37 & $7,25 \%$ \\
\hline & 510 & $100,00 \%$ \\
\hline
\end{tabular}

A Tabela II apresentada a composição da amostra por setor de atividade. Para se diferenciarem os setores de atividade das empresas, utilizou-se a nomenclatura estatística para as atividades económicas usada na Comunidade Europeia, NACE Rev. 2..

\footnotetext{
${ }^{7}$ Para a definição de grande empresa, teve-se como referência o número 1 do artigo 2º do anexo da Recomendação da Comissão 2003/361/CE, de 6 de Maio de 2003, no qual é definida a categoria de micro, pequenas e médias empresas.
} 
A amostra é essencialmente constituída pelo setor das Atividades de Consultoria, Científicas, Técnicas e Similares (34,51\%) e pelo setor das Indústrias Transformadoras (29,22\%).

Tabela II - Composição da amostra por setor de atividade

\begin{tabular}{|c|l|c|c|}
\hline \multicolumn{1}{|c}{ Setor } & Número de empresas & $(\%)$ \\
\hline B & Indústrias Extrativas & 8 & $1,57 \%$ \\
\hline C & Indústrias Transformadoras & 149 & $29,22 \%$ \\
\hline D & Produção e Distribuição de Eletricidade, Gás, Vapor e Ar frio & 8 & $1,57 \%$ \\
\hline & $\begin{array}{l}\text { Captação, Tratamento e Distribuição de Água; Saneamento, } \\
\text { E }\end{array}$ Gestão de Resíduos e Despoluição & 4 & \\
\hline F & Construção & 20 & $0,78 \%$ \\
\hline & $\begin{array}{l}\text { Comércio por Grosso e a Retalho; Reparação de Veículos } \\
\text { G }\end{array}$ & & $3,92 \%$ \\
\hline H & Transportes e Armazenagem & 43 & \\
\hline I & Atividades de Alojamento e Restauração & 15 & $2,43 \%$ \\
\hline J & Informação e Comunicação & 9 & $1,76 \%$ \\
\hline M & Atividades de Consultoria, Científicas, Técnicas e Similares & 53 & $10,39 \%$ \\
\hline N & Atividades Administrativas e dos Serviços de Apoio & 176 & $34,51 \%$ \\
\hline Q & Saúde Humana e Ação Social & 17 & $3,33 \%$ \\
\hline R & Atividades Artísticas, de Espetáculos e Recreativas & 4 & $0,78 \%$ \\
\hline Total & 4 & $0,78 \%$ \\
\hline
\end{tabular}

\subsection{MEDIÇÃO DE ACCRUAL EARNINGS MANAGEMENT}

Os accruals podem ser subdivididos em accruals não discricionários e discricionários. Enquanto que os accruals não discricionários não são influenciados pela tomada de decisão dos gestores, uma vez que provêm da normal atividade da empresa, os accruals discricionários podem ser geridos pelos gestores conforme os objetivos estratégicos estipulados para um determinado período.

Desta forma, o nível de $A E M$ é determinado pela medida de accruals discricionários, em valor absoluto, calculada através do modelo de Jones modificado (Dechow et al., 1995), ajustando a variação das vendas tendo em conta a variação das receitas do mesmo período, com o intuito de ver reduzido o erro dos accruals discricionários correspondente às vendas.

Dechow et al. (1995) propõem o cálculo dos accruals discricionários a partir da regressão dos accruals totais, tendo em conta o ano e setor de atividade de cada empresa, já que o nível de accruals depende do tipo de negócio da empresa, ou seja, estimou-se uma regressão cross-sectional para cada ano e setor de atividade. Assim, os accruals totais são expressos da seguinte forma:

$$
\text { Accruals }_{i, t}=\Delta C A_{i, t}-\Delta C L_{i, t}-\Delta \operatorname{Cash}_{i, t}-\operatorname{Dep}_{i, t}
$$

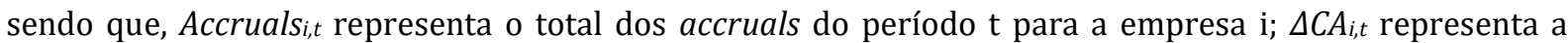
variação do ativo corrente entre o período t e t-1; $\Delta C L_{i, t}$ representa a variação do passivo corrente entre 0 período t e t-1; $\Delta \operatorname{Cash}_{i, t}$ representa a variação de caixa e equivalentes de caixa entre o período t e t-1; e Dep $_{i, t}$ representa as depreciações e amortizações do período t.

De seguida, e de forma a calcular os accruals discricionários, recorreu-se à seguinte regressão:

$$
\frac{\text { Accruals }_{i, t}}{A_{i, t-1}}=\beta_{1}\left(\frac{1}{A_{i, t-1}}\right)+\beta_{2}\left(\frac{\Delta R E V_{i, t}-\Delta \text { Debtors }_{i, t}}{A_{i, t-1}}\right)+\beta_{3}\left(\frac{P P E_{i, t}}{A_{i, t-1}}\right)+\varepsilon_{i, t}
$$


sendo que, $\beta_{1}$, $\beta_{2}$ e $\beta_{3}$ correspondem aos parâmetros específicos de cada ano e setor de atividade, $\triangle R E V_{i, t}$ representa a variação das vendas no período t; $\Delta$ Debtors ${ }_{i, t}$ representa a variação de clientes no período t; $P P E_{i, t-1}$ representa o ativo fixo tangível no período $t$; e $\varepsilon_{i, t}$ representa os resíduos obtidos entre o valor estimado pelo modelo e o valor efetivo no período $t$.

Conforme o estudo de Dechow et al. (1995), todos os termos da equação (2) são divididos pelo ativo total do período anterior $\left(A_{i, t-1}\right)$ como forma de controlar as diferenças de dimensão das empresas da amostra recolhida, evitando-se problemas de heterocedasticidade.

Assim, a nossa medida de AEM, os accruals discricionários (DiscAccruals), corresponde aos resíduos da regressão (2), $\varepsilon_{i, t}$.

\subsection{MEDIÇÃO DE REAL EARNINGS MANAGEMENT}

Segundo Roychowdhury (2006), o nível de REM é obtido com base no cálculo de três métricas, isto é, através do abnormal level dos fluxos de caixa operacionais (CFO), dos custos de produção (PROD) e das despesas discricionárias. Pelo facto de a base de dados Amadeus não apresentar informação suficiente para o cálculo das despesas discricionárias, optou-se por analisar apenas os abnormal levels de CFO e de PROD.

De acordo com Roychowdhury (2006), os abnormal levels de CFO são gerados quando os gestores aumentam os descontos no preço dos produtos vendidos pela empresa ou oferecem condições de crédito mais favoráveis aos seus clientes, com o propósito de aumentarem as vendas durante um determinado ano. No entanto, este crescimento das vendas é apenas temporário, ou seja, quando se põem em prática as medidas acima mencionadas são gerados maiores fluxos de caixa nesse período, que diminuem assim que a empresa restabelece a sua normal atividade.

Relativamente aos abnormal levels de $P R O D$, são gerados quando se produz uma quantidade superior à necessária, de forma a assegurar a procura esperada e na tentativa de aumentar os resultados. 0 aumento da produção proporciona uma maior distribuição dos custos fixos por um maior número de unidades produzidas, fazendo com que o custo fixo unitário reduza. Desta forma, os custos totais de produção irão sofrer uma diminuição se não houver qualquer aumento no custo marginal por unidade que supere a redução dos custos fixos unitários. Assim, a empresa terá um custo das vendas menor, possibilitando o relato de melhores margens operacionais.

Roychowdhury (2006), Cohen et al. (2008) e Cohen \& Zarowin (2010) defendem que as empresas que apresentam menores abnormal levels de $C F O$ utilizam com maior frequência as estratégias de $R E M$, graças ao aumento de descontos no preço dos produtos vendidos ou à criação frequente de condições de crédito mais favoráveis para os clientes, de forma a acelerar as vendas num determinado ano. As empresas que apresentam maiores abnormal levels de $C P$ utilizam, também, com maior frequência as estratégias de $R E M$, pois os gestores aumentam a produção de forma a diminuírem os custos das vendas e aumentarem as suas margens operacionais num determinado ano.

Para a estimação de cada modelo correspondente a cada uma das métricas de REM: Abnormal CFO e Abnormal PROD. As medidas foram calculadas com base nos estudos de Dechow et al. (1998) e Roychowdhury (2006). Foram estimadas regressões cross-sectional para cada ano e setor de atividade.

O normal CFO é expresso através de uma função linear das vendas e da variação das vendas num determinado período, tendo sido calculado como se segue:

$$
\frac{C F O_{i, t}}{A_{i, t-1}}=\alpha_{0}+\alpha_{1}\left(\frac{1}{A_{i, t-1}}\right)+\beta_{1}\left(\frac{S_{i, t}}{A_{i, t-1}}\right)+\beta_{2}\left(\frac{\Delta S_{i, t}}{A_{i, t-1}}\right)+\varepsilon_{i, t}
$$

sendo que, $C F O_{i, t}$ representa o fluxo de caixa operacional no período $\mathrm{t}$ da empresa i, $S_{i, t}$ representa as vendas totais no período $\mathrm{t}, \Delta S_{i, t}$ representa a variação das vendas totais entre o período t e t-1 e $\varepsilon_{i, t}$ representa o resíduo da estimativa no período t. Todos os termos são divididos pelo ativo total do período anterior $\left(A_{i, t-1}\right)$ para que seja possível controlar as diferenças de dimensão das empresas da amostra recolhida. 
O Actual CFO foi calculado da seguinte forma:

$$
\text { Actual } C F O_{i, t}=N I_{i, t}-\left(\Delta C A_{i, t}-\Delta C L_{i, t}-\Delta \operatorname{Cash}_{i, t}+\Delta D e b t_{i, t}-\operatorname{Dep}_{i, t}\right)
$$

sendo que, $N I_{i, t}$ representa o resultado líquido no período t; $\Delta C A_{i, t}$ representa a variação do ativo corrente entre o período t e t-1; $\Delta C L_{i, t}$ representa a variação do passivo corrente entre o período t e t-1; $\Delta$ Cash $_{i, t}$ representa a variação de caixa e equivalentes de caixa entre o período t e $\mathrm{t}-1 ; \Delta D e b t_{i, t}$ representa a variação da parcela de endividamento de curto prazo incluída no passivo corrente entre o período t e t-1; e Dep $_{i, t}$ representa as depreciações e amortizações do período t.

Sendo assim, o abnormal CFO é obtido através da subtração entre o actual CFO e o normal CFO.

Para calcular a segunda medida de REM, abnormal PROD, começou-se por estimar o normal level do custo das vendas e do crescimento de inventários da seguinte forma:

$$
\frac{\operatorname{CoGS}_{i, t}}{A_{i, t-1}}=\alpha_{0}+\alpha_{1}\left(\frac{1}{A_{i, t-1}}\right)+\beta\left(\frac{S_{i, t}}{A_{i, t-1}}\right)+\varepsilon_{i, t}
$$

sendo que, $C O G S_{i, t}$ representa o custo das vendas da empresa i no período t.

$$
\frac{\Delta I N V_{i, t}}{A_{i, t-1}}=\alpha_{0}+\alpha_{1}\left(\frac{1}{A_{i, t-1}}\right)+\beta_{1}\left(\frac{\Delta S_{i, t}}{A_{i, t-1}}\right)+\beta_{2}\left(\frac{\Delta S_{i, t-1}}{A_{i, t-1}}\right)+\varepsilon_{i, t}
$$

sendo que, $\Delta I N V_{i, t}$ representa a variação do inventário da empresa i entre o período t e t-1.

Assim, o Normal PROD é estimado através das equações (5) e (6), como se segue:

$$
\frac{P R O D_{i, t}}{A_{i, t-1}}=\alpha_{0}+\alpha_{1}\left(\frac{1}{A_{i, t-1}}\right)+\beta_{1}\left(\frac{S_{i, t}}{A_{i, t-1}}\right)+\beta_{2}\left(\frac{\Delta S_{i, t}}{A_{i, t-1}}\right)+\beta_{3}\left(\frac{\Delta S_{i, t-1}}{A_{i, t-1}}\right)+\varepsilon_{i, t}
$$

sendo que, $P R O D_{i, t}$ representa os custos de produção da empresa i no período t.

Uma vez que a base de dados não continha o custo das vendas para grande parte das empresas incluídas na amostra, o custo das vendas foi determinado, segundo Burgstahler \& Eames (2006), da seguinte forma:

$$
\text { Actual } \operatorname{COGS}_{i, t}=S_{i, t}-O I_{i, t}
$$

sendo que, $O I_{i, t}$ representa o resultado operacional da empresa i no período $t$.

Já o actual level do crescimento do inventário foi determinado da seguinte forma:

$$
\text { Actual } \Delta I N V_{i, t}=\text { Stock }_{i, t}-\text { Stock }_{i, t-1}
$$

sendo que, Stock $k_{i, t}$ representa o inventário da empresa i no período t.

O Actual PROD não é mais do que a soma dos valores resultantes das equações (8) e (9).

O Abnormal PROD é obtido através da subtração entre o Actual PROD e o Normal PROD. 
Por forma a analisar o efeito de ambas as componentes das estratégias de $R E M$, optou-se por calcular uma variável agregada representativa do nível de utilização de estratégias de $R E M, R E M_{i, t}$. De acordo com Gaio (2010), para calcular a variável agregada $R E M_{i, t}$,elaborou-se o ranking das empresas da amostra de 0 a 100, para cada uma das métricas anteriores, $A b n o r m a l_{C} C F O_{i, t}$ e $A b n o r m a l \_P R O D_{i, t} .0$ nível de utilização de estratégias de $R E M$ da empresa i no período $\mathrm{t}, R E M_{i, t}$, foi obtido através do cálculo da média de cada ranking de ambas as variáveis Abnormal_CFO ${ }_{i, t}$ e $A b n o r m a l_{-} P R O D_{i, t}$ para cada empresa. Quanto maior for o ranking de uma empresa, maior será o nível de utilização de estratégias de REM por essa empresa.

\subsection{MODELO EMPÍRICO}

O objetivo deste estudo é averiguar de que forma as estratégias de gestão de resultados, $A E M$ e $R E M$, são utilizadas em empresas cotadas da U.E., Para tal, foi estimado o seguinte modelo empírico:

$$
\begin{gathered}
\text { DisAccruals }_{i, t}=\alpha_{0}+\alpha_{1} \text { REM }_{i, t}+\alpha_{2} \text { Size }_{i, t}+\alpha_{3} \text { Growth }_{i, t}+\alpha_{4} \text { ROA }_{i, t}+\alpha_{5} \text { Debt }_{i, t}+\alpha_{6} \text { Big }_{i, t}+ \\
\alpha_{7} \text { Country }_{i}+\alpha_{8} \text { Industry }_{i}+\alpha_{9} \text { Year }_{t}+\varepsilon_{i, t}
\end{gathered}
$$

sendo que Size é a dimensão da emprea; Growth representa as oportunidades de crescimento da empresa; $R O A$ é a rendibilidade líquida do ativo; Debt é o nível de endividamento; e Big4 indica se a empresa é auditada por uma das empresa de auditoria Big4. Foram ainda adicionados ao modelo controlos para os efeitos das diferentes caraterísticas dos países (Country), Setores de atividade (Industry) e anos (Year). A definição das variáveis é apresentada com maior detalhe no Apêndice, bem como a referência a estudos anteriores que sustentam a sua escolha e o comportamento esperado nos resultados de cada uma das variáveis.

Se $\alpha_{1}>0$ então é expetável que as estratégias de $A E M$ e $R E M$ sejam utilizadas de forma complementar pelas empresas da amostra. Alternativamente, se $\alpha_{1}<0$ então espera-se que as estratégias de $A E M$ e $R E M$ sejam utilizadas de forma substituta pelas mesmas empresas.

\section{ANÁLISE DE RESULTADOS}

\subsection{ESTATÍSTICAS DESCRITIVAS}

A Tabela III apresenta as estatísticas descritivas das variáveis do modelo empírico. 0 valor médio dos accruals discricionários (DisAccruals) das empresas analisadas foi de -0,0007 e mediana de 0,0265. Esta mediana positiva poderá indicar que o nível dos accruals discricionários efetivamente realizado pelas empresas é maior do que o nível esperado, o que implica que as empresas usam accruals discricionários para aumentar os seus resultados.

Tabela III - Estatísticas descritivas

\begin{tabular}{|c|c|c|c|c|c|c|}
\hline \multicolumn{2}{|c}{ Variável } & Média & Mediana & Desvio Padrão & Mínimo & Máximo \\
\hline DisAccruals & 4080 & $-0,00070$ & 0,02650 & 0,95086 & $-5,09973$ & 5,03984 \\
\hline Abnormal_CFO & 4080 & 0,09381 & 0,08974 & 0,03579 & $-0,09149$ & 0,45763 \\
\hline Abnormal_PROD & 4080 & 0,95936 & 0,88576 & 0,48062 & 0,05857 & 3,19114 \\
\hline Size & 4080 & 13,67894 & 13,41107 & 1,89724 & 9,97714 & 18,64954 \\
\hline Growth & 4080 & 0,05217 & 0,04436 & 0,15405 & $-0,72108$ & 2,61210 \\
\hline ROA & 4080 & 0,04790 & 0,04439 & 0,05857 & $-0,32163$ & 0,41484 \\
\hline Debt & 4080 & 0,19858 & 0,18710 & 0,15223 & 0,000000 & 1,06910 \\
\hline Big4 & 4080 & 0,81372 & 0,50000 & 0,70710 & 0 & 1 \\
\hline
\end{tabular}


Já o valor médio dos abnormal levels do CFO (Abnormal_CFO) das empresas que compõem a amostra tomou o valor de 0,0938 e mediana de 0,0897, enquanto que o valor médio dos abnormal levels PROD (Abnormal_PROD) foi de 0,9594 e mediana 0,8858. De acordo com os resultados de Joosten (2012), as medianas positivas também aqui verificadas poderão indicar que as empresas em análise fazem gestão de resultados através de operações reais para aumentarem os seus resultados, o que é consistente com estudos anteriores que indicam que as empresas usam práticas de REM para gerirem os resultados de forma ascendente (Roychowdhury, 2006; Cohen et al., 2008; Gunny, 2010; Zang, 2012).

Em média, as empresas que compõem a amostra apresentam uma taxa de crescimento anual das vendas de 5,22\%, uma rendibilidade líquida do ativo de 4,79\%, consistente com o estudo de Zang (2012), e um rácio de endividamento de, aproximadamente, $19,86 \%$, valor muito semelhante com o obtido por Badertscher (2011). Consistente com os resultados de Chen et al. (2012), cerca de 81,37\% das empresas da amostra são auditadas por uma das Big4.

A Tabela IV apresenta os coeficientes de correlação de Pearson entre as variáveis utilizadas no modelo empírico. As correlações apresentam valores inferiores a 0,38, o que sugere a não existência de problemas de multicolinearidade. A medida de AEM está negativamente correlacionada com ambas as medidas de REM, o que sugere uma relação de substituição.

Tabela IV - Matriz de correlações de Pearson

\begin{tabular}{|c|c|c|c|c|c|c|c|c|}
\hline & DisAcrcuals & A_CFO & A_PROD & Size & Growth & ROA & Debt & Big4 \\
\hline DisAcrcuals & 1,0000 & & & & & & & \\
\hline$A_{-} C F O$ & $-0,044^{* * *}$ & 1,0000 & & & & & & \\
\hline$A \_P R O D$ & $-0,030^{*}$ & $0,378^{* * *}$ & 1,0000 & & & & & \\
\hline Size & $-0,020$ & $-0,092^{* * *}$ & $-0,289^{* * *}$ & 1,0000 & & & & \\
\hline Growth & $0,032^{* * *}$ & $0,261^{* * *}$ & $0,147^{* * *}$ & $-0,055^{* * *}$ & 1,0000 & & & \\
\hline$R O A$ & $0,148^{* * *}$ & $0,355^{\text {*** }}$ & $0,219^{* * *}$ & $-0,041^{* * *}$ & $0,238^{* * *}$ & 1,0000 & & \\
\hline Debt & $-0,050^{* * *}$ & $-0,191^{* * *}$ & $-0,296^{* * *}$ & $0,190^{* * *}$ & $-0,072^{* * *}$ & $-0,355^{* * *}$ & 1,000 & \\
\hline Big4 & $-0,049^{* * *}$ & $0,073^{* * *}$ & $-0,043^{* * *}$ & $0,359^{* * *}$ & $-0,019$ & $0,058^{* * *}$ & $-0,046^{* * *}$ & 1,000 \\
\hline
\end{tabular}

\subsection{RESULTADOS DA REGRESSÃO LINEAR}

A Tabela V apresenta os resultados obtidos da regressão linear estimada (10). Analisando a variável independente de interesse, $R E M$, verifica-se que esta apresenta um coeficiente negativo e estatisticamente significativo a um nível de significância de 1\%. Este resultado revela existir evidência estatística de uma relação negativa entre as duas estratégias de gestão de resultados, sugerindo que $A E M$ e $R E M$ são utilizadas de forma substituta pelas empresas da amostra, consistente com os resultados de estudos anteriores (Badertscher, 201;, Joosten, 2012; Zang, 2012).

Relativamente às variáveis de controlo, apenas as variáveis ROA e Big4 apresentam coeficientes estatisticamente significativos (nível de significância a 1\%). 0 coeficiente positivo da variável $R O A$ sugere que níveis de rendibilidade mais elevados estão associados à utilização de estratégias de $A E M$ para aumentar os resultados. Ou seja, empresas mais rentáveis tendem a gerir os resultados de forma ascendente, tal como defendido por Carlson \& Bathala (1997) e Chen et al. (2012).

Quanto à auditoria da empresa, verifica-se que o coeficiente da variável Big4 é negativo, em conformidade com os estudos de Chen et al. (2012), Zang (2012), Badertscher (2011) e Barton (2002), que defendem que empresas auditadas pelas Big4 tendem a fazer gerir os resultados de forma descendente.

Por fim, rejeita-se igualmente a hipótese da nulidade conjunta dos coeficientes das variáveis explicativas, uma vez que o $p$-value da estatística F é nulo, significando que as variáveis incluídas no modelo utilizado são conjuntamente significativas para explicar a variação da medida de $A E M$.

Na origem desta associação negativa podem estar vários fatores já identificados na literatura. 0 trade-off entre as estratégias de gestão de resultados por parte dos gestores pode ser realizado em função dos custos relativos de cada estratégia que derivam, nomeadamente, das restrições associadas a cada uma delas (Zang, 2012). De facto, existe evidencia de que as práticas de $A E M$ são mais fáceis de detetar do que as de REM devido ao superior escrutínio e monitorização por parte dos auditores e entidades reguladoras (Matsumoto, 2002; Graham et al., 2005; , Cohen et al., 2008). Existe também evidencia que, enquanto as práticas de REM ocorrem durante o ano, as práticas de AEM concentram-se mais no final o ano, onde 
existe normalmente uma maior pressão para a gestão de resultados (Gunny, 2010; Zang, 2012). 0 cariz de reversão dos accruals pode também justificar esta associação negativa pois os gestores podem ter flexibilidade limitada quanto à gestão de accruals, estando condicionados pelas operações de negócio da empresa e pelas práticas de AEM executadas em anos anteriores (Barton et al., 2002; Gunny, 2010), tendo por isso que recorrer em substituição a práticas de $R E M$.

Tabela V - Accrual vs. real earnings management

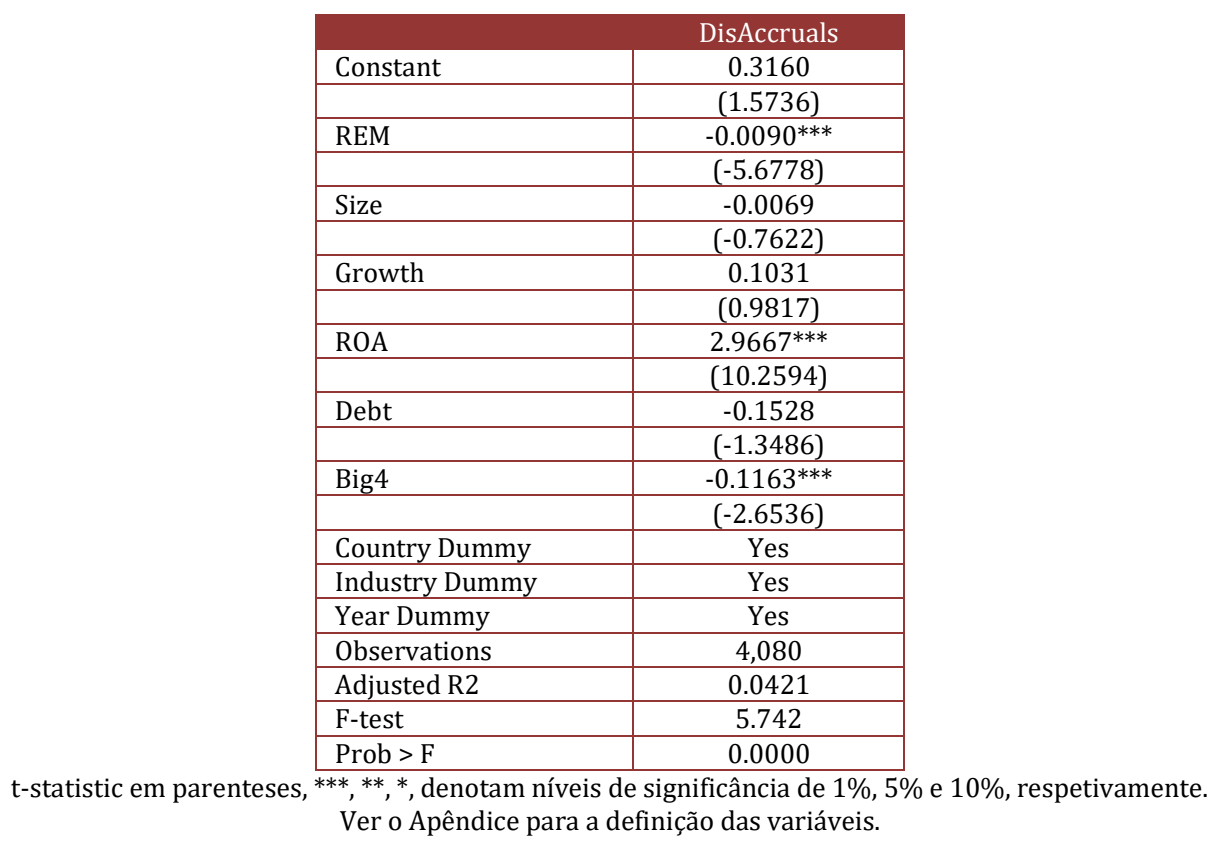

\subsection{ANÁLISE DE ROBUSTEZ}

Segundo Chen et al. (2012), a utilização de estratégias de AEM no período corrente está positivamente associada com a utilização de estratégias de AEM no período precedente, sugerindo uma utilização de estratégias de gestão de resultados estrategicamente consistente. No entanto, Zang (2012) afirma que quanto maior for o nível de accruals discricionários do período anterior, maiores serão os custos de se utilizarem estratégias de AEM no período corrente, defendendo que esta variável apresenta uma associação negativa com AEM. Assim, de forma a testar se o efeito do nível de accruals discricionários praticado no período anterior influência a forma como as empresas cotadas da U.E. utilizam as estratégias de gestão de resultados, $A E M$ e REM, adicionou-se ao modelo base, Equação (10), a variável que representa os accruals discricionários do ano anterior: DisAccrualsi,t-1. A Tabela VI apresenta os resultados obtidos.

A introdução do nível de accruals discricionários do ano anterior não alterou as conclusões anteriores. A variável independente de interesse, REM, continua a apresentar um coeficiente negativo e estatisticamente significativo a um nível de significância de 1\%, sugerindo que as estratégias de gestão de resultados, AEM e REM, são utilizadas de forma substituta pelas empresas cotadas da amostra.

No que diz respeito à variável DisAccrualsi,t-1, o coeficiente negativo e estatisticamente significativo a $1 \%$, sugere que a estratégia de $A E M$ no período corrente está negativamente associada com a estratégia de $A E M$ no período precedente, o que está em conformidade com o estudo Zang (2012). Isto significa que quanto maior for a utilização de estratégias de $A E M$ no período precedente para gerirem os resultados de forma ascendente, maior será a tendência para as empresas porem em prática estratégias de $A E M$ para gerirem os resultados de forma descendente no período corrente. 
Tabela VI - Impacto de accrual earnings management do período anterior

\begin{tabular}{|c|c|}
\hline & DisAccruals \\
\hline Constant & 0.3250 \\
\hline & $(1.6247)$ \\
\hline REM & $-0.0094^{* * *}$ \\
\hline & $(-5.9289)$ \\
\hline Size & -0.0069 \\
\hline & $(-0.7715)$ \\
\hline Growth & 0.1106 \\
\hline & (1.0577) \\
\hline ROA & $3.1033^{* * *}$ \\
\hline & $(10.7379)$ \\
\hline Debt & -0.1690 \\
\hline & $(-1.4968)$ \\
\hline Big4 & $-0.1251^{* * *}$ \\
\hline & $(-2.8648)$ \\
\hline DisAccruals $_{\mathrm{i}, \mathrm{t}-1}$ & $-0.0891^{* * *}$ \\
\hline & $(-5.7616)$ \\
\hline Country Dummy & Yes \\
\hline Industry Dummy & Yes \\
\hline Year Dummy & Yes \\
\hline Observations & 4,080 \\
\hline Adjusted $\mathrm{R}^{2}$ & 0.0499 \\
\hline F-test & 6.859 \\
\hline Prob $>$ F & 0 \\
\hline
\end{tabular}

\section{CONSIDERAÇÕES FINAIS}

Neste estudo, procurou-se analisar de que forma é que as estratégias de gestão de resultados, aem e rem, são utilizadas por empresas cotadas da u.e., isto é, se são aplicadas de forma complementar ou substituta, no curso normal da sua atividade de negócio, utilizando uma amostra constituída por 510 empresas, entre o ano de 2009 e o ano de 2016.

Os resultados sugerem que as estratégias de gestão de resultados, $A E M$ e REM são usadas de forma substituta, o que está em conformidade com Badertscher (2011), Joosten (2012) e Zang (2012), entre outros. Ou seja, existe um trade-off na prática das estratégias tendo em conta o custo-benefício associado resultante dos constrangimentos e custos de médio e longo prazo associados a cada uma delas.

Existe também evidencia de que empresas mais rentáveis tendem a gerir os resultados de forma ascendente, tal como defendido por Carlson \& Bathala (1997) e Chen et al. (2012) e que empresas auditadas por uma empresa Big4 tendem a fazer gerir os resultados de forma descendente, em conformidade com os estudos de Chen et al. (2012), Zang (2012), Badertscher (2011) e Barton (2002), devido provavelmente à maior atenção por parte aos auditores às práticas de gestão de resultados de forma ascendente.

Análises adicionais indicam que o efeito do nível de AEM do ano anterior está relacionado com o nível praticado no ano corrente, apesar de não alterar a relação de substituição verificada entre $A E M$ e $R E M$, sugerindo que quanto maior for a utilização accruals no período precedente para gerir os resultados, maior será a tendência para as empresas porem em prática estratégias de REM para compensar o efeito reversivo dos accruals.

Este estudo contribui mais especificamente para a ainda escassa literatura sobre o efeito conjunto das duas estratégias de gestão de resultados, bem como para a literatura de gestão de resultados que é maioritariamente focada em $A E M$.

Os resultados deste estudo são do interesse dos diversos intervenientes do processo de relato financeiro, nomeadamente entidade reguladoras, auditores e investidores. A literatura tem identificado uma tendência crescente para a prática de $R E M$, cujas consequências para o negócio e desempenho futuro das empresas podem ser negativas (Dechow et al., 2003; Ewert \& Wagenhofer, 2005; Roychowdhury, 2006; Zang, 2012; Roychowdhury, 2006). Assim, este estudo contribui para uma maior compreensão de como as empresas, concretamente as cotadas europeias, podem gerir as estratégias de gestão de resultados e as possíveis consequências dessa gestão. 
A principal limitação deste estudo é a dimensão da amostra que foi consideravelmente reduzida devido à falta de dados para o cálculo das diferentes medidas de gestão de resultados e também pelos procedimentos metodológicos adotados com vista à obtenção de resultados mais robustos.

Para investigações futuras, sugere-se o estudo de diferentes caraterísticas do sistema de governação das sociedades na utilização de estratégias de $A E M$ e REM. Seria igualmente interessante alargar este estudo às empresas não cotadas, já que estas representam o grosso do tecido empresarial europeu.

\section{REFERÊNCIAS}

[1] Badertscher, B. A. (2011). Overvaluation and the choice of alternative earnings management mechanisms. Accounting Review, 86(5), 1491-1518.

[2] Barton, J., Simko, P. J., \& DeFond, M. L. (2002). The Balance Sheet as an Earnings Management Constraint. The Accounting Review, 77(2002), 1-27.

[3] Becker, C. L., Defond, M. L., Jiambalvo, J., \& Subramanyam, K. R. (2003). The Effect of Audit Quality on Earnings Management. Auditing: A Journal of Practice \& Theory. Contemporary Accounting Research, 15(1), 109-126.

[4] Brown, L. D., Hagerman, R. L., Griffin, P. A., \& Zmijewski, M. E. (1987). An evaluation of alternative proxies for the market's assessment of unexpected earnings. Journal of Accounting and Economics, 9(2), 159-193.

[5] Bruns, W. J., \& Merchant, K. A. (1990). The Dangerous Morality of Managing Earnings. Management Accounting. Management Accounting, 72(2), 22-25.

[6] Burgstahler, D., \& Eames, M. (2006). Management of earnings and analysts' forecasts to achieve zero and small positive earnings surprises. Journal of Business Finance and Accounting, 33(5-6), 633-652.

[7] Carlson, S. J., \& Bathala, C. T. (1997). Ownership Differences and firms' income smoothing behavior. Journal of Business Finance and Accounting, 24(2), 179-196.

[8] Chen, C.-L., Huang, S.-H., \& Fan, H.-S. (2012). Complementary association between real activities and accrualsbased manipulation in earnings reporting. Journal of Economic Policy Reform, 15(2), 93-108.

[9] Comissão das Comunidades Europeias (2003). RECOMENDAÇÃO DA COMISSÃO de 6 de Maio de 2003 relativa à definição de micro, pequenas e médias empresas [Em linha]. Disponível em: https://www.iapmei.pt/getattachment/PRODUTOS-E-SERVICOS/Qualificacao-Certificacao/CertificacaoPME/Recomendacao-da-Comissao-2003-361-CE.pdf

[10] Cohen, D. A., Dey, A., \& Lys, T. Z. (2008). Real and Accrual-based Earnings Management in the Pre- and PostSarbanes-Oxley Periods. Accounting Review, 83(3), 757-787.

[11] Cohen, D. A., \& Zarowin, P. (2010). Accrual-based and real earnings management activities around seasoned equity offerings. Journal of Accounting and Economics, 50(1), 2-19.

[12] Coppens, L. \& Peek, E. (2005). An analysis of earnings management by European private firms. Journal of International Accounting, Auditing and Taxation, 14, 1-17.

[13] Datta, S., Iskandar-Datta, M., \& Singh, V. (2013). Product market power, industry structure, and corporate earnings management. Journal of Banking and Finance, 37(8), 3273-3285.

[14] Dechow, P., Sloan, R., \& Sweeney, A. (1995). Detecting Earnings Management. The Accounting Review, 70(2), 193-225.

[15] Dechow, P. M., Kothari, S. P., \& Watts, R. L. (1998). The relation between earnings and cash flows. Journal of Accounting and Economics, 25(2), 133-168.

[16] Dechow, P. M., Richardson, S. A., \& Tuna, I. (2003). Why are earnings kinky? An examination of the earnings management explanation. Review of accounting studies, 8(2), 355-384.

[17] Degeorge, F., Patel, J., \& Zeckhauser, R. (1999). Earnings Management to Exceed Thresholds Earnings Management to Exceed Thresholds. Journal of Business, 72(1), 1-33.

[18] wert, R., \& Wagenhofer, A. (2005). Economic effects of tightening accounting standards to restrict earnings management. Accounting Review, 80(4), 1101-1124.

[19] Fields, T. D., Lys, T. Z., \& Vincent, L. (2001). Empirical research on accounting. Journal of Accounting and Economics, 31(1-3), 255-307.

[20] Francis, J., Schipper, K., \& Vincent, L. (2003). The relative and incremental explanatory power of earnings and alternative (to earnings) performance measures for returns. Contemporary Accounting Research, 20, 121-164.

[21] Freeman, R.E. (1984). Strategic Management: A Stakeholder Approach, Boston: pitman. 
[22] Gaio, C. (2010). The Relative Importance of Firm and Country Characteristics for Earnings Quality around the World. European Accounting Review, 19(4), 693-738.

[23] Graham, J. R., Harvey, C. R., \& Rajgopal, S. (2005). The economic implications of corporate financial reporting. Journal of Accounting and Economics, 40(1-3), 3-73.

[24] Gunny, K. A. (2010). The relation between earnings management using real activities manipulation and future performance: Evidence from meeting earnings benchmarks. Contemporary Accounting Research, 27(3), 855888.

[25] Healy, P. M., \& Palepu, K. G. (1993). The Effect of Firms' Financial Disclosure Strategies on Stock Prices. Accounting Horizons, 7(1), 1-11.

[26] Healy, P. M., \& Wahlen, M. . (1999). A review of the earnings management literature and its implications for standard setting. Accounting Horizons, 13(4), 365-383.

[27] Jones, J. J. (1991). Earnings Management During Import Relief Investigations. Journal of Accounting Research, $29(2), 193-228$.

[28] Joosten, C. (2012). Real earnings management and accrual-based earnings management as substitutes. Thesis. University of Tilburg, 1-54.

[29] Matsumoto, D. A. (2002). Management's Incentives to Avoid Negative Earnings Surprises. The Accounting Review, 77(3), 483-514.

[30] Mizik, N., \& Jacobson, R. (2012). Earnings Inflation through Accruals and Real Activity Manipulation: Its Prevalence at the Time of an SEO and the Financial Market Consequences. Unpublished Manuscript, Columbia University Graduate School of Business, New York, 1-45.

[31] Myers, J. N., Myers, L. A., \& Skinner, D. J. (2007). Earnings Momentum and Earnings Management. Journal of Accounting, Auditing \& Finance, 22(2), 249-284.

[32] Nelson, M. W., Elliott, J. A., \& Tarpley, R. L. (2003). How are earnings managed? Examples from Auditors. Accounting Horizons (Supplement), 17-35.

[33] Nelson, M. W., Elliott, J. a, Tarpley, R. L., \& Gibbins, M. (2002). Evidence from Auditors about Managers' and Auditors' Earnings Management Decisions. The Accounting Review, 77, 175-202.

[34] Payne, J. L., \& Robb, S. W. G. (2000). Earnings Management: The Effect of Ex Ante Earnings Expectations. Journal of Accounting, Auditing \& Finance, 15(4), 371-392.

[35] Roychowdhury, S. (2006). Earnings management through real activities manipulation. Journal of Accounting and Ecnomics, 42(3), 335-370.

[36] Schipper, K. (1989). Commentary on Earnings Management. Accounting Horizons, 91-103.

[37] Zang, A. Y. (2012). Evidence on the trade-off between real activities manipulation and accrual-based earnings management. Accounting Review, 87(2), 675-703. 


\section{APÊNDICE - DEFINIÇÃO DAS VARIÁVEIS INDEPENDENTES DE CONTROLO}

\begin{tabular}{|c|c|c|}
\hline Variável & Descrição da variável & Revisão da Literatura \\
\hline Size & $\begin{array}{l}\text { Dimensão da empresa } \\
\text { medida através do } \\
\text { logaritmo natural do } \\
\text { total de ativos. }\end{array}$ & $\begin{array}{l}\text { Visto que as empresas de maior dimensão estão sujeitas a maiores pressões de } \\
\text { mercado, poderão aplicar mais estratégias de gestão de resultados. Porém, as } \\
\text { empresas de maior dimensão estão também sujeitas a um maior escrutínio por parte } \\
\text { dos auditores, reguladores e intervenientes no mercado (Chen et al., 2012) e } \\
\text { encontram-se numa fase de maior maturação, menor volatilidade dos resultados e } \\
\text { maior facilidade na diversificação do risco entre divisões e atividades de negócio } \\
\text { (Gaio, 2010). Assim, de acordo com Roychowdhury (2006) e Chen et al. (2012) } \\
\text { espera-se que esta variável apresente um coeficiente negativo. }\end{array}$ \\
\hline Growth & $\begin{array}{l}\text { Perspetiva de } \\
\text { crescimento da empresa } \\
\text { medida como a variação } \\
\text { percentual anual das } \\
\text { vendas. }\end{array}$ & $\begin{array}{l}\text { A taxa de crescimento das vendas pode indicar não as perspetivas de crescimento, } \\
\text { mas também as oportunidades de negócio e de investimento. Segundo Datta et al., } \\
\text { 2013, empresas com mais perspetivas de crescimento tendem a praticar mais gestão } \\
\text { de resultados pelo que se espera que esta variável apresente um coeficiente positivo. }\end{array}$ \\
\hline$R O A$ & $\begin{array}{l}\text { Rendibilidade líquida do } \\
\text { ativo calculado pelo } \\
\text { rácio entre resultado } \\
\text { líquido e total do ativo. }\end{array}$ & $\begin{array}{l}\text { Segundo Burgstahler \& Eames (2006) e Chen et al. (2012), empresas com menor } \\
\text { rendibilidade têm um maior incentivo para gerirem os resultados para alcançar os } \\
\text { seus objetivos, esperando-se que esta variável apresente coeficiente negativo. }\end{array}$ \\
\hline Debt & $\begin{array}{l}\text { Nível de endividamento } \\
\text { da empresa calculado } \\
\text { pelo rácio entre o } \\
\text { passivo e o total de } \\
\text { ativos. }\end{array}$ & $\begin{array}{l}\text { Segundo Burgstahler \& Eames (2006) e Chen et al. (2012), empresas com um maior } \\
\text { nível de endividamento tendem a utilizar mais estratégias de gestão de resultados, de } \\
\text { forma a evitarem a violação das cláusulas contratuais e conseguirem melhores } \\
\text { condições de crédito. No mesmo sentido, Roychowdhury (2006) defende que as } \\
\text { empresas com um maior nível de endividamento utilizam mais estratégias de } R E M \\
\text { por forma a evitar maus resultados. Contudo, outros autores, como Datta et al. } \\
\text { (2013), defendem que empresas com um maior nível de endividamento poderão } \\
\text { sofrer restrições quanto à prática de gestão de resultados, uma vez que poderá } \\
\text { existir um maior controlo das cláusulas contratuais por parte dos credores, } \\
\text { aumentando assim a dificuldade em fazer gestão de resultados. Como tal, esta } \\
\text { variável poderá apresentar um coeficiente quer negativo quer positivo. }\end{array}$ \\
\hline Big4 & $\begin{array}{l}\text { Variável dummy que } \\
\text { toma o valor " } 1 \text { " se a } \\
\text { empresa i é auditada } \\
\text { por uma Big } 4 \text { e "0" caso } \\
\text { contrário, no período t. }\end{array}$ & $\begin{array}{l}\text { Segundo Chen et al. (2012) e Zang (2012), uma empresa auditada por uma das Big4 } \\
\text { sofre maiores restrições quanto à utilização de estratégias de gestão de resultados, } \\
\text { esperando-se que esta variável apresente um coeficiente negativo. }\end{array}$ \\
\hline Country & $\begin{array}{l}\text { Variável dummy que } \\
\text { toma valor "1" se a } \\
\text { empresa i pertence ao } \\
\text { país respetivo 0" caso } \\
\text { contrário. }\end{array}$ & $\begin{array}{l}\text { Variável dicotómica que pretende controlar o impacto das diferenças institucionais e } \\
\text { caraterísticas dos países nas práticas de gestão de resultados. Estipulou-se que o país } \\
\text { base neste estudo seria Finlândia por opção. }\end{array}$ \\
\hline Industry & $\begin{array}{l}\text { Variável dummy que } \\
\text { toma o valor " } 1 \text { " se a } \\
\text { empresa i é do setor } \\
\text { respetivo e "0" caso } \\
\text { contrário. }\end{array}$ & $\begin{array}{l}\text { Variável dicotómica que pretende controlar o impacto das diferenças nas } \\
\text { caraterísticas dos setores de atividade de cada empresa na prática de gestão de } \\
\text { resultados. Estipulou-se que o setor de atividade base deste estudo seria o setor das } \\
\text { Indústrias Extrativas (NACE, Rev. } 25 \text { a 9) por opção. }\end{array}$ \\
\hline Year & $\begin{array}{l}\text { Variável dummy que } \\
\text { toma valor "1" se os } \\
\text { valores pertencem ao } \\
\text { ano respetivo e "0" caso } \\
\text { contrário. }\end{array}$ & $\begin{array}{l}\text { Variável dicotómica que pretende controlar o impacto das diferenças dos anos na } \\
\text { prática de gestão de resultados. Estipulou-se que o ano base seria } 2009 .\end{array}$ \\
\hline
\end{tabular}




\section{Capítulo 14}

\section{A evidenciação da DVA agrega valor às Empresas do Novo Mercado da BM\&FBOVESPA? Evidências trazidas através de estudo em painel e do Modelo de Ohlson}

\section{Roque Brinckmann}

Fábio Minatto

Resumo: Desde 2008 as empresas do Novo Mercado (NM) da BM\&FBOVESPA (BM\&F) são obrigadas a publicar a DVA conforme estabelece a Lei 11.638/07, embora várias já o fizessem por iniciativa própria na expectativa de incorporação de valor à firma. 0 objetivo deste estudo é avaliar se o impacto informacional da publicação da DVA está significativamente associado ao valor das firmas do NM da BM\&F nos períodos de 2006 a 2014 e de 2009 a 2014, este último que sucede àquela Lei. 0 Modelo de Ohlson (MO) é utilizado para testar duas hipóteses, a primeira se as evidenciações trazidas pela DVA estiveram positivamente associadas ao preço de mercado daquelas empresas no período de 2006 a 2014, a segunda, se após a vigência da Lei 11.638/07 estas evidenciações trouxeram maior geração de valor. Sobre uma amostra que compreendeu somente as publicações uniformes e contínuas da DVA das empresas em foco no período estipulado, foi aplicado o MO adaptado para comprovação das hipóteses, seguido de inferência por dados em painel quanto ao impacto informacional segundo as hipóteses formuladas. Os resultados apontam que no período de 2006 a 2014, pela H1 os critérios do R² e ECM evidenciam que a DVA agrega maior valor às firmas do NM da BM\&F, já no período de 2009 a 2014, após adoção da Lei 11.638/07, pela H2 os critérios AIC e BIC mostram que as evidenciações trazidas pela DVA das empresas do NM da BM\&F acrescem relevância de valor em relação ao período anterior à adoção da referida Lei. Conclui-se destacando a inovação deste trabalho, que apresenta duas metodologias de valoração das firmas adequadas à utilização de modelos aninhados (nested) e não-aninhados (nonnested).

Palavras-chave: Demonstração do Valor Adicionado. Valor de mercado. Modelo de Ohlson. Dados em painel. 


\section{INTRODUÇÃO}

Em vista da adoção das International Financial Reporting Standards (IFRS) pelo Brasil, consubstanciada inicialmente pela Lei n. 11638/07, produziram-se modificações normativas importantes na contabilidade brasileira a partir de 2008, entre elas a obrigatoriedade da elaboração e publicação da Demonstração do Valor Adicionado (DVA) pelas empresas listadas na BM\&FBOVESPA (a partir daqui BM\&F), bem como por aquelas empresas a partir de então consideradas de grande porte. A importância desta demonstração pode ser observada pela definição dada pelo Comitê de Pronunciamentos Contábeis (CPC), que afirma que a DVA "proporciona a investidores e outros usuários, o conhecimento de informações de natureza econômica e social, o que se traduz por uma melhor avaliação das atividades da entidade dentro da sociedade na qual está inserida" (CPC 09, 2008).

O Novo Mercado (a partir daqui NM) foi lançado pela BM\&F como segmento de listagem em 2002 e desde então exige das empresas o mais alto nível de governança corporativa, o que permite melhor proteção aos acionistas em geral, inclusive com tag along de 100\%, e maior grau de disclosure, sendo uma de suas características mais importantes a condição única de emissão de ações ordinárias (ON) com direito a voto (SROUR, 2005). Várias destas empresas já elaboravam e publicavam a DVA sem aquela exigência legal, estando este disclosure voluntário dentro da proatividade habitual esperada das empresas do NM, em tese motivada pelos incentivos recebidos pelo administrador para divulgá-la, fato que leva a certo grau de discricionariedade (YAMAMOTO; SALOTTI, 2006 apud MAPURUNGA et al., 2011, p.264).

Justifica-se este estudo pelas ideias expostas, cabendo questionar acerca do impacto informacional da DVA sobre os valores das firmas do NM da BM\&F, no sentido de avaliar a sua existência e qualidade de influência sobre o valor destas empresas, resultado da percepção provocada pelas divulgações contábeis sobre as decisões de mercado. Decorre deste questionamento o objetivo geral deste estudo, que é o de avaliar se o impacto informacional da DVA está significativamente associado ao valor das firmas do NM da BM\&F no período de 2006 a 2014, tendo sido o período escolhido segundo quesito metodológico apresentado mais adiante em seção própria.

Para atingir o objetivo geral foram cumpridas as seguintes etapas: (i) a definição de uma amostra intencional de publicações uniformes e contínuas da DVA das empresas em foco no período estipulado, com base em número adequado de elementos; (ii) estudo, adaptação e aplicação do Modelo de Ohlson (a partir daqui MO) para implementação da comprovação das hipóteses de trabalho e (iii) a inferência por dados em painel quanto ao impacto informacional das publicações da DVA, segundo o objetivo e hipóteses traçadas.

\section{REVISÃO DA LITERATURA}

\subsection{MODELO DE OHLSON}

Em seu trabalho seminal de 1995, James A. Ohlson introduziu uma forma inovadora para se estimar o valor de mercado de uma empresa (OHLSON, 1995). Segundo o modelo, o valor de mercado de uma empresa pode ser calculado através de sua composição de dependência em relação à soma de duas variáveis: (i) ao valor contábil contemporâneo de seu patrimônio líquido; (ii) ao lucro contemporâneo adicionado dos lucros futuros trazidos a valor presente equivalente por uma taxa de juros livre de risco, com as premissas: (i) de que os dividendos futuros são irrelevantes para definir o preço das ações, esta premissa decorre do fato de que, pelo modelo aqui estudado, os dividendos atuais já estão considerados na valoração do patrimônio líquido atual, reduzindo-o em relação ao patrimônio líquido do período passado; (ii) que por esta razão, estes mesmos dividendos não alteram o lucro contemporâneo (e são considerados pelo modelo como submetidos a risco neutro), mas alteram negativamente os lucros futuros; (iii) e do mesmo modo, os lucros descontados a valor presente equivalente por uma taxa de juros livre de risco não alteram o valor das ações. (MOGLIANI e MILLER, 1961 apud CUPERTINO e LUSTOSA, 2004).

Uma simplificação do MO delineado no estudo de Ohlson (1995) oferece o valor da firma pela adição do valor contábil contemporâneo de seu patrimônio líquido ao valor atual dos lucros residuais futuros esperados (COELHO; AGUIAR, 2008). Assim, este MO simplificado utilizado como benckmark neste estudo, contém o relacionamento do preço da ação com o valor contábil de seu PL e de seus lucros, além de um termo de estocástico resultante da inferência que por sua vez inclui outras informações de valor relevante das firmas e que é ortogonal às variáveis independentes (OHLSON, 1995; MITRIONE; TANEWSKI; BIRT, 2011; COLLINS; MAYHEW; WEISS, 1997). 


\subsection{DELINEAMENTO DO MODELO DE OHLSON}

Historicamente, os trabalhos empíricos sobre avaliação de empresas costumaram utilizar o fluxo descontado dos dividendos futuros esperados (PLENBORG, 2002). Para consolidar esta afirmação, neste trabalho foi realizada uma pesquisa em artigos integrais da base de dados Science Direct (Elsevier), primeiramente pelas expressões <expected AND future AND dividends>, depois refinadas pela expressão $<$ model of discount of dividends>. Estas expressões foram utilizadas por Cupertino e Lustosa (2004). Esta pesquisa retornou 4.411 resultados, confirmando o intenso uso deste modelo de valoração. Ohlson (1995) adota este esquema como ponto de partida para o desenvolvimento de seu modelo baseado em lucros residuais (ou anormais).

O lucro normal é aquele obtido como o retorno sobre o capital investido no início do período de apuração ao qual se refere, o que equivale ao valor do PL do período anterior multiplicado por uma taxa de juros pelo uso do capital investido. Já o lucro anormal é aquele obtido por uma taxa de retorno que excedesse o custo de capital da firma. Significa dizer que quando o lucro restar positivo após a subtração do custo do uso do capital se estará diante de uma situação de lucro residual anormal. Esta consideração constitui vantagem do M0, porque resolve a diferença entre o valor de mercado e o valor contábil da firma, uma vez que a lucratividade futura passa a ser calculada pelo valor presente equivalente dos lucros residuais líquidos estimados (OHLSON, 1995).

Conforme Mitrione; Tanewski; Birt (2011), vários trabalhos se utilizam do MO para verificar o impacto informacional da relevância de valor das informações contábeis nas decisões tomadas pelos participantes do mercado. 0 MO simplificado tem servido como benchmark para examinar como o valor de mercado se relaciona com a disclosure contábil (MITRIONE; TANEWSKI; BIRT, 2011). Neste trabalho foi realizada uma pesquisa em artigos da base de dados Science Direct (Elsevier), primeiramente pela expressão <ohlson AND model>; em seguida foram aplicados filtros para retirar matérias de outras áreas que não contabilidade ou finanças; ao final, a pesquisa retornou 2.700 resultados, o que demonstra o volumoso acervo de pesquisas que utilizam este modelo em contabilidade ou finanças. Outro aspecto também a ser aproveitado aqui é o de que a divulgação das informações contábeis constitui peça fundamental para a eficiência e funcionamento ótimos de um mercado de capitais (MITRIONE; TANEWSKI; BIRT, 2011). Esta afirmação também foi confirmada por pesquisa na mesma base de dados anterior, agora com as expressões <accounting AND disclosure AND efficient market AND relevance AND reliability>, pesquisa esta que retornou 676 resultados, confirmando assim o encadeamento dos temas em larga escala e em estudos relevantes. Alguns estudos merecem destaque, conforme Quadro 1.

QUADRO 1 - Estudos com a aplicação do Modelo de Ohlson.

\begin{tabular}{|c|c|l|}
\hline \multicolumn{2}{|c|}{$\begin{array}{c}\text { Ano do } \\
\text { estudo }\end{array}$} & \multicolumn{1}{c|}{ Abordagem } \\
\hline $\begin{array}{c}\text { Hanlon, Myers e } \\
\text { Shevlin }\end{array}$ & 2003 & $\begin{array}{l}\text { Examinam o estudo de Harris e Kemsley (J. Account. Res. (1999) p.275) sobre a } \\
\text { taxação dos lucros retidos sobre a distribuição dos dividendos versus o retorno } \\
\text { sobre o capital aplicado pelos sócios (livre de impostos). }\end{array}$ \\
\hline Jeon, Kang e Lee & 2004 & $\begin{array}{l}\text { Estudam a relevância das informações contábeis fornecidas pelas empresas } \\
\text { hoteleiras da Coréia, as quais possuem alto custo de capital. }\end{array}$ \\
\hline Ballas e Hevas & 2005 & $\begin{array}{l}\text { Investigam como o valor das firmas é percebido pelos investidores de quatro países } \\
\text { diferentes, por um lado pela ótica do país, por outro pela ótica do segmento } \\
\text { específico da indústria. }\end{array}$ \\
\hline Loh e Mian & 2006 & $\begin{array}{l}\text { Validam o Modelo de Ohlson (1995) com seus achados, ao fornecerem apoio } \\
\text { empírico quando enfatizam o papel dos ganhos futuros para prever os movimentos } \\
\text { de preços de ações (valor da firma). }\end{array}$ \\
\hline $\begin{array}{c}\text { Tawatnuntachai e } \\
\text { Yaman }\end{array}$ & 2007 & $\begin{array}{l}\text { Mostram que os investidores não reagem significativamente a flutuações } \\
\text { contemporâneas (curto prazo) dos lucros. }\end{array}$ \\
\hline $\begin{array}{c}\text { Dahmash, Durand } \\
\text { e Watson }\end{array}$ & 2009 & $\begin{array}{l}\text { Examinam a relevância e a confiabilidade do goodwill relatado e de ativos intangíveis } \\
\text { identificáveis sob as normas australianas, no período de 1994 a 2003. }\end{array}$ \\
\hline Alali e Foote & 2012 & $\begin{array}{l}\text { Analisam a relevância de valor da informação contábil sob as IFRS na bolsa de } \\
\text { valores de Abu Dabi (Abu Dhabi Stock Exchange-ADX). }\end{array}$ \\
\hline Palea & 2014 & $\begin{array}{l}\text { O trabalho investiga se as demonstrações financeiras do ano de 2006 são úteis para } \\
\text { os investidores do mercado de capitais e em que medida estas demonstrações que } \\
\text { iniciaram a ser elaboradas pelo padrão IFRS em 2005 relevam mais valor do que } \\
\text { aquelas estruturadas segundo os GAAP na Itália. }\end{array}$ \\
\hline
\end{tabular}


No Quadro 1 são apresentados os estudos filtrados dos resultados obtidos conforme anteriormente exposto, numa ordem cronológica que contemplou pelo menos três anos anteriores ao período de tempo aqui analisado até o trabalho de Palea (2014), que se debruça sobre a relevância das informações contábeis segundo o padrão das IFRS e GAAP na Itália, mas somente no ano de 2006, porém análogo ao objeto da presente pesquisa, que abrange o período de 2006 a 2014 .

\section{METODOLOGIA DA PESQUISA}

\subsection{ENQUADRAMENTO METODOLÓGICO}

Conforme Gil (2010), quanto à natureza esta pesquisa define-se como descritiva, uma vez que "tem como objetivo a descrição das características de determinada população através de amostra selecionada", que neste estudo corresponde à dinâmica do valor de mercado das empresas do NM da BM\&F diante do impacto informacional trazido pela DVA. Ainda segundo o mesmo autor, quanto ao objetivo principal esta pesquisa enquadra-se como descritiva, pois a busca de tal dinâmica se refere à sua existência ou não, mas não à explicação dos fatores que a determinam. Ainda é realizado um levantamento bibliográfico da literatura sobre o Modelo de Ohlson, o que empresta o cunho exploratório ao estudo.

Quanto ao fundamento, este estudo utiliza uma abordagem quantitativa alcançada pelo uso de técnicas estatísticas com base em dados em painel. A amostra da população composta de todas as empresas do NM foi filtrada de modo a só incluir aquelas empresas que apresentaram as DVA de forma contínua e uniforme ao longo do período de 2006 a 2014. Este período foi arbitrado por ser o único que permitia uma amostra com um número mínimo de elementos suficiente para robustecer a estatística utilizada, portanto tratou-se de uma amostra intencional, não-probabilística, o que impede a propagação dos resultados para a população (SILVA, 2010). Por sua vez, a coleta de dados é tipificada como secundária, uma vez que os dados foram obtidos das DVA publicadas pelas empresas na BM\&F e, pela mesma razão, a pesquisa conforma-se como documental (BEUREN et al., 2010).

\subsection{PROCEDIMENTOS PARA COLETA E ANÁLISE DOS DADOS}

A população constituiu-se das 128 empresas pertencentes ao segmento do NM listadas na BM\&F em 13 de outubro de 2015. Inicialmente dois critérios de intenções foram determinados: (i) que a amostra deveria conter somente empresas que publicaram a DVA de maneira contínua e uniforme; (ii) que o ano de limite superior seria o de 2014, pois já haveria estas publicações na data de início da pesquisa, e que o ano de limite inferior deveria ser no mínimo o de 2006, pois haveria assim um mínimo de dois anos de análise anteriores a vigência da Lei 11.638/07 para comparar com a dinâmica dos anos seguintes a 2008, ano este em que a Lei passou a vigorar e que exatamente por esta razão não foi considerado no período de análise, pois tratou-se de um ano de acomodação da Lei.

Estabelecidos estes critérios, o levantamento finalizou com uma amostra de 16 empresas no período abrangido entre os anos de 2006 a 2014 (Quadro 2), dispostas num painel fortemente balanceado de um conjunto de 144 observações válidas.

Quadro 2 - Empresas que compuseram a amostra final da pesquisa.

\begin{tabular}{|c|l|c|l|c|l|}
\hline № & \multicolumn{2}{c}{ Razão Social } & № & \multicolumn{2}{c|}{ Razão Social } \\
\hline 1 & BRF-Brasil Foods S.A. & 7 & Grendene S.A. & 13 & Porto Seguro S.A. \\
\hline 2 & $\begin{array}{l}\text { Cia Saneamento de Minas } \\
\text { Gerais - Copasa MG }\end{array}$ & 8 & $\begin{array}{l}\text { M. Dias Branco S.A. Ind. Com. } \\
\text { de Alimentos }\end{array}$ & 14 & $\begin{array}{l}\text { Cia Saneamento Básico do } \\
\text { Estado de São Paulo - Sabesp }\end{array}$ \\
\hline 3 & Cia Hering & 9 & Iochpe Maxion S.A. & 15 & Tractebel Energia S.A. \\
\hline 4 & $\begin{array}{l}\text { EDP - Energias do Brasil } \\
\text { S.A. }\end{array}$ & 10 & Localiza Rent a Car S.A. & 16 & Ultrapar Participações S.A. \\
\hline 5 & Equatorial Energia S.A. & 11 & Indústrias Romi S.A. & & \\
\hline 6 & Eternit S.A. & 12 & Natura Cosméticos S.A. & & \\
\hline
\end{tabular}




\subsection{FORMULAÇÃO DAS HIPÓTESES CONFORME REVISÃO DA LITERATURA}

Aproveita-se neste estudo o MO reduzido como benchmark contra a relevância informacional do acréscimo de outras informações ao modelo. No caso do presente estudo, cabe testar se a publicação da DVA está significativamente associada ao valor das firmas pertencentes ao segmento do Novo Mercado (NM). Além disso, caso se confirme tal associação, a pesquisa também examina se ela é relevante depois da introdução da obrigatoriedade de confecção e publicação da DVA a partir da Lei 11.638/07.

Foram aqui desenvolvidas duas hipóteses de pesquisa, as quais derivam das constatações trazidas anteriormente em relação ao MO. Para tanto, inicialmente é construído um MO simplificado para as 16 empresas do NM que compõem a amostra. Este modelo serve então como benchmark para testar de que forma o valor contábil do PL e os lucros estão significativamente associados ao preço das ações.

Conforme já demonstrado previamente, diversos estudos estendem este MO simplificado pela adição de variáveis contábeis a fim de testar seu impacto no ajuizamento de valor das empresas. 0 raciocínio resultante é o de que se existe alguma associação significativa entre o PL e lucros com o preço das ações, então é possível buscar se há incremento estatístico desta significância na relevância de valor do PL e lucros pela adição da variável DVA ao modelo. Inicialmente neste MO simplificado as variáveis independentes são representadas pelos valores contábeis do PL e dos lucros, enquanto que para a variável dependente, valor da firma, é utilizado como proxy o preço das ações da empresa três meses após o término do ano fiscal. Esta escolha se dá porque as empresas normalmente liberam suas demonstrações financeiras cerca de três meses após o final de seu ano fiscal (AHMED; FALK, 2006), fato confirmado na Lei n. 6.404/76, que pelo art. 132 comanda que anualmente a Assembleia Geral Ordinária (AGO) deverá ser realizada até 4 meses após o fim do exercício social, enquanto que pelo art. 133 exige que os administradores façam tal comunicação à AGO até 30 dias antes do prazo final, desta forma, o prazo limite será o dia 30 de março do ano seguinte ao exercício. Desta forma, a divulgação da DVA, em função do que é mencionado no art. 132 e complementado pelo inciso II do art. 133 da mesma Lei, deverá ocorrer até 90 dias após o encerramento do exercício.

A escolha do preço das ações nessa data serve como referência do verdadeiro valor intrínseco da firma (proxy), já que as taxas de retorno sobre os investimentos não se alteram substancialmente nos meses que sucedem os três meses após o fim do ano fiscal, quando as posições de investimento são tomadas em função da transmissão de novas informações, as quais então provocarão uma reação no preço das ações (OU; PENMAN, 1989).

Assim, duas hipóteses foram formuladas:

H1: a evidenciação da DVA contribui positivamente e significativamente no senso de valor das empresas do NM, no período entre 2006 e 2014.

Para tanto, como variáveis independentes são utilizados os valores do PL e dos lucros das 16 empresas da amostra, no período de 2006 a 2014, mais a variável DVA. Para a variável dependente, valor da firma, é utilizado o preço das ações da empresa três meses após o término do ano fiscal.

H2: Após a adoção das IFRS pela Lei 11.638/07, a evidenciação obrigatória da DVA possui mais relevância de valor se comparada com o período anterior àquela Lei.

Pela segunda hipótese deseja-se identificar se a divulgação das informações trazidas pelas DVA das empresas do NM possui mais relevância de valor em relação ao período anterior à adoção. Para tanto, como variáveis independentes são utilizados os valores do PL e dos lucros, mais a variável DVA das 16 empresas da amostra, mas em dois painéis distintos, um para o período antes da adoção, de 2006 a 2007, e outro para o período após a adoção e vigor da Lei n. 11638/07, de 2009 a 2014. 0 ano de 2008 foi eliminado porque foi considerado um ano de acomodação, já que a Lei determinou este ano como de adequação às novas normas. Para variável dependente, valor da firma, em ambos os painéis continua sendo utilizado o preço das ações da empresa três meses após o término do ano fiscal.

Os modelos desenvolvidos referem-se ao MO simplificado para benchmark e o MO ampliado pela DVA para comprovação da Hipótese 1, sendo este último ainda fracionado em dois períodos para comprovação da 
Hipótese 2. Importante salientar que as variáveis foram escaladas pelo número de ações ordinárias a fim de eliminar o efeito tamanho das empresas (BARTH; CLINCH, 2001).

\section{ANÁLISE DOS RESULTADOS OBTIDOS}

\subsection{O MODELO DE OHLSON SIMPLIFICADO COMO BENCHMARK}

O MO simplificado utilizado como benckmark contém o relacionamento do preço da ação com o valor contábil de seu PL e de seus lucros, bem como um termo que inclui outras informações de valor relevante das firmas:

Equação 1: MO Simplificado como Benchmark

$$
P_{i t 90}=\alpha_{0}+\alpha_{1} V C A+\alpha_{2} L L A+\varepsilon_{i t}
$$

Em que:

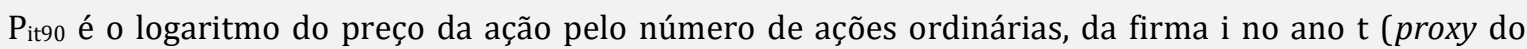
valor da firma);

$\alpha_{0}, \alpha_{1}$ e $\alpha_{2}$ são os parâmetros lineares do modelo;

VCA $A_{i t}$ é a variável independente logaritmo do valor do patrimônio líquido pelo número de ações ordinárias, da firma i no ano t;

LLA $A_{\text {it }}$ é a variável independente logaritmo do valor do lucro líquido pelo número de ações ordinárias, da firma i no ano t;

$\varepsilon_{\text {it }}$ é o termo que contém outras informações de valor relevante da firma i no ano t, ou o termo de erro estocástico NID $\left(0, \sigma^{2}\right)$.

\subsection{MODELO DE OHLSON AMPLIADO PARA COMPROVAÇÃO DAS HIPÓTESES}

O MO agora é ampliado pela inclusão das informações trazidas pela DVA. O modelo testa a Hipótese 1: as evidenciações trazidas pela DVA das empresas do NM no período entre 2006 e 2014 são positivamente associadas ao preço de mercado, e a Hipótese 2: a divulgação destas informações após a adoção das IFRS possuem mais relevância de valor em relação ao período anterior à adoção (período 2006-2007 contra o período 2009-2014).

Equação 2: MO Ampliado

$$
P_{i t 90}=\beta_{0}+\beta_{1} V C A+\beta_{2} L L A+\beta_{3} D V A+\varepsilon_{i t}
$$

Em que:

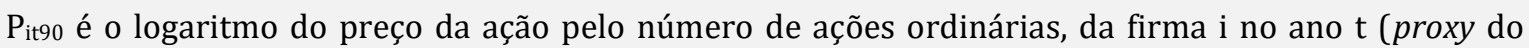
valor da firma);

$\beta_{0}, \beta_{1}, \beta_{2}$ e $\beta_{3}$ são os parâmetros lineares do modelo;

$V_{C A}$ it é a variável independente logaritmo do valor do patrimônio líquido pelo número de ações ordinárias subtraído do logaritmo do valor da DVA pelo número de ações ordinárias, da firma i no ano $\mathrm{t}$;

$L_{L} A_{i t}$ é a variável independente logaritmo do valor do lucro líquido pelo número de ações ordinárias subtraído do logaritmo do valor da DVA pelo número de ações ordinárias, da firma i no ano t;

DVA $_{\text {it }}$ é a variável independente logaritmo do valor da DVA pelo número de ações ordinárias, da firma i no ano t; 
$\varepsilon_{\text {it }}$ é o termo que contém outras informações de valor relevante da firma i no ano t, ou o termo de erro estocástico $\sim \operatorname{NID}\left(0, \sigma^{2}\right)$.

\subsection{ANÁLISE EMPÍRICA}

Primeiramente foram realizados diagnósticos nos dados brutos. Na Tabela 1 são apresentadas as principais estatísticas descritivas.

Tabela 1 - Estatísticas descritivas dos dados brutos.

\begin{tabular}{|c|c|c|c|c|}
\hline Estatísticas & pit90 & vca & lla & dva \\
\hline Média & 25,99064 & 4447971 & 645926,9 & 3013313 \\
\hline Desvio padrão & 18,62495 & 4690136 & 580478,1 & 2755877 \\
\hline Mínimo & 2,283136 & 92222,66 & $-47406,13$ & 308860 \\
\hline Percentil 25 & 11,95228 & 1098168 & 201030,3 & 1141514 \\
\hline Percentil 50 & 22,71358 & 2455127 & 475005,9 & 2009179 \\
\hline Percentil 75 & 36,53305 & 6269910 & 903416,3 & 4069747 \\
\hline Máximo & 103,307 & $1,96 e+07$ & 2462447 & $1,41 \mathrm{e}+07$ \\
\hline Assimetria & 1,382032 & 1,655274 & 1,22734 & 1,868272 \\
\hline Curtose & 5,750118 & 5,092206 & 3,818028 & 7,07997 \\
\hline Variância & 346,8886 & $2,20 \mathrm{e}+13$ & $3,37 e+11$ & $7,59 e+12$ \\
\hline
\end{tabular}

O exame da Tabela 1 mostra que a média está acima da mediana em todas as variáveis, indicador de assimetria positiva, a qual coloca maior inércia à esquerda da função distribuição de probabilidades, onde se concentram então os valores maiores, o que implica não-normalidade da densidade da distribuição, o que segundo Verbeek (2004) torna os valores críticos menores do que aqueles presentes numa aproximação da normal pela distribuição t em uma regressão por mínimos quadrados ordinários (MQO). A problemática de não normalidade confirma-se pela aplicação do Teste W de Shapiro-Wilk (Tabela 2).

Tabela 2 - Teste W de normalidade de Shapiro-Wilk.

\begin{tabular}{|c|c|c|c|c|c|}
\hline Variável & $\mathrm{n}$ o de obs. & $\begin{array}{c}\text { Teste W dos } \\
\text { coeficientes }\end{array}$ & $\begin{array}{c}\text { V: Matr. Cov. } \\
\mathrm{n} \times \mathrm{n}\end{array}$ & Estatística z & Significância \\
\hline pit90 & 144 & 0,89846 & 11,409 & 5,507 & 0,00000 \\
\hline vca & 144 & 0,77193 & 25,626 & 7,338 & 0,00000 \\
\hline lla & 144 & 0,86800 & 14,832 & 6,101 & 0,00000 \\
\hline dva & 144 & 0,81081 & 21,258 & 6,915 & 0,00000 \\
\hline
\end{tabular}

Além disso, todas as curtoses são positivas e acima do valor 3, indicador de rarefação de casos nas caudas e que então a maior parte da variância dos dados está influenciada por desvios de valores extremos (outliers), o que fará com que estes pontos pesem na estimação de MQ0, o que irá modificar as estimações de forma muito significante (BALTAGI, 2008). Quanto aos outliers, Greene (2003) ensina que não se deve descartá-los de uma série temporal em painel, pois estas discrepâncias uma vez remediadas acrescentam poder explicativo ao modelo, ideia ratificada por Tabachnick e Fidell (2007). A fim de resolver a questão de normalidade associada à presença de valores extremos, optou-se pela transformação log-normal (Tabachnick e Fidell, 2007; Greene, 2003). Para eliminar efeitos de escala devidos aos tamanhos diferenciados das firmas entre si, todas as variáveis foram deflacionadas pelo número de ações ordinárias, conforme prescrito por Barth e Clinch (2001). 


\subsubsection{HETEROCEDASTICIDADE}

Conforme Tabachnick e Fidell (2007), do problema anterior costuma resultar o fenômeno da heterocedasticidade. Este fenômeno, neste estudo, se agrava por grandes erros de medição nas variáveis valor do patrimônio líquido (vca) e demonstração do valor adicionado (dva), que em algumas empresas sofrem variações extremas de valor por questões específicas de cada firma. A presença de heterocedasticidade não é necessariamente fatal para uma análise, mas é mais adequado tratá-la para emprestar maior poder de predição aos resultados calculados. Antes de tratá-la, faz-se necessário escolher o modelo que melhor lide com a heterogeneidade intrínseca em dados de painel. Na Tabela 3 segue o resultado do teste de heterocedasticidade modificado de Wald para variáveis agrupadas, o qual ratifica a presença de heterocedasticidade nos dados das 16 empresas. A escolha deste teste se deu pela robustez que apresenta diante da não-normalidade (GREENE, 2003).

Tabela 3 - Teste modificado de Wald para heterocedasticidade em grupo.

$\mathrm{H}_{0}: \sigma_{\mathrm{i}}{ }^{2}=\sigma^{2}$ para $\mathrm{i}=1, \ldots, \mathrm{E}_{\mathrm{n}}{ }^{{ }^{1}}$

${ }^{*}$ Sendo En o número de empresas: unidades transversais (cross sectional)

$\chi^{2}(16)=4,1 \mathrm{e}+05$

Estat. $\chi^{2}=0,0000$

\subsubsection{HETEROGENEIDADE}

A principal característica de dados agrupados em painel refere-se à heterogeneidade temporal não observável e intrínseca entre os indivíduos recolhidos em dados de painel, além da dependência existente entre as seções transversais. Estas duas situações são então possíveis de serem controladas através da escolha de um modelo adequado em painel (BALTAGI; MOSCONE, 2010). No trabalho de modelagem foram seguidos os ensinamentos de Greene (2003), que em seu capítulo 13 Models for Panel Data indica as principais considerações para escolha entre os modelos teóricos. Neste trabalho a escolha recaiu sobre o modelo de Efeitos Fixos, cuja melhor razão para a escolha é a de que o Modelo de Ohlson pressupõe a existência de outras informações, as quais não são observáveis, mas que segundo premissa do próprio MO correlacionam-se com as variáveis independentes do modelo simplificado. Para validar a escolha, alguns testes foram realizados conforme demonstrado a seguir.

a) Teste de Hausman, pelo qual são comparados os modelos de Efeitos Fixos e Efeitos Aleatórios entre si. 0 resultado do teste é apresentado na Tabela 4 e por ela se percebe que a estatística do Teste de Hausman revela que o uso de Efeitos Fixos é válido para modelar este estudo.

Tabela 4 - Teste de Hausman entre Efeitos Fixos e Efeitos Aleatórios.

\begin{tabular}{|c|c|c|c|c|}
\hline & $\begin{array}{c}\text { (b) } \\
\text { E_Fixos }\end{array}$ & $\begin{array}{c}\text { (B) } \\
\text { E_Aleatórios }\end{array}$ & $\begin{array}{c}(\mathrm{b}-\mathrm{B}) \\
\text { Diferença }\end{array}$ & $\begin{array}{c}\operatorname{raiz}\left(\operatorname{diag}\left(V_{-} b-V_{-} B\right)\right. \\
\text { Desvio padrão }\end{array}$ \\
\hline vca & $2,72 \mathrm{e}-06$ & $1,69 \mathrm{e}-06$ & $1,03 e-06$ & $3,84 \mathrm{e}-07$ \\
\hline lla & 0,000023 & 0,0000204 & $2,63 e-06$ & $1,15 e-06$ \\
\hline dva & $-3,45 e-06$ & $-2,34 e-06$ & $-1,10 \mathrm{e}-06$ & $5,80 \mathrm{e}-07$ \\
\hline
\end{tabular}

Observações:

$\mathrm{b}=$ consistente sob $\mathrm{H}_{0}$ e $\mathrm{H}_{\mathrm{a}}$; obtido por Efeitos Fixos

$\mathrm{B}=$ inconsistente sob $\mathrm{H}_{\mathrm{a}}$, eficiente sob $\mathrm{H}_{0}$; obtido por Efeitos Aleatórios

Teste de $\mathrm{H}_{0}$ : diferença nos coeficientes é não sistemática

$\left.\chi^{2}(3)=(b-B)^{\prime}\left[\left(V_{-} b-V_{-} B\right)^{-1}\right)\right](b-B)$

$\chi^{2}(3)=9,53$

Estat. $\chi^{2}=0,0230$ 
b) Teste de parâmetros das variáveis temporais do tipo dummy, a fim de verificar a significância conjunta de seus coeficientes sobre o preço das ações. 0 resultado trazido na Tabela 5 demonstra que, conjuntamente, as dummies temporais influenciam o valor da empresa e assim reafirmam a validade do modelo de Efeitos Fixos para tratamento do problema em estudo (GREENE, 2003).

Tabela 5 - Teste conjunto de significância das dummies temporais em Efeitos Fixos

\begin{tabular}{|c|c|}
\hline$(1$ & Dummy ano $2007=0$ \\
\hline (2 & Dummy ano $2008=0$ \\
\hline$(3$ & Dummy ano $2009=0$ \\
\hline$(4$ & Dummy ano $2010=0$ \\
\hline$(5$ & Dummy ano $2011=0$ \\
\hline$(6$ & Dummy ano $2012=0$ \\
\hline$(7$ & Dummy ano $2013=0$ \\
\hline$(\varepsilon$ & Dummy ano $2014=0$ \\
\hline \multicolumn{2}{|c|}{$\mathrm{F}(8, \quad 117)=5,50$} \\
\hline
\end{tabular}

c) Teste para verificar se os regressores são estritamente exógenos dentro de cada seção transversal, isto é, se não há cross-sectional dependence, o que também costuma ser chamado de correlação contemporânea. A Tabela 6 mostra o resultado do Teste de Pesaran (2004), pela qual se vê que o teste rechaça a possibilidade de existência de correlação. A escolha do teste se justifica por se adaptar ao caso presente em que se têm N e T não largos (SARAFIDIS et al, 2006).

Tabela 6 - Teste de Pesaran de independência cross-sectional.

\begin{tabular}{|l|c|c|c|c|c|c|}
\multicolumn{2}{r}{ pit90 } & Coeficientes & $\begin{array}{c}\text { Desvio } \\
\text { Padrão }\end{array}$ & $t$ & P>t & \multicolumn{2}{c|}{$\begin{array}{c}\text { Intervalos dos } \\
\text { Coeficientes a } \\
\text { 95\% de significância }\end{array}$} \\
\cline { 3 - 8 } & & & & & & \\
\hline constante & $-10,98184$ & 0,1871378 & $-58,68$ & 0,000 & $-11,35245$ & $-10,61122$ \\
\hline vca & 0,0777781 & 0,1696202 & 0,46 & 0,647 & $-0,2581458$ & 0,4137021 \\
\hline lla & 0,2131892 & 0,052362 & 4,07 & 0,000 & 0,109489 & 0,3168894 \\
\hline dva & 0,6713334 & 0,1758458 & 3,82 & 0,000 & 0,3230799 & 1,019587 \\
\hline 2007 & $-0,2189931$ & 0,1280654 & $-1,71$ & 0,090 & $-0,47262$ & 0,0346338 \\
\hline 2008 & $-0,752394$ & 0,1258604 & $-5,98$ & 0,000 & $-1,001654$ & $-0,5031341$ \\
\hline 2009 & $-0,187424$ & 0,1323871 & $-1,42$ & 0,160 & $-0,4496098$ & 0,0747617 \\
\hline 2010 & $-0,1800665$ & 0,1318911 & $-1,37$ & 0,175 & $-0,44127$ & 0,081137 \\
\hline 2011 & 0,0040287 & 0,1301226 & 0,03 & 0,975 & $-0,2536722$ & 0,2617297 \\
\hline 2012 & 0,095132 & 0,1320112 & 0,72 & 0,473 & $-0,1663092$ & 0,3565735 \\
\hline 2013 & $-0,027669$ & 0,1293875 & $-0,21$ & 0,831 & $-0,2839134$ & 0,2285771 \\
\hline 2014 & $-0,246329$ & 0,1306825 & $-1,88$ & 0,062 & $-0,5051316$ & 0,0124881 \\
\hline
\end{tabular}

$\mathrm{R}^{2}$ : within $=0,7748$ Estat. $\mathrm{F}=0,0000$

Teste de Pesaran de independência cross-sectional $=-1,669$ Prob $=0,0951$

Valor absoluto da média dos elementos da matriz $=0,395$ 


\subsubsection{TESTE DA HIPÓTESE 1}

A Tabela 7 apresenta o coeficiente $\mathrm{R}^{2}$ dos efeitos fixos no modelo aumentado em relação ao benchmark.

Tabela 7 - Equação 1 (Benchmark).

\begin{tabular}{|c|c|c|c|c|c|c|}
\hline pit90 & Coeficientes & $\begin{array}{c}\text { Desvio } \\
\text { Padrão } \\
\text { (Jackknife) }\end{array}$ & $\mathrm{t}$ & $\mathrm{P}>\mathrm{t}$ & \multicolumn{2}{|c|}{$\begin{array}{c}\text { Intervalos dos } \\
\text { Coeficientes a } \\
95 \% \text { de significância }\end{array}$} \\
\hline constante & $-11,05657$ & 0,0589142 & $-187,67$ & 0,0000 & $-11,17216$ & $-10,94099$ \\
\hline vca & 0,6016847 & 0,0258233 & 23,30 & 0,0000 & 0,2920768 & 0,3646846 \\
\hline lla & 0,3283807 & 0,0185041 & 17,75 & 0,0000 & $-11,17216$ & $-10,94099$ \\
\hline
\end{tabular}

$\mathrm{R}^{2}$ : within $=0,7094$

Estat. $\mathrm{F}=0,0000$

Por sua vez, a Tabela 8 apresenta o coeficiente $\mathrm{R}^{2}$ dos efeitos fixos quando da introdução da DVA no modelo aumentado em relação ao benchmark.

Tabela 8 - Equação 2 (com DVA).

\begin{tabular}{|c|c|c|c|c|c|c|}
\hline pit90 & Coeficientes & $\begin{array}{c}\text { Desvio } \\
\text { Padrão } \\
\text { (Jackknife) }\end{array}$ & $\mathrm{t}$ & $\mathrm{P}>\mathrm{t}$ & \multicolumn{2}{|c|}{$\begin{array}{c}\text { Intervalos dos } \\
\text { Coeficientes a } \\
\text { 95\% de significância }\end{array}$} \\
\hline constante & $-11,05054$ & 0,0577347 & $-191,40$ & 0,000 & $-11,16381$ & $-10,93727$ \\
\hline vca & 0,1889774 & 0,0630636 & 3,00 & 0,003 & 0,0652508 & 0,3127041 \\
\hline lla & 0,2667043 & 0,0200819 & 13,28 & 0,000 & 0,227305 & 0,3061036 \\
\hline dva & 0,4757369 & 0,0665865 & 7,14 & 0,000 & 0,3450986 & 0,6063752 \\
\hline
\end{tabular}

$\mathrm{R}^{2}$ : within $=0,7212$

Estat. $\mathrm{F}=0,0000$

Nota-se que os s coeficientes no seu conjunto e em ambas as equações são significativos e assim explicam o modelo.

Comparando os resultados da Tabela 8 com os da Tabela 7, pela Tabela 8 percebe-se aumento no $\mathrm{R}^{2}$ dos efeitos fixos quando da introdução da DVA no modelo aumentado em relação ao benchmark (Tabela 7). Também observa-se que todos os coeficientes das três variáveis Patrimônio Líquido (vca), Lucro líquido (lla) e a própria DVA são significativos, além de ser constatada uma forte participação na explicação do modelo, pois em $72,12 \%$ dos dados as variáveis confirmam o comportamento da pit90. Os sinais em ambas as regressões também são os esperados.

O R quadrado ajustado $\left(\mathrm{R}^{2}\right)$ somente ganha corpo quando a nova variável DVA é introduzida no processo de regressão. Wooldridge (2005) explica que o $\mathrm{R}^{2}$ pode ser usado como critério de escolha entre modelos não-aninhados (nonnested) competidores entre si, uma vez que o $\mathrm{R}^{2}$ considera a variância explicada da variável dependente, não apenas a sua variação, ou seja, como se vê pela Tabela 9, a entrada da DVA no modelo provê maior $\mathrm{R}^{2}$. Pelo EQM pode-se medir a acurácia da bondade da medida das diferenças entre dois modelos, diferenças estas que são chamadas de resíduos. Pela Tabela 9 se percebe a diminuição do tamanho do EQM com o acréscimo da DVA, o que representa maior explicação do comportamento dos valores das ações (pit90).

Tabela 9 - Comparação entre modelos pelo $R^{2}$ (R quadrado ajustado) e EQM.

\begin{tabular}{|c|c|c|}
\hline Varáveis & Sem dva & Com dva \\
\hline Constante & $-11,056573^{* * *}$ & $-11,050541^{* * *}$ \\
\hline Vca & $0,60168469^{* * *}$ & $0,18897743^{* *}$ \\
\hline Lla & $0,3283807^{* * *}$ & $0,26670432^{* * *}$ \\
\hline Dva & & $0,47573691^{* * *}$ \\
\hline Número de observações & 1224 & 1224 \\
\hline $\mathrm{R}^{2}$ : R quadrado & 0,70942572 & 0,72123473 \\
\hline $\mathrm{R}^{2}: \mathrm{R}$ quadrado ajustado & 0,70532973 & 0,7170706 \\
\hline EQM: Erro Quadrático Médio & 0,39152829 & 0,38364896 \\
\hline Log-likelihood & $-579,97218$ & $-554,58083$ \\
\hline
\end{tabular}




\subsubsection{TESTE DA HIPÓTESE 2}

O teste Likelihood-ratio não pode ser utilizado aqui por conta de que ambos os modelos a serem comparados possuem agora o mesmo número de variáveis. Outros testes que se utilizam da estatística $\chi^{2}$ (Qui-quadrado) também não devem ser utilizados porque os tamanhos das duas amostras são diferentes, o que afeta este tipo de estatística cuja base de cálculo utiliza as frequências observadas e esperadas.

Nesta hipótese os modelos são aninhados (nested), o que torna o método comparativo pelos critérios AIC e BIC mais amplo e irrestrito quanto a possíveis vieses relativos a questões de aninhamento. Além disso, estes procedimentos também penalizam o incremento nos graus de liberdade em contrapartida às melhorias introduzidas pela adição da variável, chegando a uma medição equilibrada do ganho de bondade no ajuste do modelo. Assim, optou-se pela aplicação geral deste procedimento nas amostras referentes aos períodos de 2006 a 2007 e 2009 a 2014. Ainda, para maior clareza e visualização os procedimentos foram aplicados tanto para sem a inclusão da DVA, como também com sua inclusão. Os resultados seguem apresentados na Tabela 10.

Tabela 10 - Comparação entre modelos, entre períodos, pelos critérios AIC e BIC.

\begin{tabular}{|c|c|c|c|c|c|c|}
\hline $2006-2007$ & N. de obs. & ll(nulo) & ll(modelo) & gl & AIC & BIC \\
\hline Sem DVA & 272 & $-72,69904$ & $-35,33857$ & 3 & 76,67713 & 87,49454 \\
\hline $2006-2007$ & N. de obs. & ll(nulo) & ll(modelo) & gl & AIC & BIC \\
\hline Com DVA & 272 & $-72,69904$ & $-34,64411$ & 4 & 77,28823 & 91,71143 \\
\hline $2009-2014$ & N. de obs. & ll(nulo) & ll(modelo) & gl & AIC & BIC \\
\hline Sem DVA & 816 & $-372,0558$ & $-106,2731$ & 3 & 218,5463 & 232,6595 \\
\hline $2009-2014$ & N. de obs. & ll(nulo) & ll(modelo) & gl & AIC & BIC \\
\hline Com DVA & 816 & $-372,0558$ & $-92,99082$ & 4 & 193,9816 & 212,7993 \\
\hline
\end{tabular}

O critério menor é melhor aponta maior qualificação da presença da DVA para o período 2009 a 2014, além disso, apesar da diferença algébrica entre os log-likelihood do modelo e do nulo não serem menores para o período 2009 a 2014, é neste período que são apresentados os menores critérios adotados, parâmetros para esta decisão. Por outro lado, faz-se importante lembrar que este teste não é exatamente comparativo, uma vez que as amostras estão separadas por períodos.

\section{CONCLUSÕES}

0 estudo realizado tem como objetivo geral avaliar se o valor gerado pela DVA está significativamente associado ao valor das firmas do NM da BM\&F e sua relevância de valor no período de 2006 a 2014 . Através das pesquisas e testes estatísticos aplicados os objetivos específicos foram alcançados pela comprovação de duas hipóteses.

Inicialmente ocorre uma dificuldade intrínseca ao projeto da pesquisa, pois a busca das hipóteses de trabalho se dá não somente sobre a avaliação de em qual período em separado em relação à Lei 11.638/07 a DVA agrega mais valor à firma, como também procura-se captar em qual dos dois períodos o acréscimo de valor à firma se dá de forma mais substanciosa, o que implica a impossibilidade de utilizar modelo nãoaninhado nesta circunstância em séries temporais. Após aprofundamento do referencial foi possível identificar a aplicação dos critérios AIC e BIC em tal situação e assim chegar a uma conclusão provada.

Pela Hipótese 1 desejava-se buscar se as evidenciações trazidas pelas DVA das empresas do NM no período entre 2006 e 2014 seriam associadas ao preço de mercado daquelas empresas e os resultados mostraram que a evidenciação da DVA contribui positivamente no senso de valor da firma pelo mercado. Os resultados mostram que pelos critérios do $\mathrm{R}^{2}$ e ECM, no período de 2009 a 2014 isoladamente (período posterior à Lei) a evidenciação da DVA agrega maior atribuição de valor às firmas do NM da BM\&F pelo mercado.

Pela Hipótese 2 buscava-se inferir se as evidenciações trazidas pela DVA das empresas do NM da BM\&F conforme a Lei 11.638/07 possuem mais relevância de valor em relação ao período anterior à adoção da referida Lei. A importância desta hipótese reside no fato de que as empresas estudadas já apresentavam a DVA por iniciativa própria. Os resultados mostram que, pelos critérios AIC e BIC aplicados nesta pesquisa 
de forma empírica e inovada, no período de 2009 a 2014 isoladamente (período posterior à Lei) a evidenciação da DVA acresce maior relevância de valor às firmas do NM da BM\&F pelo mercado.

Portanto, os achados trazidos pelos testes das duas hipóteses sugerem que relatórios contábeis da DVA adicionam valor às empresas que os evidenciam, e mais ainda, se tal evidenciação faz-se obrigatória no ordenamento jurídico, tanto mais valor é acrescido. Estas constatações mostram que os investidores buscam sempre maiores informações de cunho contábil e que as leis emprestam maior confiabilidade decorrente do controle legal inerente.

Para outros trabalhos são propostas pesquisas que se debrucem sobre outros relatórios contábeis, bem como outros agrupamentos de empresas, a fim de aferir o comportamento da informação contábil na geração de valor para o mercado.

\section{REFERÊNCIAS}

[1] AHMED, K. e FALK, H. The Value Relevance of Management's Research and Development Reporting Choice: Evidence from Australia. Journal of Accounting and Public Policy, 25, p. 231-264, 2006.

[2] ALALI, Fatima A.; FOOTE, Paul Sheldon. The Value Relevance of International Financial Reporting Standards: Empirical Evidence in an Emerging Market. The International Journal of Accounting, v. 47, n. 1, p. 85-108, 2012.

[3] BALLAS, Apostolos A.; HEVAS, Dimosthenis L. Differences in the valuation of earnings and book value: Regulation effects or industry effects? The International Journal of Accounting, v. 40, n. 4, p. 363-389, 2005.

[4] BALTAGI, Badi H.; MOSCONE, Francesco. Health care expenditure and income in the OECD reconsidered: Evidence from panel data. Economic Modelling, n. 27, p.804-811, 2010.

[5] BALTAGI, Badi H. Econometrics. 4. ed. Berlin: Springer, 2008.

[6] BARTH, Mary E.; CLINCH, Greg. Scale Effects in Capital Markets-Based Accounting Research. Working Paper, funded from the Financial Research Initiative and GSB Trust Faculty Fellowship, Graduate School of Business, Stanford University, 2001.

[7] BEUREN, Ilse Maria et al. Como Elaborar Trabalhos Monográficos em Contabilidade: Teoria e Prática. 3. ed. São Paulo: Atlas, 2010.

[8] BRASIL. Lei n. 6.404 de 15 de dezembro de 1976. Dispõe sobre as Sociedades por Ações.

[9] ____. Lei n. 11.638 de 28 de dezembro de 2007. Dispõe sobre as sociedades por ações e de grande porte.

[10] COELHO, Antônio C. Dias; AGUIAR, Andson Braga de. Relacionamento entre Persistência do Lucro Residual e Participação de Mercado em Firmas Brasileiras de Capital Aberto. Revista de Contabilidade e Organizações, v. 3, n. 2, p.3-18, 18 mai./ago, 2008.

[11] COLLINS, Daniel W.; MAYDEW, Edward L.; WEISS, Ira S. Changes in the value-relevance of earnings and book values over the past forty years. Journal of Accounting and Economics, v. 24, n. 1, p. 39-67, 1997.

[12] CPC. Comitê de Pronunciamentos Contábeis. CPC 09: Demonstração do Valor Adicionado. 2008. Disponível em: <http://www.cpc.org.br/pdf/CPC_09.pdf>. Acesso em: 20 abr. 2016.

[13] CUPERTINO, César Medeiros; LUSTOSA, Paulo Roberto B. The Ohlson Model of Evaluation of Companies: Tutorial for Use. Brazilian Business Review, v. 1, n. 1, 2004. Disponível em: <http://ssrn.com/abstract=704761> Acesso em: 19 de nov. 2015.

[14] DAHMASH, Firas N.; DURAND, Robert B.; WATSON, John. The value relevance and reliability of reported goodwill and identifiable intangible assets. The British Accounting Review, v. 41, n. 2, p. 120-137, 2009.

[15] GIL, Antonio Carlos. Como elaborar projetos de pesquisa. 5. ed. São Paulo: Editora Atlas, 2010.

[16] GREENE, William H. Econometric analysis. 5 ed. New Jersey: Prentice Hall, 2003.

[17] HANLON, Michelle; MYERS, James N.; SHEVLIN, Terry. Dividend taxes and firm valuation: a re-examination. Journal of Accounting and Economics, v. 35, n. 2, p. 119-153, 2003.

[18]JEON, Sungil; KANG, Inwon; LEE, Sangjae. The relationship between persistence of abnormal earnings and usefulness of accounting information in hotel companies. Tourism Management, v. 25, n. 6, p. 735-740, 2004.

[19] LOH, Roger K.; MIAN, G. Mujtaba. Do accurate earnings forecasts facilitate superior investment recommendations? Journal of Financial Economics, v. 80, n. 2, p. 455-483, 2006.

[20] MAPURUNGA, Patrícia Vasconcelos Rocha et al . Determinantes do nível de disclosure de instrumentos financeiros derivativos em firmas brasileiras. Revista Contabilidade e Finanças, São Paulo, v. 22, n. 57, Dec. 2011. 
Disponível em: <http://www.scielo.br/scielo.php?script=sci_arttext\&pid=S1519-70772011000300003 \&lng=en\&nrm=iso>. Acesso em: 12 fev. 2016.

[21] MITRIONE, Lorena; TANEWSKI, George; BIRT, Jacqueline. Value Relevance of Research and Development Expenditure in the Australian Health Care Industry. Working paper n. 193, Accounting and Finance Association of Australia and New Zealand, OpenConf Peer.

[22] OHLSON, J. A. Earnings, Book Values, and Dividends in Equity Valuation. Contemporary Accounting Research, v. 11, p. 661-687, 1995.

[23] OU, Jane A.; PENMAN, Stephen H. Financial statement analysis and the prediction of stock returns. Journal of Accounting and Economics, v. 11, n. 4, p. 295-329, 1989.

[24] PALEA, Vera. Are IFRS value-relevant for separate financial statements? Evidence from the Italian stock market. Journal of International Accounting, Auditing and Taxation, v. 23, n. 1, p.1-17, 2014.

[25] PESARAN, M.H. General Diagnostic Tests for Cross Section Dependence in Panels. Working Paper n. 435. Faculty of Economics, University of Cambridge, 2004. Disponível em: <http://www.econ.cam.ac.uk/ dae/repec/cam/pdf/cwpe0435.pdf> Acesso em: 26 de nov. 2015.

[26] PLENBORG, Thomas. Firm valuation: comparing the residual income and discounted cash flow approaches. Scandinavian Journal of Management, v. 18, p. 303-318, 2002.

[27] SARAFIDIS, V.; YAMAGATA T.; ROBERTSON D. A Test of Cross Section Dependence for a Linear Dynamic Panel Model with Regressors. Working Paper. Faculty of Economics, University of Cambridge, 2006. Disponível em: <http://www.econ.cam.ac.uk/faculty/robertson/HCSDtest14Feb06.pdf> Acesso em: 30 de nov. 2015.

[28] SILVA, Antônio Carlos Ribeiro da. Metodologia da pesquisa aplicada à contabilidade: orientações de estudos, projetos, artigos, relatórios, monografias, dissertações, teses. 3. ed. São Paulo: Editora Atlas, 2010.

[29] SROUR, Gabriel. Práticas diferenciadas de governança corporativa: um estudo sobre a conduta e a performance das firmas brasileiras. Revista Brasileira de Economia Rio de Janeiro, v. 59, n. 4, 2005. Disponível em <http://www.scielo.br/scielo.php?script=sci_arttext\&pid=S0034-71402005000400006\&lng=en\&nrm=iso>. Acesso em: 12 feb. 2016.

[30] TABACHNICK, B.G; FIDELL, L.S. Using Multivariate Statistics. Pearson International. 5. ed. 2007.

[31] TAWATNUNTACHAI, Oranee.; YAMAN, Devrim. Do investors overreact to earnings warnings? Review of Financial Economics, v. 16, n. 2, p. 177-201, 2007.

[32] VERBEEK, Marno. A Guide to modern econometrics. 2. ed. West Sussex: John Wiley \& Sons Ltd, 2004.

[33] WOOLDRIDGE, Jeffrey M. Introductory Econometrics: A Modern Approach. 3. ed. Thomson: South-Western, 2006. 


\section{Capítulo 15}

\section{Análise das provisões nas empresas petrolíferas: BRICS versus NYSE}

\section{Bruno Augusto Dias Gonçalves \\ Maisa de Souza Ribeiro \\ Livia Maria Lopes Stanzani \\ Mariana Simões Ferraz do Amaral Fregonesi}

Resumo: Esta pesquisa teve por objetivo investigar os elementos que compõem as provisões de empresas petrolíferas dos BRICS de forma comparada às maiores empresas deste setor classificadas na Bolsa de Valores de Nova York - NYSE. Formaram-se dois grupos de cinco empresas cada, as quais passaram por análise de conteúdo das notas explicativas sobre passivos. Os resultados demonstraram que as provisões predominantes são as relativas à restauração das áreas exploradas e, com menor expressividade, as de natureza ambiental e relacionadas com pessoal, neste último caso, prioritariamente, vinculadas com planos de benefícios de aposentadoria. Em linhas gerais, observou-se que o BRICS comporta empresas maiores do que as listadas na NYSE; ser grande não implica em ter transparência nas demonstrações financeiras; notou-se, também, que as reversões de provisões estavam presentes, apenas, nas demonstrações das empresas da NYSE. Os dados demonstram ainda que as provisões de recuperação das áreas exploradas oneram, significativamente, os passivos das empresas menores, implicando em maior risco para os nelas envolvidos.

Palavras-chave: provisões contábeis; setor petrolífero; BRICS. 


\section{INTRODUÇÃO}

O setor petrolífero é uma fonte de energia relevante, com forte representatividade na economia, seja por sua essencialidade ou pelas dificuldades e riscos da extração (Machado \& Godoy, 2013; Santos, Marques \& Silva, 2006). Segundo Aguiar e Godoy (2012, p. 351-352), a "atividade de exploração e produção de óleo e gás (E\&P) caracteriza-se por ser tipicamente de capital intensivo, envolver altos riscos e longos prazos de maturação dos investimentos". Tais riscos e particularidades se refletem no montante de passivos deste setor e, portanto, na situação financeira das companhias.

O reconhecimento contábil das obrigações das empresas é fundamental para subsidiar o usuário da informação sobre o grau de comprometimento dos ativos mantidos pela organização, bem como seu fluxo de caixa futuro, principalmente, quando são de ordem relevante. Assim, toda exigibilidade deve ser registrada tão logo seu fato gerador aconteça ou no momento em que o gestor toma conhecimento da sua existência. Este último aspecto pode trazer alguma subjetividade para a informação contábil - "tão logo o gestor tome conhecimento da sua existência". Como nem todos os reconhecimentos de obrigações podem ser embasados em documentações objetivas e emitidas por terceiros, em algumas situações faz-se uso de estimativas pautadas em bases confiáveis. A fragilidade inerente ao uso da estimativa decorre da possibilidade de privilegiar interesses unilaterais, como a redução do grau de endividamento, o aumento do lucro ou a omissão de responsabilidades cuja natureza possa ser comprometedora para a imagem da organização. Com o risco da subjetividade envolvido nesse tipo de reconhecimento, o nível de detalhamento passa a ser fundamental para a transparência do processo de prestação de contas das empresas.

Levitt (1998, p. 80) ressaltou que "investidores tecnicamente preparados precisam de informações úteis e relevantes para tomar as suas decisões de investimento" e, isso é o que as normas de contabilidade têm tentado alcançar com as diretrizes estabelecidas, além de reduzir a assimetria de informações. Neste contexto, empresas que apresentam maior clareza em suas informações contábeis podem atender de forma mais fidedigna a seus investidores, e proporcionar aos mesmos uma informação mais pertinente com a realidade da entidade. 0 elaborador da informação contábil pode atender às normas com distintos níveis de profundidade na informação prestada.

Verrecchia (2001, p. 97-98) acredita que a redução da assimetria é o caminho para que haja integração entre a eficiência das escolhas contábeis, os incentivos para divulgação e a interação entre o mercado de capitais e seus investidores.

Com o crescimento econômico das últimas décadas, países emergentes, como os pertencentes ao BRICS: Brasil, Rússia, Índia, China e África do Sul ganham relevância porque representam alternativas interessantes de investimentos para todo o mundo, e, ainda, porque passam a ter recursos para fortalecer o mercado de capitais local. Logo, sendo a informação contábil a linguagem universal dos negócios, esperase encontrar condições confiáveis e comparáveis nas demonstrações financeiras divulgadas ao público.

O International Accounting Standard Board (IASB), corroborado pelo Comitê de Pronunciamentos Contábeis (CPC), visando promover a convergência das normas contábeis internacionais, tem emitido diretrizes a fim de orientar os procedimentos contábeis para identificar, mensurar e divulgar os eventos e transações de natureza econômica e financeira que afetam as organizações. No caso específico das obrigações para com terceiros, emitiram o IAS 37 - Provisions, Contingent Liabilities and Contingent Assets (IAS 37), traduzido no Brasil pelo CPC 25 - Provisões, Passivos Contingentes e Ativos Contingentes (CPC25).

Mas, antes do IASB, já em 1975, o Financial Accounting Standard Board - FASB já se pronunciava sobre o assunto, tendo emitido seu SFAS 5 sobre provisões e contingências; fortalecendo as discussões sobre o nível de probabilidade que identificam as provisões e as contingências (provável, possível e remoto).

Segundo o International Financial Reporting Standards - IFRS (2016), os países têm convergido às normas contábeis internacionais de maneiras e, em épocas, diferentes. Alguns fizeram a adoção completa aos parâmetros das normas internacionais, como o Brasil, enquanto outros ainda se encontram em transição, como China e Índia. Na Rússia, a adesão às normas internacionais deu-se a partir de 2012. Na Índia, ainda não é obrigatório, no entanto, existe uma propensão para a adoção das Indian Accounting Standards (substancialmente convergentes com o IFRS), de maneira gradativa, a qual se tornou voluntária a partir do ano de 2015 e obrigatório a partir do exercício de 2016-2017. Na China, as normas nacionais são consistentes com as internacionais. Já na África do Sul, as referidas normas internacionais estão vigentes desde 2005 (IFRS, 2016). Diante desse cenário, observa-se que as informações contábeis das empresas 
petrolíferas nesses países podem ter diferenças significativas em função do estágio de adoção da padronização internacional, bem como, da resistência à sua aceitação, como é o caso dos Estados Unidos.

Pesquisas envolvendo empresas petrolíferas já trataram dos aspectos relacionados com a contabilização e evidenciação no setor, com ênfase para as metodologias de avaliação das reservas de petróleo - "método dos esforços bem-sucedidos" e "método do custo total" (Dyckman \& Smith, 1979; Godoy, 2004). Santos et al. (2006) investigaram o custo de abandono nas empresas petrolíferas. Aguiar \& Godoy (2012) analisaram a relação do preço do petróleo com as despesas de impairment. Santos (2012) analisou as características da informação contábil divulgada pelas empresas do setor petrolífero. Machado \& Godoy (2013) estudaram a estrutura de capital das companhias do referido setor. Santos \& Santos (2014) trataram do lobbying no contexto da regulação contábil no setor. Misuno \& Osmundsen (2015) pesquisaram o value relevance em fluxos de caixas e em accruals no setor petrolífero.

Farias (2004) analisou se as empresas do setor químico e petroquímico sediadas no Brasil, no período de 1999 e 2001, estariam divulgando o que as normas recomendavam. Os resultados mostraram que apesar de ser grande o número de empresas que reconheceram passivos contingentes em seus balanços patrimoniais, muitas notas explicativas não informaram vários aspectos descritivos recomendados, como os critérios de avaliação das contingências, sua natureza, a probabilidade de ocorrência e a movimentação do período. Correa, Gonçalves \& Moraes (2015) investigaram provisões em empresas do setor petrolífero, mas se restringiram aos aspectos ambientais, mais especificamente, quais informações ambientais eram mais divulgadas, entre 2011 e 2013. Concluíram que eram as relativas às políticas e às informações financeiras ambientais, referentes à seguro, desmantelamento das áreas exploradas, gastos relacionados com assoreamento de rios e licenças ambientais. Mas, quais outras obrigações das empresas do setor petrolífero são definidas com base em estimativas? Ou seja, qual a composição das provisões das empresas do setor?

Nesse contexto, esta pesquisa pretende investigar os elementos que compõem as obrigações constituídas com base em estimativas e demonstrar se existem semelhanças quanto à natureza e à movimentação na evidenciação de informações sobre provisões das empresas do setor petrolífero dos BRICS e as maiores listadas na Bolsa de Valores de Nova York (NYSE).

A escolha do setor petrolífero se deu em razão da especificidade, alto risco e semelhança na estrutura geral da atividade econômica: grande porte em termos de ativos operacionais e destaque no mercado em função do produto. Desta forma, este estudo se justifica por evidenciar o grau de clareza e detalhamento das empresas de petróleo representantes dos BRICS comparativamente às maiores empresas listadas na NYSE, no que tange às informações contábeis referentes a provisões. A finalidade da comparação é verificar se o grupo de empresas dos países emergentes tem alguma semelhança de comportamento em relação aos mais desenvolvidos, visto que a discussão sobre a necessidade de transparência já está difundida há bastante tempo.

Trata-se de uma pesquisa qualitativa de natureza exploratória e descritiva, que se valeu de análise de conteúdo das notas explicativas de provisões nas demonstrações financeiras das companhias analisadas as maiores de cada país do BRICS e da NYSE.

\section{FUNDAMENTAÇÃO TEÓRICA}

A busca por maior disclosure e clareza nas informações divulgadas tem aumentado com o passar dos anos, resultando em uma tendência contínua de harmonização na divulgação das demonstrações contábeis por todo o mundo. Entre essas informações, aquelas referentes às obrigações mantidas pelas companhias são especialmente relevantes para a tomada de decisão pois estão muito associadas com riscos para a continuidade da companhia.

De acordo com Farias (2004, p. 66), "a divulgação tem como um dos principais objetivos fornecer informações para tomada de decisões, o que pressupõe que os dados sejam relevantes e apropriados". Sendo assim, as notas explicativas referentes às provisões deveriam ser bastante esclarecedoras e objetivas.

\subsection{PROVISÕES}

As provisões são definidas a partir do conceito de passivo. A estrutura conceitual da contabilidade define passivo como "uma obrigação presente da entidade, derivada de eventos passados, cuja liquidação se 
espera que resulte na saída de recursos da entidade capazes de gerar benefícios econômicos" (CPC 00, p. 26). O CPC 25 (2009), que trata especificamente do tema, separa três grandes grupos de passivos: as contas a pagar, dívidas certas e formalmente acordadas; os passivos derivados de apropriações por competência (accruals), obrigações que embora, às vezes seja necessário estimar o valor ou prazo da dívida, a incerteza é geralmente muito pequena; e provisões, obrigações com prazo ou valor incertos.

Segundo Ribeiro, Ribeiro \& Weffort (2013, p. 40), “as provisões são componentes importantes de um sistema contábil e se prestam a atender ao regime de competência dos fatos ocorridos, diferenciando-se do regime de caixa, o qual depende da entrada ou saída de recursos financeiros"; desta forma, as provisões observam os fatos econômicos, independente dos fluxos de caixa envolvidos.

Outra característica importante relacionada às provisões é que a saída de recursos para liquidar a obrigação pode depender de um evento futuro incerto que não está sob o controle da entidade. Assim, passivos que são definidos com base em legislação, ou outra forma de normatização, e não dependem de evento incerto não mais se caracterizam como provisões, mas, sim, como obrigações efetivas, como por exemplo, o valor de férias a pagar, reconhecido pelo regime de competência mensal, com base nos parâmetros da legislação trabalhista.

De acordo com o CPC 25 (2009), uma provisão deve ser contabilizada pela melhor estimativa do desembolso exigido para liquidar a obrigação presente na data do balanço apenas quando todas as seguintes condições forem satisfeitas:

- $\quad$ a entidade tem uma obrigação presente (legal ou não formalizada) como resultado de evento passado;

- Seja provável que será necessária uma saída de recursos que incorporam benefícios econômicos para liquidar a obrigação; e

- $\quad$ possa ser feita uma estimativa confiável do valor da obrigação.

Quando um evento incerto que envolve o risco de desembolso por parte da empresa não atende a essas condições, mas o risco envolvido não é remoto, tal evento não é contabilizado, mas é divulgado como um passivo contingente (CPC 25, 2009). Assim, a empresa deve trazer em nota explicativa o detalhamento das provisões reconhecidas nas informações contábeis e, também, o detalhamento dos passivos contingentes e dos riscos envolvidos para o caixa futuro do negócio.

Tais informações podem ser de fundamental importância no conjunto das demonstrações financeiras da empresa, principalmente, quando envolvem porte e riscos elevados, como o petrolífero. Bertoli e Ribeiro (2006, p. 133) afirmaram, em seu estudo sobre passivo ambiental, que "as Demonstrações Contábeis que não apresentam as devidas provisões, relatam informações distorcidas, com o montante dos passivos subavaliados e o patrimônio líquido e o resultado de cada período superavaliados".

No setor petrolífero e de extração de minerais, é comum a provisão para recuperação da área degradada, assumindo diversas denominações: abandono, descomissionamento, desmantelamento, entre outros. 0 objetivo dessa provisão é o reconhecimento da obrigação de tratamento da área explorada na medida em que as atividades evoluem. Tal prática teve início das normas contábeis americanas e, depois se estendeu para outros como o Brasil; ela decorre da existência de obrigação legal e setorial de restauração dos locais explorados. 0 montante do custo do abandono ou do desmantelamento é relevante por envolver toda a área explorada durante a operação, assim, Santos et al. (2006) o consideram vital para a viabilidade do empreendimento:

[...] o custo de abandono é um componente fundamental em qualquer análise de viabilidade econômica de projetos de exploração e produção de óleo e gás. Tais custos são extremamente elevados e chegam a exceder, em alguns casos, aos investimentos incorridos para a construção da infraestrutura e instalação dos equipamentos necessários à produção (Santos et al., 2006, p. 55).

As estimativas do custo de abandono devem ser consideradas como parte dos custos capitalizados do ativo (poços, equipamentos e instalações), tendo como contrapartida no passivo, o valor correspondente às obrigações futuras do desmantelamento, remoção e restauração dos campos petrolíferos. A evidenciação dessa informação é essencial para que os usuários externos da informação contábil possam avaliar adequadamente a empresa. 


\subsection{DISCLOSURE DAS INFORMAÇÕES}

Segundo Kim (1993), acionistas mais bem informados exigem um nível de divulgação menor, ao passo que os acionistas que não têm acesso as informações privilegiadas que foram divulgadas ou não concordam com a estrutura de divulgação podem exercer pressão sobre o nível de disclosure que está sendo desenvolvido pela organização.

Iudícibus (2006) afirma que as informações contábeis devem ser úteis para o usuário em sua tomada de decisão, proporcionando comparabilidade entre diferentes entidades. Assim, segundo o autor, a divulgação deve apresentar informação quantitativa e qualitativa ordenadamente, a fim de propiciar informação relevante ao usuário. No entanto, ressalta que "ocultar ou fornecer informação demasiadamente resumida é tão prejudicial quanto fornecer informações em excesso" (Iudícibus, 2006, p. 129). Sendo assim, a qualidade da informação divulgada pelas empresas não deve ser analisada tendo como base a extensão das notas explicativas, mas sim o conteúdo informativo nelas apresentados, de forma objetiva e transparente.

Dantas, Zendersky \& Niyama (2004, p. 3) ressaltam ainda que não basta apenas a divulgação da informação por parte dos gestores, mas esta deve ser apresentada ao usuário juntamente com suas características quantitativas e qualitativas, de maneira a possibilitar a compreensão das atividades envolvidas e os riscos existentes, sempre da forma mais relevante possível. Assim, as informações podem ser expressas de modos diferentes pelas empresas, inclusive dentro mesmo setor econômico. Elas ainda podem ser quantitativas (financeiras ou físicas) e qualitativas. Enquanto a informação quantitativa mensura valores e estabelece parâmetros, a informação qualitativa complementa os relatórios na medida em que aumenta sua compreensibilidade.

De acordo com Hendriksen e Van Breda (2012, p. 516), "a relevância de certos tipos de informação não quantitativa pode ser determinada pela relevância dos dados quantitativos aos quais está relacionada". Deve-se observar que, na atualidade, muitas informações de natureza física têm sido inseridas nas notas explicativas, como volume de produção, de insumos ou de resíduos. Isto surge buscando-se melhorar o entendimento e aproximar a realidade da entidade e usuário da informação contábil.

Sendo assim, esta pesquisa pretendeu visualizar um conjunto de divulgações sobre provisões, do mesmo setor, com a finalidade de identificar o grau de clareza e transparência que se oferece ao público, bem como o comportamento do conjunto em si.

\subsection{BRICS}

A fim de justificar a análise dos países emergentes neste estudo, buscou-se trazer para a pesquisa um pouco da representatividade e importância deste grupo no cenário mundial. O grupo dos BRICS é formando por países que são caracterizados por serem emergentes e abertos e estarem unidos em função de esforços pelo bem comum. Esta denominação se deu em função de apresentarem crescimento econômico considerável nos últimos anos e serem responsáveis pela elevada representatividade de suas economias em âmbito mundial. Em 2014, o PIB conjunto dos cinco países do BRICS era de US\$16,9 trilhões, sendo que a China sozinha foi responsável por US\$10,3 trilhões. Ao passo que os demais países analisados, considerados desenvolvidos, foram responsáveis pelo PIB conjunto de US\$25,8, dos quais atribui-se aos Estados Unidos, US\$ 17,4. Logo, excluindo-se os dois países por estarem muito acima da média de cada grupo, observa-se que o volume do PIB produzido pelos países dos BRICS continua bastante relevante quando comparados aos países desenvolvidos (US\$ 6,6 e US\$ 8,4, respectivamente) (THE WORLD BANK).

A Tabela 1 e a Tabela 2 demonstram por meio da elevação do PIB a importância dos países BRICS versus os não-BRICS. Evidencia-se, entre outros fatores, que os primeiros têm mais oportunidades de crescimento que os demais que já alcançaram patamares de estabilização ou têm custos elevados de ingresso. 
Tabela 1- Crescimento dos BRICS em relação ao ano anterior

\begin{tabular}{|l|c|}
\hline \multicolumn{1}{|l|}{ Ranking PIB-BRICS } & Crescimento em 2014 \\
\hline China & $7,3 \%$ \\
\hline Índia & $7,3 \%$ \\
\hline Rússia & $0,6 \%$ \\
\hline África do Sul & $1,5 \%$ \\
\hline Brasil & $0,1 \%$ \\
\hline
\end{tabular}

Fonte: The World Bank

Tabela 2- Crescimento dos países desenvolvidos em relação ao ano anterior

\begin{tabular}{|l|c|}
\multicolumn{1}{c|}{ Ranking PIB - Países Desenvolvidos } & Crescimento em 2014 \\
\hline Noruega & $2,2 \%$ \\
\hline França & $0,2 \%$ \\
\hline Itália & $(0,4) \%$ \\
\hline Reino Unido & $2,9 \%$ \\
\hline Estados Unidos & $2,4 \%$ \\
\hline
\end{tabular}

Fonte: The World Bank

Fonseca (2012, p.14) afirma que os BRICS estão ficando cada vez mais relevantes, cada um por seus motivos próprios, sejam econômicos, políticos ou estratégicos. Ainda segundo o autor:

[...] a China é vista como um dos motores da economia mundial; a Rússia demonstra grande peso em questão de segurança - devido ao seu grande arsenal nuclear - e em produção de energia; a Índia devido a sua grande influência regional e peso demográfico, a África do Sul destaca-se por ser uma grande produtora de commodities; e o Brasil por ser fundamental em negociações ambientais, sustentabilidade e comércio.

Com o crescimento acelerado, as empresas dos países do BRICS se tornaram muito interessantes para investidores internacionais e aumentou a pressão sobre o nível de disclosure das informações por essas organizações. Nesse contexto, este estudo deverá contribuir apontando pontos fortes e oportunidades de melhorias na divulgação das empresas petrolíferas desses países.

\section{METODOLOGIA}

Para alcançar o objetivo proposto neste estudo, foi realizada pesquisa qualitativa de natureza exploratória e descritiva com base nas demonstrações financeiras das maiores companhias de petróleo dos países do BRICS e das cinco maiores listadas na Bolsa de Valores de Nova York - NYSE. Em ambos os casos, o porte foi definido em função do valor dos ativos. Cada país foi representado por sua maior empresa, quando havia mais de uma. 0 número de cinco países, cujas empresas estivessem na NYSE, foi definido em função de ser esta a quantidade de empresas representantes do grupo BRICS.

Das referidas demonstrações foram extraídas as informações referentes às provisões. Com a finalidade de torná-las comparáveis, todas foram transformadas em dólares de acordo com a taxa cambial do dia 31 de dezembro de 2014, obtida por meio do site do Banco Central do Brasil. É importante destacar que duas das empresas do BRICS não encerram suas demonstrações contábeis em 31 de dezembro, mas sim, em 30 de junho e 31 de março, respectivamente, Sasol e ONGC.

A amostra dos países do BRICS é composta pelas cinco empresas de maior volume de ativos por país, identificadas no ranking da Platts Top 250 Global Energy Company Rankings ${ }^{\text {TM }}$, que é uma empresa provedora de avaliações de preços de mercado e de desempenho das maiores empresas de energia ao redor do mundo. A amostra utilizada representa, aproximadamente, $2 \%$ da população total das 250 empresas do ranking. As informações sobre as provisões foram obtidas nas respectivas demonstrações financeiras referentes ao ano de 2014. As empresas que compõem a amostra são Sasol, ONGC, GazProm, PetroChina e Petrobras.

As maiores empresas petrolíferas, que serviram de base para comparação, foram selecionadas entre as maiores petrolíferas mundiais dos primeiros cinco e distintos países classificados na Bolsa de Valores de Nova York, por valor de mercado. Foram excluídas, entretanto, empresas situadas em países que compunham o BRICS (Petrochina e China Petroleum e Chemical Corporation) e, as empresas americanas 
que não tinham a primeira maior classificação, como a Chevron e a Occidental Petroleum Corporation. Além disso, as empresas que pertenciam ao setor de energia, mas que não se limitavam a produção petrolífera, também foram excluídas. Sendo assim, as empresas selecionadas, em ordem de classificação, foram: Exxon Mobil (EUA); TotalFinaElf S.A (França); British Petroleum (Reino Unido); ENI S.p.A (Itália) e Statoil (Noruega).

Considerando-se que nem todos os países adotaram as normas internacionais de contabilidade ou não tiveram tempo de proceder a todas as adaptações, optou-se por restringir a investigação a dois requisitos de informação que poderiam subsidiar adequadamente potenciais usuários - a natureza e a movimentação das provisões -, além da materialidade das provisões em relação ao total das obrigações das companhias. Os dados foram analisados por meio de estatística descritiva e os resultados estão apresentados a seguir.

\section{RESULTADOS}

\subsection{CARACTERIZAÇÃO DA AMOSTRA CONSIDERANDO O PORTE}

O objetivo da classificação das empresas por porte é demonstrar a grandeza dos grupos empresariais envolvidos bem como a existência de heterogeneidade dentro dos próprios grupos. A Tabela 3 apresenta a classificação por volume de valor de ativos.

Tabela 3- Relação das empresas e respectivos portes, representados por ativo

\begin{tabular}{|c|c|c|c|c|c|}
\hline Empresa & $\begin{array}{c}\text { BRICS } \\
\text { País }\end{array}$ & $\begin{array}{c}\text { Ativo em milhões de } \\
\text { dólares }\end{array}$ & Empresa & $\begin{array}{l}\text { NYSE } \\
\text { País }\end{array}$ & $\begin{array}{c}\text { Ativo em milhões } \\
\text { de dólares }\end{array}$ \\
\hline Petrochina & China & $387.650,09$ & Exxon Mobil & EUA & $349.493,00$ \\
\hline Petrobras & Brasil & $298.688,00$ & BP & Reino Unido & $284.305,00$ \\
\hline GazProm & Rússia & $279.591,59$ & Total & França & $229.798,00$ \\
\hline ONGC & Índia & $51.433,60$ & Eni S.p.A & Itália & $177.597,64$ \\
\hline Sasol & África do Sul & $24.222,29$ & Statoil & Noruega & $132.374,89$ \\
\hline
\end{tabular}

Observa-se que as empresas destaques de cada um dos grupos são aquelas representantes dos países com maior PIB e apresentam significativa diferença em relação às empresas da $2^{\mathrm{a}}$ posição. Relevante observar, também, que o porte da empresa chinesa é maior do que o da americana - tratando-se de países em desenvolvimento versus desenvolvido, o esperado era o inverso. Destacam-se no grupo BRICS, as empresas classificadas em $4^{\underline{a}}$ e $5^{\underline{a}}$ posição com valores de ativos inferior às demais, a Petrochina chega a ser 16 vezes maior do que a empresa Sasol da África do Sul, demonstrando com isso a diversidade dentro do BRICS. De forma geral, observa-se que as três maiores empresas do BRICS são maiores do que as maiores empresas petrolíferas listadas na bolsa da NYSE.

\subsection{CLASSIFICAÇÃO E ANÁLISE DOS PASSIVOS E PROVISÕES}

Para verificar com maior detalhamento as características das provisões e o respectivo impacto no balanço patrimonial, foram analisadas as notas explicativas sobre as provisões de cada uma das companhias, com o objetivo de verificar a relevância dos valores estimados. Assim, observa-se por meio da Tabela 4 que, exceto por uma empresa em cada grupo (Petrobrás e BP), todas as demais mantém seus passivos em ordem compatível com a grandeza dos ativos. Vale ressaltar que a petrolífera brasileira era a mais endividada em 31.12.14, entre outros fatores, pela crise local provocada por problemas administrativos e políticos revelados a partir do ano de referência deste estudo. 
Tabela 4 - Classificação das empresas de acordo com o tamanho de seus passivos.

\begin{tabular}{|c|c|c|c|c|c|}
\hline \multicolumn{3}{|c|}{ BRICS } & \multicolumn{3}{|c|}{ NYSE } \\
\hline Empresa & País & $\begin{array}{l}\text { Passivo em milhões } \\
\text { de dólares }\end{array}$ & Empresa & País & $\begin{array}{c}\text { Passivo em milhões de } \\
\text { dólares }\end{array}$ \\
\hline Petrobras & Brasil & $181.708,09$ & BP & Reino Unido & $171.663,00$ \\
\hline Petrochina & China & $175.207,22$ & Exxon Mobil & EUA & $168.429,00$ \\
\hline GazProm & Rússia & $76.441,42$ & Total & França & $136.267,00$ \\
\hline ONGC & Índia & $23.663,45$ & Eni S.p.A & Itália & $102.032,37$ \\
\hline Sasol & África do Sul & $9.117,58$ & Statoil & Noruega & $81.217,80$ \\
\hline
\end{tabular}

A confrontação das provisões com o passivo total das companhias está exposta na Tabela 5. Observa-se que, embora, o maior volume seja das empresas chinesa (Petrochina) e brasileira (Petrobras), a maior relevância em relação ao total do passivo está na indiana e na africana, ONGC e Sasol, que são as que possuem menor volume de ativos e passivos do grupo do BRICS. Ainda que nominalmente os valores possam ser bem menores do que o das demais, podem representar incertezas significativas para as companhias envolvidas, tornando, com isso, a transparência esperada nas notas explicativas um quesito primordial.

Tabela 5- Análise da dependência do passivo do BRICS.

\begin{tabular}{|l|c|c|c|c|}
\multicolumn{1}{|c|}{ Empresa } & País & Provisões & Passivo Total & Provisões / Passivo (\%) \\
\hline ONGC & Índia & $4.993,64$ & $23.663,45$ & $21,1 \%$ \\
\hline Sasol & África do Sul & $1.867,60$ & $9.117,58$ & $20,5 \%$ \\
\hline Petrochina & China & $17.583,93$ & $175.207,22$ & $10,0 \%$ \\
\hline GazProm & Rússia & $5.630,97$ & $76.441,42$ & $7,4 \%$ \\
\hline Petrobras & Brasil & $9.806,87$ & $181.708,09$ & $5,4 \%$ \\
\hline
\end{tabular}

Para o grupo de referência, a Tabela 6 revela que, embora o maior volume absoluto de provisões esteja na empresa de maior passivo, a maior participação percentual das provisões no conjunto das obrigações para com terceiros está na empresa Statoil (norueguesa) e a Eni (italiana), também as menores empresas analisadas em questão de valor de mercado e ativos. Ressalta-se que a segunda posição em termos de passivo total é da empresa americana (Exxon), todavia, o montante das provisões desta é expressivamente menor em relação às demais, sugerindo menor utilização dos mecanismos de estimativas para definição de obrigações ou uma gestão mais eficiente de seus riscos.

Tabela 6 - Análise da dependência do passivo da NYSE.

\begin{tabular}{|c|c|c|c|c|}
\hline Empresa & País & Provisões & Passivo Total & Provisões/ Passivo (\%) \\
\hline Statoil & Noruega & $18.009,64$ & $81.217,80$ & $22,2 \%$ \\
\hline Eni S.p.A & Itália & $20.906,18$ & $102.032,37$ & $20,5 \%$ \\
\hline BP & Reino Unido & $32.898,00$ & $171.663,00$ & $19,2 \%$ \\
\hline Total & França & $17.545,00$ & $136.267,00$ & $12,9 \%$ \\
\hline Exxon Mobil & EUA & $13.424,00$ & $168.429,00$ & $8,0 \%$ \\
\hline
\end{tabular}

Observa-se nos dois grupos que o volume de provisões não corresponde ao total das obrigações ou porte das empresas, mas, em ambos os grupos, empresas menores se destacaram com maior proporção de provisões dentro do passivo total. Entre outros fatores, o volume de gastos para recuperação da área é expressivo, constituindo, portanto, parte significativa das obrigações destas companhias.

Assim, observou-se que há cifras importantes definidas com base em estimativas, portanto, sujeito a variadas doses de subjetivismo, passa-se a análise da natureza das obrigações estimadas envolvidas.

Analisou-se, ainda, a média da participação das provisões no passivo em cada grupo, informação apresentada na Tabela 7. Constatou-se que a média é relativamente maior nos países da NYSE, o que pode sugerir que estas companhias apresentam um volume maior de provisionamentos e que, apesar da maior 
incerteza com relação às suas obrigações, elas também podem apresentar maior transparência nas informações divulgadas, reduzindo seu risco.

Tabela 7- Média de dependência do passivo.

\begin{tabular}{|c|c|c|}
\hline Dependência do passivo & \multicolumn{1}{c|}{ BRICS } & NYSE \\
\hline Média & $12,63 \%$ & $16,53 \%$ \\
\hline
\end{tabular}

\subsection{NATUREZA DAS PROVISÕES}

Com relação à classificação das provisões apresentadas pelas empresas, foi feita uma segregação quanto à natureza de cada uma delas, a fim de verificar quais as classes de provisões e eventos mais relatados e comuns entre as companhias petrolíferas destes dois grupos analisados. A Tabela 8 e a Tabela 9 sintetizam as informações que foram encontradas.

Tabela 8 - Análise da natureza dos provisionamentos do BRICS (Empresas dos BRICS)

\begin{tabular}{|c|c|c|c|c|c|c|}
\hline Natureza & Sasol & ONGC & Petrochina & GazProm & Petrobras & TOTAL \\
\hline Fiscais & $11 \%$ & $0 \%$ & $0 \%$ & NR & $1 \%$ & $1 \%$ \\
\hline Cíveis & $0 \%$ & $0 \%$ & $0 \%$ & NR & $7 \%$ & $2 \%$ \\
\hline Ambiental & $52 \%$ & $0 \%$ & $0 \%$ & NR & $0 \%$ & $3 \%$ \\
\hline Pessoal & $29 \%$ & $11 \%$ & $100 \%$ & NR & $7 \%$ & $57 \%$ \\
\hline Garantias & $0 \%$ & $0 \%$ & $0 \%$ & NR & $0 \%$ & $0 \%$ \\
\hline Descomissionamento & $0 \%$ & $87 \%$ & $0 \%$ & NR & $84 \%$ & $37 \%$ \\
\hline Outras & $8 \%$ & $2 \%$ & $0 \%$ & NR & $0 \%$ & $1 \%$ \\
\hline Total & $100 \%$ & $100 \%$ & $100 \%$ & NR & $100 \%$ & $100 \%$ \\
\hline
\end{tabular}

Como é possível observar na Tabela 8, quando o foco é o grupo dos BRICS a maior parte dos provisionamentos é relativa a empregados (57\%) e descomissionamento (37\%). Mas fica evidente a heterogeneidade do grupo. A natureza pessoal só é dominante em uma das empresas, 100\% na Petrochina, nas demais, essa natureza não tem representação significativa.

Já o descomissionamento é provisão relevante em duas empresas, ONGC e Petrobras, mas não aparece nas demais. A única das empresas que apresenta a natureza ambiental é a sulafricana Sasol.

Tabela 9 - Análise da natureza dos provisionamentos do grupo NYSE (Empresas da NYSE)

\begin{tabular}{|c|c|c|c|c|c|c|}
\hline Natureza & Exxon & Eni S.p.A & $\mathrm{BP}$ & Statoil & Total & TOTAL \\
\hline Fiscais & $0 \%$ & $15 \%$ & $14 \%$ & $0 \%$ & $6 \%$ & $9 \%$ \\
\hline Cíveis & $0 \%$ & $0 \%$ & $0 \%$ & $0 \%$ & $0 \%$ & $0 \%$ \\
\hline Ambiental & $0 \%$ & $18 \%$ & $19 \%$ & $0 \%$ & $6 \%$ & $11 \%$ \\
\hline Pessoal & $0 \%$ & $9 \%$ & $0 \%$ & $0 \%$ & $0 \%$ & $2 \%$ \\
\hline Garantias & $0 \%$ & $0 \%$ & $0 \%$ & $0 \%$ & $0 \%$ & $0 \%$ \\
\hline Descomissionamento & $100 \%$ & $55 \%$ & $57 \%$ & $87 \%$ & $75 \%$ & $71 \%$ \\
\hline Outras & $0 \%$ & $3 \%$ & $9 \%$ & $13 \%$ & $14 \%$ & $8 \%$ \\
\hline Total & $100 \%$ & $100 \%$ & $100 \%$ & $100 \%$ & $100 \%$ & $100 \%$ \\
\hline
\end{tabular}

Já no grupo da NYSE (Tabela 9) verifica-se que a maior parte das obrigações com provisão é destinada a descomissionamento (71\%). Assim, a restauração do local explorado é regra geral para as empresas analisadas nesse grupo, está presente em diversas empresas, independente do porte ou da localização. A natureza ambiental é mais presente neste grupo, apenas duas das cinco empresas não informaram provisões desta natureza. 
A informação sobre provisão de obrigações com pessoal existe em todos os países dos BRICS e, entre os países desenvolvidos, apenas, na Eni S.p.A. Há de se ressaltar que é bastante recente o entendimento de que obrigações com pessoal, decorrente dos direitos adquiridos em função de serviços prestados não constituem motivo para provisões, mas sim, obrigações líquidas e certas, calculadas de acordo com o contrato de trabalho e as diretrizes da legislação trabalhista. Não houve elementos para identificação, mas pode ser que parte das obrigações trabalhistas identificadas nas várias empresas ainda contenha a prática de tratar qualquer dívida com os empregados como provisões.

A Gazprom não divulga a segregação de suas provisões detalhada por natureza, embora apresente algumas destas informações em forma de texto e divulgue a movimentação do saldo total de provisionamentos.

Quanto às menções sobre provisões fiscais e cíveis, estas existem claramente na Sasol, Petrobrás, Eni S.p.A, BP e Total.

\subsection{MOVIMENTAÇÃO DAS PROVISÕES}

Considerando que a movimentação das provisões pode ser um quesito de alta importância para entender os eventos que afetam as empresas em cada período, como também, para observar a relevância dos valores que compõem o fluxo, avalia-se na sequência as informações fornecidas pelas empresas (Tabela 10 e Tabela 11).

Tabela 10 - Análise das movimentações do período - BRICS (Em milhões de dólares)

\begin{tabular}{|c|c|c|c|c|c|c|}
\hline Movimentações & Sasol & ONGC & $\begin{array}{c}\text { Empresas dos } \\
\text { BRICS } \\
\text { Petrochina }\end{array}$ & GazProm & Petrobras & TOTAL \\
\hline Saldo inicial & 1408,84 & NR & 15228,27 & 4089,42 & 7389,13 & 28115,66 \\
\hline Acréscimos & 618,21 & NR & 2480,51 & 4796,91 & 3306,23 & 11201,86 \\
\hline Baixas & $-209,41$ & NR & $-124,85$ & $-2327,57$ & $-888,49$ & $-3550,32$ \\
\hline Reversão & $-1,47$ & NR & 0,00 & $-927,79$ & 0,00 & $-929,26$ \\
\hline Efeitos conversão & 51,42 & NR & 0,00 & 0,00 & & 51,42 \\
\hline Saldo final & 1867,59 & 4993,64 & 17583,93 & 5630,97 & 9806,87 & \\
\hline
\end{tabular}

Observa-se que, exceto a ONGC (Índia), todas as demais empresas do BRICS forneceram informações sobre a movimentação das contas de provisões, sendo que o destaque especial é da GazProm (Rússia), seja pela expressividade dos valores, como também, da movimentação; foi a companhia com movimentação mais expressiva no período, em todos os quesitos - entradas, saídas e reversão. Com relação à diferença entre saldo inicial e final, as empresas que apresentaram maior diferença de valores no período, representada por novos ingressos, foram Petrobrás e Petrochina. Nota-se que houve pouca movimentação de baixa ou reversão, exceto na GazProm.

Ressalta-se que o montante de passivos e de participação das provisões nestes geram a expectativa de explicações, contudo, não é o que se viu, principalmente, em relação à ONGC, que, como vimos anteriormente, tem expressiva parte de seu passivo definido por estimativas - situação em explicações detalhadas seriam bastante plausíveis. 
Tabela 11 - Análise das movimentações do período- NYSE (Em milhões de dólares)

\begin{tabular}{|l|c|c|c|c|c|c|}
\multicolumn{1}{|c}{ Movimentações } & Exxon & Eni S.p.A & BP & Statoil & Total & \multicolumn{1}{c|}{ TOTAL } \\
\hline Saldo inicial & 12988,00 & 17490,47 & 31960,00 & 15728,24 & 17517,00 & 82695,71 \\
\hline Acréscimos & 2219,00 & 4740,97 & 6268,00 & 4603,06 & 2285,00 & 17897,03 \\
\hline Baixas & $-875,00$ & $-1746,74$ & $-4258,00$ & $-2053,26$ & 0,00 & $-8058,00$ \\
\hline Reversão & 0,00 & $-348,62$ & $-431,00$ & $-1476,20$ & $-1029,00$ & $-3284,82$ \\
\hline Efeitos conversão & $-908,00$ & 770,12 & $-641,00$ & 1207,80 & $-1228,00$ & 108,92 \\
\hline Saldo final & $\mathbf{1 3 4 2 4 , 0 0}$ & $\mathbf{2 0 9 0 6 , 2 0}$ & $\mathbf{3 2 8 9 8 , 0 0}$ & $\mathbf{1 8 0 0 9 , 6 4}$ & $\mathbf{1 7 5 4 5 , 0 0}$ & \\
\hline
\end{tabular}

No caso das empresas dos países desenvolvidos, as movimentações no período não foram significativas frente ao montante de provisionamento existente em cada uma delas (Tabela 11). No grupo, as que apresentaram maior diferença entre o saldo inicial e final foram a Eni e a Statoil, 21 e 15\%, respectivamente, novamente as duas últimas no ranking de porte. Neste grupo, a frequência de baixas e reversões são maiores do que no BRICS. A baixa é representativa da realização das estimativas feita em períodos anteriores; as reversões presentes em todas, exceto a Exxon, é representativa de ajustes de provisões feitas anteriormente; são informações relevantes, principalmente, na medida em que revelam os valores que oneraram resultados de períodos passados.

\section{CONSIDERAÇÕES FINAIS}

O objetivo desta pesquisa foi o de investigar os elementos que compõem as provisões nas empresas petrolíferas do BRICS, tendo como parâmetro de comparação as maiores listadas na Bolsa de Valores de Nova York (NYSE). 0 estudo se deu com base em análise de conteúdo das notas explicativas de provisões obtidas nas demonstrações contábeis das empresas envolvidas, relativas ao ano de 2014.

Observando-se o conjunto de dados dos dois grupos BRICS e NYSE, notamos que a ordem de grandeza de ativos e passivos é coincidente, visto que em ambos os casos apenas as primeiras empresas inverteram suas posições quando confrontado o ranking de ativos e passivos, e as demais mantiveram sua proporcionalidade entre direitos e obrigações exibidos no balanço. Quanto à participação das provisões no total do passivo, esta não obedeceu a uma determinada ordem nos BRICS e na NYSE, porém, os dados mostraram algo interessante. Coincidentemente, as menores empresas com relação a volume de ativos também foram as maiores em quantidade de provisionamentos, evidenciando uma relação de inversão, e de elevada incerteza nas demonstrações contábeis dessas companhias.

Nas empresas pertencentes à NYSE, nota-se que as duas menores companhias com relação ao volume de ativos, Statoil e Eni, são as que apresentam maior volume de provisionamentos em relação a seus passivos e às demais empresas. Enquanto que a maior empresa do grupo, a Exxon Mobil, encontra-se na última classificação, com apenas $8 \%$ de provisionamentos no período. Já no grupo do BRICS foi encontrada esta mesma relação, sendo que as menores empresas em termos de ativos, Sasol e OGNC, foram as que apresentaram maior proporcionalidade de provisionamentos. No entanto, existe uma singularidade neste grupo, a Sasol apresenta seus valores contábeis em uma razão mais de duas vezes menor que a OGNC, apontando para uma maior insegurança da empresa sulafricana com relação às suas provisões do que existe para a empresa indiana.

Assim, a confrontação dos resultados obtidos demonstrou que a evidenciação das provisões nas empresas sediadas em países emergentes (BRICS) ainda é pouco diferenciado entre as diversas naturezas e que os provisionamentos são encontrados em menor volume financeiro, enquanto que nas empresas da NYSE as informações apresentam-se em maior volume financeiro. Constatou-se ainda que a natureza das provisões é apresentada de maneiras diferentes entre esses dois grupos de empresas. Enquanto no BRICS a maior parte dos provisionamentos é referente a pessoal, na NYSE encontrou-se grande quantidade de provisões referentes a questões ambientais - o que era esperado inicialmente devido ao setor que está sendo pesquisado.

Ainda, para sustentar a comparabilidade dos resultados das duas amostras, foi analisada também a média de provisionamentos existente entre os países emergentes e desenvolvidos durante o ano de 2014. Os resultados apontam para um maior volume de provisionamentos dentre os países da NYSE do que no BRICS, indicando um maior nível de incerteza presente no balanço destas companhias, mas sugerindo maior transparência. 
Desta forma, ao final desta última etapa, buscou-se encontrar características que justificassem as semelhanças e diferenças existentes entre países emergentes e desenvolvidos e assim contribuir para a redução da assimetria de informação das demonstrações contábeis no tratamento de provisões e passivos contingentes.

Os resultados demostraram que a heterogeneidade impera entre as companhias analisadas; estar na NYSE não implica ser melhor ou maior sempre, bem como, empresas do BRICS se destacam por comportamento exemplares no que concerne a subsidiar o processo decisório daqueles que estão fora da companhia e, neste caso, há de se ressaltar que as demonstrações contábeis da Petrobras são exemplares. A Petrochina é a maior empresa de petróleo, mesmo em relação às de países desenvolvidos listadas na NYSE, contudo, seu detalhamento sobre suas provisões é paupérrimo. Entre as empresas da NYSE, as que oferecem melhor nível de detalhamento são a italiana e a britânica. Assim, observa-se que as várias discussões sobre melhor informar, de dar mais transparência para os usuários externos não tem sido aplicada de forma adequada pelas companhias analisadas, independente do grupo a que estavam vinculadas. Obviamente, que o período de transição entre o momento atual e a completa implementação de normas internacionais de contabilidade pode melhorar o cenário, mas provavelmente, não no curto prazo.

Observou-se que as provisões existentes em, praticamente, todos os países são as relacionadas com descomissionamento ou recuperação de áreas após o fim da exploração e, com frequência bem menor, provisões ambientais e provisões com pessoal; sobre esta última fica a dúvida sobre a existência de obrigações de valores incertos ou provisões constituídas em base em prática anterior, na qual toda obrigação constituída com base em cálculos internos da companhia recebiam a denominação de provisão, mesmo que baseada em leis e contratos de trabalho. Tais resultados, com a predominância das provisões para descomissionamento e causas ambientais justificam o fato de os estudos anteriores na área petrolífera terem se concentrados nestes temas. Outro aspecto interessante revelado pelo estudo estava na movimentação das provisões durante o período, dado que nas empresas do BRICS elas concentram em novas entradas e, nas empresas da NYSE, além de terem movimentação completa, possuem com frequência, e em valores expressivos, as reversões, que servem para corrigir excessos de estimativas em períodos anteriores, mas, também, poderia atender, não em todos os casos, interesses de gerenciamento de resultados.

\section{REFERÊNCIAS}

[1] Aguiar, J.C.; Godoy, C.R. (2012). Redução ao Valor Recuperável de Ativos: um Estudo nas Empresas do Setor Petrolífero Mundial. In Revista de Educação e Pesquisa em Contabilidade (REPeC), 6(4), pp. 351-366, Brasília. Recuperado em 10 de janeiro, 2016, de www.repec.org.br.

[2] Bertoli A.L; Ribeiro, M.S. (2006). Passivo ambiental: estudo de caso da Petróleo Brasileiro S.A - Petrobrás. A repercussão ambiental nas demonstrações contábeis, em consequência dos acidentes ocorridos. Revista de Administração Contemporânea, 10(2), Curitiba. Recuperado em 10 de janeiro, 2016, de www.anpad.org.br/rac/.

[3] Brasil. (2007). Lei 11.638, de 28 de dezembro de 2007. Altera e revoga dispositivos da Lei no 6.404, de 15 de dezembro de 1976, e da Lei no 6.385, de 7 de dezembro de 1976, e estende às sociedades de grande porte disposições relativas à elaboração e divulgação de demonstrações financeiras. Recuperado em 10 de fevereiro, 2016, de http://www.planalto.gov.br/ccivil_03/_ato2007-2010/2007/lei/l11638.htm.

[4] Comitê de Pronunciamentos Contábeis - CPC. (2011). Pronunciamento Técnico CPC 00 (R1)

[5] Estrutura Conceitual para Elaboração e Divulgação de Relatório Contábil-Financeiro. Recuperado em 5 de julho, 2013, de http://static.cpc.mediagroup.com.br/Documentos/147_CPC00_R1.pdf.

[6] Comitê de Pronunciamentos Contábeis - CPC. (2009). Pronunciamento Técnico CPC 25. Provisões, Passivos Contingentes e Ativos Contingentes. Recuperado em 5 de julho, 2013, de http://www.cpc.org.br/pdf/CPC_25.pdf.

[7] Correa, J. C.; Gonçalves, M.N.; Moraes, R.O. (2015). Disclosure Ambiental das Companhias do Setor de Petróleo, Gás e Biocombustíveis Listadas na BM\&FBovespa: Uma Análise à Luz da Teoria da Legitimidade. Revista de Gestão Ambiental e Sustentabilidade - GeAS, 4 (3). Recuperado em 10 de janeiro, 2016, de www.revistageas.org.br/.

[8] Dantas, J.A.; Zendersky, H.C.; Niyama, J.K. (2004). A dualidade entre os benefícios do disclosure e a relutância das organizações em aumentar o grau de evidenciação. Anais do encontro da associação nacional de pós-graduação e pesquisa em administração, Curitiba, PR, Brasil, 28.

[9] Dyckman, T.R.; Smith, A.J. (1979). Financial, Accounting and Reporting by Oil and Gas Producing Companies. Journal of Accounting and Economics, 1, pp. 45-75. 
[10] Farias, M. R. (2004). Divulgação do passivo: um enfoque sobre o passivo contingente no setor químico e petroquímico. Dissertação de Mestrado em Ciências Contábeis, Faculdade de Economica, Administração e Contabilidade da Universidade de São Paulo, São Paulo, SP, Brasil.

[11] Fonseca Jr, Gelson. (2012). Brics: notas e questões. In: Fundação Alexandre de Gusmão. O Brasil, os BRICS e a Agenda Internacional. Brasília: FUNAG, pp. 13-31. Recuperado em 1 de janeiro, 2013, de http://www.funag.gov.br/biblioteca/dmdocuments/ OBrasileosBrics.pdf.

[12] Godoy, C. R. (2004). Evidenciação Contábil e as Avaliações pelo Fluxo de Caixa Descontado e pela Teoria das Opções: Um Estudo Aplicado à Indústria Petrolífera Mundial. Tese de doutorado em Controladoria e Contabilidade, Faculdade de Economia, Administração e Contabilidade da Universidade de São Paulo, São Paulo, SP, Brasil.

[13] Hendriksen, E. S.; Van Breda, M. F. (2012). Teoria da contabilidade. (5 ed). São Paulo: Atlas.

[14] IFRS. (2016). IFRS application around the world. Jurisdictional profile. Recuperado em 10 de fevereiro, 2016, de http://www.ifrs.org/Use-around-the-world/Pages/Jurisdiction-profiles.aspx

[15] Iudícibus, S. (2006). Teoria da contabilidade. São Paulo: Atlas.

[16] Kim, O (1993). Disagreements among shareholders over a firm's disclosure policy. The Journal of Finance, v. 48, p. 747-760.

[17] Levitt, A. (1998). The importance of high quality accounting standards. Accounting Horizons, 12, pp. 79-82.

[18] Machado, J.H. M.; Godoy, C.R. (2013). Fatores Determinantes da Estrutura de Capital nas Companhias Integradas de Petróleo. Revista de Contabilidade e Controladoria - RC\&C. 5(1), p. 82-98, Curitiba.

[19] Misund, B.; Osmundsen, P. (2015). The Value Relevance of Accounting Figures in the Oil \& Gas Industry: Cash Flow or Accrual? In Petroleum Accounting and Financial Management Journal, 34 (2), pp. 90-110.

[20] Ribeiro, A. C.; Ribeiro, M.S.; Weffort, E.F.J. (2013). Provisões, contingências e o pronunciamento CPC 25: as percepções dos protagonistas envolvidos. Revista Universo

[21] Contábil, 9 (3), pp. 38-54. Recuperado em 10 de janeiro, 2016,

http://proxy.furb.br/ojs/index.php/universocontabil/article/view/3309.

[22] Santos, O. M.; Marques, J.A.V.C.; Silva, P.D.A. (2006). O Custo de Abandono nas Empresas Petrolíferas. Revista de Contabilidade e Finanças - USP, São Paulo, 41, pp. 56 - 71. Recuperado em 1 de janeiro, 2013, http://www.scielo.br/pdf/rcf/v17n41/v17n41a05.pdf.

[23] _ (2012). Lobbying na regulação contábil: evidências do setor petrolífero e qualidade da informação. Tese de doutorado em Controladoria e Contabilidade, Faculdade de Economia, Administração e Contabilidade, Universidade de São Paulo, São Paulo, SP, Brasil.

[24] _ _ Santos, A. (2014). Lobbying na Regulação Contábil: Evidências do Setor Petrolífero. Revista de Contabilidade e Finanças - USP, São Paulo, 25(65), pp. 124-144. Recuperado em 1 de janeiro, 2013, http://www.scielo.br/pdf/rcf/v25n65/1519-7077-rcf-25-650124.pdf.

[25] THE WORLD BANK. GDP at Market Prices (current US\$). Recuperado em 23 de fevereiro, 2016, http://data.worldbank.org/indicator/NY.GDP.MKTP.CD.

[26] _ _ _ GDP Growth (annual \%). Recuperado em 23 de fevereiro, http://data.worldbank.org/indicator/NY.GDP.MKTP.KD.ZG.

[27] Verrecchia, R. (2001). Essays on disclosure. Journal of Accounting and Economics, Amsterdam, 32 (1-3), pp. 97-180. 


\title{
Capítulo 16
}

Aderência aos indicadores da Global Reporting Initiative (GRI) em empresas do setor de alimentos no Brasil e América Latina

\author{
Enio Antunes Rezende \\ Savio de Araújo Almeida
}

Resumo: Os relatórios de sustentabilidade são uma tendência entre empresas que buscam a transparência e comunicação com seus stakeholders. Ao longo dos anos, foram desenvolvidos modelos de relatório na busca pela padronização da divulgação das informações, a exemplo das diretrizes da Global Reporting Initiative (GRI). Entretanto, surgem dúvidas a respeito da evidenciação das informações tal como apresentadas pelas empresas. Este trabalho se propôs a fazer uma análise descritiva e exploratória sobre as práticas de evidenciação ambiental em empresas do setor de alimentos e bebidas no Brasil e América Latina que seguem o modelo da GRI.A base da pesquisa foram os relatórios de sustentabilidade divulgados pelas organizações, se limitando àqueles que seguem a versão GRI-G4 das diretrizes. 0 estudo combinou métodos tanto qualitativos quanto quantitativos. Os procedimentos metodológicos consistiram na análise e classificação das informações tal como apresentadas nos relatórios com o objetivo de obter um índice que representa o nível de aderência aos indicadores de desempenho ambiental propostos pela GRI.Foi possível notar que as empresas, ainda que do mesmo setor, se encontram em diferentes estágios no que se refere às suas práticas de evidenciação ambiental. Os resultados também revelaram uma fragilidade do setor na América Latina no que tange à aderência aos indicadores ambientais, especialmente considerando temas importantes para a região. Por outro lado, foi possível perceber que o Brasil se encontra em uma posição favorável no contexto da América Latina, apresentando uma evolução do cenário à nível nacional nos últimos anos. Dessa forma, os resultados deixaram claro que existe espaço para melhoria da evidenciação de aspectos ambientais nas empresas sob estudo, considerando o modelo GRI-G4, de forma que seja possível fornecer informações com maior qualidade e confiabilidade para os principais interessados.

Palavras-chave: sustentabilidade, relatórios sustentabilidade, indicadores de sustentabilidade, relatório GRI. 


\section{INTRODUÇÃO}

O setor de alimentos e bebidas se configura como um dos mais relevantes para a economia do Brasil e devido a sua base técnica relacionar-se intrinsecamente com o meio ambiente, destacando-se a sua dependência dos recursos naturais; existem importantes questões ambientais a serem consideradas no processo de gestão ambiental das empresas atuantes no setor. (LINS; OUCHI, 2007).

Segundo Camargo (2009), a transparência e inovação em comunicação constituem, hoje, fatores-chave para o processo de decisão do consumidor. Além disso, existe uma pressão crescente dos stakeholders no sentido de que as empresas se tornem mais transparentes e divulguem o seu desempenho relacionado ao meio ambiente e sociedade (DARBY; JENKINS, 2006).

Nesse sentido, deve-se considerar a importância da ampliação da transparência sobre o tema da sustentabilidade dos recursos naturais uma vez que as empresas têm deveres e responsabilidades em relação às partes interessadas, o que necessariamente inclui o fornecimento de informações transparentes e confiáveis (MARTINI; SILVA; MATTOS, 2014). Assim, tem crescido o número de empresas divulgando detalhes sobre suas práticas de sustentabilidade em relatórios disponíveis publicamente (ROCA; SEARCY, 2012).

Destacam-se os esforços em desenvolver modelos que permitem integrar a sustentabilidade aos objetivos do negócio, viabilizando a divulgação de demonstrações relacionadas às ações socioambientais empresariais de forma padronizada. Atualmente, a nível mundial, as diretrizes da Global Reporting Initiative (GRI) constituem o modelo dominante de relatório de sustentabilidade. Entretanto, por se tratar de um modelo de adesão voluntária, surgem dúvidas sobre as informações tal como divulgadas nos relatórios.

A partir desse fato, percebe-se a oportunidade de aproveitar a disponibilidade dos dados das empresas do setor de alimentos e bebidas para avaliar algumas questões relacionadas ao nível de aderência de companhias do Brasil e demais países da América Latina tomando como base o modelo de relatório de sustentabilidade proposto pela Global Reporting Initiative (GRI). Assim, este trabalho se propõe a analisar o nível de aderência em relatórios divulgados por empresas do setor de alimentos e bebidas de países da América Latina aos indicadores ambientais do modelo proposto pela GRI em sua versão G4.

\section{REVISÃO BIBLIOGRÁFICA}

\subsection{INDICADORES E RELATÓRIOS DE SUSTENTABILIDADE}

Atualmente, as empresas vivem sob um processo de definição de padrões e metodologias de se reportar as práticas de sustentabilidade (CNI, 2012). Assim, surgem novas ferramentas de avaliação da relação das empresas para com o meio ambiente, como os relatórios de sustentabilidade. De acordo com Daub (2007), os relatórios de sustentabilidade têm sua origem no final dos anos 90, tendo sido antes precedidos por três tipos de relatórios: anuais (de caráter financeiro), ambientais e sociais.

Segundo o Instituto Ethos (2007), um relatório de sustentabilidade é a melhor maneira de saber o que está sendo feito pelas empresas nas áreas social, ambiental e econômica, além de permitir a comunicação sobre suas principais práticas. Para Lozano (2006), é também uma forma de as empresas comunicarem aos stakeholders os seus esforços empreendidos na busca pelo desenvolvimento sustentável.

Segundo a GRI (2015, p. 3):

0 relato de sustentabilidade auxilia as organizações a estabelecer metas, aferir seu desempenho e gerir mudanças com vistas a tornar suas operações mais sustentáveis. Relatórios de sustentabilidade divulgam informações sobre os impactos de uma organização - sejam positivos ou negativos - sobre o meio ambiente, a sociedade e a economia.

Dentre os tipos de relatório de sustentabilidade mais utilizados pelo mercado, considerando os aspectos ambientais, é possível destacar: Global Reporting Initiative (GRI), Índice de Sustentabilidade Dow Jones (ISDJ), e Índice de Sustentabilidade Empresarial da Bovespa (ISE). Dentre todos, destaca-se a GRI, uma das estruturas mais utilizadas para o desenvolvimento e elaboração de relatórios de sustentabilidade pelas organizações a nível mundial. 


\subsection{GLOBAL REPORTING INITIATIVE (GRI)}

A GRI (Global Reporting Initiative) corresponde ao conjunto de diretrizes para a elaboração de relatórios de sustentabilidade mais conhecido e aplicado no mundo (HALE; HELD, 2011). A GRI tem como objetivo apresentar diretrizes a serem seguidas pelas empresas para elaboração de um relatório de sustentabilidade (SINGH et al., 2009). Sua importância diz respeito à garantia da divulgação consistente e de qualidade de informações relacionadas à sustentabilidade (MARIMON et al., 2012).

A organização GRI foi criada em 1997 através da união da CERES (Coalition for Environmentally Responsible) e PNUMA (Programa das Nações Unidas para o Meio Ambiente) tendo por objetivo melhorar a qualidade, o rigor e a aplicabilidade dos relatórios de sustentabilidade das empresas (GRI, 2015). Ela surge com o objetivo de elevar as práticas no reporte da sustentabilidade a um nível de qualidade tal como apresentado pelos relatórios financeiros. As diretrizes contidas no modelo GRI (atualmente em sua versão G4) ajudam na identificação dos impactos das atividades das empresas sobre o meio ambiente, economia e sociedade. Segundo Campos et al. (2013, p. 5), "essas diretrizes consistem em princípios para a definição do conteúdo do relatório, em orientações para garantir a qualidade das informações relatadas e indicadores de desempenho com o mesmo peso e importância".

O modelo da GRI, atualmente em sua quarta geração, apresenta cada vez mais importância pois permite o estabelecimento de princípios essenciais sobre o desempenho ambiental, social e de governança das empresas (BASSETTO, 2010). Além disso, segundo Leite Filho, Prates e Guimarães (2009), ele também permite a padronização na divulgação das informações de sustentabilidade, importantes para comparações de desempenho, além de facilitar a implementação de um processo de melhoria contínua na empresa.

No contexto de desenvolvimento sustentável, as diretrizes da GRI constituem a ponte entre empresas e governos, permitindo que ambos contribuam positivamente para os Objetivos de Desenvolvimento Sustentável propostos pela ONU, contribuindo para o processo de decisão sustentável necessário para que os objetivos sejam atingidos. Isso é alcançado através do fornecimento de padrões para relatos em sustentabilidade, ajudando na transparência das informações, em um melhor processo de tomada de decisões e na obtenção de melhores e maiores resultados (GRI, 2017).

\section{METODOLOGIA}

\subsection{AMOSTRA}

A pesquisa é baseada em relatórios de sustentabilidade lançados seguindo as diretrizes GRI-G4 por empresas do setor de alimentos de bebidas do Brasil e demais países da América Latina. Foi considerado o ano de 2016, no qual houve a maior aderência à quarta geração das diretrizes como forma de viabilizar a comparação entre as empresas e também obter resultados mais consolidados e relativamente atuais. A amostra é composta por 24 empresas de 7 países distintos. Os relatórios foram obtidos através dos sites das empresas em questão.

\subsection{COLETA E ANÁLISE DOS DADOS}

O foco do trabalho é o desempenho ambiental tal como relatado pelas empresas consideradas e, dessa forma, apenas aspectos (temas) e indicadores referentes à categoria ambiental do relatório serão analisados. Os indicadores relacionados à categoria ambiental do modelo de relatório da GRI foram resumidos no Quadro 1. 
Quadro 1 - Indicadores da categoria ambiental, por Aspecto Material

\begin{tabular}{|c|c|c|}
\hline Aspecto & Indicador & Descrição \\
\hline \multirow{2}{*}{ Materiais } & G4-EN1 & Materiais usados, discriminados por peso ou volume \\
\hline & G4-EN2 & Percentual de materiais usados provenientes de reciclagem \\
\hline \multirow{5}{*}{ Energia } & G4-EN3 & Consumo de energia dentro da organização \\
\hline & G4-EN4 & Consumo de energia fora da organização \\
\hline & G4-EN5 & Intensidade energética \\
\hline & G4-EN6 & Redução do consumo de energia \\
\hline & G4-EN7 & Reduções nos requisitos de energia relacionados a produtos e serviços \\
\hline \multirow{3}{*}{ Água } & G4-EN8 & Total de retirada de água por fonte \\
\hline & G4-EN9 & Fontes hídricas significativamente afetadas por retirada de água \\
\hline & G4-EN10 & Percentual e volume total de água reciclada e reutilizada \\
\hline \multirow{4}{*}{ Biodiversidade } & G4-EN11 & $\begin{array}{l}\text { Unidades operacionais próprias, arrendadas ou administradas dentro ou } \\
\text { nas adjacências de áreas protegidas e áreas de alto valor para a } \\
\text { biodiversidade situadas fora de áreas protegidas }\end{array}$ \\
\hline & G4-EN12 & $\begin{array}{l}\text { Descrição de impactos significativos de atividades, produtos e serviços } \\
\text { sobre a biodiversidade em áreas protegidas e áreas de alto valor para a } \\
\text { biodiversidade situadas fora de áreas protegidas }\end{array}$ \\
\hline & G4-EN13 & Habitats protegidos ou restaurados \\
\hline & G4-EN14 & $\begin{array}{l}\text { Número total de espécies incluídas na lista vermelha da IUCN e em listas } \\
\text { nacionais de conservação com habitats situados em áreas afetadas por } \\
\text { operações da organização, discriminadas por nível de risco de extinção }\end{array}$ \\
\hline \multirow{7}{*}{ Emissões } & G4-EN15 & Emissões diretas de gases de efeito estufa (GEE) (Escopo 1) \\
\hline & G4-EN16 & $\begin{array}{l}\text { Emissões indiretas de gases de efeito estufa (GEE) provenientes da } \\
\text { aquisição de energia } \\
\text { (Escopo 2) }\end{array}$ \\
\hline & G4-EN17 & Outras emissões indiretas de gases de efeito estufa (GEE) (Escopo 3) \\
\hline & G4-EN18 & Intensidade de emissões de gases de efeito estufa (GEE) \\
\hline & G4-EN19 & Redução de emissões de gases de efeito estufa (GEE) \\
\hline & G4-EN20 & Emissões de substâncias que destroem a camada de ozônio (SDO) \\
\hline & G4-EN21 & Emissões de Nox, Sox e outras emissões atmosféricas significativas \\
\hline \multirow{3}{*}{ Efluentes e resíduos } & G4-EN22 & Descarte total de água, discriminado por qualidade e destinação \\
\hline & G4-EN23 & Peso total de resíduos, discriminado por tipo e método de disposição \\
\hline & G4-EN24 & Número total e volume de vazamentos significativos \\
\hline \multirow{2}{*}{ Efluentes e resíduos } & G4-EN25 & $\begin{array}{l}\text { Peso de resíduos transportados, importados, exportados ou tratados } \\
\text { considerados perigosos nos termos da Convenção da Basileia e percentual } \\
\text { de resíduos transportados internacionalmente }\end{array}$ \\
\hline & G4-EN26 & $\begin{array}{l}\text { Identificação, tamanho, status de proteção e valor da biodiversidade de } \\
\text { corpos d'água e habitats relacionados significativamente afetados por } \\
\text { descartes e drenagem de água realizados pela organização }\end{array}$ \\
\hline \multirow[b]{2}{*}{ Produtos e serviços } & G4-EN27 & Extensão da mitigação de impactos ambientais de produtos e serviços \\
\hline & G4-EN28 & $\begin{array}{l}\text { Percentual de produtos e suas embalagens recuperados em relação ao } \\
\text { total de produtos vendidos, discriminado por categoria de produtos }\end{array}$ \\
\hline Conformidade & G4-EN29 & $\begin{array}{l}\text { Valor monetário de multas significativas e número total de sanções não } \\
\text { monetárias aplicadas em decorrência da não conformidade com leis e } \\
\text { regulamentos ambientais }\end{array}$ \\
\hline Transportes & G4-EN30 & $\begin{array}{l}\text { Impactos ambientais significativos decorrentes do transporte de produtos } \\
\text { e outros bens e materiais usados nas operações da organização, bem como } \\
\text { do transporte de seus empregados }\end{array}$ \\
\hline Geral & G4-EN31 & $\begin{array}{l}\text { Total de investimentos e gastos com proteção ambiental, discriminado por } \\
\text { tipo }\end{array}$ \\
\hline \multirow{2}{*}{$\begin{array}{l}\text { Avaliação Ambiental } \\
\text { de Fornecedores }\end{array}$} & G4-EN32 & $\begin{array}{l}\text { Percentual de novos fornecedores selecionados com base em critérios } \\
\text { ambientais }\end{array}$ \\
\hline & G4-EN33 & $\begin{array}{l}\text { Impactos ambientais negativos significativos reais e potenciais na cadeia } \\
\text { de fornecedores e medidas tomadas a esse respeito }\end{array}$ \\
\hline $\begin{array}{l}\text { Mecanismos de } \\
\text { Queixas e } \\
\text { Reclamações } \\
\text { Relacionadas a } \\
\text { Impactos Ambientais }\end{array}$ & G4-EN34 & $\begin{array}{l}\text { Número de queixas e reclamações relacionadas a impactos ambientais } \\
\text { protocoladas, processadas e solucionadas por meio de mecanismo formal }\end{array}$ \\
\hline
\end{tabular}


A etapa de coleta de dados se procedeu com o acesso aos relatórios de sustentabilidade das empresas. Para a análise dos relatórios foi utilizada a metodologia proposta por Dias (2006) a qual busca verificar a aderência aos formalmente chamados de indicadores essenciais estabelecidos pelo GRI considerando companhias brasileiras. Dessa maneira, inicialmente, as informações contidas nos indicadores dos relatórios foram, através de comparação, classificadas conforme o modelo que pode ser visto no Quadro 2.

Quadro 2 - Modelo de classificação das informações dos indicadores

\begin{tabular}{|c|c|c|c|}
\hline Categoria & Sigla & Classificação & Definição \\
\hline \multirow{4}{*}{ 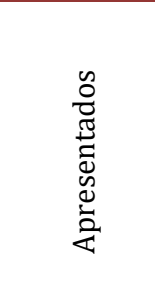 } & APL & Aderência plena & $\begin{array}{l}\text { Todos os dados solicitados pelo indicador foram fornecidos } \\
\text { pela organização, conforme as diretrizes }\end{array}$ \\
\hline & $\mathrm{AP}$ & Aderência parcial & $\begin{array}{l}\text { Apenas parte dos dados solicitados pelas diretrizes foram } \\
\text { apresentados pela organização }\end{array}$ \\
\hline & $\mathrm{D}$ & Dúbio & $\begin{array}{l}\text { As informações fornecidas pela organização não são } \\
\text { suficientes para avaliar se a aderência é plena ou parcial }\end{array}$ \\
\hline & I & Indiferente & $\begin{array}{l}\text { As informações fornecidas pela organização diferem } \\
\text { daquelas solicitadas pelas diretrizes }\end{array}$ \\
\hline \multirow{4}{*}{ 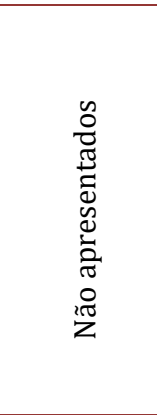 } & ND & Não disponível & $\begin{array}{l}\text { A organização reconhece que a informação solicitada é } \\
\text { pertinente às suas atividades, porém, ela ainda não possui } \\
\text { condições de fornecê-la }\end{array}$ \\
\hline & NA & Não aplicável & $\begin{array}{l}\text { A organização reconhece que os dados solicitados pelo } \\
\text { indicador não são pertinentes às suas atividades ou ao } \\
\text { setor/indústria em que ela atua }\end{array}$ \\
\hline & OJ & $\begin{array}{l}\text { Omitido } \\
\text { justificativa }\end{array}$ & $\begin{array}{l}\text { A organização omite a informação solicitada pelo indicador } \\
\text { por decisão própria, porém, apresentando uma justificativa } \\
\text { para isso }\end{array}$ \\
\hline & 0 & Omitido & $\begin{array}{l}\text { Nada se é comentado pela organização, semelhante a como } \\
\text { se o indicador em questão não existisse }\end{array}$ \\
\hline
\end{tabular}

Fonte: adaptado de Dias (2006).

A metodologia desenvolvida por Dias (2006) e chamada posteriormente de GAPIE (Grau de Aderência Plena aos Indicadores Essenciais) por Carvalho (2007), consiste no cálculo do índice GAPIE obtido através da fórmula contida na Figura 1.

Figura 1 - Cálculo do GAPIE (Grau de Aderência Plena aos Indicadores Essenciais)

$$
\text { GAPIE }=\frac{\text { Total de indicadores APL }+ \text { Total de indicadores OJ }}{\text { Número total de indicadores }- \text { Total de indicadores NA }}
$$

Fonte: adaptado de Dias (2006).

\subsection{ANÁLISE DOS RESULTADOS}

Os índices GAPIE referentes a cada uma das empresas consideradas na pesquisa foram submetidos a análises gráficas e estatísticas para responder às principais questões propostas na pesquisa.

Os índices foram analisados segundo recomendam Castro, Siqueira e Macedo (2011), que propõem níveis de classificação de acordo com o índice GAPIE calculado (Quadro 3).

Quadro 3 - Níveis de classificação do índice GAPIE

\begin{tabular}{|c|c|}
\hline Faixa & Classificação \\
\hline$\left.0\right|_{-} 0,25$ & Baixo \\
\hline $0,\left.25\right|_{-} 0,62$ & Médio \\
\hline $0,\left.62\right|_{-} 1$ & Alto \\
\hline
\end{tabular}

Fonte: adaptado de Castro, Siqueira e Macedo (2011). 
Assim, espera-se obter resultados capazes de responder à principal questão apresentada no estudo, seja ela: existem diferenças nos níveis de aderência aos indicadores ambientais do modelo de relatório de sustentabilidade da GRI considerando empresas do setor de alimentos e bebidas da América Latina?

\section{RESULTADOS E DISCUSSÃO}

A origem dos relatórios de países da América Latina sobre o total de relatórios de sustentabilidade analisados para o ano de 2016 é representada pela Figura 2 abaixo.

Figura 2 - Origem dos relatórios na América Latina (ano 2016)

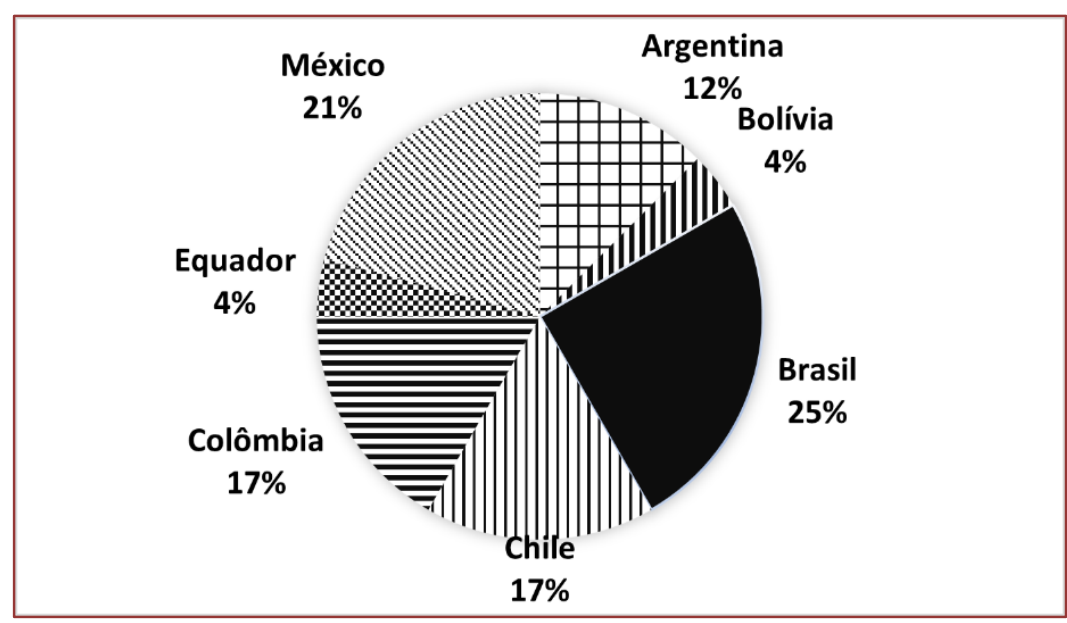

Fonte: elaborado pelos autores.

Assim, com 25\%, o Brasil é o país com o maior número de publicações de relatórios de sustentabilidade seguindo as diretrizes GRI-G4 no ano de 2016. o país é seguido pelo México (21\%) e Colômbia e Chile, empatados com 17\% cada. Analisando anos anteriores, essa é uma tendência que se confirma, com o Brasil sendo o maior responsável pelos relatórios na região com uma média também de $24 \%$ nos últimos 3 anos.

Através da metodologia proposta por Dias (2006), foi calculado o índice GAPIE para cada uma das empresas da América Latina consideradas no ano de 2016. Com base nos resultados obtidos, as empresas foram ranqueadas com base nos índices GAPIE obtidos. Os foram resumidos no Quadro 4 . 0 ranking completo das empresas se encontra no Apêndice A.

Quadro 4 - Ranking das empresas da América Latina com base no GAPIE

\begin{tabular}{|c|c|c|c|}
\hline Posição & País & Empresa & GAPIE \\
\hline $1 \stackrel{0}{0}$ & Argentina & Coca-Cola Andina & 0,7647 \\
\hline $2^{\circ}$ & Brasil & BRF (Brasil Foods) & 0,7647 \\
\hline 3 은 & Chile & $\mathrm{CCU}$ & 0,6764 \\
\hline $4^{\circ}$ & México & Coca-Cola FEMSA & 0,647 \\
\hline $5^{\circ}$ & Colômbia & Riopaila Castilla S.A. & 0,5 \\
\hline $6^{\circ}$ & Brasil & Nestlé Brasil & 0,4706 \\
\hline $7^{\circ}$ & Argentina & Grupo Arcor & 0,4412 \\
\hline $8^{\circ}$ & Equador & Moderna Alimentos & 0,4411 \\
\hline 90 & Brasil & JBS S.A. & 0,3529 \\
\hline $10^{\underline{0}}$ & Chile & Santa Isabel Cencosud & 0,3529 \\
\hline
\end{tabular}


Dessa forma, considerando o índice GAPIE, é possível notar que, com relação à aderência aos indicadores da categoria ambiental, o Brasil obtém os melhores resultados dentre as empresas de mesmo setor consideradas no âmbito da América Latina. Levando em conta apenas os 10 melhores resultados, o Brasil aparece com três empresas (BRF, Nestlé e JBS), seguido pela Argentina e Chile, ambos com duas empresas.

Por outro lado, considerando as médias das empresas em cada um dos países, o Brasil fica atrás da Argentina, com uma média de 0,3970 contra 0,4608, porém, superior à média latino-americana que é de 0,37. Os resultados gerais se encontram na Figura 3.

Figura 3 - Box-plot dos índices GAPIE por país

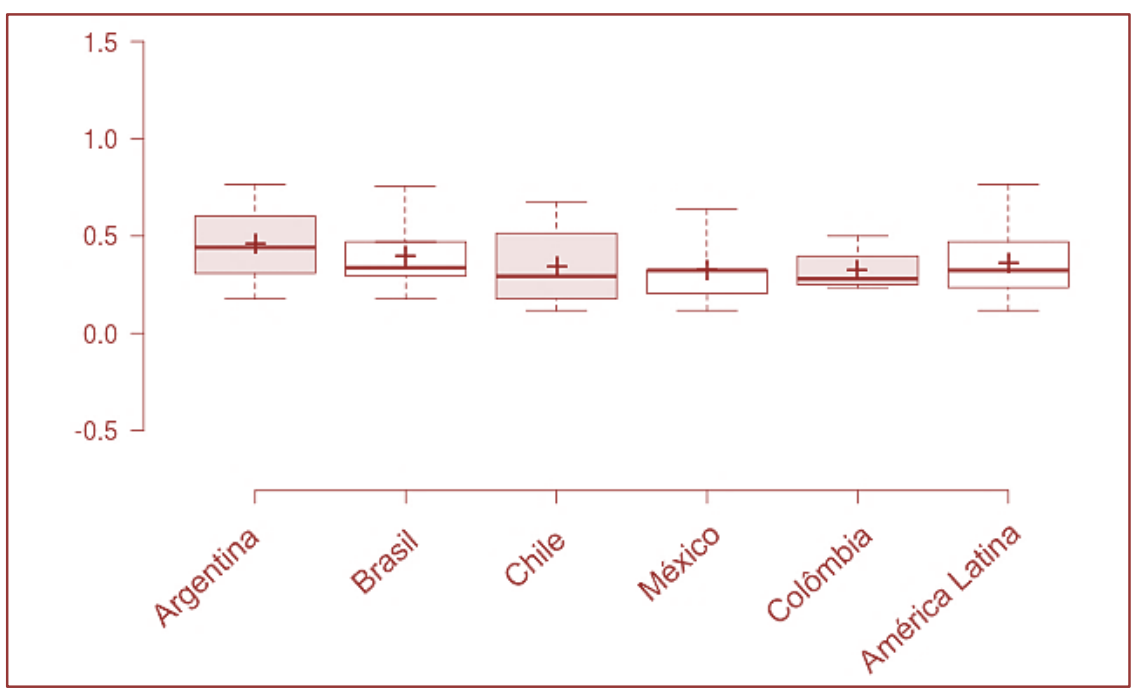

Fonte: elaborado pelos autores.

Analisando a amostra como um todo, o cenário se apresenta da seguinte maneira: do total de empresas analisadas, apenas 8,3\% atingiu um índice GAPIE superior a 0,75; 12,5\% entre 0,5 e 0,75; 45,8\% acima de 0,25 e abaixo de 0,5; e 33,3\% das empresas com índice abaixo de 0,25. Segundo a classificação proposta por Castro, Siqueira e Macedo (2011), do total de empresas analisadas, oito obtém classificação "baixa", doze classificação "média" e apenas quatro empresas recebem, com base no seu nível de evidenciação, a classificação "alta", aproximadamente $16,67 \%$ da amostra.

Muitas empresas não reportaram um grande número de indicadores ou, quando o fizeram, o indicador apresentado não trazia todas as informações necessárias, fato que vai de encontro às recomendações da organização. Além disso, embora a GRI permita a omissão de indicadores, desde que fundamentado, esse recurso foi pouco utilizado pelas empresas, destacando-se o grande número de indicadores omitidos sem qualquer tipo de justificativa como se simplesmente não existissem. Isso, de certa maneira, se reflete nos resultados obtidos - apenas quatro das empresas analisadas atingiram o nível de classificação "alto".

Analisando a diferença entre a primeira e a última empresa no ranking geral, é possível perceber um significativo distanciamento - uma diferença de quase 0,65. Assim, é possível notar que, considerando um mesmo setor, as empresas se encontram em diferentes estágios no que diz respeito aos seus níveis de evidenciação relacionados aos indicadores de desempenho ambiental da GRI estudados, ainda que os produtos resultados de suas operações possam ser diferentes.

\section{CONSIDERAÇÕES FINAIS}

A Global Reporting Initiative (GRI) consiste em uma organização que se propôs a desenvolver diretrizes que permitam a divulgação de informações sobre questões econômicas, ambientais e sociais nas empresas de forma padronizada. Dessa maneira, é possível que as organizações elaborem e divulguem relatórios confiáveis e de alta qualidade, importantes para a comunicação e transparência com os stakeholders bem como sociedade em geral.

No presente estudo, teve-se como objetivo verificar, por parte de empresas do setor de alimentos e 
bebidas da América Latina, a aderência aos indicadores de desempenho ambiental disponibilizados em seus relatórios de sustentabilidade divulgados no ano de 2016 seguindo o modelo da GRI. 0 trabalho limitou-se aos indicadores de desempenho ambiental das diretrizes da GRI.

Pode-se observar entre os resultados desse trabalho que, embora as empresas consideradas façam parte do mesmo setor e da mesma região, elas não se encontram em um mesmo nível ou estágio no que se refere à aderência aos indicadores da GRI, resultados semelhantes aos encontrados por Dias (2006). Também chegaram a conclusões semelhantes os trabalhos de Castro, Siqueira e Macedo (2011), Helou (2015), Nascimento et al. (2011) e Travassos et al. (2014).

Os resultados obtidos também mostram que o Brasil se encontrava em uma posição de relativa vantagem no que se refere ao cenário de relatórios de sustentabilidade no setor, quando comparado a países da mesma região em 2016, tanto na questão da quantidade de relatórios disponibilizados por ano, em relação ao total da região, quanto dos graus de evidenciação da categoria ambiental, tal como representados pelo índice GAPIE.

De modo adicional, a partir da análise do índice GAPIE foi possível perceber que apenas quatro das empresas apresentaram um nível de aderência considerado alto, enquanto que a maioria foi classificada com um grau médio ou baixo.

Já a média do índice GAPIE referente à América Latina encontrada a partir dos relatórios estudados foi considerada média-baixa. Mais do que lacunas na qualidade dos relatórios em sustentabilidade estudados nos contextos brasileiro e latino americano, ressalta-se que a literatura tem apontado a ocorrência falhas de governança e/ou regulação na gestão ambiental de empresas adotantes do GRI ocasionadas pelo caráter voluntário, amplo e relativamente genérico do modelo. (FERREIRA-QUILICE \& CALDANA, 2015).

O debate das causas do nível de aderência encontrado no contexto latino americano foge ao escopo deste trabalho, entretanto alguns autores ressaltam que ao, focar mais na transparência das ações ambientais do que a sua efetiva certificação, o modelo GRI poderia limitar busca da sustentabilidade a longo prazo em alguns casos, considerando tanto a legitimidade quanto a eficácia das práticas de gestão ambiental relatadas. (ROCHA, 2012); (FERREIRA-QUILICE \& CALDANA, 2015); (MASCENA, et al., 2018).

Ou seja, para além das questões referentes ao uso e aderência dos indicadores, percebe-se que ainda existe um caminho longo a ser percorrido na questão dos relatórios de sustentabilidade que seguem as diretrizes da GRI. Espera-se que ocorra no futuro próximo a disponibilização aos stakeholders de versões com melhor abrangência e capacidade de padronização, e que principalmente, incluam o recurso de certificação, dado que a confiabilidade é um atributo-chave na geração de valor do setor de alimentos e bebidas e suas cadeias produtivas relacionadas.

Como agenda de pesquisa, sugere-se o desenvolvimento trabalhos focados no envolvimento de diferentes grupos de stakeholders sobre a qualidade e nível de evidenciação apresentados pelos relatórios de sustentabilidade no setor de alimentos e bebidas.

Cabe destacar ainda as iniciativas de divulgação das informações presentes em relatórios GRI em diferentes desenhos, formatos e plataformas, voltados para outros públicos, além de acionistas, investidores e demais stakeholders especializados.

Entende-se que o avanço na comunicação multimídia da questão ambiental pelas empresas na era digital é aspecto fundamental para o uso dos relatórios não apenas como ferramenta de prestação de contas corporativo, mas também da validação e legitimação dos sistemas de gestão ambientais empresariais. Afinal, qual seria o objetivo principal desses relatórios, senão o aprimoramento constante do desempenho ambiental da empresa e a sua comunicação?

\section{REFERÊNCIAS}

[1] BASSETTO, L. I. A incorporação da responsabilidade social e sustentabilidade: um estudo baseado no relatório de gestão 2005 da companhia paranaense de energia - COPEL. Gestão \& Produção, v. 17, n. 3, p. 639-651, 2010.

[2] CAMARGO, R. Z. Responsabilidade social das empresas: formações discursivas em confronto. 2009. $229 \mathrm{f}$. Tese de Doutorado. Tese (Doutorado em Ciências da Comunicação) - Departamento de Propaganda, Relações Públicas e Turismo Escola de Comunicação e Artes, Universidade de São Paulo, São Paulo, 2009.

[3] CAMPOS, L. M. S. et al. Relatório de sustentabilidade: perfil das organizações brasileiras e estrangeiras segundo o padrão da Global Reporting Initiative. Gest. Prod., São Carlos, v. 20, n. 4, p. 913-926, 2013. 
[4] CARVAlHO, F. M. Análise da utilização dos indicadores essenciais da Global Reporting Initiative nos Relatórios Sociais de empresas latino-americanas. 2007. 133 f. Dissertação (Mestrado em Ciências Contábeis) FACC/UFRJ, Rio de Janeiro, 2007.

[5] CASTRO, F. A. R.; SIQUEIRA, J. R. M; MACEDO, M. A. S. Análise da utilização dos indicadores essenciais da versão "G3", da Global Reporting Initiative, nos relatórios de sustentabilidade das empresas do setor de energia elétrico sul americano. Revista de Informação Contábil, v. 4, n. 4, p. 83-102, 2011.

[6] CNI - CONFEDERAÇÃO NACIONAL DA INDÚSTRIA. Sustentabilidade na indústria da alimentação: uma visão de futuro para a Rio+20. Encontro da Indústria para a Sustentabilidade, Brasília, p. 40, 2012.

[7] DARBY, L.; JENKINS, H. Applying sustainability indicators to the social enterprise business model: The development and application of an indicator set for Newport Wastesavers, Wales. International Journal of Social Economics, v. 33, n. 5/6, p. 411-431, 2006.

[8] DAUB, C. Assessing the quality of sustainability reporting: an alternative methodological approach. Journal of Cleaner Production, v. 15, p. 75-85, 2007.

[9] DIAS, L. N. S. Análise da utilização dos indicadores do Global Reporting Initiative nos relatórios sociais em empresas brasileiras. Dissertação (Mestrado em Ciências Contábeis) - FACC/UFRJ, Rio de Janeiro, 2006.

[10] FERREIRA-QUILICE, T; CALDANA, A. C. F. Aspectos negativos no modelo de reporte proposto pela GRI: a opinião das organizações que reportam. Revista de Administração, v. 50, n. 4, p. 405-415, 2015.

[11] INSTITUTO ETHOS. Guia para Elaboração de Balanço Social e Relatório de Sustentabilidade, 2007. Disponível em < https://www3.ethos.org.br/wp-content/uploads/2012/12/1Vers\%C3\%A3o-2007.pdf>. Acesso em: 29 nov. 2017.

[12] GRI - GLOBAL REPORTING INITIATIVE. G4 Diretrizes para Relato de Sustentabilidade. São Paulo: GRI, 2015.

[13] _. GRI and the Sustainable Development Goals. Disponível em: <https://www.globalreporting.org/information/SDGs/Pages/SDGs.aspx > Acesso em: 02 nov. 2017.

[14] HALE, T; HELD, D. Handbook of transnational governance. Polity, 2011.

[15] HELOU, M. M. Análise do uso do modelo Global Reporting Initiative para elaboração de Relatórios de Sustentabilidade: um estudo em empresas do setor alimentício ao redor do mundo. São Paulo: FGV, 2015.

[16] LEITE FILHO, G. A.; PRATES, L. A.; GUIMARÃES, T. N. Análise dos níveis de evidenciação dos relatórios de sustentabilidade das empresas brasileiras A+ do Global Reporting Initiative (GRI) no ano de 2007. Revista de Contabilidade e Organizações, v. 3, n. 7, p. 43-59, 2009.

[17] LINS, C.; OUCHI, H. C. Sustentabilidade corporativa - Alimentos e Bebidas. Rio de Janeiro: FBDS, 2007.

[18] LOZANO, R. A tool for a graphical assessment of sustainability in universities (GASU). Journal of Cleaner Production, Londres, v. 14, n. 2, p. 963-72. 2006.

[19] MARIMON, F. et al. The worldwide diffusion of the global reporting initiative: what is the point? Journal of Cleaner Production, v. 33, p. 132-144, 2012.

[20] MARTINI, L. C.; SILVA, E. R.; MATTOS, U. A. O. Análise da transparência corporativa por meio dos relatórios de sustentabilidade com base na Global Reporting Initiative de empresas do setor brasileiro de energia elétrica. Sistemas \& Gestão, v. 9, n. 1, p. 34-46, 2014.

[21] MASCENA, K. M. C.; FISCHMANN, A. A.; BOAVENTURA, J. M. G. Priorização de stakeholders em empresas que divulgam relatórios GRI no Brasil. BBR. Brazilian Business Review, v. 15, n. 1, p. 17-32, 2018.

[22] NASCIMENTO, V. M. et al. Análise da utilização dos indicadores essenciais da versão G3, do GRI, dos relatórios das empresas do setor bancário brasileiro. In: In: CONGRESSO USP DE CONTROLADORIA E CONTABILIDADE, 11, 2011, São Paulo. Anais... São Paulo: 2011.

[23] ROCA, L. C.; SEARCY, C. An analysis of indicators disclosed in corporate sustainability reports. Journal of Cleaner Production, v. 20, n. 1, p. 103-118, 2012.

[24] SINGH, R. K. et al. An overview of sustainability assessment methodologies. Ecological indicators, v. 9, n. 2, p. 189-212, 2009.

[25] ROCHA, T. A. C. Análise do relatório GRI enquanto ferramenta para a mensuração da sustentabilidade empresarial. 2012. Tese de Doutorado. Universidade de São Paulo.

[26] TRAVASSOS, S. K. M. et al. Uso dos Indicadores Essenciais da GRI nos Relatórios das Empresas dos Setores de Petróleo, Gás e Biocombustível e de Utilidade Pública no Brasil. Revista de Gestão Ambiental e Sustentabilidade, v. 3, n. 2, 2014. 
APÊNDICE A - ÍNDICE GAPIE PARA EMPRESAS DA AMÉRICA LATINA DO SETOR DE ALIMENTOS E BEBIDAS (ANO 2016)

\begin{tabular}{|c|c|c|c|}
\hline Posição & País & Empresa & GAPIE \\
\hline $1^{\circ}$ & Argentina & Coca-Cola Andina & 0,7647 \\
\hline $2^{\circ}$ & Brasil & BRF (Brasil Foods) & 0,7647 \\
\hline $3^{\circ}$ & Chile & $\mathrm{CCU}$ & 0,6764 \\
\hline $4^{\circ}$ & México & Coca-Cola FEMSA & 0,6470 \\
\hline $5^{\circ}$ & Colômbia & Riopaila Castilla S.A. & 0,5000 \\
\hline $6^{\circ}$ & Brasil & Nestlé Brasil & 0,4706 \\
\hline $7^{0}$ & Argentina & Grupo Arcor & 0,4412 \\
\hline $8^{\circ}$ & Equador & Moderna Alimentos & 0,4411 \\
\hline $9^{\circ}$ & Brasil & JBS S.A. & 0,3529 \\
\hline $10^{\circ}$ & Chile & Santa Isabel Cencosud & 0,3529 \\
\hline $11^{\circ}$ & Brasil & Citrosuco & 0,3235 \\
\hline $12^{\circ}$ & México & Grupo Bimbo & 0,3235 \\
\hline $13^{\circ}$ & México & Soriana & 0,3235 \\
\hline $14^{\circ}$ & Brasil & Minerva Foods & 0,2941 \\
\hline $15^{\circ}$ & Colômbia & Postobon & 0,2941 \\
\hline $16^{\circ}$ & Colômbia & Alpina & 0,2647 \\
\hline $17^{\circ}$ & Chile & Los Fiordos & 0,2352 \\
\hline $18^{\circ}$ & Colômbia & Colombina & 0,2352 \\
\hline $19^{\circ}$ & Bolívia & FINO & 0,2059 \\
\hline $20^{\circ}$ & México & Grupo Lala & 0,2058 \\
\hline $21^{\circ}$ & Argentina & Eco de los Andes & 0,1765 \\
\hline $22^{\circ}$ & Brasil & AmBev & 0,1765 \\
\hline $23^{\circ}$ & Chile & Carozzi & 0,1176 \\
\hline $24^{\circ}$ & México & Grupo Bepensa & 0,1176 \\
\hline
\end{tabular}




\section{Capítulo 17}

Fertilizantes e sua relevância para o agronegócio brasileiro

Gabriel Severiano da Silva

João Víctor Carrelas dos Santos

Nathiely de Freitas Silvestre

Resumo: Fertilizantes são insumos químicos que aumentam a fertilidade das culturas, contribuindo diretamente para a expansão da produtividade nas produçõesagrícolas. 0 Brasil é um dos maiores players no mercado de importação, em conjunto a grandes importadores tais como: China, Índia e Estados Unidos. 0 objetivo deste estudo é demonstrar a relevância dos fertilizantes para o agronegócio brasileiro e de como a importação desse produto causa impacto na balança comercial nacional. Serão apresentados também, a cadeia produtiva e os principais terminais que realizam a descarga desses insumos químicos no porto de Santos. A partir das pesquisas bibliográficas realizadas, foi possível entender a relação da importação entre abastecimento mundial e a tendência do elevado consumo interno desses produtos.

Palavras-Chave: Fertilizantes. Agronegócio. Importação. 


\section{INTRODUÇÃO}

O Brasil é um dos maiores consumidores de fertilizantes do mundo, ficando atrás apenas da China, Índia e Estados Unidos. Em 2018, foram consumidos cerca de 7\% de fertilizantes dentro do território nacional, o que evidencia a dependência que o país possui desses insumos químicos. A soja é um dos produtos mais cultivados em solo nacional, utilizando cerca de $40 \%$ de fertilizantes importados. Os principais nutrientes aplicados são: nitrogênio, fósforo e potássio (NPK). (RICHETTI, 2018)

Desse modo, o setor de fertilizantes tem obtido grande crescimento não apenas exteriormente, como também nacionalmente. De acordo com aAssociação Internacional de Fertilizantes (IFA), no que se refere ao consumo, o Brasil tem superado muitos outros países na utilização de fertilizantes. Isso é facilmente explicado pela crescente importância do país nas produções agrícolas.

Este trabalho tem por objetivo geral evidenciar a importância dos fertilizantes para o agronegócio nacional e tem-se como objetivo específico levantar e compilar dados a respeito da importação de fertilizantes no porto de Santos e os terminais operadores. A seguir, será apresentado o conceito de fertilizante bem como suas classificações, a necessidade desse produto no agronegócio brasileiro, a análise dos dados de importação nacional e no porto de Santos, seguido da metodologia e considerações finais.

\section{FUNDAMENTAÇÃO TEÓRICA}

\subsection{FERTILIZANTES E SUAS CLASSIFICAÇÕES}

No século XVII, o agrônomo alemão Carl Sprengel (1787-1859) fez importante constatação acerca da produtividade das culturas que impactou diretamente a indústria química e o agronegócio brasileiro. Ao observar que muitas vegetações não evoluíam, Sprengel constatou que isso ocorria não pela ausência de nutrientes necessários em grandes quantidades, como água e dióxido de carbono, mas pela falta de substâncias que as plantas carecem em menores quantidades (REETZ, 2017).

Portanto, devido à deficiência do solo em não conter todos os nutrientes vitais para a sobrevivência de determinadas culturas, faz-se o uso de fertilizantes. Segundo Harold Reetz (2017), define-se fertilizantes como o manejo de nutrientes necessários para os sistemas de produção agrícolas com o intuito de aumentar a fertilidade das vegetações, e consequentemente, proporcionar insumos fundamentais para a sociedade e animais.

Os elementos químicos contidos nos fertilizantes, mediante a quantidade ou porção, podem ser classificados em duas categorias: micronutrientes (boro, cloro, cobre, ferro, manganês, molibdênio, zinco, sódio, silício e cobalto) e macronutrientes (carbono, hidrogênio, oxigênio, nitrogênio, fósforo, potássio, cálcio, magnésio e enxofre). É válido evidenciar que as deficiências mais comuns são de nitrogênio, fósforo e potássio (DIAS e FERNANDES, 2006).

De acordo com Brito e Pontes (2009), a indústria de fertilizantes desenvolveu-se no país não apenas por conta do crescimento da procura por esses produtos, que foi fomentada essencialmente pela modernização das técnicas agrícolas, mas também pela pretensão de diminuir a importação dessas mercadorias para iniciar a produção nacional. Destarte, entre os anos de 1974 e 1980, o governo Federal através do Programa Nacional de Fertilizantes e Calcário Agrícola incentivou o aumento da produção de amônia e fertilizantes nitrogenados, de ácido fosfórico e fertilizantes fosfatados. Passados alguns anos, algumas companhias e subsidiárias foram surgindo no Brasil com o intuito de explorar as jazidas de fosfato e extrair outros compostos, porém, o país não obteve muito crescimento como produtor de fertilizantes em geral, sendo um dos maiores players no mercado de importação (BRITO e PONTES, 2009).

\subsection{RELEVÂNCIA DOS FERTILIZANTES PARA O AGRONEGÓCIO BRASILEIRO}

É imprescindível mencionar a relevância dos fertilizantes para o agronegócio no país, visto que, nos últimos anos os progressos técnicos no setor agropecuário têm obtido grandes avanços. De acordo com Marcos Neves (2016), o conceito de agronegócio é novo no Brasil, mas a sua primeira aparição foi em 1957 num estudo feito pelos professores John Davis e Ray Goldberg na Universidade de Harvard. Davis e Goldberg definem agronegócio como: "a soma total das operações de produção e distribuição de suprimentos agrícolas, do armazenamento, processamento e distribuição dos produtos agrícolas e itens produzidos partir deles." 
Considerando essa afirmação, é possível observar que o agronegócio envolve todos os setores (produtor, processador, comercializador) dos mais variados produtos. Além de possuir grande participação na economia nacional (Produto Interno Bruto), esse setor detém ampla capacidade empregadora e geração de renda, alcançando notável visibilidade em aspecto global (NEVES, 2016).

Em conformidade com o Ministério da Economia, Indústria, Comércio Exterior e Serviços (MDIC), os fertilizantes contendo nitrogênio, fósforo e potássio ocupam a $15^{\circ}$ posição no ranking de Importações Totais e $12^{\circ}$ colocação no ranking de importações dos Produtos Manufaturados. Desde janeiro de 2019 até setembrodesse mesmo ano, 5.828.657 toneladas foram importadas, sendo o Rio Grande do Sul a UF com maior participação em âmbito nacional.

Segundo Costa e Silva (2012), o que alavancou a expansão da produção de alimentos foi o crescimento populacional, que veio acompanhado pelo aumento da renda em mercados emergentes e a modificação na dieta das pessoas. Juntamente desses aspectos, vale ressaltar que a tendência de combustíveis derivados do petróleo mediante biocombustíveis acaba criando uma pressão sobre a majoração da produção agrícola. Ultimamente, além do uso de fertilizantes, as pesquisas com sementes geneticamente modificadas têm apresentado resultados positivos que contribuem para com a prosperidade das produções no agronegócio brasileiro.

\subsection{CADEIA PRODUTIVA DE FERTILIZANTES}

Cadeia produtiva pode ser definida como todas as fases de produção de um bem, desde o planejamento inicial até o consumidor final. No caso dos fertilizantes, a cadeia inicia-se na extração da matéria prima culminando no agricultor. Na figura 1, é possível observar a cadeia de produção da indústria de fertilizantes, onde esse insumo está englobado.

Figura 1 - Cadeia de produção da indústria de fertilizantes

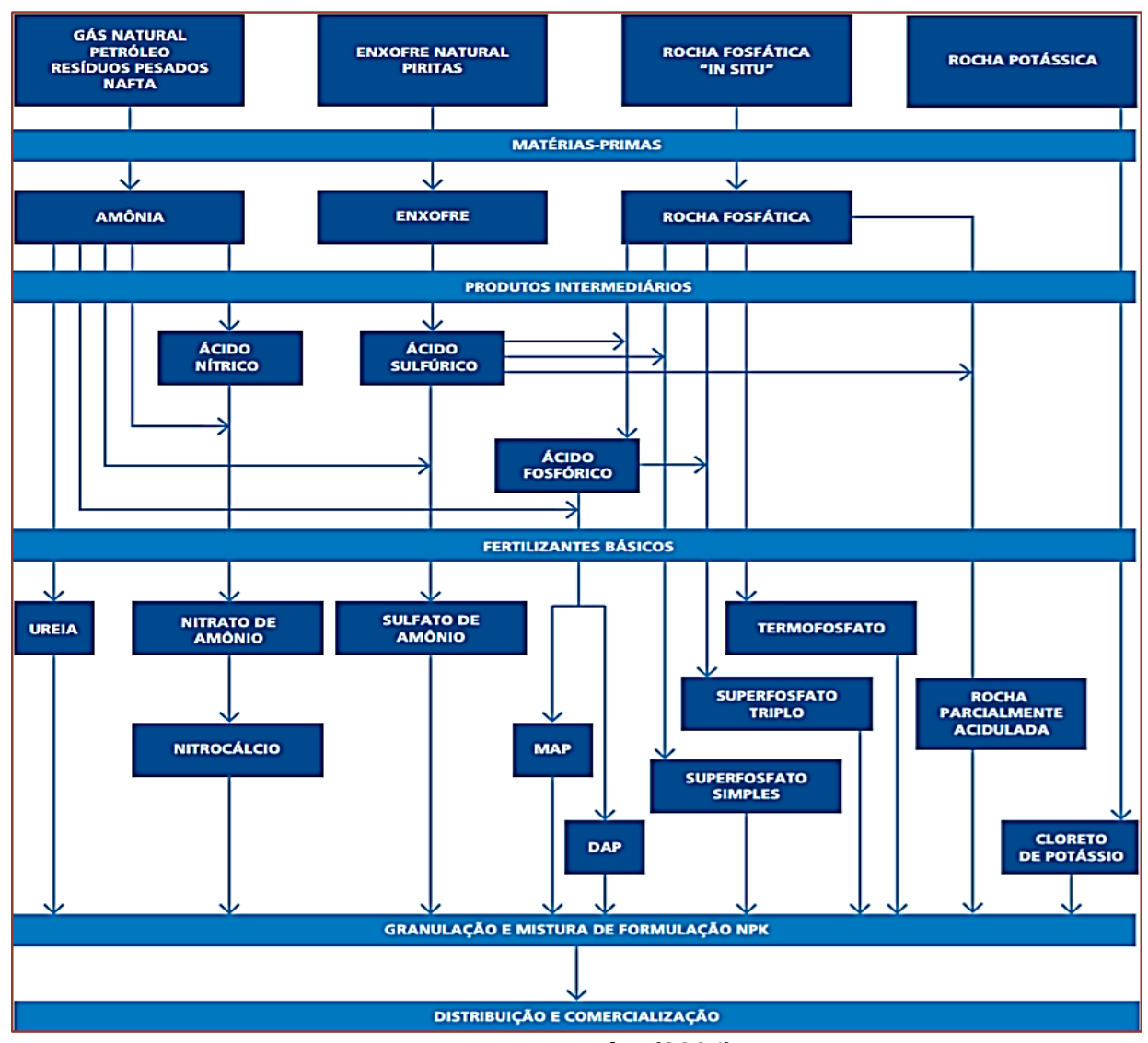

Fonte: Dias e Fernandes (2006)

Conforme os autores da figura 1, a primeira etapa é a extração de minerais que proporcionam as matérias primas básicas (rocha fosfática, rocha potássica, enxofre, e gás natural ou nafta). Mediante os insumos 
produzidos da indústria extrativa, são produzidas matérias primas básicas e intermediárias, como o ácido sulfúrico e ácido fosfórico. Em seguida, surge na cadeia a indústria de fabricação, onde originam-se: o superfosfato simples (SSP); superfosfato triplo (TSP); fosfato de amônio (MAP e DAP), ureia, sulfato de amônio, termofosfatos, rocha fosfática parcialmente articulada e nitrato de amônio.

Por fim, tem-se o processo de granulação e mistura de fertilizantes, onde são originados os fertilizantes macronutrientes finais: nitrogênio, fósforo e potássio.

\subsection{NECESSIDADE DE IMPORTAÇ̃̃O}

A balança comercial brasileira tem grande sustentação no agronegócio. Com o passar dos anos, a necessidade de fertilização vem crescendo, pois, esses produtos aceleram o crescimento da produção agrícola, tornando-se um recurso imprescindível para a economia nacional. Desta forma, importa-se bastante, considerando que mais de $70 \%$ dos fertilizantes consumidos no Brasil são importados (ESALGLOG, 2016).

Essa dependência provém da falta de tecnologia para modelar e usar minérios, uma vez que, o país naturalmente possui esses recursos, além dos investimentos necessários possuírem alto custo, daí o interesse das empresas na importação.

A estratégia de importar fertilizantes tem sido adotada perenemente no cotidiano nacional, indo de encontro com a produção nacional. Foram analisados dados da importação em valor F.O.B "free on board" (livre ao bordo do navio), onde de acordo com Wolffenbüttel (2006) é uma cláusula de contrato internacional pertencente ao grupo International Commercial Terms. Ao passo que, livre indica que a mercadoria foi desembraçada na alfândega de partida estando disponível para ser levada, isto quer dizer que a responsabilidade do exportador acaba quando a mercadoria entra no navio. No gráfico 1, enfatiza-se o crescimento e importância da importação.

Gráfico 1 - Valores em dólares das importações de fertilizantes pelo Brasil e pelo Porto de Santos respectivamente

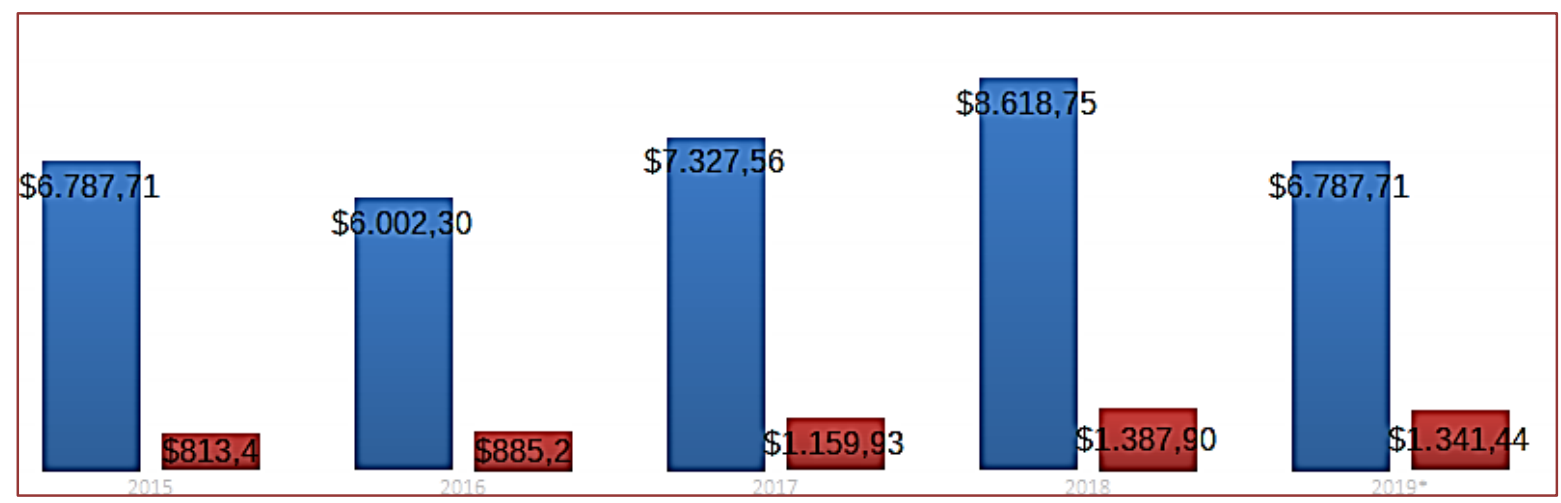

Fonte: Adaptado de MDIC (2019)

\subsection{IMPORTAÇÃO BRASILEIRA DE FERTILIZANTES}

Devido à carência de minerais no solo do Brasil, é de suma importância para o agronegócio o uso de fertilizantes, que são importados pela razão de haverdificuldades de produzir esses insumos químicos em solo nacional. Segundo levantamento da Organização das Nações Unidas para a Alimentação e a Agricultura (FAO, 2019), o Brasil é o segundo maior país em exportação agrícola, atrás apenas dos EUA. A falta de produção de insumos químicos em território é a principal deficiência que fomenta a dependência do mercado externo. Na figura 2, é possível notar a predominância do uso de fertilizantes importados classificados por componentes. 
Figura 2 - Produção e Importação de Matérias Primas - Mil Toneladas - Nutrientes Janeiro - Abril - 2019

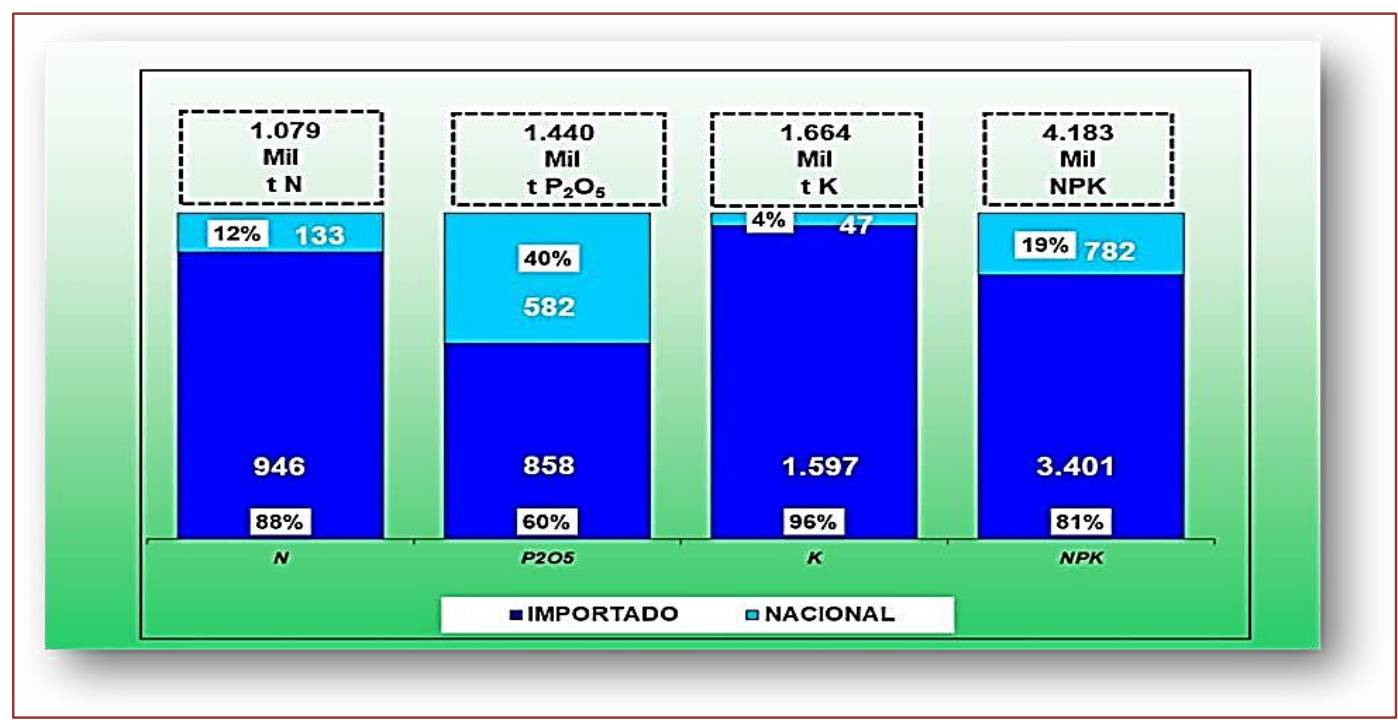

Fonte: Associação Nacional para Difusão de Adubos (ANDA) - elaborado por: Associação dosMisturadores de Adubos (AMA) (2019)

\subsubsection{VOLUME DE FERTILIZANTES EXPORTADOS}

Em 2019, de janeiro até agosto o volume de fertilizantes importados pelo Brasil, segundo a Agência Nacional de Transporte Aquaviário (ANTAQ) foi de 18.091 .607 ton. Um aumento de 10,25\% em comparação ao mesmo período do ano passado. Os principais portos brasileiros na movimentação deste produto são, Paranaguá em primeiro lugar, movimentando dentro desse período 5.211 milhares de toneladas e, em segundo lugar o porto de Santos, movimentando no mesmo período 2.617 milhares de toneladas.

Dentro dessa quantidade de produtos importados a maior parte destina-se para a região Centro-Oeste está concentrada a maior parte de cultivos de soja e milho, que são respectivamente os maiores usuários de fertilizantes no agronegócio do Brasil.

Figura 3 - Consumo de fertilizantes por cultura e área plantada no Brasil em 2018

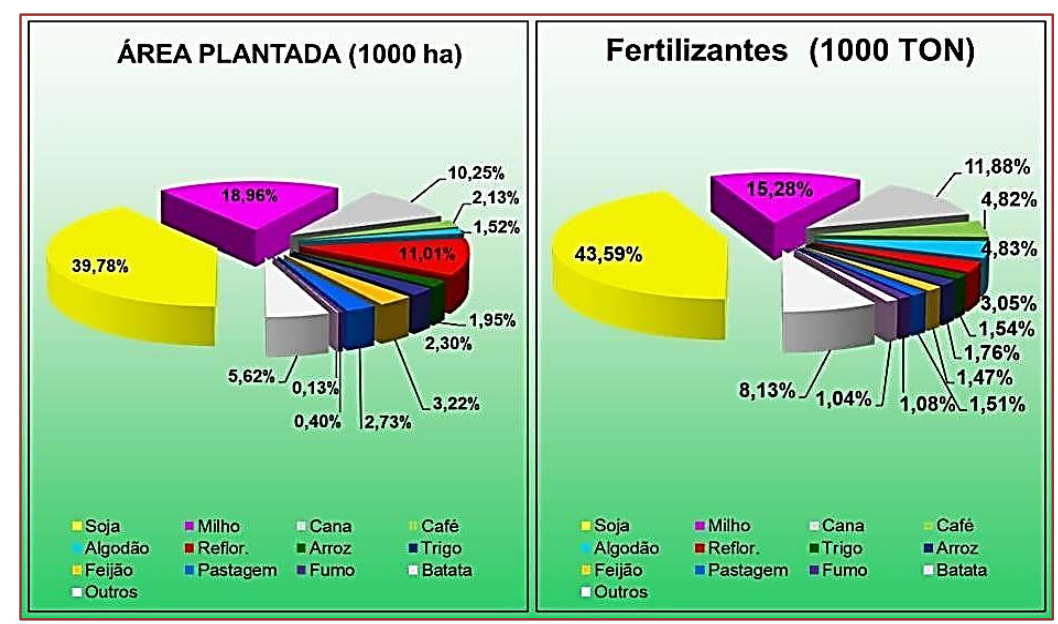

Fonte: AMA (2018) 


\subsubsection{CUSTOS}

Em questão de valores, o preço varia de acordo com o mineral especifico dofertilizante, a produção no país de origem, entre outros fatores de mercado.

Figura 4 - Evolução dos preços de fertilizantes nitrogenados importados - CFR -valores em dólares/toneladas - janeiro/17 - abril/19

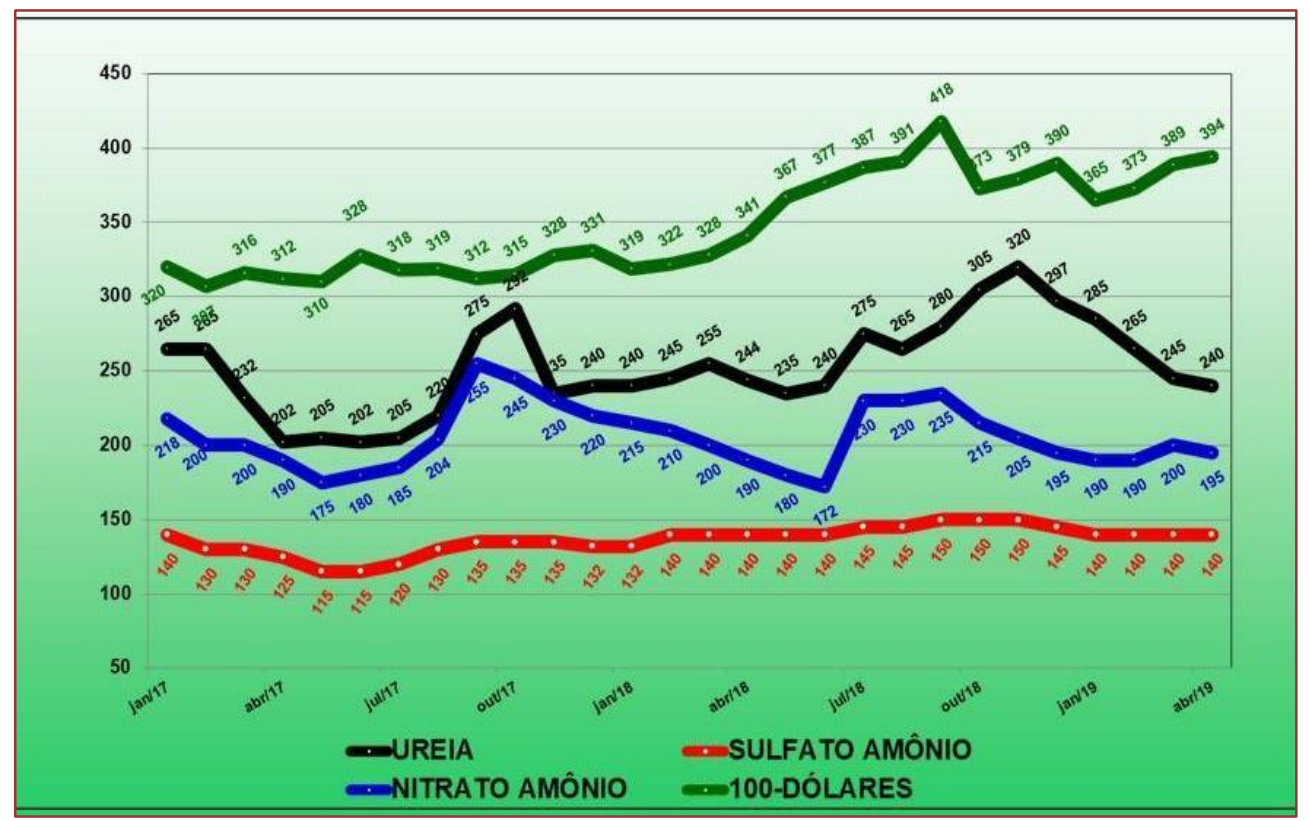

Fonte: AMA BRASIL (2019)

\subsection{BALANÇA COMERCIAL}

Conforme dados do MDIC, de janeiro até setembro de 2019 o Brasil exportou US\$ 167,2 bilhões e importou o correspondente a US\$133,5 bilhões. Sendo assim, alcançou superávit em sua receita, até o momento obtendo um saldo de US\$33,6bilhões, conforme ilustra o gráfico 2.

Gráfico 2 - Balança comercial brasileira de jan. até set/2019

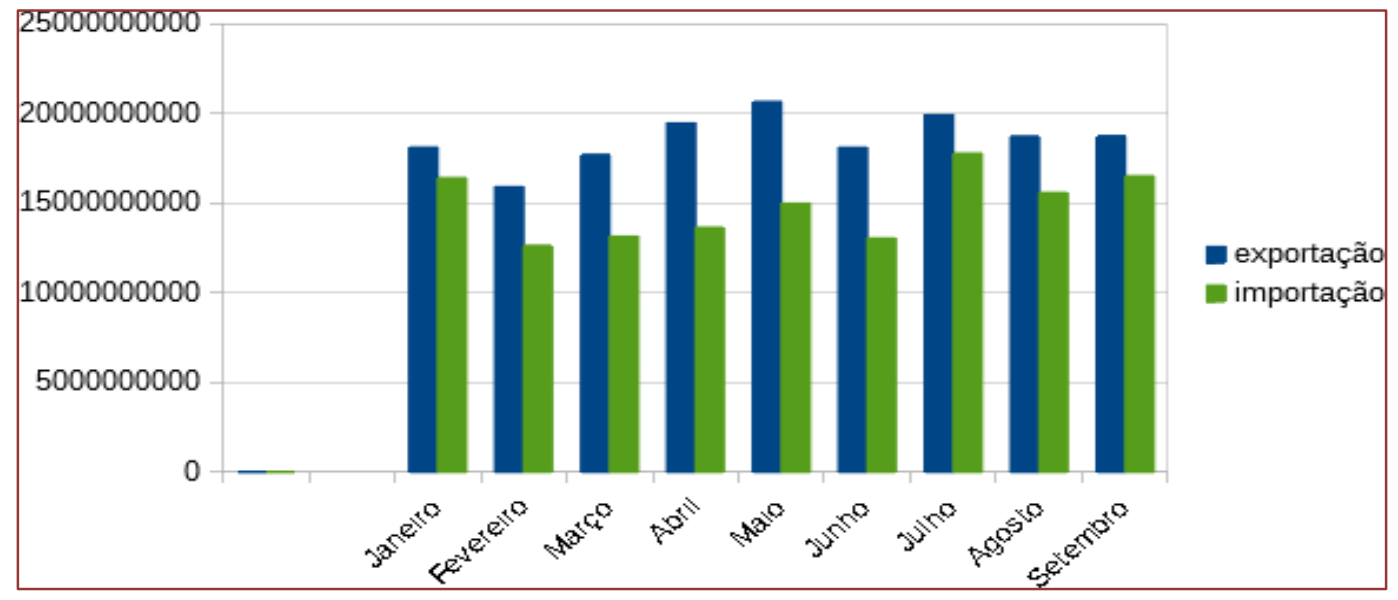

Fonte: Adaptado pelos autores 


\subsection{PAÍSES FORNECEDORES}

A Importação é caracterizada por trazer de outros países produtos e serviços, e perante a legislação brasileira, a importação efetiva-se quando é aplicado o desembaraço aduaneiro (LOPEZ e GAMA, 2013). Pode-se observar na figura 5, que o Brasil importa produtos de diversos países, é importante também destacar arelevância da China e Estados Unidos como principais fornecedores de mercadorias.

Figura 5 - Mapa das importações brasileiras

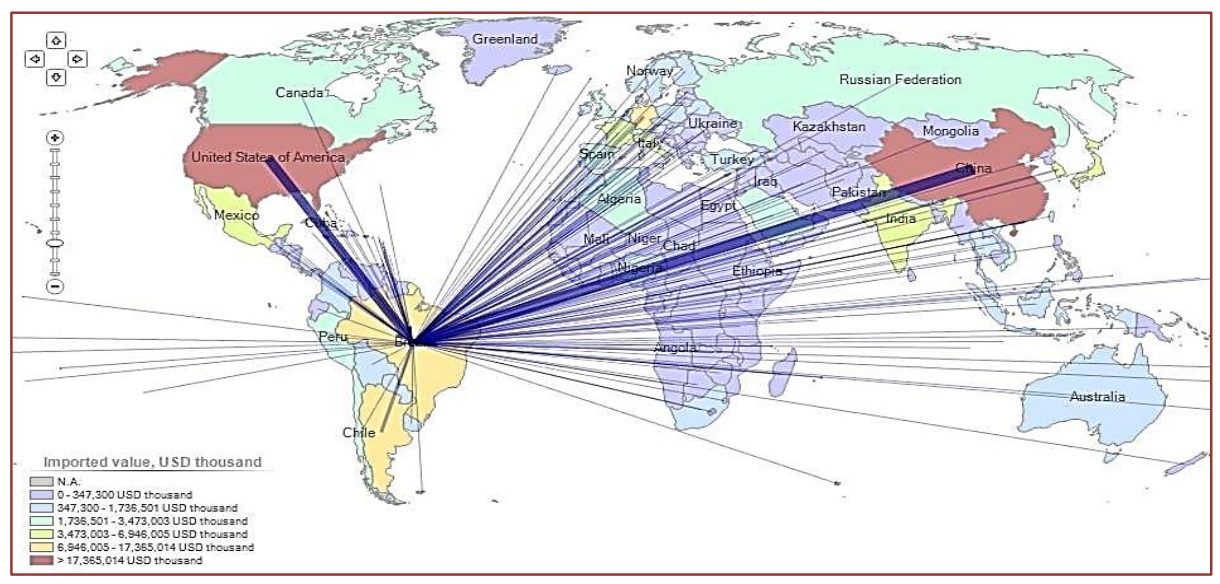

Fonte:International TradeCentre(2019)

Diante a urgência dos nutrientes primários para atender à necessidade global de alimentos, garantindo cultivos salutíferos, o Brasil recorre a diversos países a fim de atingir abundancia em sua lavra. Em valor percentual, os principais países fornecedores do grupo de fertilizantes, capítulo 31 em 2018 foram: Rússia com 22\%, Canadá 11.8\%, Estados Unidos 8.6\%, Marrocos 7.4\% e China 7.4\%. Na figura 6, é possível visualizar o mapa dos países importadores de fertilizantes.

Figura 6 - Mapa das importações dos fertilizantes

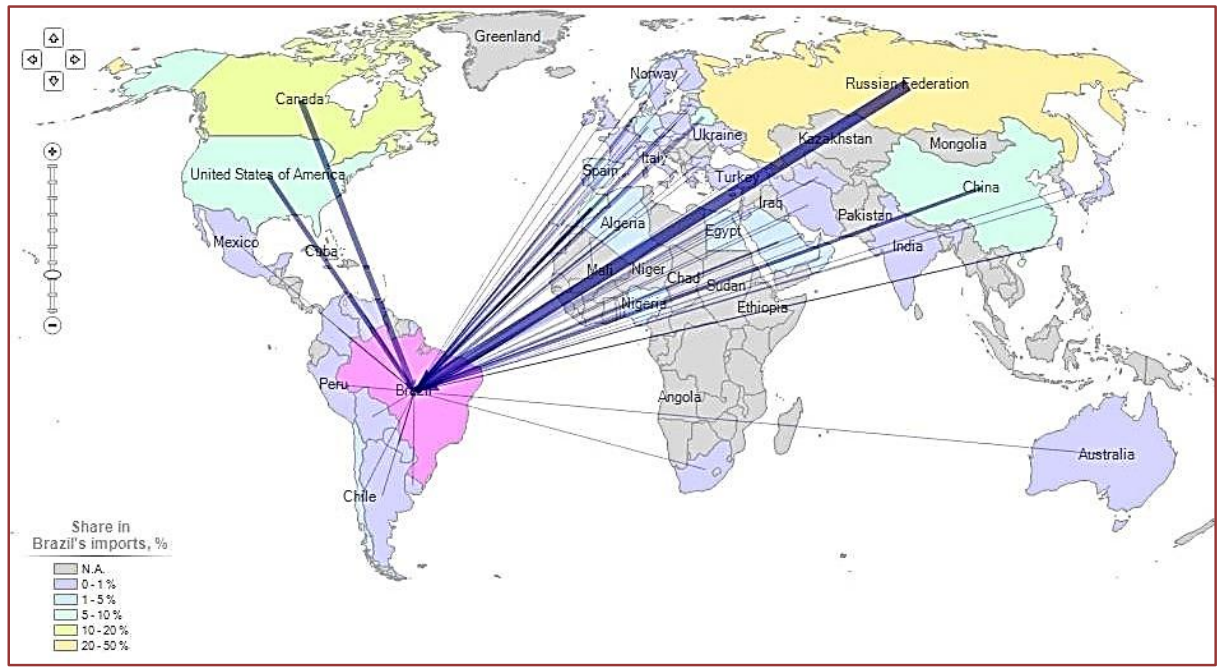

Fonte: International Trade Centre (2019) 


\subsection{PRINCIPAIS TERMINAIS QUE OPERAM FERTILIZANTES NO PORTO DE SANTOS}

Conforme dados do MDIC, o valor FOB no Porto de Santos proveniente de importações até o mês de setembro de 2019, totalizou em US\$ 1.387.900.542,00. Comparado a dados do ano passado, este valor já ultrapassou o número de importações realizadas no ano integral de 2018, o que evidencia a relevância desse setor para a economia brasileira.

No Complexo Portuário Santista, existem dois terminais responsáveis pela descarga de fertilizantes, o Terminal Marítimo do Guarujá S/A (TERMAG) localizado na margem esquerda do Porto de Santos, e o Pérola Terminais de Granéis, localizado na margem direita no município de Santos. O TERMAG está autorizado a operar o Nitrato de Amônio, considerado um produto perigoso (AFONSO; MORAES; GONÇALVES, 2018).

A descarga desses produtos é realizada através de guindastes com grab, onde os produtos são captados nos porões dos navios e levados até as esteiras rolantes através de funis para que sejam armazenados.

\subsubsection{MOVIMENTAÇÃO PORTUÁRIA}

Segundo dados da ANTAQ, o porto de Santos até o mês de agosto de 2019, movimentou 448.905 em toneladas de fertilizantes, ocorrendo aumento de 7,37\% emrelação ao ano anterior.

\subsubsection{PRANCHA MÉDIA}

A prancha média é o indicador da produtividade de um porto, terminal ou berço, mediante a movimentação de um certo segmento de mercadorias. Essamedida corresponde ao tempo de operação das embarcações, gerando dois objetos:prancha média operacional (PMO) e prancha média geral (PMG).

O objetivo da PMO consiste no tempo da operação, considerando data/hora do fim sob data/hora do começo da operação. Enquanto os objetivos da PMG é avaliar a duração de atracação, sendo porto a diferença entre data/hora da desatracação pela data/hora da atracação (Kirchner 2016).

Figura 7 - Prancha média geral granel sólido em ton/hora.

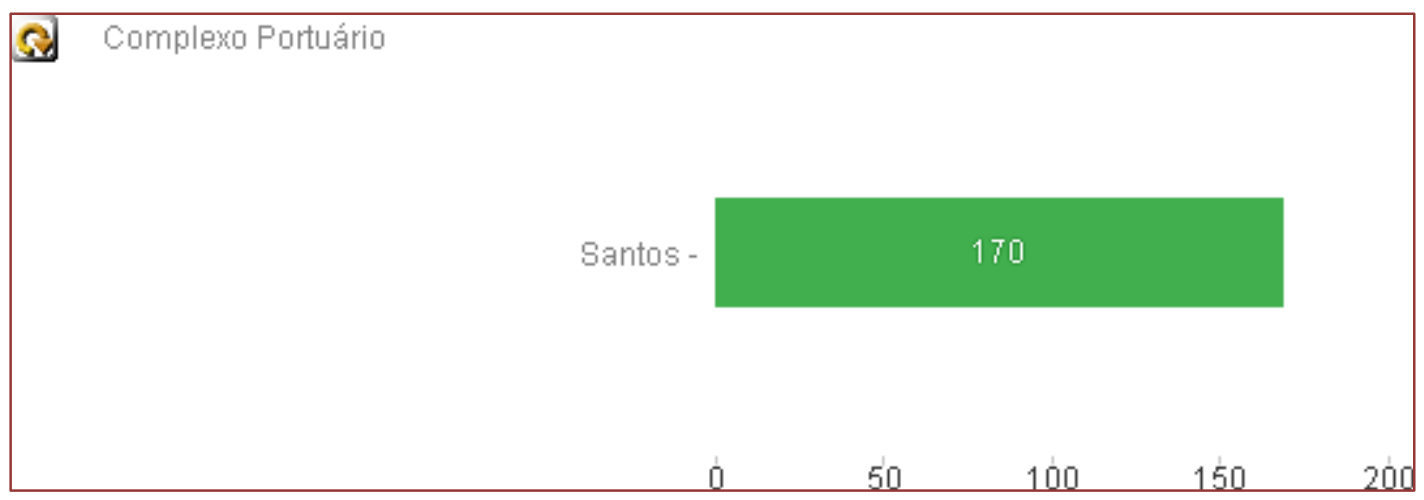

Fonte: Antaq (2019) 
Figura 8 - Prancha média operacional granel sólido em ton/hora.

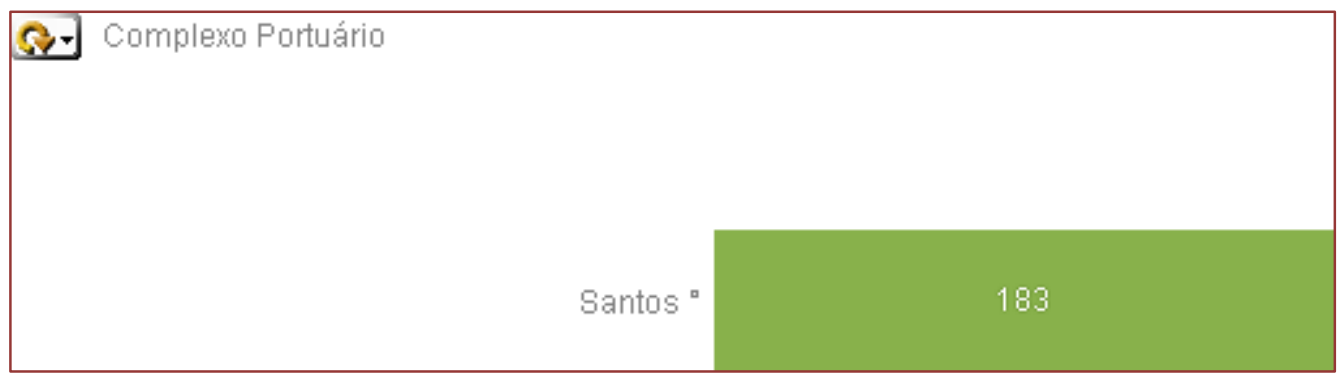

Fonte: Antaq (2019)

\section{PROCEDIMENTOS METODOLÓGICOS}

Quando se faz menção à relevância da importação de fertilizantes para o agronegócio brasileiro, deseja-se ampliar o conhecimento do tema concomitantemente com o intuito de manifestar a importância da existência de estudos a respeito das novas tendências na produção agrícola em função da demanda mundial.

Para Severino (1941), existem diferentes modos para se praticar a investigação científica, em decorrência de perspectivas epistemológicas que podem ser adotadas e dos diferentes enfoques que se podem assumir em relação ao objetopesquisado. Dessa forma, esse trabalho tem natureza de pesquisas bibliográficas.

Considerando que este tema é de grande magnitude para a economia nacional, a proposta do estudo é evidenciar o valor das importações de fertilizantes para o agronegócio brasileiro, bem como a dimensão do seu uso nas produções agrícolas e destaque no mercado internacional.

Segundo Severino (1941, p. 122-123), a pesquisa bibliográfica é efetuada a partir do registro de pesquisas anteriores, em documentos impressos, como: livro, artigos, teses etc.

\section{CONSIDERAÇÕES FINAIS}

O principal emprego de fertilizantes no Brasil é para a correção do soloque tem deficiências de nutrientes. A evolução experimentada nos últimos anos do agronegócio brasileiro fez com que crescesse a necessidade de aumentar o consumo de fertilizantes. 0 pequeno volume da produção nacional não atende à demanda existente, levando a uma maior dependência de importação desses produtos.

Os elementos químicos mais consumidos pelo Brasil são: o nitrogênio, fósforo e potássio (NPK), pertencentes ao grupo de macronutrientes. Os elevados níveis de importação desses fertilizantes implica na alta relevância queo agronegócio possui na balança comercial.

Mediante o uso desses produtos nas produções agrícolas, a produtividadee manutenção das culturas podem ser realizadas, mantendo abastecidas apopulação civil e animal.

Apesar de importar grandes quantidades de fertilizantes, ainda há lucro nas receitas por conta do superávit. Portanto, tanto em questões de sobrevivência como de economia, esse produto é indispensável para o mundo.

\section{REFERÊNCIAS}

[1] AMA. Associação dos Misturadores de Adubos do Brasil, 2019. Disponível em:https://amabrasil.agr.br/web/. Acesso em: 04 out 2019.

[2] ANDA. Associação Nacional para a Difusão de Adubos, 2019. Disponível em: http://anda.org.br/. Acesso em: 09 out 2019.

[3] ANTAQ. Agência Nacional de Transportes Aquaviário, 2019. Disponível em: http://web.antaq.gov.br/Portal/default.asp?. Acesso em: 06 out 2019.

[4] COSTA, L. M.; SILVA, M. F. O. A indústria química e o setor de fertilizantes, 2012. Disponível em: https://web.bndes.gov.br/bib/jspui/bitstream/1408/2025/1/A\%20ind\%C3\%BAstria\%20 
qu\%C3\%ADmica\%20e\%20o\%20setor\%20de\%20fertilizantes_P_A.pdf. Acesso em: 19 ago 2019.

[5] ESALQLOG. Mercado brasileiro está dependente de fertilizantes importados, 2016. Disponível em https://esalqlog.esalq.usp.br./mercado-brasileiro-esta- dependente-de-fertilizantes-importados. Acesso em: 22 ago 2019.

[6] FAO. Organização de Nações Unidas para a Alimentação e a Agricultura, 2019. Disponível em: http://www.fao.org/brasil/pt. Acesso em: 09 out 2019

[7] FAVANEVES. Vai agronegócio, 2016. Disponível em:

[8] http://www.favaneves.org/wp-content/uploads/2016/12/vai-agronegocio-marcos-fava- neves.pdf. Acesso em: 05 out 2019.

[9] INTERNATIONAL TRADE CENTRE. Trade Map, 2019. Disponível em:https://www.trademap.org/. Acesso em: 3 nov 2019.

[10] MDIC. Balança Comercial brasileira: Acumulado do ano, 2019. Disponível em: http:www.mdic.gov.br/comercio-exterior/estatisticas-de-comercio-exterior/balanca- comercial-brasileira-acumuladodo-ano. Acesso em: 26 ago 2019.

[11] REETZ. H. F. Fertilizantes e seu uso eficiente. $1^{\circ}$ ed. Paris, França. IFA. Maio 2016.

[12] RICHETTI, P. Tendências da produção de fertilizantes no Brasil, 2018. Disponível em: https://www.noticiasagricolas.com.br/artigos/artigos- principais/221636-tendencias-da-producao-de-fertilizantesno-brasil-por-priscila- richetti.html\#.XcXp1VdKjIX. Acesso em: 10 out 2019. 


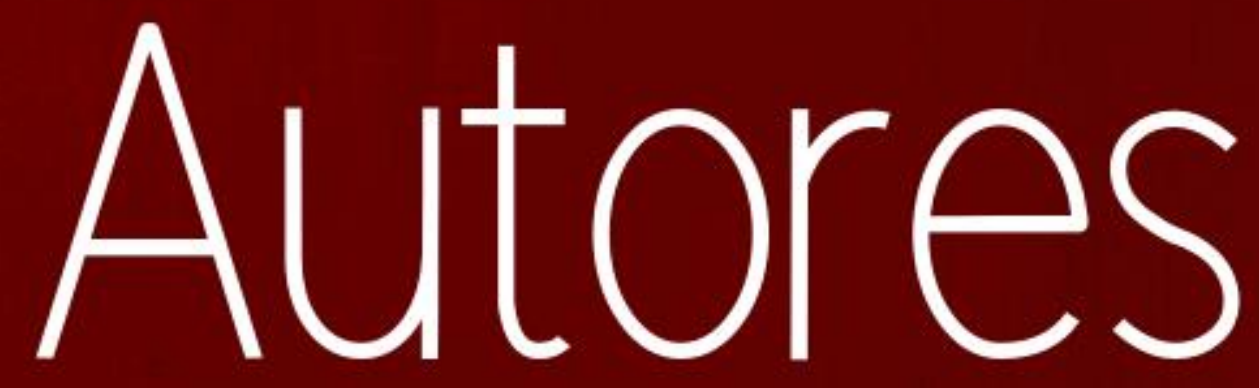




\section{ELIZANGELA DE JESUS OLIVEIRA (ORGANIZADORA)}

Professora Doutora da Universidade Federal do Amazonas. Doutorado em Administração pela UNIMEP - UNIVERSIDADE METODISTA DE PIRACICABA e Mestre em Administração pela FPL FUNDAÇÃO PEDRO LEOPOLDO DE MINAS GERAIS. Possui graduação em Administração pela UNIMONTES- Universidade Estadual de Montes Claros (2008). Especialista em Design Instrucional para Educação a Distância pela UNIFEI- Universidade Federal de Itajubál. Possui experiência como docente na Graduação Presencial dos cursos de Administração, Engenharias, e Cursos Superiores em Tecnologia de Logística, Comércio Exterior e Gestão Portuária e Gestão de Recursos Humanos. Estuda o tema felicidade no trabalho nas organizações e desenvolve consultoria na área de gestão de pessoas.

\section{SUELÂNIA CRISTINA GONZAGA DE FIGUEIREDO (ORGANIZADORA)}

Possui graduação em Economia pela Universidade Regional do Cariri URCA (1987), mestrado em Desenvolvimento Regional pela Universidade Federal do Amazonas UFAM (2008) e doutorado em Ciências da Educação pela Universidade Nihon Gakko Paraguai (2018). Atualmente é Coordenadora de Pesquisa e Extensão do Instituto Metropolitano de Ensino IME, atuando principalmente nos seguintes temas: Pesquisa e Extensão, Iniciação Científica, Sustentabilidade Ambiental, Articulação Pesquisa, Ensino, Extensão e Responsabilidade Social na formação acadêmica. Idealizadora e organizadora do Congresso Científico FAMETRO, realizando um trabalho de incentivo à produção e publicação acadêmica. Responsável pelo Programa de Intercâmbio e Mobilidade Acadêmicos do IME. Coordenadora de Pesquisa e extensão da Faculdade Santa TeresaManaus-Am

\section{EZEQUIEL REDIN (ORGANIZADOR)}

Professor Adjunto do Instituto de Ciências Agrárias da Universidade Federal dos Vales do Jequitinhonha e Mucuri (UFVJM) e Vice-Coordenador do Programa de Pós-Graduação Interdisciplinar em Estudos Rurais). Membro da Academia Centro Serra de Letras, ocupando a cadeira n. 21. Membro dos Comitês de avaliação da FAPERGS/RS, FAPESC/SC e FAPITEC/SE. Editor do Periódico Extensão Rural (Santa Maria). Tesoureiro da Associação Riograndense dos Tecnólogos (ARTECNOL). Formado na licenciatura do Programa Especial de Graduação de Formação Pedagógica de Professores (PEG/UFSM - 2012-2013). Formado no curso de Filosofia Licenciatura (UFSM - 2016-2019). Formado no Mestrado em Extensão Rural (2009-2011). Formado na Pós-graduação em Gestão Pública Municipal (2010-2011). Formado na Pós-graduação em Tecnologias de Informação e Comunicação aplicadas à Educação (UFSM - 2013-2014). Formado na Pós-graduação em Ensino de Sociologia no Ensino Médio (2014-2015). Formado na Pós-graduação em Ensino de Filosofia no Ensino Médio (2017-2018). Doutorado em Extensão Rural pelo Programa de Pós-graduação em Extensão Rural (2011-2015). Foi o criador da Pósgraduação Lato Sensu e Coordenador do Curso de Pós-graduação em Agronegócios da Faculdade Metodista de Santa Maria (2017-2018). Foi Coordenador do Curso de Administração (2018-2018). Foi Coordenador do Curso de Ciências Contábeis (2018-2018). Foi Assessor da Pós-graduação da Faculdade Metodista de Santa Maria (2017-2018).

\section{ARTHUR ANTONIO SILVA ROSA (ORGANIZADOR)}

Mestre em Administração pela Faculdade de Gestão e Negócios (FAGEN) da Universidade Federal de Uberlândia (UFU), na linha de pesquisa de Finanças. Graduado em Administração pela Faculdade de Gestão e Negócios (FAGEN) da Universidade Federal de Uberlândia (UFU). Possui interesse de pesquisas nas temáticas relacionadas à Finanças Corporativas e Mercado de Capitais.

\section{ANA MARGARIDA OLIVEIRA}

Concluiu o Mestrado em Contabilidade, Fiscalidade e Finanças Empresariais no ISEG - Instituto Superior de Economia e Gestão, Universidade de Lisboa. Atualmente, é consultora fiscal na KPMG Portugal. 


\section{ANGÉLICA MASSUQUETTI}

Possui doutorado em Desenvolvimento, Agricultura e Sociedade pela Universidade Federal Rural do Rio de Janeiro (UFRRJ) (2008) e fez Doutorado Sanduíche na Ecole des Hautes Etudes en Sciences Sociales - Paris/França (2003/2004). Possui mestrado em Economia Rural (1998) e graduação em Ciências Econômicas (1994) pela Universidade Federal do Rio Grande do Sul (UFRGS). Vinculou-se à UNISINOS em 2000, dedicando-se a projetos de pesquisa e ao ensino em nível de Graduação e de Pós-Graduação, na área de Economia, em cursos da Escola de Gestão e Negócios da UNISINOS. É professora permanente no Programa de Pós-Graduação em Economia (PPGE), Editora Assistente da Revista Perspectiva Econômica e Colíder do Grupo de Pesquisa: Integração Econômica Internacional (UNISINOS-CNPq).

\section{ARACELIS GOIS MORALES RIGOLDI}

Doutora em Administração pela Universidade Metodista de Piracicaba UNIMEP (2019). Mestre em Cultura e Turismo pela Universidade Estadual de Santa Cruz UESC/UFBA (2004). Especialista em Administração de Marketing e Propaganda na Universidade Estadual de Londrina - UEL (2012). Bacharel em Administração pela Faculdade FACCAT - Tupã (2012) e Bacharel em Turismo pela Universidade Estadual de Ponta Grossa - UEPG (2001). Secretaria municipal de Cultura e Turismo da Prefeitura da Estância Turística de Tupã no período de 2005-2012. Turismóloga concursada na Prefeitura da Estância Turística de Tupã. Docente nas Faculdades FADAP/FAP e na Rede Gonzaga de Ensino REGES - Osvaldo Cruz nos cursos de Administração. Tem experiência na área administração pública, políticas públicas, planejamento estratégico, gestão de negócio, empreendedorismo, metodologia cientifica, planejamento turístico, planejamento e organização de eventos, turismo e políticas públicas e educação turística.

\section{ARMANDO VAZ SAMPAIO}

Possui graduação em Engenharia Agronômica pela Universidade de São Paulo (1988), mestrado em Ciências (Economia Aplicada) pela Universidade de São Paulo (1995) e doutorado em Ciências (Economia Aplicada) pela Universidade de São Paulo (2000). Atualmente é Professor Associado da Universidade Federal do Paraná. Tem experiência na área de Economia, com ênfase em Métodos e Modelos Matemáticos, Econométricos e Estatísticos, atuando principalmente nos seguintes temas: modelos econométricos, modelos matematicos, mercado de trabalho, modelos dsge e matriz de contabilidade social.

\section{AZAMOR CIRNE DE AZEVEDO FILHO}

Professor Adjunto do Departamento de Finanças e Contabilidade do Centro de Ciências Sociais Aplicadas da Universidade Federal da Paraíba, Campus I. Tem Doutorado em Engenharia Mecânica pela Universidade Estadual de Campinas (UNICAMP), Mestrado em Engenharia Mecânica pela Universidade Federal da Paraíba (UFPB, 1997), Graduação em Engenharia de Minas pela Universidade Federal da Paraíba (UFPB), e Graduação em Engenharia Civil (UFPB).

\section{BRUNO AUGUSTO DIAS GONÇALVES}

Graduado em Ciências Contábeis pela Faculdade de Economia, Administração e Contabilidade de Ribeirão Preto: FEA-RP/USP (Universidade de São Paulo). Possui certificações profissionais ANBIMA: CPA-20 e Certificação de Especialista em Investimento (CEA). Atua profissionalmente na área de Corporate and Investment Banking.

\section{CECÍLIA MORAES SANTOSTASO GERON}

Doutora, Mestre e Graduada em Contabilidade pela FEA USP. Sócia da Praesum Contabilidade Internacional desde 1994, atuando com consultoria contábil e tributária para empresas de médio e grande porte. Professora do Programa de Pós-Graduação em Controladoria e Finanças Empresariais da Universidade Presbiteriana Mackenzie, atuando como pesquisadora da área de contabilidade para usuários externos, incluindo temas como adoção das IFRS e seus efeitos e a 
utilização de novas tecnologias de comunicação de informações financeiras ao mercado. Vice Presidente Adjunta da Regional São Paulo e Diretora Executiva de Normas Contábeis da ANEFAC.

\section{CRISTINA GAIO}

Professora de Contabilidade no ISEG- Instituto Superior de Economia e Gestão, Universidade de Lisboa. Concluiu um Mestrado em Contabilidade na University of Wisconsin - Madison (EUA) e um Doutoramento em Gestão no ISCTE-Instituto Universitário de Lisboa. Os seus interesses de investigação são principalmente nas áreas de contabilidade financeira, qualidade dos relatórios financeiros e não financeiros e contabilidade de gestão. 0 seu trabalho tem sido publicado em revistas internacionais de referência. Atualmente, ensina contabilidade financeira a nível de licenciatura, mestrado e doutoramento. Tem também uma vasta experiência em educação executiva. É diretora do Mestrado em Contabilidade, Fiscalidade e Finanças Empresariais no ISEG.

\section{DIOGO HENRIQUE SILVA DE LIMA}

Contador, Mestre e Doutor em Ciências Contábeis. Professor Associado do DCC/UFRN.

\section{EDMERY TAVARES BARBOSA}

Professora Dedicação Exclusiva do Departamento de Finanças e Contabilidade da Universidade Federal da Paraíba (UFPB). Doutoranda em Ciências Contábeis pela Falcuté en Sciences de l'Administration de l'Université Laval - Québec - Canadá. Mestra em Ciências Contábeis pelo Programa Pós-Graduação em Ciências Contábeis da Universidade Regional de Blumenau (FURB) Graduada em Ciências Contábeis (UFPB).

\section{ERIVAN FERREIRA BORGES}

Doutor em Ciências Contábeis (2012). Mestre em Administração (2005), Especialização em Contabilidade Gerencial (2001) e Graduação em Ciências Contábeis (1999). Professor Efetivo (Associado) do Departamento de Ciências Contábeis da UFRN, em nível de graduação, e pósgraduação. Professor permanente do Programa Pós-Graduação em Ciências Contábeis da UFRN. Chefe do Departamento de Ciências Contábeis UFRN(2015.2/2019.1).

\section{FÁBIO MINATTO}

Doutorando no Programa de Pós-Graduação em Contabilidade (PPGC) da Universidade Federal de Santa Catarina (UFSC). Mestre pelo Programa de Pós-Graduação em Contabilidade da UFSC (2020). Bacharel em Ciências Contábeis pela Universidade Federal de Santa Catarina (2017). Possui interesse em estudos que analisam informações econômico-financeiras divulgadas por organizações de modo geral, com ênfase em entidades esportivas.

\section{FERNANDO DA COSTA BARROS}

Bacharel em Administração pela Pontifícia Universidade Católica de Minas Gerais (2016) com especialização em MBA em Controladoria e Finanças pela Universidade Cruzeiro do Sul (2019). Atualmente, graduando em Engenharia Civil pelo Instituto Federal Minas Gerais - Campus Avançado Piumhi.

\section{GABRIEL SEVERIANO DA SILVA}

Estudante de Gestão portuária na faculdade de tecnologia (FATEC) Rubens Lara, com término em 2021. Possui certificados de congressos; três artigos científicos aprovados; visitas técnicas em fábricas e navios. 


\section{GRAZIELA OSTE GRAZIANO CREMONEZI}

Doutorado em Administração pela UNINOVE, Mestrado em Administração pela UNIMEP, MBA em Gestão de Pessoas e graduação em Administração pela UNIMEP. Professora e coordenadora dos cursos presenciais de Administração e Tecnólogo em Recursos Humanos do UNISAL-PIRACICABA. Coordenadora dos cursos EAD do UNISAL/PIRACICABA: Marketing, Administração, Ciências Contábeis, Logística e Processos Gerenciais. Professora da graduação e pós graduação na Escola de Engenharia de Piracicaba e da FATEC- Centro Paula Souza de Piracicaba e Americana. Professora orientadora dos trabalhos de conclusão de curso do MBA - PECEGE - ESALQ/USP. Professora do Programa de Mestrado e Doutorado em Administração da UNISUL. Foi professora por 8 anos do programa de Mestrado e Doutorado em Administração, na linha de pesquisa de Estudos Organizacionais e Gestão de Pessoas. Possui experiência em gestão e editoração de periódico científico. Formação em curso de High Performance Coaching HPC - Modalidade Self, Life, Professional e também de Analyst of Profile Behavioral. Pesquisadora e com publicação em livros e periódicos nacionais e internacionais na área de Marketing, Estudos Organizacionais e Gestão de Pessoas. Desenvolve e ministra cursos e treinamentos in company.

\section{HUMBERTO COELHO DE MELO}

Engenheiro Civil (2008) e Mestre em Construção Civil (2014) pela UFMG. Pós-graduado em Gestão de Projetos pela Fundação Dom Cabral (2010), em Licenciamento Ambiental pela PUC-MG (2009) e em Docência no Ensino Superior pela Universidade Cruzeiro do Sul (2019). Coach Profissional desde 2020. Em 2020 assumiu a direção do IFMG Piumhi, onde desenvolve atividades de Ensino, Pesquisa e Extensão, além de já ter exercido o cargo de Diretor de Ensino, Pesquisa e Extensão; atuou como responsável pelo desenvolvimento de projetos, fiscalização de obras, reformas e manutenção das edificações e da infraestrutura do IFMG Bambuí; atuou como Engenheiro de Projetos na Vale quando coordenou o desenvolvimento de projetos no Brasil, em países da África e na Austrália; atuou no projeto Minas-Rio da Anglo American, em Conceição do Mato Dentro - MG.

\section{INAJÁ ALLANE SANTOS GARCIA}

Professora Assistente da Faculdade de Ciências Contábeis da Universidade Federal do Pará (UFPA). Doutoranda em Ciências Contábeis pela Universidade Federal da Paraíba (UFPB). Mestra em Ciências Contábeis pelo Programa Multiinstitucional e Inter-Regional de Pós-Graduação em Ciências Contábeis (UnB/UFPB/UFRN). Graduada em Ciências Contábeis (UFPB).

\section{IRMA MILAGROS CARHUANCHO-MENDOZA}

Doctora en Administración, PhD. y Maestría en Finanzas, Magister en Entornos virtuales de aprendizaje con estudios en Estados Unidos, Panamá y Argentina. Especialista en investigaciones mixtas con desarrollo de propuestas. Ponente en eventos académicos a nivel internacional como Cuba, Colombia, Ecuador y México. Investigadora registrada en Renacyt - Concytec de Perú. Autora del libro de Metodología de la Investigación holística y artículos publicados en revistas indexadas en el área de Marketing, Finanzas, Administración y Educación.

\section{JOÃO VÍCTOR CARRELAS DOS SANTOS}

Aluno de gestão portuária na Fatec Rubens Lara, atualmente trabalhador autônomo desenvolvendo sua capacidade administrativa e operacional. Possui artigo aprovado em congresso.

\section{JOEL DE JESUS MACEDO}

Doutor em Desenvolvimento Econômico pela Universidade Federal do Paraná; Mestre em Engenharia de Produção; Graduado em Ciências Econômicas pela Universidade Federal do Paraná. Atualmente é economista na Companhia de Saneamento do Paraná. Pesquisador de métodos de otimização, técnicas de Data Envelopment Analysis (DEA), Stochastic Production Frontier (SFA). Consultor nas áreas de finanças públicas e de mercado de capitais. Professor de graduação e pósgraduação das disciplinas de estatística, métodos quantitativos, microeconomia, orçamento 
empresarial. Especialista em Regulação Econômica, formação de preços, estudos tarifários, economia de redes e saneamento básico. Recebeu por dois anos consecutivos (2010-2011), no Congresso Internacional de Administração, o Prêmio de melhor artigo na área de Pesquisa Operacional. Autor dos livros: Controle Interno e Externo na Administração Pública; Gestão estratégica de custos; Análise Projetos e Orçamento Empresarial; Dualidade linear para determinação de preço justo.

\section{JOSÉ ALVES DANTAS}

Contador, Mestre e Doutor em Ciências Contábeis. Professor Adjunto do CCA/UnB.

\section{JOSÉ DIONÍSIO GOMES DA SILVA}

Graduado em Ciências Contábeis pela Universidade Federal do Rio Grande do Norte (1980), Especialista em Gestão Universitária pela Universidade Federal do Rio Grande do Norte (1995), Mestre em Administração pela Universidade Federal do Rio Grande do Norte (1991) e Doutor em Controladoria e Contabilidade pela Universidade de São Paulo (2000). Professor da Universidade Federal do Rio Grande do Norte.

\section{KARINA TOLEDO SOLHA}

Docente e pesquisadora do curso de Turismo da Escola de Comunicações e Artes, da Universidade de São Paulo. Docente do Programa de Pós Graduação Humanidades, Direitos e outras Legitimidades, da FFCLCH/USP. Livre-docente na área de especialidade Desenvolvimento do Turismo, com a tese Trajetória do turismo rural em São Paulo: um segmento em construção". Doutora e Mestre em Ciências da Comunicação (ECA/USP), Bacharel em Turismo (ECA/USP). Tem larga experiência docente em cursos de graduação e pós-graduação em Turismo e de gestão universitária. Atuou como consultora em vários projetos educacionais e de planejamento turístico. Tem artigos e livros publicados sobre o tema. Atualmente é coordenadora do CETES - Centro de Estudos de Turismo e Desenvolvimento Social, que desenvolve estudos e projetos de desenvolvimento turístico. É editora adjunta da revista Turismo em Análise (USP). Parecerista "ad hoc" de agências de fomento à pesquisa. Membro permanente da Comissão Científica do Congresso Latino Americano de Investigação Turística (CLAIT).Auditora internacional da UNWTO, no programa QUEST. Tem interesse nas temáticas de turismo rural, planejamento e gestão de destinos turísticos.

\section{KELLY MILAGRITOS CASANA-JARA}

Médico Cirujano con Especialidad en Medicina Legal, Maestra en Ciencia Criminalística y Doctora en Gestión Pública y Gobernabilidad. Catedrática de Pre y Posgrado en diversas Universidades. Cuenta con Registro de Investigador María Rostworowski III (CONCYTEC). Entre sus publicaciones destacan: Estudio de las denuncias penales por Responsabilidad profesional médica en el Instituto de medicina legal de Lima, Perú; Características de la muerte de mujeres por violencia según las necropsias realizadas en la morgue del Callao.

\section{LILIAN APARECIDA TREFF}

Gerente do Núcleo Estratégico de Programas, Projetos e Processos da Faculdade de Medicina da Universidade de São Paulo. Especialista na criação de Metodologia de Gerenciamento de Projetos e implantação de PMO. Mestrado Profissionalizante em Gestão Empresarial, Pós-Graduação, LatoSensu em Didática do Ensino Superior (Universidade Presbiteriana Mackenzie), Especialização em Gestão de Projetos (Fundação Vanzolini - USP) e Gestão do Conhecimento, Ed. Corporativa e Aprendizagem Organizacional - FIA/USP. Formação Internacional Agile with Atlassian (Sydney, Austrália) Jira Destacada experiência nacional e internacional de 15 anos em cargos de liderança na área de Gestão de Projetos e Processos, Gestão da Mudança, Planejamento Estratégico e Gestão de Pessoas. Certificada Personal \& Professional Coaching; (SBC); Executive Coaching pelas organizações Metaforum Internacional - Human Change Association. 


\section{LINAMARA RIZZO BATTISTELLA}

Professora Titular do Departamento de Medicina Legal, Ética Médica, Medicina Social e do Trabalho da Faculdade de Medicina da Universidade de São Paulo (2005). É Especialista em Medicina Física e Reabilitação, e suas áreas de interesse são Avaliação Funcional e Qualidade de Vida - em especial, Classificação Internacional da Funcionalidade, Incapacidade e Saúde (CIF). Presidente do Conselho Diretor do Instituto de Medicina Física e Reabilitação do HCFMUSP e Instituto de Reabilitação Lucy Montoro, e Co-Coordenadora do Grupo de Desenvolvimento das Diretrizes de Reabilitação Relacionada à Saúde da OMS/WHO, desde 2012. Coordenadora do Programa de Residência em Medicina Física e Reabilitação da FMUSP. Foi Secretária de Estado do Governo de São Paulo, de 2008 a 2018.

\section{LÍVIA MARIA LOPES STANZANI}

Possui Mestrado em Controladoria e Contabilidade pela Faculdade de Economia, Administração e Contabilidade de Ribeirão Preto (FEA-RP/USP). Graduada em Ciências Contábeis pela FEARP/USP. Atua como docente em cursos de graduação e pós-graduação. Ministra disciplinas nas áreas de Contabilidade Financeira, Finanças e Contabilidade Tributária. Atua nos seguintes temas de pesquisa: Financial Accounting, Taxes and Behavioural Finance.

\section{LÚBIA TAMIRES RINTZEL}

Possui graduação em Ciências Econômicas pela Universidade de Passo Fundo (2015), Mestrado em Economia pelo Programa de Pós-Graduação em Economia (PPGE) - Linha de Pesquisa: Inovação e Aglomerados Produtivos Locais, pela Universidade do Vale do Rio dos Sinos (2017) e Especialista em Teorias e Metodologias da Educação pelo Instituto Federal do Rio Grande do Sul (2021). Atua como Professora de Ensino Superior e Técnica Extensionista PEIEX - Apex-Brasil.

\section{MACIO A ALBUQUERQUE}

Possui graduação em Estatística pela Universidade Estadual da Paraíba (1987), graduação em matemática pela Universidade Estadual da Paraíba (1990), mestrado em Biometria e Estatística Aplicada pela Universidade Federal Rural de Pernambuco (2005) e doutorado em Biometria e Estatística Aplicada. Atualmente é t 40 retide da Universidade Estadual da Paraíba. Tem experiência na área de Probabilidade e Estatística, com ênfase em Probabilidade e Estatística

\section{MAISA DE SOUZA RIBEIRO}

Professora Titular do Departamento de Contabilidade da FEA-RP/USP. Possui Mestrado e Doutorado em Controladoria e Contabilidade pela FEA/USP. Atua na área de contabilidade financeira, com ênfase em temas relacionados à sustentabilidade, como contabilidade ambiental, responsabilidade socioambiental, créditos de carbono, relato integrado e objetivos do desenvolvimento sustentável.

\section{MARCELA BARBOSA DE MORAES}

Bolsista de Extensão Nacional CNPq na área de Inovação, desenvolvendo o trabalho de Orientadora do Programa ALI SEBRAE/SP (2019/2020). Doutora em Administração pela Universidade Nove de Julho (UNINOVE), mestre em Gestão e Desenvolvimento Regional e bacharel em Ciências Econômicas pela Universidade de Taubaté (UNITAU). Atualmente, é professora e pesquisadora do Mestrado Acadêmico em Planejamento e Desenvolvimento Regional e do Mestrado Profissional em Gestão e Desenvolvimento Regional da UNITAU. A pesquisa está concentrada em Empreendedorismo, Estratégia, Inovação e Desenvolvimento Regional com foco em pequenas e médias empresas de base tecnológica. Lidera o grupo de pesquisa sobre Empreendedorismo Estratégico em Pequenas e Médias Empresas de Base Tecnológica. Participa do grupo de estudos sobre administração de pequenas organizações e empreendedorismo (Grupo APOE) criado e coordenado pelo prof. Dr. Edmilson de Oliveira Lima. Associada da AIREPME (Association Internationale de Recherche en Entrepreneuriat et PME), do Academy of Management 
(AOM) e da ANEGEPE (Associação Nacional de Estudos em Empreendedorismo e Gestão de Pequenas Empresas). Tem numerosas publicações incluindo livro e artigos acadêmicos nacionais e internacionais, além de numerosas apresentações de trabalho em congressos nacionais e internacionais.

\section{MARIANA SIMÕES FERRAZ DO AMARAL FREGONESI}

Professora do Departamento de Contabilidade da FEA-RP/USP. Possui Mestrado e Doutorado em Controladoria e Contabilidade pela FEA/USP. Atua principalmente nos seguintes temas de pesquisa: gestão financeira, contabilidade societária, responsabilidade social e terceiro setor.

\section{MARLI TEREZINHA VIEIRA}

Atua como professora pesquisadora na Universidade Federal do Tocantins no curso de Ciências Contábeis e no mestrado profissional PROFNIT. Coordenou o Curso de graduação em Ciências Contábeis entre os anos de 2013 e 2015. Exerceu a função de pro reitora e assessora na PROAPUFT e Diretora de politicas educacionais na PROGRAD UFT. Atuou como perita contábil na Justiça estadual e Federal. É membro do programa de voluntariado da classe contábil , academia Tocantinense de Ciências Contábeis e associação de peritos do Estado do Tocantins. É graduada em Ciências Contábeis e Direito, pela Universidade de Passo Fundo (RS) ,especialista em controladoria (UPF) mestre em Ciências Contábeis pela Fundação Universidade Regional de Blumenau(SC) e doutora em Administração pela Universidade Metododista de Piracicaba (SP). Atua na área de pesquisa em inovação, gestão das organizações, pessoas e responsabilidade social na perspectiva de modelo para implantação de ações. Avaliadora de cursos, Reconhecimento e Renovação de Reconhecimento, portaria MEC INEP 1.064, DE 14 DE DEZEMBRO DE 2018.

\section{MARTA CRISTINA PELUCIO GRECCO}

Doutora em Administração de Empresas pelo Mackenzie (2013), com doutorado-sanduíche na Universidad de Salamanca (2012), graduação em Ciências Contábeis pela FEA-USP (1989) e mestrado em Controladoria e Contabilidade pela FEA-USP (2001). Professora e pesquisadora do Programa de Pós Graduação em Ciências Contábeis da Faculdade FIPECAFI. Atuou como professora visitante na Universidad de Huelva na Espanha em 2015-2016 com desenvolvimento de projeto de pesquisa em XBRL, com fomento da Fundación Carolina. É membro do SMEIG (SME Implementation Group of IFRS). É sócia da Praesum Contabilidade Internacional desde 1995. Presidente da ANEFAC.

\section{MICHELI APARECIDA LUNARDI}

Doutoranda em Ciências Contábeis na FURB. Mestre em Ciências Contábeis pelo PPGCC da Universidade Regional de Blumenau - FURB. Graduada em Ciências Contábeis pela Universidade do Estado de Santa Catarina (UDESC). Especialização em Controladoria e finanças pelo Programa de Pós-Graduação da Universidade do Estado de Santa Catarina.

\section{NATHIELY DE FREITAS SILVESTRE}

Estudante cursando o 5ํㅜ período de Gestão Portuária na Faculdade de Tecnologia (FATEC) Rubens Lara. Atualmente, estagia na área operacional em uma agência marítima localizada em Santos. Apresentações de artigos relevantes aprovados em congresso: 1. Fertilizantes e sua Relevância para o Agronegócio Brasileiro. In: Congresso Internacional de Tecnologia e Gestão - CITEG, 2019, Santos. 2. Óleo Bunker: A alteração na IMO 2020 e seu impacto no afretamento marítimo. In: FATEC LOG, 2020, Bragança Paulista. Em 2019, fez visita técnica ao porto de Itajaí - SC. 


\section{NYALLE BARBOZA MATOS}

Professora Assistente da Universidade Estadual do Amazonas. Graduada em Ciências Contábeis pela Universidade Federal do Rio Grande do Norte (2012), Mestre pela Universidade de Brasília (2015) e Doutora pela Universidade de Brasília.

\section{PROF. DR. ENIO ANTUNES REZENDE}

Departamento de Ciências Exatas e Tecnológicas - DCET Universidade Estadual de Santa Cruz UESC

\section{RAMYLLA DE ALMEIDA BATISTA}

Possui graduação em Engenharia Civil pela Universidade Federal de Campina Grande(2013) e graduanso em Contabilidade pela Universidade Estadual da Paraíba

\section{ROQUE BRINCKMANN}

Pós-Doutor pela Universidad de León. Doutor e Mestre pelo PPGEP/UFSC. Especialista em Finanças pelo CAD/UFSC. Engenheiro Civil pela PUC/RS. Professor Associado na UFSC/CSE/CCN. Atua em análises avançadas nas áreas da Contabilidade, Administração e Economia.

\section{SÁVIO DE ARAÚJO ALMEIDA}

Departamento de Ciências Exatas e Tecnológicas - DCET Universidade Estadual de Santa Cruz UESC

\section{STELLA MARIA GOMES TOMÉ}

Possui graduação em Tecnologia em Informática pela Universidade do Estado de Minas Gerais Campus de Passos - UEMG (2003). É Especialista em Informática em Educação pela Universidade Federal de Lavras - UFLA (2007). Mestre em Economia Doméstica pela Universidade Federal de Viçosa - UFV (2011). Docente desde 2004, do ensino básico, técnico e tecnológico do Instituto Federal Minas Gerais.

\section{TATIANA GAMA RICCI}

Doutoranda em Controladoria e Finanças Empresariais na Universidade Presbiteriana Mackenzie. Mestre em Controladoria pela Mackenzie (2015). Graduação em Ciências Contábeis pela Instituição Toledo de Ensino de Bauru. Atualmente é analista administrativo do setor contábil fiscal da empresa Sociedade de Abastecimento de Água e Saneamento S.A e responsável pela elaboração do Relato Integrado. Possui experiência de mais de 15 anos em contabilidade fiscal, tributária e gestão de pessoas. Experiência também na área de Contabilidade Pública e Lei de Responsabilidade Fiscal. Professora de Pós Graduação de Estratégia de Custos, Gestão de Tributos, Planejamento Tributário e Contabilidade Pública. Diretora ANEFAC regional Campinas Contabilidade Internacional.

\section{TIAGO WICKSTROM ALVES}

Possui graduação em Ciências Econômicas pela Universidade Federal de Santa Maria (1990), mestrado em Economia Rural pela Universidade Federal do Rio Grande do Sul (1995) e doutorado em Economia pela Universidade Federal do Rio Grande do Sul (1999). Atua na Universidade do Vale do Rio dos Sinos, onde foi Coordenador Adjunto da Graduação do curso de Ciências Econômicas, Coordenador do PPG de Economia, Coordenador do PPG de Ciências Contábeis e Diretor do Centro de Ciências Econômicas. Atualmente leciona na graduação do curso de Ciências Econômicas, no PPG de Economia e no PPG de Ciências Contábeis e é líder do Grupo de Pesquisa intitulado: Mercados e Competitividade de instituições de Ensino Superior. Tem experiência na 
área de Economia Rural, Microeconomia e Métodos Quantitativos, atuando principalmente nos seguintes temas: Custos, Avaliação de Desempenho das Organizações, Análise da Competitividade das Instituições e Mercado de Ensino Superior; fundamentados em Microeconomia Aplicada e Economia Comportamental.

\section{TOBIAS RIBEIRO FERREIRA}

Graduado em Engenharia Civil pela Universidade Federal de Goiás, Especialista em Docência pelo Instituto Federal de Minas Gerais (IFMG - Campus Arcos), Mestre em Estruturas e Construção Civil pela Universidade Federal de Uberlândia (UFU). Professor EBTT do IFMG - Campus Piumhi.

\section{VALÉRIA RUEDA ELIAS SPERS}

Doutora em Ciências Sociais pela Pontifícia Universidade Católica de São Paulo - PUCSP (2004), mestre em Educação pela Universidade Estadual de Campinas - UNICAMP (1997), especialista em marketing pela Universidade São Judas Tadeu (1988), graduada em Administração pelo Centro Universitário Salesiano Dom Bosco (1987). Foi docente permanente do Programa de PósGraduação Mestrado Profissional e Doutorado em Administração da UNIMEP até julho de 2018. Atualmente docente do Centro Universitário Atenas - MG com dedicação de 12 horas. Consultora na área de Gestão e no Mercado Educacional. Atua na área de Administração, com ênfase em Estudos Organizacionais, Gestão de Pessoas, Responsabilidade Social, Terceiro Setor, Governança Corporativa, Liderança e Gestão Turística.

\section{VICTOR GODEIRO DE MEDEIROS LIMA}

Doutorando (UnB), Mestre (UnB/UFPB/UFRN) e Bacharel (UFRN) em Ciências Contábeis.

\section{WAGNER LUIZ DE OLIVEIRA}

Mestre em gestão e desenvolvimento regional pela Universidade de Taubaté, pós-graduado com MBA em gerencia em logistica e operações integradas pela Universidade de Taubaté (UNITAU), graduado em administração de empresas e logistica e transporte pela ETEP-Faculdades. Atualmente, atua como docente no curso de gestão de negócios e inovação na FATEC de Pindamonhnagaba e também como docente no curso de desenvolvimento de sistemas na FATEC de Taubaté. Sou mediador online da disciplina de projeto integrador do curso de gestão pública da Universidade Virtual de São Paulo a UNIVESP. Atuo como professor junto ao SEBRAE ministrando oficinas práticas com foco no empreendedorismo e gestão de empresas para empreendedores. Possuo grande experiência em sistemas de informação ERP voltados a administração de materiais e logística. 
